University of Rhode Island

DigitalCommons@URI

Open Access Dissertations

1996

\title{
Study and Analysis of the Water Quality of the Blackstone River Watershed
}

Shahriar Mahbub Alam

University of Rhode Island

Follow this and additional works at: https://digitalcommons.uri.edu/oa_diss

\section{Recommended Citation}

Alam, Shahriar Mahbub, "Study and Analysis of the Water Quality of the Blackstone River Watershed" (1996). Open Access Dissertations. Paper 548.

https://digitalcommons.uri.edu/oa_diss/548

This Dissertation is brought to you for free and open access by DigitalCommons@URI. It has been accepted for inclusion in Open Access Dissertations by an authorized administrator of DigitalCommons@URI. For more information, please contact digitalcommons-group@uri.edu. 
STUDY AND ANALYSIS OF THE WATER QUALITY. OF THE BLACKSTONE RIVER WATERSHED

BY

SHAHRIAR MAHBUB ALAM

A DISSERTATION SUBMITTED IN PARTIAL FULFILLMENT OF THE REQUIREMENTS FOR THE DEGREE OF DOCTOR OF PHILOSOPHY

$\mathbb{N}$

CIVIL AND ENVIRONMENTAL ENGINEERING 


\title{
DOCTOR OF PHILOSOPHY DISSERTATION
}

OF

\author{
SHAHRIAR MAHBUB ALAM
}

APPROVED:

Dissertation Committee

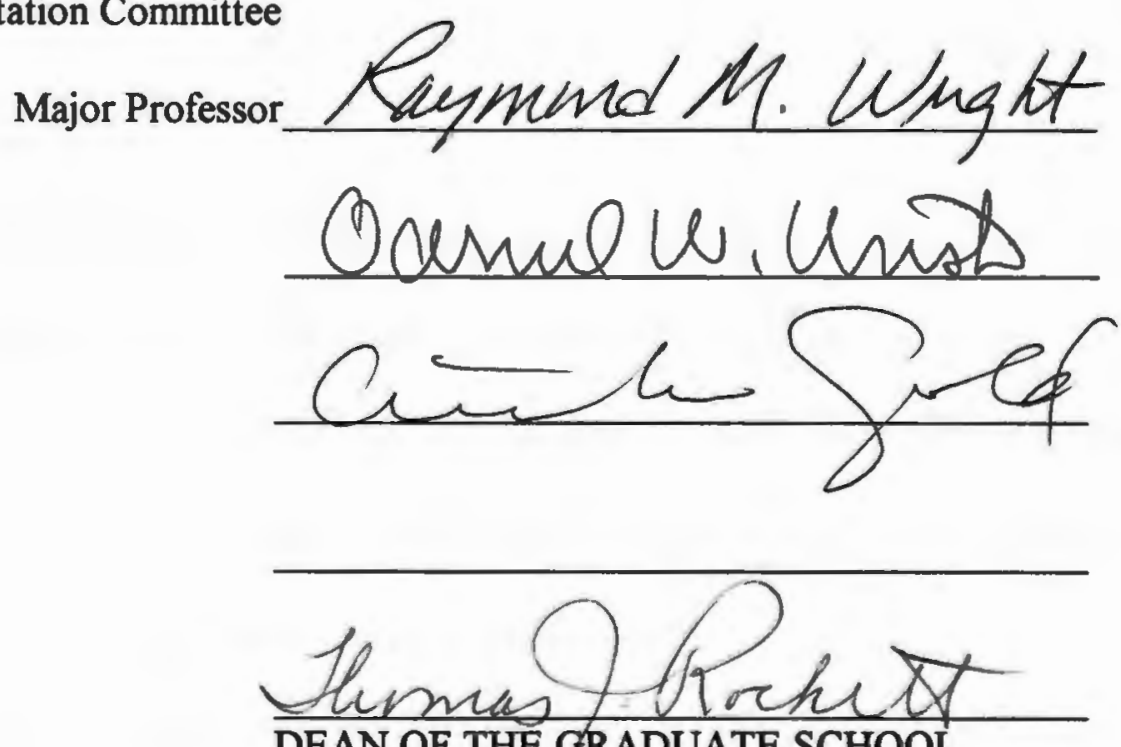

DEAN OF THE GRADUATE SCHOOL 


\section{ABSTRACT}

Wet weather water quality of the Blackstone River was analyzed. Three wet weather events were successfully captured for the wet weather program: Storm 1 (September 22-24, 1992), Storm 2 (November 2-5, 1992) and Storm 3 (October 12-14, 1993). Grab samples were collected at specific time intervals throughout the Blackstone River watershed. The concentrations and EMC's (event mean concentration) for different constituents were determined. Two types of violations were compared for fecal coliform in the Blackstone River: $\log$ mean $>200 \mathrm{md} / 100 \mathrm{ml}$ and $10 \%$ of samples exceeding 400 $\mathrm{md} / 100 \mathrm{ml}$. Acute and chronic criteria were compared with the concentrations measured for trace metals to determine violations. These criteria are used to protect the public health and the environment.

Concentration data and flow data were used to calculate mass loadings. EMCs and average flows were used to determine the value of EMM (event mean mass) at a particular station. A comparison of wet and total loadings were provided and tributary wet load rankings were determined. Net gains and losses per reach were calculated and major point sources and non point sources were compared.

Net pollutant changes in a reach help to identify locations of major pollutant sources. The results of this evaluation also provided insight into the relative importance of each reach through a system ranking. The ranking for each storm was calculated for both wet and total loads. The ranking, without point sources for the wet load, were also calculated for each storm. A comparison of wet and dry weather sources for different constituents was provided. 
A procedure was developed to separate runoff and resuspension. This procedure was demonstrated for the reach between BWW07 and BWW08 (Rice City Pond). This reach appears to be a major source of resuspension. An estimate of annual loadings at the MA/RI state line and end of river (to Narragansett Bay) was provided. The annual loads were divided into two parts: contribution by dry weather and contribution by wet weather. Total loadings for a particular year were determined by adding wet loads with dry loads for that year.

The analysis of the concentration data showed that wet weather did impact the water quality of the Blackstone River. For UBWPAD there was no violation of maximum ammonia discharge during dry weather conditions but violations did occur in two out of three storms during wet weather (Storm 1 and Storm 3). During peak flow fecal coliforms from Worcester passed by UBWPAD without instream disinfection. This was due to the higher flows at the WWTF and the lower chlorine residual concentrations. Significantly more stations had fecal coliform violations under wet weather than dry weather.

Wet weather caused acute criteria violations. During the height of the storm, instream hardness drops resulting in lower acute criteria concentrations. The more stringent criteria typically coincided with maximum instream concentrations. The result is the possibility of short term violations. The cause of higher metal concentration may be resuspension of the bottom sediments due to high flow and velocity, runoff, or poor performance of treatment facilities subjected to increased flow during the storm.

Pollutants associated with wet weather may come from either new sources (runoff induced) or old sources (river sediments). It is important to note that the former may be 
easier to control and regulate than the later. The data indicate clearly that with only minor exceptions more wet load entered the river during these periods than dry load.

The information collected during the wet weather sampling program provided insights into the behavior of the sources during varying storm conditions. A relationship was developed between rainfall and wet loadings using the data collected during the three storms and previous wet weather data available for the state line and end of river. Regression plots were done for trace metals, nutrients and TSS. These equations were used to estimate the annual wet loading rates for the Blackstone River.

The dry weather data was sufficient to permit the calibration and verification of a model to describe trace metal transport as well as a model for dissolved oxygen. The dry weather models were used to estimate baseline mass loadings under steady state flow. The relationships were developed and used to estimate the annual dry weather contributions at MA/RI state line (BWW13) and end of the river (BWW21). These dry weather loadings can be compared with the annual wet weather loadings. In the long run this is exactly what is needed to allow decisions into pollutant control. 


\section{ACKNOWLEDGMENTS}

Every step towards progress is a culmination of the efforts of many people. Hence I take this opportunity to express my thanks to all the people who have directly or indirectly contributed in the creation of this dissertation. Few. people who immensely contributed in many different ways are mentioned below.

I would like to express my profound gratitude and sincerest appreciation to my advisor Dr. Raymond M. Wright for his valuable counseling, continuous encouragement, constant guidance and patience throughout the course of this study. Whenever I saw his smiling face I forgot my tiredness and got refueled for next action. He will be a role model and mentor in my future life.

I am also thankful to Dr. Daniel W. Urish for his support, advice and time. Thanks to Dr. Arthur J. Gold for his valuable comments and support during this study. I want to thank Dr. Josef Gorres for his support, time and serving as my defense committee chair. Thanks to Dr. Kelvin Poon and Dr. Wayne Lee for their time and serving in my committee.

I would like to thank every body who supported me during the worse time of my wife's accident. Special thanks to Civil Engineering department, Mrs Ann West of ISO, Mr. and Mrs. Wright, Mr. and Mrs. Urish, Mrs. Virginia, other friends and fellow students for their support when I needed it waiting in the hospital corridor, special care unit and during surgical operation of my wife.

I am very grateful to my family and to my wife's family for their encouragement and moral support. They have been a constant source of inspiration in my pursuit of learning and advancement.

Finally, I would like to thank my lovely wife, Tinku, for her love, support, cooking and cleaning during the period of the research. Hope finishing this dissertation would make her happy and end all her complains. 


\section{DEDICATION}

I want to dedicate this dissertation to the memory of my beloved MOTHER:

"Late Mrs. ZULEKHA BEGUM" who died in 1993 due to Brest Cancer (May peace be on her and may Allah keep her in Heaven, which is the final destiny of all of us), for whom I pray and cry every day, every night, every moment and will be praying and crying for the rest of my life.

I wish to rest in final peace at the feet of my mother after my death. But, before that I want to do some good things in her memory which will be beneficiary to mankind (may Allah accept my wish).

I hope, wish and pray that no mother in the world dies due to Brest Cancer or any other disease leaving their child crying. Let all of us get together and do some good things in the memory of our mothers which will be beneficiary to mankind. 
PAGE

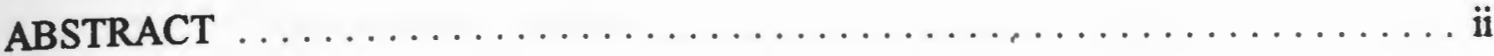

ACKNOWLEDGEMENT $\ldots \ldots \ldots \ldots \ldots \ldots \ldots \ldots \ldots \ldots \ldots$

DEDICATION $\ldots \ldots \ldots \ldots \ldots \ldots \ldots \ldots \ldots \ldots \ldots \ldots \ldots \ldots \ldots \ldots \ldots \ldots \ldots$

TABLE OF CONTENTS $\ldots \ldots \ldots \ldots \ldots \ldots \ldots \ldots \ldots \ldots \ldots \ldots \ldots$ vii

LIST OF TABLES $\ldots \ldots \ldots \ldots \ldots \ldots \ldots \ldots \ldots \ldots \ldots \ldots \ldots \ldots \ldots \ldots \ldots \ldots \ldots \ldots$

LIST OF FIGURES $\ldots \ldots \ldots \ldots \ldots \ldots \ldots \ldots \ldots \ldots \ldots \ldots \ldots \ldots \ldots \ldots$

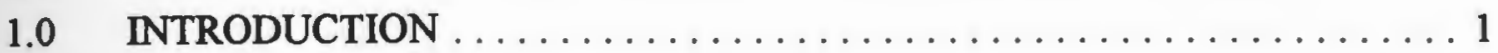

1.1 Significance of the Study $\ldots \ldots \ldots \ldots \ldots \ldots \ldots \ldots \ldots$

1.2 Water Quality Studies Performed on the Blackstone River ........ 3

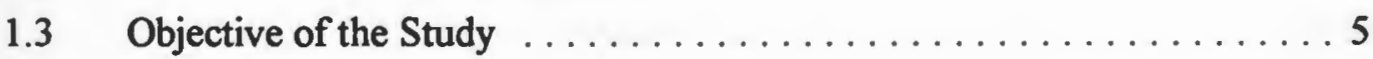

2.0 LITERATURE REVIEW $\ldots \ldots \ldots \ldots \ldots \ldots \ldots \ldots \ldots \ldots \ldots \ldots \ldots$

$2.1 \quad$ Urban Runoff $\ldots \ldots \ldots \ldots \ldots \ldots \ldots \ldots \ldots \ldots$

$2.2 \quad$ Law and Regulations $\ldots \ldots \ldots \ldots \ldots \ldots \ldots \ldots \ldots$

2.3 Sediment Erosion and Resuspension $\ldots \ldots \ldots \ldots \ldots \ldots \ldots \ldots$

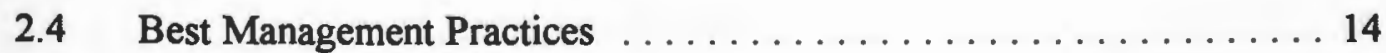

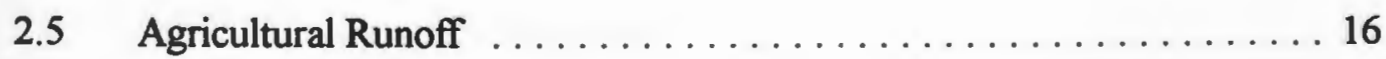

2.6 Computer Programs and Models Available $\ldots \ldots \ldots \ldots \ldots$

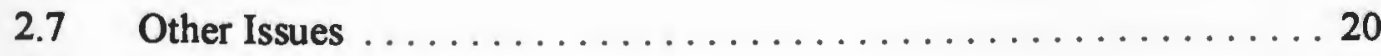


$3.1 \quad$ Water Quality Sampling $\ldots \ldots \ldots \ldots \ldots \ldots \ldots \ldots \ldots \ldots \ldots \ldots$

3.1.1 Water Quality Sampling Stations ............. 23

3.1.2 Dry Weather Field and Sampling Program . . . . . . . . 26

3.1.3 Wet Weather Field and Sampling Program .......... 27

3.1.3.1 Rainfall Criteria ..................... 27

3.1.3.2 Field and Sampling Program ........... 28

3.2 Methods and Methodologies . . . . . . . . . . . . . . 29

4.0 SYSTEM HYDROLOGY AND HYDRAULICS $\ldots \ldots \ldots \ldots \ldots \ldots$

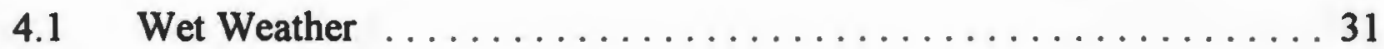

4.1.1 Rainfall .......................... 31

4.1.1.1 Rainfall Network .................... 31

4.1.1.2 Rainfall Characteristics ................ 34

4.1.1.3 Total Rainfall .................... 34

4.1 .2 System Flows $\ldots \ldots \ldots \ldots \ldots \ldots \ldots \ldots \ldots \ldots$

4.2 Hydraulic Structures or Controls $\ldots \ldots \ldots \ldots \ldots \ldots \ldots 6 . \ldots 6$

4.2.1 Dams and Impoundments $\ldots \ldots \ldots \ldots \ldots \ldots \ldots 68$

4.2.1.1 Fisherville Pond ................. 68

4.2.1.2 Rice City Pond .................... 70

4.2.1.3 Hydropower Stations ............... 71

4.2.2 Blackstone River Canal . . . . . . . . . . . . . . 72

5.0 WET WEATHER WATER QUALITY INTERPRETATION $\ldots \ldots \ldots \ldots 73$

5.1 Water Quality Concentrations . . . . . . . . . . . . . 76 
5.1.1 Comparison Between Dry and Wet Weather Concentrations ... 76

5.1 .1 .1 Nutrients .................... 76

5.1 .1 .2 Trace Metals .................. 85

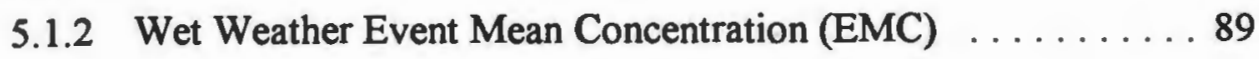

5.1.2.1 Nutrients ....................... 92

5.1.2.2 Conventional .................. 98

5.1.2.3 Trace Metals ..................... 101

5.1.2.4 EMC Comparison With Other Rivers .......... 103

5.1.2.5 EMC Comparison With NURP Studies ........ 108

5.1.3 Hardness, $\mathrm{Cl}, \mathrm{Na}, \mathrm{pH}$, Temperature and $\mathrm{DO} \ldots \ldots \ldots 108$

6.0 WATER QUALITY CRITERIA VIOLATION $\ldots \ldots \ldots \ldots \ldots \ldots \ldots \ldots$

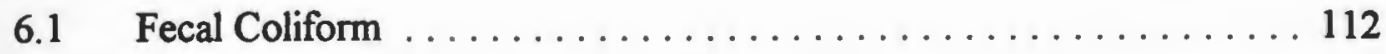

6.2 Acute and Chronic Trace Metal Criteria $\ldots \ldots \ldots \ldots \ldots \ldots$

6.2 .1 Lead . . . . . . . . . . . . . . . . . . . 119

6.2 .2 Copper .............................. 127

6.2 .3 Cadmium .............................. 127

6.2.4 Chromium and Nickel ................. 128

7.0 WET WEATHER POLLUTANT LOADINGS $\ldots \ldots \ldots \ldots \ldots \ldots \ldots$

$7.1 \quad$ Mass Loading Estimates . . . . . . . . . . . . . . . . . . . . . 129

7.2 Wet Weather Event Mean Mass (EMM) . . . . . . . . . 129

7.2.1 Nutrients .............................. 131

7.2 .2 Conventional ............................ 134

7.2.3 Trace Metals ........................ 136

7.3 Comparison of Wet and Total Loadings .............. 140

7.3.1 Nutrients ............................. 143

7.3.2 Conventional ......................... 143 
7.3.3 Trace Metals

7.4 Net Gain and Loss Per Reach . . . . . . . . . . 145

7.5 Major Point Sources vs Nonpoint Sources .............. 146

8.0 SYSTEM RANKINGS $\ldots \ldots \ldots \ldots \ldots \ldots \ldots \ldots \ldots \ldots \ldots \ldots \ldots \ldots$

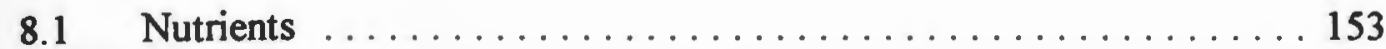

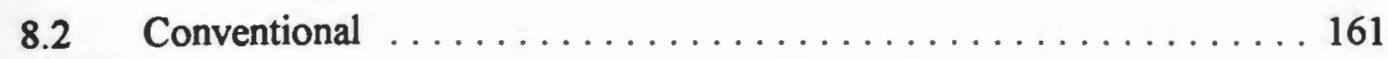

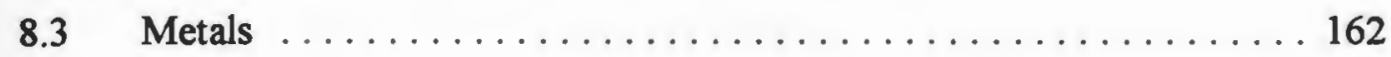

8.4 Comparison Between Wet and Dry Weather Rankings ........ 164

8.5 Comparison of Loads for Different River Systems $\ldots \ldots \ldots \ldots 6$

9.0 CHARACTERIZATION OF NONPOINT LOADS - RUNOFF VS RESUSPENSION .......................... 171

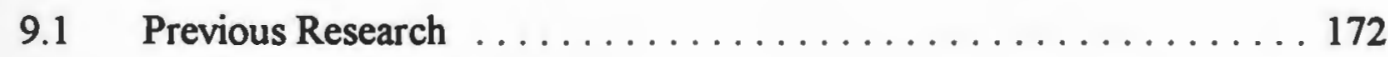

9.2 Blackstone River Application $\ldots \ldots \ldots \ldots \ldots \ldots \ldots \ldots \ldots$

10.0 ANNUAL LOADING RATES $\ldots \ldots \ldots \ldots \ldots \ldots \ldots \ldots \ldots \ldots \ldots \ldots$

10.1 Dry Weather Estimates . . . . . . . . . . . . . . . . . . 179

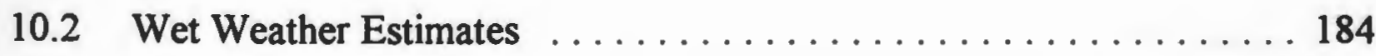

10.3 Determination of Annual Load ................. 186

10.4 Load at State Line and End of River . . . . . . . . . . . 191

11.0 SUMMARY OF WET WEATHER INTERPRETATION - CONCLUSIONS AND RECOMMENDATIONS . . . . . . . . . . . . . . . . . . . 194

11.1 Research Questions ....................... 195 


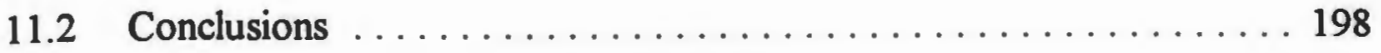

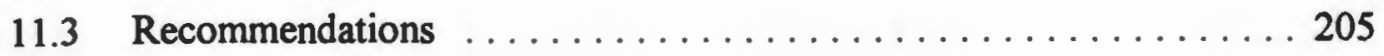

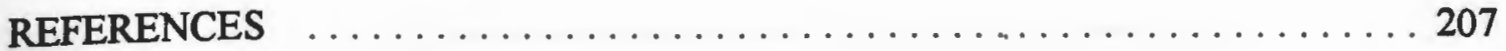

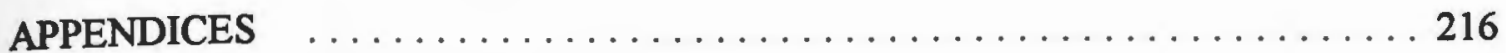

APPENDIX A Raw Data Files for the Blackstone River Surveys . . 216

APPENDIX B Wet Weather Concentration/Mass Loading Figures for Selected Constituents .............. 241

APPENDIX C Wet Weather Concentration/Mass Loading Figures

for Selected Stations for $\mathrm{Pb} \ldots \ldots \ldots \ldots . \ldots 260$

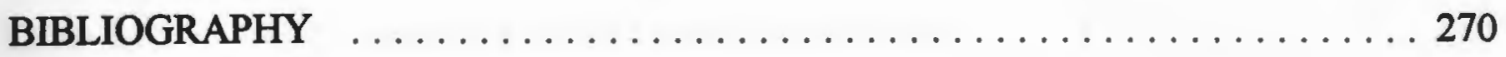




\section{LIST OF TABLES}

Table 3.1 Water Quality Sampling Stations Locations $\ldots \ldots \ldots \ldots$

Table 4.1 Precipitation Log of Three Storms for Blackstone River Wet Weather Studies .......................... 33

Table $4.2 \quad$ Average Rainfall Characteristics $\ldots \ldots \ldots \ldots \ldots \ldots \ldots \ldots$

Table 4.3 Summary Table of Rainfall for Individual Subwatersheds ... . . . . 44

Table 4.4 Summary Table of Rainfall for Cumulative Subwatersheds . . . . . 45

Table 4.5 Blackstone River Flow Summary - Storm $1 \ldots \ldots \ldots$

Table 4.6 ' Blackstone River Flow Summary - Storm $2 \ldots \ldots . \ldots . \ldots$

Table 4.7 Blackstone River Flow Summary - Storm $3 \ldots \ldots \ldots$

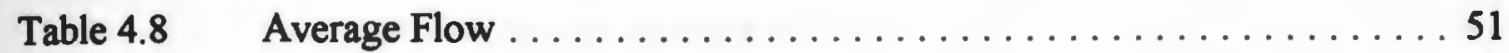

Table $4.9 \quad$ Hydrograph Characteristics - Storm $1 \ldots \ldots \ldots \ldots \ldots \ldots \ldots$

Table $4.10 \quad$ Hydrograph Characteristics - Storm $2 \ldots \ldots \ldots \ldots \ldots$

Table 4.11 Hydrograph Characteristics - Storm $3 \ldots \ldots \ldots \ldots 5$

Table 4.12 Dams and Impoundments on Blackstone River ... . . . . . . . 69

Table 5.1 Comparison of Metals Between Dry and Wet Weather @ UBWPAD .. 87

Table 5.2 Comparison of Metals Between Dry and Wet Weather @ Woonsocket . 88

Table $5.3 \quad$ Event Mean Concentration (EMC) for Storm $1 \ldots \ldots \ldots$

Table 5.4 Event Mean Concentration (EMC) for Storm $2 \ldots \ldots \ldots$

Table 5.5 Event Mean Concentration (EMC) for Storm $3 \ldots \ldots \ldots$

Table 5.6 EMC's for Storm 1, Storm 2 and Storm 3 for the Blackstone River . 106

Table 5.7 EMC's for Blackstone, Moshassuck, Woonasquatucket, Pawtuxet 
Table 5.8 Comparison of EMCs of Blackstone River at Worcester (BWW00) With National NURP, Michigan NPDES and Michigan NURP . . . . . 109

Table 6.1 Fecal Coliform Violations in Accordance with Class B Water Criteria for Dry and Wet Weather .................... 115

Table 6.2 Summary of EPA's Fresh Water Aquatic Life Criteria for Total Metal 117

Table 6.3 Blackstone River Wet Weather Summary of Acute and Chronic Criteria Violations ( Storm 1, Storm 2 and Storm 3) ......... 123

Table 6.4 Acute and Chronic Criteria Violations Comparison for Dry and Wet Weather

Table 7.1 - Blackstone River Wet Weather Wet Loading Summary, \% Total Averaged Across All Storms

Table 7.2 Blackstone River Wet Weather Wet Loading Summary, \% Total Averaged Across All Stations . . . . . . . . . . . . . . . 142

Table 7.3 Blackstone River Wet Load Point vs Nonpoint Percentages . . . . . . 149

Table 7.4 Blackstone River Total Load Point vs Nonpoint Percentages . . . . . 150

Table 7.5 Summary Average of Wet and Total Load Point vs Nonpoint Percentages .......................... 152

Table 8.1 Average Blackstone River Wet Weather Rankings, Wet Load . . . . . 154

Table 8.2 Average Blackstone River Wet Weather Rankings, Total Load . . . . 156

Table 8.3 Average Blackstone River Wet Weather Rankings, Wet Load, without Point Sources ........................ 158

Table 8.4 Average Blackstone River Wet and Dry Weather Rankings (Total Load) 165

Table 8.5 1988-89 NBP Tributary Wet loads and Rankings $\ldots \ldots \ldots \ldots$

Table 8.6 1988-89 NBP Wet Loads for Blackstone, Moshassuck, Woonasquatucket, Pawtuxet and Ten Mile Rivers 169 
Table $8.7 \quad$ 1992-93 Tributary Wet Loads Estimates and Rankings . . . . . . . 170

Table 9.1 Resuspended Loading Predictive Equations (Load vs Flow) . . . . . 175

Table 9.2 Runoff and Resuspended Loads Between BWW07 and BWW08 _. 177

Table 10.1 Dry Weather Predictive Equations (Concentration vs Flow) ... . . 183

Table 10.2 Comparison Between Model and Nixon (1991)

Regression @ BWW21 ..........................185

Table 10.3 Wet load Regression Data for Rainfall vs Load for BWW21

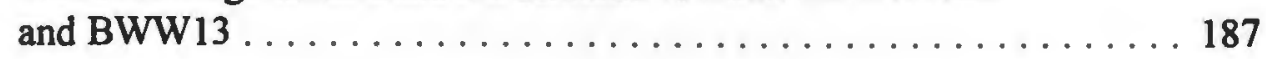

Table 10.4 Wet Weather Predictive Equations for BWW21 (Load vs Rainfall) . . 188

Table 10.5 Wet Weather Predictive Equations for BWW13 (Load vs Rainfall) . . 189

Table 10.6 Annual Mass Loading Forecast Summary for Blackstone River at State Line (BWW13) and End of River (BWW21) ....... 192 


\section{LIST OF FIGURES}

Figure $3.1 \quad$ Sampling Station Location $\ldots \ldots \ldots \ldots \ldots \ldots \ldots \ldots \ldots \ldots \ldots \ldots \ldots$

Figure 4.1 Raingages Location For Blackstone River Wet Weather Studies . . . . 32

Figure 4.2 Rainfall For Blackstone River Wet Weather Studies .......... 35

Figure 4.3 Rainfall Watersheds Distribution - Storm $1 \ldots \ldots \ldots \ldots$

Figure 4.4 Rainfall Watersheds Distribution - Storm $2 \ldots \ldots \ldots \ldots \ldots$

Figure $4.5 \quad$ Rainfall Watersheds Distribution - Storm $3 \ldots \ldots \ldots \ldots$

Figure 4.6 Thiessen Polygons - Storm $1 \ldots \ldots \ldots \ldots \ldots \ldots \ldots \ldots \ldots \ldots \ldots$

Figure 4.7 Thiessen Polygons - Storm $2 \ldots \ldots \ldots \ldots \ldots \ldots \ldots \ldots \ldots \ldots$

Figure 4.8 Thiessen Polygons - Storm $3 \ldots \ldots \ldots \ldots \ldots \ldots \ldots \ldots \ldots$

Figure 4.9 Spatial and Temporal Flow Profile Presentation - Storm $1 \ldots \ldots 6$

Figure 4.10 Spatial and Temporal Flow Profile Presentation - Storm $2 \ldots . \ldots 57$

Figure 4.11 Spatial and Temporal Flow Profile Presentation - Storm $3 \ldots \ldots 8$

Figure 4.12 Hydrograph Comparison - Storm $1 \ldots \ldots \ldots \ldots \ldots$

Figure 4.13 Hydrograph Comparison - Storm $2 \ldots \ldots \ldots \ldots \ldots \ldots \ldots \ldots$

Figure 4.14 Hydrograph Comparison - Storm $3 \ldots \ldots \ldots \ldots \ldots \ldots$

Figure 4.15 Hydrograph Comparison - Headwaters .............. 64

Figure 4.16 Hydrograph Comparison - State Line $\ldots \ldots \ldots \ldots \ldots \ldots$

Figure 4.17 Hydrograph Comparison - Mouth of The River $\ldots \ldots \ldots 6$

Figure 4.18 Example of Concave Base Flow Separation $\ldots \ldots \ldots 67$

Figure 5.1 Flow Chart Describing Water Quality Evaluation of Wet

Weather Concentration ........................ 74 
Figure 5.2 Flow Chart Describing Determination of Runoff/Resuspension and Annual Loading Rate . . . . . . . . . . . . . . 75

Figure 5.3 3-D Flat Ammonia Concentration Presentation - Storm $2 \ldots \ldots 77$

Figure 5.4 3-D Flat Nitrate Concentration Presentation - Storm $2 \ldots \ldots \ldots \ldots$

Figure 5.5 3-D Flat Ammonia Concentration Presentation - Storm $1 \ldots \ldots \ldots 80$

Figure 5.6 3-D Flat Nitrate Concentration Presentation - Storm $1 \ldots \ldots \ldots$. . . 81

Figure 5.7 3-D Flat Phosphate Concentration Presentation - Storm $1 \ldots \ldots \ldots 84$

Figure 5.8 3-D Flat Chromium Concentration Presentation - Storm $1 \ldots \ldots$

Figure 5.9 - 3-D Flat Lead Concentration Presentation - Storm $1 \ldots \ldots \ldots$

Figure 5.10 EMC Plots for $\mathrm{NO}_{3}$ and $\mathrm{NH}_{3}$ for Storms 1,2 and $3 \ldots \ldots \ldots$

Figure 5.11 EMC Plots for $\mathrm{PO}_{4}, \mathrm{FC}$ and $\mathrm{EC}$ for Storms 1,2 and $3 \ldots \ldots 9$

Figure 5.12 EMC Plots for TSS, VSS and $\mathrm{Pb}$ for Storms 1,2 and $3 \ldots \ldots 9$

Figure 5.13 EMC Plots for $\mathrm{Cl}$ and $\mathrm{Na}$ for Storms 1,2 and $3 \ldots \ldots \ldots 2$

Figure 5.14 EMC Plots for $\mathrm{Cd}, \mathrm{Cr}$ and $\mathrm{Cu}$ for Storms 1,2 and $3 \ldots \ldots \ldots 104$

Figure 5.15 EMC Plots for Ni, $\mathrm{Zn}$, and BOD for Storms 1, 2 and $3 \ldots \ldots \ldots$

Figure 6.1 3-D Flat Fecal Coliform Load Presentation - Storm $1 \ldots \ldots \ldots 113$

Figure 6.2 Example Figure of $\mathrm{Pb}$ Showing Acute and Chronic Criteria Violation

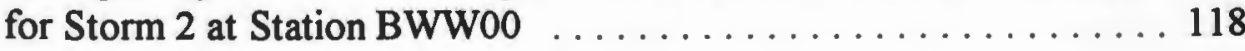

Figure 6.3 3-D Flat Acute Criteria Violations for Total Pb - Storm $3 \ldots \ldots \ldots 120$

Figure 6.4 3-D Flat Acute Criteria Violations for Total $\mathrm{Cu}$ - Storm $2 \ldots \ldots 121$

Figure 6.5 3-D Flat Acute Criteria Violations for Total Cd - Storm $1 \ldots \ldots 122$

Figure 7.1 Example figure of $\mathrm{Cr}$ Showing Mass Loading Calculation for Storm 2 at Station BWW04 . . . . . . . . . . . . . . . 130 
Figure 7.2 EMM Plots for $\mathrm{NO}_{3}$ and $\mathrm{NH}_{3}$ for Storms 1, 2 and 3

Figure 7.3 EMM Plots for $\mathrm{PO}_{4}, \mathrm{FC}$ and $\mathrm{EC}$ for Storms 1,2 and $3 \ldots \ldots 133$

Figure 7.4 EMM Plots for TSS, VSS and $\mathrm{Pb}$ for Storms 1,2 and $3 \ldots \ldots 135$

Figure 7.5 EMM Plots for $\mathrm{Cl}$ and $\mathrm{Na}$ for Storms 1,2 and $3 \ldots \ldots \ldots 137$

Figure 7.6 EMM Plots for $\mathrm{Cd}, \mathrm{Cr}$ and $\mathrm{Cu}$ for Storms 1,2 and $3 \ldots \ldots 138$

Figure 7.7 EMM Plots for $\mathrm{Ni}, \mathrm{Zn}$, and BOD for Storms 1,2 and $3 \ldots \ldots 139$

Figure 7.8 Example figure of Wet Load Showing Gain and Loss for TSS,

$\mathrm{Cu}$ and $\mathrm{Pb}$ for Storm $2 \ldots \ldots \ldots \ldots \ldots \ldots \ldots \ldots \ldots \ldots$

Figure 7.9 Example Plot of Wet Load Showing Point and Non Point Sources

- Comparison for $\mathrm{Pb}$ Storms 1, 2 and $3 \ldots \ldots \ldots \ldots \ldots . \ldots 148$

Figure 9.1 Example Plot of Regression Line of $\mathrm{Pb}$ for Resuspended Load vs

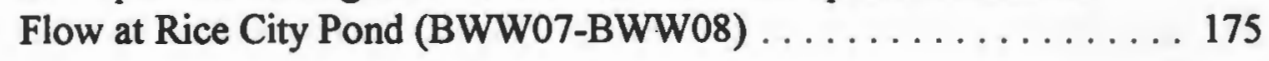

Figure 9.2 Example figure of Resuspended and Runoff Load Calculation of $\mathrm{Pb}$ for Storm 2 at Rice City Pond (BWW07-BWW08) ........ 176

Figure 10.1 Post Audit @ MA/RI State Line (BWW13) ............ 180

Figure 10.2 Post Audit @ End of River (BWW21) ................... 181

Figure 10.3 Example Plot of Model Regression, Nixon Regression with 6-Real

Data Points for $\mathrm{Pb}$ at End of River (BWW21) .......... 185

Figure 10.4 Example Plot of Model Regression for Load vs Rainfall for $\mathrm{Cu}$ at End of River (BWW21) $\ldots \ldots \ldots \ldots \ldots \ldots \ldots$

Figure 10.5 Example Plot of Model Regression for Load vs Rainfall for $\mathrm{Cu}$ at State Line (BWW13) 


\section{CHAPTER 1}

1.0 Introduction

The Blackstone River is an interstate waterway with its headwaters in Worcester, Massachusetts. It flows south through Pawtucket, Rhode Island into the Providence River and finally upper Narragansett Bay. The watershed area covers $480 \mathrm{mi}^{2}\left(1230 \mathrm{~km}^{2}\right)$ and its length is approximately $48 \mathrm{mi}(76.8 \mathrm{~km})$. The major tributaries to the river are the Quinsigamond, Mumford, West, Branch, Mill and Peter's Rivers. Quinsigamond, Mumford, and West rivers flows in to the Blackstone River in Massachusetts, and Mill, Branch and Peters rivers in Rhode Island. Although Mill and Peters Rivers enter the Blackstone River in Rhode Island, the majority of their watersheds is in Massachusetts. The Blackstone River basin area is approximately 44 miles long and 12 miles wide and about two thirds of the basin area is in Massachusetts and the other one third is in Rhode Island. The Blackstone River flows south from Worcester through the Massachusetts towns of Millbury, Sutton, Grafton, Northbridge, and Uxbridge and through the Rhode Island towns of Woonsocket, Millville, Lonsdale and Pawtucket.

\subsection{Significance of the Study}

Narragansett Bay is Rhode Island's greatest resource where human activities include fishing and recreation. The Blackstone River, the second largest freshwater source to Narragansett Bay, is also the largest source of many pollutants. Wright et al. (1991) identified the Blackstone River as the major source of both nutrients and trace 
metals.

The Blackstone River has a long history of pollution. The states of Rhode Island and Massachusetts are very interested in resolving the water quality problems of the river and ultimately improving its overall resource value. America's industrial revolution began here. Attracted to the water power that the river provided, Samuel Slater established the first successful water-powered textile mill in the United States in 1790. The historic Slater Mill is still there along the Blackstone River in Pawtucket, Rhode Island. Subsequently numerous mills were built along the entire length of the Blackstone River. By 1800, Pawtucket alone contained 29 cotton mills (Kipp et al. 1992). The Blackstone averaged one dam for every mile of stream by 1830 . Other industries also flourished along the Blackstone River, including textile machinery manufacturers, metal platters, tanneries, wire and steel mills, and woodworking companies.

The Blackstone provided another valuable function for industry: waste disposal. Toxic waste from fabric dying, leather tanning, manufacturing and metalworking were dumped in the river. In the mid-nineteenth century, complaints about the appearance and odor of the Blackstone River were being raised. In the late nineteenth and early twentieth centuries, the Blackstone River was called "the world's busiest river," due to the number of mills along its bank, many of which relied on the river for power. Another term used to describe the Blackstone River was "an industrial stream"; today, that term might be translated to mean "polluted stream". Sewage and wastes were inadequately regulated prior to the enactment of the Clean Water Act in 1972 and were usually discharged directly into the river in large quantities. The legacy of about two centuries of pollution is 
still present in the river sediments and continued industrial discharge.

1.2 Water Quality Studies Performed on the Blackstone River

The Narragansett Bay Project (NBP) funded several water quality monitoring surveys to identify the water pollution problems in the Bay. Several of these studies included major tributaries, including the Blackstone River, at their mouths for monitoring numerous parameters including conventional and toxic pollutants (Wright et al. 1991; Pilson and Hunt 1989; Doering et al. 1989; Metcalf and Eddy 1991).

Quinn (1989) identified the Blackstone River as the major source of solids and petroleum hydrocarbons (PHCs), and a significant source of polycyclic aromatic hydrocarbons (PAHs) to Narragansett Bay based on the SINBADD cruises. Latimer (1989) also identified the Blackstone River as a major source of polychlorinated biphenyl (PCB).

Wright et al. (1990) examined three recent water quality surveys (SPRAY, SINBADD, and the wet weather study for the NBP) and identified the Blackstone River as a major source of most of the pollutants. The Blackstone River also ranked first or second for almost all pollutants (nutrients and trace metals) during the three wet weather events surveyed for the NBP project (Wright et al. 1991).

The Massachusetts Department of Environment Protection (MADEP) classified the Blackstone River as class B. Nearly the entire length in Massachusetts, is considered not to support the designated uses due to coliform, metals, dissolved oxygen (DO), and nutrients (MADEP 1990). The Rhode Island Department of Environmental Management 
(RIDEM) classified its portion of the river as class C. The entire length in Rhode Island, is considered not to support the designated uses due to metals, nutrients and coliform (RIDEM 1990).

Wright (1988) and Quinn et al. (1988) found that levels of cadmium, copper, lead and PCBs were already exceeding RI freshwater aquatic life chronic criteria, where the river entered Rhode Island from Massachusetts. In addition, copper concentrations also exceeded the acute criteria. Wright (1988) also concluded that inputs from Rhode Island's discharges were relatively insignificant compared to loads coming from Massachusetts. Other studies have found water quality criteria to be violated throughout the Blackstone, in both states and during dry and wet weather conditions (Wright et al. 1991; RIDEM 1990; USEPA 1983; Save The Bay 1990).

There were 41 permitted dischargers (Point Sources) to the Blackstone River and its tributaries, 28 of these are industrial and 13 are municipal (Kipp et al. 1992). The municipal dischargers included 11 waste water treatment facilities ( WWTF). Only two WWTFs have pretreatment programs (Upper Blackstone Water Pollution Abatement District (UBWPAD) and Woonsocket WWTF) and one (UBWPAD) provides seasonal nitrification.

Nonpoint sources to the Blackstone River may include agricultural and urban runoff, soil erosion and sediment resuspension, leachate from landfills, leaking underground storage tanks, hazardous waste sites, and effluent from failed septic systems. Usually wet weather exacerbates the loadings from these sources. Little data exists for nonpoint sources and associated pollutant loadings to the Blackstone but they are likely a 
significant input. One study by EPA found that Lake Quinsigamond was experiencing eutrophic condition due to runoff of phosphorous, and bacterial pollution was widespread as a result of sewage contamination of storm drains via routes such as illegal connections and infiltration (USEPA 1983).

An estimated 2,180,00 cubic yards of contaminated sediments in the Massachusetts portion of the Blackstone River alone is reported by McGinn (1981). These sediments trapped behind current or former impoundments, have been identified as a potential major source of pollutants to the Blackstone River. During the period of rainfall or high flow conditions these sediments are resuspended and carried downstream, therefore contributing to water quality problems.

\subsection{Objective of the Study}

While some studies have been conducted on localized segments of the river, the lack of a comprehensive water quality survey for the entire river is identified as a hindrance to developing an understanding of the trends and kinetics of the pollutants in the river. As a result, the Blackstone River Initiative (BRI) was established by the U. S. Environmental Protection Agency (USEPA) with the Massachusetts Department of Environmental Protection (MADEP), Rhode Island Department of Environmental Management (RIDEM) and the Civil Engineering Department of the University of Rhode Island (CVE-URI). This study will be the first comprehensive watershed wide wet weather study.

BRI had two programs: one for dry weather and the other for wet weather. Three 
surveys were done successfully for the dry weather program (July 1991; August 1991; and October 1991). Three storms were successfully captured for the wet weather program (September 1992; November 1992; and October 1993).

The goal of this research is to characterize the water quality of the Blackstone River watershed under wet weather and provide a comparison of results with dry weather conditions. The objectives included:

1) The determination of the impact of wet weather on the water quality of the Blackstone River;

2) The identification of the major pollutant sources and/or areas in the Blackstone River watershed and the development of system rankings; and

3) The determination of the relative importance between nonpoint and point sources and the development of annual loading rates for selected constituents. 


\section{CHAPTER 2}

\section{$2.0 \quad$ Literature Review}

Millions of Americans make their living from the nation's waters. They fish and swim for recreation, or choose to locate their homes or businesses near waterways. The report, based on data collected in 1991-92, shows that America's waters are indeed in trouble. Approximately $40 \%$ of the waters are not suitable for simple activities such as fishing or swimming (Browner 1994). Polluted runoff (nonpoint source pollution) is the single greatest threat remaining to America's rivers, lakes, and estuaries. All pollution abatement efforts were aimed at controlling the point source pollution although more than $50 \%$ of the total water quality problems are nonpoint source related (Novotny and Chesters 1981).

Water bodies receive pollutants such as: silt, pesticides and fertilizer, whenever it rains. Pollutants are carried off farms, suburban lawns, industrial plants, and city streets into the rivers and lakes during the storm events. Controlling runoff from fields and streets is more difficult than controlling the pollution emitted from the end of a pipe (point source). Polluted water that flow from the land to streams is a problem that has long been neglected and has not been properly addressed. Nonpoint source pollution has increased in the U.S. and in the world. Mitchell (1996) found as much as $80 \%$ of water pollution is nonpoint source related and it has largely escaped the attention of regulators.

Water quality problems in rivers, lakes and continental shelves are widespread (Andersson and Rydberg 1988; Fransz and Verhagen 1985; Lancelot et al. 1987; 
Rosenberg 1985; Rosenberg and Loo 1988; Wulff and Rahm 1988). Water quality in streams, rivers, lakes and coastal waters may change due to pollution. Watersheds are modified by alterations in vegetation, sediment balance, fertilizer use and the conversion of forests and grasslands to farms and cities (Aber et al. 1989; Borman and Likens 1979; Schlosser and Karr 1981; White et al. 1981).

About $\$ 40.5$ billion in federal money plus some $\$ 25$ billion more in state and local funds have been invested in the fight against water pollution (Taylor 1987). The quality of some 47,000 miles of monitored streams is markedly improved but 311,000 miles of water have worsened or remained unchanged. The cleaner the water becomes, the more attractive it becomes to the people to settle near it. The new development near the cleaner water starts the pollution cycle all over again. U.S. residents spent $\$ 62.7$ billion on pollution abatement and control (PAC) in 1983. This spending was for regulation and monitoring, pollution abatement, and research and development (U. S. Department of Commerce 1985). Regulation and monitoring is a government activity that stimulates and guides action to reduce pollutant. Pollution abatement directly reduces pollutant by preventing the generation of pollutant, recycling them, or treating them prior to discharge. Research and development supports abatement and helps increase the efficiency of regulation and monitoring.

Quantification of these watershed/water-quality relationships is important. Understanding the consequences of existing or potential watershed changes leads to the possibilities for preventing or remedial action. 


\subsection{Urban Runoff}

The discharge of storm water into navigable waterways is recognized as a widespread problem. Urban runoff discharge is partially responsible for the degradation of U.S. waterways. A leading cause of water quality impairment is the pollution from diffuse, i.e. nonpoint sources (Skoch 1993). The stormwater pollution problem is difficult to solve primarily because it is easily created. A discharge occurs whenever rainwater falls on contaminated soils or piles of materials containing pollutants. This stormwater then carries the contaminants into waterways.

Analyzing pollutants in discharges at the end of the pipe were traditionally emphasized. A number of recent initiatives taken by EPA will change the direction of monitoring in general (Cook et al. 1994).

Combined sewer overflow (CSO) discharges pose a serious threat to receiving water quality in many urban drainage basins. Wright et al. (1992) studied the CSOs in Providence and modeled the impact of Providence sewer system to the Narragansett Bay in Rhode Island.

Cave and Roesner (1994) summarized previous stormwater monitoring programs and the Nationwide Urban Runoff Program (NURP). A comparison of the EMC values of selected constituents of NURP data collected in the early 1980s with the National Pollutant Discharge Elimination System (NPDES) data collected in 1991-1993 in the State of Michigan was presented by them. The constituents analyzed and presented by the study included total suspended solids (TSS), chemical oxygen demand (COD), biochemical oxygen demand (BOD), total phosphorous, dissolved phosphorous, total 
Kjeldahl nitrogen (TKN), nitrite+ nitrate nitrogen, fecal coliform (FC), lead, zinc and copper. A comparison of EMC values of this study at an urban station (BWW00) with NURP studies are provided in Chapter 5 (Table 5.6).

Thomas and McClelland (1994) described a regional stormwater monitoring plan developed and implemented in the Atlanta Region to comply with NPDES rules. Similar studies were done in Dallas-Ft Worth, Texas (Brush et al. 1994) and Santa Clara Valley, California (Cooke et al. 1994). Brown et al. (1994) presented the methods and procedures developed by the City of Austin, Texas, Stormwater Monitoring Program to ensure the quality of stormwater monitoring data produced.

Turner and Rabalais (1991) studied the changes in the water quality of the Mississippi River. In terms of length, discharge, and sediment yield, the main river channel is the third, eighth, and sixth, respectively, largest river in the world (Milliman and Meade 1983). Water quality in the river has almost certainly changed this century as a result of the watershed changes and changes in fertilizer use. The authors studied three indicators of water quality: phosphorous (as total phosphorous), silicon (as silicate), and dissolved inorganic nitrogen (as nitrate). They used water quality data primarily from the Water Quality or Water Supply Papers series of the US Geological Survey and also data supplied by the New Orleans Sewerage and Water Control Board. They compared the mean concentrations of nitrate, silicate, and total phosphorous for four lower Mississippi River stations. 


\section{$2.2 \quad$ Law and Regulations}

There was no major legislation dealing with nonpoint pollution until the U.S. Congress passed the Federal Water Pollution Control Act in 1972. The general population was not even aware of the problem until the late 1960s. The National Environmental Policy Act (NEPA) was designed to protect natural and environmental resources. Safe Drinking Water Act of 1974 was designed to protect the nation's drinking waters. Toxic Substances Control Act of 1976 is the primary legislative document controlling the toxic substance in the environment. The Federal Water Pollution Control Act with its 1977 amendments, known as "The Clean Water Act", recognized cleaning up nonpoint sources to solve the nation's water quality problem.

The Clean Water Act charges the Environmental Protection Agency (EPA) with policing the release of toxic chemicals into the nation's rivers, lakes and streams. By law, industrial firms may not release anything into these waters without first obtaining an EPA permit to do so. A new analysis by the General Accounting Office (GAO), a congressional watchdog agency, found that some $77 \%$ of the toxic pollutants discharged were not listed on their permits (Science News 1994). About $85 \%$ of the facilities, majority of the toxic pollutants discharged were not controlled through the permit process.

Need for the revisions for stormwater regulations provided under the Clean Water Act of 1977 were required to be able to address pollution problems more effectively and realistically (Tucker et al. 1995). Under the existing program, all municipal and local governments are required to obtain NPDES permits for rainwater runoff discharged into receiving water. This and other regulations have been found to create significant 
budgetary problems for local officials throughout the U.S.

Urban stormwater runoff is receiving increased attention from the US EPA. It issued the final rule to implement Section 402 (P) of the Clean Water Act in 1990. This rule requires cities over 100,000 in population to obtain stormwater permits under the NPDES. The management of nonpoint sources of water pollution is often complicated. Defining the specific sources, pollutants, or both is difficult and costly task. A report to Congress By U.S. EPA (1984) identified five major categories of nonpoint pollution: agricultural; silvicultural; mining; construction; and urban. Nonpoint inputs from urban and industrial locations, forests, agricultural areas, and mining activities contain different types of pollutants and represent different transport patterns.

\subsection{Sediment Erosion and Resuspension}

Several studies were done in the past on modeling sediment transport and deposition (Arnolds et al. 1995; Cao et al. 1995; Mertes 1994). French (1995) proposed a new methodology to measure the maximum depth of deposition that occurs when a steep slope channel changes to a milder slope. Garbrecht et al. (1995) presented a new sediment transport capacity algorithm for measuring large scale propagation and redistribution of sediments in channel networks. The proposed algorithm uses existing sediment transport equations and generated consistent results for a wide range of flow and sediment characteristics.

Srivasta and Contractor (1992) evaluated the bed-load and suspended-load transport of sediments. Gomez (1991) reviewed the development of knowledge and 
research into bedload transport during the past century. Particular emphasis was placed on the development of methods of predicting and estimating bedload discharge, and problems involved in using field data.

The amount of sediment moving into a part of the channel must equal the channel's capacity to move the sediment out of that channel segment. Otherwise sediment will either be deposited ultimately filling the channel or the force of the moving water will erode the channel banks and bed to restore the balance. Obtaining accurate measurements of sediment movement is very difficult. The complete understanding of bedload transport requires the development of reliable apparatus and techniques for predicting, measuring, and sampling bedload in rivers. The Agricultural Research Services (ARS) conducted some research in this field. Their engineers developed a sampling box for collecting coarse sediment and a sonar detection system for tracking sediment movement (Becker 1994).

A study done by Haster and James (1994) found different land surfaces contribute sediments differently. A better estimate of the total sediment load could be determined by representing each of the major land surfaces independently. They proposed a mathematical model for representing the washoff of sediments from small urban watersheds during storm events.

Universal soil loss equation (USLE) is the most widely used method of soil loss prediction. USLE was developed largely through the work of Wischmeier and Smith (1978). More than 8000 plot-years of erosion data were collected from 36 locations in 21 states and were used. Ease of application was a prime consideration in the development 
of the USLE. This emperical method was originally developed for soil conservation work in cropland areas. The equation has since been adapted and interpreted for other erosion loss problems.

The USLE is the product of six factors:

$$
A=\text { RKLSCP }
$$

where $A=$ calculated soil loss, $R=$ rainfall erosivity factor, $L=$ slope length,$K=$ soil erodibility factor, $\mathbf{S}=$ slope gradient factor, $\mathrm{C}=$ crop management factor, and $\mathrm{P}=$ erosion control practice factor. The equation was free of some of the geographical and climatic restrictions of earlier methods of soil loss prediction. It was developed largely in the eastern two-thirds of the USA and so it is not necessarily applicable outside that area.

\subsection{Best Management Practices}

"Best Management Practice (BMP) means a practice or combination of practices that is determined by state (or designated area-wide planning agency) after problem assessment, examination of alternative practices, and appropriate public participation to be the most effective practicable (including technological, economic, and institutional considerations) means of preventing or reducing the amount of pollution generated by nonpoint sources to a level compatible with water quality goals" (Novotny and Chesters 1981).

BMP is an innovative storm-water-management program which involves the consideration of storm-water runoff as a potential resource rather than as a problem (BouSabb 1993). BMPs are implemented to prevent future deterioration in the water quality 
and to check existing pollutants in the water. The aim of the project is to control runoff at the surface instead of constructing expensive treatment plants at the discharge point.

Wetlands are valuable as sinks, sources and transformers of a multitude of chemical, biological, and generic materials. Wetlands are found to cleanse polluted waters, prevent floods, protect shorelines, and recharge groundwater aquifers and provide shelters for rare plant, fish and wildlife.

Inland wetlands function as basins in the watershed that retain and detain water at various flood stages. Retained water leaves the surface water via evapo-transpiration and the delayed release of flood water causes less damage in the downstream. Coastal wetlands protect fast lands from erosion and buffer coastal flooding and sea level rise.

Wetlands remove nutrients and significant amounts of metals and reduce the sediment load transported in streams (Kibby, 1978). Wetlands act as a fish nursery, protect wildlife and sometimes add visual and aesthetic values.

Most stormwater permits require early action BMPs which include reduction of sources of pollutants through public education. One of the least costly and most effective ways to reduce nonpoint source pollution is storm drain stenciling. This approach addresses urban water pollution where it often starts, in the storm drain system of our communities. Storm drain stenciling is very simply, public education in the streets. It consists of volunteers painting, with a stencil, a pollution prevention message on the entrances to the drains throughout a city. While messages can vary, one study (Cobourn 1994) found it to be effective to state merely, "No Dumping; Drains to River." Changes in rainfall/runoff characteristics of an area as affected by some management 
practices such as livestock grazing can be estimated using rainfall simulation (Frasier et al. 1995). Streambank fencing is a management practice which keeps livestock and streams separated. This has the potential to decrease soil loss by preventing the mechanical breakdown of the streambank by livestock. It also serves as a vegetative filter to entrap soil lost from the surface of the grazed area as it moves toward the stream and prevents animals from defecating directly into the river. Owens et al. (1996) found average monthly sediment concentrations in the storm runoff were considerably lower after the stream was fenced away from grazing livestock.

A watershed rehabilitation program was undertaken for the Redwood National Park (Griffin 1990). Watershed rehabilitation consisted primarily of small- scale laborintensive techniques. Channel water table control can improve water use efficiency within a watershed. It reduce demands on other water sources to facilitate irrigation; improve crop yields; and reduce the transport of fertilizer nutrients, in particular nitrogen, to sensitive receiving surface waters (Evans et al. 1992). The success of watershed-scale projects are influenced by several factors such as: soils, crops, and topography within the watershed; the percentage of the watershed area cropped; hydraulic properties of the watershed; seasonal rainfall; and management strategies.

\subsection{Agricultural Runoff}

Soileau et al. (1994) conducted a study to evaluate the effects of tillage on sediment, nitrogen, and phosphorous runoff losses from a representative watershed planted to cotton. Comparisons were made for three years of conventional tillage 
followed by three years of conservation tillage. This study showed that for both tillage systems, sediment losses were less than 11,200 kilograms per hectare per year and a cotton residue cover during winter months was effective in minimizing total annual soil losses.

Isensee and Sadeghi (1993) studied the impact of tillage practice on runoff and pesticide transport. Comis (1992) found that no-till, an energy-saving method of planting without prior ploughing, keeps the surface flow and erosion to a minimum. It allows less topsoil and chemicals to reach streams, rivers, and lakes for contaminating the water.

Runoff and erosion are increased by decreased vegetative cover, increased soil compaction, and/or cutting of stream banks. Several studies were done to understand the impact of vegetation on runoff. Johnson and Blackburn (1989) found runoff produced with a rainfall simulator was two to three times greater from a bare treatment than from natural or clipped treatments. He also found the soil losses were about 20 times greater for a bare treatment than from natural or clipped treatments. The percent bare ground is the most important factor explaining soil loss, and as the ground cover increases, soil sediment in the runoff decreases (Hofmann and Ries 1991; Zobisch 1993; Costin 1980; Lang 1979).

A study done in Latvia showed that concentrations in river water increased 5-10 times that of background values as a result of fertilizer application and marsh land destruction (Tsirkunov et al. 1992). Greater flow velocity might be the reason for the bigger load transport during a storm event. 
2.6 Computer Programs and Models Available

Some computer programs were developed in recent years to understand and model pollution and tracking pollution sources.

QUAL2E was developed by EPA and went through several revisions (EPA 1987). This program is used to simulate DO, BOD, temperature, algae as chlorophyll a, organic nitrogen as $\mathrm{N}$, ammonia as $\mathrm{N}$, nitrite as $\mathrm{N}$, nitrate as $\mathrm{N}$, organic phosphorous as $\mathrm{P}$, dissolved phosphorous as $\mathrm{P}$, coliforms, arbitrary nonconservative constituents and three conservative constituents. It allows for multiple waste discharges, withdrawals, tributary flows, and incremental inflow and outflow. QUAL2E operates in steady-state modeling conditions.

Wright et al. (1985) developed PAWTOXIC model to simulate the trace metal in the Pawtuxet River, Rhode Island. The successful calibration and validation exercise indicates that the model can be confidently used as a predictive tool. This model is extensively used by the RIDEM.

Agricultural Non-Point-Source (AGNPS) pollution model identifies watershed sites that could possibly carry pollutant such as pesticides, fertilizers or sediments (Comis 1995). The AGNPS divides watersheds into grids, each grid cell containing information such as soil type, topography, land use, chemicals applied, tillage method etc. The pollution potential is then calculated on a per-grid basis.

A model was developed to simulate the suspended transport of the fine-grained sediment, both cohesive and noncohesive, in the Pawtuxet River, Rhode Island (Ziegler and Nisbet 1994). The SEDZL modeling framework has been modified to include the 
simulation of noncohesive suspended transport. The hydrodynamic and sediment transport models were calibrated and validated during a 33-day period, which included two high-flow events.

A computer-aided methodology was designed by Reinelt et al. (1988) to aid in the determination of water quality and ecological change resulting from nonpoint sources of water pollution. A case study example on the Stillaguamish River Basin in Washington State is provided also in the article.

An integrated rainfall-runoff and runoff-receiving water-quality modeling protocol was developed by Warwick and Edgmon (1988) to quantify the impact of combined sewer overflow events on in-stream dissolved oxygen concentration.

Storm Water Management Model (SWMM) was developed to simulate and design of combined or storm water sewer systems (EPA 1971). Its use for simulating nonpoint pollution processes and problems is limited. The program is large and requires an extensive amount of input data.

Storage, Treatment and Overflow Model (STORM) was developed for the U.S. Army Corps of Engineers (STORM 1975). This program can simulate quantity and quality of runoff from small urban watersheds. Nonurban areas can also be included in this program. Total and volatile particulates, biochemical oxygen demand (BOD), total nitrogen and orthophosphate can be modeled using STORM. It is a medium-sized program but requires a substantial amount of input data.

Nonpoint Simulation Model (NPS) simulates pollution from a maximum of five different land use categories in a single operation (Donigian and Crawford 1976). It 
allows for simulation of runoff, water temperature, Dissolved oxygen (DO) and sediments. The Overland Flow and Pollution Generation Model (LANDRUN) was primarily used for modeling effects of various land uses on the pollutant loading to the Great Lakes (Novotny et al. 1979). It is a medium sized program and can be run on a storm event basis or continuously.

\subsection{Other Issues}

The third world is counting heavily on water resource development to foster economic growth. Many nations also rely on hydroelectric development to reduce dependence on costly fuel oil. Many of the benefits of water resources development in the third world have been lost because of soil erosion, sedimentation and serious water quality problems have arisen (Southgate and Macke 1989). Sometimes pollution is a political and cultural problem in the third world countries. Alley (1994) described the impact of waste on the river Ganges in India and addressed the tensions played out in the community as government agencies developed the category of environmental pollution in official policy.

Sometimes, in the developed countries, opposition and various lobbyist groups can influence the release of documents by government agencies on pollution. One such case occurred in the United States. Due to the criticism from various quarters, the EPA has decided against the release of a report on sediment contamination point sources (entitled 'National Sediment Contaminant Point Sources Inventory: Analysis of Release Data for 1992'). This report ranks the importance of point sources in sediment contamination all 
over the U.S. (Renner 1996).

\subsection{Conclusions}

A comprehensive wet and dry weather water quality study has not been done on an interstate river which has influence from both urban and rural areas. The Blackstone River Initiative (BRI) study will be the first of such a kind in the U.S. sponsored by the U. S. EPA. Wright et al. (1994) presented the summary of the field program for the wet weather studies of the BRI. A previous study done on Narragansett Bay identified the Blackstone Rtver as the number one polluted river and as the major sources of both nutrients and trace metals (Wright et al. 1991) to the Narragansett Bay.

While some studies have been conducted on localized segments of the river, The lack of a comprehensive water quality survey for the entire river is identified as a hindrance to developing an understanding of the trends and kinetics of the pollutants in the river. So it is very useful and will be very interesting to study the pollution problems in the Blackstone River for wet weather conditions and to compare these results with dry weather. 


\section{CHAPTER 3}

\subsection{Program Description and Methodology}

The Blackstone River Initiative was a joint effort between the EPA, MADEP, RIDEM and Civil and Environmental Engineering Department (CVE) at University of Rhode Island (URI).

The responsibility of the dry weather field program design and execution was headed up by the EPA. The field program was a joint effort by all groups. All samples were collected and analyzed under the control of CVE-URI with the exception of toxicity, which was handled by EPA-Lexington and fecal coliforms, which was analyzed by MADEP-Lawrence. The preliminary assessment of the dry weather data was completed by MADEP and expanded by CVE-URI. The modeling efforts were completed by the CVE-URI.

The responsibility of the wet weather field program design and execution was headed up by CVE-URI. The field program was a joint effort by CVE-URI, EPA, and MADEP. All samples were collected and analyzed under the control of CVE-URI with the exception of toxicity, which was handled by EPA-Lexington.

This dissertation details the result of these efforts as well as the collection and analysis of wet weather Storm 3 (October 1993) samples. The interpretation of the wet weather data (all three storms) and the integration of the results with the dry weather data (all three surveys) are also completed in this dissertation. 


\subsection{Water Quality Sampling \\ 3.1.1 Water Quality Sampling Stations}

There were a total of 21 river stations for the dry weather surveys and listing of the stations and a location map are provided in Table 3.1 and Figure 3.1. Fifteen of these stations were located along the Blackstone River and 6 near the mouth of the major tributaries. Dry weather stations are coded with the prefix BLK. In addition, 2 point source discharges were sampled, these included the UBWPAD and Woonsocket WWTF for both pre and post chlorination.

For the wet weather surveys stations are coded with the prefix BWW. A total of thirteen water quality stations were sampled along the Blackstone River, as well as six tributaries and five point sources discharges. These included from upstream to downstream three direct discharges to the Blackstone River including the combined sewerage overflow (CSO) facility in Worcester (BWW22) (between BWW00 and BWW01), UBWPAD (BWW23) (between BWW01 and BWW02), and Woonsocket WWTF (BWW24) (between BWW17 and BWW18), and two direct discharges to the Seekonk River below the mouth of the Blackstone River including Bucklin Point Narragansett Bay Commission Facility (BP NBC) (BWW25) (below BWW21) and the BP NBC by-pass (BWW26) (below BWW21). The NBC by-pass flowed over a weir at the northern end of the facility and received no treatment.

River mile points are listed from the mouth of the river starting with mile point 0 . Only minor station modifications occurred between the dry and wet surveys. Stations were selected to isolate wet weather problem areas such as point sources, impoundments, 


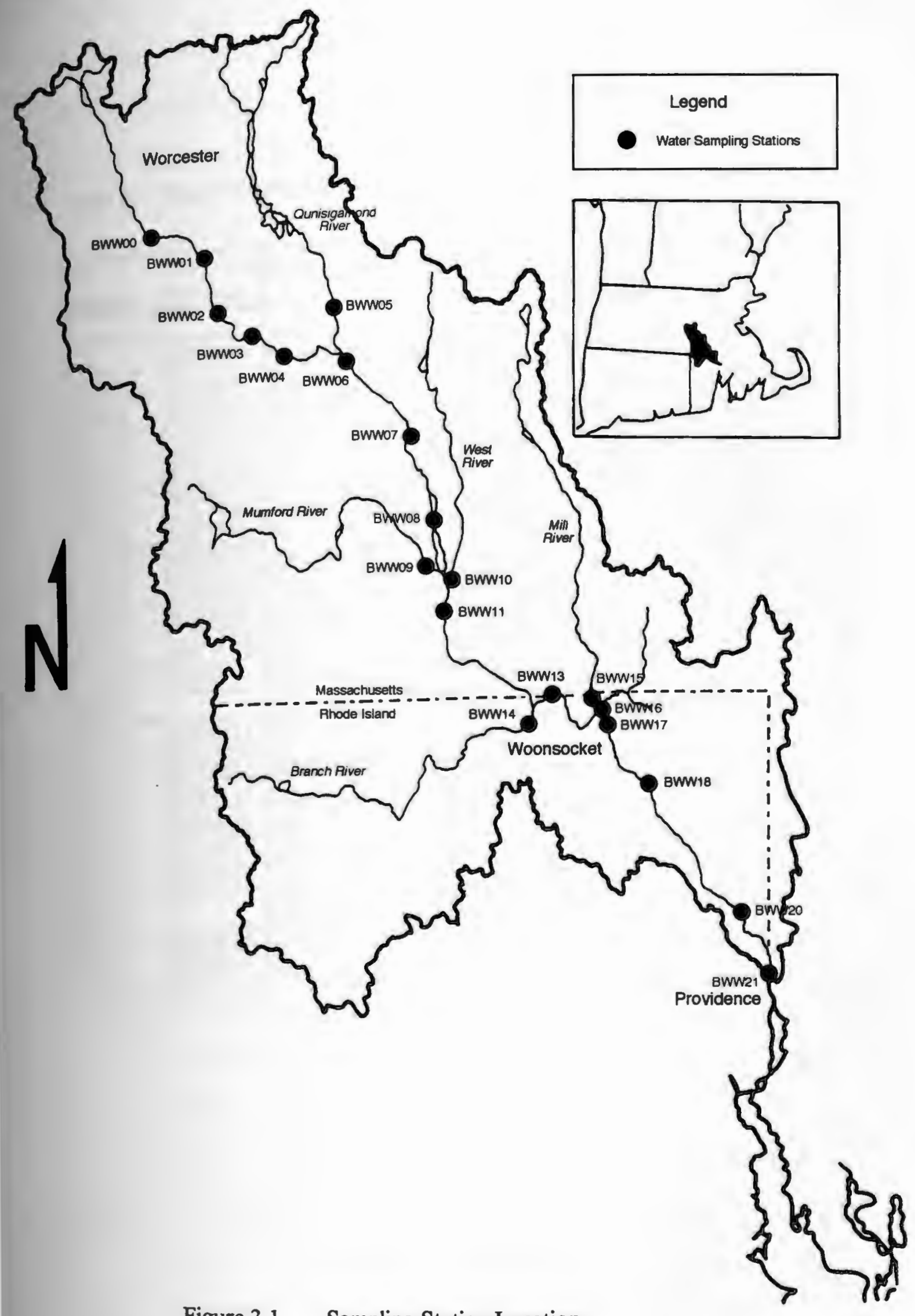

Figure 3.1 Sampling Station Location 
Table 3.1 Water Quality Sampling Stations Location

\begin{tabular}{|l|l|l|l|l|}
\hline $\begin{array}{l}\text { Dry } \\
\text { Weather }\end{array}$ & $\begin{array}{l}\text { Wet } \\
\text { Weather }\end{array}$ & River & Location & City \\
\hline & & & & \\
\hline & BWW00 & Blackstone & Greenwood St. & Worcester, MA \\
\hline BLK01 & BWW01 & Blackstone & Millbury St. & Worcester, MA \\
\hline BLK02 & BWW02 & Blackstone & McCraken Rd. & Millbury, MA \\
\hline BLK03 & & Blackstone & Riverlin St. & Mllibury, MA \\
\hline BLK04 & BWW04 & Blackstone & Blackstone St. (Singing Dam & Sutton, MA \\
\hline BLK05 & BWW05 & Quinsigamond & Millbury St. & Grafton, MA \\
\hline BLK06 & BWW06 & Blackstone & Route 122A & Grafton, MA \\
\hline BLK07 & BWW07 & Blackstone & Riverdale St. & Northbridge, MA \\
\hline BLK08 & BWW08 & Blackstone & Hartford St. (Rice City Pond & Uxbridge, MA \\
\hline BLK09 & BWW09 & Blackstone & Medon St. (Rte 16) & Uxbridge, MA \\
\hline BLK10 & BWW10 & West & Centerville (Off Rte. 16) & Uxbridge, MA \\
\hline BLK11 & BWW11 & Blackstone & Rte. 122 Bridge & Uxbridge, MA \\
\hline BLK12 & & Blackstone & Rte. 122 (Near USGS Gage) & Milville, MA \\
\hline BLK13 & BWW14 & Branch & Rte. 146A & Slatersville, RI \\
\hline BLK14 & BWW13 & Blackstone & Bridge St. (State Boundary) & Blackstone, MA \\
\hline BLK15 & BWW15 & Mill & Winter St. & Woonsocket, MA \\
\hline BLK16 & BWW16 & Peters & Rte. 114 & Woonsocket, MA \\
\hline BLK17 & BWW17 & Blackstone & Hamlet Ave. (Rte. 122, 126) & Woonsocket, MA \\
\hline BLK18 & BWW18 & Blackstone & Manville Hill Rd. & Cumberland, RI \\
\hline BLK19 & & Blackstone & School St./Albion Rd. & Cumberland, RI \\
\hline BLK20 & BWW20 & Blackstone & Lonsdale Ave. & Lonsdale, RI \\
\hline BLK21 & BWW21 & Blackstone & Main St. (Slater's Mill) & Pawtucket, RI \\
\hline & & & & \\
\hline
\end{tabular}


combined sewer overflows and junk yards and to provide sufficient spatial detail in the system. The stations were compatible with previous water quality studies along the river. Station BWW00 was added to isolate the Worcester CSO outfall.

\subsubsection{Dry Weather Field and Sampling Program}

The dry weather program consisted of three 48 hour surveys: July 10-11, 1991 for Survey 1, August 14-15, 1991 for Survey 2 and October 2-3, 1991 for Survey 3.

Grab samples for dissolved oxygen (DO) were collected every six hours over the 48 hour period. Temperature, $\mathrm{pH}$, and conductivity readings were taken in the field concurrently with the DO samples.

For the instream sampling, four sets of discrete grab samples were collected once every six hours over the first 24-hour period for each of the three surveys. The samples were analyzed for five-day carbonaceous biochemical oxygen demand (CBOD), total suspended solids (TSS), volatile suspended solids (VSS), chloride, total Kjeldahl-nitrogen (TKN), dissolved ammonia-nitrogen $\left(\mathrm{NH}_{3}\right)$, dissolved nitrate-nitrogen $\left(\mathrm{NO}_{3}\right)$, dissolved orthophosphorus $\left(\mathrm{PO}_{4}\right)$, total and dissolved metals (cadmium, chromium, copper, lead, and nickel) and hardness (calcium and magnesium).

Fecal coliform samples were collected during the 0400 run on the first day of each survey. Samples were also collected for chlorophyll a analyses, on the 0400 and 1600 river runs, on the first day of each survey period.

Samples were collected using teflon buckets, and pre-cleaned plastic bottles provided by the University of Rhode Island (URI). Samples were stored under ice for 
transport. All samples were transported at the end of each survey run to the laboratory conducting the analyses. Chemical, nutrient, metal, and chlorophyll analyses were conducted by URI. Fecal coliform analyses were performed by the Massachusetts Department of Environmental Protection (MADEP). Dissolved oxygen determinations were performed by the MADEP and EPA field personnel.

\subsubsection{Wet Weather Field and Sampling Program}

\subsubsection{Rainfall Criteria}

Establishing rainfall criteria is critical to the success of the monitoring program and the interpretation of the data. Isolation of the effect of a discrete event to permit the characterization of runoff and the determination of the impact on receiving water quality was the basic objective. Rainfall criteria were set ahead of the field program and included:

- Minimum rainfall total of 0.5 inches

- Minimum rainfall duration of six (6) hours

- Minimum antecedent dry period (ADP) of three (3) days

- Minimum number of three (3) post-storm dry days

A rainfall monitoring network was established to cover the study area, consisting of six gages maintained by the National Weather Service, 4 URI gages and 2 gages maintained by municipal wastewater treatment facilities. Locations and rainfall details are provided in the next chapter.

The criteria is designed to sample storms associated with frontal systems that provide uniform rainfall over the watershed. Storm development and movement were 
tracked by meteorologists with the final decision for the call of the storm provided by

URI.

\subsubsection{Field and Sampling Program}

Three storms were successfully monitored on 09/22/92, 11/02/92 and 10/14/93, meeting all rainfall criteria with total rainfalls of 0.55 inches $(14 \mathrm{~mm}), 0.92$ inches $(23 \mathrm{~mm})$ and 0.8 inches $(20.3 \mathrm{~mm})$, respectively. The rainfall coverage for Storm 1 and Storm 2 were relatively uniform. Storm 3 ranged from 1.3 inches $(33 \mathrm{~mm})$ in the north at Worcester, MA to 0.55 inches $(14 \mathrm{~mm})$ in the south. Rainfall characteristics and stream flow determinations are discussed in detail in Section 4.

A prestorm sample was collected 3-4 hours in advance of the storm to define the baseline dry weather loads. Initially, sampling was set at a higher frequency to identify the local storm water and first flush contribution to the receiving water. A total of 15 samples were taken for each location starting at 3 hour intervals from time 0 (observed runoff) and continuing through 12 hours ( 5 samples), followed every 4 hours for the next 36 hours (9 samples) with one sample on the third day to define the end of storm. Samples were transported to a field lab centrally located in the watershed for processing and distribution.

Each station was sampled at the surface. Field measurements included temperature, $\mathrm{pH}$, conductivity and dissolved oxygen. Laboratory chemical analysis included TSS, VSS, BOD, chloride, sodium, $\mathrm{NH}_{3}$ and $\mathrm{NO}_{3}$ as $\mathrm{N}, \mathrm{PO}_{4}$ as $\mathrm{P}$, total trace metals (cadmium, chromium, copper, lead, nickel and zinc), hardness (calcium and magnesium), fecal coliform and $E$. coli. 
Samples were collected using teflon buckets, and pre-cleaned plastic bottles. Samples were stored in ice for transport. Chemical, nutrient, and metal analyses were conducted by URI. Fecal coliform analyses were performed by Biological Analytical Laboratories (BAL).

Samples at the two WWTFs, UBWPAD and Woonsocket, were collected at the same frequency as the instream samples and analyzed for the same set of constituents given above.

\subsection{Methods and Methodologies}

To determine the impact of wet weather on the water quality of the Blackstone River the following was accomplished:

The samples were collected prior to the storm, during the storm and for several hours after the storm. These data coupled with stream flows allow for the calculation of mass loading curves. These then may be interpreted to estimate dry weather baseline conditions from prestorm data and, for comparison, wet weather loads from integration of the mass curves. In addition to this, the trace metal data allow for a comparison between observed in stream concentrations and acute and chronic criteria violations.

To identify the major pollutant sources and/or areas in the Blackstone River watershed and the development of system rankings, the following was accomplished:

Pollutant sources associated with wet weather may come from either new sources (runoff induced) or old sources (river sediments). It is important to note that the former 
may be easier to control and regulate than the latter. The sampling program and analysis of the data give the net gain and losses between the reaches. Gains identify the nonpoint sources and the analysis of data for the waste water treatment facilities (WWTF) provide the loadings from point sources. Arranging these according to the percent loading contribution lead to the system ranking.

To determine the relative importance between non-point and point sources and the development of annual loading rates for selected constituents, the following was accomplished:

The information collected during the wet weather sampling program provide insights into the behavior of the sources during varying storm conditions. This information is used to calculate empirical relationships between wet weather mass loadings and rainfall characteristics for individual reaches of the river. These relationships are used with historic rainfall records to estimate annual loading rates for wet load.

The dry weather data was sufficient to permit the calibration and verification of a model to describe trace metal transport as well as a model for dissolved oxygen. The dry weather models are used to estimate baseline mass loadings under any steady state flow. The models are then used to estimate the annual dry weather contributions at any location in the river. These then are compared with the wet load to provide a comparison between the annual wet versus dry weather loadings. In the long run this is exactly what is needed to allow decisions into pollutant control. Addition of dry and wet loads give the total annual load for a particular year. 


\section{CHAPTER 4}

4.0 System Hydrology and Hydraulics

4.1 Wet Weather

\subsubsection{Rainfall}

'Sampling was successfully completed for three events: Storm 1 - September 22 24, 1992; Storm 2 - November 2-5, 1992 and Storm 3 - October 12-16, 1993.

\subsubsection{Rainfall Network}

There were a total of 16 raingages in the rainfall network (Figure 4.1). Not all of these gages were available for each storm. Each station is coded by the following: R1N, where $R_{-}=$rainfall station; $1=$ station identification numbered from north to south; and $\mathrm{N}$ $=$ the group responsible for the gage (for instance, $N=$ National Weather Service (NWS), $\mathrm{U}=\mathrm{URI}, \mathrm{M}=$ Municipal, $\mathrm{S}=$ State) (Table 4.1)

The National Weather Service (NWS) operates seven stations either in or just outside the watershed. Two of these stations which are located at major airports (R1N and $\mathrm{R} 1 \mathrm{~N}$ ) and record precipitation continuously. The other five stations are managed by the NWS's Northeast River Forecast Center. The data at these stations are manually collected daily by 0900 and are reported as a total precipitation amount pertaining to the previous 24 hour period. Three of these stations are inside the watershed (R6N, R7N and $\mathrm{R} 11 \mathrm{~N}$ ) and two are to the east (R5N and $\mathrm{R} 8 \mathrm{~N}$ ). Three gages were maintained by municipalities at wastewater treatment facilities (WWTF) (R4M, R10M, and R13M) and 


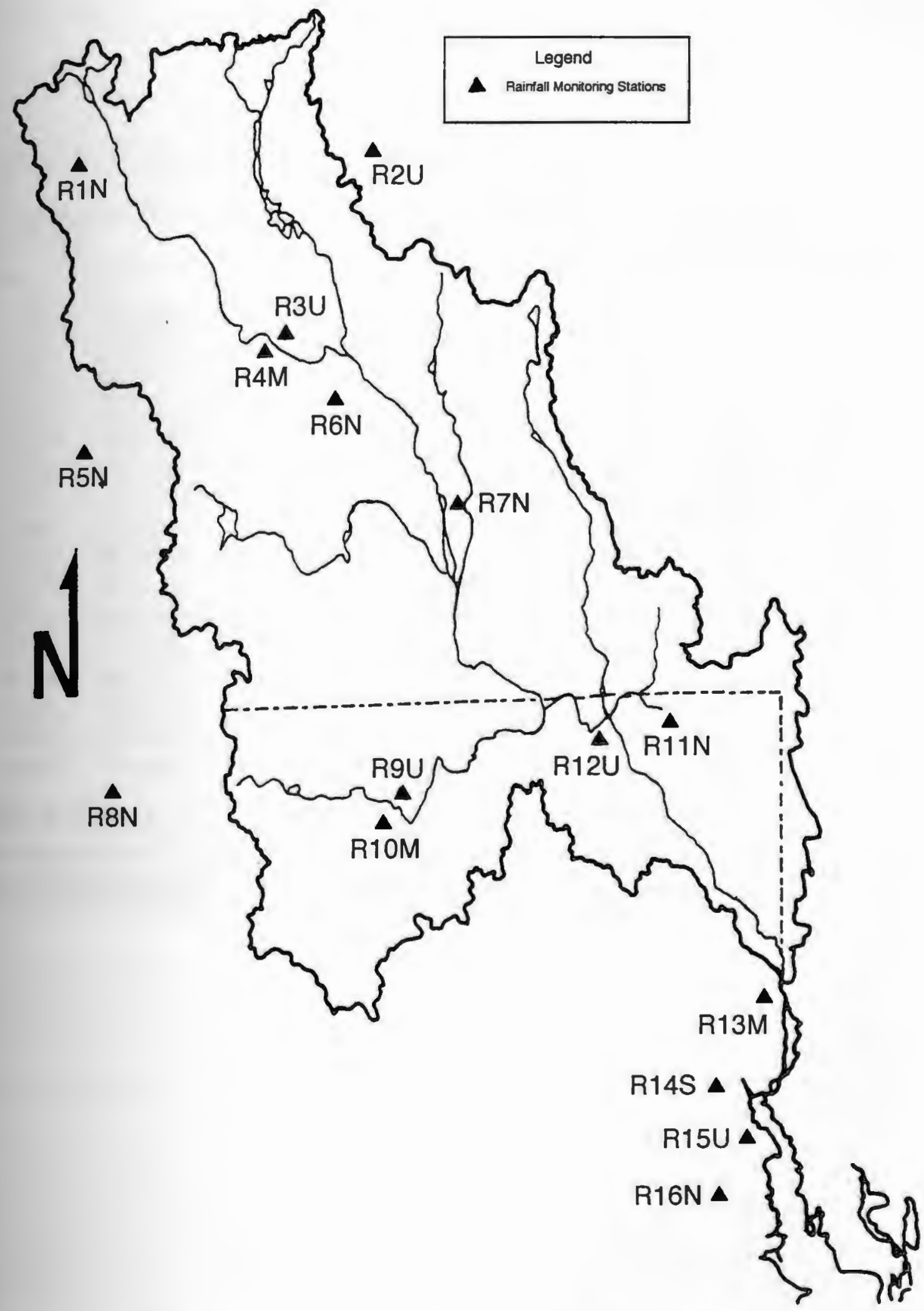

Figure 4.1 Raingages Location For Blackstone River Wet Weather Studies 
Table 4.1 Precipitation Log of Three Storms for Blackstone River Wet Weather Studies

\begin{tabular}{|l|l|c|c|c|c|c|}
\hline Gage Name & \multicolumn{1}{|c|}{ Location } & Maintained & Type & \multicolumn{3}{|c|}{ Rainfall in inch } \\
\cline { 5 - 7 } & & By & & Storm-1 & Storm-2 & Storm-3 \\
\hline & & & & & & \\
R1N & Worcester Airport, MA & NWS & 1 & 0.44 & 0.98 & 1.30 \\
R2U & Westborough WWTF, MA & URI & 1 & NA & 0.83 & 0.85 \\
R3U & Millbury WWTF, MA & URI & 1 & NA & 0.77 & NA \\
R4M & Millbury WWTF, MA & WWTF & 2 & 0.66 & 0.62 & NA \\
R5N & Buffumville, MA & NWS & 2 & 0.63 & 0.99 & 1.15 \\
R6N & Northbridge, MA & NWS & 2 & 0.54 & 0.94 & 0.69 \\
RTN & West Hill Dam & NWS & 2 & 0.53 & 0.89 & 0.90 \\
R8N & Putnam, CT & NWS & 2 & 0.63 & 0.84 & 1.15 \\
R9U & Burriville WWTF, RI & URI & 1 & NA & 0.85 & NA \\
R10M & Burriville WWTF, RI & WWTF & 2 & 0.74 & NA & 0.48 \\
R11N & Woonsocket, RI & NWS & 2 & 0.56 & 0.86 & 0.61 \\
R12U & Woonsocket WWTF, RI & URI & 1 & 0.46 & 0.78 & NA \\
R13M & Bucklin Pt. WWTF, RI & WWTF & 2 & 0.49 & NA & NA \\
R14S & Providence, RI & DEM & 2 & 0.51 & NA & NA \\
R15U & Fields Point WWTF, Prov., & URI & 1 & 0.62 & 0.76 & NA \\
R16N & TF Green Airport, Warwick, & NWS & 1 & 0.62 & 0.80 & 0.27 \\
\hline
\end{tabular}


one station (R14S) by the RIDEM. These data were also daily totals typically collected by 0700 each day.

To complete the rainfall network, URI established five additional stations with automatic tipping bucket rain gages (R2U, R3U, R9U, R12U and R15U).

\subsubsection{Rainfall Characteristics}

A summary of the total rainfall records at each station is also given in Table 4.1. The temporal pattern of each storm has been represented by a series of hyetographs (Figure 4.2). The three gages presented on this figure include the most northern station (R1N), a central station (R12U) and the most southern station (R16N).

Each storm's distribution across the watershed is illustrated by total rainfall lines of equal precipitation (Isoheytal lines). These are presented in Figures 4.3 to 4.5.

\subsubsection{Total Rainfall}

The simplest approach to developing equivalent uniform depth of precipitation over an area is to approximate the depth with an average storm of all raingages. However, this procedure is not acceptable if the gages are not evenly spaced or if the precipitation is irregularly distributed over the drainage area. The Thiessen method provides a means of weighting the precipitation at gages in proportion to a representative area. Each gage is assumed to represent all points closer to it than to any other gage. These areas are determined by connecting adjacent gages by lines and then constructing perpendicular bisectors to these lines. The area contained in the resulting polygons are 

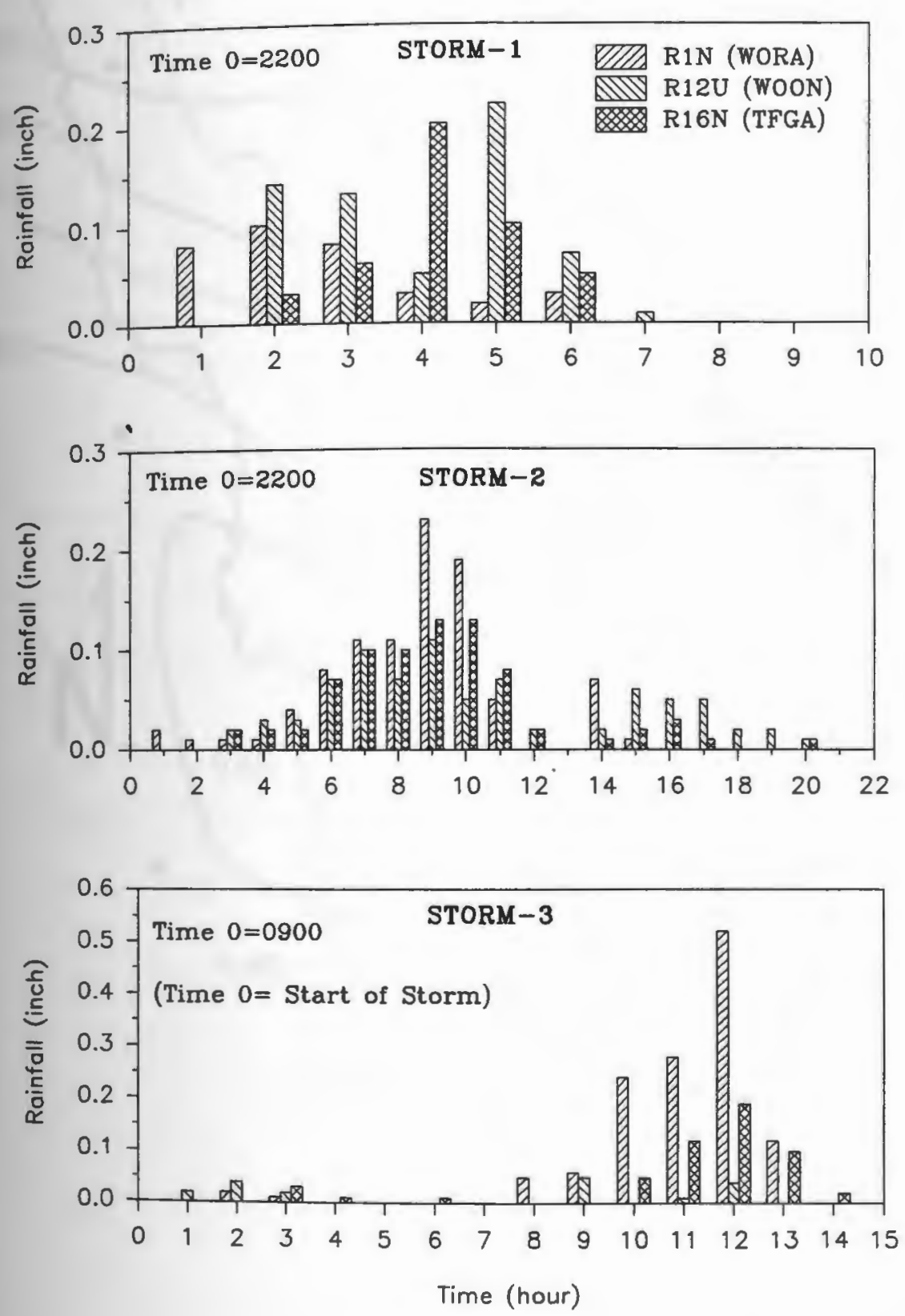

Figure 4.2 Rainfall For Blackstone River Wet Weather Studies 


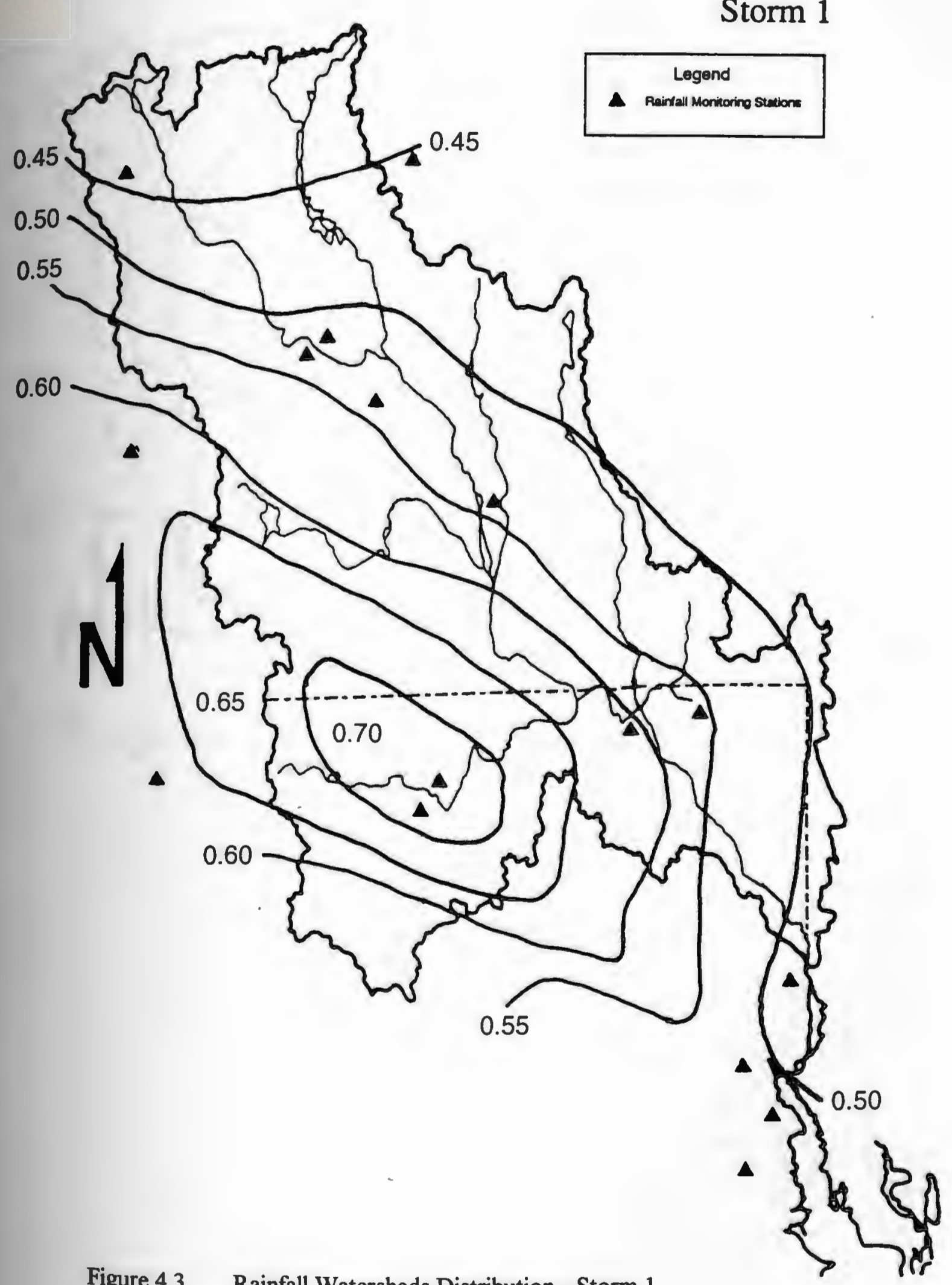

Figure 4.3 Rainfall Watersheds Distribution - Storm 1 


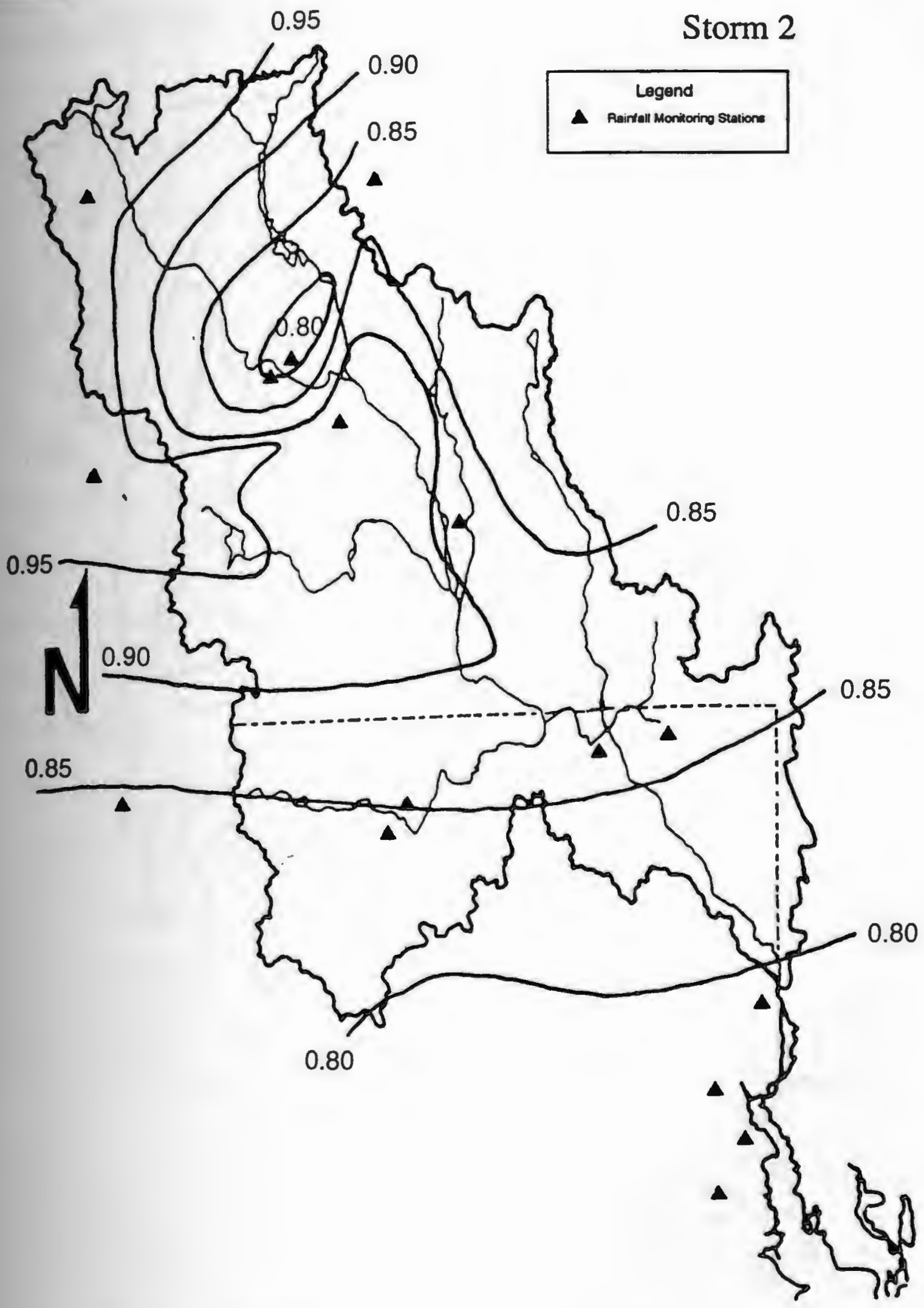

Figure 4.4 Rainfall Watersheds Distribution - Storm 2 


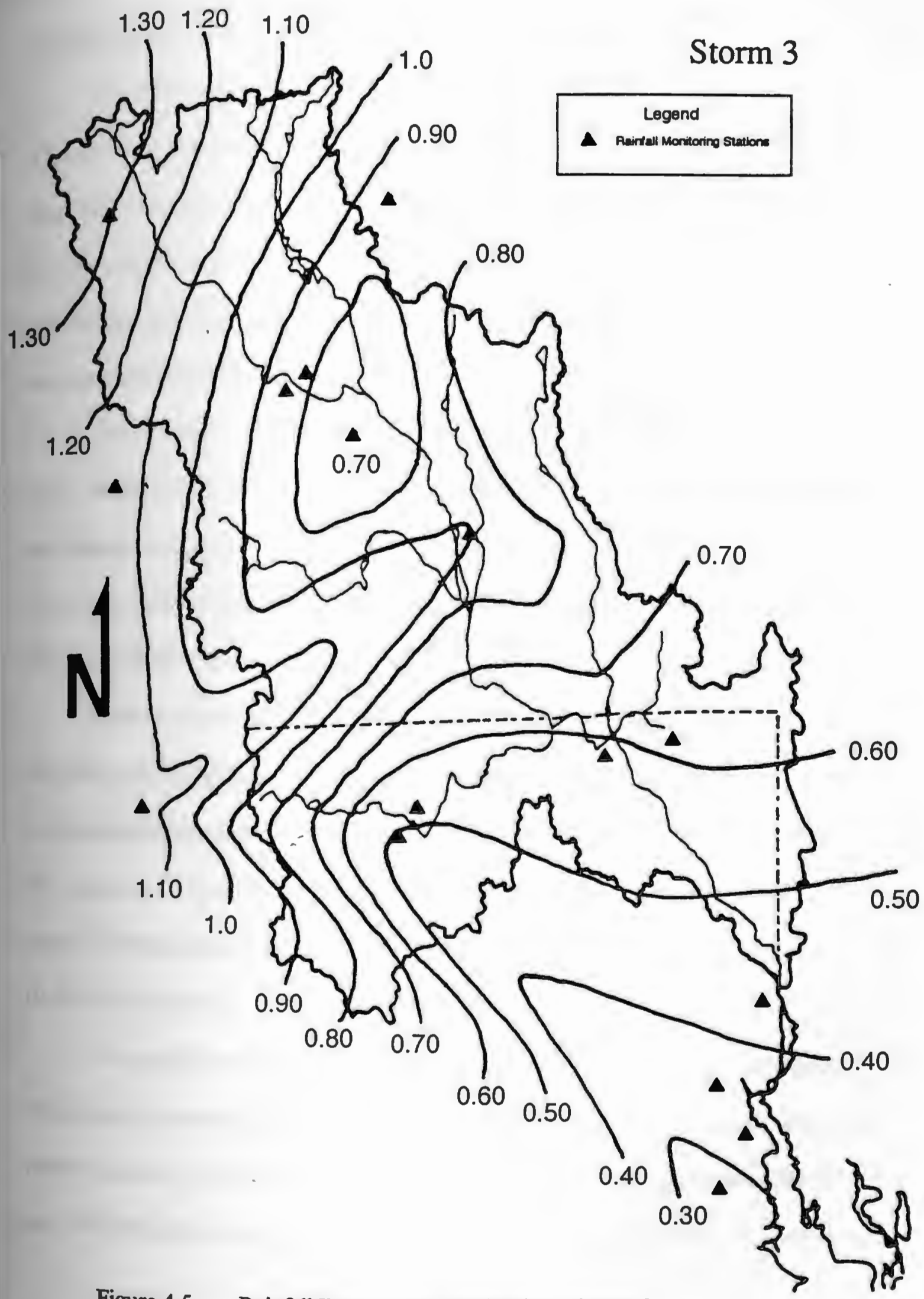

Figure 4.5 Rainfall Watersheds Distribution - Storm 3 
than determined and each gage reading is weighted by the area.

The Thiessen polygons developed for the three storms are given in Figures 4.6 to 4.8. The watershed weighted average is included in the storm summaries of Table 4.2. Each storm met the minimum rainfall criteria as described in Section 3. Storm 1 had the lowest watershed total rainfall of 0.56 inches. Storms 2 and 3 were similar with 0.88 and 0.81 inches, respectively, however the range and distribution of rainfall in the watershed was dramatically different.

Total rainfall was also determined as it relates to the direct drainage for each water quality station. First, subbasin areas were determined for each station and overlaid with the Thiessen polygons. Total rainfalls for these subbasins between stations were determined (Table 4.3). Second, the total rainfalls were determined for the cumulative drainage area from headwaters to the river mouth (Table 4.4).

Storm 1 had a relatively uniform distribution of rainfall ranging from 0.44 inches in the north to 0.74 inches at a location central to the watershed. The lowest rainfall total in a subwatershed was 0.46 inches in the watershed area between BWW01 and BWW02 and the largest was 0.72 for the area in the Branch River watershed above BWW14. In general, the cumulative rainfall totals increased as you proceeded down the watershed ( 0.49 to 0.56 inches).

The rainfall distribution for storm 2 was also uniformly distributed and ranged from a high in the north of 0.99 inches to the low in the south of 0.76 inches. The lowest rainfall total in a subwatershed was 0.78 inches in the watershed area between BWW01 and BWW02 and the largest was 0.96 in the headwaters above BWW01. In general, the 


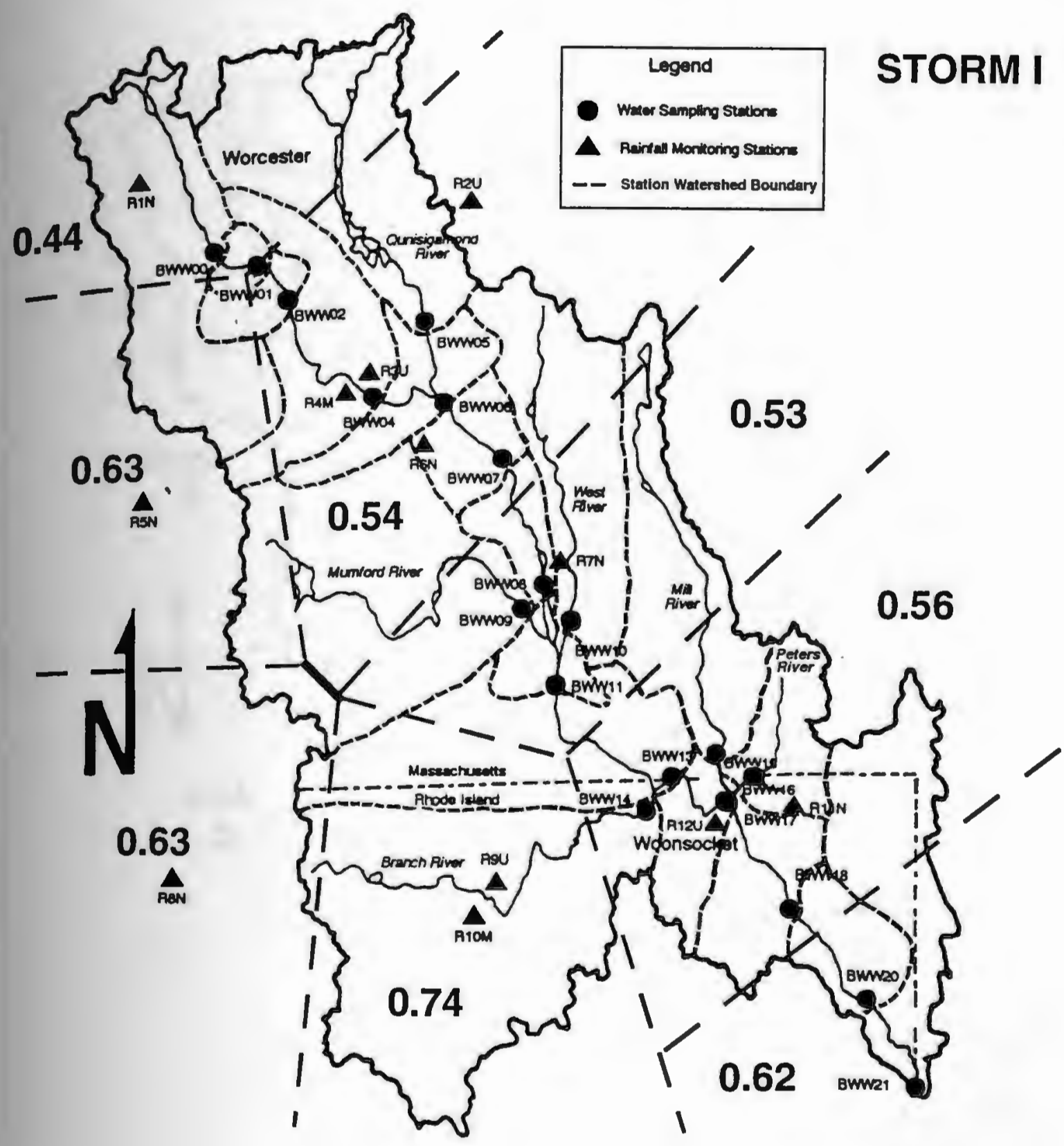

Figure 4.6 Thiessen Polygons - Storm 1 


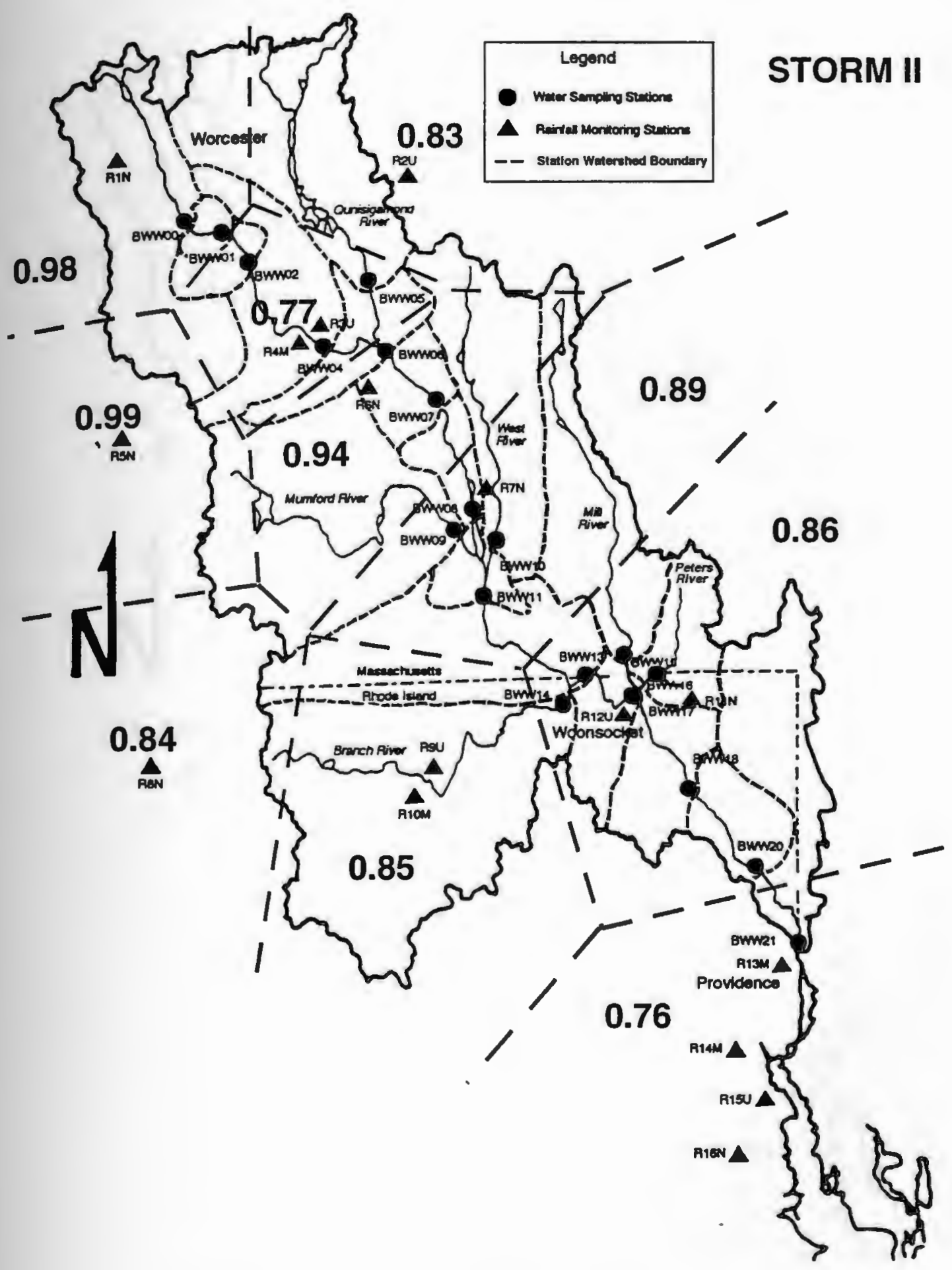

Figure 4.7 Thiessen Polygons - Storm 2 


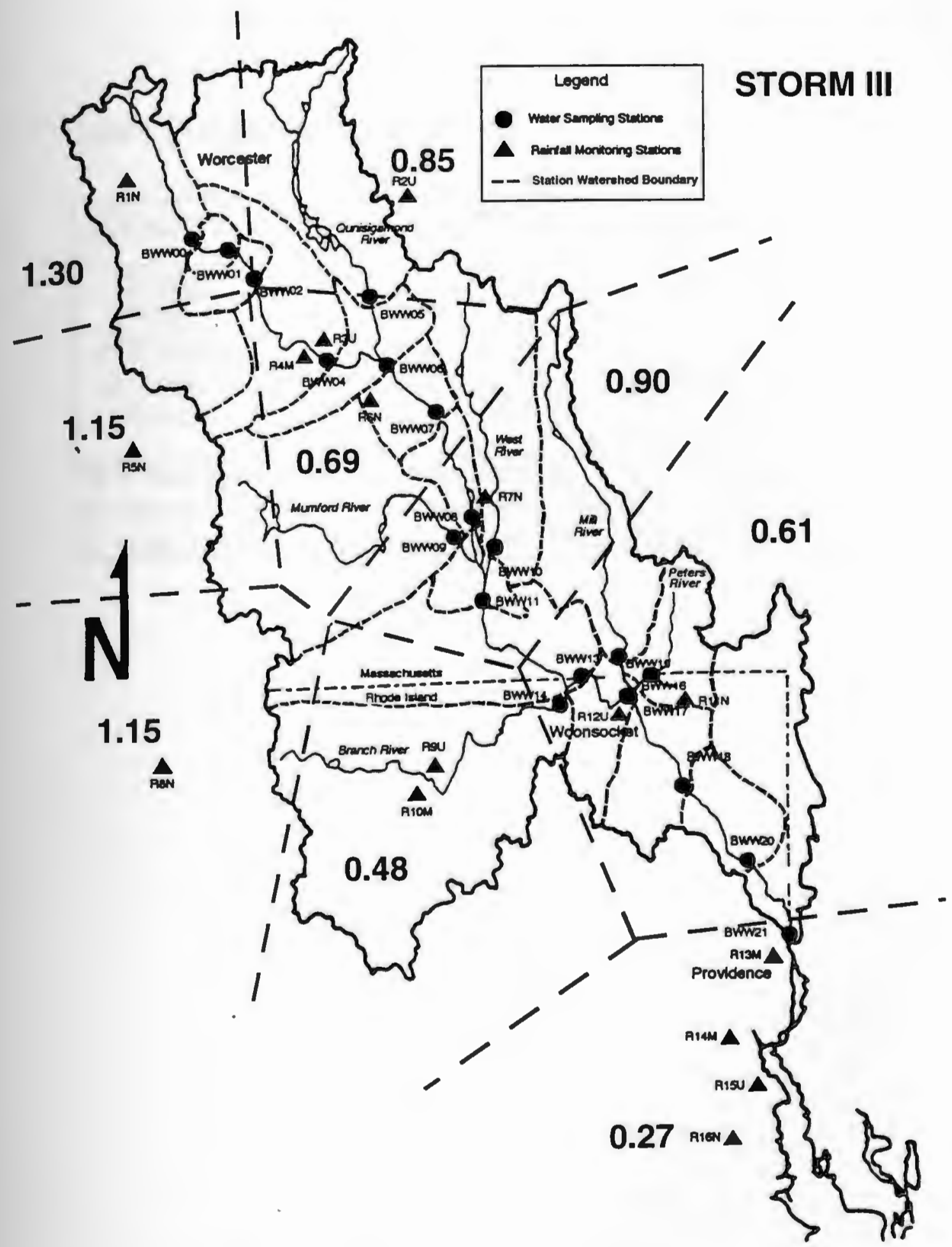

Figure 4.8 Thiessen Polygons - Storm 3 
Table 4.2 Average Rainfall Characteristics

\begin{tabular}{|l|c|c|c|}
\hline Characteristic & Storm 1 & Storm 2 & Storm 3 \\
\hline & & & \\
\hline TR (inch) & 0.558 & 0.881 & 0.809 \\
\hline D (hrs) & 6 & 16 & 8.5 \\
\hline ADP (days) & 11 & 8 & 8 \\
\hline PI (in/hr) & $0.20(\mathrm{R} 12 \mathrm{U})$ & $0.23(\mathrm{R} 1 \mathrm{~N})$ & $0.52(\mathrm{R} 1 \mathrm{~N})$ \\
\hline AI (in/hr) & 0.09 & 0.06 & 0.1 \\
\hline & & & \\
\hline
\end{tabular}


Table 4.3 Summary Table of Rainfall For Individual Subwatersheds

\begin{tabular}{|c|c|c|c|c|}
\hline \multirow{2}{*}{ Station } & Area & \multicolumn{3}{|c|}{ Rainfall (inch) } \\
\cline { 3 - 5 } & Sq. Mile & Storm 1 & Storm 2 & Storm 3 \\
\hline & & & & \\
\hline BWW00 & 60.5 & 0.494 & 0.955 & 1.253 \\
\hline BWW01 & 15.5 & 0.440 & 0.857 & 1.300 \\
\hline BWW02 & 6.2 & 0.461 & 0.784 & 1.129 \\
\hline BWW04 & 16.7 & 0.534 & 0.792 & 0.864 \\
\hline BWW05 & 34.2 & 0.473 & 0.857 & 0.944 \\
\hline BWW06 & 16.5 & 0.540 & 0.848 & 0.713 \\
\hline BWW07 & 6.0 & 0.540 & 0.940 & 0.690 \\
\hline BWW08 & 6.1 & 0.533 & 0.907 & 0.827 \\
\hline BWW09 & 68.5 & 0.560 & 0.928 & 0.881 \\
\hline BWW10 & 37.4 & 0.535 & 0.899 & 0.827 \\
\hline BWW11 & 2.3 & 0.530 & 0.890 & 0.900 \\
\hline BWW14 & 93.1 & 0.723 & 0.850 & 0.513 \\
\hline BWW13 & 13.4 & 0.617 & 0.861 & 0.665 \\
\hline BWW15 & 23.0 & 0.525 & 0.883 & 0.820 \\
\hline BWW16 & 11.6 & 0.510 & 0.860 & 0.610 \\
\hline BWW17 & 20.0 & 0.510 & 0.860 & 0.603 \\
\hline BWW18 & 12.2 & 0.510 & 0.860 & 0.610 \\
\hline BWW20 & 13.6 & 0.495 & 0.860 & 0.610 \\
\hline BWW21 & 23.3 & 0.502 & 0.844 & 0.594 \\
\hline & & & & \\
\hline
\end{tabular}


Table 4.4 Summary Table of Rainfall For Cumulative Subwatersheds

\begin{tabular}{|c|c|c|c|c|}
\hline \multirow[t]{2}{*}{ Station } & \multirow{2}{*}{$\begin{array}{c}\text { Area } \\
\text { Sq. Mile }\end{array}$} & \multicolumn{3}{|c|}{ Rainfall (inch) } \\
\hline & & Storm 1 & Storm 2 & Storm 3 \\
\hline BWW00 & 60.5 & 0.494 & 0.955 & 1.253 \\
\hline BWW01 & 75.9 & 0.483 & 0.935 & 1.263 \\
\hline BWW02 & 82.1 & 0.481 & 0.923 & 1.253 \\
\hline BWW04 & 98.8 & 0.490 & 0.901 & 1.187 \\
\hline BWW06 & 149.5 & 0.492 & 0.885 & 1.079 \\
\hline BWW07 & 155.5 & 0.493 & 0.887 & 1.064 \\
\hline BWW08 & 161.6 & 0.495 & 0.888 & 1.055 \\
\hline BWW11 & 269.8 & 0.517 & 0.900 & 0.978 \\
\hline BWW13 & 376.3 & 0.572 & 0.886 & 0.852 \\
\hline BWW17 & 430.9 & 0.565 & 0.884 & 0.832 \\
\hline BWW18 & 443.1 & 0.563 & 0.883 & 0.826 \\
\hline BWW20 & 456.7 & 0.561 & 0.883 & 0.819 \\
\hline BWW21 & 480.0 & 0.558 & 0.881 & 0.809 \\
\hline
\end{tabular}


cumulative rainfall totals decreased as you proceeded down the watershed $(0.96$ to 0.88 inches).

In contrast, Storm 3 had within it several intense thunderstorms which affected the drainage area along the western boundary and the headwaters to the north in Worcester (Figure 4.5). As a result, rainfall totals ranged from 0.27 inches along the southern border in Providence to 1.3 inches in the headwaters. The lowest rainfall total in a subwatershed was 0.59 inches in the watershed area between BWW20 and BWW21 and the largest was 1.30 in the watershed area between BWW00 and BWW01. There was a significant detrease in the cumulative rainfall totals as you proceeded down the watershed (1.25 to 0.81 inches).

These rainfall characteristics, especially the quantity and time distribution of the precipitation, will be one of the factors in governing the rate and distribution of runoff.

\subsubsection{System Flows}

There are three permanent USGS gaging stations in the watershed. These are located on the Quinsigamond River at North Grafton, MA (upstream of BWW05), Branch River at Forestdale, RI (upstream of BWW14) and Blackstone River at Woonsocket, RI (BWW17).

USGS also established six temporary gaging stations for this study. These included four on the Blackstone River (BWW01, BWW04, BWW11 and BWW20) and two on tributaries (Mumford BWW09 and Peters BWW16). All flows observed during the water quality surveys fell within the range of flows used for the stage discharge 
relationships.

For the remaining stations, reference points were established at each location for measurement of river stage. These reference points were monitored under a wide range of flow conditions. River flow profiles were developed for each measurement using the model, QUAL2E. The detailed procedure is described elsewhere in Wright et al. (1996).

The flow estimates and river stages were used to develop stage-discharge relationships at these stations. All flows observed during the water quality surveys fell within this flow range.

During the wet weather surveys river stage was recorded at each station for each water quality sample. Flows were then determined from the USGS or URI stagedischarge relationships for each station. The flows are summarized in the Tables 4.5 to 4.7.

Flows from the two WWTFs and the Worcester CSO facility were obtained from facility personnel. These are summarized in Table 4.8.

In general, there are several rainfall and watershed characteristics which influence the shape of the hydrograph. These include but are not limited to: (a) rainfall distribution or pattern; (b) hourly intensity; 1 watershed time to concentration (including all variables impacting this calculation, i.e. watershed slope and percent impervious); and (d) upstream regulation.

The classic shape of a hydrograph includes a rising limb, peak flow and falling limb. Often times the hydrograph is directly a reflection of a dominant watershed characteristic. For instance, different types of flow regulation, such as river reservoirs, 
Table 4.5 Blackstone River Flow Summary - Storm 1

\begin{tabular}{|c|c|c|c|c|c|c|c|c|c|c|c|}
\hline \multirow{2}{*}{$\begin{array}{c}\text { Station } \\
\text { Run }\end{array}$} & \multicolumn{9}{|c|}{ FLOW (cfs) } \\
\hline & BWW00 & BWW01 & BWW02 & BWW04 & BWW05 & BWW06 & BWW07 & BWW08 & BWW09 & BWW10 \\
\hline$P$ & 15.3 & 16.5 & 73.3 & 79.0 & 4.50 & 79.7 & 107 & 109 & 11.5 & 7.64 \\
\hline 0 & 38.3 & 41.2 & 107 & 93.0 & 3.80 & 67.4 & 95.0 & 124 & 12.0 & 7.94 \\
\hline 3 & 172 & 185 & 268 & 182 & 6.20 & 111 & 99.0 & 129 & 14.2 & 9.42 \\
\hline 6 & 59.5 & 64.0 & 156 & 245 & 6.20 & 111 & 101 & 115 & 14.8 & 9.07 \\
\hline 9 & 53.7 & 57.8 & 142 & 163 & 7.90 & 141 & 103 & 111 & 13.6 & 9.07 \\
\hline 12 & 43.1 & 46.4 & 118 & 144 & 9.30 & 166 & 104 & 108 & 12.5 & 9.24 \\
\hline 16 & 33.8 & 36.3 & 88.9 & 116 & 9.30 & 166 & 111 & 125 & 12.0 & 9.24 \\
\hline 24 & 21.9 & 23.5 & 49.6 & 80.0 & 6.70 & 120 & 123 & 130 & 11.5 & 9.24 \\
\hline 32 & 15.3 & 16.5 & 49.6 & 53.0 & 5.60 & 100 & 120 & 136 & 11.0 & 8.74 \\
\hline 40 & 21.9 & 23.5 & 80.8 & 66.0 & 5.10 & 90.0 & 123 & 136 & 9.29 & 8.90 \\
\hline & & & & & & & & & & \\
\hline
\end{tabular}

\begin{tabular}{|c|c|c|c|c|c|c|c|c|c|}
\hline Station & \multicolumn{9}{|c|}{ FLOW (cfs) } \\
\hline Run & BWW11 & BWW13 & BWW14 & BWW15 & BWW16 & BWW17 & BWW18 & BWW20 & BWW21 \\
\hline & & & & & & & & & \\
\hline P & 133 & 169 & 32.8 & 6.30 & 2.37 & 162 & 181 & 210 & 239 \\
\hline 0 & 142 & 188 & 42.0 & 5.80 & 3.61 & 163 & 205 & 220 & 250 \\
\hline 3 & 173 & 232 & 54.7 & 12.4 & 13.2 & 292 & 250 & 253 & 288 \\
\hline 6 & 160 & 214 & 50.1 & 12.4 & 11.0 & 250 & 210 & 241 & 275 \\
\hline 9 & 155 & 205 & 46.1 & 12.4 & 7.23 & 205 & 226 & 259 & 295 \\
\hline 12 & 162 & 209 & 42.8 & 10.2 & 10.5 & 214 & 226 & 265 & 302 \\
\hline 16 & 155 & 200 & 41.5 & 8.72 & 6.25 & 215 & 186 & 215 & 245 \\
\hline 24 & 148 & 192 & 40.6 & 16.7 & 4.00 & 209 & 226 & 247 & 281 \\
\hline 32 & 166 & 210 & 39.8 & 16.7 & 4.00 & 209 & 226 & 271 & 309 \\
\hline 40 & 177 & 218 & 36.4 & 15.0 & 4.00 & 289 & 315 & 253 & 288 \\
\hline & & & & & & & & & \\
\hline
\end{tabular}


Table 4.6 Blackstone River Flow Summary - Storm 2

\begin{tabular}{|c|c|c|c|c|c|c|c|c|c|c|}
\hline \multirow{2}{*}{$\begin{array}{c}\text { Station } \\
\text { Run }\end{array}$} & \multicolumn{10}{|c|}{ BLOW (cfs) } \\
\hline & BW00 & BWW01 & BWW02 & BWW04 & BWW05 & BWW06 & BWW07 & BWW08 & BWW09 & BWW10 \\
\hline P & 72.0 & 77.4 & 107 & 108 & 2.41 & 111 & 100 & 206 & 33.6 & 12.8 \\
\hline 0 & 72.0 & 77.4 & 107 & 108 & 2.55 & 153 & 100 & 160 & 33.6 & 13.0 \\
\hline 3 & 62.0 & 70.5 & 130 & 135 & 3.01 & 175 & 120 & 106 & 33.6 & 13.2 \\
\hline 6 & 172 & 185 & 245 & 220 & 4.09 & 194 & 149 & 139 & 44.4 & 14.4 \\
\hline 9 & 228 & 245 & 453 & 320 & 7.60 & 240 & 225 & 171 & 60.8 & 17.9 \\
\hline 12 & 163 & 175 & 264 & 380 & 10.7 & 286 & 302 & 211 & 76.7 & 19.4 \\
\hline 16 & 193 & 208 & 268 & 320 & 13.7 & 334 & 367 & 269 & 86.1 & 21.0 \\
\hline 20 & 116 & 125 & 222 & 273 & 15.3 & 286 & 339 & 393 & 104 & 20.0 \\
\hline 24 & 118 & 122 & 177 & 231 & 15.8 & 245 & 250 & 437 & 96.5 & 20.7 \\
\hline 28 & 128 & 138 & 150 & 202 & 15.8 & 217 & 235 & 287 & 104 & 22.0 \\
\hline 32 & 126 & 135 & 142 & 172 & 15.8 & 179 & 221 & 283 & 104 & 22.7 \\
\hline 36 & 126 & 135 & 142 & 142 & 15.3 & 141 & 215 & 287 & 104 & 23.4 \\
\hline 40 & 181 & 130 & 156 & 142 & 15.3 & 141 & 205 & 283 & 104 & 25.2 \\
\hline 44 & 121 & 130 & 156 & 165 & 14.8 & 179 & 200 & 287 & 100 & 26.8 \\
\hline 48 & 113 & 122 & 177 & 191 & 14.8 & 245 & 208 & 269 & 92.9 & 27.2 \\
\hline 72 & 57.0 & 61.5 & 103 & 108 & 15.8 & 126 & 183 & 279 & 73.8 & 28.8 \\
\hline & & & & & & & & & & \\
\hline
\end{tabular}

\begin{tabular}{|c|c|c|c|c|c|c|c|c|c|}
\hline \multirow{2}{*}{$\begin{array}{c}\text { Station } \\
\text { Run }\end{array}$} & \multicolumn{9}{|c|}{ FLOW (cfs) } \\
\hline & & & & & & & & & \\
\hline P & 252 & 321 & 67.6 & 9.82 & 6.20 & 259 & 295 & 327 & 294 \\
\hline 0 & 207 & 274 & 66.2 & 9.44 & 5.91 & 286 & 272 & 302 & 311 \\
\hline 3 & 177 & 221 & 68.4 & 9.82 & 5.62 & 282 & 265 & 294 & 302 \\
\hline 6 & 208 & 273 & 74.2 & 11.5 & 8.27 & 288 & 272 & 302 & 208 \\
\hline 9 & 258 & 352 & 101 & 19.7 & 29.9 & 310 & 451 & 500 & 410 \\
\hline 12 & 331 & 408 & 99.4 & 21.6 & 27.5 & 328 & 395 & 438 & 458 \\
\hline 16 & 410 & 482 & 105 & 20.1 & 27.5 & 365 & 500 & 554 & 458 \\
\hline 20 & 482 & 635 & 116 & 16.1 & 19.6 & 445 & 451 & 500 & 446 \\
\hline 24 & 568 & 676 & 121 & 18.0 & 21.3 & 529 & 526 & 583 & 564 \\
\hline 28 & 576 & 541 & 127 & 21.6 & 17.9 & 675 & 597 & 662 & 684 \\
\hline 32 & 562 & 540 & 129 & 24.0 & 17.9 & 693 & 767 & 851 & 890 \\
\hline 36 & 530 & 545 & 129 & 24.0 & 16.4 & 663 & 712 & 790 & 820 \\
\hline 40 & 506 & 545 & 130 & 23.2 & 16.4 & 640 & 712 & 790 & 820 \\
\hline 44 & 479 & 546 & 130 & 30.7 & 13.7 & 660 & 730 & 810 & 799 \\
\hline 48 & 482 & 519 & 128 & 20.8 & 11.5 & 600 & 628 & 697 & 956 \\
\hline 72 & 477 & 497 & 113 & 18.0 & 10.9 & 569 & 568 & 631 & 702 \\
\hline & & & & & & & & & \\
\hline
\end{tabular}


Table 4.7 Blackstone River Flow Summary - Storm 3

\begin{tabular}{|c|c|c|c|c|c|c|c|c|c|c|}
\hline \multirow{2}{*}{$\begin{array}{c}\text { Station } \\
\text { Run }\end{array}$} & \multicolumn{9}{|c|}{ FLOW (cfs) } \\
\hline & BWW00 & BWW01 & BWW02 & BWW04 & BWW05 & BWW06 & BWW07 & BWW08 & BWW09 & BWW10 \\
\hline P & 38.0 & 41.2 & 60.4 & 85.8 & 8.26 & 47.9 & 114 & 141 & 16.6 & 9.07 \\
\hline 0 & 38.0 & 41.2 & 73.3 & 85.8 & 8.62 & 28.3 & 114 & 219 & 23.1 & 9.24 \\
\hline 9 & 530 & 570 & 829 & 74.6 & 20.2 & 179 & 201 & 117 & 38.8 & 11.9 \\
\hline 12 & 407 & 438 & 637 & 541 & 20.8 & 406 & 421 & 174 & 41.2 & 12.8 \\
\hline 16 & 140 & 150 & 165 & 295 & 25.8 & 406 & 570 & 364 & 37.1 & 12.6 \\
\hline 20 & 128 & 138 & 153 & 178 & 26.9 & 166 & 300 & 414 & 17.8 & 12.1 \\
\hline 24 & 122 & 131 & 147 & 198 & 29.9 & 194 & 278 & 352 & 29.5 & 12.6 \\
\hline 28 & 109 & 117 & 130 & 203 & 28.8 & 179 & 287 & 332 & 29.5 & 11.7 \\
\hline 32 & 48.4 & 52.0 & 130 & 166 & 26.5 & 179 & 265 & 294 & 25.8 & 11.7 \\
\hline 36 & 160 & 108 & 107 & 155 & 24.7 & 210 & 244 & 301 & 25.8 & 12.1 \\
\hline 44 & 76.0 & 81.7 & 103 & 125 & 22.7 & 174 & 238 & 283 & 27.3 & 13.0 \\
\hline 52 & 76.0 & 81.7 & 105 & 135 & 21.9 & 59.9 & 144 & NA & 25.1 & NA \\
\hline 72 & NA & NA & NA & NA & NA & NA & NA & NA & 26.6 & NA \\
\hline & & & & & & & & & & \\
\hline
\end{tabular}

\begin{tabular}{|c|c|c|c|c|c|c|c|c|c|}
\hline $\begin{array}{c}\text { Station } \\
\text { Run }\end{array}$ & \multicolumn{70}{|c|}{ BWW11 } & BWW13 & BWW14 & BWW15 & BWW16 & BWW17 & BWW18 & BWW20 & BWW21 \\
\hline & & & & & & & & & \\
\hline P & 232 & 278 & 40.6 & 1.87 & 1.61 & 165 & 140 & 255 & 155 \\
\hline 0 & 179 & 227 & 43.2 & 1.80 & 1.52 & 172 & 180 & 300 & 200 \\
\hline 9 & 402 & 473 & 62.1 & 7.60 & 6.51 & 204 & 118 & 231 & 131 \\
\hline 12 & 173 & 236 & 58.2 & 5.10 & 4.39 & 246 & 180 & 300 & 200 \\
\hline 16 & 218 & 278 & 54.4 & 4.20 & 3.58 & 207 & 136 & 250 & 150 \\
\hline 20 & 371 & 428 & 48.4 & NA & 3.58 & 223 & 202 & 323 & 223 \\
\hline 24 & 524 & 580 & 45.0 & 4.20 & 3.58 & 420 & 303 & 437 & 385 \\
\hline 28 & 490 & 545 & 44.5 & 3.80 & 3.23 & 797 & 582 & 746 & 337 \\
\hline 32 & 376 & 429 & 45.0 & 3.60 & 3.06 & 551 & 329 & 464 & 646 \\
\hline 36 & 318 & 370 & 45.0 & 3.80 & 3.23 & 416 & 320 & 455 & 365 \\
\hline 44 & 297 & 349 & 45.0 & 3.60 & 3.06 & 416 & 238 & 363 & 355 \\
\hline 52 & NA & NA & 44.5 & 5.90 & 5.09 & 406 & 295 & 427 & 363 \\
\hline 72 & 258 & 309 & NA & NA & NA & 280 & NA & NA & 327 \\
\hline & & & & & & & & & \\
\hline
\end{tabular}

Note: NA $=$ not available 
Table 4.8 Average Flow

\begin{tabular}{|c|c|c|c|c|c|}
\hline Station & \multicolumn{5}{|c|}{ Average Flow (cfs) } \\
\hline Survey & BWW22 & BWW23 & BWW24 & BWW25 & BWW26 \\
\hline & & & & & \\
\hline Storm 1 & NA & 50.1 & 9.48 & 34.9 & 31.0 \\
\hline Storm 2 & NA & 51.9 & 10.0 & 35.6 & 38.6 \\
\hline Storm 3 & 246 & 49.6 & 9.91 & 32.8 & 34.2 \\
\hline & & & & & \\
\hline
\end{tabular}

BWW22 (WOOR CSO) flow average of 2.93 hrs. during the storm; BWW23 (UBWPAD BWW24 (WOON); BWW25 (BP NBC); BWW26 (BP NBC By-Pass)

Note : NA = not available 
leave an obvious imprint on the downstream flow profiles usually dampening the runoff hydrograph and extending the time of its impact. An unusual hydrograph response speed (fast or slow) would be a direct indication of the shape of the watershed and/or the percent of area that is impervious.

A summary of the hydrograph characteristics are given in Table 4.9 to 4.11 . The base flow is the prestorm flows as indicated at the time of Run P sampling. The average flows are for the sampling period beginning with Run 0 . The peak flows indicate maximum hydrograph flow. Several general observations can be made from the 3dimensional flow plots (Figures 4.9 - 4.11) and individual hydrograph comparisons (Figures 4.12 - 4.14) made below:

- $\quad$ Storm 1 (Figure 4.9 and 4.12) - Storm 1 was a short (6 hrs), relatively light, well distributed rainfall ( 0.56 inches). The runoff from the headwaters in Worcester resulted in a classic hydrograph at BWW01 with flows increasing from baseline of about $15 \mathrm{cfs}$ to a maximum of $185 \mathrm{cfs}$ at run time 3 hours (Point A). The hydrograph at BWW06 was impacted by local direct drainage during run times 3 and 6 hrs. By run time 9 hrs the hydrograph from the headwaters had arrived at BWW06 although the peak flow had decreased and the hydrograph had been attenuated due to channel storage over the 7.5 miles. In Fisherville Pond between BWW06 and BWW07, the hydrograph from Worcester was completely attenuated, adding to the base flow of the river. The storm track placed the headwater flows between BWW07 and BWW08 at the end of the sampling period (Point B). The additional flows from the three major tributaries central to the 
Table 4.9 Hydrograph Characteristics - Storm 1

\begin{tabular}{|l|c|c|c|c|c|c|}
\hline Station & $\begin{array}{c}\text { Peak Flow } \\
\text { (cfs) }\end{array}$ & $\begin{array}{c}\text { Time to peak } \\
\text { (hrs) }\end{array}$ & $\begin{array}{c}\text { Base Flow } \\
\text { (cfs) }\end{array}$ & $\begin{array}{c}\text { Wet Volume } \\
\text { (M cft) }\end{array}$ & $\begin{array}{c}\text { Total Volum } \\
\text { (M cft) }\end{array}$ & $\begin{array}{c}\text { N } \\
\text { (hrs) }\end{array}$ \\
\hline & & & & & & \\
\hline BWW00 & 172 & 3.50 & 15.3 & 3.63 & 5.77 & 36.2 \\
\hline BWW01 & 185 & 3.50 & 16.5 & 3.63 & 5.82 & 36.0 \\
\hline BWW02 & 268 & 4.50 & 73.3 & 4.07 & 15.5 & 37.3 \\
\hline BWW04 & 245 & 6.25 & 79.0 & 5.31 & 16.9 & 38.0 \\
\hline BWW05 & 9.30 & 14.3 & 4.50 & 0.43 & 1.03 & 34.2 \\
\hline BWW06 & 166 & 12.3 & 79.7 & 9.39 & 20.7 & 39.6 \\
\hline BWW07 & 123 & 24.3 & 107 & 5.36 & 27.0 & 39.8 \\
\hline BWW08 & 136 & 33.5 & 109 & 4.20 & 34.7 & 39.9 \\
\hline BWW09 & 14.8 & 6.25 & 11.5 & 0.10 & 1.63 & 36.6 \\
\hline BWW10 & 9.42 & 3.25 & 7.64 & 0.07 & 1.34 & 34.5 \\
\hline BWW11 & 173 & 2.00 & 133 & 1.37 & 24.4 & 42.0 \\
\hline BWW13 & 232 & 3.25 & 169 & 2.91 & 31.1 & 43.4 \\
\hline BWW14 & 54.7 & 3.25 & 32.8 & 1.46 & 6.45 & 37.8 \\
\hline BWW15 & 12.4 & 3.25 & 6.30 & 1.24 & 2.54 & 32.8 \\
\hline BWW16 & 13.2 & 3.25 & 2.37 & 0.44 & 0.80 & 30.7 \\
\hline BWW17 & 292 & 2.25 & 162 & 5.60 & 35.4 & 44.0 \\
\hline BWW18 & 265 & 1.25 & 181 & 3.43 & 36.1 & 44.1 \\
\hline BWW19 & 265 & 14.5 & 210 & 5.32 & 48.3 & 44.3 \\
\hline BWW20 & 302 & 14.5 & 239 & 6.41 & 56.1 & 44.5 \\
\hline & & & & & & \\
\hline
\end{tabular}

Note: $\mathbf{M ~ c f t}=$ Million cu . $\mathrm{f}$. 
Table 4.10 Hydrograph Characteristics - Storm 2

\begin{tabular}{|l|c|c|c|c|c|c|}
\hline Station & $\begin{array}{c}\text { Peak Flow } \\
\text { (cfs) }\end{array}$ & $\begin{array}{c}\text { Time to peak } \\
\text { (hrs) }\end{array}$ & $\begin{array}{c}\text { Base Flow } \\
\text { (cfs) }\end{array}$ & $\begin{array}{c}\text { Wet Volume } \\
\text { (M cft) }\end{array}$ & $\begin{array}{c}\text { Total Volume } \\
\text { (M cft) }\end{array}$ & $\begin{array}{c}\text { N } \\
\text { (hrs) }\end{array}$ \\
\hline & & & & & & \\
\hline BWW00 & 193 & 9.50 & 72.0 & 8.09 & 22.6 & 36.2 \\
\hline BWW01 & 245 & 9.00 & 77.4 & 8.66 & 23.9 & 36.0 \\
\hline BWW02 & 453 & 10.0 & 107 & 11.7 & 34.4 & 37.3 \\
\hline BWW04 & 380 & 13.5 & 108 & 15.0 & 39.4 & 38.0 \\
\hline BWW05 & 15.8 & 5.20 & 2.41 & 1.39 & 2.75 & 34.2 \\
\hline BWW06 & 334 & 18.0 & 111 & 17.4 & 44.5 & 39.6 \\
\hline BWW07 & 367 & 18.0 & 100 & 19.6 & 46.4 & 39.8 \\
\hline BWW08 & 437 & 24.5 & 206 & 26.1 & 62.1 & 39.9 \\
\hline BWW09 & 100 & 20.0 & 11.0 & 7.45 & 17.4 & 36.6 \\
\hline BWW10 & 21.0 & 17.0 & 12.8 & NA & NA & 34.5 \\
\hline BWW11 & 576 & 24.0 & 252 & 35.5 & 88.7 & 42.0 \\
\hline BWW13 & 676 & 22.5 & 321 & 43.1 & 116 & 43.4 \\
\hline BWW14 & 101 & 11.0 & 67.6 & 11.2 & 31.3 & 37.8 \\
\hline BWW15 & 21.6 & 13.0 & 9.82 & 2.75 & 5.57 & 32.8 \\
\hline BWW16 & 29.9 & 9.00 & 6.20 & 1.31 & 2.68 & 30.7 \\
\hline BWW17 & 693 & 31.5 & 259 & 49.7 & 145 & 44.0 \\
\hline BWW18 & 767 & 31.5 & 295 & 68.3 & 155 & 44.1 \\
\hline BWW20 & 851 & 32.5 & 327 & 75.3 & 172 & 44.3 \\
\hline BWW21 & 890 & 33.0 & 294 & 85.1 & 179 & 44.5 \\
\hline & & & & & & \\
\hline
\end{tabular}

Note $: \mathrm{NA}=$ not available $; \mathrm{M} \mathrm{cft}=$ Million $\mathrm{cu} . \mathrm{ft}$. 
Table 4.11 Hydrograph Characteristics - Storm 3

\begin{tabular}{|l|c|c|c|c|c|c|}
\hline Station & $\begin{array}{c}\text { Peak Flow } \\
\text { (cfs) }\end{array}$ & $\begin{array}{c}\text { Time to peak } \\
\text { (hrs) }\end{array}$ & $\begin{array}{c}\text { Base Flow } \\
\text { (cfs) }\end{array}$ & $\begin{array}{c}\text { Wet Volume } \\
\text { (M cft) }\end{array}$ & $\begin{array}{c}\text { Total Volum } \\
\text { (M cft) }\end{array}$ & $\begin{array}{c}\text { N } \\
\text { (hrs) }\end{array}$ \\
\hline & & & & & & \\
\hline BWW00 & 530 & 8.50 & 38.0 & 21.5 & 30.2 & 36.2 \\
\hline BWW01 & 570 & 8.00 & 41.2 & 22.7 & 32.5 & 36.0 \\
\hline BWW02 & 829 & 8.50 & 60.4 & 29.6 & 41.9 & 37.3 \\
\hline BWW04 & 746 & 9.00 & 85.8 & 30.4 & 53.6 & 38.0 \\
\hline BWW05 & 29.9 & 22.5 & 8.26 & 2.24 & 4.58 & 34.2 \\
\hline BWW06 & 406 & 15.0 & 47.9 & 27.0 & 47.5 & 39.6 \\
\hline BWW07 & 570 & 20.0 & 114 & 25.2 & 55.6 & 39.8 \\
\hline BWW08 & 414 & 24.0 & 141 & 23.7 & 65.2 & 39.9 \\
\hline BWW09 & 38.8 & 15.0 & 16.6 & 1.63 & 5.39 & 36.6 \\
\hline BWW10 & 13.0 & 15.5 & 9.07 & 0.27 & 1.91 & 34.5 \\
\hline BWW11 & 494 & 27.0 & 232 & 30.2 & 73.6 & 42.0 \\
\hline BWW13 & 580 & 26.0 & 225 & 31.2 & 90.7 & 43.4 \\
\hline BWW14 & 62.1 & 11.0 & 40.6 & 1.18 & 8.40 & 37.8 \\
\hline BWW15 & 7.60 & 10.0 & 0.87 & 0.26 & 0.63 & 32.8 \\
\hline BWW16 & 6.51 & 9.00 & 1.61 & 0.25 & 0.53 & 30.7 \\
\hline BWW17 & 797 & 28.5 & 165 & 39.0 & 91.6 & 44.0 \\
\hline BWW18 & 582 & 32.0 & 140 & 27.7 & 73.1 & 44.1 \\
\hline BWW20 & 750 & 31.0 & 250 & 28.3 & 107 & 44.3 \\
\hline BWW21 & 646 & 36.0 & 55.0 & 34.4 & 113 & 44.5 \\
\hline & & & & & & \\
\hline
\end{tabular}

Note: $\mathbf{M ~ c f t}=$ Million cu. $\mathrm{ft}$. 


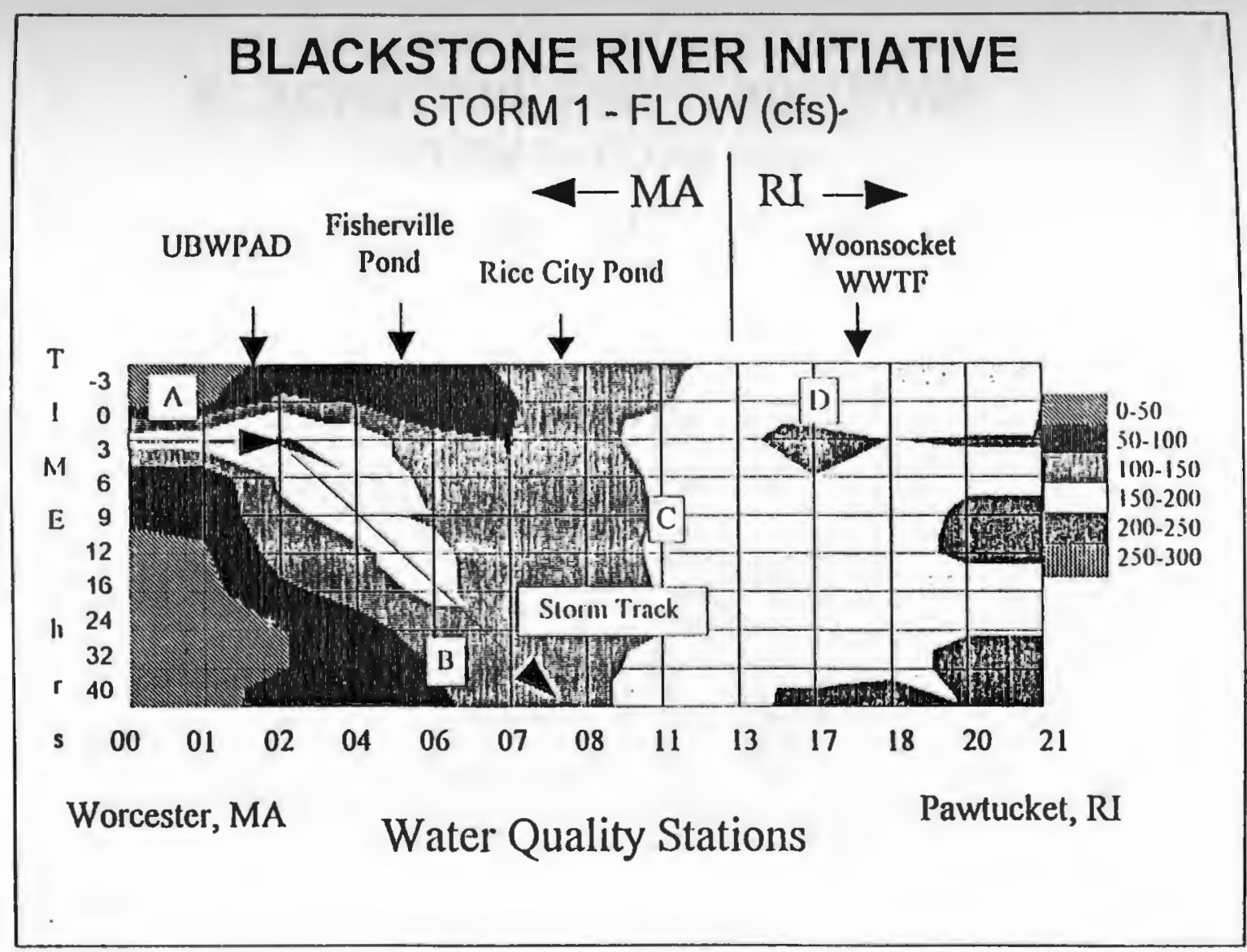

Figure 4.9 Spatial and Temporal Flow Profile Presentation - Storm 1 (Storm Track = Peak Signal Passage from Worcester) 


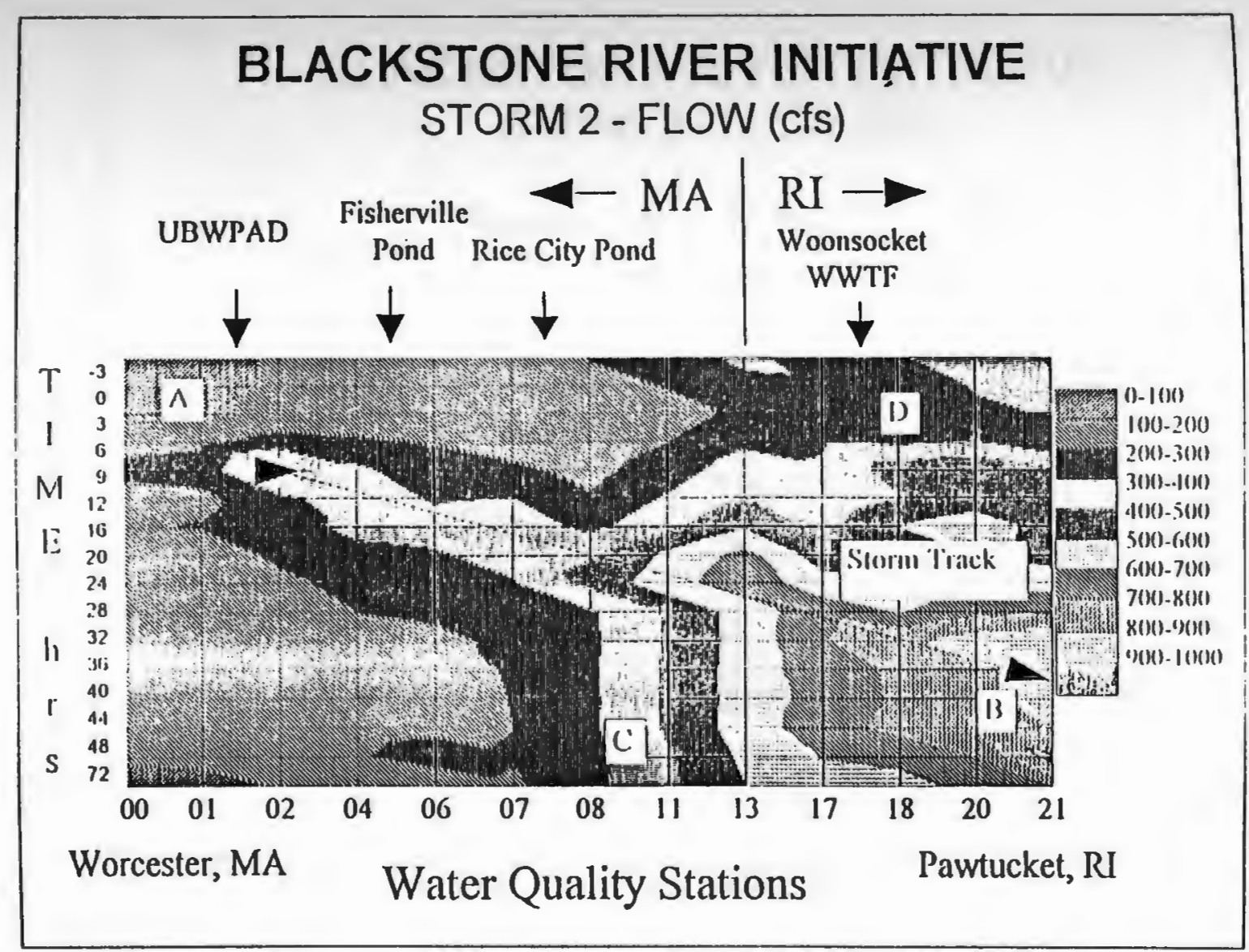

Figure 4.10 Spatial and Temporal Flow Profile Presentation - Storm 2 (Storm Track = Peak Signal Passage from Worcester) 


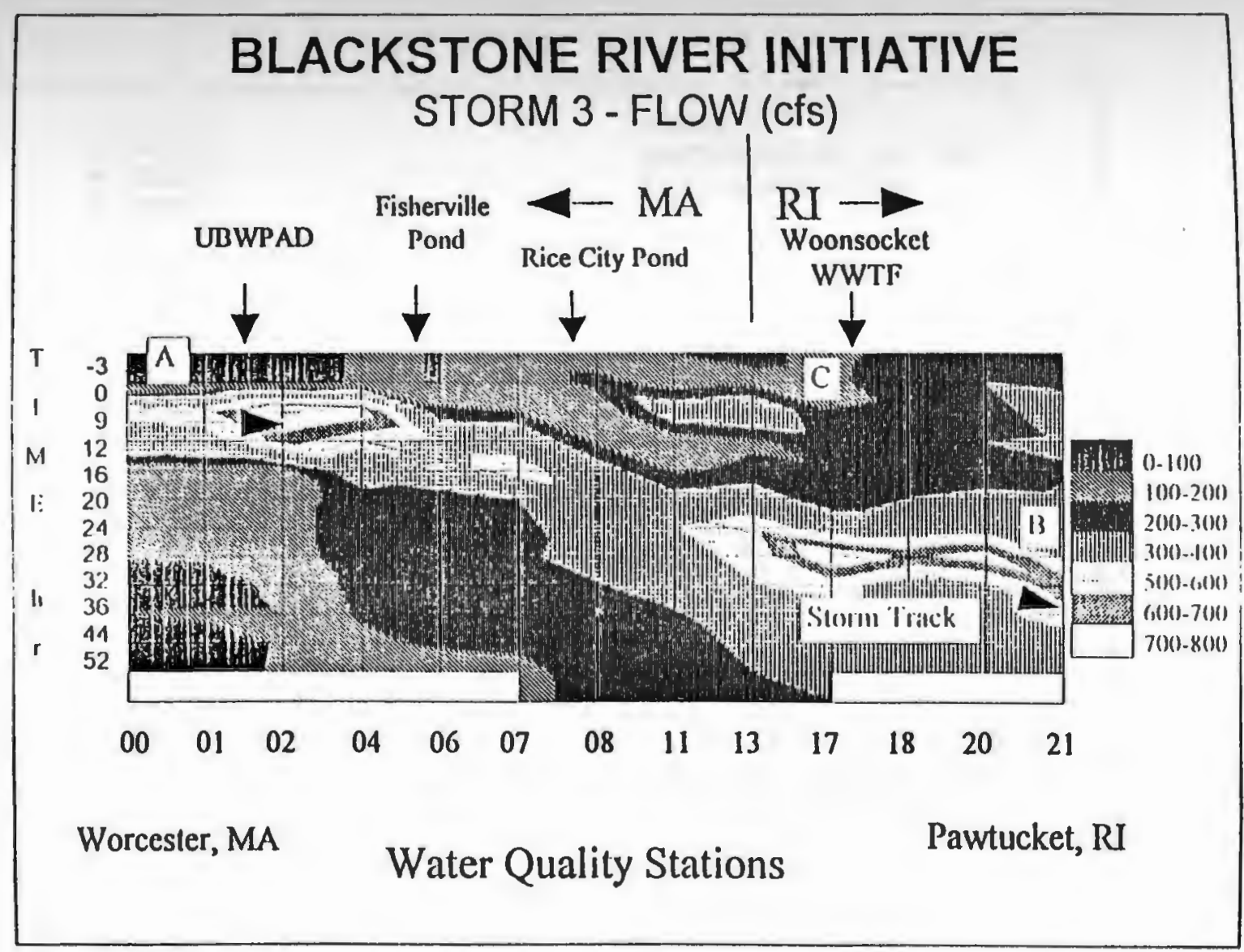

Figure 4.11 Spatial and Temporal Flow Profile Presentation - Storm 3 (Storm Track = Peak Signal Passage from Worcester) 


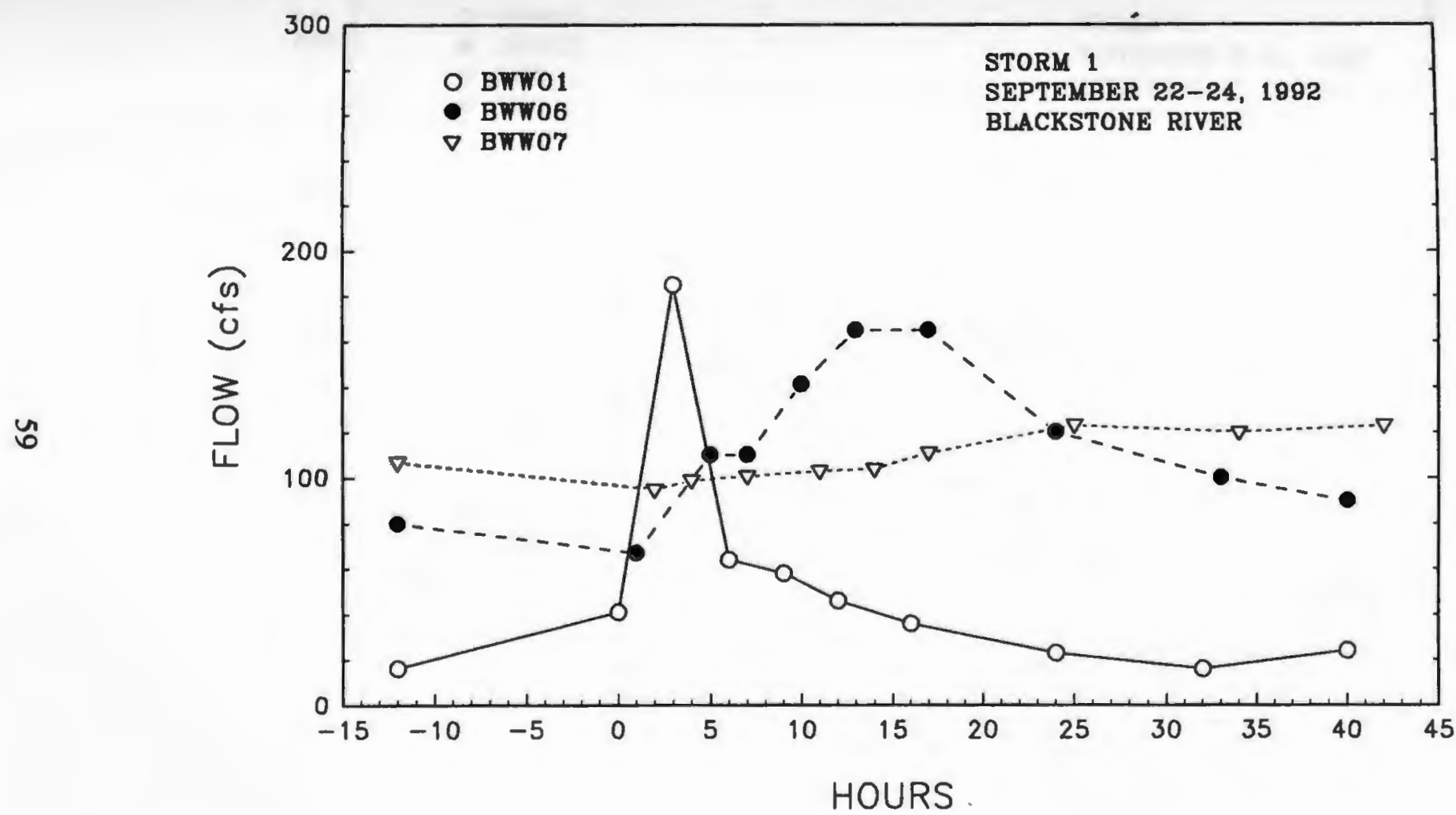

Figure 4.12 Hydrograph Comparison - Storm 1 


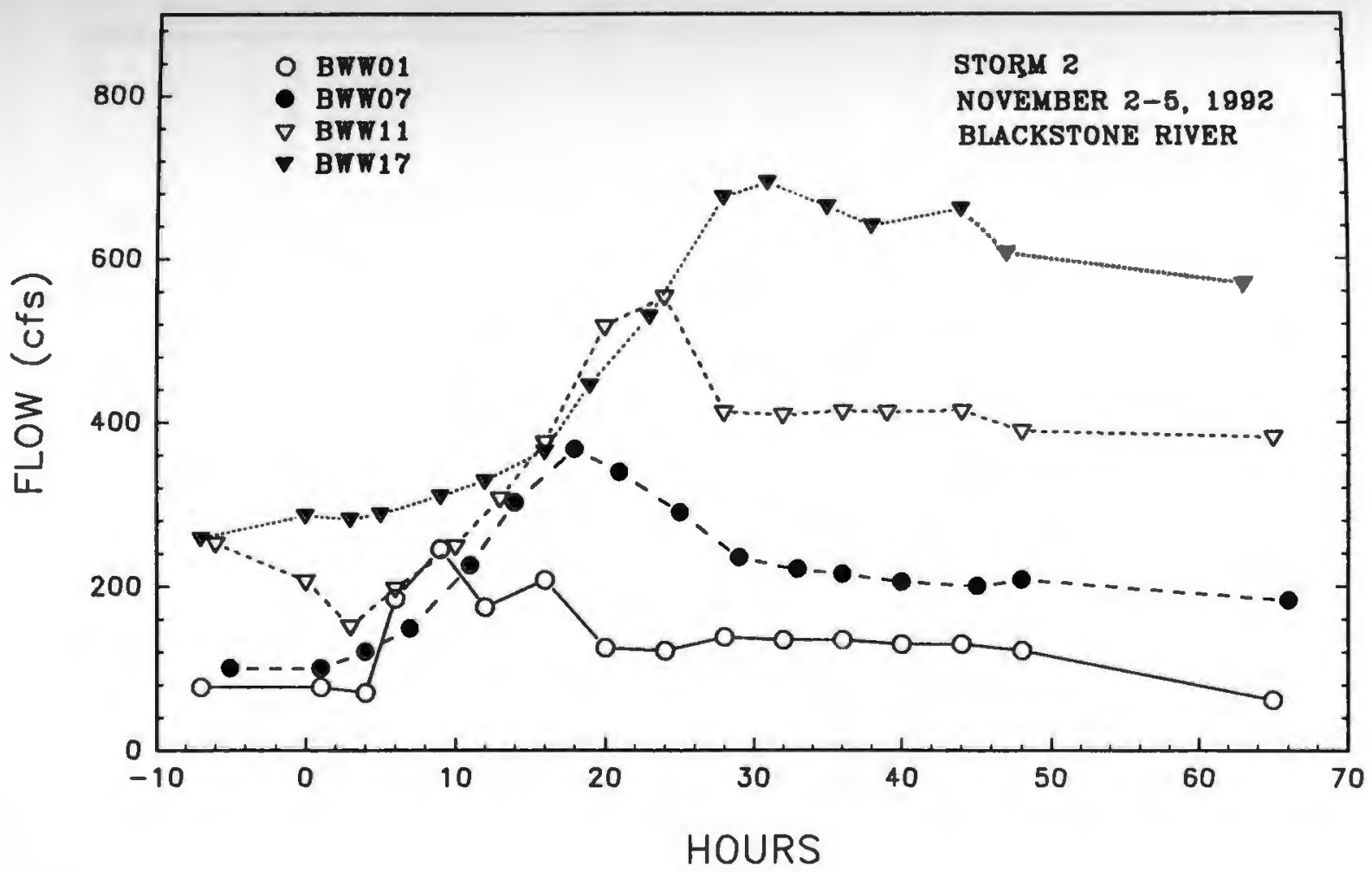

Figure 4.13 Hydrograph Comparison - Storm 2 


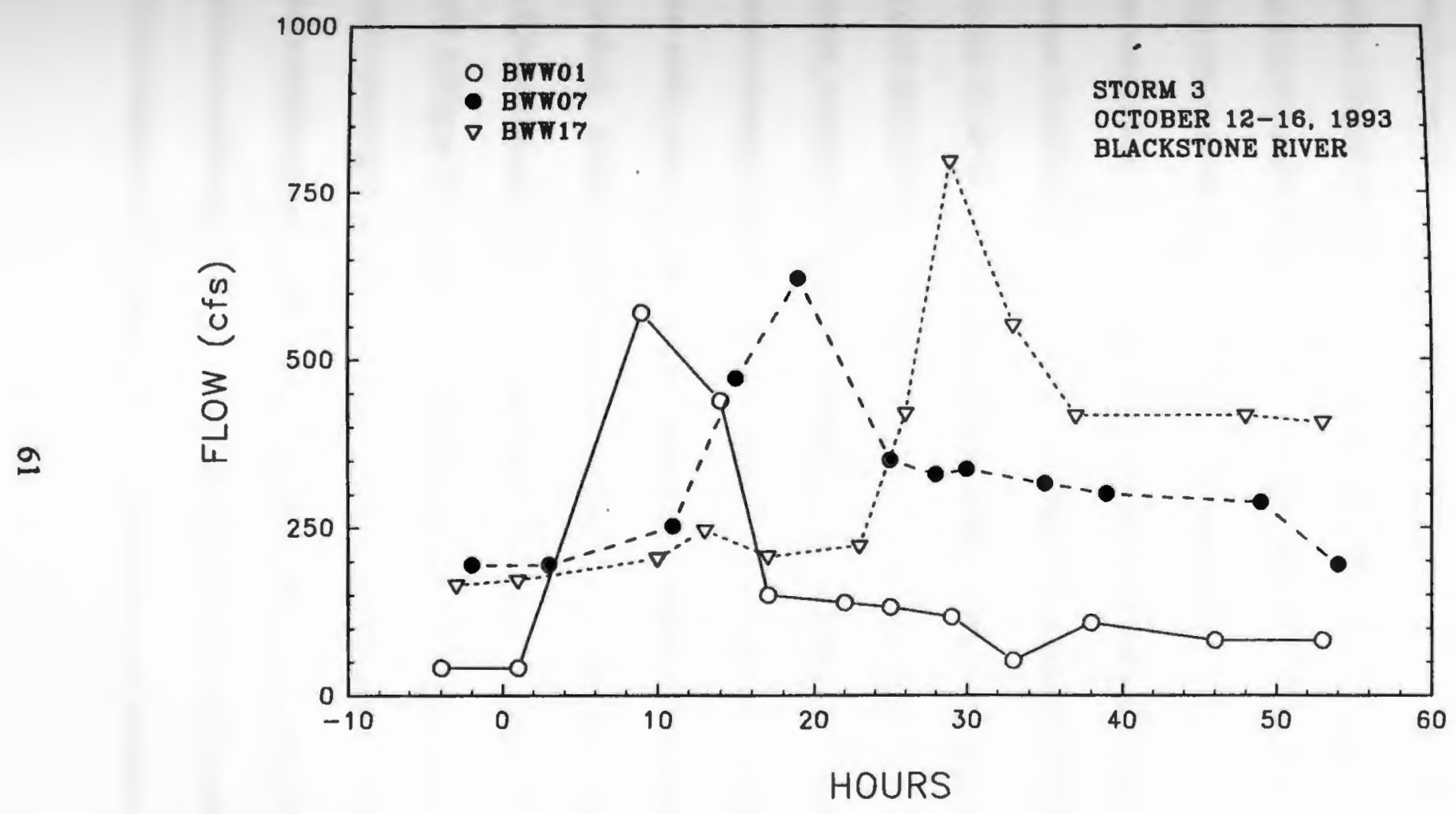

Figure 4.14 Hydrograph Comparison - Storm 3 
watershed (Mill, Peters and Branch) are observed at Point $C$. The hydrograph signatures below this station typically reflected local drainage area runoff. The most prominent of these is the runoff from the Woonsocket area identified as Point D. In most cases flows returned to prestorm conditions within the 40 hour sampling period.

- Storm 2 (Figure 4.10 and 4.13) - Storm 2 was a long (20 hrs), moderate, well distributed rainfall ( 0.88 inches). The peak flows and volumes steadily increase along the watershed. The flows from Worcester were highest between the 6-12 hour nins (Point $\mathrm{A}$ ). The track of the storm can be seen arriving at BWW08 between 20-24 hours. The arrival of the headwaters flows at BWW21 were between 36-48 hours (Point B). Unlike Storm 1, baseflows remained high even in the post storm period. This was attributed to the storm's characteristics (long duration, moderate rainfall and, therefore, high infiltration). The influence of the central tributaries is again evident at Point $\mathrm{C}$. The extended high flows beyond the storm track, are due to the longer, more gradual release of flows from the tributary watersheds. Local drainage runoff is again seen in the Woonsocket area as well as the downstream stations bracketing Central Falls and Pawtucket (Point D).

Storm 3 (Figure 4.11 and 4.14) - Storm 3 was a convective storm with most of the rainfall occurring in a 5 hour period. It was not well distributed with the heaviest of the rainfall occurring in Worcester. This resulted in a runoff signal from the headwaters in Worcester (Point A) that dominated the runoff profiles throughout the entire length of the Blackstone. The Worcester signal appeared at BWW08 
between hours 16-20. The peak flows arrived at BWW21 between hours 28 and 36 (Point B). The rainfall from the local drainage areas in the lower sections of the watershed were evident, especially between BWW11 and BWW17 (Point C), but had a relatively minor impact on the hydrographs.

Hydrographs have been compared at three key locations: headwaters BWW01; MA/RI state line BWW13 and mouth of the river BWW21 in Figures 4.15 to 4.17, respectively.

Several'procedures are available for separation of the hydrographs into baseflow and direct runoff. These are well documented in hydrology texts (McCuen 1989; Viessman, Lewis and Knapp 1990; Wanielista 1990). The procedures include straight-line baseflow separation, constant slope baseflow separation, concave baseflow separation and the master depletion curve method. Caution must be used when interpreting direct runoff volumes in downstream reaches for as hydrographs are routed downstream, runoff flows become attenuated and some of the direct runoff volume will begin to appear as river baseflow.

The concave baseflow separation method was used in this study. An example of this method is given in Figure 4.18. The initial recession curve is projected downward from $\mathrm{A}$ to $\mathrm{C}$, which lies directly under the peak flow. The curve is then extended from $\mathrm{C}$ to a point $\mathrm{D}$ on the falling limb of the hydrograph $\mathrm{N}$ days after the peak. The value of $\mathrm{N}$ is determined from an empirical relationship provided in the references listed above. It takes the general form of $\mathrm{N}=1.0 \mathrm{~A}^{\mathrm{b}}$ where $\mathrm{A}$ is in square miles and $\mathrm{b}$ is a constant that may be 


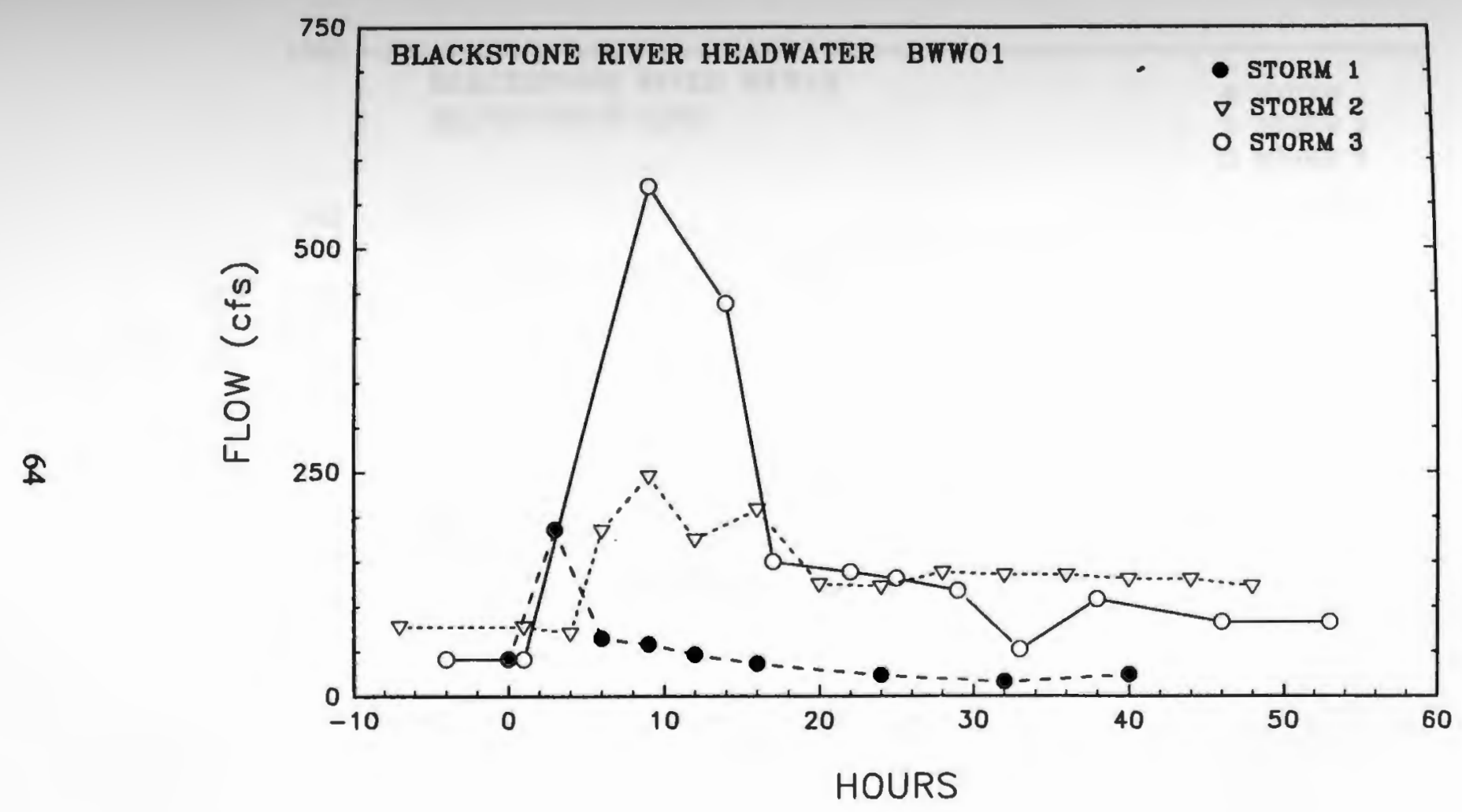

Figure 4.15 Hydrograph Comparison - Headwaters 


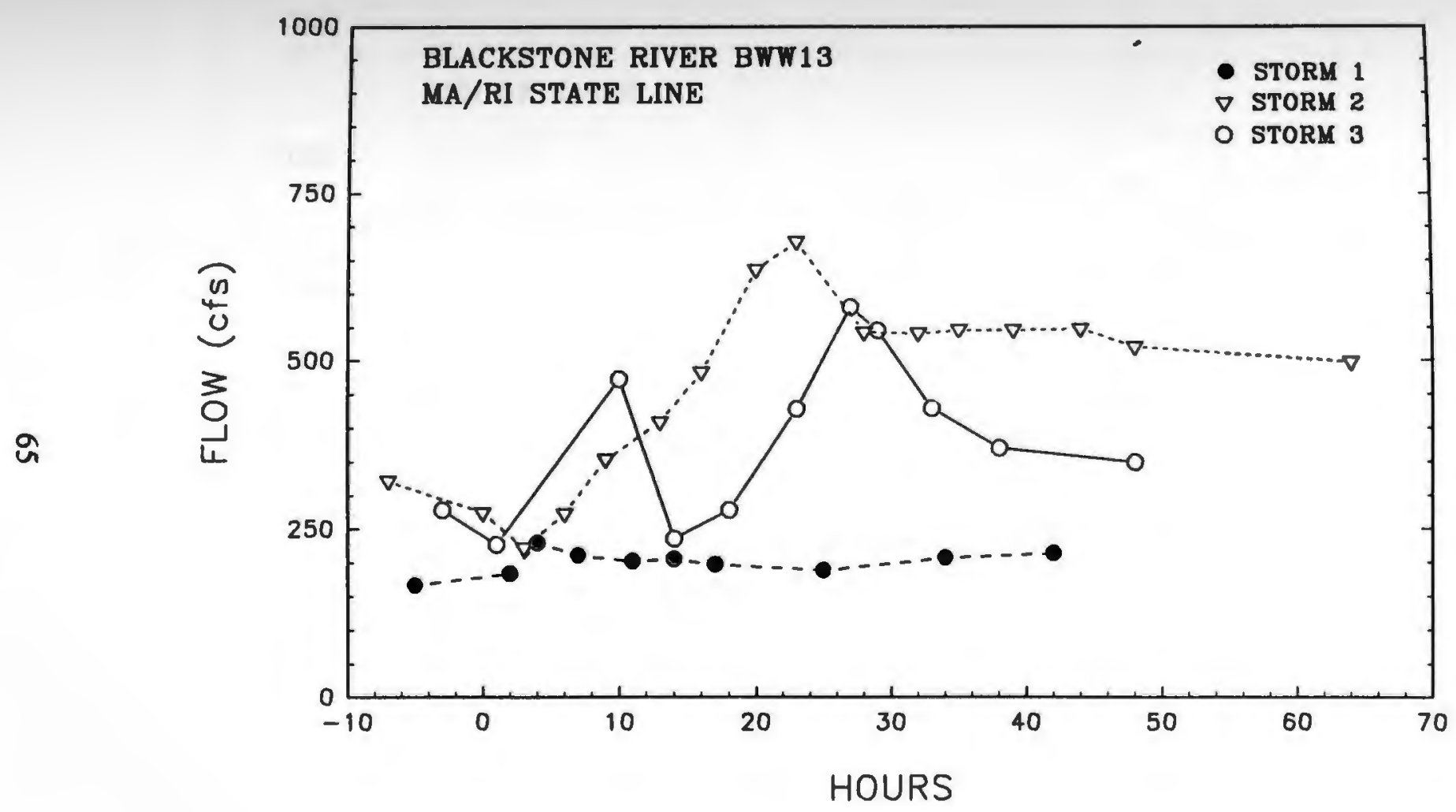

Figure 4.16 Hydrograph Comparison - State Line 


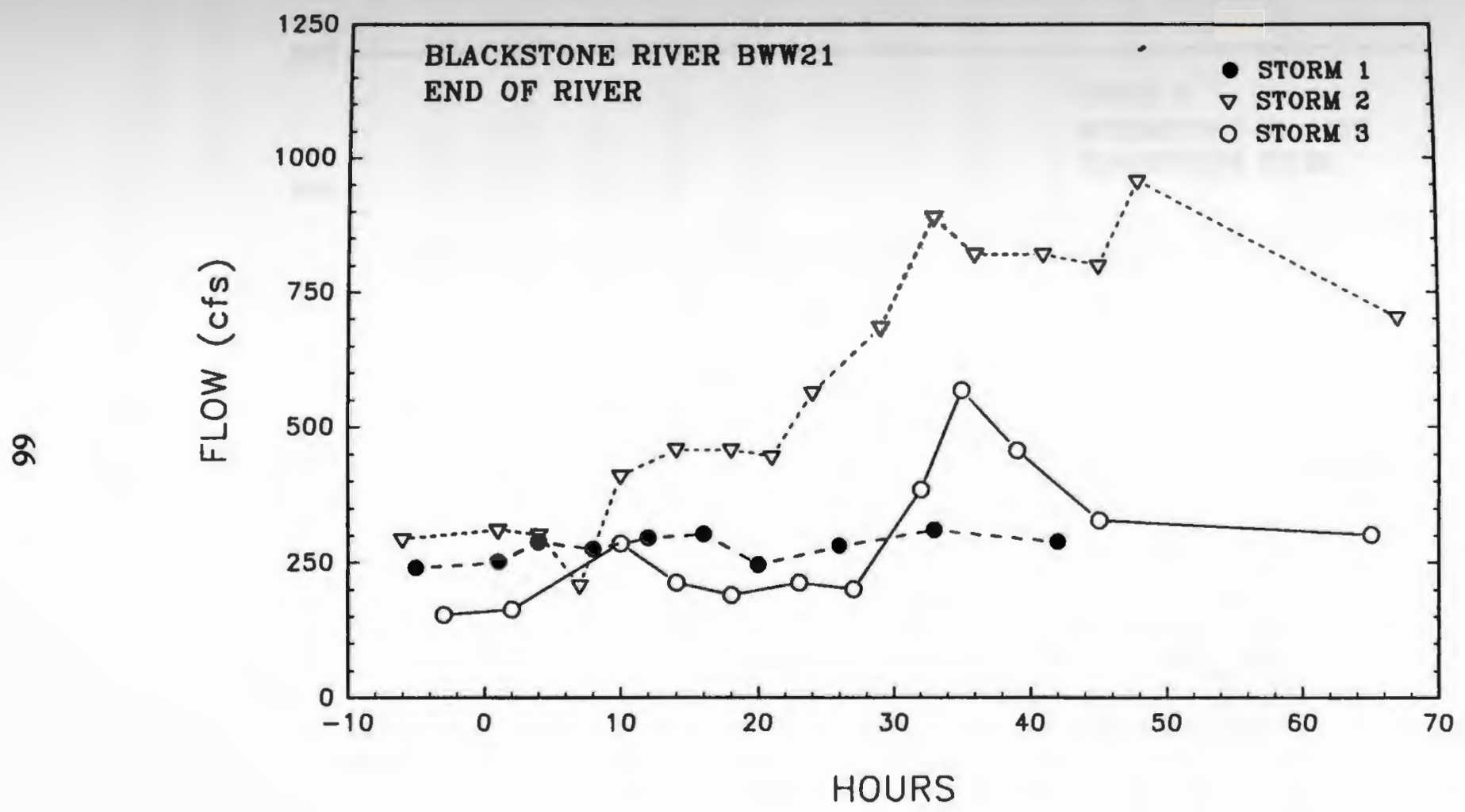

Figure 4.17 Hydrograph Comparison - Mouth of The River 


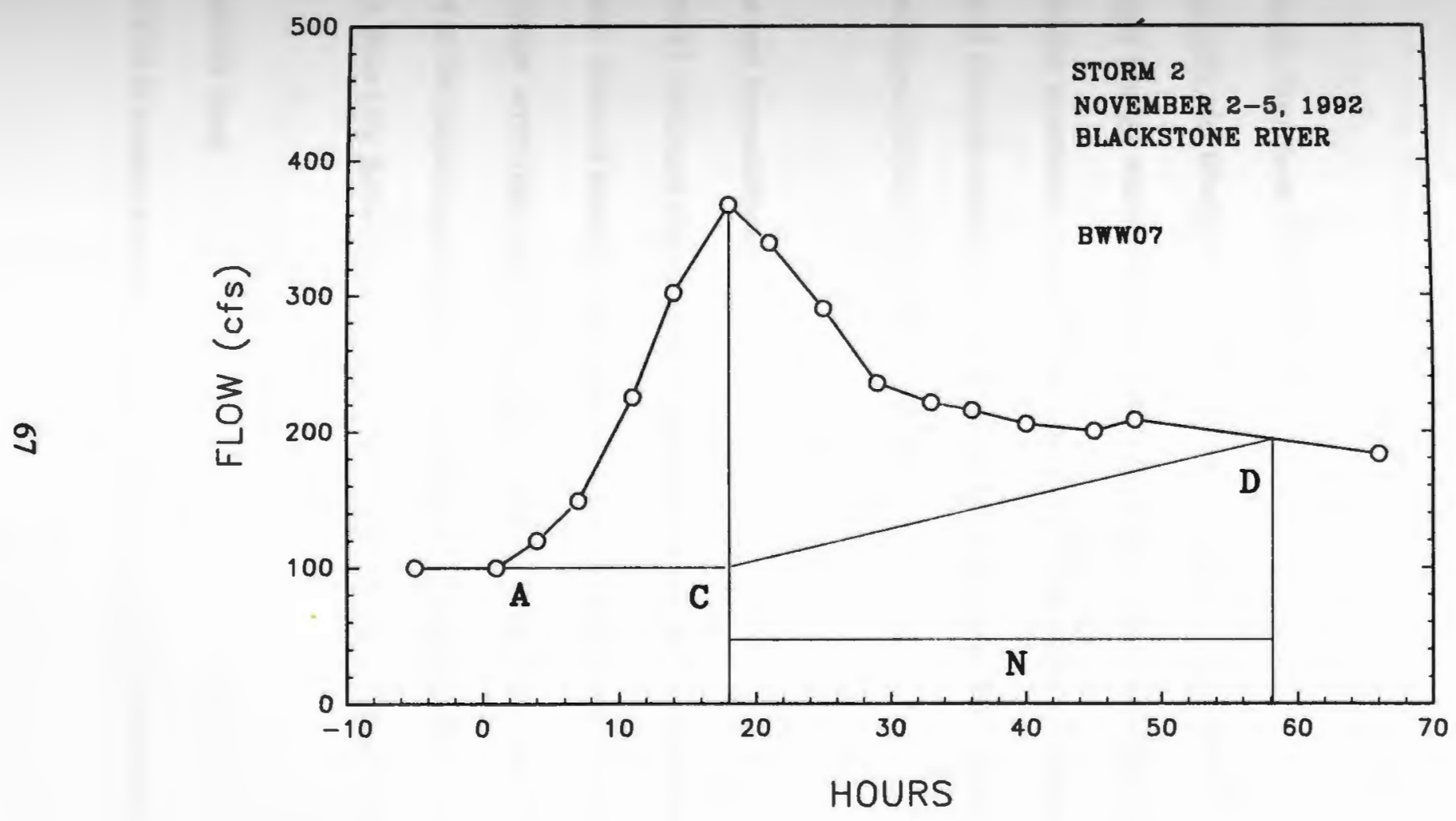

Figure 4.18 Example of Concave Base Flow Separation 
determined specific to the watershed. The default value for $b$ is typically taken as 0.2 , however, based on the response of the hydrographs in storm $1, \mathrm{~b}$ was set at 0.1 . The results are summarized in Table 4.9 to 4.11 including the direct runoff volume (in millions of cubic feet) and the average baseflow during the period of direct runoff (in cubic feet per second).

\subsection{Hydraulic Structures or Controls}

Historically, the Blackstone River has been a river in constant demand for its ability to supply energy, water supply or waste transport. The result was the construction of major hydraulic structures to control the river flow on the order of one per mile. Today, many of these structures have been removed. The ones that remain today (Table 4.12) have an impact on the river's water quality.

\subsubsection{Dams and Impoundments}

Nearly 45 dams and impoundments once existed on the Blackstone River, today only 19 remain. Some of them are still utilized for hydropower generation, but the majority no longer serve their original purpose. Many of these dams are in poor condition.

Three of the major impoundments along the river are Fisherville (between stations BWW04-06), Rice City (between stations BWW07-08) and Rochdale ponds.

\subsubsection{Fisherville Pond}

Fisherville is located downstream of the confluence of the Blackstone and 
Table 4.12 Dams and Impoundments on Blackstone River

\begin{tabular}{|c|c|c|c|c|c|c|}
\hline No. & Name & River Mile & Code No.a & $\begin{array}{c}\text { Storagea } \\
\text { (acre-feet) }\end{array}$ & Height & Reference \\
\hline & & & & & & \\
\hline 1 & McCracken Rd. & 43.9 & NA & NA & 4 & 2 \\
\hline 2 & Millbury Electric & 41 & MA00578 & 77 & 4 & 3 \\
\hline & Substation & & & & & \\
\hline 3 & Singing Dam & 39.8 & MA01180 & 60 & 14 & 2 \\
\hline 4 & Wilkinsonville & 39.2 & NA & NA & 4 & 3 \\
\hline 5 & Saundersville & 38.7 & NA & NA & 4 & 3 \\
\hline 6 & Fisherville & 36.5 & MA00577 & 250 & 4 & 2 \\
\hline 7 & Farnumsville & 35.6 & MA00576 & 85 & 4 & 3 \\
\hline 8 & Riverdale & 31.9 & MA00942 & 88.5 & 10 & 2 \\
\hline 9 & Rice City Pond & 27.8 & MA00935 & 1762 & 10 & 2 \\
\hline 10 & Tupperware & 17.8 & MA00096 & 305 & 15 & 2 \\
\hline 11 & Blackstone & 16.5 & NA & NA & 4 & 3 \\
\hline 12 & Thundermist & 14.3 & RI03902 & 300 & 18 & 2 \\
\hline 13 & Manville & 9.9 & RI00809 & 58 & 17 & 2 \\
\hline 14 & Albion & 8.2 & RI00808 & 495 & 6 & 2 \\
\hline 15 & Ashton & 6.8 & RI00807 & NA & 7 & 3 \\
\hline 16 & Lonsdale & 4.1 & RI01705 & NA & 4 & 1 \\
\hline 17 & Central Falls & 2.0 & RI00401 & 80 & 13 & 1 \\
\hline 18 & Pawtucket & 0.8 & RI00402 & 150 & 14 & 1 \\
\hline 19 & Slaters Mill & 0.0 & RI04270 & NA & 18 & 1 \\
\hline & & & & & & \\
\hline 15 & Cors of E & & & & 17 \\
\hline
\end{tabular}

1 = Army Corps of Engineers (COE 1973); 2 = Personal Communication (MADEP 1992);

3 =Field Survey; $a=$ COE (1994); NA = Not Available 
Quinsigamond Rivers. The pond has maximum storage of 1360 acre-feet and drainage area of 134 square miles and the dam was constructed in 1882 . It was constructed mainly to supply water to the now-abandoned Fisherville Mill Complex. The earthen dam is 10 feet high and 650 feet long, with a 200 feet long stone masonry spillway. Blackstone Canal is connected to the pond by a diversion structure (no longer in operation)

The 185 acre pond was drained in 1982 and has not been reflooded. MADEP raised the question concerning the safety of the dam. Partial reflooding of the pond happens caused by the obstruction at the outlet due to floating debris. The sediments behind the dam are contaminated with metals and organics.

\subsubsection{Rice City Pond}

The original purpose of the Rice City Pond (RCP) dam was to impound water to supply the Blackstone Canal during low flow periods. The reservoir area is about 800 feet wide and 4000 feet long. The drainage area of the dam is 204 square miles and maximum pool storage is 1762 acre-feet.

The main spillway is about 6 feet high and 50 feet long and the second spillway is about 75 feet long and 5 feet high. The elevation of the RCP has dropped in recent years causing the historic sediments to be exposed.

RCP was created in 1865 by owners of the Stanley Woolen Mill. In 1917 RCP was dammed to its highest elevation and remained unchanged till 1955. The RCP was a major settling pond for raw sewage dischargers, textile mill, metal plating, wire manufacturing, orchard pesticides, soil erosion from poor agricultural practices, auto 
graveyards and many other undocumented industrial and commercial wastes (Wright et. al., 1996).

Hurricane Diane of 1955 damaged the RCP severely. Flooding left about 200 feet wide breach. The dam was reconstructed afterwards with a lowering of dam height about 5 feet. The flood carried most of the contaminated sediments to downstream. With the lowering of the impoundment, the river has craved channels through the soft sediments. The result is a movement of this sediment into the water column and river even under average flow conditions. The impoundment has the potential for a significant non point source of any constituent either recently or historically deposited in the impoundment.

\subsubsection{Hydropower Stations}

The Farnumsville hydropower facility was constructed prior to Federal Energy Regulatory Commission (FERC) licensing. So it has no FERC oversite or any other regulatory control. It is located just upstream of the Riverdale impoundment and has influence on the daily fluctuation of the flow of the river.

The Riverdale facility is located in Northbridge, MA. FERC issued a 30 year licence to a wire manufacturer for power generation in 1987. The reservoir impounded is approximately 88.5 acre feet with 1400 feet of backwater. The steel and concrete dam is about 14 feet high and 142 feet long. No minimum flow appear to be in the permit.

The gross storage of the Thundermist Dam in Woonsocket, $\mathrm{RI}$ is $\mathbf{3 0 0}$ acre-feet (per FERC). The old dam was replaced with 40 feet high and 266 feet long concrete overflow Dam in 1960 . The maximum flow diverted is $1000 \mathrm{cfs}$, according to EPA. 
The Elizabeth Mill Dam also known as Pawtucket (RI) Dam is a granite masonry dam of 10 feet high, 156 feet long, with one feet flashboards on it. The gross storage of the dam is about 150 acre-feet and has a capacity of 670 kilowatts. The maximum diversion by the hydropower plant is $1060 \mathrm{cfs}$ (per licence application).

\subsubsection{Blackstone River Canal}

The construction of the Blackstone Canal was finished in 1828. The Canal essentially channelized the Mill Brook from the basin at Central Street to the Blackstone River south of the Cambridge and Millbury Street intersection.

When the Canal was in operation the number of industries in Worcester increased as the transportation problems were diminished. The population increased by 37 percent from 1825 to 1830 , and the value of manufactured goods expanded drastically.

The Canal had a significant influence on the cultural, social and industrial development of Worcester. The rapid growth of Worcester attracted many immigrants. Since Worcester was still a pedestrian city, the settlement of the immigrants was based upon the proximity to many companies, which were located on the Canal's vicinity.

Today the Canal is only watered for approximately 6 miles. A detailed description of the canal and its history is provided elsewhere (BRVNHC 1993). 


\section{CHAPTER 5}

Wet Weather Water Quality Interpretation

The two flow charts presented in Figures 5.1 and 5.2 describe the method followed in interpreting the wet weather data. Chapter 5 includes a presentation of individual concentrations and event mean concentrations (EMCs). Chapter 6 deals with criteria and violations. Chapter 7 uses the concentration and flow data to develop the mass loadings and gains/losses. System rankings and hot spot identification are provided in Chapter 8. A method for separating resuspended and runoff loadings is described in Chapter 9. An estimate of annual loadings at the MA/RI state line and end of river is provided in Chapter 10. Summary and conclusions are drawn in Chapter 11.

Three wet weather events were monitored for this study: September 22-24, 1992 (Storm 1), November 2-5, 1992 (Storm 2) and October 12-14, 1993 (Storm 3). Specific characteristics of the storms were provided in Chapter 4. Grab samples were collected at specific time intervals throughout the Blackstone River watershed and analyzed for 14 constituents. Details of the sampling protocol were given in Chapter 3. A complete listing of all data is provided in Appendix A. Mass loadings for each constituent per station per storm were calculated using the stream flows of Chapter 4. Individual station concentration and mass loading curves were developed. About 1000 profiles were developed during the course of this analysis. A subset of them specific to lead for three storms are provided in Appendix C. 


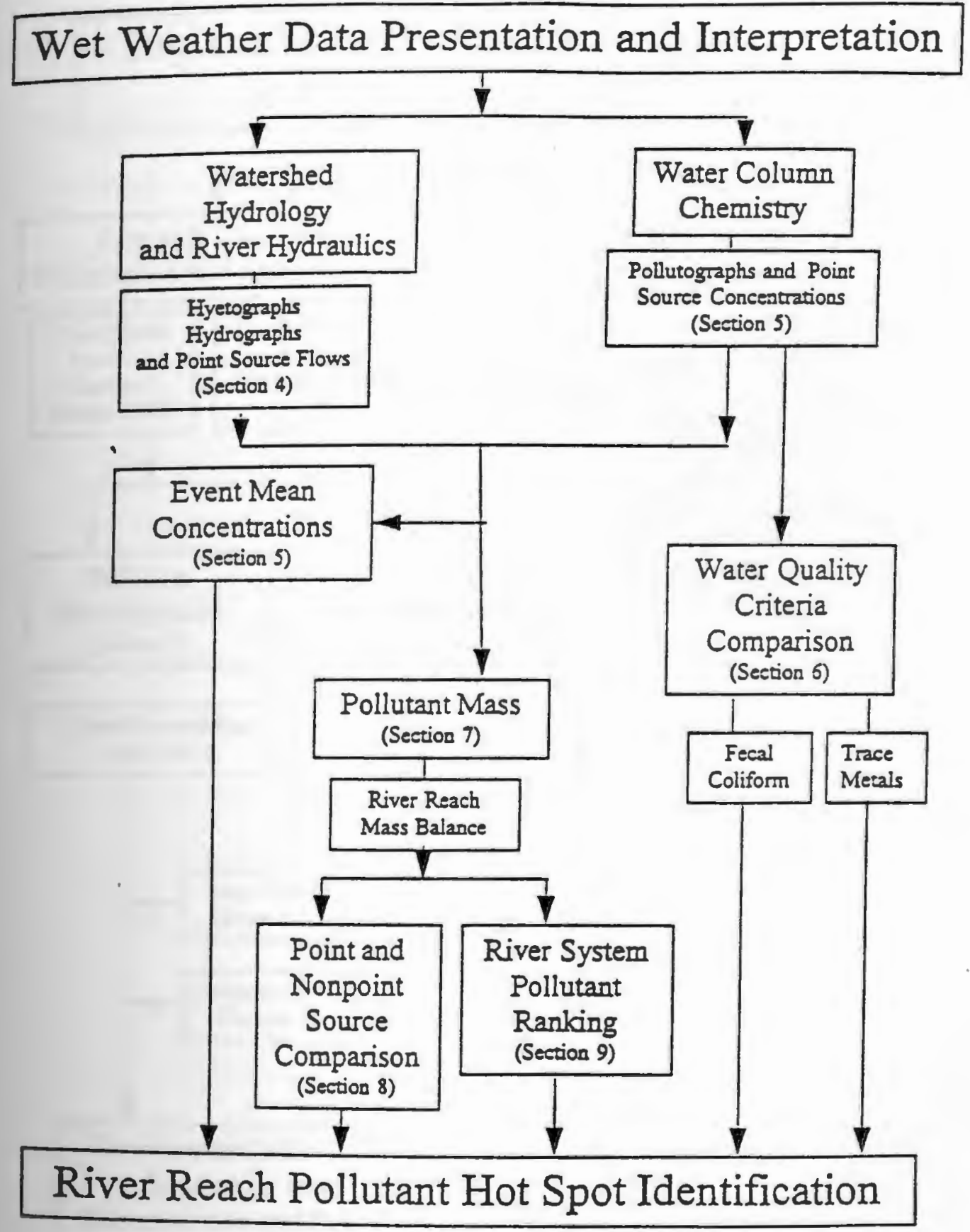

Figure 5.1

Flow Chart Describing Water Quality Evaluation of Wet Weather Concentration 


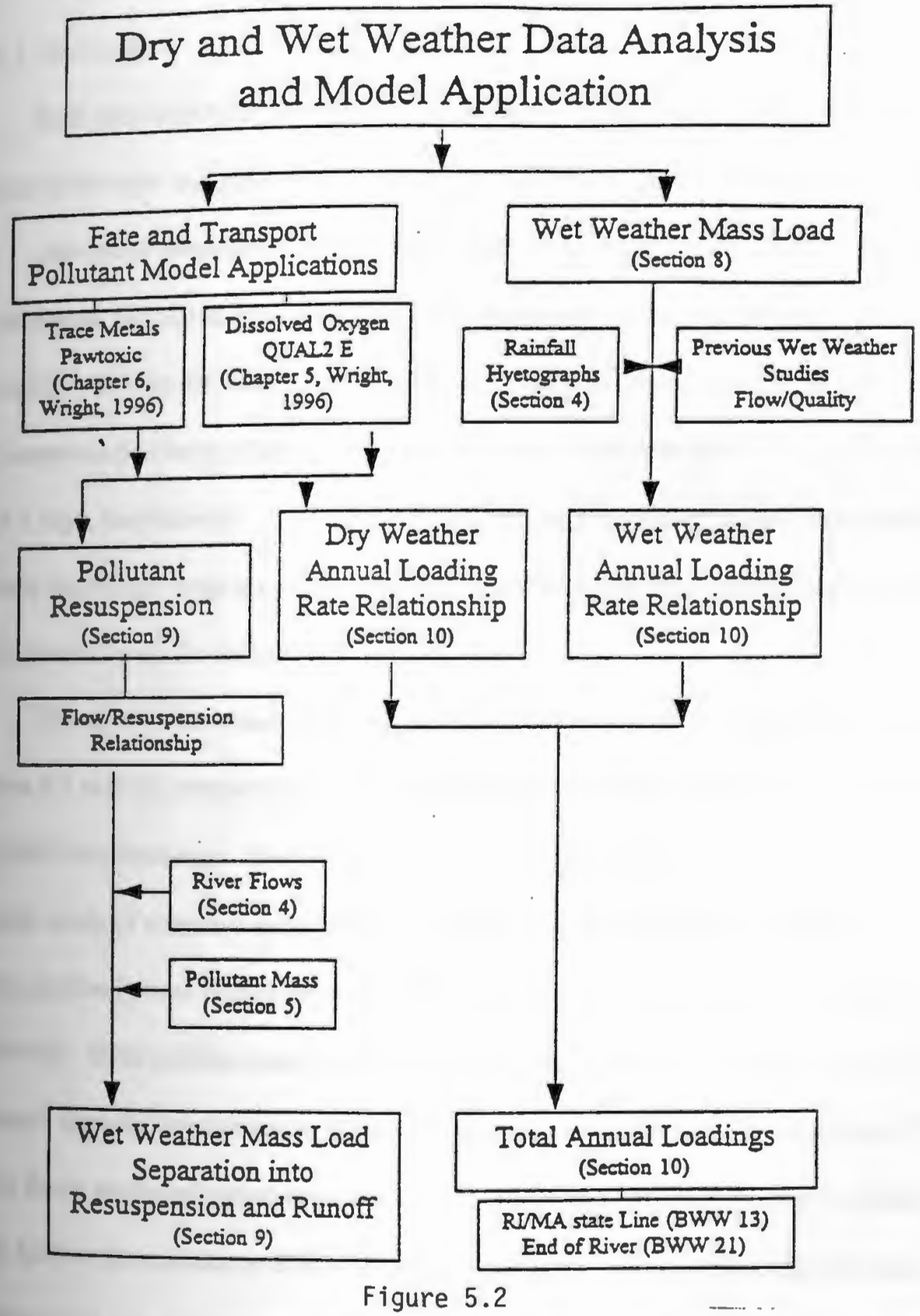

Flow Chart Describing Determination of Runoff/Resuspension and Annual Loading Rate 
5.1 Water Quality Concentration

5.1.1 Comparison Between Dry and Wet Weather Concentrations

\subsubsection{Nutrients}

Both the UBWPAD and Woonsocket wastewater treatment facilities are the major sources of nitrogen and phosphorous under dry weather conditions (Wright et al., 1996). Advanced treatment (nitrification) is required for UBWPAD, as stated in their federal permit \#MA0102369. The permit divides the year into three time frames:

November 1 to May 15; May 16 to May 31; and June 1 to October 31 . The maximum daily ammonia discharge allowed by the permit for the three time periods are, 12.5, 7.5 and $2.5 \mathrm{mg} /$, respectively. The Woonsocket facility is a secondary facility and, therefore, typically discharges large quantities of ammonia and relatively low levels of nitrate. There are no permit levels for ammonia for Woonsocket.

Nitrate and Ammonia - The ammonia and nitrate profiles for Storm 2 are given in Figures 5.3 and 5.4, respectively. For ammonia points A and B represent the location of the UBWPAD discharge. Since nitrification was not occurring in the November storm, the high levels of ammonia occurred before, during and after the storm. Likewise, the nitrate profiles (points A-B) indicate nitrification was occurring in the reaches below UBWPAD. Both profiles clearly indicate the storm track (Peak Concentration/Flow Passage) from the headwaters in Worcester, though the results were quite different. The higher flows produced higher ammonia concentrations and extended these concentrations much further downstream to BWW08 in Rice City Pond. Nitrate concentrations were smaller in this same path suggesting that nitrification, which would normally have been 


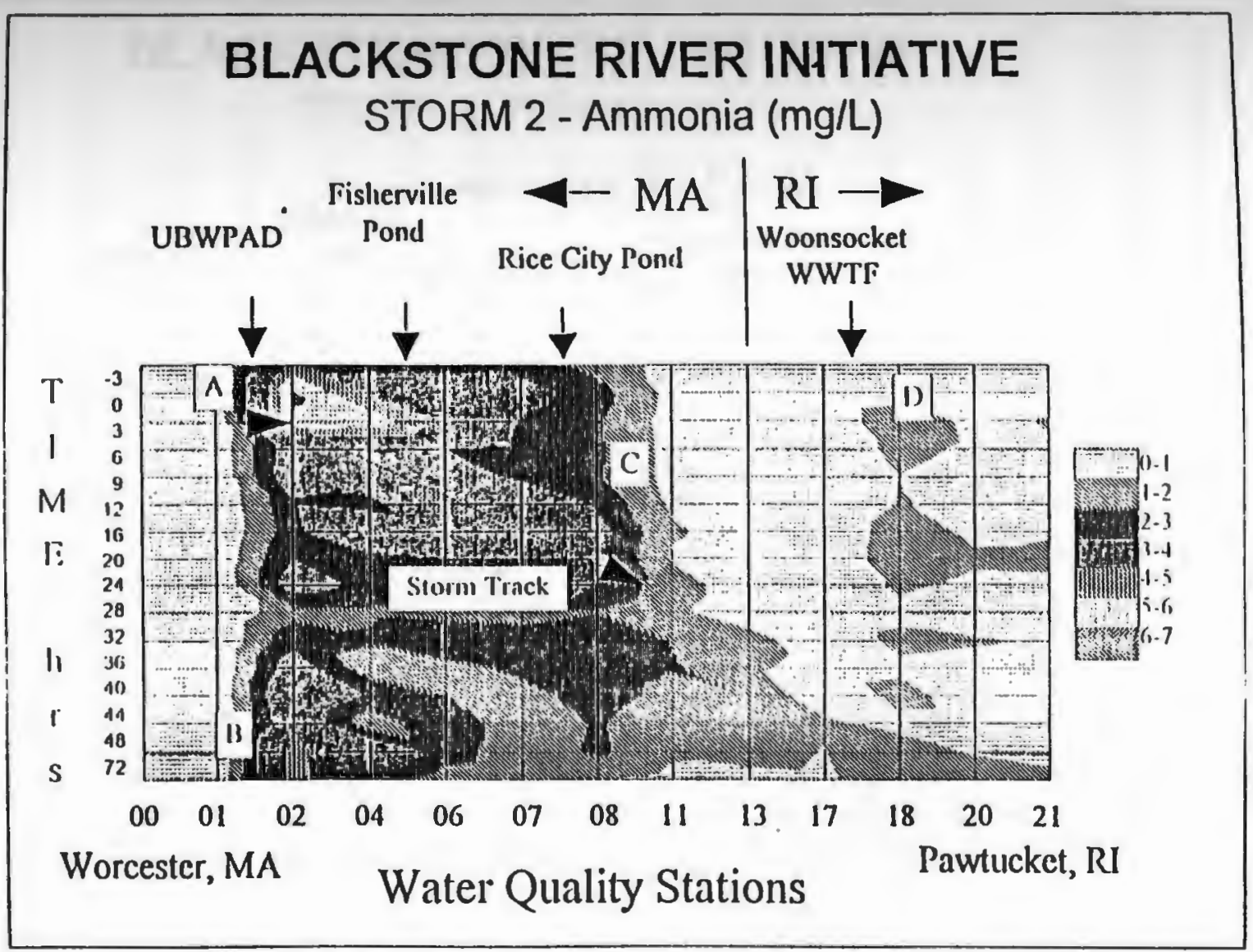

Figure 5.3 3-D Flat Ammonia Concentration Presentation - Storm 2 (Storm Track = Peak Signal Passage from Worcester) 


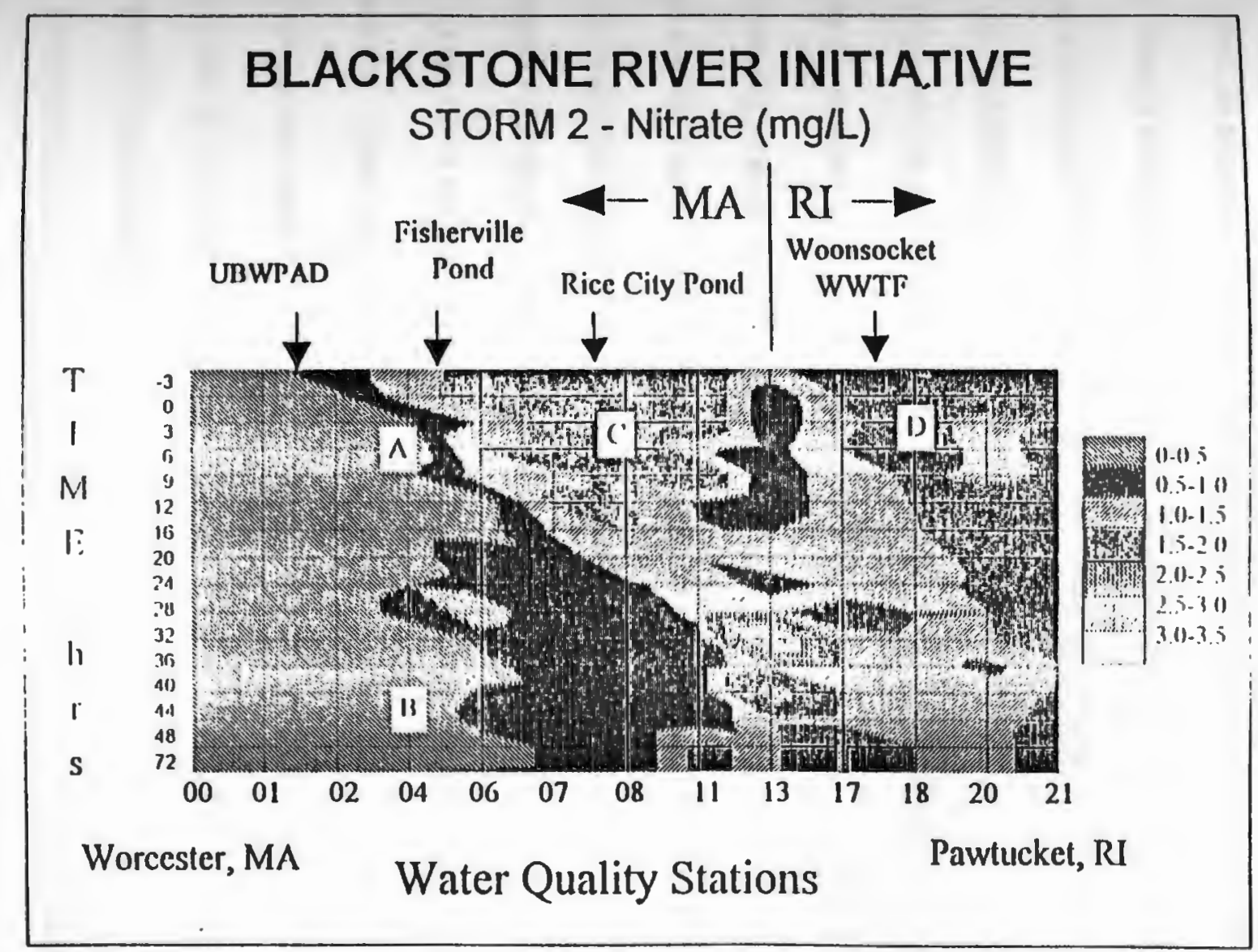

Figure 5.4 3-D Flat Nitrate Concentration Presentation - Storm 2 
occurring in these reaches, was delayed due to the high flows and faster times of travel.

The ammonia and nitrate profiles for Storm 1 are given in Figures 5.5 and 5.6, respectively. For ammonia points $\mathrm{A}$ and $\mathrm{B}$ again represent the UBWPAD discharge point. However, unlike Storm 2 ammonia concentrations do not remain high in the post storm hours. This is as expected given that nitrification should have been occurring in the facility. What is striking about this profile, is the response of the facility to the storm hydrograph that passed through the facility. The result was poorer treatment at the facility causing the discharge of a high, short term spike of ammonia.

There was no violation of the daily maximum ammonia discharge of $2.5 \mathrm{mg} / \mathrm{l}$ during the dry weather surveys. The maximum concentrations discharged by UBWPAD for the three dry weather surveys of July, August and October 1991 were 1.1, 0.60 and $0.80 \mathrm{mg} / \mathrm{l}$ and the average concentrations discharged were $0.44,0.25$ and $0.40 \mathrm{mg} /$.

By comparison under wet weather conditions violations of ammonia concentrations did occur in two out of three storms (Storm 1 and Storm 2). During Storm 1, 3 out of 10 samples collected at UBWPAD violated the maximum limit of 2.5 $\mathrm{mg} / \mathrm{l}$ ammonia. These violations coincided with peak storm flows. During Storm 2 when no nitrification was required 10 out of 16 samples collected at UBWPAD violated the maximum limit of $12.5 \mathrm{mg} / \mathrm{l}$ ammonia. Again these violations coincided with peak flows and the period immediately after.

The maximum ammonia concentrations discharged by UBWPAD during the three storm events were 4.3, 20.6 and $2.1 \mathrm{mg} / \mathrm{f}$ for Storm 1, 2 and 3, respectively, and the average concentrations discharged were $2.21,13.2$ and $0.76 \mathrm{mg} /$. 


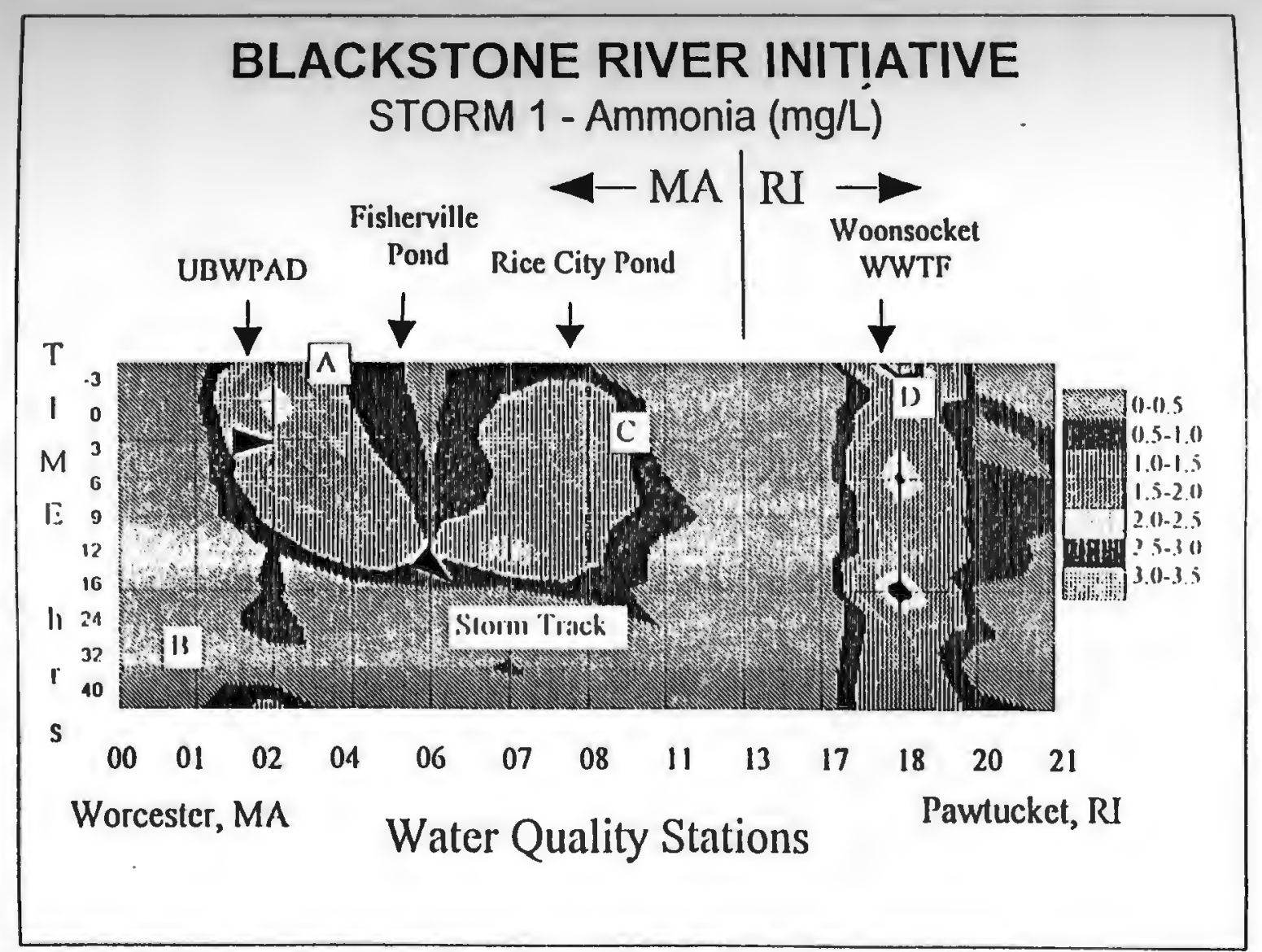

Figure 5.5 3-D Flat Ammonia Concentration Presentation - Storm 1 (Storm Track = Peak Signal Passage from Worcester) 


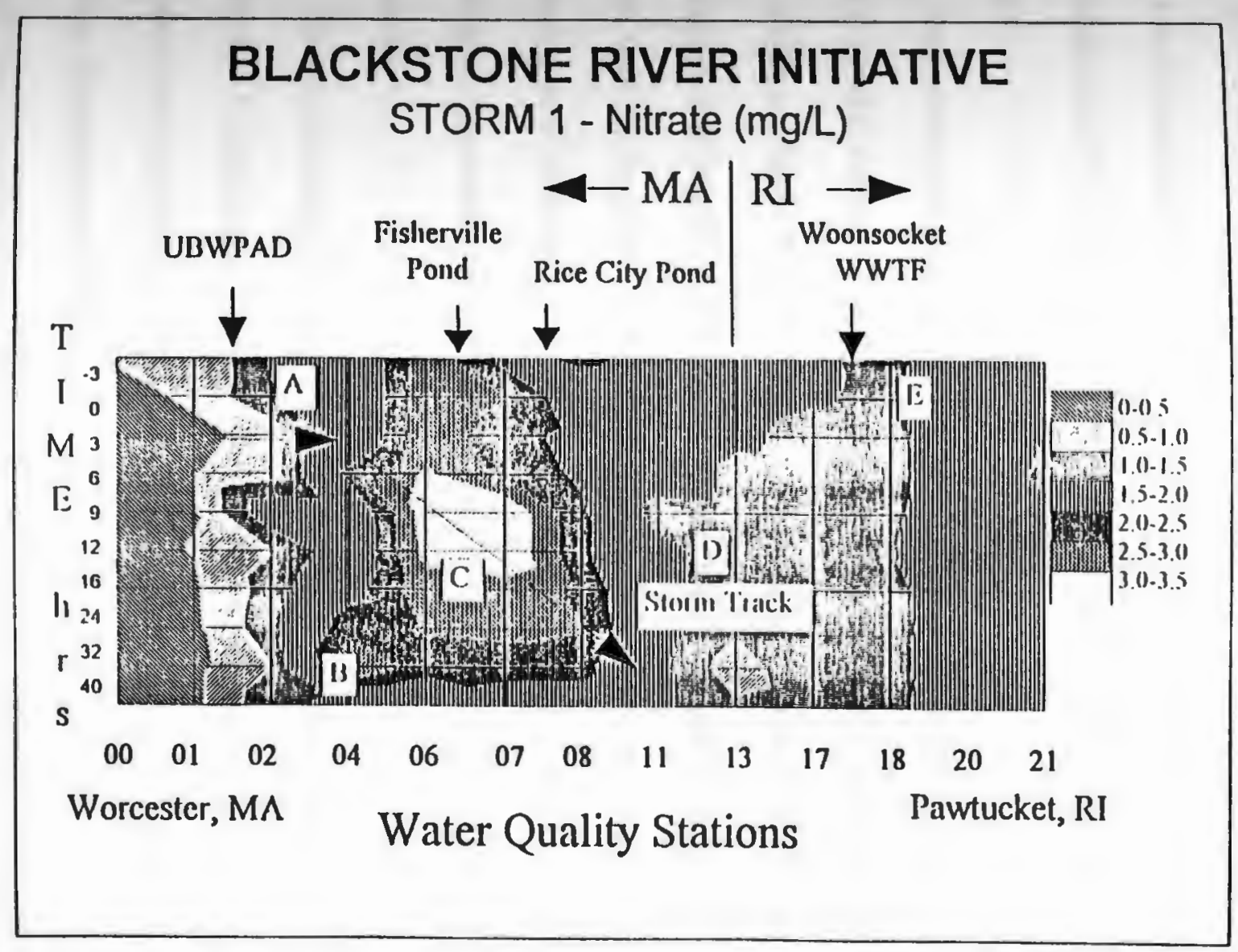

Figure 5.6 3-D Flat Nitrate Concentration Presentation - Storm 1 (Storm Track = Peak Signal Passage from Worcester) 
The maximum concentrations of ammonia discharged by Woonsocket during the dry weather surveys were $28.6,16.8$ and $15.8 \mathrm{mg} /$ and the average concentrations were $28.1,13.1$ and $11.1 \mathrm{mg} /$. For wet weather the maximum concentrations were generally higher at 34.3 and $33.6 \mathrm{mg} /$ and the average concentrations were 24.3 and $26.0 \mathrm{mg} /$ for Storm 1 and 2, respectively. For Storm 3, the maximum and average ammonia concentrations were very low at 0.53 and $0.38 \mathrm{mg} /$, respectively. The cause of this is unknown.

Two other significant increases of ammonia appear in these figures (Figures 5.3 and 5.5). Point $C$ marks the reaches between BWW07-11 which encompasses the reaches above, within and below Rice City Pond. The earlier peak between hours 3-6 is related to local drainage area runoff or reach resuspension. The later peak at about hour 12 is more reflective of the storm track from the Worcester headwaters. Point D marks the Woonsocket WWTF discharge. The signal is consistent in space and time and supports the finding in dry weather survey (Wright et al. 1996) that Woonsocket is a major source of ammonia.

The nitrate profile for Storm 1 (Figure 5.6) shows a high ridge line between points A-B, which is a result of the UBWPAD discharge. The increase of nitrate (instream nitrification) between BWW04-08 at hours 6-16 (Point C) coincides with the ammonia loss during the height of the storm.

At point $\mathrm{D}$ in Figure 5.6 concentrations of nitrate decline. This is due to both dilution from the 3 tributaries coming in between BWW08 and BWW13, as well as the nitrate uptake associated with plant productivity. 
The ridge of higher concentrations at E occurs between BWW18 and BWW20 and is a direct result of instream nitrification of Woonsocket's ammonia load. In both Figures 5.5 and 5.6 the storm track from the headwaters in Worcester and the UBWPAD are evident. Storm 3 profiles are similar to Storm 1.

Phosphate - Similar to dry weather, under wet weather conditions dissolved orthophosphate profiles are dominated by the two point sources, UBWPAD and Woonsocket. An example of the phosphorous profile is presented in Figure 5.7 for Storm 1. The most striking feature of this figure is the ridge line of high concentrations at UBWPAD between stations BWW01 and BWW02 (Points A and B). The high discharge of phosphorous from UBWPAD is continuous and independent of the storm events. In general, the phosphorous profile shows a reduction in concentration below Rice City Pond (BWW08), an increase due to the Woonsocket facility's discharge and then a decline to station BWW21. The decrease in concentration below Rice City Pond, as well as in the reaches below the Woonsocket facility, are related to dilution from incoming tributaries and uptake due to plant productivity.

There is no permit requirement for phosphorous for either UBWPAD or Woonsocket. The maximum concentrations discharged by UBWPAD for the three dry weather surveys of July, August and October 1991 were $3.0,3.0$ and $3.4 \mathrm{mg} /$, respectively and the average concentrations discharged were $2.30,2.36$ and $3.03 \mathrm{mg} / \mathrm{l}$. In comparison the maximum concentration discharged during the three storm events were $2.09,1.61$ and $1.98 \mathrm{mg} /$ for Storms 1,2 and 3, respectively, and the average concentrations discharged were $1.52,1.16$ and $1.35 \mathrm{mg} / 1$. The lower concentrations 


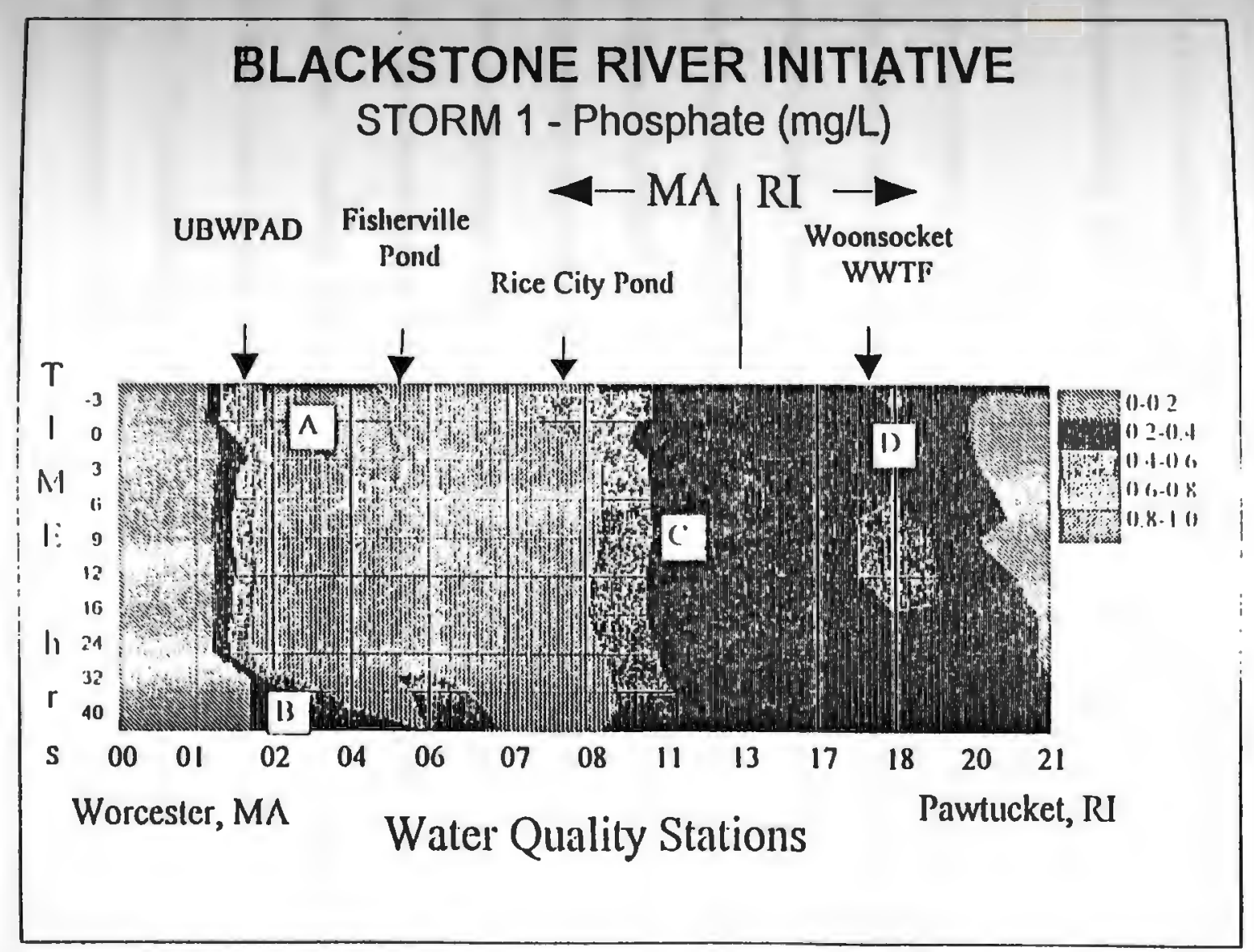

Figure 5.7 3-D Flat Phosphate Concentration Presentation - Storm 1 
during the storm events are a result of dilution by higher facility flows.

The maximum concentrations discharged by Woonsocket for dry weather were $3.9,4.9$ and $4.2 \mathrm{mg} / \mathrm{l}$ and the average concentrations discharged were $3.3,3.36$ and 4.0 mgl. The maximum concentrations discharged during the three storm events were slightly higher: 5.97, 7.16 and $6.86 \mathrm{mg} /$, for Storms 1,2 and 3, respectively, as were the average concentrations of $3.92,4.43$ and $5.21 \mathrm{mg} /$.

\subsubsection{Trace Metals}

The UBWPAD was shown to be a major source of most metals to the Blackstone River under dry weather, steady-state conditions (Wright et al., 1996). The Woonsocket facility was also indicated as a significant source for several metals. A comparison between the two surveys (dry vs wet) for these two facilities has been made below. Data has been presented as survey average concentration and as a maximum concentration range. The average survey concentration was obtained by averaging all data from the three 1991 dry weather surveys to provide a single dry weather average concentration for each constituent. Similarly, all wet weather data from the three 1992/3 wet weather surveys were averaged to provide a single wet weather average concentration for each constituent. The maximum concentration range includes the maximum concentrations reported for each survey.

$U B W P A D$ - For the UBWPAD several metals were influenced by the higher storm flows through the facility. The following general observations can be made based on the comparison of averages: under storm flows chromium concentrations doubled; copper 
and nickel concentrations did not change significantly and cadmium and lead concentrations decreased (Table 5.1).

A comparison of maximum wet weather and dry weather concentrations lead to the following observations: for chromium the wet weather range was significantly higher; for lead, copper and nickel the wet weather maximum concentration ranges were slightly lower and for cadmium the wet weather range was significantly lower (Table 5.1).

Woonsocket - For the Woonsocket WWTF several metals were influenced by the higher storm flows through the facility. The following general observations can be made based on the comparison of averages: under storm flows copper and lead concentrations increased significantly; chromium concentrations did not change significantly and cadmium and nickel concentrations decreased (Table 5.2).

A comparison of maximum wet weather and dry weather concentrations lead to the following observations: for cadmium, copper and lead the wet weather ranges were significantly higher; for chromium the dry and wet weather maximum concentration ranges were similar and for nickel the wet weather range was significantly lower (Table 5.2).

Based on these comparisons, and the fact that no record or data support that metal loadings have changed between 1991 and 1993, one possible cause of the relatively high metal concentrations observed at UBWPAD (chromium) and the Woonsocket WWTF (chromium, copper and lead) may have been from sources in the system triggered under wet weather conditions. On the other hand, the decrease in some concentrations at UBWPAD (cadmium, copper, lead and nickel) and the Woonsocket WWTF (cadmium) may be more a result of the dilution from runoff. The exception to this was the unusually 
Table 5.1 Comparison of Metals Between Dry and Wet Weather @ UBWPAD

\begin{tabular}{|c|c|c|c|c|c|}
\hline Facility & $\begin{array}{c}\text { Metal } \\
(\mu \mathrm{g} / \mathrm{l})\end{array}$ & $\begin{array}{c}\text { Average } \\
\text { Dry Weather }\end{array}$ & $\begin{array}{c}\text { Average } \\
\text { Wet Weather }\end{array}$ & $\begin{array}{c}\text { Maximum } \\
\text { Dry Weather }\end{array}$ & $\begin{array}{c}\text { Maximum } \\
\text { Wet Weather }\end{array}$ \\
\hline \multirow{3}{*}{ UBWPAD } & $\mathrm{Cd}$ & 3.9 & 1.6 & $3.2-6.8$ & $0.9-2.9$ \\
\cline { 2 - 6 } & $\mathrm{Cr}$ & 4.5 & 9.1 & $2.7-7.5$ & $6.8-31.5$ \\
\cline { 2 - 6 } & $\mathrm{Cu}$ & 40 & 36 & $41.4-61.1$ & $21.1-74.1$ \\
\cline { 2 - 6 } & $\mathrm{Pb}$ & 4.4 & 2.7 & $2.4-8.6$ & $3.4-5.7$ \\
\cline { 2 - 7 } & $\mathrm{Ni}$ & 39 & 29 & $25.8-163$ & $26.1-46.7$ \\
\hline
\end{tabular}


Table 5.2 Comparison of Metals Between Dry and Wet Weather @ Woonsocket

\begin{tabular}{|c|c|c|c|c|c|}
\hline Facility & $\begin{array}{c}\text { Metal } \\
(\mu \mathrm{g} / \mathrm{l})\end{array}$ & $\begin{array}{c}\text { Average } \\
\text { Dry Weather }\end{array}$ & $\begin{array}{c}\text { Average } \\
\text { Wet Weather }\end{array}$ & $\begin{array}{c}\text { Maximum } \\
\text { Dry Weather }\end{array}$ & $\begin{array}{c}\text { Maximum } \\
\text { Wet Weather }\end{array}$ \\
\hline Woonsocket & $\mathrm{Cd}$ & 2.9 & 1.5 & $1.7-5.9$ & $2.7-11.5$ \\
\cline { 2 - 6 } & $\mathrm{Cr}$ & 4.4 & 5.3 & $3.3-14.7$ & $6.7-8.0$ \\
\cline { 2 - 6 } & $\mathrm{Cu}$ & 31 & 51 & $20.0-46.2$ & $61.9-97.1$ \\
\cline { 2 - 6 } & $\mathrm{Pb}$ & 7.2 & 16 & $6.0-21.0$ & $21.6-31.4$ \\
\cline { 2 - 6 } & $\mathrm{Ni}$ & 160 & 5.4 & $79-256$ & $5.6-10.6$ \\
\hline
\end{tabular}


high post chlorination concentration of nickel at the Woonsocket facility in 1991.

River Profile - Under dry weather conditions the metal concentrations along the river were categorized into two general profiles (Wright et al., 1996). Under wet weather these same patterns appear similar but magnified. The first pattern generally describes cadmium, chromium, copper, nickel and zinc. It was consistent with the dry weather surveys in that the major increase occurred between BWW01-04. This reach includes UBWPAD and several other potential non point sources of metal pollution. The other consistent increase in metals occurred in the reaches above, in and immediately below Rice City Pond (BWW07-11) due most likely to sediment resuspension. Example figure for chromium for Storm 1 is provided in Figure 5.8.

The other pattern was specific to lead and showed a significant source of the metal in the headwaters above BWW00. Example figure for lead for Storm 1 is provided in Figure 5.9. The UBWPAD was not significant relative to the headwater source. A secondary source of lead was associated with resuspension in the river reaches surrounding Rice City Pond (BWW07-11). The source of lead in the headwaters is not known. Further investigation within the Worcester collection system is warranted.

The concentration profiles were developed for all trace metals per station per storms and a subset of them specific to lead is provided in Appendix B.

\subsubsection{Wet Weather Event Mean Concentration (EMC)}

Since wet weather concentrations are time-varying one way to represent the data is to develop event mean concentrations (EMCs). The EMC is used to represent a flow 


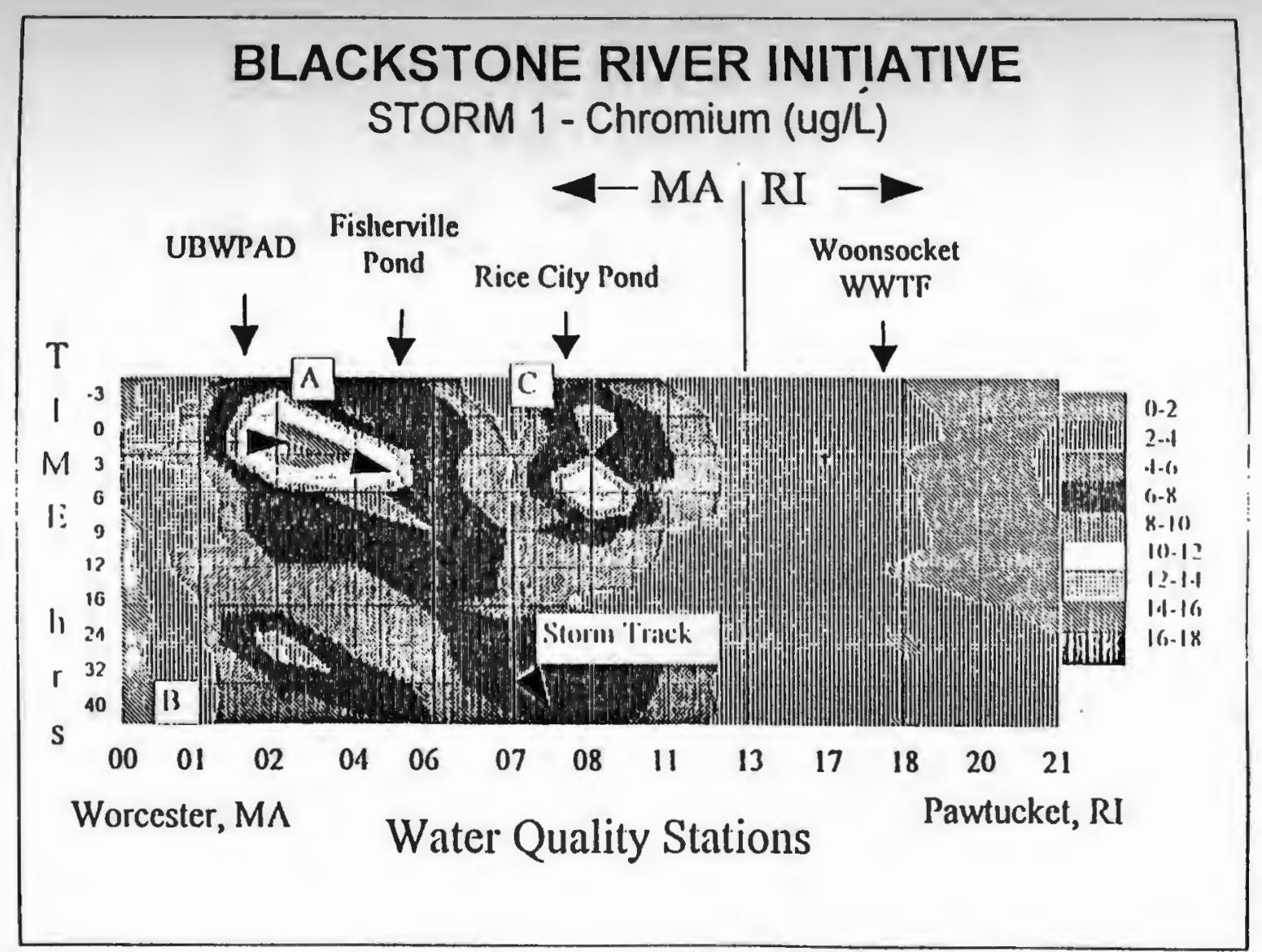

Figure 5.8 3-D Flat Chromium Concentration Presentation - Storm 1 (Storm Track = Peak Signal Passage from Worcester) 


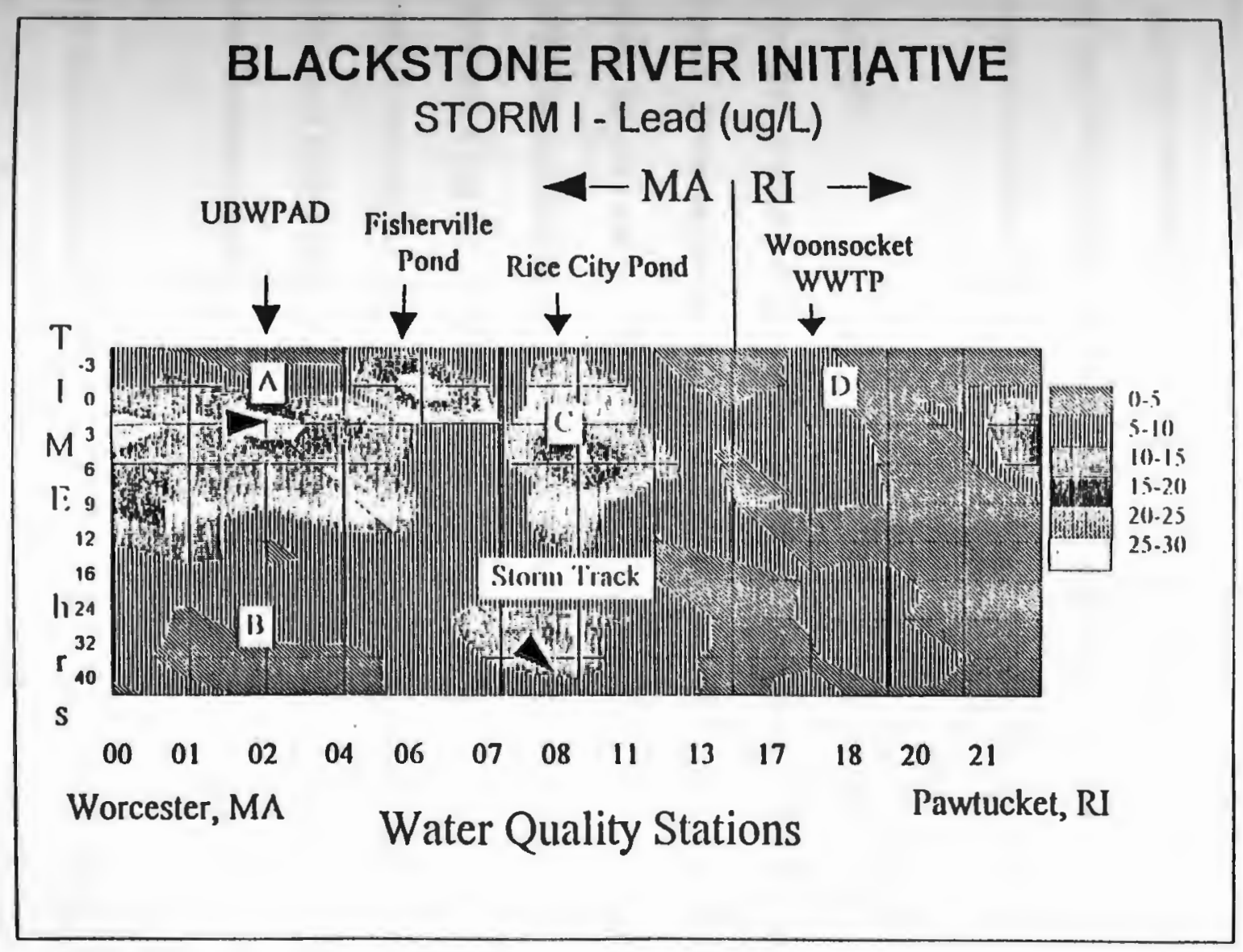

Figure 5.9 3-D Flat Lead Concentration Presentation - Storm 1 (Storm Track = Peak Signal Passage from Worcester) 
weighted concentration of any water quality parameter during a single storm event. EMCs for each station were calculated by summing the products of concentration and flow for each time interval and then dividing by the total flow. A watershed EMC for the Blackstone River was determined by averaging the EMCs for all stations. Tables 5.3, 5.4 and 5.5 represent the EMC values for Storms 1, 2 and 3, respectively, and Table 5.6 represents the EMCs for the entire Blackstone River watershed. Figures 5.10 to 5.15 show the spatial variation of EMCs for the 16 constituents for the three storms.

\subsubsection{Nutriehts}

The EMC profiles in Figure 5.10 reflected the operation of UBWPAD with respect to nitrification. It was established earlier that nitrification was being provided at the facility during Storms 1 and 3. The instream data supported this with high nitrate EMCs below UBWPAD and comparatively low ammonia levels. The reverse was true for Storm 2 when nitrification was not being provided at the facility.

Instream nitrification was evident in all three storms, but particularly in Storm 2, where there was a decline in ammonia below BWW02 with a resulting rise in nitrate. To a lesser degree instream nitrification was also seen in the reaches below the Woonsocket discharge.

The decrease of nitrate in the Storm 1 profile was most likely due to nitrate uptake by plants. Nitrate loss due to plant uptake was observed and documented in the two summer dry weather surveys in July and August (Wright et al., 1996). It did not occur in the third survey in October, since plant production was very low. Storm 1 occurred in 
Table 5.3 Event Mean Concentration (EMC) For Storm 1

\begin{tabular}{|c|c|c|c|c|c|c|c|c|}
\hline Station & $\mathrm{Cd}$ & $\mathrm{Cr}$ & $\mathrm{Cu}$ & $\mathrm{Ni}$ & $\mathrm{Pb}$ & $\mathrm{Zn}$ & $\mathrm{TSS}$ & $\mathrm{VSS}$ \\
\hline & ug/ & ug/ & ug/ & $\mathrm{ug} /$ & $\mathrm{ug} /$ & $\mathrm{ug} /$ & $\mathrm{mg} /$ & $\mathrm{mg} / 1$ \\
\hline & & & & & & & & \\
\hline BWW00 & 0.61 & 2.47 & 6.45 & 3.10 & 19.7 & 33.5 & 6.41 & 2.76 \\
\hline BWW01 & 0.35 & 4.08 & 9.36 & 3.89 & 14.2 & 46.4 & 13.1 & 5.10 \\
\hline BWW02 & 0.90 & 10.8 & 14.3 & 10.4 & 13.2 & 64.1 & 7.55 & 4.50 \\
\hline BWW04 & 1.26 & 8.99 & 38.3 & 21.4 & 10.1 & 55.4 & 16.0 & 6.88 \\
\hline BWW06 & 1.00 & 7.15 & 31.8 & 18.3 & 9.83 & 38.5 & 7.40 & 3.42 \\
\hline BWW07 & 0.81 & 5.11 & 24.5 & 16.1 & 8.28 & 30.3 & 7.28 & 2.93 \\
\hline BWW08 & 1.10 & 8.40 & 28.4 & 16.4 & 12.4 & 41.3 & 9.80 & 3.30 \\
\hline BWW11 & 0.71 & 4.89 & 17.1 & 11.3 & 7.12 & 26.8 & 5.47 & 2.61 \\
\hline BWW13 & 0.45 & 2.86 & 11.0 & 8.28 & 4.34 & 17.5 & 3.67 & 2.07 \\
\hline BWW17 & 0.39 & 2.98 & 10.4 & 7.61 & 6.36 & 22.8 & 5.04 & 2.39 \\
\hline BWW18 & 0.43 & 2.16 & 11.8 & 5.85 & 4.82 & 35.0 & 4.70 & 2.94 \\
\hline BWW20 & 0.33 & 1.69 & 10.5 & 4.80 & 3.87 & 25.8 & 2.74 & 1.86 \\
\hline BWW21 & 0.38 & 2.05 & 10.4 & 4.62 & 6.76 & 25.1 & 2.75 & 1.78 \\
\hline & & & & & & & & \\
\hline
\end{tabular}

\begin{tabular}{|c|c|c|c|c|c|c|c|c|}
\hline Station & EC & FC & NH3 & NO3 & PO4 & BOD & Cl & Na \\
\hline & $\mathrm{md} / 100 \mathrm{ml}$ & $\mathrm{md} / 100 \mathrm{ml}$ & $\mathrm{mg} /$ & $\mathrm{mg} /$ & $\mathrm{mg} /$ & $\mathrm{mg} /$ & $\mathrm{mg} /$ & $\mathrm{mg} / 1$ \\
\hline & & & & & & & & \\
\hline BWW00 & 2690 & 6190 & 0.17 & 0.32 & 0.02 & 4.16 & 43.7 & 19.2 \\
\hline BWW01 & 3850 & 11400 & 0.22 & 0.43 & 0.02 & 5.42 & 84.3 & 34.8 \\
\hline BWW02 & 0.55 & 340 & 1.54 & 1.14 & 0.73 & 5.99 & 91.3 & 49.6 \\
\hline BWW04 & 88.5 & 735 & 1.04 & 2.14 & 0.80 & 5.25 & 86.6 & 48.1 \\
\hline BWW06 & 173 & 607 & 0.49 & 3.25 & 0.74 & 4.33 & 81.9 & 46.6 \\
\hline BWW07 & 182 & 784 & 0.81 & 3.00 & 0.65 & 2.48 & 82.0 & 46.6 \\
\hline BWW08 & 41.5 & 189 & 0.83 & 2.54 & 0.64 & 2.85 & 81.2 & 45.5 \\
\hline BWW11 & 105 & 228 & 0.31 & 1.77 & 0.37 & 2.24 & 69.7 & 38.5 \\
\hline BWW13 & 139 & 594 & 0.05 & 1.29 & 0.28 & 1.75 & 60.9 & 34.2 \\
\hline BWW17 & 958 & 2230 & 0.04 & 1.37 & 0.24 & 1.67 & 59.0 & 30.8 \\
\hline BWW18 & 49.1 & 394 & 2.42 & 1.33 & 0.41 & 1.73 & 83.8 & 49.0 \\
\hline BWW20 & 40.2 & 117 & 0.55 & 1.99 & 0.26 & 1.67 & 84.6 & 49.5 \\
\hline BWW21 & 319 & 2290 & 0.37 & 1.73 & 0.17 & 1.34 & 76.3 & 44.4 \\
\hline & & & & & & & & \\
\hline
\end{tabular}


Table 5.4 Event Mean Concentration (EMC) For Storm 2

\begin{tabular}{|c|c|c|c|c|c|c|c|c|}
\hline Station & $\mathrm{Cd}$ & $\mathrm{Cr}$ & $\mathrm{Cu}$ & $\mathrm{Ni}$ & $\mathrm{Pb}$ & $\mathrm{Zn}$ & $\mathrm{TSS}$ & $\mathrm{VSS}$ \\
\hline & $\mathrm{ug} / 1$ & $\mathrm{ug} /$ & $\mathrm{ug} / 1$ & $\mathrm{ug} / 1$ & $\mathrm{ug} /$ & $\mathrm{ug} /$ & $\mathrm{mg} /$ & $\mathrm{mg} /$ \\
\hline & & & & & & & & \\
\hline BWW00 & 0.05 & 1.45 & 7.80 & 2.23 & 11.4 & 27.6 & 11.8 & 6.51 \\
\hline BWW01 & 0.09 & 3.27 & 10.6 & 4.60 & 11.9 & 45.3 & 13.6 & 6.32 \\
\hline BWW02 & 1.12 & 7.02 & 15.9 & 12.3 & 11.7 & 46.9 & 19.6 & 13.9 \\
\hline BWW04 & 1.85 & 9.07 & 23.0 & 13.9 & 15.9 & 56.3 & 17.8 & 11.8 \\
\hline BWW06 & 1.41 & 5.62 & 17.5 & 10.5 & 13.2 & 43.7 & 10.7 & 5.51 \\
\hline BWW07 & 1.20 & 3.93 & 14.1 & 9.72 & 7.36 & 41.6 & 6.05 & 3.09 \\
\hline BWW08 & 1.72 & 6.69 & 18.6 & 11.8 & 11.4 & 45.0 & 8.83 & 3.83 \\
\hline BWW11 & 1.23 & 6.91 & 17.2 & 7.68 & 10.6 & 41.1 & 11.4 & 4.24 \\
\hline BWW13 & 0.51 & 3.52 & 9.46 & 5.00 & 6.31 & 21.8 & 4.10 & 2.07 \\
\hline BWW17 & 0.54 & 2.49 & 8.68 & 5.39 & 5.21 & 19.3 & 4.11 & 1.76 \\
\hline BWW18 & 0.51 & 2.33 & 9.87 & 4.72 & 4.28 & 21.3 & 6.83 & 3.93 \\
\hline BWW20 & 0.48 & 1.85 & 8.73 & 6.05 & 4.79 & 24.6 & 7.04 & 4.05 \\
\hline BWW21 & 0.54 & 1.68 & 8.21 & 4.97 & 5.97 & 26.4 & 4.81 & 2.33 \\
\hline & & & & & & & & \\
\hline
\end{tabular}

\begin{tabular}{|c|c|c|c|c|c|c|c|c|}
\hline Station & EC & FC & NH3 & NO3 & PO4 & BOD & Cl & Na \\
\hline & $\mathrm{md} / 100 \mathrm{ml}$ & $\mathrm{md} / 100 \mathrm{ml}$ & $\mathrm{mg} /$ & $\mathrm{mg} /$ & $\mathrm{mg} /$ & $\mathrm{mg} /$ & $\mathrm{mg} /$ & $\mathrm{mg} /$ \\
\hline & & & & & & & & \\
\hline BWW00 & 2780 & 4900 & 0.07 & 0.12 & 0.04 & 6.30 & 54.2 & 22.6 \\
\hline BWW01 & 3570 & 5800 & 0.17 & 0.24 & 0.03 & 7.19 & 77.4 & 31.2 \\
\hline BWW02 & 8160 & 22200 & 3.87 & 0.28 & 0.41 & 7.80 & 81.5 & 40.4 \\
\hline BWW04 & 4840 & 26100 & 3.21 & 0.43 & 0.47 & 9.13 & 78.5 & 27.9 \\
\hline BWW06 & 3500 & 17400 & 3.27 & 0.74 & 0.42 & 7.54 & 80.9 & 32.1 \\
\hline BWW07 & 1580 & 8350 & 2.75 & 0.94 & 0.43 & 5.37 & 78.7 & 37.2 \\
\hline BWW08 & 1250 & 7240 & 2.49 & 1.07 & 0.45 & 4.89 & 82.3 & 39.7 \\
\hline BWW11 & 350 & 3030 & 1.17 & 1.23 & 0.27 & 4.51 & 62.2 & 29.8 \\
\hline BWW13 & 328 & 764 & 0.79 & 1.50 & 0.18 & 2.62 & 56.9 & 25.5 \\
\hline BWW17 & 402 & 836 & 0.44 & 1.63 & 0.19 & 2.48 & 59.1 & 26.0 \\
\hline BWW18 & 215 & 895 & 1.20 & 1.45 & 0.28 & 3.31 & 65.3 & 31.7 \\
\hline BWW20 & 88.8 & 409 & 0.79 & 1.44 & 0.26 & 3.76 & 71.0 & 30.7 \\
\hline BWW21 & 516 & 2110 & 0.79 & 1.69 & 0.23 & 4 & 71.3 & 27.1 \\
\hline
\end{tabular}


Table 5.5 Event Mean Concentration (EMC) For Storm 3

\begin{tabular}{|c|c|c|c|c|c|c|c|c|}
\hline Station & $\mathrm{Cd}$ & $\mathrm{Cr}$ & $\mathrm{Cu}$ & $\mathrm{Ni}$ & $\mathrm{Pb}$ & $\mathrm{Zn}$ & $\mathrm{TSS}$ & $\mathrm{VSS}$ \\
\hline & ug/ & ug/ & $\mathrm{ug} /$ & ug/ & ug/ & ug/ & $\mathrm{mg} /$ & $\mathrm{mg} /$ \\
\hline & & & & & & & & \\
\hline BWW00 & 0.36 & 7.28 & 19.2 & 3.94 & 41.1 & 35.8 & 28.8 & 9.15 \\
\hline BWW01 & 0.40 & 6.12 & 19.1 & 5.35 & 33.5 & 91.6 & 28.5 & 8.33 \\
\hline BWW02 & 0.79 & 7.60 & 29.0 & 11.6 & 30.6 & 52.7 & 24.2 & 8.61 \\
\hline BWW04 & 0.50 & 4.41 & 14.9 & 8.32 & 10.4 & 22.6 & 44.5 & 15.5 \\
\hline BWW06 & 0.53 & 3.89 & 19.4 & 9.19 & 16.4 & 36.2 & 26.0 & 9.49 \\
\hline BWW07 & 0.46 & 4.06 & 19.3 & 10.6 & 11.7 & 32.6 & 10.3 & 5.61 \\
\hline BWW08 & 0.54 & 8.83 & 25.6 & 11.4 & 19.1 & 51.0 & 17.2 & 5.27 \\
\hline BWW11 & 0.57 & 5.93 & 20.0 & 9.74 & 16.8 & 41.7 & 14.5 & 7.35 \\
\hline BWW13 & 0.36 & 2.77 & 10.6 & 8.24 & 6.17 & 16.5 & 5.93 & 3.80 \\
\hline BWW17 & 0.25 & 2.34 & 10.4 & 7.84 & 8.17 & 17.2 & 7.79 & 3.71 \\
\hline BWW18 & 0.25 & 1.85 & 10.7 & 7.18 & 5.74 & 17.9 & 7.08 & 3.96 \\
\hline BWW20 & 0.21 & 1.74 & 11.9 & 6.61 & 6.41 & 16.7 & 10.5 & 3.61 \\
\hline BWW21 & 0.24 & 1.77 & 9.81 & 5.34 & 5.68 & 15.0 & 8.64 & 4.70 \\
\hline & & & & & & & & \\
\hline
\end{tabular}

\begin{tabular}{|c|c|c|c|c|c|c|c|c|}
\hline Station & EC & FC & NH3 & NO3 & PO4 & BOD & Cl & Na \\
\hline & $\mathrm{md} / 100 \mathrm{ml}$ & $\mathrm{md} / 100 \mathrm{ml}$ & $\mathrm{mg} /$ & $\mathrm{mg} /$ & $\mathrm{mg} /$ & $\mathrm{mg} /$ & $\mathrm{mg} /$ & $\mathrm{mg} /$ \\
\hline & & & & & & & & \\
\hline BWW00 & 9120 & 22200 & 0.05 & 0.22 & 0.01 & 5.66 & 35.8 & 18.3 \\
\hline BWW01 & 5590 & 9850 & 0.06 & 0.34 & 0.01 & 6.60 & 41.6 & 26.6 \\
\hline BWW02 & 781 & 5910 & 0.35 & 1.35 & 0.28 & 7.19 & 57.6 & 36.8 \\
\hline BWW04 & 2040 & 5280 & 0.29 & 1.34 & 0.26 & 6.38 & 60.2 & 27.2 \\
\hline BWW06 & 1510 & 3170 & 0.18 & 1.61 & 0.35 & 4.21 & 63.4 & 38.2 \\
\hline BWW07 & 315 & 2350 & 0.18 & 1.72 & 0.31 & 4.36 & 68.5 & 40.2 \\
\hline BWW08 & 486 & 2250 & 0.17 & 1.64 & 0.30 & 4.13 & 68.1 & 39.8 \\
\hline BWW11 & 239 & 807 & 0.11 & 0.69 & 0.26 & 3.53 & 68.5 & 40.5 \\
\hline BWW13 & 120 & 201 & 0.06 & 1.81 & 0.30 & 2.02 & 66.6 & 40.8 \\
\hline BWW17 & 722 & 1490 & 0.03 & 1.87 & 0.06 & 2.12 & 68.4 & 40.9 \\
\hline BWW18 & 282 & 2460 & 0.21 & 2.44 & 0.39 & 1.98 & 77.2 & 48.4 \\
\hline BWW20 & 291 & 728 & 0.26 & 2.31 & 0.57 & 1.95 & 75.1 & 47.0 \\
\hline BWW21 & 1090 & 1480 & 0.11 & 2.27 & 0.40 & 1.79 & 74.0 & 46.5 \\
\hline & & & & & & & & \\
\hline
\end{tabular}


EMC Plots for $\mathrm{NO}_{3}$ and $\mathrm{NH}_{3}$
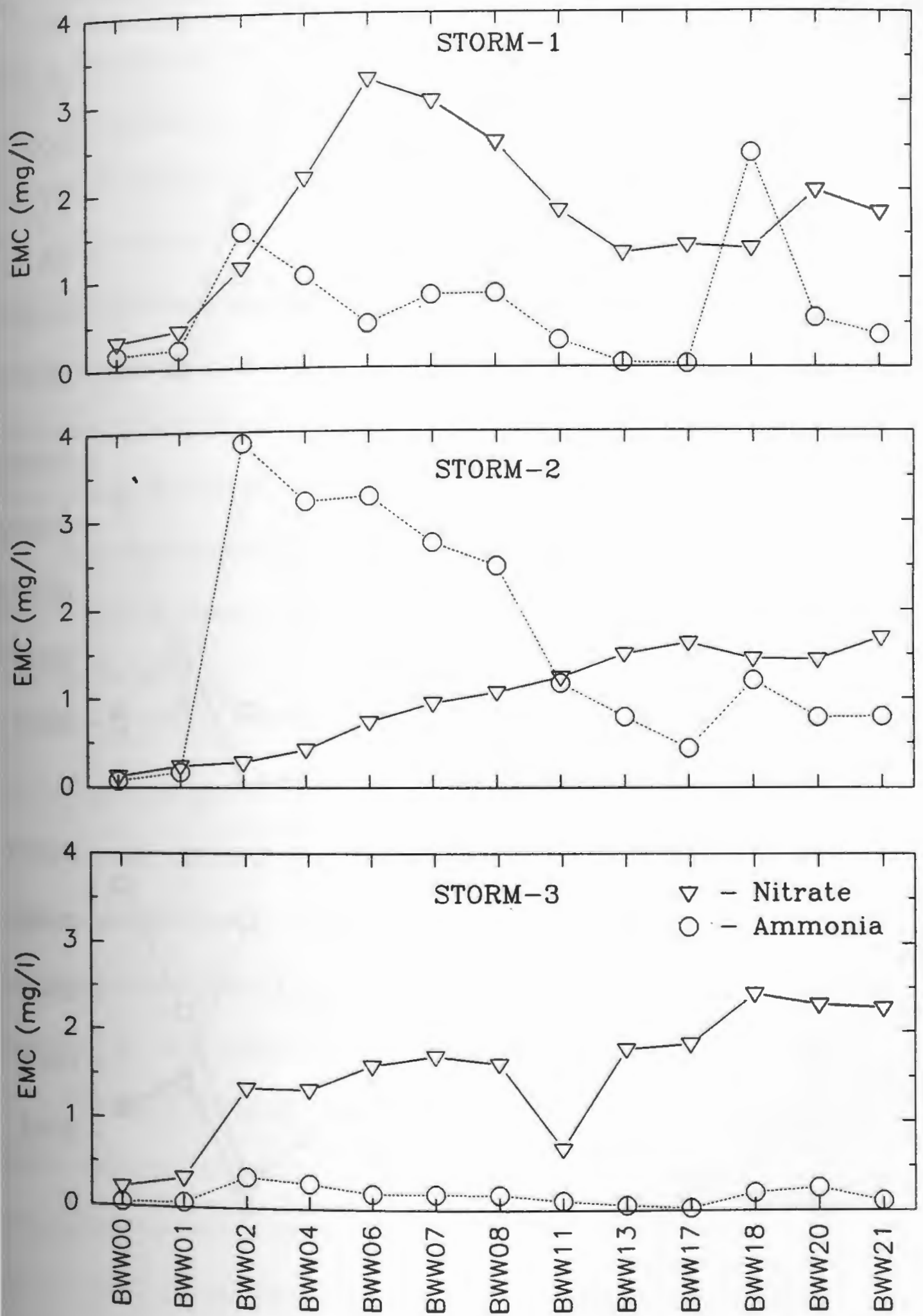

Figure 5.10 EMC Plots for $\mathrm{NO}_{3}$ and $\mathrm{NH}_{3}$ for Storms 1, 2 and 3 
EMC Plots for $\mathrm{PO}_{4}, \mathrm{FC}$ and $\mathrm{EC}$
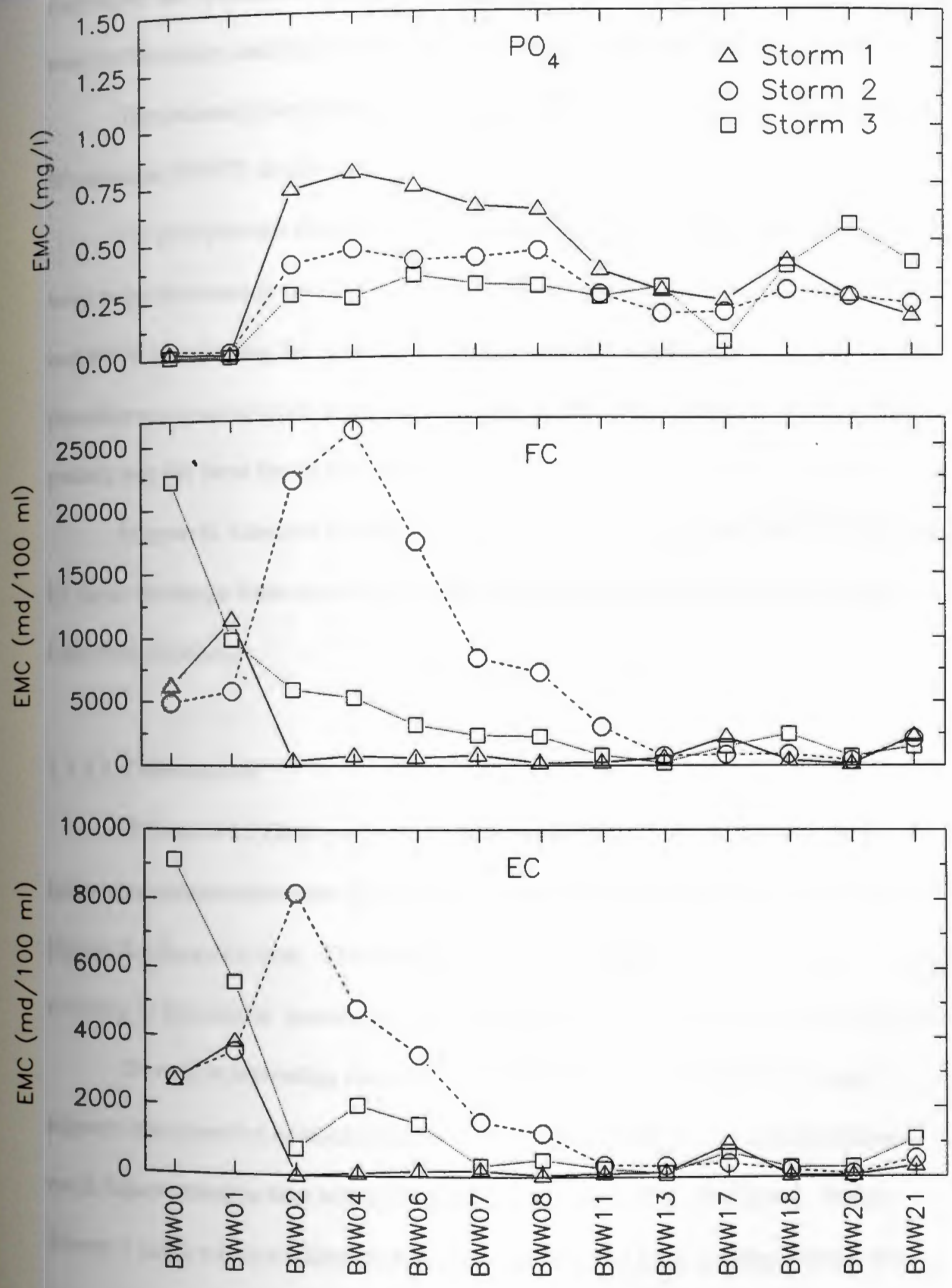

Figure 5.11 EMC Plots for $\mathrm{PO}_{4}, \mathrm{FC}$ and $\mathrm{EC}$ for Storms 1, 2 and 3 
September and appears to be within the high productivity period, whereas Storm 2 and 3 were in November and October and were within the low plant productivity period.

The increase in ammonia EMCs between BWW17 and BWW18 were due to the Woonsocket WWTF discharge.

For phosphorous the headwater concentrations were generally very low. There were major increases in the EMCs between BWW01 and BWW02 and between BWW17 and BWW18 reflecting the two major treatment facilities (Figure 5.11). Elsewhere, the phosphorous concentration declined due to dilution and plant uptake. The phosphorous pattern was the same for all three storms.

In general, based on the EMC profiles, the nutrient concentrations were dominated by direct discharge from the two major point sources or instream nitrification resulting from their discharge.

\subsubsection{Conventional}

TSS and VSS EMC profiles are presented in Figure 5.12. In general, the headwater concentrations are significant, often with concentrations that are amongst the highest for the entire river. This was opposite to the findings of the dry weather surveys, evidence to the relative importance of urban runoff as a major source of solid loadings.

There is an interesting pattern between BWW01 and BWW02 which again supports the operation of nitrification in the UBWPAD. With nitrification providing a much higher retention time within the facility, solids removal is often better. During Storms 1 and 3 where nitrification was occurring, the TSS EMC profiles actually show a 
EMC Plots for TSS, VSS and Pb
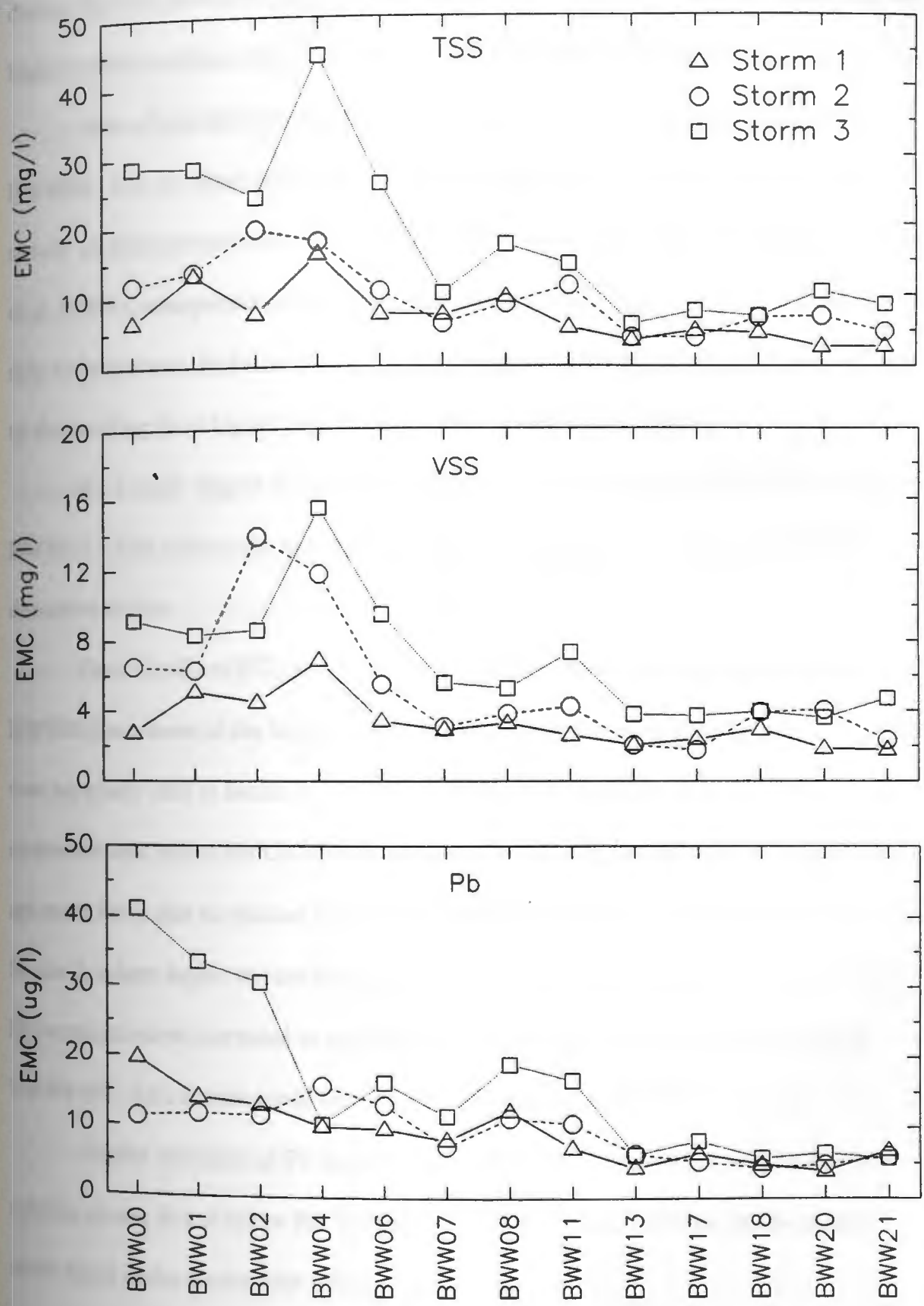

Figure 5.12 EMC Plots for TSS, VSS and $\mathrm{Pb}$ for Storms 1, 2 and 3 
decline between BWW01 and BWW02. Storm 2 provides a different result reflecting the higher solids load from the UBWPAD when nitrification was not occurring.

Also of interest is the increase of solids for Storm 3 between BWW02 and BWW04. It is not clear what source or sources have caused this increase, but based strictly on the concentration profiles and the knowledge of this area discussed by Wright et al. (1996), resuspension of bottom sediments or a sloughing of materials off the bottom may be important. In Storm 2 this increase in concentration is not evident due most likely to the masking from higher concentrations from upstream reaches.

To a lèsser degree increases in solids could also be seen between BWW07 to BWW11. This reflects the resuspension of bottom sediments from Rice City Pond described earlier.

Fecal Coliform (FC) and E. Coli (EC) concentrations in the headwaters (above BWW00) are some of the highest concentrations along the entire river (Figure 5.11). This was especially true in Storm 3. The sharp decreases in the instream FC and EC concentrations below the UBWPAD (between BWW01 and BWW02) for Storms 1 and 3 are most likely due to residual chlorine in the facilities effluent. This was not the case in Storm 2, where higher stream flows resulted in lower residual chlorine. In fact, FC and EC concentrations increased to their highest levels in the reaches immediately below UBWPAD. This impact could be felt as far downstream as BWW08.

Similar increases of FC and EC are evident in the Woonsocket area in the river reaches above, in and below the Woonsocket facility. Fecal Coliform are discussed in more detail in the section that follows. 
BOD has a similar trend for all three storms. Generally it increases after UBWPAD discharge and decreases to the mouth of the river (Figure 5.15). BOD does not appear strongly influenced by the storm related sources but appears governed by the two major point sources.

The sharp increase in the instream chloride $(\mathrm{Cl})$ and sodium $(\mathrm{Na})$ concentrations below the UBWPAD (between BWWOI and BWW02) for Storms 1 and 3 are most likely due to residual chlorine and sodium in the facilities effluent (Figure 5.13). This was not the case in Storm 2 for $\mathrm{Cl}$, where higher stream flows resulted in higher dilution and lower residual chlorine. The sharp decrease in concentrations below BWW08 for Storms 1 and 2 were due to dilution by the tributaries, Mumford, West and Branch Rivers. Storm 3 was different in nature as discussed in Chapter 4. It had a rainfall total of 1.3 inches at the headwaters and decreased to 0.27 inches at the southern border of Rhode Island. There was no sharp decrease of concentrations below BWW08 for both $\mathrm{Cl}$ and $\mathrm{Na}$.

\subsubsection{Trace Metals}

Compared to the other metals, lead's major source appeared to be in the headwaters (above BWW00). In fact, the headwater concentrations were typically the highest concentration along the entire river (Figure 5.12).

Neither the UBWPAD or Woonsocket facilities appeared to have any impact on these profiles. A consistent increase of lead did appear between BWW07 and BWW08 in Rice City Pond and was probably due to sediment resuspension.

The other 5 metals $(\mathrm{Cd}, \mathrm{Cr}, \mathrm{Cu}, \mathrm{Ni}$ and $\mathrm{Zn}$ ) had similar profiles in that there 
EMC Plots for $\mathrm{Cl}$ and $\mathrm{Na}$
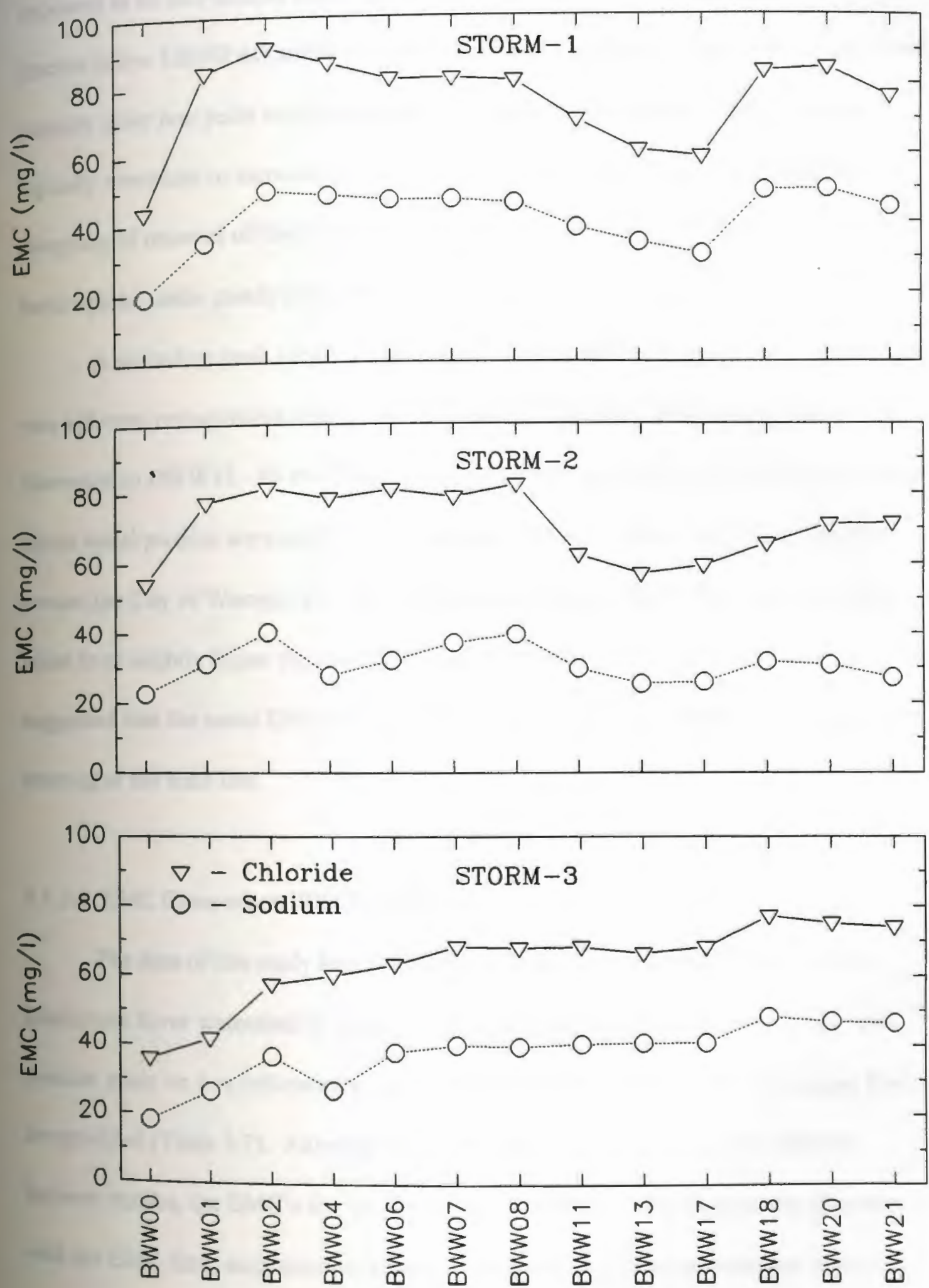

Figure 5.13 EMC Plots for $\mathrm{Cl}$ and $\mathrm{Na}$ for Storms 1, 2 and 3 
appeared to be two distinct peaks (Figure 5.14 and 5.15). The first occurred in the reaches below UBWPAD and was associated with the wastewater facilities discharge and possibly other non point sources of metals. In addition, concentrations, on average, typically continued to increase through BWW04. This might reflect the resuspension or sloughing of material off the bottom that may be an end result of the process of luxury metal uptake under steady state conditions.

A secondary peak consistently occurred around BWW08, again the probable cause was sediment resuspension within Rice City Pond. Below BWW08 the profiles quickly decreased to BWW13. As the Blackstone River enters and passes through Rhode Island all the metal profiles were either flat or declining with only minor exceptions typically around the City of Woonsocket. Concentrations in Rhode Island were generally either equal to or slightly higher than the Worcester headwater concentrations. These data suggested that the metal EMC profiles in Rhode Island were governed by concentrations entering at the state line.

\subsubsection{EMC Comparison With Other Rivers:}

The data of this study have been summarized as average EMCs for the entire Blackstone River watershed in Table 5.6. For comparison, results from an earlier wet weather study on five tributaries to the Providence River, including the Blackstone River, are provided (Table 5.7). Although the rainfall characteristics were quite different between studies, the EMC's for the Blackstone are similar. Rankings are not provided with the EMC data, since concentrations are influenced by flow and rankings have more 
EMC Plots for $\mathrm{Cd}, \mathrm{Cr}$ and $\mathrm{Cu}$
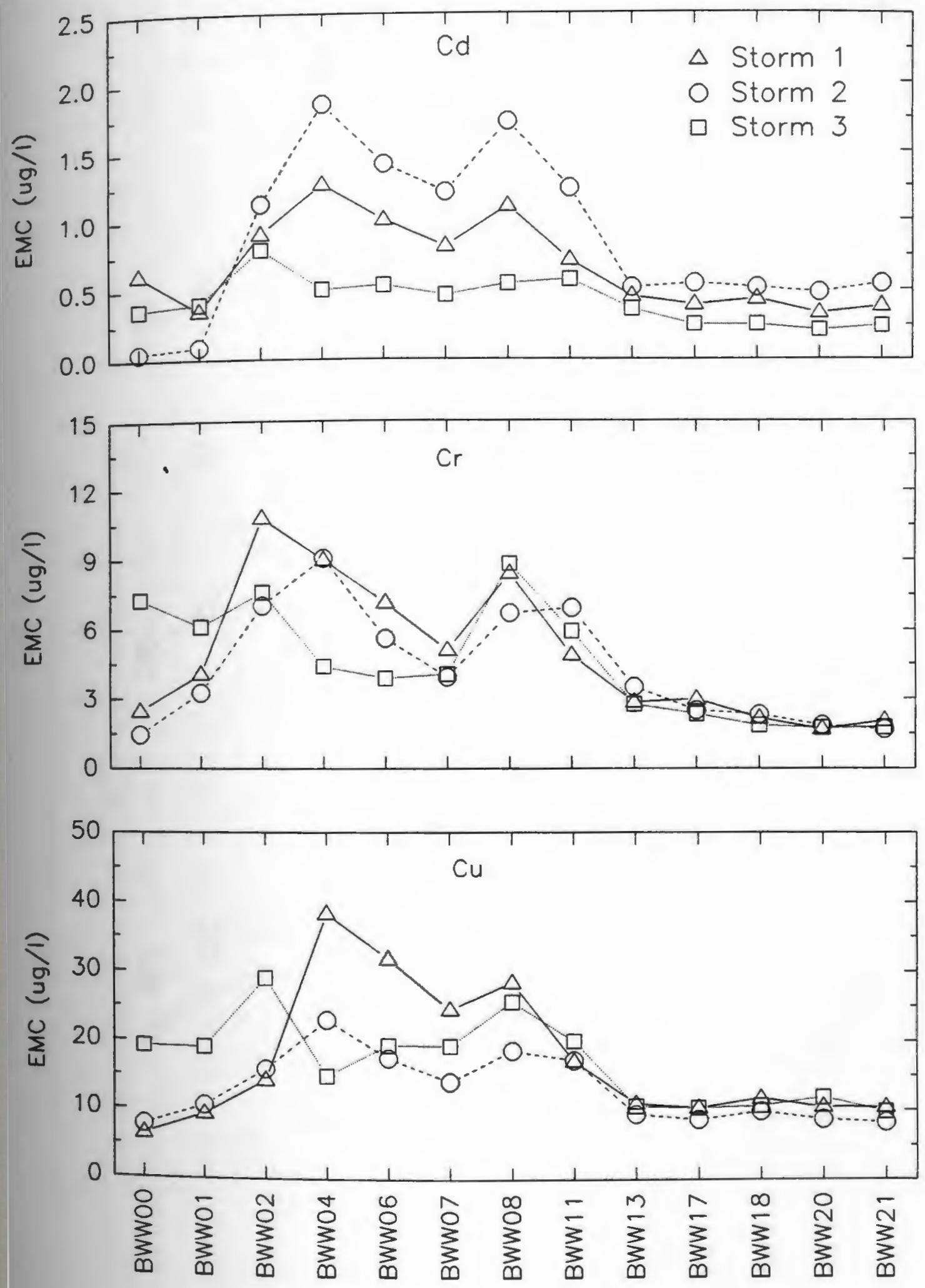

Figure 5.14 EMC Plots for $\mathrm{Cd}, \mathrm{Cr}$ and $\mathrm{Cu}$ for Storms 1,2 and 3 
EMC Plots for $\mathrm{Ni}, \mathrm{Zn}$ and BOD
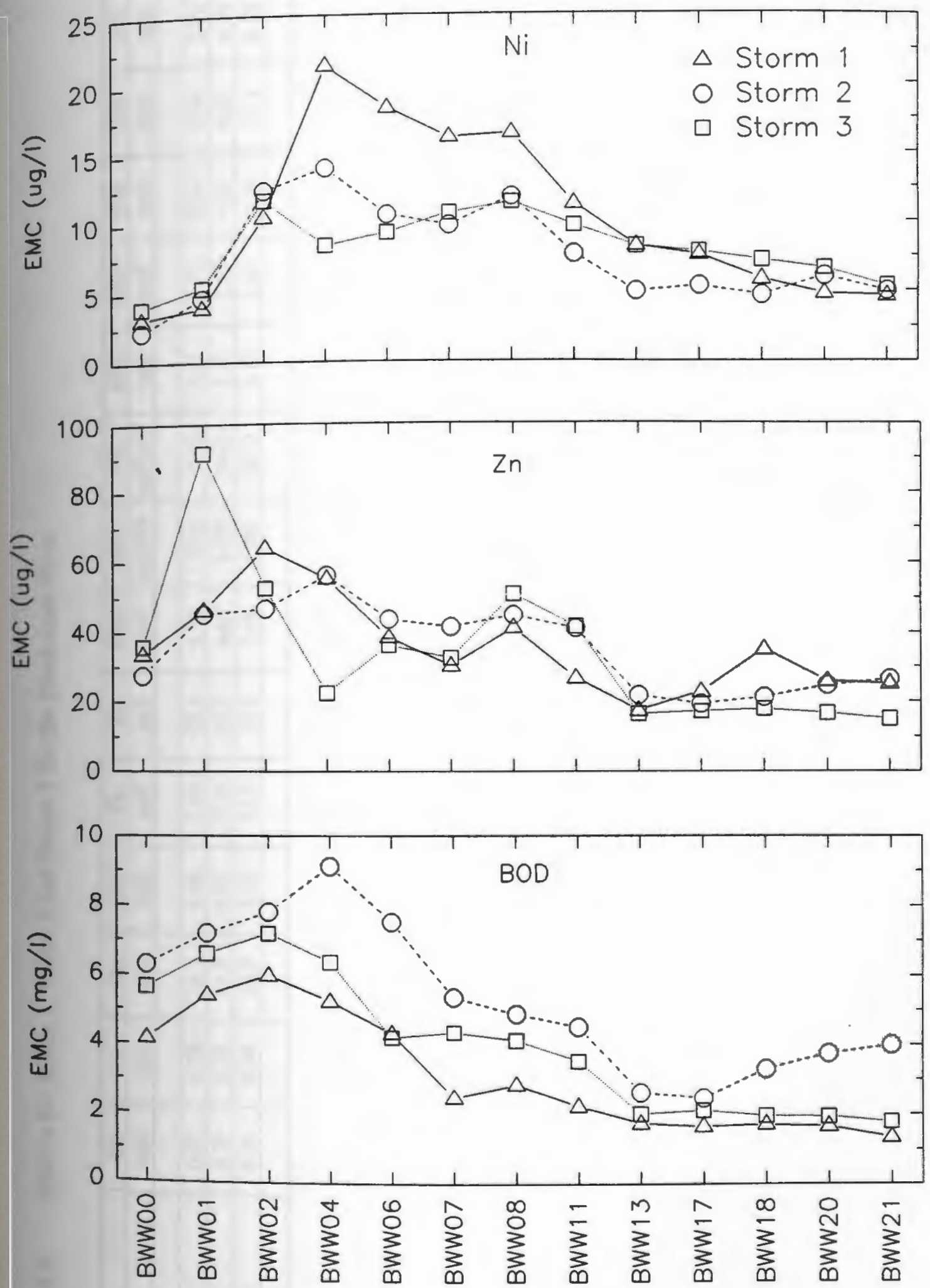

Figure 5.15 EMC Plots for Ni, Zn and BOD for Storms 1, 2 and 3 
Table 5.6 EMC's for Storm 1, Storm 2 and Storm 3 for the Blackstone River

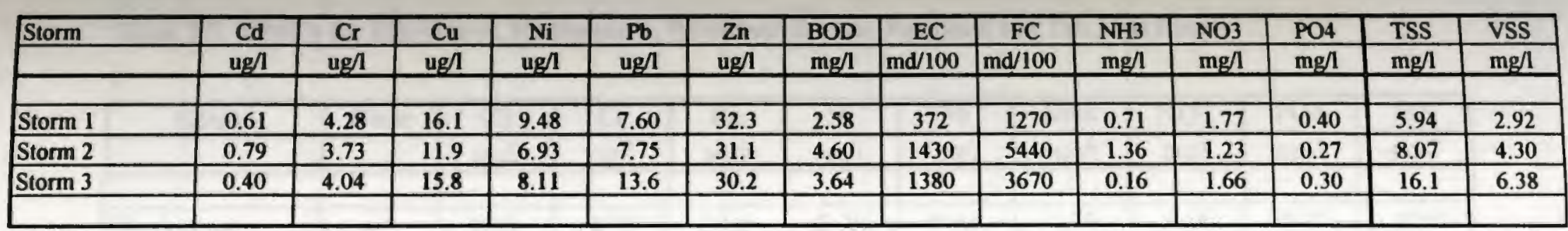


Table 5.7 EMC's for Blackstone, Moshassuck, Woonasquatucket, Pawtuxet and Ten Mile Rivers

\begin{tabular}{|l|c|c|c|c|c|c|c|c|c|c|}
\hline \multicolumn{1}{|c|}{ Station } & Code & $\mathrm{Cd}$ & $\mathrm{Cr}$ & $\mathrm{Cu}$ & $\mathrm{Ni}$ & $\mathrm{Pb}$ & $\mathrm{NH} 4$ & $\mathrm{NO3}$ & $\mathrm{PO4}$ & $\mathrm{TSS}$ \\
\hline & & $\mathrm{ug} / \mathrm{l}$ & $\mathrm{ug} / 1$ & $\mathrm{ug} / \mathrm{l}$ & $\mathrm{ug} / \mathrm{l}$ & $\mathrm{ug} / 1$ & $\mathrm{mg} / 1$ & $\mathrm{mg} / 1$ & $\mathrm{mg} / 1$ & $\mathrm{mg} / \mathrm{l}$ \\
\hline & & & & & & & & & & \\
\hline Blackstone & $\mathrm{a}-1$ & 0.60 & 4.00 & 14.6 & 8.20 & 9.60 & 0.70 & 1.60 & 0.30 & 10.0 \\
\hline Blackstone & $\mathrm{a}-2$ & 0.40 & 1.80 & 9.50 & 5.00 & 6.10 & 0.40 & 1.90 & 0.30 & 5.40 \\
\hline Blackstone & $\mathrm{b}$ & 0.94 & 6.82 & 12.5 & 10.7 & 8.25 & 0.25 & 5.42 & 0.67 & 10.1 \\
\hline Moshassuck & $\mathrm{b}$ & 0.39 & 7.10 & 20.2 & 7.76 & 20.9 & 0.15 & 2.08 & 0.11 & 17.5 \\
\hline Woonasquatucket & $\mathrm{b}$ & 0.31 & 3.39 & 8.98 & 6.13 & 8.06 & 0.10 & 3.26 & 0.22 & 10.5 \\
\hline Pawtuxet & $\mathrm{b}$ & 1.06 & 4.43 & 11.9 & 12.7 & 7.53 & 1.04 & 4.03 & 0.52 & 21.0 \\
\hline Ten Mile & $\mathrm{b}$ & 1.06 & 7.58 & 14.7 & 44.0 & 4.13 & 0.10 & 4.92 & 0.27 & 5.35 \\
\hline & & & & & & & & & & \\
\hline
\end{tabular}

a-1: This study whole river; a-2: this study BWW21; b: NBP study Wright et. al. (1988) 
meaning when presented as mass loads. This has been done in a later section.

\subsubsection{EMC Comparison With NURP Studies}

The EMCs at Worcester (BWW00) have been compared with National NURP, Michigan NPDES and Michigan NURP studies in Table 5.8. Worcester is an urban city, so comparison of its EMCs with the NURP studies is appropriate. All EMCs are found to be lower than the other NURP Studies. For example, BOD is found to be about two times lower than the National NURP data and about five times lower than the Michigan NPDES and NURP data and lead is about eight, two and four times lower than the National NURP and Michigan NPDES and NURP data. The values reported in Table 5.8 were obtained based on the values reported by Cave et al. (1994).

\subsubsection{Hardness, $\mathrm{Cl}, \mathrm{Na}, \mathrm{pH}$, Temperature and $\mathrm{DO}$}

Hardness concentrations $\left(\mathrm{mg} /\right.$ as $\mathrm{CaCO}_{3}$ ) were determined specific to each sample taken for the three storms captured. Hardness-based equations (Table 6.2) were used to calculate the acute and chronic toxicity criteria of each trace metals in the next section. Concentration profiles of hardness along with chloride and sodium were developed per station per storm. The same profiles were developed for $\mathrm{DO}$, temperature and $\mathrm{pH}$. Example plots for selected stations are provided in Appendix B.

Generally the concentrations of hardness decreased at or near the peak flows and increased again with time. This was significant in the headwaters and upper part of the river for all three storms (Figure B.1). At and near the mouth of the river, the decrease in 
Table 5.8 Comparison of EMCs of Blackstone River at Worcester (BWW00) with National NURP, Michigan NPDES and Michigan NURP

\begin{tabular}{|l|c|c|c|c|c|}
\hline Constituents & Units & $\begin{array}{c}\text { Worcester } \\
(\text { BWW00) }\end{array}$ & $\begin{array}{c}\text { National } \\
\text { NURP }\end{array}$ & $\begin{array}{c}\text { Michigan } \\
\text { NPDES }\end{array}$ & $\begin{array}{c}\text { Michigan } \\
\text { NURP }\end{array}$ \\
\hline BOD & $\mathrm{mg} / \mathrm{L}$ & 5.37 & 11.7 & 23.7 & 25 \\
\hline TSS & $\mathrm{mg} / \mathrm{L}$ & 15.7 & 149.7 & 103.3 & 139 \\
\hline Dissolved - $\mathrm{P}$ & $\mathrm{mg} / \mathrm{L}$ & 0.02 & 0.17 & 0.15 & 0.08 \\
\hline NO2+NO3 & $\mathrm{mg} / \mathrm{L}$ & 0.22 & 0.88 & 1.70 & 0.76 \\
\hline Lead, total & $\mathrm{ug} / \mathrm{L}$ & 24.1 & 177.0 & 56.8 & 96.4 \\
\hline Copper, total & $\mathrm{ug} / \mathrm{L}$ & 11.2 & 47.8 & 41.5 & 20.8 \\
\hline Zinc, total & $\mathrm{ug} / \mathrm{L}$ & 32.3 & 519.8 & 338.9 & 152.3 \\
\hline & & & & & \\
\hline
\end{tabular}

Note: National NURP, Michigan NPDES and Michigan NURP

EMC values are taken from Cave et al., 1994. 
hardness concentrations at peak flows were not significant for two (Storms 1 and 2) out of three storms (Figures B.3 and B.6). Storm 3 had a significant decrease in concentrations near the mouth of the river (Figure B.9). The decrease in hardness due to dilution by high flows would lower the toxicity criteria of violations. Therefore, there may be more violations at and near the headwaters than at the mouth of the river. Also there might be more violations associated with wet weather rather than dry weather.

Chloride and sodium showed a similar trend to hardness, decreasing in concentration at or near the peak flows. We know that chloride is a conservative constituent, so the concentrations must decrease with increase in flows.

The $\mathrm{pH}$ did not vary significantly with time and stations. The value of $\mathrm{pH}$ was typically between 6.0 and 6.5 for all stations and storms. The profiles for $\mathrm{pH}$ were generally flat (Figure B.10).

Temperature varied according to the season and time. Storm 1 (September) had much higher temperatures than Storms 2 and 3 (November and October). The general pattern was higher temperature at the beginning of the storm and decreased with time with some noise.

The DO profiles generally showed a little decrease in DO concentrations at the peak high flows due to dilution and increased with time again with some noise in it. Reaeration, DO in incoming tributaries and algal photosynthesis are the sources of DO and the sinks include: CBOD, NBOD, SOD and algal respiration. Presence of nutrients and sunlight time controls the photosynthesis of algae thus affecting the DO system. The DO dynamics are complex and described in details elsewhere (Wright et al. 1996). 
The impact of wet weather on DO is not significant. There was a small decrease in DO concentrations at or near the peak flows due to dilution. There were no violations of the DO criteria $(5.0 \mathrm{mg} / \mathrm{l})$ in the mainstem stations of the Blackstone River for all three storms observed for this study. Only tributary stations BWW05 had 1 violation (prestorm sample) out of 16 samples collected for Storm 2 and BWW15 had 2 violations out of 13 samples collected for Storm 3. 
CHAPTER 6

6.0 Water Quality Criteria Violation

6.1 Fecal Coliform

The Blackstone River headwaters appear to be the major source of fecal coliform (FC) under wet weather conditions. Other notable increases in concentration occur at Fisherville Pond, Rice City Pond and some individual river reaches between stations BWW11 to BWW17. Figure 6.1 is an example of a 3-D FC profile. Residual chlorine from the UBWPAD appears to be an effective disinfectant in the reaches at and below its discharge (Point A to B) with one major exception. At peak flow between time 0 and 6 hours, fecal coliforms get by the UBWPAD without instream disinfection. This is probably due to the lower instream chlorine residual resulting from the higher flows in the river and in the facility.

FC concentrations increase between BWW11 and BWW17 (point C in Figure 6.1). The source appears to be independent of the storm occurring before, during and after rainfall. The high FC concentrations from the Branch River (BWW14) and Peters River (BWW16) may be responsible for this. The FC ranges for Branch River were: 280-6200, $60-400$ and $230-5800 \mathrm{md} / 100 \mathrm{ml}$ for Storms 1,2 and 3, respectively. The average FC concentrations were 2350,249 and $1434 \mathrm{md} / 100 \mathrm{ml}$ for Storm 1, 2 and 3, respectively. The FC ranges for the Peters River were: 300-39000, 14000-79000 and 63-94000 $\mathrm{md} / 100 \mathrm{ml}$ for Storm 1, 2 and 3, respectively. The average FC counts for the three storms were 9531,42909 and $26757 \mathrm{md} / 100 \mathrm{ml}$, respectively. 


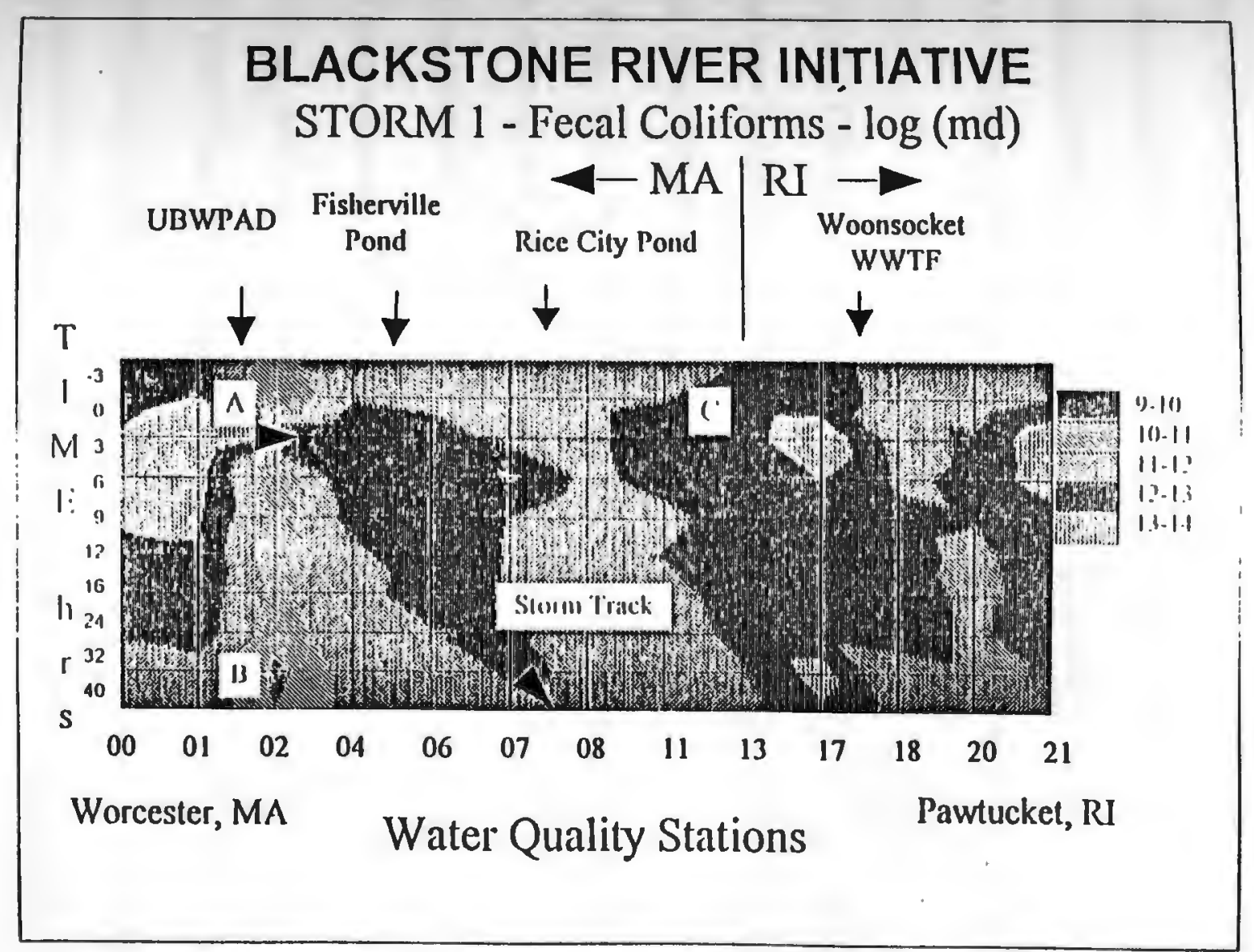

Figure 6.1 3-D Flat Fecal Coliform Load Presentation - Storm 1 (Storm Track= Peak Signal Passage from Worcester) 
The dry weather data also indicated these two tributaries had relatively high FC concentrations. The average FC concentrations for Branch River were 160, 220 and 460 $\mathrm{md} / 100 \mathrm{ml}$ for Surveys 1, 2 and 3, respectively. The average FC counts for the Peters River were 380,1060 and $260 \mathrm{md} / 100 \mathrm{ml}$.

Storm track of FC for Storm 1 (Figure 6.1) match perfectly with the storm track of the hydrograph for Storm 1 (Figure 4.9) returning to background concentrations at BWW08 at 40 hours. Maximum FC loads were typically seen along the storm track for all three storms.

Table 6.1 shows the criteria violation for Storms 1,2 and 3. Two types of violations were considered: Violation A was the $\log$ mean $>200 \mathrm{md} / 100 \mathrm{ml}$; and Violation B was $10 \%$ of samples exceeding $400 \mathrm{md} / 100 \mathrm{ml}$.

Under dry weather conditions Type A violations occurred in the mainstem stations BWW01, BWW04, BWW06 and in the tributary stations Branch River (BWW14) and Peters River (BWW16) (Table 6.1).

Under wet weather all stations along the mainstem Blackstone River had violations of both Type A and Type B for all three storms with the exception of BWW02, BWW08, BWW11, BWW18 and BWW20 for storm 1 and BWW13 for storm 3. BWW11 and BWW18 had only Type B violations for Storm 1 (Table 6.1). The tributary stations BWW14 and BWW16 had both Type A and Type B violations. BWW09 had no violations at any time. Under wet weather no FC samples were collected at tributary stations BWW05 (Quinsigamond River), BWW10 (West River), and BWW15 (Mill River). 
Table 6.1 Fecal Coliform Violation in Accordance With Class B Water Criteria for Dry and Wet Weather

\begin{tabular}{|c|c|c|c|}
\hline \multirow{2}{*}{$\begin{array}{l}\text { Stration ID } \\
\text { BWW/BLK }\end{array}$} & \multicolumn{2}{|c|}{ Violation-A } & Violation-B \\
\cline { 2 - 4 } & Dry Weather & Wet Weather & Wet Weather \\
\hline & & & \\
\hline 00 & No Samples & $1,2,3$ & $1,2,3$ \\
\hline 01 & $1,2,3$ & $1,2,3$ & $1,2,3$ \\
\hline 02 & No Violation & 2,3 & 2,3 \\
\hline 03 & 1,2 & No Samples & No Samples \\
\hline 04 & $1,2,3$ & $1,2,3$ & $1,2,3$ \\
\hline 06 & 1,2 & $1,2,3$ & $1,2,3$ \\
\hline 07 & 3 & $1,2,3$ & $1,2,3$ \\
\hline 08 & 2 & 2,3 & 2,3 \\
\hline 11 & No Violation & 2,3 & $1,2,3$ \\
\hline 12 & No Violation & No Samples & No Samples \\
\hline 13 & No Violation & 1,2 & 1,2 \\
\hline 17 & 1,3 & $1,2,3$ & $1,2,3$ \\
\hline 18 & 3 & 2,3 & $1,2,3$ \\
\hline 19 & No Violation & No Samples & No Samples \\
\hline 20 & 1 & 2,3 & 2,3 \\
\hline 21 & 1 & $1,2,3$ & $1,2,3$ \\
\hline & & & \\
\hline
\end{tabular}

TRIBUTARIES

\begin{tabular}{|c|c|c|c|}
\hline 05 & No Violation & No Samples & No Samples \\
\hline 09 & 1 & No Violation & No Violation \\
\hline 10 & No Violation & No Samples & No Samples \\
\hline 14 & 2,3 & $1,2,3$ & $1,2,3$ \\
\hline 15 & No Violation & No Samples & No Samples \\
\hline 16 & $1,2,3$ & $1,2,3$ & $1,2,3$ \\
\hline
\end{tabular}

Note: Violations $A=\log$ Mean $>200 \mathrm{md} / 100 \mathrm{ml}$; Violations $B=10 \%$ of Samples Exceeding $400 \mathrm{md} / 100 \mathrm{ml} \mathrm{1,} \mathrm{2,3} \mathrm{=} \mathrm{Surveys}$ (i.e. Dry Weather Surveys1, 2, 3; Wet Weather Storms 1, 2, 3) 
Significantly more stations had violations of both Type A and Type B for wet weather versus dry weather. This comparison is provided in Table 6.1. The high loading at the headwaters seems to be the main cause of the FC problems under wet weather conditions. The river receives benefit from high residual chlorine from UBWPAD during most time periods. The exception is at or near peak storm flow. There are more violations in Storm 2 and 3 than in Storm 1. This is probably due to the fact that Storm 1 was smaller than Storm 2 and 3.

\subsection{Acute and Chronic Trace Metal Criteria}

Acute and chronic toxicity criteria for metals are used to protect the public health and the environment. These criteria prevent the surface waters from becoming unsuitable for fishing, swimming and other beneficial uses. A comparison of concentration data to these criteria may be used to assess the degree of waste water treatment needed to meet water pollution control requirements, establish acceptable receiving concentrations and assess the suitability of environmental conditions for aquatic life.

EPA has developed acute and chronic toxicity criteria based on hardness numbers for total metal concentrations. The EPA's fresh water aquatic life criteria is listed in Table

6.2. Criteria used in the analysis to follow were calculated by using these hardness-based equations. The hardness concentrations were determined specific to each sample taken. Individual pollutographs were plotted by station with the criteria for each metal. These plots provide insight into the question of whether wet weather causes acute criteria violations. Figure 6.2 is an example of a pollutograph and is an illustration of just such a 
Table 6.2 Summary of EPAs Fresh Water Aquatic Life Criteria for Total Metal

\begin{tabular}{|c|c|c|}
\hline Name & Acute $(\mu \mathrm{g} / \mathrm{L})$ & Chronic $(\mu \mathrm{g} / \mathrm{L})$ \\
\hline Cadmium & $\mathrm{e}^{\left(1.12 \mathrm{~B}^{*}[\mathrm{nnH}]-3.828\right)}$ & $\mathrm{e}^{(0.7852 *[\mathrm{n} H]-3.49)}$ \\
\hline Chromium & $\mathrm{e}^{(0.819 *[\mathrm{nH}]+3.688)}+16$ & $\mathrm{e}^{(0.819 *[\mathrm{nH}]+1.561)}+11$ \\
\hline Copper & $\mathrm{e}^{(0.9422 *[\ln H]-1.464)}$ & $\mathrm{e}^{(0.8545 \cdot[\ln H]-1.465)}$ \\
\hline Lead & $\mathrm{e}^{(1.273 *[\ln H]-1.46)}$ & $\mathrm{e}^{\left(1.273^{*}[\mathrm{lnH}-1.465)\right.}$ \\
\hline Nickel & $\mathrm{e}^{\left(0.846^{*}[\ln H]+3.3612\right)}$ & $e^{\left(0.846^{*}[\ln H]+1.1645\right)}$ \\
\hline
\end{tabular}

Note: $\mathrm{H}$ is the hardness $\left(\mathrm{mg} / \mathrm{L}\right.$ as $\mathrm{CaCO}_{3}=2.497[\mathrm{Ca}]+4.118[\mathrm{Mg}]$; The source of the equations is Water Quality Standards Handbook. 

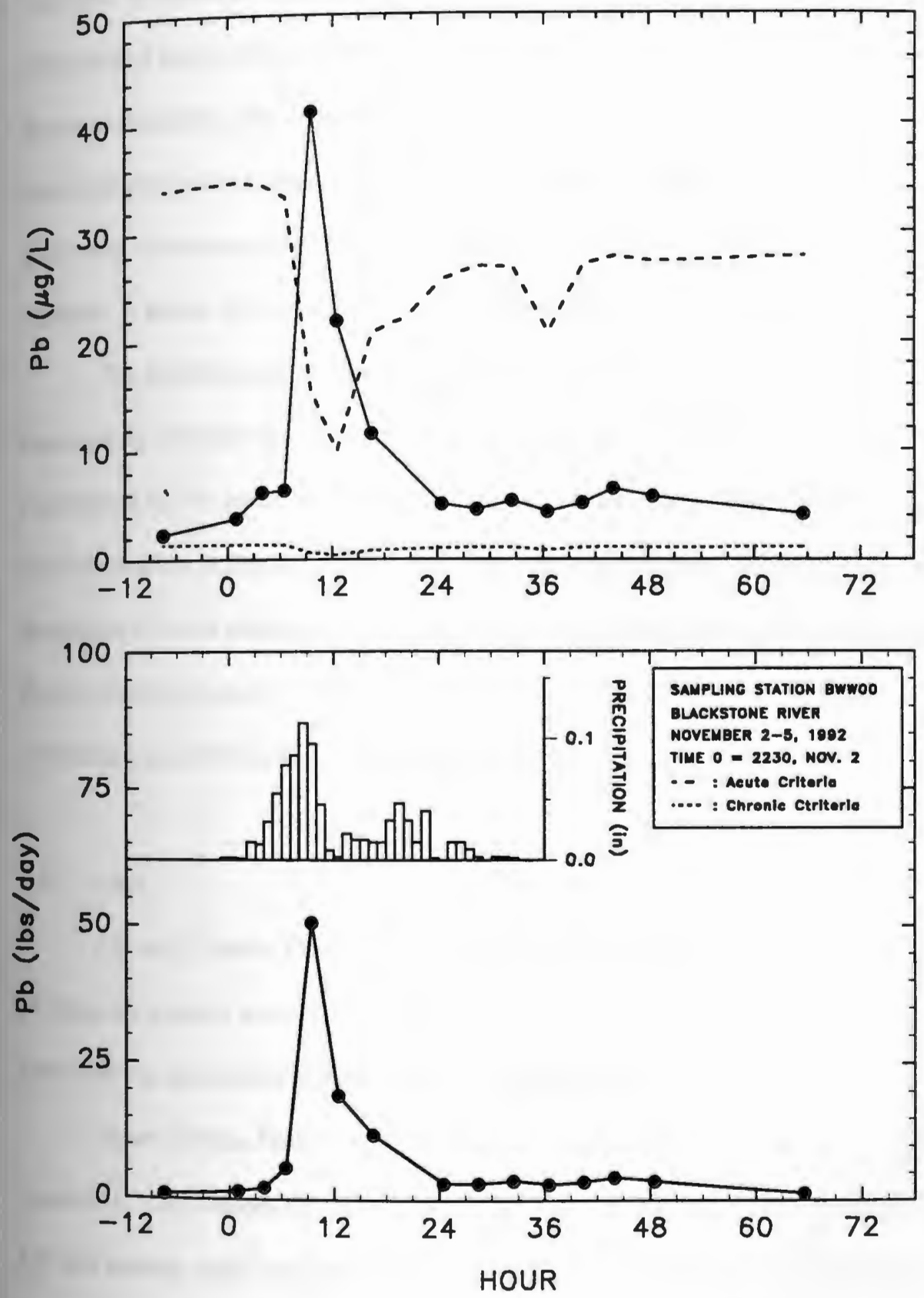

Figure 6.2 Example Figure of $\mathrm{Pb}$ Showing Acute and Chronic Criteria Violation for Storm 2 at Station BWW0O 
violation. It shows all 12 samples violated lead chronic criteria but only 2 samples violated lead acute criteria for Storm 3 at BWW00. These violations occurred during the height of the storm, when instream hardness dropped resulting in lower acute criteria. The more stringent criteria typically coincided with maximum instream concentrations. Similar plots were developed per station for all trace metals ( 120 plots) during the course of this analysis. A subset of these specific to lead is provided in Appendix C.

The individual pollutographs can be combined for each storm in a single profile representing the entire storm and river in time and space. The violations can also be represented for the entire river in a similar manner. Examples of these figures for acute criteria are given in Figures 6.3-6.5. These figures represent the location, duration and magnitude of acute violations by constituent by storm. A complete summary of violations for wet weather is given in Table 6.3. Comparison between dry and wet weather violations is provided in table 6.4. Each metal is discussed individually below.

\subsubsection{Lead}

Chronic Criteria Violations - Chronic criteria violations occur at all stations for all three dry weather surveys and all three wet weather storms. Violations are greater at the headwater station and around Rice City Pond (Tables 6.3 and 6.4).

Acute Criteria Violations - The only violations under dry weather conditions occurred at two stations (BWW06 and BWW07) during the first survey in July 1991. For wet weather acute violations start typically at the headwaters in conjunction with runoff (peak hydrograph flow). The figure for Storm 3 (Figure 6.3) is an excellent 


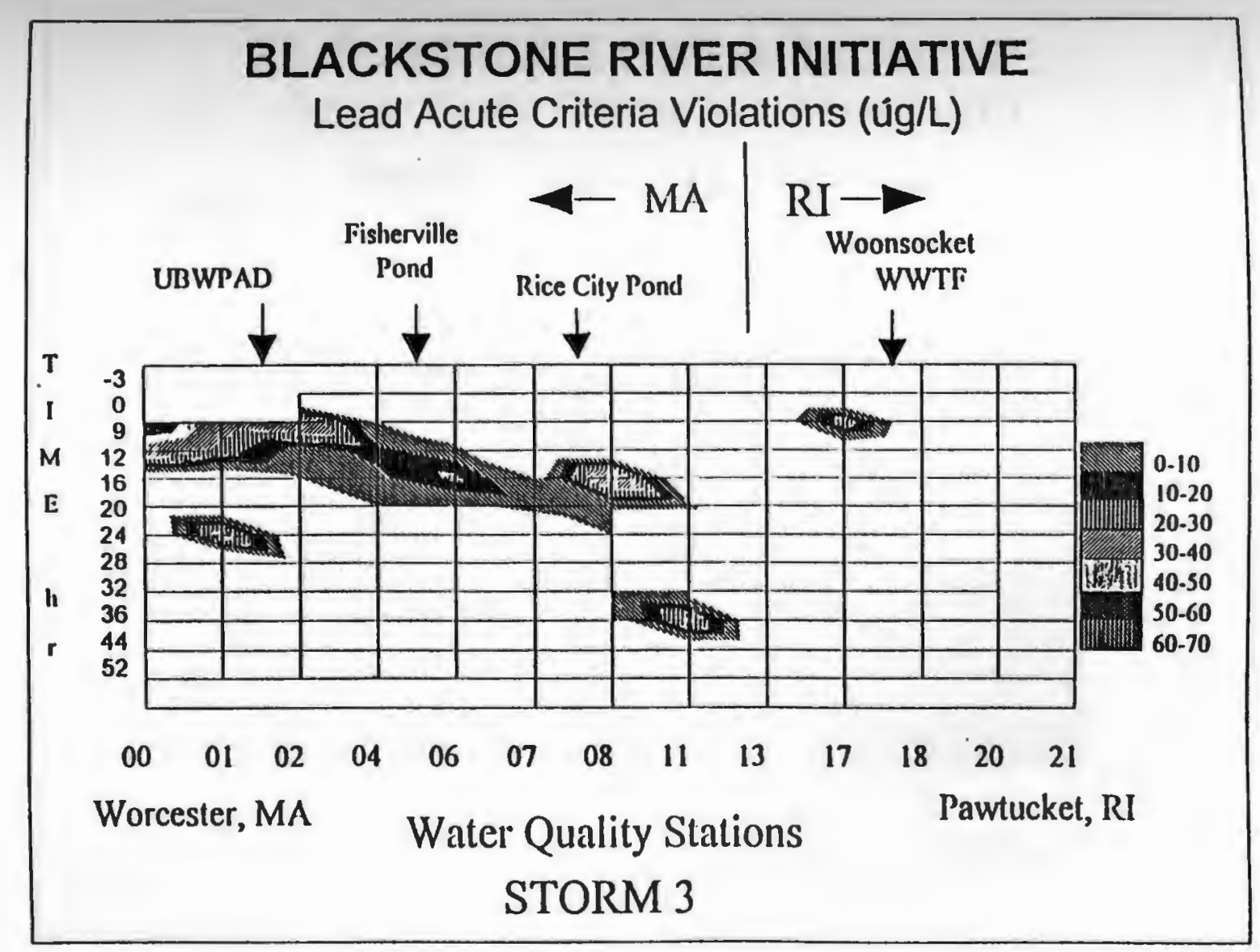

Figure 6.3 3-D Flat Acute Criteria Violations for Total Pb - Storm 3 


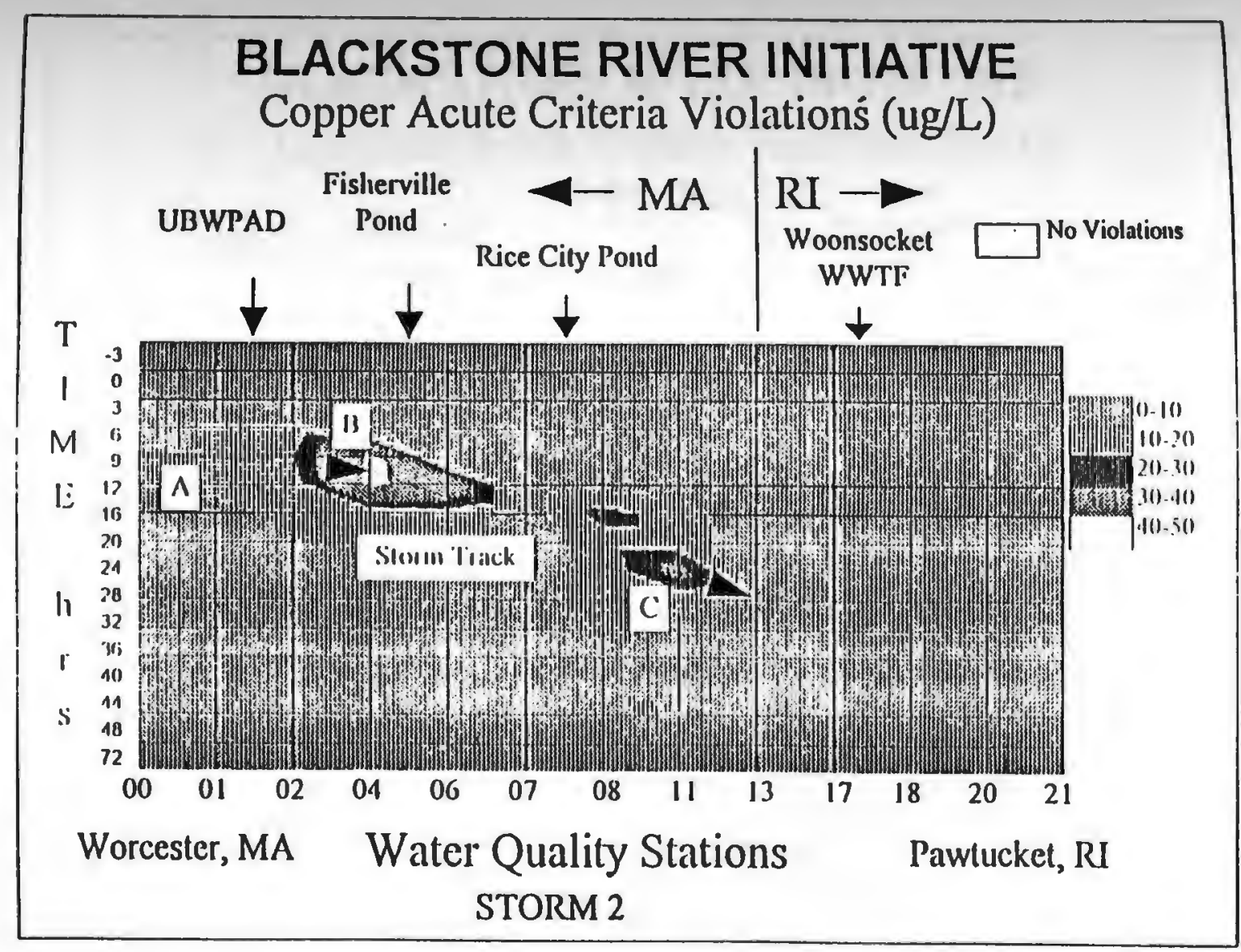

Figure 6.4 3-D Flat Acute Criteria Violations for Total Cu - Storm 2 (Storm Track = Peak Signal Passage from Worcester) 


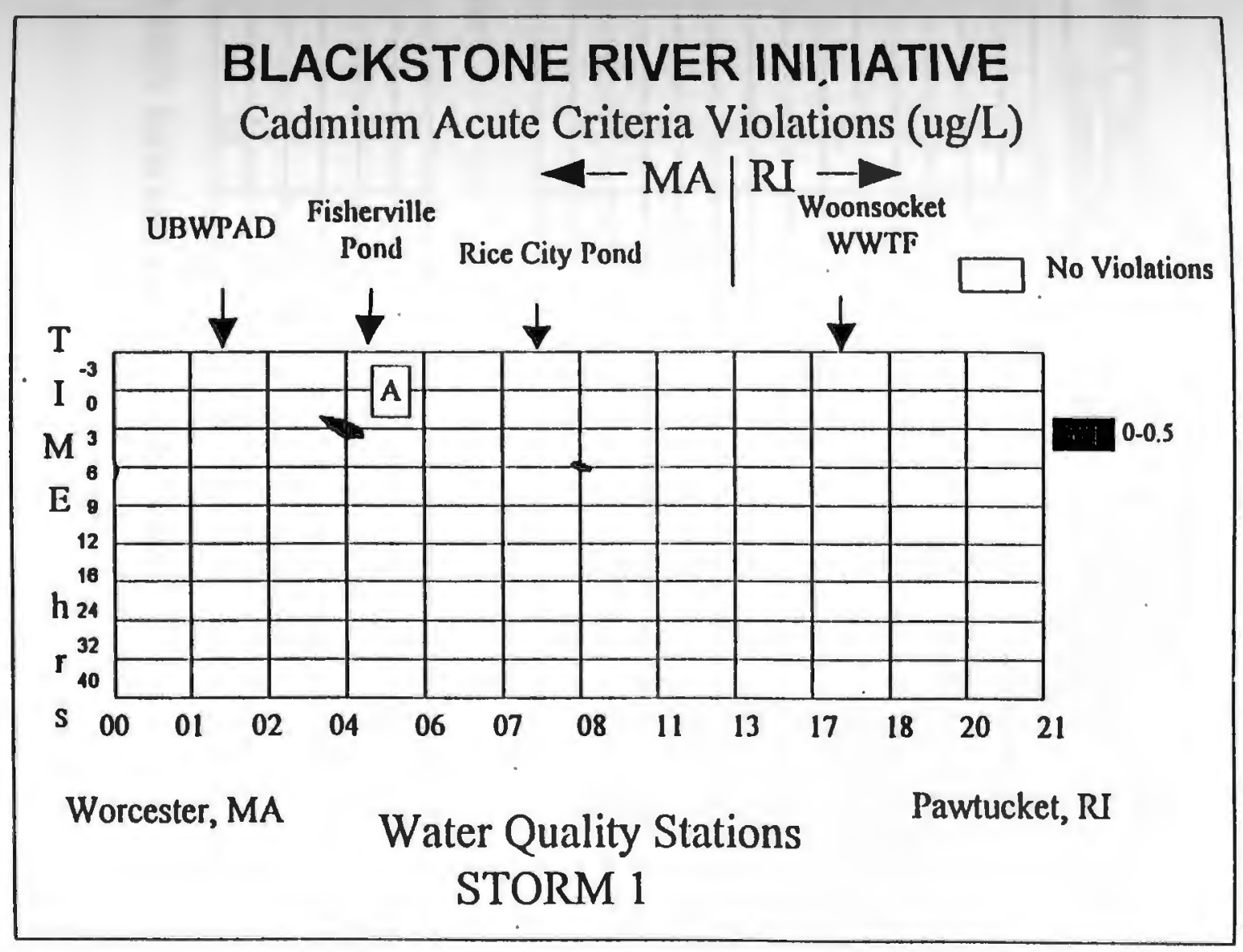

Figure 6.5 3-D Flat Acute Criteria Violations for Total Cd - Storm 1 
Table 6.3 Blackstone River Wet Weather Summary of Acute and Chronic Criteria Violations, Storm 1

\begin{tabular}{|c|c|c|c|c|c|c|c|}
\hline \multirow{3}{*}{ STATIONS } & & \multicolumn{2}{|c|}{$\mathrm{Cd}$} & \multicolumn{2}{|c|}{$\overline{\mathrm{Cu}}$} & \multicolumn{2}{|c|}{$\overline{\mathrm{Pb}}$} \\
\hline & Total & Acute & Chronic & Acute & Chronic & Acute & Chronic \\
\hline & \# Sample & \# Violation & \# Violation & \# Violation & \# Violation & \# Violation & \# Violation \\
\hline BWW00 & 10 & 1 & 3 & 2 & 3 & 2 & 10 \\
\hline BWW01 & 10 & 0 & 0 & 1 & 3 & 0 & 10 \\
\hline BWW02 & 10 & 0 & 6 & 6 & 6 & 0 & 10 \\
\hline BWW04 & 10 & 1 & 10 & 10 & 10 & 0 & 10 \\
\hline BWW06 & 10 & 0 & 10 & 10 & 10 & 0 & 10 \\
\hline BWW07 & 10 & 0 & 5 & 10 & 10 & 0 & 10 \\
\hline BWW08 & 10 & 1 & 9 & 10 & 10 & 0 & 10 \\
\hline BWW11 & 10 & 0 & 5 & 10 & 10 & 0 & 10 \\
\hline BWW13 & 10 & 1 & 1 & 10 & 10 & 0 & 10 \\
\hline BWW17 & 10 & 0 & 0 & 10 & 10 & 0 & 10 \\
\hline BWW18 & 10 & 0 & 0 & 10 & 10 & 0 & 10 \\
\hline BWW20 & 10 & 0 & 0 & 9 & 10 & 0 & 10 \\
\hline BWW21 & 10 & 0 & 1 & 6 & 10 & 0 & 10 \\
\hline & & & & & & & \\
\hline
\end{tabular}

Tributaries

\begin{tabular}{|l|c|c|c|c|c|c|c|}
\hline BWW05 & 10 & 0 & 0 & 0 & 0 & 0 & 2 \\
\hline BWW09 & 10 & 0 & 0 & 0 & 0 & 0 & 10 \\
\hline BWW10 & 10 & 0 & 0 & 0 & 0 & 0 & 6 \\
\hline BWW14 & 10 & 0 & 0 & 1 & 7 & 0 & 5 \\
\hline BWW15 & 10 & 0 & 0 & 1 & 1 & 0 & 10 \\
\hline BWW16 & 10 & 1 & 0 & 1 & 2 & 1 & 10 \\
\hline
\end{tabular}

Note: $\mathrm{Cr}$ and $\mathrm{Ni}$ has no acute and chronic criteria violation 
Table 6.3 Storm 2 (Continued)

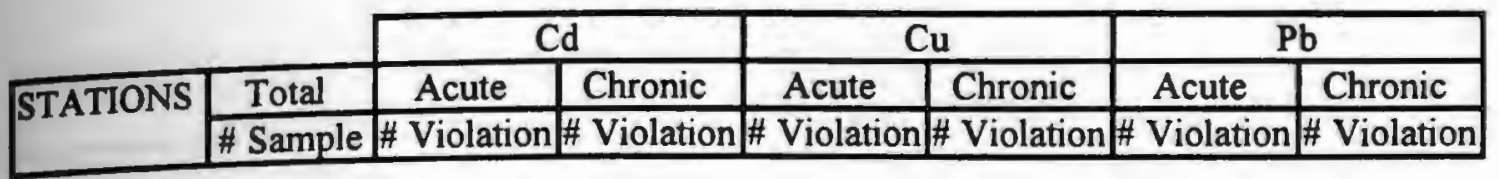

\begin{tabular}{|l|c|c|c|c|c|c|c|}
\hline BWW00 & 15 & 0 & 0 & 3 & 4 & 2 & 15 \\
\hline BWW01 & 16 & 0 & 0 & 5 & 7 & 2 & 16 \\
\hline BWW02 & 16 & 3 & 10 & 9 & 16 & 1 & 16 \\
\hline BWW04 & 16 & 3 & 12 & 9 & 14 & 2 & 16 \\
\hline BWW06 & 16 & 3 & 14 & 16 & 16 & 1 & 16 \\
\hline BWW07 & 15 & 1 & 15 & 16 & 16 & 0 & 15 \\
\hline BWW08 & 16 & 8 & 16 & 16 & 16 & 0 & 16 \\
\hline BWW11 & 16 & 6 & 16 & 16 & 16 & 1 & 16 \\
\hline BWW13 & 16 & 0 & 11 & 16 & 16 & 0 & 16 \\
\hline BWW17 & 16 & 1 & 7 & 15 & 15 & 0 & 16 \\
\hline BWW18 & 16 & 1 & 9 & 16 & 16 & 1 & 16 \\
\hline BWW20 & 16 & 0 & 7 & 10 & 15 & 0 & 16 \\
\hline BWW21 & 16 & 0 & 7 & 9 & 13 & 0 & 16 \\
\hline & & & & & & & \\
\hline
\end{tabular}

Tributaries

\begin{tabular}{|l|l|l|l|l|l|l|l|}
\hline BWW05 & 15 & 0 & 0 & 0 & 0 & 0 & 10 \\
\hline BWW09 & 16 & 0 & 0 & 0 & 0 & 1 & 15 \\
\hline BWW10 & 16 & 0 & 0 & 0 & 0 & 0 & 16 \\
\hline BWW14 & 16 & 0 & 0 & 1 & 7 & 1 & 16 \\
\hline BWW15 & 16 & 0 & 0 & 1 & 2 & 0 & 16 \\
\hline BWW16 & 16 & 0 & 0 & 2 & 4 & 0 & 16 \\
\hline
\end{tabular}

Note: $\mathrm{Cr}$ and $\mathrm{Ni}$ has no acute and chronic criteria violation 
Table 6.3 Storm 3 (Continued)

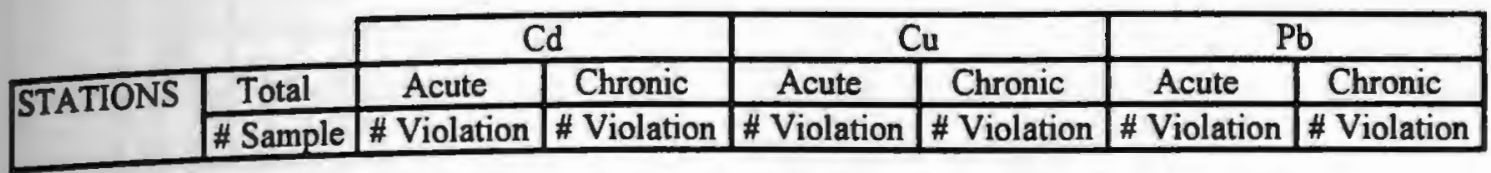

\begin{tabular}{|l|c|c|c|c|c|c|c|}
\hline BWW00 & 12 & 0 & 2 & 2 & 2 & 2 & 12 \\
\hline BWW01 & 12 & 0 & 4 & 5 & 6 & 3 & 12 \\
\hline BWW02 & 12 & 0 & 3 & 11 & 12 & 2 & 11 \\
\hline BWW04 & 11 & 1 & 3 & 9 & 12 & 3 & 9 \\
\hline BWW06 & 12 & 0 & 4 & 10 & 12 & 2 & 12 \\
\hline BWW07 & 13 & 0 & 1 & 13 & 13 & 1 & 12 \\
\hline BWW08 & 13 & 0 & 5 & 10 & 12 & 2 & 12 \\
\hline BWW11 & 13 & 0 & 4 & 11 & 12 & 2 & 11 \\
\hline BWW13 & 13 & 0 & 2 & 10 & 10 & 0 & 12 \\
\hline BWW17 & 13 & 0 & 0 & 12 & 12 & 1 & 13 \\
\hline BWW18 & 12 & 0 & 0 & 9 & 11 & 0 & 12 \\
\hline BWW20 & 12 & 0 & 0 & 11 & 11 & 0 & 12 \\
\hline BWW21 & 12 & 0 & 0 & 10 & 11 & 0 & 11 \\
\hline & & & & & & & \\
\hline
\end{tabular}

Tributaries

\begin{tabular}{|l|c|c|c|c|c|c|c|}
\hline BWW05 & 12 & 0 & 0 & 0 & 0 & 0 & 6 \\
\hline BWW09 & 13 & 0 & 0 & 0 & 0 & 0 & 13 \\
\hline BWW10 & 13 & 0 & 0 & 0 & 0 & 0 & 11 \\
\hline BWW14 & 12 & 0 & 0 & 0 & 0 & 0 & 11 \\
\hline BWW15 & 13 & 0 & 0 & 0 & 0 & 0 & 12 \\
\hline BWW16 & 13 & 0 & 0 & 0 & 0 & 0 & 13 \\
\hline
\end{tabular}

Note: $\mathrm{Cr}$ and $\mathrm{Ni}$ has no acute and chronic criteria violation 
Table 6.4 Acute and Chronic Criteria Violations Comparison for Dry and Wet Weather

\begin{tabular}{|c|c|c|c|c|c|c|c|c|c|c|c|c|}
\hline & \multicolumn{4}{|c|}{$\mathrm{Cd}$} & \multicolumn{4}{|c|}{$\mathrm{Cu}$} & \multicolumn{4}{|c|}{$\mathrm{Pb}$} \\
\hline \multirow{2}{*}{$\begin{array}{l}\text { Stration ID } \\
\text { BWw/BLK }\end{array}$} & \multicolumn{2}{|c|}{ Acute } & \multicolumn{2}{|c|}{ Chronic } & \multicolumn{2}{|c|}{ Acute } & \multicolumn{2}{|c|}{ Chronic } & \multicolumn{2}{|c|}{ Acute } & \multicolumn{2}{|c|}{ Chronic } \\
\hline & Dry & Wet & Dry & Wet & Dry & Wet & Dry & Wet, & Dry & Wet & Dry & Wet \\
\hline & & & & & & & & & & & & \\
\hline 00 & NS & 1 & NS & 1,3 & NS & $1,2,3$ & NS & $1,2,3$ & NS & $1,2,3$ & NS & $1,2,3$ \\
\hline 01 & NV & NV & 3 & 3 & 3 & $1,2,3$ & $1,2,3$ & $1,2,3$ & NV & 2,3 & $1,2,3$ & $1,2,3$ \\
\hline 02 & $1,2,3$ & 2 & $1,2,3$ & $1,2,3$ & $1,2,3$ & $1,2,3$ & $1,2,3$ & $1,2,3$ & NV & 2,3 & $1,2,3$ & $1,2,3$ \\
\hline 03 & $1,2,3$ & NS & $1,2,3$ & NS & $1,2,3$ & NS & $1,2,3$ & NS & NV & NS & $1,2,3$ & $\mathrm{NS}$ \\
\hline 04 & $1,2,3$ & $1,2,3$ & $1,2,3$ & B & $1,2,3$ & $1,2,3$ & $1,2,3$ & $1,2,3$ & NV & 2,3 & $1,2,3$ & $1,2,3$ \\
\hline 06 & $1,2,3$ & 2 & $1,2,3$ & $1,2,3$ & $1,2,3$ & $1,2,3$ & $1,2,3$ & $1,2,3$ & 1 & 2,3 & $1,2,3$ & $1,2,3$ \\
\hline 07 & NV & 2 & $1,2,3$ & $1,2,3$ & $1,2,3$ & $1,2,3$ & $1,2,3$ & $1,2,3$ & 1 & 3 & $1,2,3$ & $1,2,3$ \\
\hline 08 & NV & 1,2 & $1,2,3$ & $1,2,3$ & $1,2,3$ & $1,2,3$ & $1,2,3$ & $1,2,3$ & NV & 3 & $1,2,3$ & $1,2,3$ \\
\hline 11 & 3 & 2 & $1,2,3$ & $1,2,3$ & $1,2,3$ & $1,2,3$ & $1,2,3$ & $1,2,3$ & NV & 2,3 & $1,2,3$ & $1,2,3$ \\
\hline 12 & 3 & NS & 2,3 & NS & $1,2,3$ & NS & $1,2,3$ & NS & NV & NS & $1,2,3$ & NS \\
\hline 13 & 3 & 1 & $1,2,3$ & $1,2,3$ & $1,2,3$ & $1,2,3$ & $1,2,3$ & $1,2,3$ & NV & NV & $1,2,3$ & $1,2,3$ \\
\hline 17 & NV & 2 & 2,3 & 2 & $1,2,3$ & $1,2,3$ & $1,2,3$ & $1,2,3$ & NV & 3 & $1,2,3$ & $1,2,3$ \\
\hline 18 & NV & 2 & 2,3 & 2 & $1,2,3$ & $1,2,3$ & $1,2,3$ & $1,2,3$ & NV & 2 & $1,2,3$ & $1,2,3$ \\
\hline 19 & NV & NS & 2,3 & NS & 2,3 & NS & $1,2,3$ & NS & NV & NS & $1,2,3$ & NS \\
\hline 20 & NV & NV & 3 & 1,2 & 2,3 & $1,2,3$ & $1,2,3$ & $1,2,3$ & NV & NV & $1,2,3$ & $1,2,3$ \\
\hline 21 & NV & NV & 3 & 2 & 2,3 & $1,2,3$ & $1,2,3$ & $1,2,3$ & NV & NV & $1,2,3$ & $1,2,3$ \\
\hline & & & & & & & & & & & & \\
\hline
\end{tabular}

TRIBUTARIES

\begin{tabular}{|c|c|c|c|c|c|c|c|c|c|c|c|c|}
\hline 05 & NV & NS & NV & NS & NV & NS & NV & NS & NV & NS & $1,2,3$ & NS \\
\hline 09 & NV & NV & NV & NV & 1,3 & & 1,3 & NV & NV & NV & $1,2,3$ & $1,2,3$ \\
\hline 10 & NV & NS & NV & NS & 1,3 & NS & 1,3 & NS & NV & NS & $1,2,3$ & NS \\
\hline 14 & NV & NV & NV & NV & 1,3 & 1,2 & $1,2,3$ & 1,2 & NV & NV & $1,2,3$ & $1,2,3$ \\
\hline 15 & NV & NS & NV & NS & 1,3 & NS & $1,2,3$ & NS & NV & NS & $1,2,3$ & NS \\
\hline 16 & NV & 1 & NV & NV & NV & 1,2 & 1,3 & 1,2 & NV & 1 & $1,2,3$ & $1,2,3$ \\
\hline
\end{tabular}

Note: 1, 2, 3 = Surveys (i.e, Dry Weather Survey 1, 2, 3; Wet Weather Storm 1, 2, 3); NS= No Samples; NV= No Violations Ni and Cr has no Acute and Chronic Criteria Violation 
example of violations coinciding with the track of the storm hydrograph from the headwaters in Worcester. The highest and most frequent violations occur at the headwater station (BWW00) decreasing downstream. The impact of the headwater peak storm flows are not limited to these upper reaches. Lead concentrations increase and the resultant violations occur in Rice City Pond due to resuspension associated with the arrival of the higher flows from Worcester (Figure 6.3).

\subsubsection{Copper}

Chronic Criteria Violations - The chronic criteria violations occur at all stations at all times for all surveys and storms (dry and wet weather) along the mainstem and the tributaries of the Blackstone River. The highest violations occur below UBWPAD and around Rice City Pond (Tables 6.3 and 6.4).

Acute Criteria Violations - In the dry weather surveys violations typically began with BWW02 (UBWPAD) and continued downstream reaching BWW18 or BWW21 (Table 6.4). The extent of the violations under wet weather conditions are similar, however, wet weather does increase the magnitude of the violation.

\subsubsection{Cadmium}

Chronic Criteria Violations - For all dry and wet weather surveys the chronic violations for $\mathrm{Cd}$ generally start directly below UBWPAD discharge. The reaches with violations typically extended at least to Woonsocket (Tables 6.3 and 6.4).

Acute Criteria Violations - Dry weather acute violations began at BWW02 and 
typically continued downstream for 3 to 4 stations. The exception was for the dry weather survey 3 which also had several violation in the reaches below Rice City Pond (Table 6.4). Similarly, under wet weather conditions most of the violations for $\mathrm{Cd}$ also occurred directly below UBWPAD and extended for several stations downstream (Table 6.3).

\subsubsection{Chromium and Nickel}

$\mathrm{Cr}$ and $\mathrm{Ni}$ concentrations were well below the acute and chronic criteria violations for all the statiòns for all three storms under wet weather and all three surveys under dry weather on the mainstem of the Blackstone River. 


\section{CHAPTER 7}

7.0 Wet Weather Pollutant Loadings

7.1 Mass Loading Estimates

The water quality data coupled with stream flows allow for the calculation of mass loading curves. About 1000 mass loadings profiles along with concentrations profiles were generated during the course of this analysis. A subset of these mass loading profiles specific to lead is provided in Appendix B. Each mass loading curve was integrated to obtain the total load (e.g. lbs) for each station for each storm. The total mass was divided by the time of the event to obtain the total loading (e.g. lbs/day) for that constituent for each station. Baseline loading rates (dry load in lbs/day) were estimated for each pollutograph from the initial (prestorm) sample and the final (post storm) samples. These rates were multiplied by the time of the event to obtain the total dry load for that station (lbs). The wet load (lbs) per station per constituent was determined by subtracting the dry load from the total load. Figure 7.1 illustrates the procedure for load calculations. Point sources loadings, including the CSO, were calculated using the average flow and average concentration during the event period.

\subsection{Wet Weather Event Mean Mass (EMM)}

The EMC data calculated in Chapter 5 were multiplied by the average flow of the corresponding stations and the correct multiplier to come up with the single mass value (lbs/day) for that station. Which will be referred as Event Mean Mass (EMM) from now 

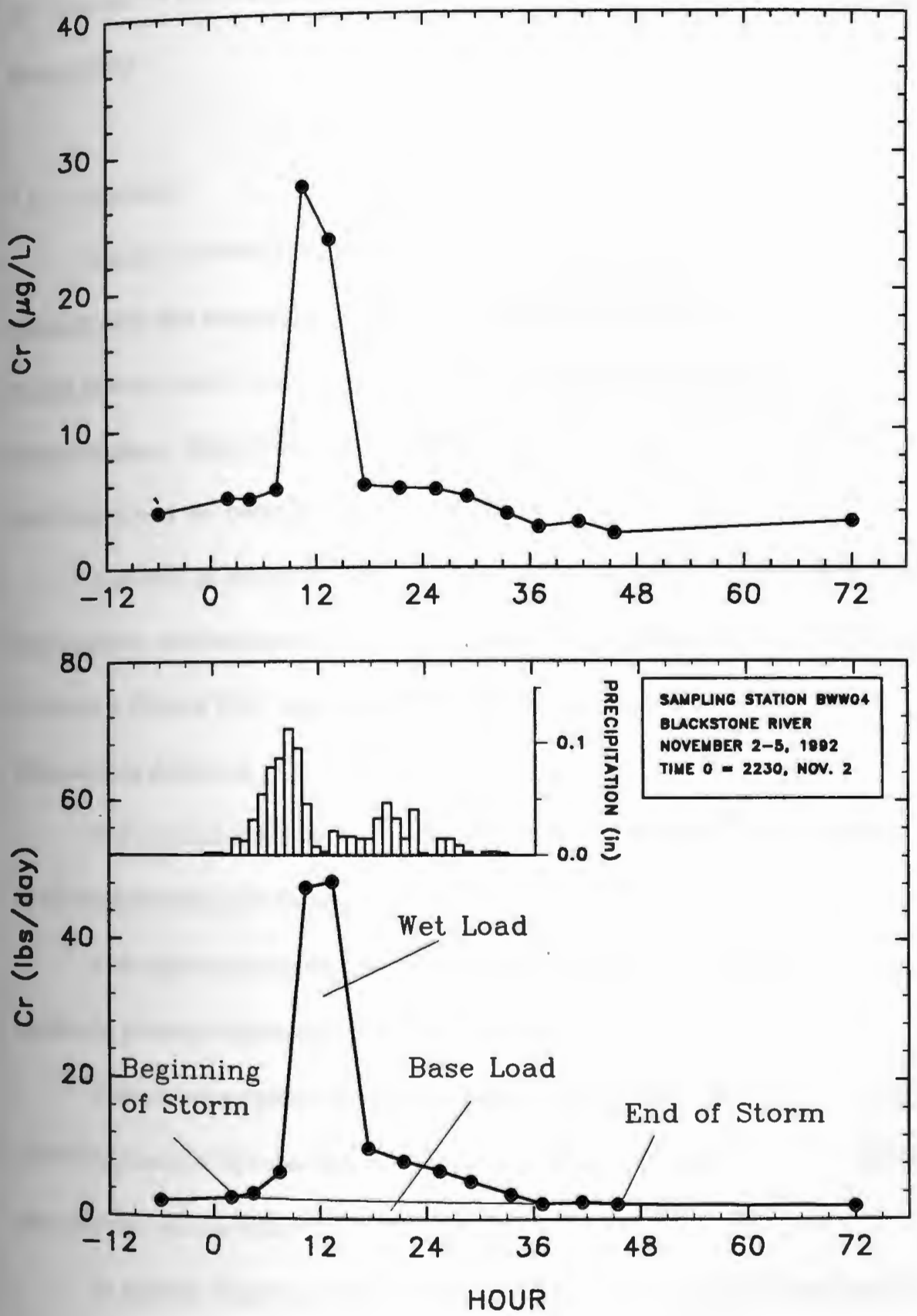

Figure 7.1 Example figure of $\mathrm{Cr}$ Showing Mass Loading Calculation for Storm 2 at Station BWW04 
on. Figures 7.2 to 7.7 show the spatial variation of EMM for the 16 constituents for the three storms.

\subsubsection{Nutrients}

Figure 7.2 reflect the operation of UBWPAD with respect to nitrification. The instream data also supported the fact that nitrification was being provided at the facility during Storms 1 and 3 with high nitrate mass below UBWPAD and comparatively low ammonia mass. Storm 2 had high ammonia mass and low nitrate mass indicating that nitrification was not being provided at the facility.

A decline in ammonia below BWW02 and an increase in nitrate support the fact that instream nitrification was occurring during the storms and it was particularly evident in Storm 2 (Figure 7.2). Instream nitrification was also seen in the reaches below the Woonsocket discharge.

The increase in ammonia mass between BWW17 and BWW18 were due to the Woonsocket facility discharge.

The decrease in nitrate mass in the Storm 1 profile was most likely due to nitrate uptake by plants as discussed in the EMC Section (Chapter 5).

Phosphorous pattern was the same for all three storms with increases of mass after UBWPAD and the Woonsocket discharge (Figure 7.3). The headwater contribution of phosphorous was very low.

In general, based on EMM profiles, the nutrient masses were dominated by direct discharge from the two major point sources or instream nitrification resulting from their 
EMM Plots for $\mathrm{NO}_{3}$ and $\mathrm{NH}_{3}$
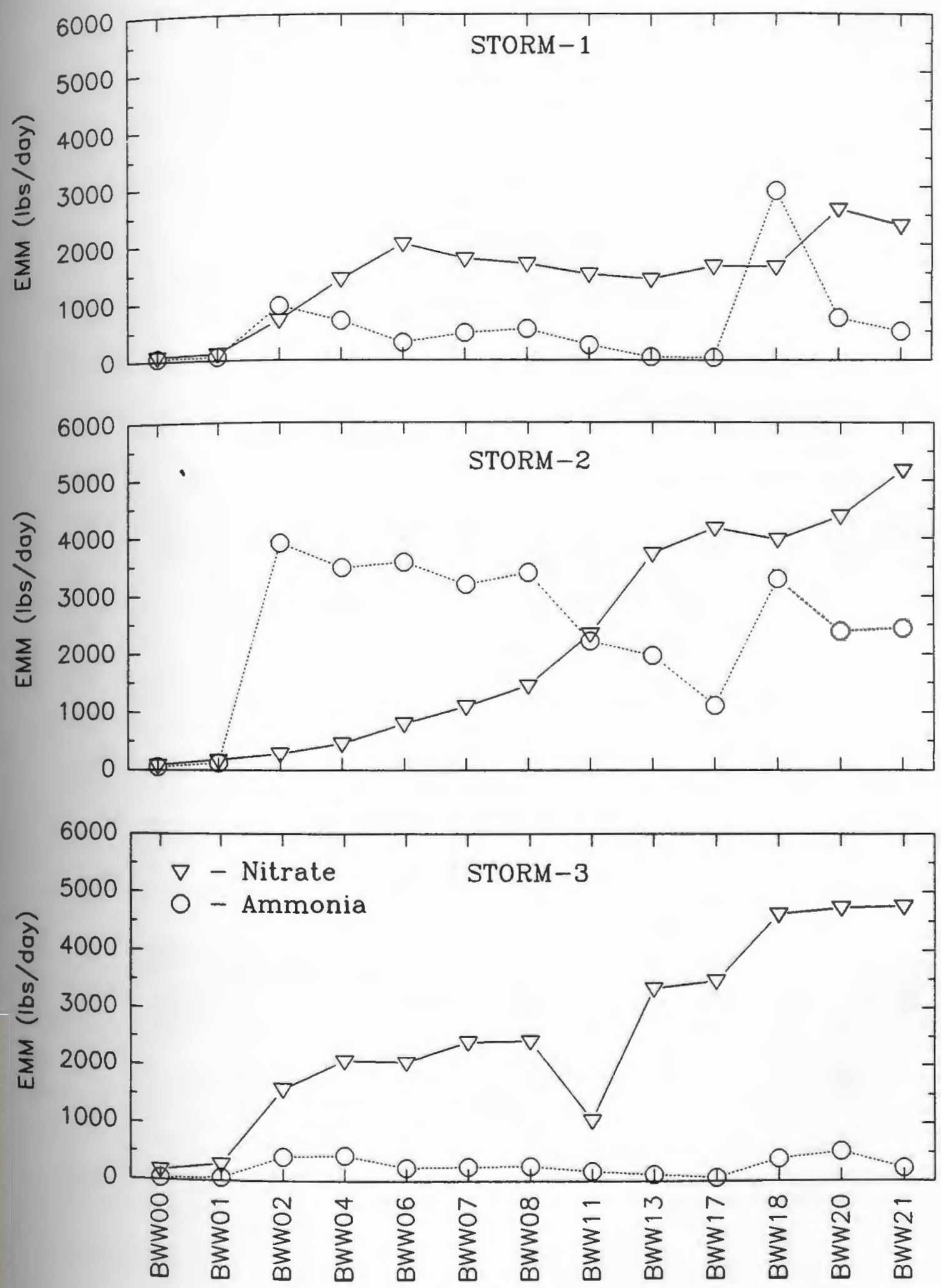

Figure 7.2 EMM Plots for $\mathrm{NO}_{3}$ and $\mathrm{NH}_{3}$ for Storms 1, 2 and 3 
EMM Plots for $\mathrm{PO}_{4}, \mathrm{FC}$ and $\mathrm{EC}$
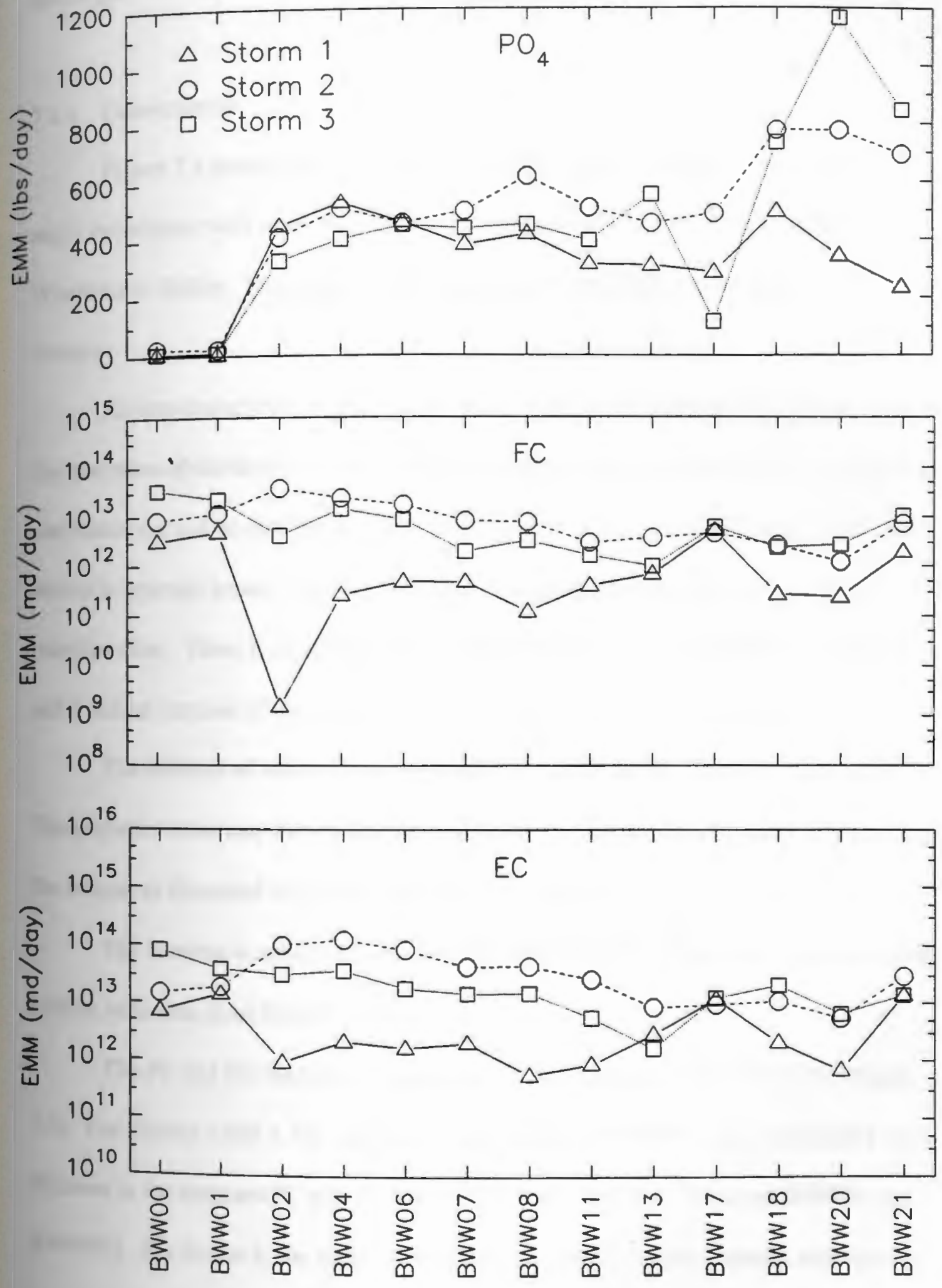

Figure 7.3 EMM Plots for $\mathrm{PO}_{4}, \mathrm{FC}$ and EC for Storms 1, 2 and 3 
EMM Plots for TSS, VSS and $\mathrm{Pb}$
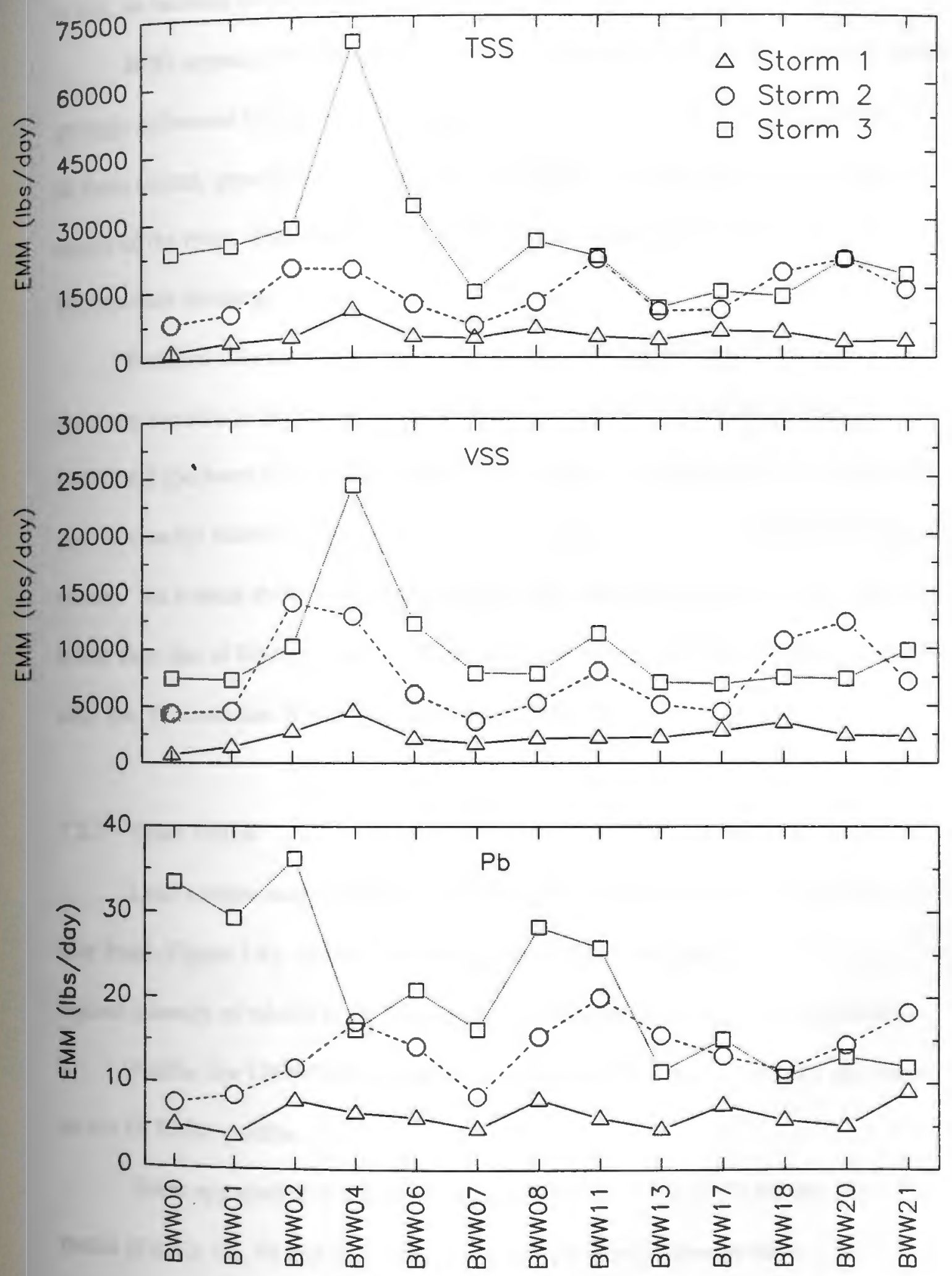

Figure 7.4 EMM Plots for TSS, VSS and Pb for Storms 1, 2 and 3 
in fact, an increase in EC and FC mass below UBWPAD.

BOD appears to be governed by the two major point sources and does not appear strongly influenced by the storm related sources (Figure 7.7). BOD has a similar trend for all three storms, generally increasing after the UBWPAD discharge and decreasing to the mouth of the river. The Storm 2 mass profile showed an increase in BOD after the Woonsocket discharge.

Residual chlorine and sodium in the facilities effluent are most likely the cause of the sharp increase in the instream chloride $(\mathrm{Cl})$ and sodium $(\mathrm{Na})$ masses below the UBWPAD (between BWW01 and BWW02) for Storms 1 and 3 (Figure 7.5). This was not the case for Storm $2 \mathrm{Cl}$, where higher stream flows resulted in lower residual chlorine masses. As a result the Cl EMM profile slope, after the UBWPAD discharge for Storm 2, is less than that of Storms 1 and 3. There is an increase in chlorine and sodium masses after the Woonsocket WWTF discharge for all three storms.

\subsubsection{Trace Metals}

Lead's major source appeared to be in the headwaters (above BWW00) and Rice City Pond (Figure 7.4). Storm 3 had the highest load coming form headwaters due to the highest intensity of rainfall at the headwaters as discussed in Chapter 4 of this report.

Neither the UBWPAD nor the Woonsocket facility appeared to have any impact on the $\mathrm{Pb}$ EMM profiles.

There appeared to be two distinct peaks (Figures 7.6 and 7.7) for the other five metals $(\mathrm{Cd}, \mathrm{Cr}, \mathrm{Cu}, \mathrm{Ni}$ and $\mathrm{Zn}$ ). All these metals had similar mass profiles. The first peak 
EMM Plots for $\mathrm{Cl}$ and $\mathrm{Na}$
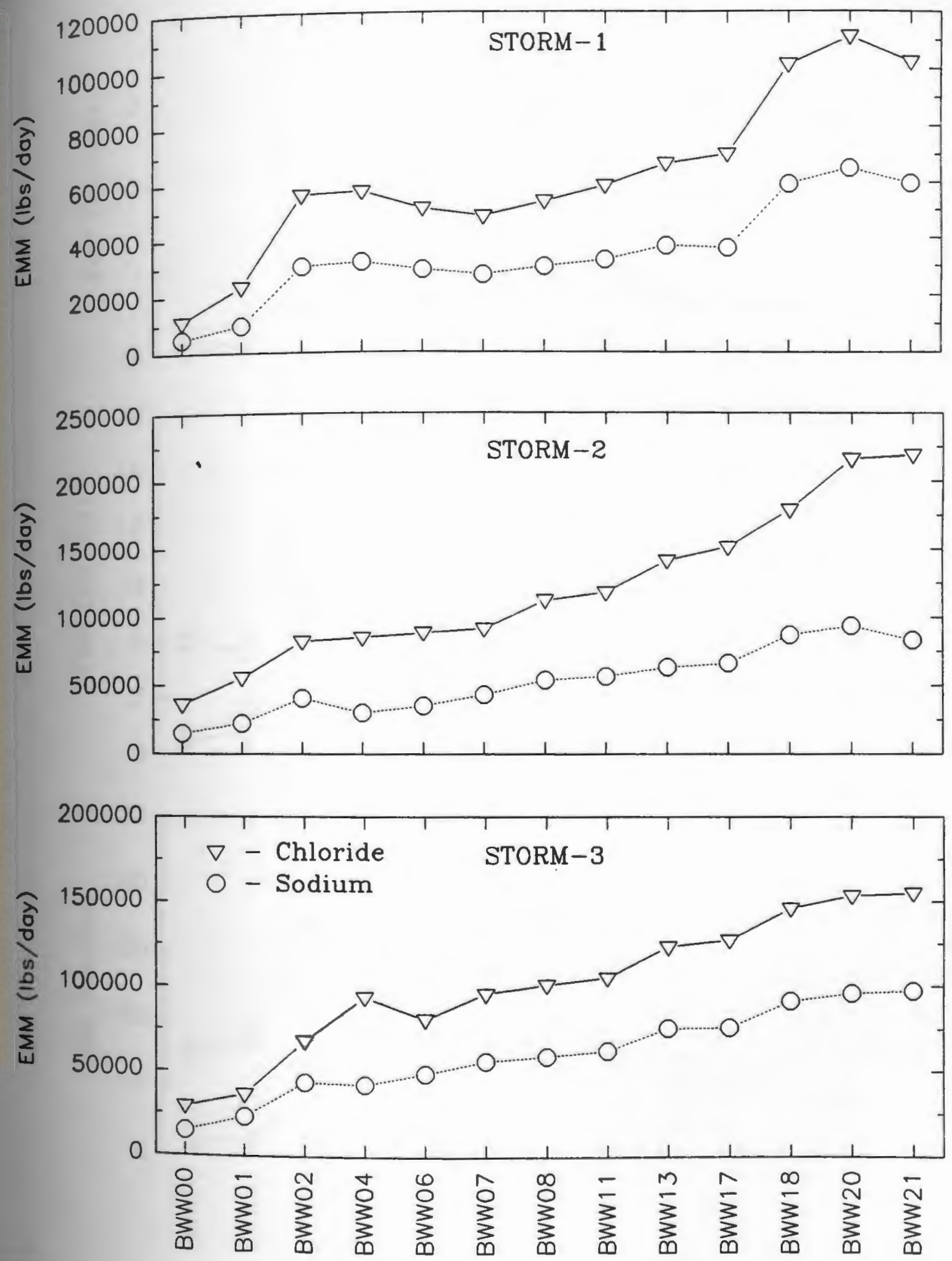

Figure 7.5 EMM Plots for $\mathrm{Cl}$ and $\mathrm{Na}$ for Storms 1, 2 and 3 
EMM Plots for $\mathrm{Cd}, \mathrm{Cr}$ and $\mathrm{Cu}$
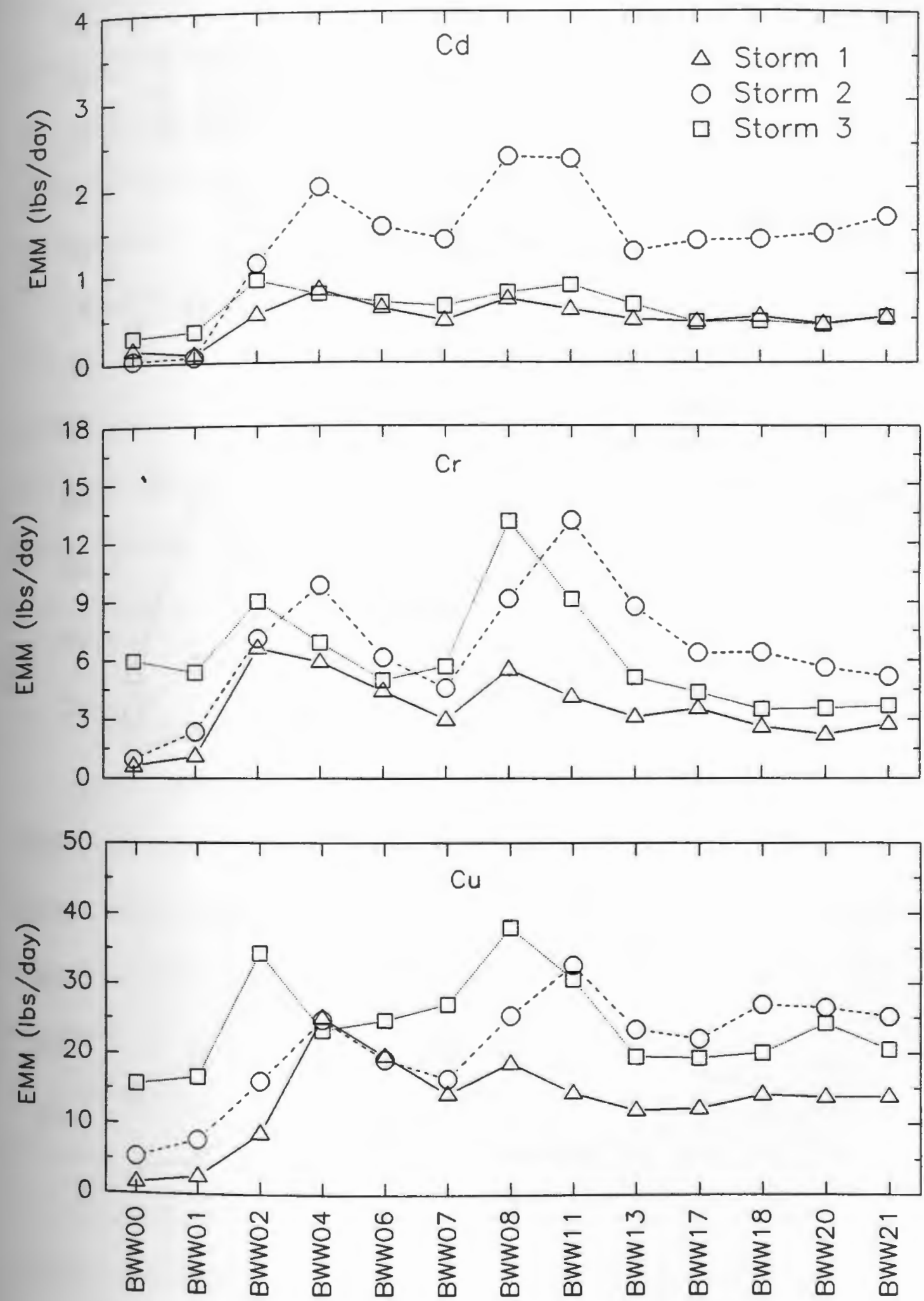

Figure 7.6 EMM Plots for $\mathrm{Cd}, \mathrm{Cr}$ and $\mathrm{Cu}$ for Storms 1, 2 and 3 


\section{EMM Plots for $\mathrm{Ni}, \mathrm{Zn}$ and $\mathrm{BOD}$}
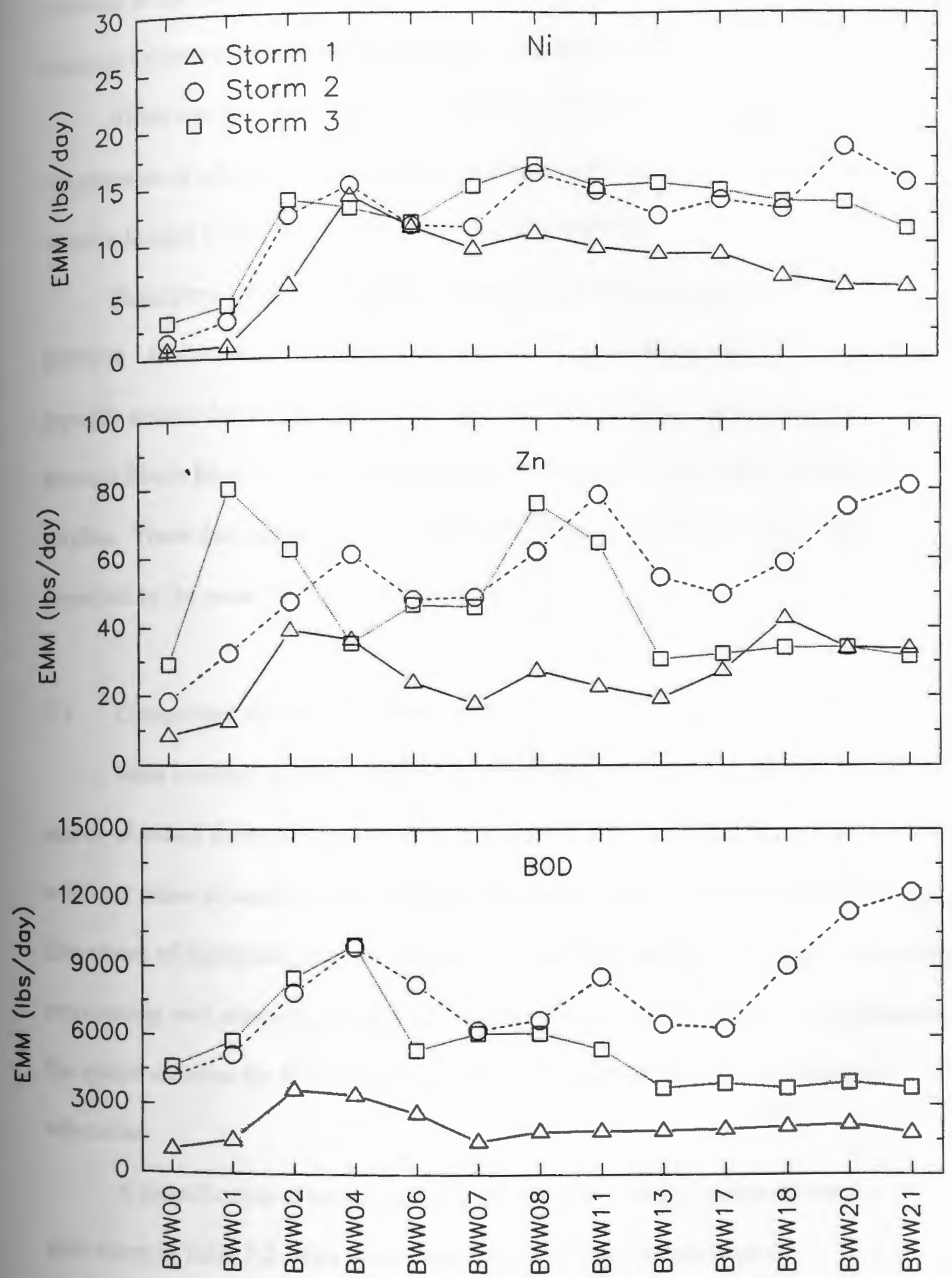

Figure 7.7 EMM Plots for $\mathrm{Ni}, \mathrm{Zn}$ and BOD for Storms 1, 2 and 3 
occurred in the reaches below UBWPAD. The wastewater facilities discharge and other nonpoint sources of metals was the probable cause of this peak.

There was a constant increase of masses up to BWW04 reflecting either the resuspension of sediments, the sloughing of material off the bottom, or Patriot Metals, which is located in the reach between BWW02 and BWW04.

Resuspension in Rice City Pond was the cause of the second peak around BWW08. All the metal mass profiles were either flat or declining with minor exceptions typically around the city of Woonsocket as the Blackstone River enters and passes through Rhodè Island. The Woonsocket facility had no significant affect on the mass profiles. These data suggested that the metal EMM profiles in Rhode Island were governed by the mass entering at the state line.

\subsection{Comparison of Wet and Total Loading}

Mass loadings provide insight into the question of whether wet loads are a major source of metals during and immediately after storm events. The data indicate clearly that with only minor exceptions more pollutants entered the river during wet period than dry. One means of highlighting this is to compare wet and dry loadings. This has been done by representing each station's wet load as a $\%$ of total load (Table 7.1). These data represent the spatial variation for all constituents along the mainstem Blackstone River and its tributaries.

A simplification of these data are presented as an average across all stations for each storm in Table 7.2. This table illustrates the variation of wet load as a $\%$ of total load 
Table 7.1 Blackstone River Wet Weather Wet Loading Summary, \% Total Averaged Across All Storms

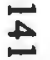

\begin{tabular}{|c|c|c|c|c|c|c|c|c|c|c|c|c|c|c|}
\hline & Cd & $\mathrm{Cr}$ & $\mathrm{Cu}$ & $\mathrm{Ni}$ & $\mathrm{Pb}$ & $\mathrm{Zn}$ & BOD & $E C$ & $F C$ & NH4 & NO3 & PO4 & TSS & VSS \\
\hline \multirow[t]{2}{*}{ Station } & Wot Laad & Wot Loed & Wot Loed & Wot Laad & Wolloed & Wot Load & Wot Load & Wot Load & Wot Load & Wol Load & Wot Load & Wot Load & Wot Load & Not Load \\
\hline & $\%$ Total & x Total & \% Total & X Totel & $\times$ Toted & x Total & \$ Total & $\%$ Total & \% Total & $\%$ Total & \% Total & \% Tolal & \% Total & \% Total \\
\hline
\end{tabular}

\begin{tabular}{|c|c|c|c|c|c|c|c|c|c|c|c|c|c|c|}
\hline BWWOO & 81.3 & 93.1 & 90.8 & 84.6 & 87.5 & 85.9 & 85.9 & 96.9 & 87.9 & 86.9 & 77.9 & 83.0 & 91.6 & 91.7 \\
\hline BWW01 & 84.9 & 74.3 & 84.3 & 69.7 & 88.1 & 80.4 & 86.9 & 96.4 & 81.0 & 84.9 & 56.3 & 81.2 & 93.6 & 81.8 \\
\hline BWWO2 & 85.8 & 75.2 & 82.3 & 62.1 & 84.6 & 72.1 & 69.3 & 75.9 & 90.0 & 73.4 & 51.9 & 77.7 & 76.0 & 74.9 \\
\hline BWW04 & 73.1 & 81.2 & 75.2 & 48.8 & 88.8 & 69.9 & 80.8 & 90.2 & 84.9 & 80.6 & 43.7 & 62.8 & 94.3 & 91.4 \\
\hline BWWos & 56.4 & 86.9 & 58.6 & 42.8 & 73.2 & 64.2 & 67.6 & 94.2 & 94.7 & 67.4 & 53.9 & 44.3 & 79.0 & 71.2 \\
\hline BWW07 & 38.6 & 59.1 & 50.1 & 37.2 & 63.3 & 54.9 & 58.2 & 88.4 & 87.7 & 67.4 & 34.5 & 47.2 & 69.3 & 65.5 \\
\hline BWWOB & 51.2 & B1.9 & 58.4 & 40.6 & 63.3 & 49.4 & 63.2 & 84.9 & 75.7 & 70.0 & 32.2 & 43.4 & 67.1 & 66.0 \\
\hline BWW11 & 54.0 & 60.2 & 56.8 & 43.2 & 67.0 & 59.1 & 58.4 & 88.1 & 82.1 & 81.6 & 45.9 & 39.2 & 66.9 & 72.7 \\
\hline BWW13 & 64.8 & 52.5 & 44.0 & 31.8 & 62.0 & 55.8 & 49.3 & 82.5 & 79.5 & 85.2 & 54.2 & 36.4 & 54.0 & 65.6 \\
\hline BWW17 & 52.6 & 51.5 & 52.3 & 40.9 & 56.2 & 54.2 & 60.0 & 95.8 & 85.9 & 82.1 & 40.5 & 42.1 & 72.7 & 74.4 \\
\hline BWW18 & 53.8 & 55.7 & 48.8 & 34.8 & 51.0 & 47.6 & 59.1 & 90.4 & 83.6 & 69.3 & 32.1 & 40.3 & 55.6 & 69.9 \\
\hline BWW20 & 49.0 & 61.4 & 51.0 & 50.4 & 55.2 & 55.5 & 59.4 & 93.0 & 77.3 & 62.4 & 38.0 & 52.7 & 71.4 & 72.9 \\
\hline BWW21 & 52.2 & 53.1 & 46.1 & 47.9 & 62.0 & 60.3 & 69.3 & 95.3 & 95.8 & 70.9 & 42.2 & 48.3 & 64.6 & 72.2 \\
\hline & & & & & & & & & & & & & & \\
\hline
\end{tabular}

Tributaries

\begin{tabular}{|c|c|c|c|c|c|c|c|c|c|c|c|c|c|c|}
\hline BWWOS & 71.1 & 82.7 & 69.3 & 72.4 & 72.7 & 56.4 & & & & & 36.4 & 65.6 & 58.4 & 73.9 \\
\hline BWw09 & 72.1 & 61.2 & 74.5 & 43.9 & 68.3 & 43.2 & 60.9 & 68.9 & 72.0 & 55.9 & 55.4 & 45.4 & 64.3 & 77.3 \\
\hline BWW10 & 44.3 & 71.7 & 54.8 & 48.0 & 57.9 & 34.3 & & & & & 47.4 & 50.2 & 69.0 & 83.9 \\
\hline BWW14 & 53.8 & 57.1 & 51.2 & 59.2 & 50.2 & 36.8 & 86.0 & 81.5 & 75.4 & 81.3 & 40.7 & 22.9 & 63.3 & 62.6 \\
\hline BWW15 & 63.4 & 60.9 & 57.1 & 44.0 & 58.3 & 35.1 & & & & & 47.9 & 50.0 & 73.3 & 77.3 \\
\hline BWW16 & 71.0 & 63.8 & 64.2 & 68.6 & 70.2 & 81.5 & 67.9 & 83.9 & 90.9 & 71.4 & 49.3 & 62.4 & 77.2 & 66.2 \\
\hline
\end{tabular}


Table 7.2 Blackstone River Wet Weather Wet Loading Summary, \% Total Averaged Across All Stations

\begin{tabular}{|c|c|c|c|c|c|c|c|c|c|c|c|c|c|c|}
\hline & $\overline{\mathrm{Cd}}$ & $\mathrm{Cr}$ & $\mathrm{Cu}$ & $\overline{\mathrm{Ni}}$ & $\overline{\mathrm{Pb}}$ & $\overline{\mathrm{Zn}}$ & $\overline{\mathrm{BOD}}$ & EC & FC & NH4 & $\mathrm{NO3}$ & $\mathrm{PO4}$ & TSS & VSS \\
\hline \multirow[t]{2}{*}{ Station } & Wet Load & Wet Load & Wet Load & Wet Load & Wet Load & Wet Load & Wet Load & Wet Load & Wet Load & Wet Load & Wet Load & Wet Load & Wet Load & Wet Load \\
\hline & $\%$ Total & $\%$ Total & $\%$ Total & $\%$ Total & $\%$ Total & $\%$ Total & $\%$ Total & $\%$ Total & $\%$ Total & $\%$ Total & $\%$ Total & $\%$ Total & $\%$ Total & $\%$ Total \\
\hline Strom & 510 & 480 & 410 & 351 & 534 & 455 & 183 & 868 & 766 & 751 & $37 ?$ & 410 & 555 & 687 \\
\hline Storm 2 & 65.9 & 68.8 & 65.1 & 49.3 & 73.4 & 63.6 & 78.2 & 90.5 & 85.9 & 69.5 & 49.0 & 64.6 & 81.7 & 68.8 \\
\hline Storm 3 & 66.3 & 78.5 & 76.8 & 62.1 & 81.5 & 77.6 & 73.7 & 93.2 & 92.7 & 77.4 & 53.1 & 54.7 & 82.5 & 86.4 \\
\hline Average & 61.4 & 65.1 & 61.3 & 48.8 & 69.4 & 62.2 & 66.7 & 90.2 & 85.1 & 74.0 & 46.4 & 53.7 & 73.5 & 74.6 \\
\hline & & & & & & & & & & & & & & \\
\hline
\end{tabular}

E 
with the change of rainfall. The same table summarizes the average wet loadings for each constituents under wet weather for the entire watershed. A comparison by constituent is provided below.

\subsubsection{Nutrients}

All the ammonia loading were above $50 \%$ and most of the nitrate loadings were below $50 \%$ for the mainstem and tributaries stations of the Blackstone River. Wet load as $\%$ total load for nitrate ranged from $78 \%$ at the headwaters to about $40 \%$ at the mouth of the river. For ammonia the values were greater than $70 \%$ for the whole length of the river with the exception of BWW01 and BWW20.

Orthophosphate wet loadings were above $50 \%$ at the headwaters but steadily declined to below $50 \%$ at the mouth of the river.

Wet loads as a percent of total loadings are summarized in Table 7.2 averaged for all storm across all stations. Wet loadings contribute more than $50 \%$ of the loadings for most of the constituents.

\subsubsection{Conventional}

With regards to the conventional constituents such as TSS, VSS, EC, FC, and BOD, all the mainstem and tributary stations of the Blackstone River had more than $50 \%$ wet load except BWW13 for BOD. The highest percentage occurred for TSS/VSS at BWW04 (94\%). The trend of higher percent wet load as the storm intensity increases is true for all these constituents. 


\subsubsection{Trace Metals}

In general, there are two observations which were consistent for all six metals. First, the highest percentage of wet load occurred at the headwaters. This reflects the importance of Worcester as a source of metals under wet weather conditions. The reduction in the percentage of wet load to total downstream is attributed to the higher more dominate point source loadings from the WWTFs, especially UBWPAD.

Second, either individually by station or based on the overall average for all stations by storm there is a positive correlation between the wet load percent of total and the rainfall intensity observed in the headwaters. This is logical and certainly supportive of the hypothesis that metal mobilization, whether by runoff or resuspension, is a function of the characteristics of the event.

A notable decrease in wet load \% at Fisherville Pond (between BWW04 and BWW06) is seen for all metals. For example $\mathrm{Cu}$ declined from $75.2 \%$ to $58.6 \%$ wet load due most likely to settling. On the other hand, an increase in wet load \% occurred in the Rice City Pond for all metals except for $\mathrm{Zn}$ due to sediment resuspension which occurred under the higher wet weather flows.

All the tributaries had greater than $50 \%$ wet load except for $\mathrm{Zn}$ and Ni. Other significant increases in \% wet load which is an indication of a wet weather source occurred: Cd between BWW11-13, and BWW20-21; Cr between BWW02-04 and BWW18-20; Cu between BWW13-17 and BWW18-20; Pb between BWW18-20 and BWW20-21; Ni between BWW18-20; Zn between BWW18-20 and BWW20-21. 
Based on the interpretation of the mass loading curves, mass balance around each reach may be made providing an estimate of pollutant gain or loss. Net pollutant changes in a reach help to identify locations of major pollutant sources. The results of this evaluation also provides insight into the relative importance of each reach through a system ranking. The following decisions were made to establish the protocol for data evaluation.

The conditions between stations are dynamic. There are potentially multiple sources of each 'constituents in each reach which may function differently depending on the rainfall characteristics. Individual measurements within a reach were limited to a select group of the major point sources (UBWPAD and Woonsocket) and tributaries. Station comparisons, only provide net gains or losses of pollutants. Specific identification of a source requires a more detailed evaluation of each reach, which was beyond the scope of this project. However, reaches identified as a hot spot may undergo a more detailed evaluation. (An example of this is the identification of Rice City Pond (river reach BWW07-08) as a source of pollutant resuspension and the subsequent speciality study summarized in Section 4.6.3 of BRI report (Wright et al., 1996)). Potential sources are usually identified based on measured land use or observations (both past and present).

The UBWPAD and Woonsocket loads were subtracted from their respective reach mass balance. The other WWTFs in the watershed discharges were not considered in the balance and, therefore, their contribution remains as a part of the net gain in a reach.

The total load net gain and loss was calculated by reach by subtracting loadings 
from consecutive stations along with other reach additions (point sources and tributaries).

For example:

$$
\text { Gains/Loss = BWW02 - BWW01 - UBWPAD (BWW23) }
$$

or

$$
\text { Gains/Loss = BWW06 - BWW04 - BWW05 (Quinsigamond River) }
$$

The wet load follows a similar procedure. An example of the net gain/loss profiles is given in Figure 7.8. Trends may be observed in these types of figures. For instance in Figure 7.8, a major gain for all three constituents (TSS, $\mathrm{Cu}$ and $\mathrm{Pb}$ ) may be seen in the reaches BWW00-04 and BWW07-11 and a major loss may be seen in the reaches BWW04-07; and BWW11-17 with some rise and fall after station BWW17. The gains and losses from these figures are used to calculate the point and nonpoint sources in the next section.

\subsection{Major Point Sources vs Nonpoint Sources}

A point source is continuous and can be readily quantified. Nonpoint sources may be difficult to identify and quantify. Surface runoff and resuspension from bottom sediment are examples of non point sources. Sources were grouped for comparison in the following manner: Point Sources Loadings = UBWPAD + WOON + WOOR CSO and; Non Point Sources Loadings $=$ Headwaters $(B W W 00)+$ Reach gains + Tributary load

Figure 7.9 is an example of point source and nonpoint source comparisons. These types of figures indicate the importance of nonpoint sources during wet weather events. The summary of the point and nonpoint sources are presented in Table 7.3 and 7.4 for 
Storm 2, Wet Load
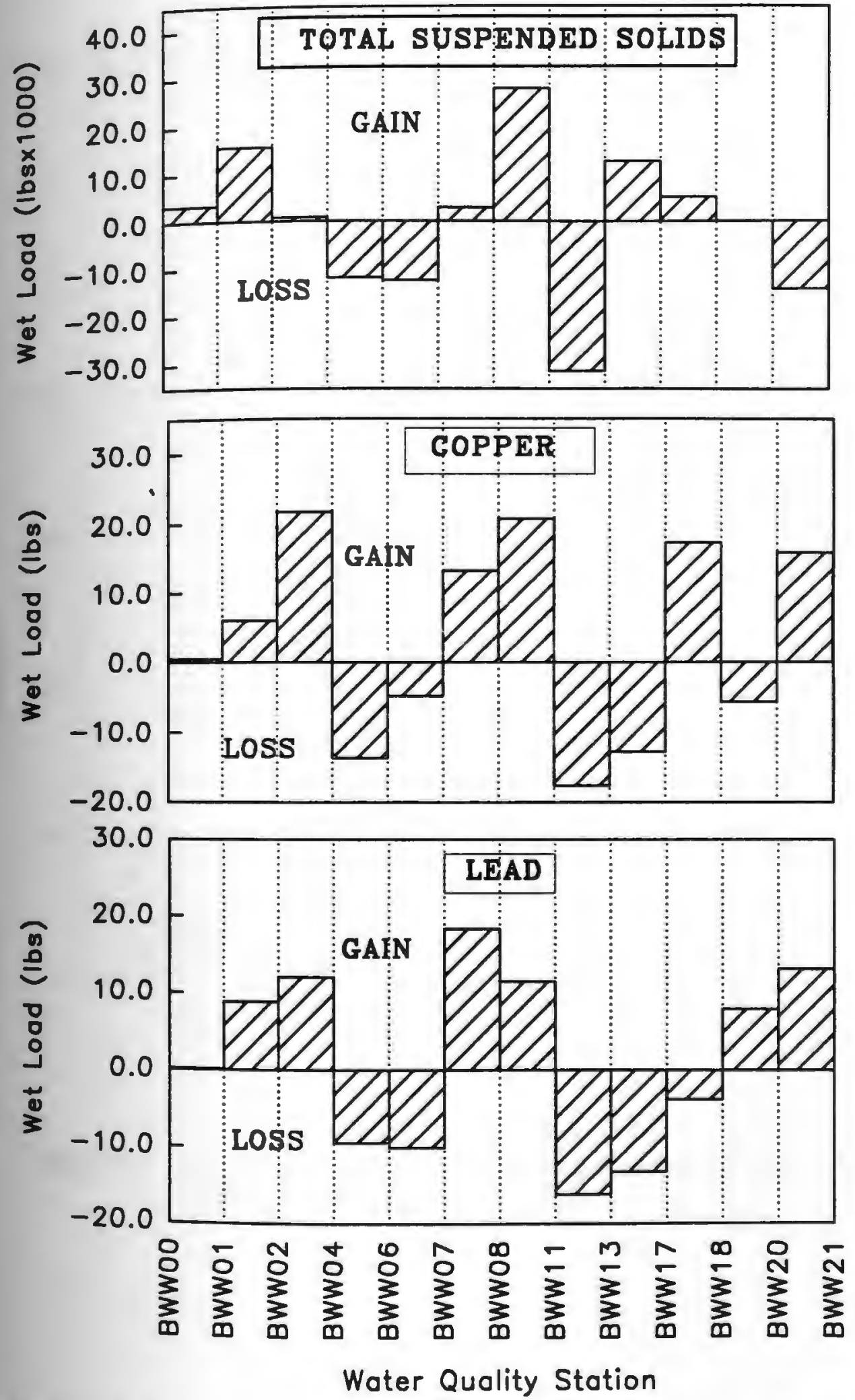

Figure 7.8 Example figure of Wet Load Showing Gain and Loss for TSS, Cu and Pb for Storm 2 
BLACKSTONE RIVER WET WEATHER STUDIES

Wet Load

Constituent: $\mathrm{Pb}$
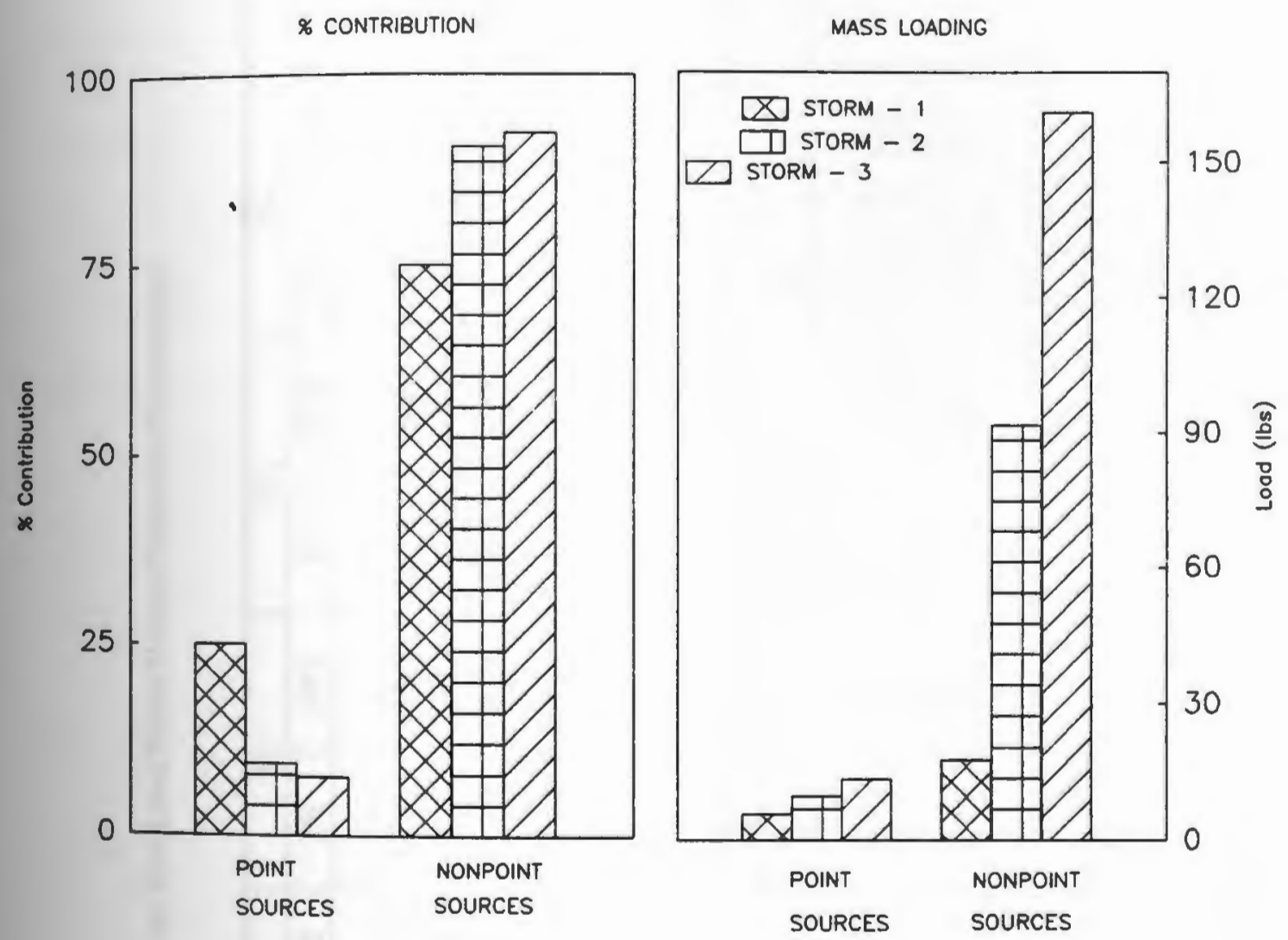

Figure 7.9 Example Plot of Wet Load Showing Point and Non Point Sources Comparison for $\mathrm{Pb}$ Storms 1, 2 and 3 
Table 7.3 Blackstone River Wet Load Point Versus Nonpoint Percentages

\begin{tabular}{|c|c|c|c|c|c|c|c|c|c|c|c|c|}
\hline & \multicolumn{2}{|c|}{$\mathrm{Cd}$} & \multicolumn{2}{|c|}{$\mathrm{Cr}$} & \multicolumn{2}{|c|}{$\mathrm{Cu}$} & \multicolumn{2}{|c|}{$\mathrm{Ni}$} & \multicolumn{2}{|c|}{$\mathrm{Pb}$} & \multicolumn{2}{|c|}{$\mathrm{Zn}$} \\
\hline Storm & PS & NPS & PS & NPS & PS & NPS & PS & NPS & PS & NPS & PS & NPS \\
\hline 1 & 32.7 & 67.3 & 55.8 & 44.2 & 53.9 & 46.2 & $\overline{69.6}$ & 30.4 & 13.2 & 868 & 483 & 517 \\
\hline 2 & 15.0 & 85.0 & 15.1 & 84.9 & 16.2 & 83.8 & 28.9 & 71.1 & 4.38 & 95.6 & 15.0 & 85.0 \\
\hline 3 & 20.9 & 79.1 & 9.53 & 90.5 & 28.0 & 72.0 & 35.6 & 64.5 & 4.38 & 95.6 & 14.3 & 85.7 \\
\hline & & & & & & & & & & & & \\
\hline
\end{tabular}

E

\begin{tabular}{|c|c|c|c|c|c|c|c|c|c|c|c|c|}
\hline & \multicolumn{2}{|c|}{ BOD } & \multicolumn{2}{|c|}{ FC } & \multicolumn{2}{|c|}{ NH3 } & \multicolumn{2}{|c|}{$\mathrm{NO3}$} & \multicolumn{2}{|c|}{ PO4 } & \multicolumn{2}{|c|}{ TSS } \\
\hline Storm & PS & NPS & PS & NPS & PS & NPS & PS & NPS & PS & NPS & PS & NPS \\
\hline 1 & 36.2 & 63.8 & 2.72 & 97.3 & 58.6 & 41.4 & 41.3 & 58.7 & 72.3 & 27.7 & 23.3 & 76.7 \\
\hline 2 & 26.2 & 73.9 & 68.2 & 31.8 & 68.0 & 32.0 & 1.89 & 98.1 & 77.2 & 22.8 & 28.4 & 71.6 \\
\hline 3 & 39.6 & 60.4 & 0.26 & 99.7 & 31.1 & 68.9 & 54.5 & 45.5 & 39.3 & 60.7 & 7.42 & 92.6 \\
\hline
\end{tabular}

PS = Point Source ; NPS = Nonpoint Source 
Table 7.4 Blackstone River Total Load Point Versus Nonpoint Percentages

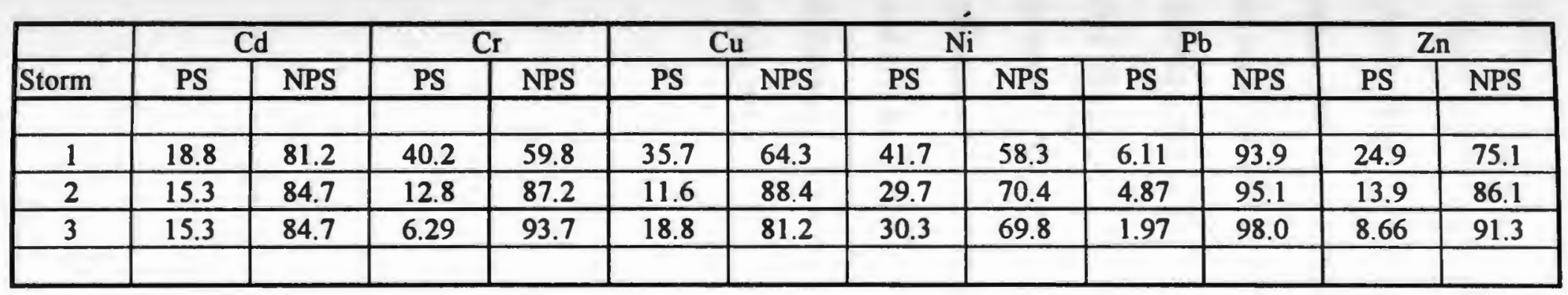

प̆

\begin{tabular}{|c|c|c|c|c|c|c|c|c|c|c|c|c|}
\hline & \multicolumn{2}{|c|}{ BOD } & \multicolumn{2}{|c|}{ FC } & \multicolumn{2}{|c|}{ NH3 } & \multicolumn{2}{|c|}{ NO3 } & \multicolumn{2}{|c|}{ PO4 } & \multicolumn{2}{|c|}{ TSS } \\
\hline Storm & PS & NPS & PS & NPS & PS & NPS & PS & NPS & PS & NPS & PS & NPS \\
\hline 1 & 39.4 & 60.6 & 1.85 & 98.2 & 49.2 & 50.8 & 27.2 & 72.8 & 81.1 & 18.9 & 16.9 & 83.1 \\
\hline 2 & 35.8 & 64.2 & 66.2 & 33.8 & 82.6 & 17.4 & 1.57 & 98.4 & 59.4 & 40.6 & 19.2 & 80.8 \\
\hline 3 & 25.9 & 74.1 & 0.07 & 99.9 & 20.1 & 80.0 & 31.5 & 68.5 & 35.9 & 64.1 & 2.42 & 97.6 \\
\hline
\end{tabular}

PS = Point Source ; NPS = Nonpoint Source 
wet and total loads.

From Table 7.4, $\mathrm{Pb}$ has non point source contribution of $93 \%-98 \%$ for the storms observed and clearly nonpoint source governed. The high concentrations of $\mathrm{Pb}$ in the headwaters and Rice City Pond during wet weather events also support this. The data in Table 7.4 shows ammonia contribution for point sources was relatively higher for Storm 2 and lower for Storms 1 and 3, which supports that nitrification was occurring at UBWPAD during Storm 1 and Storm 3 and no nitrification occurred during Storm 2. It is clear from these tables that non point sources govern are higher for most constituents with the exception of ammonia and orthophosphate which are governed by point sources.

Point and non-point sources loads are summarized in Table 7.5 averaged for all storm across all stations. Non-point sources contribute more than $50 \%$ of the loadings for most of the constituents. 
Table 7.5 Summary Average of Wet and Total Load Point Versus Nonpoint Percentages

\begin{tabular}{|c|c|c|c|c|c|c|c|c|c|c|c|c|}
\hline Average & \multicolumn{2}{|c|}{$\overline{C d}$} & \multicolumn{2}{|c|}{$\mathrm{Cr}$} & \multicolumn{2}{|c|}{$\mathrm{Cu}$} & \multicolumn{2}{|c|}{$\mathrm{Ni}$} & \multicolumn{2}{|c|}{$\mathrm{Pb}$} & \multicolumn{2}{|c|}{$\mathrm{Zn}$} \\
\hline Load & PS & NPS & PS & NPS & PS & NPS & PS & NPS & PS & NPS & PS & NPS \\
\hline Wet & 22.9 & 77.1 & 26.8 & 73.2 & 32.7 & 67.3 & 44.7 & 55.3 & 7.33 & 92.7 & 25.9 & 74.1 \\
\hline Total & 16.5 & 83.5 & 19.8 & 80.2 & 22.1 & 78.0 & 33.9 & 66.1 & 4.32 & 95.7 & 15.8 & 84.2 \\
\hline
\end{tabular}

$\vec{s}$

\begin{tabular}{|c|c|c|c|c|c|c|c|c|c|c|c|c|}
\hline Average & \multicolumn{2}{|c|}{ BOD } & \multicolumn{2}{c|}{ FC } & \multicolumn{2}{c|}{ NH3 } & \multicolumn{2}{c|}{ NO3 } & \multicolumn{3}{c|}{ PO4 } & \multicolumn{2}{c|}{ TSS } \\
\hline Load & PS & NPS & PS & NPS & PS & NPS & PS & NPS & PS & NPS & PS & NPS \\
\hline & & & & & & & & & & & & \\
\hline Wet & 34.0 & 66.0 & 23.7 & 76.3 & 52.6 & 47.4 & 32.6 & 67.5 & 62.9 & 37.1 & 19.7 & 80.3 \\
\hline Total & 33.7 & 66.3 & 22.7 & 77.3 & 50.6 & 49.4 & 20.1 & 79.9 & 58.8 & 41.2 & 12.8 & 87.2 \\
\hline & & & & & & & & & & & & \\
\hline
\end{tabular}

PS = Point Source ; NPS = Nonpoint Source 


\section{CHAPTER 8}

\subsection{System Ranking}

A system ranking was made using the net gains for each reach and loads from the point sources, headwaters and tributaries. UBWPAD and Woonsocket were the only point sources considered for ranking calculations. The tributaries are grouped as BWW05, BWW09+BWW10, BWW14, and BWW15+BWW16. The ranking for each storm was calculated for both wet and total loads. The summary rankings for wet and total loads are provided in Tables 8.1 and 8.2 , respectively.

The percent loadings for each reach tributary combination, the headwater station and each point source were averaged to get the contribution and ranking for all three storms.

A ranking, without point sources for the wet load, were also calculated for each storm and given in Table $\mathbf{8 . 3}$.

\subsection{Nutrients $\left(\mathrm{NO}_{3}, \mathrm{PO}_{4}, \mathrm{NH}_{4}\right)$}

Wet and Total Load - UBWPAD is the most important source for nutrients for both wet and total load and delivers almost $1 / 3$ of the total loadings for ammonia. The second most important source is Woonsocket. Normally treatment facilities has high ammonia loadings and in the previous section it was found that ammonia is mostly controlled by point sources (Table 7.5). Form Table 8.1 and 8.2, $60 \%$ of this ammonia point source loading is coming from UBWPAD and about $40 \%$ from Woonsocket. 
Table 8.1 Average Blackstone River Wet Weather Rankings, Wet Load

\begin{tabular}{|c|c|c|c|c|c|c|c|c|c|c|c|c|}
\hline & \multicolumn{2}{|l|}{$\mathrm{Cd}$} & \multicolumn{2}{|l|}{$\mathrm{Cr}$} & \multicolumn{2}{|l|}{$\mathrm{Cu}$} & \multicolumn{2}{|l|}{$\mathrm{Ni}$} & \multicolumn{2}{|l|}{$\mathrm{Pb}$} & \multicolumn{2}{|l|}{$\mathrm{Zn}$} \\
\hline Ranking & Source & \%Load & Source & \%Load & Source & \%Laad & Source & \%Load & Source & \%Load & Source & \%Load \\
\hline & & & & & & & & & & & & \\
\hline 1 & UBWPAD & 18.2 & UBWPAD & 25.7 & UBWPAD & 26.2 & UBWPAD & 42.7 & BWW00 & 31.1 & UBWPAD & 16.0 \\
\hline 2 & BWW02-04 & 15.6 & BWW01-02 & 15.1 & BWW02-04 & 12.6 & BWW18-20 & 12.5 & BWW07-08 & 14.5 & BWW00 & 14.2 \\
\hline 3 & BWW01-02 & 14.3 & BWW07-08 & 14.1 & BWW07-08 & 11.1 & BWW07-08 & 10.8 & BWW01-02 & 13.9 & BWW00-01 & 13.2 \\
\hline 4 & BWW07-08 & 12.4 & BWw00 & 13.7 & BWW00 & 10.9 & BWw13-17 & 7.22 & BWW20-21 & 13.8 & WOON & 8.60 \\
\hline 5 & BWW20-21 & 7.64 & BWW08-11 & 8.63 & WOON & 5.88 & BWw01-02 & 6.94 & BWW13-17 & 4.54 & BWW18-20 & 7.90 \\
\hline 6 & BWW11-13 & 6.99 & BWW02-04 & 6.58 & BWW01-02 & 5.71 & BWWOO & 6.13 & BWW02-04 & 4.27 & BWW07-08 & 7.73 \\
\hline 7 & BWW00 & 6.76 & BWW13-17 & 4.31 & BWW13-17 & 5.52 & BWW02-04 & 5.08 & BWW18-20 & 3.85 & BWW01-02 & 6.58 \\
\hline 8 & BWW08-11 & 6.23 & WOON & 2.70 & BWW08-11 & 5.37 & BWW00-01 & 1.77 & UBWPAD & 3.64 & BWW20-21 & 5.62 \\
\hline 9 & WOON & 4.22 & BWW18-20 & 2.03 & BWW17-18 & 4.50 & BWW08-11 & 1.43 & WOON & 3.38 & BWW08-11 & 5.32 \\
\hline 10 & BWW13-17 & 3.32 & BWW20-21 & 1.86 & BWW20-21 & 4.12 & WOON & 1.42 & BWW08-11 & 2.80 & BWW02-04 & 3.36 \\
\hline 11 & $B W W 18-20$ & 2.32 & BWW00-01 & 1.33 & BWW18-20 & 3.85 & BWW06-07 & 1.14 & $B W W 15+16$ & 1.06 & BWW13-17 & 3.02 \\
\hline 12 & BWw00-01 & 0.50 & BWw06-07 & 0.98 & BWW06-07 & 1.39 & BWw15+16 & 0.66 & BWW14 & 1.05 & BWW04-06 & 2.05 \\
\hline 13 & WoOW CSO & 0.49 & BWW14 & 0.93 & BWW00-01 & 0.79 & BWW04-06 & 0.66 & $B W W 09+10$ & 1.00 & BWW17-18 & 1.52 \\
\hline 14 & BWW9+10 & 0.40 & BWW9+10 & 0.76 & WOOR CSO & 0.70 & BWW05 & 0.51 & BWW17-18 & 0.39 & BWw09+10 & 1.44 \\
\hline 15 & BWW15+16 & 0.23 & BWW17-18 & 0.65 & BWw09+10 & 0.68 & BWW14 & 0.42 & WOOR CSO & 0.35 & WOOR CSO & 1.30 \\
\hline 16 & BWW05 & 0.21 & BWW15+16 & 0.30 & BWw15+16 & 0.36 & WOOR CSO & 0.40 & BWW05 & 0.33 & BWW14 & 1.02 \\
\hline 17 & BWW14 & 0.19 & BWW05 & 0.23 & BWW14 & 0.33 & BWW09+10 & 0.20 & BWw00-01 & 0.06 & BWW15+16 & 0.80 \\
\hline 18 & & & WOOR CSO & 0.19 & BWW05 & 0.09 & & & BWW04-06 & 0.03 & BWW06-07 & 0.25 \\
\hline 19 & & & & & & & & & & & BWW05 & 0.13 \\
\hline & & & & & & & & & & & & \\
\hline
\end{tabular}

WOON $=$ Woonsocket WWTF, WOOR CSO $=$ Worcester CSO 
Table 8.1 Wet Load (Continued)

\begin{tabular}{|c|c|c|c|c|c|c|c|c|c|c|c|c|}
\hline & \multicolumn{2}{|c|}{$\overline{\mathrm{BOD}}$} & \multicolumn{2}{|l|}{$\overline{F C}$} & \multicolumn{2}{|c|}{$\mathrm{NH3}$} & \multicolumn{2}{|c|}{ NO3 } & \multicolumn{2}{|l|}{ PO4 } & \multicolumn{2}{|l|}{ TSS } \\
\hline Ranking & Source & \%Load & Source & \%Load & Source & \%load & Source & \%Load & Source & \%Load & Source & \%Load \\
\hline & & & & & & & & & & & & \\
\hline 1 & UBWPAD & 24.1 & BWW00 & 32.69 & UBWPAD & 31.2 & UBWPAD & 26.2 & UBWPAD & 42.0 & BWW02-04 & 24.2 \\
\hline 2 & BWWOO & 17.4 & UBWPAD & 16.24 & BWW17-18 & 23.4 & BWW11-13 & 21.1 & WOON & 27.7 & BWW00 & 14.4 \\
\hline 3 & BWW01-02 & 10.6 & BWW $20-21$ & 14.44 & WOON & 20.8 & $B W W 20-21$ & 12.2 & BWW17-18 & 7.72 & WOON & 11.3 \\
\hline 4 & BWW20-21 & 9.74 & BWW01-02 & 10.55 & BWW01-02 & 9.83 & BWW18-20 & 9.56 & BWW07-08 & 5.06 & BWW13-17 & 9.77 \\
\hline 5 & WOON & 8.42 & BWW13-17 & 8.73 & BWW06-07 & 2.96 & BWW04-06 & 7.29 & BWW06-07 & 4.52 & BWW08-11 & 7.68 \\
\hline 6 & BWW02-04 & 7.26 & BW $00-01$ & 4.68 & BWW02-04 & 2.89 & WOON & 6.27 & BWW02-04 & 2.57 & UBWPAD & 7.12 \\
\hline 7 & $B W W 13-17$ & 5.90 & BWW15+16 & 4.12 & BWW20-21 & 1.63 & BWW02-04 & 4.57 & BWW11-13 & 2.45 & BWW07-08 & 5.96 \\
\hline 8 & BWW17-18 & 4.06 & BWW02-04 & 3.73 & BWW04-06 & 1.61 & BWW08-11 & 3.00 & BWW01-02 & 1.55 & BWW01-02 & 5.30 \\
\hline 9 & WOOR CSO & 3.73 & BWW14 & 2.46 & BWW00 & 1.34 & BWW13-17 & 2.27 & BWW18-20 & 1.29 & BWW00-01 & 3.65 \\
\hline 10 & BWW07-08 & 2.73 & WOON & 1.05 & WOOR CSO & 1.25 & BWW00 & 1.63 & BWW13-17 & 1.23 & BWW18-20 & 3.61 \\
\hline 11 & BW00-01 & 1.96 & BWW06-07 & 0.82 & BWW07-08 & 1.12 & BWW07-08 & 1.31 & BWW00 & 1.09 & WOOR CSO & 1.45 \\
\hline 12 & BWW14 & 1.82 & BWW04-06 & 0.22 & BWW14 & 0.86 & BWW14 & 0.96 & BWW08-11 & 0.99 & BWW14 & 1.43 \\
\hline 13 & BWW09+10 & 0.91 & BWW08-11 & 0.18 & BWW15+16 & 0.41 & BWW17-18 & 0.90 & BWW20-21 & 0.63 & BWW17-18 & 1.43 \\
\hline 14 & BWW08-11 & 0.80 & BWW09+10 & 0.09 & BWW08-11 & 0.38 & BWW15+16 & 0.70 & BWW14 & 0.45 & BWW15+16 & 1.32 \\
\hline 15 & BWW15+16 & 0.69 & & & BWW05 & 0.09 & BWW00-01 & 0.58 & WOOR CSO & 0.35 & BWW06-08 & 1.21 \\
\hline 16 & & & & & BWW13-17 & 0.07 & BWW09+10 & 0.58 & BWW15+16 & 0.18 & BWW09+10 & 0.07 \\
\hline 17 & & & & & BWW09+10 & 0.07 & BWW01-02 & 0.41 & BWW09+10 & 0.14 & BWW05 & 0.07 \\
\hline 18 & & & & & BWW00-01 & 0.06 & BWW06-07 & 0.28 & BWW05 & 0.05 & & \\
\hline 19 & & & & & & & WOOR CSO & 0.08 & & & & \\
\hline 20 & & & & & & & BWW05 & 0.01 & & & & \\
\hline & & & & & & & & & & & & \\
\hline
\end{tabular}

WOON $=$ Woonsocket WWTF, WOOR CSO $=$ Worcester CSO 
Table 8.2 Average Blackstone River Wet Weather Rankings, Total Load

\begin{tabular}{|c|c|c|c|c|c|c|c|c|c|c|c|c|}
\hline & \multicolumn{2}{|c|}{$\overline{C d}$} & \multicolumn{2}{|l|}{$\mathrm{Cr}_{\mathrm{r}}$} & \multicolumn{2}{|c|}{$\mathrm{Cu}$} & \multicolumn{2}{|l|}{$\mathrm{Ni}$} & \multicolumn{2}{|l|}{$\mathrm{Pb}$} & \multicolumn{2}{|l|}{$\mathrm{Zn}$} \\
\hline Ranking & Source & \%Load & Source & \%Load & Source & $\%$ Load & Source & \%Load & Source & $\%$ Load & Source & \%Load \\
\hline & & & & & & & & & & & & \\
\hline 1 & BWW02-04 & 15.1 & BWW07-08 & 21.6 & BWW02-04 & 22.3 & UBWPAD & 32.7 & BWW00 & 38.9 & BWW00 & 17.4 \\
\hline 2 & UBWPAD & 14.5 & UBWPAD & 18.5 & UBWPAD & 17.8 & $B W W 02-04$ & 14.6 & BWW07-08 & 15.3 & BWW00-01 & 16.5 \\
\hline 3 & BWW07-08 & 14.0 & BWW00 & 18.3 & BWW00 & 17.1 & BWW00 & 11.0 & BWW01-02 & 11.1 & BWW07-08 & 10.0 \\
\hline 4 & BWW00 & 12.8 & BWW01-02 & 14.2 & BWW07-08 & 11.6 & BWW07-08 & 9.89 & BWW20-21 & 9.26 & UBWPAD & 9.64 \\
\hline 5 & BWW01-02 & 11.2 & BWW13-17 & 8.43 & BWW01-02 & 8.46 & BWW18-20 & 8.31 & BWW13-17 & 4.95 & BWW01-02 & 6.41 \\
\hline 6 & BWW11-13 & 8.14 & BWW02-04 & 6.85 & WOON & 4.31 & BWW06-07 & 5.36 & BWW02-04 & 3.66 & WOON & 6.18 \\
\hline 7 & BWW20-21 & 7.40 & BWW00-01 & 4.16 & BWW08-11 & 3.59 & BWW01-02 & 4.55 & BWW04-06 & 3.56 & BWW17-18 & 5.43 \\
\hline 8 & BWW18-20 & 5.20 & BWW20-21 & 2.30 & BWW06-07 & 3.55 & BWW13-17 & 4.26 & $B W W 18-20$ & 3.42 & BWW18-20 & 5.02 \\
\hline 9 & BWW13-17 & 3.34 & WOON & 1.92 & BWW17-18 & 3.18 & BWW00-01 & 2.79 & UBWPAD & 2.36 & BWW20-21 & 3.65 \\
\hline 10 & WOON & 3.28 & BWW14 & 1.46 & BWW18-20 & 2.33 & BWW02-04 & 1.65 & WOON & 1.96 & $\mathrm{BWW02-04}$ & 3.26 \\
\hline 11 & BWW02-04 & 1.69 & BWW09+10 & 0.90 & BWWO0-0I & 1.71 & BWW15+16 & 1.33 & BWW14 & 1.76 & BWW08-11 & 3.21 \\
\hline 12 & BWW08-11 & 0.99 & BWW18-20 & 0.63 & BWW20-21 & 1.34 & WOON & 1.13 & $B W W 15+16$ & 1.29 & BWW13-17 & 2.79 \\
\hline 13 & BWW14 & 0.73 & BWW15+16 & 0.42 & BWW14 & 1.11 & BWW11-13 & 1.07 & BWw09+10 & 1.27 & BWW04-06 & 2.39 \\
\hline 14 & BWW09+10 & 0.55 & BWW05 & 0.24 & BWW09+10 & 0.70 & BWWI4 & 0.61 & BWW08-11 & 0.85 & $B W W 06-07$ & 2.36 \\
\hline 15 & BWW00-01 & 0.48 & & & BWW15+16 & 0.46 & BWW09+10 & 0.33 & BWW05 & 0.32 & BWW14 & 2.29 \\
\hline 16 & BWW15+16 & 0.27 & & & BWW13-17 & 0.41 & BWW05 & 0.32 & & & BWW09+10 & 2.02 \\
\hline 17 & BWW05 & 0.24 & & & BWw05 & 0.07 & & & & & $B W W 15+16$ & 1.10 \\
\hline 18 & & & & & & & & & & & BWW05 & 0.33 \\
\hline & & & & & & & & & & & & \\
\hline
\end{tabular}

WOON $=$ Woonsocket WWTF, WOOR CSO $=$ Worcester CSO 
Table 8.2 Total Load (Continued)

\begin{tabular}{|c|c|c|c|c|c|c|c|c|c|c|c|c|}
\hline & \multicolumn{2}{|c|}{$\mathrm{BOD}$} & \multicolumn{2}{|c|}{ FC } & \multicolumn{2}{|c|}{ NH3 } & \multicolumn{2}{|c|}{ NO3 } & \multicolumn{2}{|c|}{$\mathrm{PO4}$} & \multicolumn{2}{|c|}{ TSS } \\
\hline Ranking & Source & \%Load & Source & \%Load & Source & \%Load & Source & \%Load & Source & $\%$ Load & Source & \%Load \\
\hline & & & & & & & & & & & & \\
\hline 1 & UBWPAD & 24.3 & BWWOO & 40.1 & UBWPAD & 31.2 & UBWPAD & 16.3 & UBWPAD & 35.3 & BWW02-04 & 28.3 \\
\hline 2 & BWWOO & 23.1 & UBWPAD & 21.6 & BWW17-18 & 22.4 & BWW11-13 & 11.1 & WOON & 22.8 & BWW00 & 25.3 \\
\hline 3 & WOON & 7.59 & BWW20-21 & 11.2 & WOON & 19.4 & BWW02-04 & 8.95 & BWW18-20 & 10.0 & WOON & 8.48 \\
\hline 4 & BWW01-02 & 7.12 & BWW13-17 & 7.55 & BWW01-02 & 12.8 & BWW18-20 & 8.45 & BWW17-18 & 6.09 & BWW00-01 & 6.64 \\
\hline 5 & BWW18-20 & 6.35 & BWW00-01 & 7.07 & BWW18-20 & 4.13 & BWW20-21 & 8.16 & BWW07-08 & 5.61 & BWW07-08 & 6.49 \\
\hline 6 & BWW00-01 & 5.64 & BWW15+16 & 4.77 & BWW00 & 2.96 & BWW11-13 & 7.69 & BWW02-04 & 5.36 & UBWPAD & 5.50 \\
\hline 7 & BWW02-04 & 4.10 & BWW14 & 2.09 & BWW06-07 & 2.51 & BWW13-17 & 7.64 & BWW06-07 & 3.31 & BWW01-02 & 5.09 \\
\hline 8 & BWW07-08 & 3.56 & BWW02-04 & 1.93 & BWW07-08 & 2.36 & BWW04-06 & 6.40 & BWWI4 & 2.45 & BWW 13-17 & 4.62 \\
\hline 9 & BWW13-17 & 3.42 & BWW02-04 & 1.28 & BWW14 & 0.89 & BWW06-07 & 5.25 & BWW01-02 & 2.32 & BWW14 & 2.09 \\
\hline 10 & BWW00-01 & 2.91 & WOON & 1.13 & BWW15+16 & 0.69 & BWW08-11 & 4.49 & BWW11-13 & 2.20 & BWW15+16 & 1.86 \\
\hline 11 & BWW14 & 2.78 & BWW17-18 & 1.08 & BWW00-01 & 0.40 & WOON & 3.64 & BWW13-17 & 2.19 & BWW $18-20$ & 1.64 \\
\hline 12 & BWW $20-21$ & 2.73 & BWW09+10 & 0.12 & BWW09+10 & 0.15 & BWW00 & 3.50 & BWW00 & 1.16 & BWW06-07 & 1.50 \\
\hline 13 & BWW04-06 & 1.42 & BWW06-07 & 0.07 & BWW13-17 & 0.04 & BWW18-20 & 2.47 & BWW9+10 & 0.90 & BWW +10 & 1.31 \\
\hline 14 & BWw09+10 & 1.42 & BWW07-08 & 0.03 & & & BWW14 & 1.94 & BWW15+16 & 0.22 & BWW17-18 & 1.04 \\
\hline 15 & BWW17-18 & 1.14 & BWW08-11 & 0.02 & & & $B W W 07-08$ & 1.50 & BWW05 & 0.05 & BWW05 & 0.12 \\
\hline 16 & BWW15+16 & 1.04 & & & & & $B W W 00-01$ & 1.07 & & & & \\
\hline 17 & BWW06-07 & 0.91 & & & & & $B W W 15+16$ & 1.07 & & & & \\
\hline 18 & BWW08-11 & 0.44 & & & & & $B W W 09+10$ & 0.31 & & & & \\
\hline 19 & & & & & & & BWW05 & 0.05 & & & & \\
\hline & & & & & & & & & & & & \\
\hline
\end{tabular}

WOON $=$ Woonsocket WWTF, WOOR CSO $=$ Worcester CSO 
Table 8.3 Average Blackstone River Wet Weather Rankings, Wet Load, without Point Sources

\begin{tabular}{|c|c|c|c|c|c|c|c|c|c|c|c|c|}
\hline & \multicolumn{2}{|c|}{$\mathrm{Cd}$} & \multicolumn{2}{|l|}{$\mathrm{Cr}$} & \multicolumn{2}{|l|}{$\mathrm{Cu}$} & \multicolumn{2}{|l|}{$\mathrm{Ni}$} & \multicolumn{2}{|l|}{$\mathrm{Pb}$} & \multicolumn{2}{|l|}{$\mathrm{Zn}$} \\
\hline Ranking & Source & \%Load & Source & \%Load & Source & \%Lasd & Source & \%Load & Source & \%Load & Source & \%Load \\
\hline & & & & & & & & & & & & \\
\hline 1 & BWW02-04 & 21.6 & BWW01-02 & 22.7 & $\mathrm{BWW02-04}$ & 21.8 & BWW18-20 & 25.3 & BWW00 & 32.9 & BWW00 & 18.9 \\
\hline 2 & BWW01-02 & 17.4 & BWW00 & 17.4 & BWW07-08 & 16.2 & BWW07-08 & 17.6 & BWW20-21 & 15.3 & BWW00-01 & 16.6 \\
\hline 3 & BWW07-08 & 15.5 & BWW07-08 & 15.6 & BWW00 & 15.0 & BWW01-02 & 12.0 & BWW07-08 & 15.0 & BWW01-02 & 12.4 \\
\hline 4 & BWW11-13 & 10.4 & BWW08-11 & 10.3 & BWW13-17 & 9.26 & BWW00 & 10.9 & BWW01-02 & 14.2 & BWW18-20 & 9.27 \\
\hline 5 & BWW20-21 & 9.33 & BWW13-17 & 9.86 & BWW01-02 & 7.47 & BWW13-17 & 10.6 & BWW13-17 & 5.05 & BWW07-08 & 8.66 \\
\hline 6 & BWW00 & 8.70 & BWW02-04 & 7.85 & BWW18-20 & 6.72 & BWW02-04 & 10.5 & BWWI8-20 & 4.43 & BWW20-21 & 6.53 \\
\hline 7 & BWw08-11 & 5.84 & BWW18-20 & 4.59 & BWW08-11 & 6.43 & BWW00-01 & 2.61 & BWW02-04 & 4.23 & BWW08-11 & 6.32 \\
\hline 8 & BWW13-17 & 3.89 & BWW00-01 & 2.72 & BWW17-18 & 5.39 & BWW04-06 & 2.12 & BWW08-11 & 4.17 & BWW13-17 & 5.78 \\
\hline 9 & BWW18-20 & 2.83 & BWW06-07 & 2.24 & BWW20-21 & 4.93 & BWW08-11 & 2.01 & BWW15+16 & 1.17 & BWW02-04 & 3.96 \\
\hline 10 & BWW00-01 & 2.61 & BWW20-21 & 2.22 & BWW06-07 & 1.88 & BWW06-07 & 1.73 & BWW14 & 1.14 & BWW17-18 & 2.95 \\
\hline 11 & WOOW CSO & 0.61 & BWW14 & 1.52 & BWW00-01 & 1.58 & $B W W 15+16$ & 1.38 & BWW09+10 & 1.06 & BWW04-06 & 2.28 \\
\hline 12 & BWW9+10 & 0.49 & $B W W 9+10$ & 0.98 & BWW09+10 & 1.10 & BWw05 & 1.28 & BWW17-18 & 0.44 & BWW09+10 & 1.72 \\
\hline 13 & BWW15+16 & 0.29 & BWW17-18 & 0.78 & WOOR CSO & 0.95 & BWW14 & 0.98 & [WOOR CSO & 0.36 & BWW14 & 1.56 \\
\hline 14 & BWW14 & 0.27 & BWW15+16 & 0.55 & BWW14 & 0.60 & WOOR CSO & 0.62 & BWW05 & 0.36 & WOOR CSO & 1.45 \\
\hline 15 & BWW05 & 0.26 & BWW05 & 0.40 & BWW15+16 & 0.56 & BWW09+10 & 0.31 & $B W W 00-01$ & 0.06 & $B W W 15+16$ & 1.16 \\
\hline 16 & & & WOOR CSO & 0.22 & BWW05 & 0.13 & & & BWW04-06 & 0.03 & BWW06-07 & 0.29 \\
\hline & & & & & & & & & & & & \\
\hline
\end{tabular}

WOON $=$ Woonsocket WWTF, WOOR CSO $=$ Worcester CSO 
Table 8.3 Without Point Sources (Continued)

\begin{tabular}{|c|c|c|c|c|c|c|c|c|c|c|c|c|}
\hline & \multicolumn{2}{|c|}{$\mathrm{BOD}$} & \multicolumn{2}{|l|}{$\mathrm{FC}$} & \multicolumn{2}{|c|}{$\mathrm{NH3}$} & \multicolumn{2}{|l|}{$\mathrm{NO}_{3}$} & \multicolumn{2}{|l|}{$\mathrm{PO} 4$} & \multicolumn{2}{|l|}{ TSS } \\
\hline Ranking & Source & \%Load & Source & \%Load & Source & \%Load & Source & \%Load & Source & \%Load & Source & $\%$ Load \\
\hline & & & & & & & & & & & & \\
\hline 1 & BWW00 & 25.5 & BWW00 & 33.7 & BWW17-18 & 44.1 & BWWI1-13 & 33.4 & BWW18-20 & 20.7 & BWW02-04 & 28.0 \\
\hline 2 & BWW01-02 & 15.5 & BWW01-02 & 20.0 & BWW01-02 & 19.2 & BWW18-20 & 15.7 & BWW17-18 & 19.1 & BWW00 & 16.0 \\
\hline 3 & BWW20-21 & 14.6 & BWW20-21 & 17.1 & BWW02-04 & 9.32 & BWW20-21 & 12.9 & BWW07-08 & 18.2 & BWW13-17 & 12.9 \\
\hline 4 & BWW02-04 & 10.6 & BWW13-17 & 8.92 & BWW06-07 & 6.01 & BWW04-06 & 8.33 & BWW02-04 & 9.06 & BWW08-11 & 10.8 \\
\hline 5 & BWW13-17 & 9.47 & BWW02-04 & 5.75 & BWW20-21 & 5.26 & BWW02-04 & 8.32 & BWW06-07 & 6.60 & BWW01-02 & 7.09 \\
\hline 6 & BWW17-18 & 5.73 & BWW15+16 & 5.61 & BWW04-06 & 5.20 & BWW13-17 & 5.15 & BWW01-02 & 5.03 & BWW07-08 & 7.02 \\
\hline 7 & WOOR CSO & 5.39 & BW00-01 & 5.03 & BWW07-08 & 2.78 & BWW08-11 & 3.16 & BWW13-17 & 4.57 & BWW00-01 & 4.88 \\
\hline 8 & BWW07-08 & 3.99 & BWW14 & 2.55 & BWW00 & 2.33 & BWWOO & 3.14 & BWWOO & 3.93 & BWW $18-20$ & 3.74 \\
\hline 9 & BW00-01 & 3.12 & BWW06-07 & 0.83 & WOOR CSO & 1.76 & BWW07-08 & 2.30 & BWW08-11 & 3.91 & BWWI7-18 & 2.01 \\
\hline 10 & BWW14 & 2.66 & BWW04-06 & 0.23 & BWW14 & 1.74 & BWW14 & 1.66 & BWW11-13 & 3.58 & BWWI4 & 1.86 \\
\hline 11 & BWW09+10 & 1.30 & BWW08-11 & 0.18 & BWW08-11 & 1.01 & $B W W 17-18$ & 1.59 & BWW20-21 & 2.48 & BWW15+16 & 1.70 \\
\hline 12 & BWW08-11 & 1.10 & $B W W 09+10$ & 0.12 & BWW15+16 & 0.63 & BWW00-01 & 1.19 & BWW09+10 & 0.99 & BWW06-08 & 1.58 \\
\hline 13 & BWW15+16 & 1.00 & & & $B W W 00-01$ & 0.20 & BWw15+16 & 1.11 & $B W W 15+16$ & 0.68 & WOOR CSO & 1.50 \\
\hline 14 & & & & & BWW13-17 & 0.15 & BWw09+10 & 0.78 & BWW14 & 0.54 & BWW09+10 & 0.82 \\
\hline 15 & & & & & BWW05 & 0.13 & WOOR CSO & 0.52 & WOOR CSO & 0.50 & BWW05 & 0.11 \\
\hline 16 & & & & & BWW09+10 & 0.11 & BWW01-02 & 0.42 & BWW05 & 0.15 & & \\
\hline & & & & & & & & & & & & \\
\hline
\end{tabular}

WOON $=$ Woonsocket WWTF, WOOR CSO $=$ Worcester CSO 
Other important sources are reach between BWW17-18 and BWW01-02. There might be some nonpoint sources in those reaches, which are triggered by the high wet weather flows.

UBWPAD is again ranked first for nitrate loadings. Woonsocket does not appear within first 10 rankings for nitrate total load and appears in 6 th position for nitrate wet load. The second important source for nitrate is reach between BWW11-13. EMC profiles also shows increase in nitrate concentrations and decrease in ammonia concentrations in that reach (Figure 5.10). So, there might be instream nitrification occurring in that reach and some other nonpoint source may be present also. Other important sources of nitrate are reach between BWW20-21, BWW18-20 and BWW04-06 (Fisherville Pond).

UBWPAD and Woonsocket are the most important sources and together delivers about $60 \%$ of the loadings for phosphate. BWW17-18, Rice City Pond (BWW07-08) and BWW18-20 are important for phosphate. Resuspension (specially in the Rice City Pond) and other non point sources are responsible for high phosphate loadings in those reaches. The headwaters are not important for nutrient loadings.

Wet Load Without Point Sources - If we delete the point sources from the system then the reach between BWW17-18 alone delivers $44 \%$ of the ammonia loadings and BWW01-02 delivers about 20\%. Other important sources are BWW02-04, BWW06-07 and BWW20-21. These loadings are due to runoff and resuspension related.

BWW11-13, BWW18-20 and BWW20-21 have the major reach gains of nitrate with $62 \%$ of the total loadings together. Other important sources are BWW04-06, 
BWW02-04 and BWW13-17. Instream nitrification and other nonpoint sources may be the cause for these increase.

BWW18-20, BWW17-18 and Rice City Pond (BWW07-08) are the major sources for phosphate without point sources and together delivers about $60 \%$ of the loadings. Other important sources are BWW02-04, BWW06-07 and BWW01-02. Resuspension and other nonpoint sources are responsible here.

8.2 Conventional (TSS, BOD, FC)

Wet and Total Load - BWW02-04, the headwaters (BWW00) and Woonsocket are the major sources for TSS delivering greater than $50 \%$ of the loadings together. Other

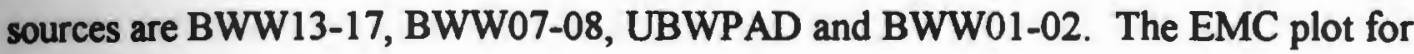
TSS (Figure 5.12) shows high concentration in the headwaters and couple of reaches downstream. That high concentration, resuspension and other nonpoint and point sources are the cause of high TSS loadings in these reaches.

UBWPAD, BWW00 and BWW01-02 are the most important sources of BOD delivering more than $50 \%$ of the loadings together. Other important sources are Woonsocket, BWW18-20 and BWW13-17. The EMC plot for BOD (Figure 5.14) shows high concentration from the headwaters up to BWW04. This high concentration in headwaters and other nonpoint and point sources are responsible for high BOD loadings in those reaches.

The headwaters are the major source for FC delivering about $1 / 3$ of the loadings. UBWPAD and BWW20-21 together delivers more than $30 \%$ of the FC loadings. EMC 
plot for FC (Figure 5.11) shows highest FC concentrations at the headwaters and then sharp decrease downstream. As discussed in Section 6.1, the residual chlorine from UBWPAD was not effective to bring down the concentrations downstream due to poor performance and high flows during Storm 2, which is responsible for UBWPAD being the second highest contributor for FC loadings. Nonpoint sources mostly controls the FC loadings.

Wet Load Without Point Sources - The headwaters are the most important source for FC, BOD and second important for TSS when the point sources are not considered.

Other important sources for TSS are BWW02-04, BWW13-17, BWW08-11, BWW01-02 and Rice City Pond (BWW07-08). Reaches between headwaters to BWW04 together delivers about $60 \%$ of the total TSS loadings without point sources.

Other important sources for BOD are BWW01-02, BWW20-21, BWW02-04 and BWW13-17. Reaches between headwaters to BWW04 together delivers more than $50 \%$ of the total BOD loadings without point sources.

BWW01-02, BWW20-21, BWW13-17 and BWW02-04 are other important sources for FC. Reaches between headwaters to BWW04 together delivers more than $60 \%$ of the total FC loadings without point sources.

\subsection{Metals $(\mathrm{Pb}, \mathrm{Cu}, \mathrm{Ni}, \mathrm{Cd}, \mathrm{Cr}, \mathrm{Zn})$}

Wet and Total Load - The headwaters and resuspension in the Rice City Pond are the most important sources of $\mathrm{Pb}$ and together responsible for about $50 \%$ of the loadings. UBWPAD and Woonsocket are not important for Pb. BWW01-02, BWW20-21 and 
BWW13-17 are within first five position and together delivers about $30 \%$ of the loadings.

EMC plots for $\mathrm{Pb}$ (Figure 5.12) also shows high concentration of $\mathrm{Pb}$ in those areas.

Resuspension and other nonpoint sources are the cause of high $\mathrm{Pb}$ loadings. Table 7.5 also supports that $\mathrm{Pb}$ is nonpoint source governed.

UBWPAD is the major source for all trace metals except $\mathrm{Pb}$ for both wet and total loadings. Woonsocket is not important for $\mathrm{Ni}, \mathrm{Cd}$, and $\mathrm{Cr}$ and delivers less than $2 \%$ loadings, but is important for $\mathrm{Cu}$ and $\mathrm{Zn}$. Rice City Pond and headwaters are important for all trace metals and appears within first five position. Resuspension is the cause of metal loadings at Rice City Pond.

BWW02-04 appears in first and second position for $\mathrm{Cu}$ and $\mathrm{Cd}$ and in 7th position for Ni. Patriot Metals is located in that reach of BWW02-04 which may be responsible for high $\mathrm{Cu}, \mathrm{Cd}$, and $\mathrm{Ni}$ loadings in this reach. BWW01-02 is important for $\mathrm{Cd}$ and $\mathrm{Cr}$.

In general, point and nonpoint sources including resuspension in the Rice City Pond are the cause of high metal loadings.

Wet Load Without Point Sources - The headwaters are the major source of $\mathrm{Pb}$ for wet load without point sources. Other important sources are BWW20-21, Rice City Pond, BWW01-02, and BWW13-17.

Headwaters and resuspension in the Rice City Pond are the most important sources for all trace metals when point sources are not considered. BWW01-02 is important for all trace metals and appears within first five rankings for Loadings without point sources. BWW02-04 is important for $\mathrm{Cu}, \mathrm{Cd}, \mathrm{Cr}$ and $\mathrm{Ni}$. 
8.4. Comparison Between Wet and Dry Weather Rankings

The comparison between dry weather and wet weather rankings for trace metals, TSS, and nutrients for the top five position are provided in Table 8.4.

UBWPAD is responsible for $49 \%$ of the load for nitrate, $62 \%$ for phosphate and $5 \%$ for ammonia under dry weather and $16 \%, 35 \%$, and $31 \%$ under wet weather, respectively. UBWPAD is in the first position for nitrate and phosphate under both dry and wet weather condition. For ammonia under dry weather, Woonsocket is in the first position with $68 \%$ and UBWPAD is not so important. Under dry weather, UBWPAD has high nitrate and low ammonia which supports that nitrification is on and the facility is performing well. Under wet weather, two out of three survey had nitrification on in the facility, but UBWPAD has low nitrate and high ammonia supporting poor performance of the facility under higher flows during the storms.

Headwater and Rice City Pond are not important sources of nutrients under either dry or wet weather. Nutrients are mostly controlled by point sources under dry weather and by point and non point sources under wet weather conditions.

UBWPAD is ranked for TSS under dry weather and Woonsocket is not. For wet weather the reverse is true. The headwaters is an important source for wet weather but not for dry weather and Rice City Pond ranked for both wet and dry weather.

Head water and resuspension in the Rice City Pond are the most important sources for $\mathrm{Pb}$ under wet weather. Resuspension in the section of river starting below Fisherville Pond (BWW07) and ending below Rice City Pond (BWW08) is the major source of Pb under dry weather. Mouth of the river (BWW20-21) is important for wet weather but not 


\section{Table 8.4 Average Blackstone River Wet and Dry Weather Rankings (Total Load)}

\begin{tabular}{|c|c|c|c|c|c|c|c|c|c|c|c|c|c|c|c|c|c|c|}
\hline \multirow[b]{2}{*}{ Renking } & \multicolumn{2}{|c|}{ Cd } & \multicolumn{2}{|c|}{$\bar{c}$} & \multicolumn{2}{|c|}{$\mathrm{Cu}$} & \multicolumn{2}{|l|}{$\overline{\mathrm{Ni}}$} & \multicolumn{2}{|l|}{$\overline{P b}$} & \multicolumn{2}{|c|}{ NH4 } & \multicolumn{2}{|l|}{$\overline{\mathrm{NO} 3}$} & \multicolumn{2}{|c|}{$\overline{P O A}$} & \multicolumn{2}{|l|}{ TSS } \\
\hline & Source & \%Lood & Sourice & Grooed & Source & \%Lloed & Sourroo & GoLoed & Source & \%Lond & Source & \%Lond & Source & \%loed & Source & \%lood & Source & \%loed \\
\hline 1 & 18 & 151 & คफल & 216 & R.YW00 & 223 & UAWPAD & 327 & RWumen & 389 & UBWPAD & 312 & UAYPAD & 163 & IRWPAD & 353 & RWw02-04 & 7 \\
\hline 2 & UBWPAD & 14.5 & UBWPAD & 18.5 & UBWPAD & 17.8 & BWW02-04 & 14.6 & BWw07-08 & 15.3 & BWW17-18 & 22.4 & $B W W 11-13$ & 11.1 & WOON & 22.8 & BWw00 & $\frac{25.3}{25.3}$ \\
\hline 3 & BWW07-08 & 140 & BWWOO & 18.3 & BWWOO & 17.1 & BWWOO & 11.0 & BWW01-02 & 11.1 & WOON & 19.4 & BWW02-04 & 8.95 & BWW18-20 & 10.0 & WOON & 8.48 \\
\hline 4 & BWWOO & 12.8 & BWW01-02 & 14.2 & BWW07-08 & 11.6 & BWW07-08 & 9.89 & BWw20-21 & 9.26 & BWW01-02 & 12.8 & BWW18-20 & 8.45 & BWW17-18 & 6.09 & BWW00-01 & 6.64 \\
\hline 5 & BWW01-02 & 11.2 & BWW13-17 & 8.43 & BWW01-02 & 8.46 & BWW18-20 & 8.31 & BWW13-17 & 4.95 & BWWI8-20 & 4.13 & BWW20-21 & 8.16 & BWW07-08 & 5.61 & BWW07.08 & 6.49 \\
\hline & & & & & & & & & & & & & & & & & & \\
\hline
\end{tabular}

\begin{tabular}{|c|c|c|c|c|c|c|c|c|c|c|c|c|c|c|c|c|c|c|}
\hline & $\bar{c}$ & & $\bar{c}$ & & $\overline{\mathbf{c}}$ & & 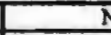 & & F & & $\overline{\mathrm{M}}$ & & $\overline{\mathrm{NC}}$ & & $\overrightarrow{\mathrm{PC}}$ & & $T S$ & \\
\hline Ranking & Source & \%lood & Soluroe & \%lood & Source & \%lood & Source & Folood & Solmoe & Yoloed & Source & \%load & Source & \%lood & Source & \%lood & Source & \%lood \\
\hline 1 & UBWPAD & 39.6 & BLKX7-08 & 37.1 & UBWPAD & 34.5 & UQBWPAD & 47.0 & BLK0406 & 22.2 & WOON & 67.9 & UBWWPAD & 48.7 & UBWPAD & 62.2 & BLK07-08 & 136 \\
\hline 2 & BLKK07-08 & 10.5 & $\operatorname{BLK} 12-13$ & 16.4 & BLLK07-08 & 17.3 & BLKK20-21 & 9.43 & BL, K06-07 & \begin{tabular}{|l|l|}
16.4 \\
\end{tabular} & BLLKa1-02 & 7.80 & BLK20-21 & 8.64 & WOON & 19.9 & BLK $20-21$ & 10.5 \\
\hline 3 & BLLKO1-02 & 8.18 & UBWPAD & 11.7 & WOON & 7.28 & BLLK01-02 & 8.49 & BLK07-08 & 12.8 & UBWPAD & 4.93 & WOON & 7.20 & BLKI2-13 & 3.06 & BLKO6 07 & 10.2 \\
\hline 4 & BLK12-13 & 7.81 & BLLKOI & 8.02 & BLLKOS-11 & 7.01 & BLKK12-13 & 6.50 & BLK12-13 & 111.7 & BLK $03-04$ & 4.33 & BLR02-03 & 5.70 & BLLK02-03 & 2.69 & UBWPAD & 8.57 \\
\hline 5 & WOON & 1.24 & BLRos-11 & 7.25 & BLLKOA-106 & 5.68 & fwo & 4.56 & BLKOE-11 & \begin{tabular}{|l|l}
7.91 \\
\end{tabular} & BLLC20-21 & 3.80 & BLK06-07 & 4.00 & BLKII-12 & 2.36 & BLKK12-13 & 8.17 \\
\hline
\end{tabular}


under dry weather for $\mathrm{Pb}$. UBWPAD and Woonsocket are not important for $\mathrm{Pb}$ and does not appear within first five rank under both wet and dry weather.

UBWPAD is a major source for $\mathrm{Cu}, \mathrm{Ni}, \mathrm{Cd}$, and $\mathrm{Cr}$ under both wet and dry weather. Woonsocket is a major source for $\mathrm{Cu}, \mathrm{Ni}$, and $\mathrm{Cd}$ under dry weather only and does not appear within first five position under wet weather. For $\mathrm{Cr}$ Woonsocket does not appear within first five rank under both dry and wet weather.

Resuspension in the Rice City Pond is an important source of all trace metals under both wet and dry weather and it is more important during wet weather, since volume and velocity of water is high and more resuspension occurs under wet weather condition.

Headwater is an important source for all trace metals under wet weather but does not appear within first five rankings under dry weather. BWW02-04 is a major source of $\mathrm{Cu}, \mathrm{Cd}$, and $\mathrm{Ni}$ under wet weather and does not appear within first five rankings under dry weather. Patriot Metals is located within the reach BWW02-04 and that may be the source for $\mathrm{Cu}, \mathrm{Cd}$, and $\mathrm{Ni}$ under wet weather. BWW01-02 is important for $\mathrm{Pb}, \mathrm{Cu}, \mathrm{Ni}$, $\mathrm{Cd}$, and $\mathrm{Cr}$ under wet weather but is only important for $\mathrm{Ni}$, and $\mathrm{Cd}$ under dry weather. BWW08-11 appears 3 time out of five trace metals in the first five rankings under dry weather but does not appear at all in the first five rankings under wet weather.

\subsection{Comparison of Load for Different River Systems}

Five major rivers contribute flows and pollutant loadings to the Providence River and Upper Narragansett Bay. The first wet weather study conducted in 1988-89 for NBP provided a ranking for these rivers for several pollutants (Wright et al. 1991). A similar 
ranking table is reproduced here (Table 8.5 ) using only the tributaries loadings.

Blackstone River ranked first for all the constituents except $\mathrm{NH}_{4}$, where it was second. In general, the rankings for the other rivers in descending order were: Pawtuxet, Woonasquatucket, Ten Mile, and Moshassuck. Blackstone River alone was contributing $41 \%-67 \%$ of the wet load delivered by the five tributaries.

Total rainfall for NBP studies for the three storms observed were in October 1988 $-0.90^{\prime \prime}$, May $1989-1.94 "$ and June $1989-0.37 "$ as compared to this study for September $1992-0.558 "$ " November $1992-0.881^{\prime \prime}$ and October $1993-0.809 "$. The data from this study have also been summarized in Table 8.6. The wet load (lbs) were calculated using the EMC values from Table 5.5 and the corresponding flows for those rivers. The wet loads were divided by the effective runoff for each storm to obtain the lbs/million cu. $\mathrm{ft}$ $\left(\mathrm{lbs} / \mathrm{M}-\mathrm{f}^{3}\right)$ values for each storm. The values were averaged for the three storms in each survey. The same flow ratios for the NBP study (BRSM : MOSH : PAWT : TENM : WOON $=1.0: 0.0776: 0.4091: 0.15527: 0.1024)$ were used to determine an estimate of effective runoff for the tributaries for the storms of this study. The wet loadings were then calculated using these runoff values (Table 8.7).

A ranking table, similar to the NBP study has been prepared and presented in Table 8.7. The 1992-93 data supports the earlier observation that the Blackstone River is the major contributor of trace metals, nitrate and orthophosphate. In general, the rankings for the other rivers in descending order are: Pawtuxet, Woonasquatucket, Ten Mile, and Moshassuck. Blackstone River alone is contributing $28 \%-64 \%$ of the wet load delivered by the five tributaries. 
Table 8.5 1988-89 NBP Tributary Wet Loads and Rankings

NBP Wet loads, Total of Three Storms

\begin{tabular}{|c|c|c|c|c|c|c|c|c|c|}
\hline Station & $\mathrm{Cd}$ & $\mathrm{Cr}$ & $\mathrm{Cu}$ & $\mathrm{Ni}$ & $\mathrm{Pb}$ & NH4 & NO3 & PO4 & TSS \\
\hline & Ibs & Ibs & Ibs & Ibs & Ibs & Ibs & lbs & Ibs & Ibs \\
\hline & & & & & & & & & \\
\hline BRSM & 36.4 & 331 & 468 & 315 & 433 & 7160 & 127000 & 13700 & 684000 \\
\hline MOSH & 0.84 & 29.5 & 45.7 & 30.7 & 46.2 & 419 & 5980 & 241 & 68900 \\
\hline PAWT & 9.52 & 87.1 & 148 & 143 & 127 & 12100 & 32900 & 5070 & 643000 \\
\hline TENM & 5.79 & 92.2 & 92.8 & 217 & 28.5 & 856 & 20200 & 1260 & 28800 \\
\hline WOON & 1.72 & 18.6 & 51.0 & 47.0 & 67.7 & 650 & 6780 & 691 & 115000 \\
\hline & & & & & & & & & \\
\hline
\end{tabular}

NBP Rankings, Wet loads

\begin{tabular}{|l|c|c|c|c|c|c|c|c|c|}
\hline Station & $\mathrm{Cd}$ & $\mathrm{Cr}$ & $\mathrm{Cu}$ & $\mathrm{Ni}$ & $\mathrm{Pb}$ & $\mathrm{NH4}$ & $\mathrm{NO}$ & PO4 & TSS \\
\hline & Rankings & Rankings & Rankings & Rankings & Rankings & Rankings & Rankings & Rankings & Rankings \\
\hline & & & & & & & & & \\
\hline BRSM & 1 & 1 & 1 & 1 & 1 & 2 & 1 & 1 & 1 \\
\hline MOSH & 5 & 4 & 5 & 5 & 4 & 5 & 5 & 5 & 4 \\
\hline PAWT & 2 & 3 & 2 & 3 & 2 & 1 & 2 & 2 & 2 \\
\hline TENM & 3 & 2 & 3 & 2 & 5 & 3 & 3 & 3 & 5 \\
\hline WOON & 4 & 5 & 4 & 4 & 3 & 4 & 4 & 4 & 3 \\
\hline & & & & & & & & & \\
\hline
\end{tabular}

NBP, Wet loads Percent

\begin{tabular}{|l|c|c|c|c|c|c|c|c|c|}
\hline Station & $\mathrm{Cd}$ & $\mathrm{Cl}$ & $\mathrm{Cu}$ & $\mathrm{Ni}$ & $\mathrm{Pb}$ & $\mathrm{NH4}$ & $\mathrm{NO3}$ & PO4 & TSS \\
\hline & $\%$ & $\%$ & $\%$ & $\%$ & $\%$ & $\%$ & $\%$ & $\%$ & $\%$ \\
\hline & & & & & & & & & \\
\hline BRSM & 67.1 & 59.3 & 58.1 & 41.8 & 61.6 & 33.7 & 65.9 & 65.3 & 44.4 \\
\hline MOSH & 1.55 & 5.28 & 5.67 & 4.08 & 6.58 & 1.97 & 3.09 & 1.15 & 4.48 \\
\hline PAWT & 17.5 & 15.6 & 18.3 & 19.0 & 18.1 & 57.2 & 17.0 & 24.2 & 41.8 \\
\hline TENM & 10.7 & 16.5 & 11.5 & 28.8 & 4.06 & 4.03 & 10.5 & 6.01 & 1.87 \\
\hline WOON & 3.17 & 3.33 & 6.33 & 6.24 & 9.64 & 3.06 & 3.51 & 3.30 & 7.49 \\
\hline
\end{tabular}

BRSM = Blackstone River, MOSH = Moshassuck River, PAWT = Pawtuxet River, $T E N M=$ Ten Mile River, WOON = Woonasquatucket River [NBP study Wright et. al. (1988)];

Total rainfall for NBP studies for three storms observed were 3.21" (October $1988-0.90^{\prime \prime}$;

May $1989-1.94^{\prime \prime}$; June $1989-0.37^{\prime \prime}$ ) 
Table 8.6 1988-89 NBP Wet Loads for Blackstone, Moshassuck, Woonasquatucket, Pawtuxet and Ten Mile Rivers

Storm Average

\begin{tabular}{|c|c|c|c|c|c|c|c|c|c|c|}
\hline Station & Flow & $\mathrm{Cd}$ & $\mathrm{Cr}$ & $\mathrm{Cu}$ & $\mathrm{Ni}$ & $\mathrm{Pb}$ & $\mathrm{NH}_{4}$ & $\mathrm{NO} 3$ & $\mathrm{PO4}$ & TSS \\
\hline & $\mathrm{M}-\mathrm{ft}^{\wedge} 3$ & Ibs/M-ft³ & Ibs/M-ft³ & Ibs/M-fit 3 & $\mathrm{Ibs} / \mathrm{M}-\mathrm{ft}^{\wedge} 3$ & Ibs/M- $\mathrm{ft}^{\wedge} 3$ & $\mathrm{Ibs} / \mathrm{M}-\mathrm{ft}^{\wedge} 3$ & $\mathrm{lbs} / \mathrm{M}-\mathrm{ft}^{\wedge} 3$ & Ibs/M-ft³ & $\mathrm{Ibs} / \mathrm{M}-\mathrm{ft}^{\wedge} 3$ \\
\hline BRSM & 306 & 00 & 071 & & 000 & 001 & 109 & 356 & 121 & 904 \\
\hline MOSH & 237 & 0.03 & 102 & 189 & 0.64 & 163 & 120 & 119 & 9.67 & 2319 \\
\hline PAWT & 125 & 0.08 & 0.31 & 1.05 & 1.36 & 0.54 & 105 & 226 & 47.9 & 2342 \\
\hline TENM & 47.5 & 0.06 & 0.55 & 0.91 & 2.94 & 0.20 & 5.24 & 234 & 8.47 & 354 \\
\hline WOON & 31.3 & 0.01 & 0.23 & 0.57 & 0.52 & 0.74 & 10.8 & 188 & 18.2 & 1414 \\
\hline & & & & & & & & & & \\
\hline
\end{tabular}

BRSM = Blackstone River; MOSH = Moshassuck River; PAWT = Pawtuxet River; TENM = Ten Mile River; WOON = Woonasquatucket River [NBP study Wright et. al. (1988)]; Ibs/M- $\mathrm{ft}^{\wedge} 3=\mathrm{lbs} / \mathrm{million} \mathrm{cu}$. $\mathrm{ft}$. 
Table 8.7 1992-93 Tributary Wet Loads Estimates and Rankings

\begin{tabular}{|c|c|c|c|c|c|c|c|c|c|c|c|}
\hline Station & Code & Flow & $\mathrm{Cd}$ & $\mathrm{Cr}$ & $\mathrm{Cu}$ & $\mathrm{Ni}$ & $\mathrm{Pb}$ & NH4 & $\mathrm{NO3}$ & $\mathrm{PO4}$ & TSS \\
\hline & & $M-t^{\wedge} 3$ & Ibs & Ibs & Ibs & Ibs & fbs & Ibs & Ibs & Ibs & Ibs \\
\hline & & & & & & & & & & & \\
\hline BWW21 & $a$ & 42.0 & 1.80 & 7.85 & 37.4 & 20.8 & 34.8 & 2600 & 6080 & 1050 & 21970 \\
\hline MOSH & $b$ & 3.26 & 0.10 & 3.33 & 5.94 & 2.10 & 5.29 & 38.9 & 388 & 31.5 & 7550 \\
\hline PAWT & 6 & 17.2 & 1.45 & 5.29 & 18.1 & 23.3 & 9.26 & 1800 & 3880 & 823 & 40200 \\
\hline TENM & b & 6.52 & 0.42 & 3.56 & 5.94 & 19.1 & 1.32 & 34.2 & 1530 & 55.2 & 2310 \\
\hline WOON & b & 4.30 & 0.06 & 0.99 & 2.47 & 2.25 & 3.18 & 46.5 & 806 & 78.2 & 6080 \\
\hline & & & & & & & & & & & \\
\hline
\end{tabular}

\begin{tabular}{|c|c|c|c|c|c|c|c|c|c|c|c|}
\hline Station & Code & Flow & Cd & $\mathrm{Cr}$ & $\mathrm{Cu}$ & $\mathrm{Ni}$ & $\mathrm{Pb}$ & NH4 & $\mathrm{NO} 3$ & PO4 & TSS \\
\hline & & $M-\pi^{\wedge} 3$ & Rankings & Rankings & Rankings & Rankings & Rankings & Rankings & Rankings & Rankings & Rankings \\
\hline & & & & & & & & & & & \\
\hline BwW21 & 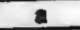 & 42.0 & 1 & 1 & 1 & 2 & 1 & 1 & 1 & 1 & 2 \\
\hline MOSH & $b$ & 3.26 & 4 & 4 & 4 & 5 & 3 & 4 & 5 & 5 & 3 \\
\hline PAWT & b & 17.2 & 2 & 2 & 2 & 1 & 2 & 2 & 2 & 2 & 1 \\
\hline TENM & b & 6.52 & 3 & 3 & 3 & 3 & 5 & 5 & 3 & 4 & 5 \\
\hline WOON & 느 & 4.30 & 5 & 5 & 5 & 4 & 4 & 3 & 4 & 3 & 4 \\
\hline & & & & & & & & & & & \\
\hline
\end{tabular}

\begin{tabular}{|c|c|c|c|c|c|c|c|c|c|c|c|}
\hline Station & Codo & Flow & $\mathrm{Cd}$ & $\mathrm{Cr}_{\mathrm{r}}$ & $\mathrm{Cu}$ & $\mathrm{Ni}$ & $\overline{P b}$ & $\overline{N H 4}$ & $\mathrm{NO3}$ & $P 04$ & TSS \\
\hline & & $\%$ & $\%$ & $\%$ & $\%$ & $\%$ & $\%$ & $\%$ & $\%$ & $\%$ & $\%$ \\
\hline BMW21 & 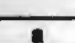 & 57.3 & 47.0 & 37.3 & 53.6 & 30.7 & 64.6 & 57.6 & 47.9 & 54.4 & 28.1 \\
\hline MOSH & $b$ & 4.45 & 2.64 & 15.9 & 8.50 & 3.10 & 9.82 & 0.86 & 3.07 & 1.55 & 9.66 \\
\hline PAWT & $b$ & 23.5 & 37.8 & 25.2 & 25.9 & 34.5 & 17.2 & 39.8 & 30.6 & 40.5 & 51.5 \\
\hline TENM & $b$ & 8.90 & 10.9 & 16.9 & 8.51 & 28.3 & 2.46 & 0.76 & 12.0 & 2.72 & 2.95 \\
\hline WOON & $b$ & 5.87 & 1.60 & 4.71 & 3.53 & 3.32 & 5.90 & 1.03 & 6.36 & 3.85 & 7.78 \\
\hline
\end{tabular}

MOSH = Moshassuck River; PAWT - Pantuxet River, TENM = Ten Mile River, WOON = Woonasquatucket River

a: this study BWW21 (EPA 1991-93) ; b: Estimates for other Tributarise Using Flow ratios of NBP study Wright ct. al. (1988)

Total mintall for NBP studies for thres storms observed were 3.21" (October 1988 - 0.80"; Mby 1989 - 1.94"; June 1989 - 0.37\%

Total raintall for EPA studies for thres storms observed were $2.25^{\circ}$ (September $1992-0.56^{\circ}$; November $1992-0.88^{\circ}$;

Oatober $1993-0.81$ ) 


\section{CHAPTER 9}

9.0 Characterization of Non Point Loads - Runoff vs Resuspension

Loadings in a river can be divided into point and nonpoint sources. Nonpoint sources can be broadly classified into two categories: runoff and resuspension. Runoff is due to overland flow and resuspension is a result of high storm flows and velocities scouring the bottom sediments. The runoff characteristics for the pollutants is considered to be a function of total rainfall, intensity of rain, duration of storm and antecedent dry period. Land characteristics such as: land use, slope and width of catchment also influences runoff characteristics of pollutants.

A new look at an old issue, that is the reduction and/or regulation of pollutant loadings, is provided by the division of the pollutograph into its three components, baseline loadings, resuspension and storm water runoff. If significant evidence is shown as to its relative importance, management alternatives are now available to reduce runoff. Bottom sediments are a reflection of the watershed history and potential interactions of these sediments during wet weather is important.

The separation of wet load into its components becomes a regulatory concern since the management for each is quite different. The resuspended bottom sediments could account for a major portion of the loadings. A procedure is discussed in this section to separate runoff and resuspension. This procedure is demonstrated for the reach between BWW07 and BWW08 (Rice City Pond). 
9.1 Previous Research

An attempt to assess the resuspension of materials in the Pawtuxet River due to wet weather was taken by Roy Chaudhury (1991). Wet weather contributions from surface runoff were evaluated using data collected during the 1988-89 NBP Wet Weather Study (Wright et al., 1991). The sampling occurred over a period of five days and the details of the sampling procedures and rainfall characteristics can be found in the literature cited above. The first attempt to assess the resuspension of material in the Pawtuxet River was made using the procedure proposed by Rayes (1987). The Pawtoxic model was used to develop the rèlationship between flow and concentration for the range of $0-450 \mathrm{cfs}$. Rayes suggested that if the assumption is made that these relationship are valid for higher flows, then the equations may be used to generate the mass of pollutant resuspension during a storm event. This attempt was not successful since when it was applied to flows $>450 \mathrm{cfs}$, the dry weather loadings were found to be greater than the wet weather loadings.

An attempt to predict flow and concentration relationships for dry weather flows ranging from $75 \mathrm{cfs}$ to $1600 \mathrm{cfs}$ was made using Pawtoxic, as an alternative to the approach by Rayes. This process involved using the average loadings from the treatment facilities and the calculation of the incremental reach flows. The details can be found in Roy Chaudhury (1991). For wet weather conditions, the prestorm sample concentration was assumed to be the equilibrium concentration. The increasing flows on the hydrograph were used to generate the baseline with resuspension mass by multiplying the flow at each sampling period by the prestorm or equilibrium concentration of the constituent. This 
established a new baseline for the evaluation of runoff. Integration of the curves gave the wet weather components associated with wet weather flows - runoff and resuspension.

The distinction between runoff and resuspension should require water quality modeling under unsteady wet weather conditions. However, since unsteady-state water quality modeling is not yet state of the art and attempts at modeling have proven to be data intensive, complex and difficult to calibrate and validate, Roy Chaudhury et al. (1993) offered an alternative. They isolated runoff and resuspension loadings for TSS, $\mathrm{Pb}, \mathrm{Cu}$, and $\mathrm{Cd}$ for this same reach for Storm 2. Four nomographs flow to resuspended loads were generated for a range of flows using the steady-state model relating Pawtoxic developed by Wright and McCarthy (1985). The resuspended loads were estimated for the monitored flows using these curves for each wet weather sampling run. The difference between resuspended loadings at BWW07 and BWW08 provided an estimate of the reach resuspension for each sampling run. The increased resuspension load was achieved by integration of the temporal variation of this loading.

\subsection{Blackstone River Application}

In this section a similar procedure was followed but the base data set for flow was extended to the 1991-1993 USGS flow record for the Blackstone River. Both nomographs and regression equations for flow vs resuspension for each constituents were developed.

The Pawtoxic model essentially simulates the fate of solids and metals through derption/desorption coupled with bottom sediment resuspension and settling. This 
model was calibrated and validated for the 1991 dry weather water quality surveys (Wright et al. 1996). For this application of the model, it was run for monthly average flow conditions for 3 year period. Incremental inflows were calculated based on the procedure discussed in Section 5 of BRI report (Wright et al. 1996). Concentrations and flows at $\mathrm{BWW} 07$ and $\mathrm{BWW} 08$ for $\mathrm{Cr}, \mathrm{Cu}, \mathrm{Pb}, \mathrm{Ni}$, and TSS were taken from the model output. Loadings at BWW08 and BWW07 were determined using the flow and concentration data. Loadings due to groundwater were also determined. The resultant increase or decrease in pollutant load in Rice City Pond was an estimate of resuspension:

\section{Mass resuspension $=$ Mass at BWW08 - Mass at BWW07 - Incremental}

\section{Groundwater Mass}

A regression was run on these data to determine a relationship for flow vs mass resuspended for each constituent $(\mathrm{Cr}, \mathrm{Cu}, \mathrm{Pb}, \mathrm{Ni}$, and TSS). Figure 9.1 is an example of these regression. The regression summaries are provided in Table 9.1.

The regression equations were then applied for the ranges of flows reported at the two stations over the 3 storms to obtain the resuspended loadings. The resuspended load was then added to the loading of BWW07 for each sample period to obtain the line of BWW07 plus resuspension (an example figure is shown in Figure 9.2). The area under each curve was integrated to determine the loadings. The difference between the load defined by BWW08 and that defined by BWW07 plus resuspension was equal to the estimate of runoff. This was done for all constituents for all three storms. Table 9.2 represents the resuspended and runoff loadings for each storm for Rice City Pond. 
Table 9.1 Resuspended Loading Predictive Equations (Load vs Flow)

\begin{tabular}{|c|c|c|c|c|}
\hline Constituents & $\mathrm{n}$ & $\mathrm{a}$ & $\mathrm{b}$ & $\mathrm{R}^{\wedge} 2$ \\
\hline & & & & \\
\hline $\mathrm{Cd}$ & 36 & 0.02 & 0.60 & 0.85 \\
\hline & & & & \\
\hline $\mathrm{Cr}$ & 36 & 0.013 & 0.84 & 0.86 \\
\hline $\mathrm{Cu}$ & 36 & 0.54 & 0.39 & 0.63 \\
\hline $\mathrm{Ni}$ & 36 & 0.10 & 0.50 & 0.67 \\
\hline $\mathrm{Pb}$ & 36 & 0.0044 & 1.14 & 0.95 \\
\hline & & & & \\
\hline $\mathrm{TSS}$ & 36 & 3.68 & 1.20 & 0.93 \\
\hline & & & & \\
\hline
\end{tabular}

Constituent (lbs/day) $=a^{*}[\text { flow }(\mathrm{cfs})]^{\wedge} \mathrm{b}$

$\mathrm{n}=$ number of observation, $\mathbf{R}^{\wedge} 2=$ Coefficient of Determination
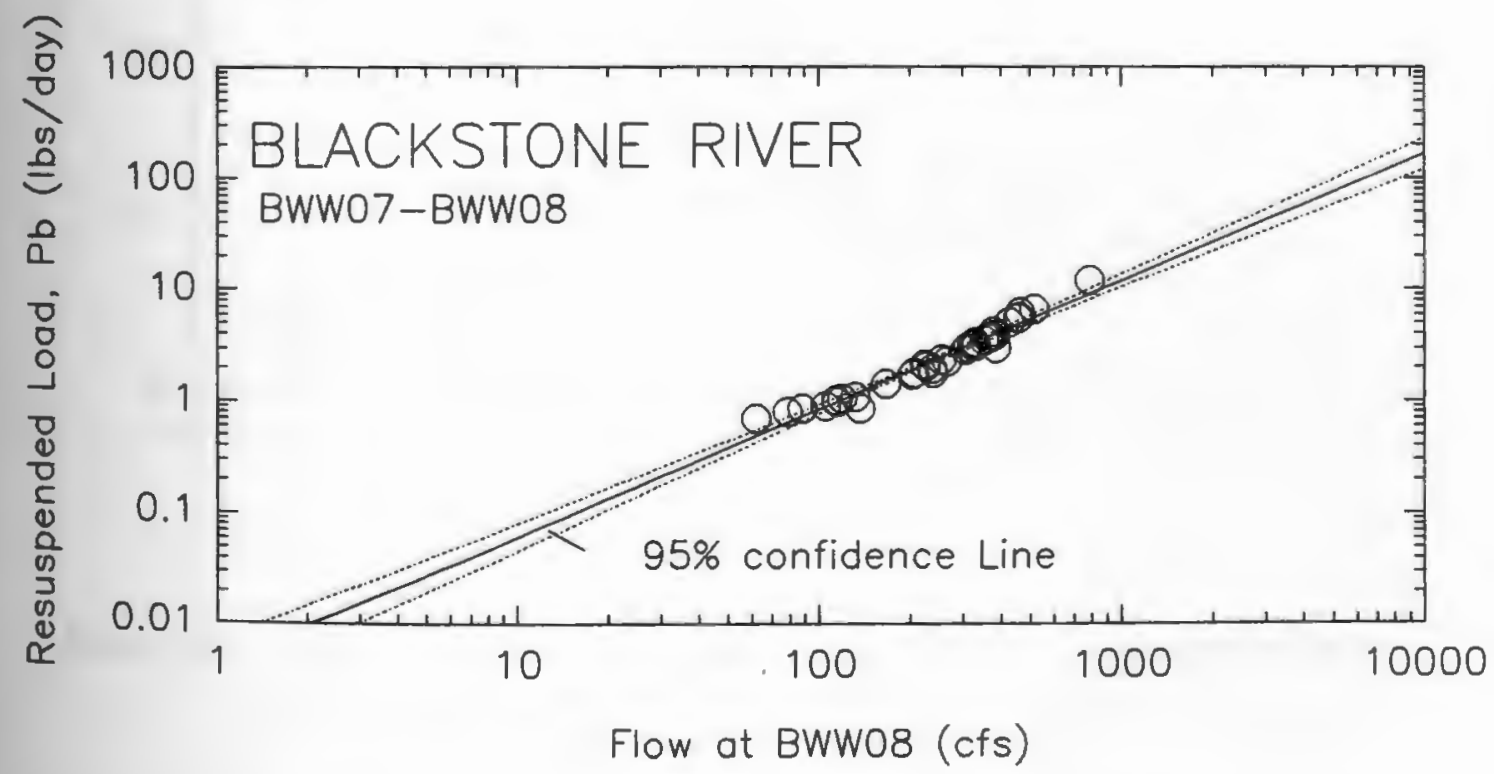

Figure 9.1 Example Plot of Regression Line of $\mathrm{Pb}$ for Resuspended Load vs Flow at Rice City Pond (BWW07-BWW08) 


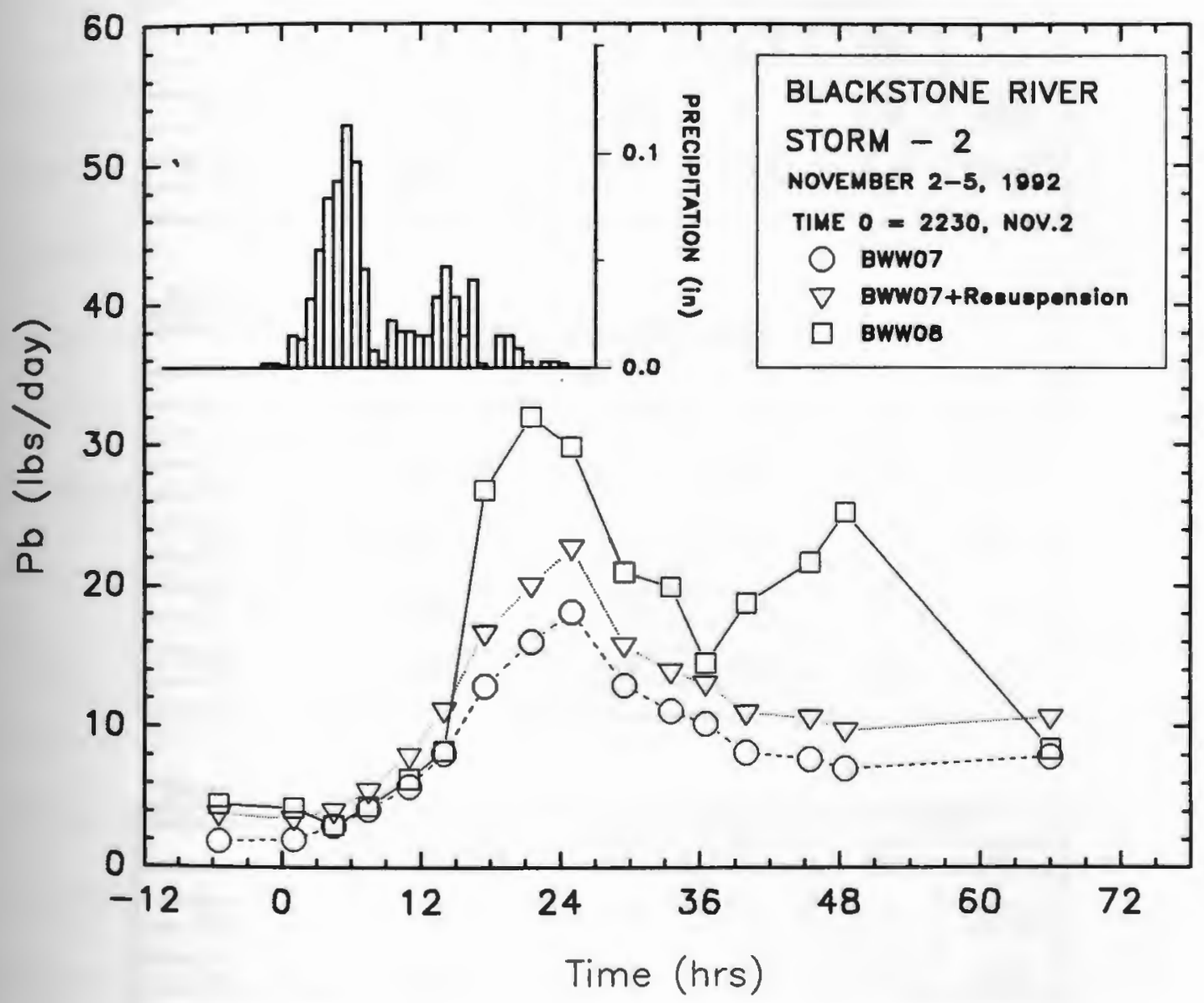

Figure 9.2 Example figure of Resuspended and Runoff Load Calculation of $\mathrm{Pb}$ for Storm 2 at Rice City Pond (BWW07-BWW08) 
Table 9.2 Runoff and Resuspended Loads Between BWW07 and BWW08

Storm-1

\begin{tabular}{|c|c|c|c|c|c|}
\hline \multirow{2}{*}{ Constituent } & Loadings Between & \multicolumn{2}{c|}{ Resuspension } & \multicolumn{2}{c|}{ Runoff } \\
\cline { 2 - 6 } & BWW07-BWW08, Ibs & Ibs & $\%$ & lbs & $\%$ \\
\hline $\mathrm{Cr}$ & 3.81 & 1.49 & 39.1 & 2.32 & 60.9 \\
\hline $\mathrm{Cu}$ & & & & & \\
\hline $\mathrm{Ni}$ & & 6.80 & 96.5 & 0.25 & 3.55 \\
\hline & 2.67 & 2.15 & 80.5 & 0.52 & 19.5 \\
\hline $\mathrm{Pb}$ & & & & & \\
\hline & 4.55 & 2.07 & 45.5 & 2.48 & 54.5 \\
\hline $\mathrm{TSS}$ & 2500 & & & & \\
\hline
\end{tabular}

Storm-2

\begin{tabular}{|c|c|c|c|c|c|}
\hline \multirow{2}{*}{ Constituent } & Loadings Between & \multicolumn{2}{c|}{ Resuspension } & \multicolumn{2}{c|}{ Runoff } \\
\cline { 2 - 6 } & BWW07-BWW08, lbs & lbs & $\%$ & lbs & $\%$ \\
\hline $\mathrm{Cr}$ & 11.8 & 4.32 & 36.8 & 7.43 & 63.2 \\
\hline $\mathrm{Cu}$ & 25.3 & 14.69 & 58.0 & 10.64 & 42.0 \\
\hline $\mathrm{Ni}$ & 13.4 & 4.34 & 32.4 & 9.04 & 67.6 \\
\hline & & & & & \\
\hline $\mathrm{Pb}$ & 22.9 & 7.91 & 34.5 & 15 & 65.5 \\
\hline & & & & & \\
\hline TSS & 10100 & 7390 & 73.2 & 2162 & 21.4 \\
\hline
\end{tabular}

Storm-3

\begin{tabular}{|c|c|c|c|c|c|}
\hline \multirow{2}{*}{ Constituent } & Loadings Between & \multicolumn{2}{c|}{ Resuspension } & \multicolumn{2}{c|}{ Runoff } \\
\cline { 2 - 6 } & BWW07-BWW08, lbs & lbs & $\%$ & Ibs & $\%$ \\
\hline $\mathrm{Cr}$ & 18.8 & 3.80 & 20.2 & 14.92 & 79.5 \\
\hline $\mathrm{Cu}$ & 25.9 & 12.08 & 46.7 & 13.76 & 53.2 \\
\hline $\mathrm{Ni}$ & & & & & \\
\hline $\mathrm{Pb}$ & 13.0 & 5.0 & 38.6 & 7.47 & 57.6 \\
\hline & 36.7 & & & & \\
\hline $\mathrm{TSS}$ & & 7.33 & 20.0 & 29.32 & 80.0 \\
\hline & 29300 & & & & \\
\hline
\end{tabular}


Resuspension of $\mathrm{Cr}$ varies between $20 \%-39 \%$, Cu between $47 \%-96 \%, \mathrm{~Pb}$ between $20 \%-46 \%$, Ni between $32 \%-81 \%$ and TSS between $31 \%-84 \%$ (Table 9.2 ). On average the percent wet load associated with resuspension for each metal was: $\mathrm{Cr}$ $32.0 \%, \mathrm{Cu}-67.0 \%, \mathrm{~Pb}-33.7 \%, \mathrm{Ni}-51.0 \%$, and $\mathrm{TSS}-64.7 \%$.

It was established in Section 6.2 that wet weather can cause acute criteria violations and the cause of higher metal concentration may be resuspension of the bottom sediments due to high flow and velocity and runoff. If we can identify the type and cause of the problem, then the regulatory agency can impose new regulations to solve the problem of pollution. This procedure, developed here, can be repeated for each hot spot identified in Chapter 8. The separation of the wet loads into runoff and resuspension components will provide us with the information whether the problem of pollution is new (runoff related) or old (resuspension of bottom sediments). The solution will be different for different cases. For example controlling the resuspension of $\mathrm{Cu}$ in Rice City Pond on average will reduce the concentration by $67 \%$, which might bring down the concentration during storm events causing no violation to occur. It was thought before that wet weather problem is related to runoff only. But in this section it was proven that resuspension as well can be an important cause of the problem and controlling it may be a solution to the wet weather pollution problem. Several control alternatives may be considered, such as: dredging, cover the bad soil with new good soil, reduction of volume and velocity of water by creation of wetlands. 


\section{CHAPTER 10}

\subsection{Annual Loading Rates}

Information developed in earlier Sections leads to the estimation of the annual loading rates. Determination of the annual loads will provide us with an idea how much pollutants are carried by the Blackstone River to Narragensett Bay each year. The annual loads were divided into two parts: contribution by dry weather flows and contribution by wet weather flows. Dry weather flow is defined as the base flow and wet weather flow is defined as the flow due to a rainfall event (flow above the base flow in the hydrograph). Annual loads were determined for the years 1991-92. USGS flow data were used for these calculations.

\subsection{Dry Weather Estimates}

The calibrated and validated QUAL2E Model (Wright et al. 1996) was run using the same database as in Chapter 9 (1991-1993 USGS data) for DO, $\mathrm{NO}_{3}, \mathrm{PO}_{4}$ and $\mathrm{NH}_{4}$. The post audit of the model, by Carrelli et al. (1995), showed a very good fit for those constituents at MA/RI state line (BWW13) and end of river (BWW21) (Figures 10.1 and 10.2 shows the comparison figures for state line and end of river respectively).

The QUAL2E model was used to develop the regressions for $\mathrm{NO}_{3}, \mathrm{PO}_{4}$ and $\mathrm{NH}_{4}$ at the MA/RI state line (BWW13) and at the end of river (BWW21). From each run of the model for a particular month and year, the flow and concentration data for each constituent at the state line and end of river were read from the output of QUAL2E. 


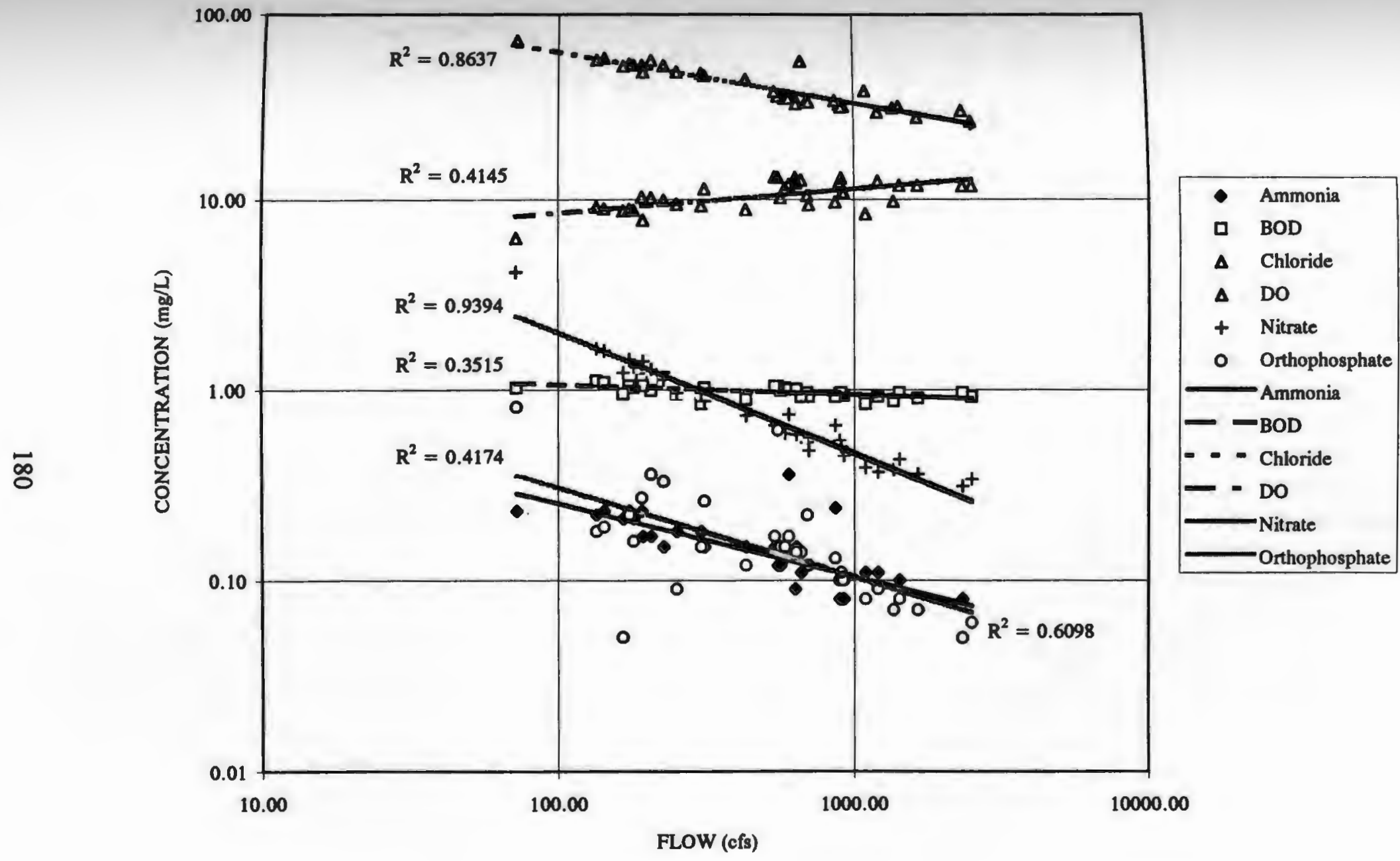

Figure 10.1 Post Audit @ MA/RI State Line (BWW13) 


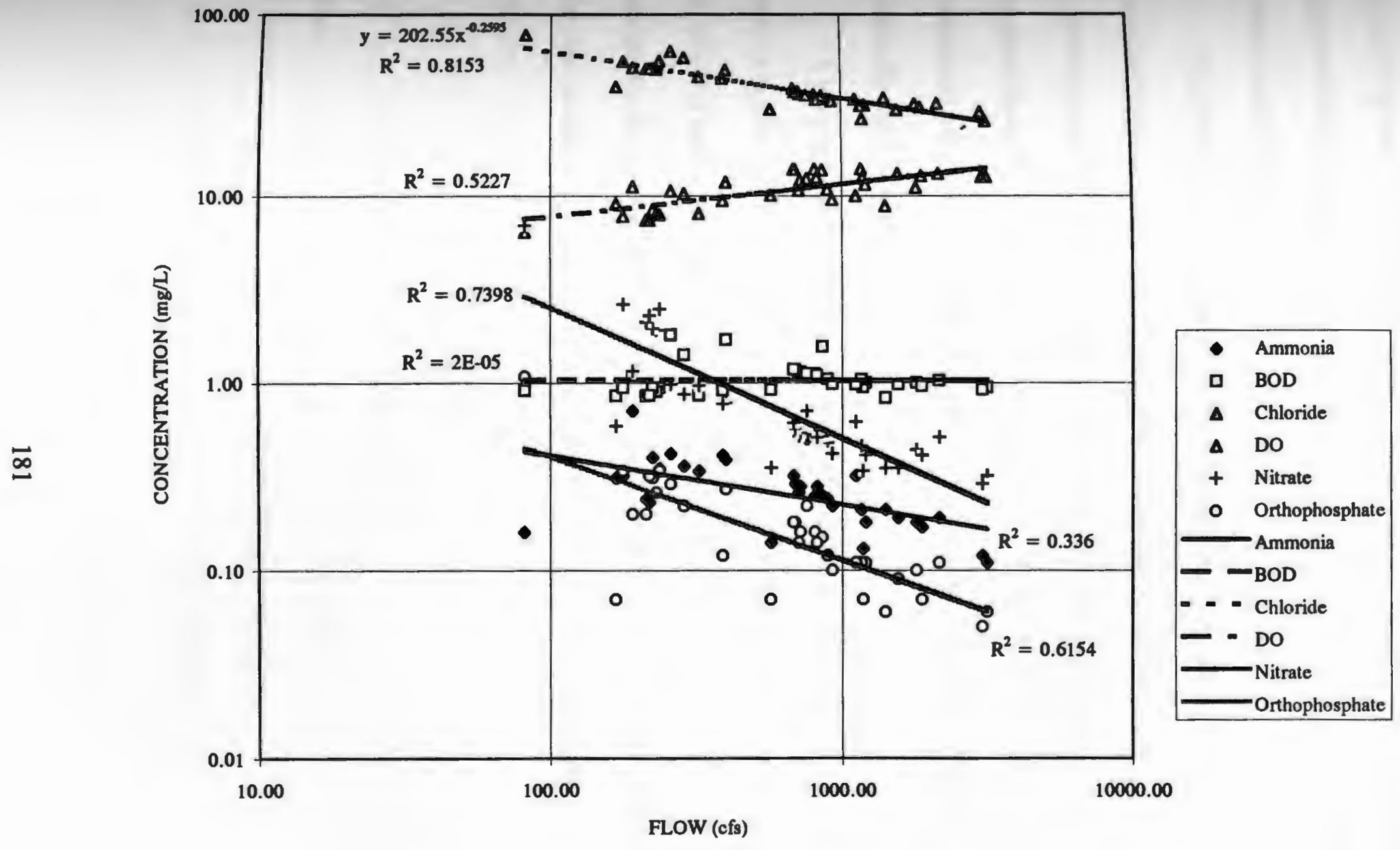

Figure 10.2 Post Audit @ End of River (BWW21) 
These data were regressed to find a relationship between flow and concentration. Log$\log$, semi-log, and arithmetic relationships were tried and with the most statistically significant results being with the $\log$ - $\log$ transformation. The results of the regression analysis is presented in Table 10.1 .

The calibrated and validated Pawtoxic Model was run for trace metals with the same database as in section 9.2 (1991-1993 USGS data). Using the output of the model for BWW13 and BWW21, concentration vs flow relationship were developed, as described above, for both stations (Table 10.1). Again log-log, semi-log, and arithmetic relationships wère tried and the log-log relationship was used which had the most statistically significant results.

A linear relationship of flows between Woonsocket USGS gage station and BWW13 and BWW21 was developed and compared with the measured flows at BWW21 and BWW13 during the three storm events. These relationship were developed to calculate the flow at BWW21 and BWW13 using the USGS flow gage at Woonsocket and later used in calculating the annual loading rate of the river. The relationships were as follows:

$$
\mathrm{Q}_{21}=1.053 \mathrm{Q}_{\mathrm{w}}+20.384
$$

and

$$
\mathrm{Q}_{13}=0.815 \mathrm{Q}_{\mathrm{w}}+21.963
$$

Where

$$
\begin{aligned}
& Q_{w}=\text { Measured Flow at Woonsocket USGS gage, cfs } \\
& Q_{21}=\text { Calculated Flow at BWW21 (end of river), cfs } \\
& Q_{13}=\text { Calculated Flow at BWW13 (MA/RI state line), cfs }
\end{aligned}
$$


Table 10.1 Dry Weather Predictive Equations (Concentration vs flow)

BWW21

\begin{tabular}{|c|c|c|c|c|}
\hline Constituents & $\mathrm{n}$ & $\mathrm{a}$ & $\mathrm{b}$ & $\mathrm{R}^{\wedge} 2$ \\
\hline $\mathrm{Cd}$ & 36 & 7.57 & -0.35 & 0.92 \\
\hline & & & & \\
\hline $\mathrm{Cr}$ & 36 & 1.04 & 0.14 & 0.48 \\
\hline $\mathrm{Cu}$ & 36 & 45.7 & -0.17 & 0.77 \\
\hline & & & & \\
\hline $\mathrm{Ni}$ & 36 & 45.3 & -0.36 & 0.91 \\
\hline $\mathrm{Pb}$ & 36 & 1.17 & 0.21 & 0.86 \\
\hline $\mathrm{NH} 4$ & 32 & 2.89 & -0.37 & 0.59 \\
\hline & & & & \\
\hline $\mathrm{NO} 3$ & 32 & 79.5 & -0.73 & 0.88 \\
\hline & & & & \\
\hline $\mathrm{PO} 4$ & 32 & 7.36 & -0.60 & 0.87 \\
\hline & & & & \\
\hline
\end{tabular}

BWW13

\begin{tabular}{|c|c|c|c|c|}
\hline Constituents & $\mathrm{n}$ & $\mathrm{a}$ & $\mathrm{b}$ & $\mathrm{R}^{\wedge} 2$ \\
\hline $\mathrm{Cd}$ & 36 & 6.17 & -0.31 & 0.91 \\
\hline & & & & \\
\hline $\mathrm{Cr}$ & 36 & 0.81 & 0.21 & 0.69 \\
\hline $\mathrm{Cu}$ & 36 & 39.2 & -0.14 & 0.71 \\
\hline $\mathrm{Ni}$ & 36 & 44.0 & -0.35 & 0.90 \\
\hline $\mathrm{Pb}$ & 36 & 0.81 & 0.29 & 0.91 \\
\hline & & & & \\
\hline $\mathrm{NH} 4$ & 32 & 1.67 & -0.40 & 0.57 \\
\hline $\mathrm{NO3}$ & & & & \\
\hline & & 29.6 & -0.60 & 0.96 \\
\hline $\mathrm{PO} 4$ & 32 & 3.77 & -0.52 & 0.77 \\
\hline & & & & \\
\hline
\end{tabular}

Constituent $(\mathrm{ug} / \mathrm{l})=\mathrm{a} *[\text { flow }(\mathrm{cfs})]^{\wedge} \mathrm{b} \quad ;[$ for $\mathrm{Pb}, \mathrm{Cu}, \mathrm{Ni}, \mathrm{Cd}, \& \mathrm{Cr}]$ Constituent $(\mathrm{mg} / \mathrm{l})=\mathrm{a} *[\text { flow }(\mathrm{cfs})]^{\wedge} \mathrm{b} \quad ;[$ for NO3, PO4, \& NH4] $\mathrm{n}=$ number of observation, $\mathbf{R}^{\wedge} 2=$ Coefficient of Determination 
A relationship was developed by Nixon et al. (1991) for $\mathrm{Pb}, \mathrm{Cu}, \mathrm{Ni}, \mathrm{Cd}$, and $\mathrm{Cr}$ with data collected at BWW21 prior to 1990 . He (Nixon) used the data collected previously by other people and relied mostly on SINBADD and SPRAY data. SINBADD data had 4 data points and SPRAY had 18 data points collected in 1985-1987. The flow vs concentrations relationships for the end of river (BWW21) were converted to flow vs load relationship ( $\mathrm{m}^{3} /$ day vs $\mathrm{kg} /$ day) and compared with the relationships developed by Nixon et al. (1991) (Table 10.2). The model and Nixon's regression was petty close as seen in Table 10.2, which again validate our model.

Model règression and Nixon's regression were plotted along with the six data points which were calculated using 1991 dry weather surveys (3 surveys), and base (dry) loadings for 1992-1993 wet weather surveys ( 3 storms). These plots suggests that our model is forecasting well. For example plot for lead is shown in Figure 10.3 and the 6data points are closer to the line represented by the model and Nixon's regression is under estimating the $\mathrm{Pb}$ loadings. The Blackstone River flow may be changed due to abandonment of several dams which were active before, so the pollution pattern may change now and certain metals concentrations may increase due to resuspension of the bottom sediments at and near the old abandoned dams.

The relationships developed earlier (Table 10.1) were used to estimate the annual dry loading rates for the Blackstone River.

\subsection{Wet Weather Estimates}

Relationships were developed between rainfall and wet weather loadings using the 
Table 10.2 Comparison Between Model and Nixon (1991) Regression @ BWW21

\begin{tabular}{|c|c|c|c|c|c|c|}
\hline & & $\mathrm{Cd}$ & $\mathrm{Cr}$ & $\mathrm{Cu}$ & $\mathrm{Ni}$ & $\mathrm{Pb}$ \\
\hline & & & & & & \\
\hline MODEL & $\log (\mathrm{a})$ & -3.94 & -6.47 & -3.77 & -3.12 & -6.65 \\
\hline & $\mathrm{b}$ & 0.65 & 1.14 & 0.83 & 0.64 & 1.21 \\
\hline & $\mathrm{R}^{\wedge} 2$ & 0.98 & 0.98 & 0.99 & 0.97 & 0.99 \\
\hline & $\mathrm{n}$ & 36 & 36 & 36 & 36 & 36 \\
\hline & & & & & & \\
\hline NIXON & $\log (\mathrm{a})$ & -6.64 & -6.6 & -4.69 & -3.07 & -5.15 \\
\hline & $\mathrm{b}$ & 1.09 & 1.15 & 0.94 & 0.7 & 0.93 \\
\hline & $\mathrm{R}^{\wedge} 2$ & 0.75 & 0.95 & 0.97 & 0.85 & 0.93 \\
\hline & $n$ & $\#$ & $\#$ & $\#$ & $\#$ & $\#$ \\
\hline & & & & & & \\
\hline
\end{tabular}

Constituent $(\mathrm{kg} /$ day $)=\log (\mathrm{a})+\mathrm{b} * \log [$ flow $(\mathrm{cu} . \mathrm{m} /$ day $)] ;$ \# = not known

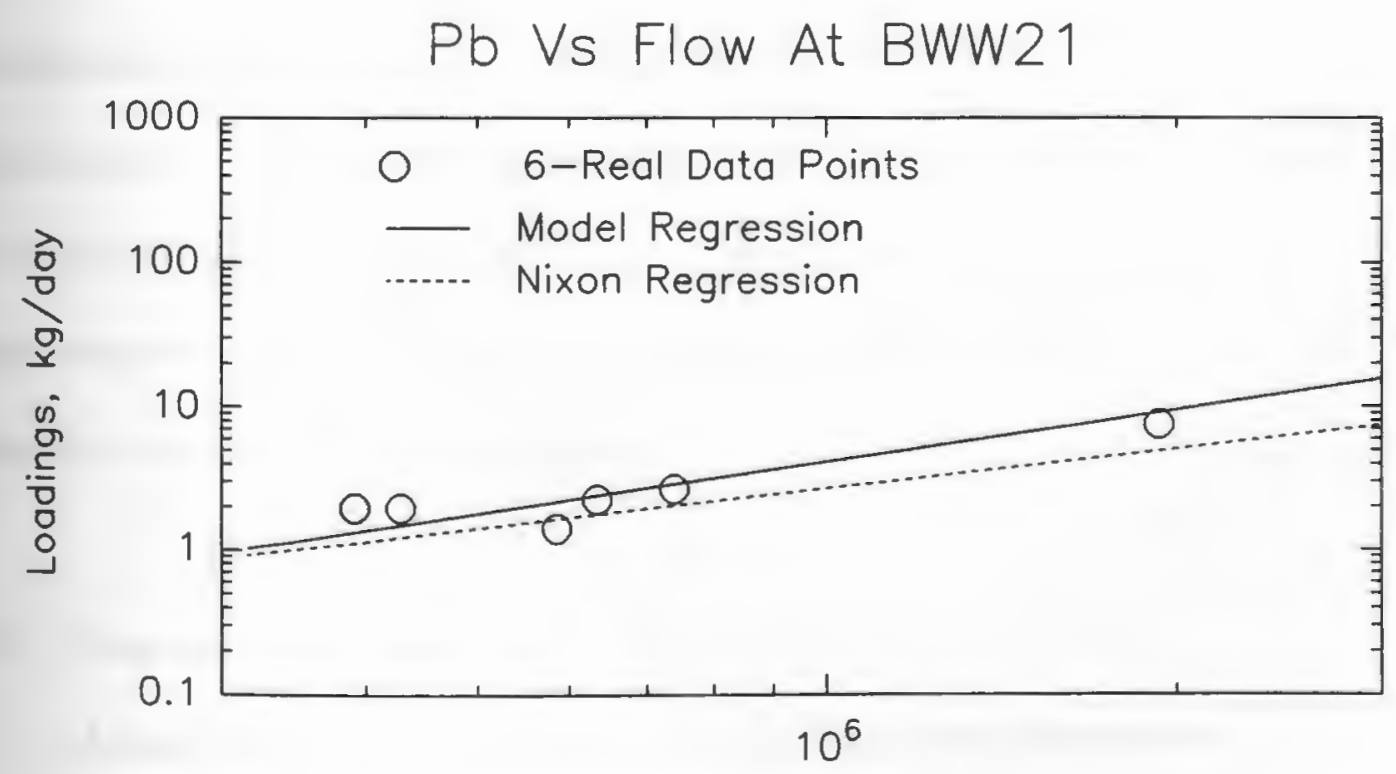

Flow, Cubic Meters/day

Figure 10.3 Example Plot of Model Regression, Nixon Regression with 6-Real Data Points for $\mathrm{Pb}$ at End of River (BWW21) 
data collected during the three storms (1992-93, EPA) and previous wet weather data available for the state line (BWW13) and end of river (BWW21) (Table 10.3). These data were taken from other two studies done by Wright et al. for Narragansett Bay Commission (NBC) (Wright et. al. 1991), and Narragansett Bay Project (NBP) (Wright et al., 1990). Those studies were done from 1987 to 1990 . The rainfall characteristics were different for different storms and total rainfall ranged from 0.21 " to $1.94 "$ ". Log-log relationships were found to better represent the data than semi-log and arithmetic relationships. Regression plots were done for trace metals, nutrients and TSS. Summary tables for the règressions for BWW21 and BWW13 are presented in Tables 10.4 and 10.5, and example plots for copper are shown in Figures 10.4 and 10.5 for each station, respectively.

These equations were used to estimate the annual wet weather loading rates for the Blackstone River. The data available had a rainfall range from 0.21 " to $1.94 "$ ". The model equations are therefore most appropriately applied to storms within that range. If the rainfall is greater than $2^{n}$, the equations will over predict the wet loadings. So, to apply the model beyond $2.0^{\prime \prime}$, further observations for rainfall in excess of 2.0 inches is needed to extend the predictive equations.

\subsection{Determination of Annual Load}

Annual loadings for 1991-92 were calculated using the equations developed in sections 10.1 (dry load) and 10.2 (rainfall events). The USGS flow data were used for these calculations. 
Table 10.3 Wet load Regression Data for Rainfall vs Load for BWW21 and BWW13

BWW 21

\begin{tabular}{|c|c|c|c|c|c|c|c|c|c|c|c|}
\hline Project & Date & Rainfall & $\overline{C d}$ & $\mathrm{Cr}$ & $\overline{\mathrm{Cu}}$ & $\overline{\mathrm{Ni}}$ & $\mathrm{Pb}$ & $\mathrm{NH4}$ & $\mathrm{NO3}$ & PO4 & TSS \\
\hline & & Inch & Lbs & Lbs & Lbs & Lbs & Lbs & Lbs & Lbs & Lbs & Lbs \\
\hline & & & & & & & & & & & \\
\hline EPA & Sep22, 1992 & 0.55 & 0.33 & 1.30 & 6.64 & 3.89 & 9.07 & 596 & 936 & 218 & 2170 \\
\hline EPA & Nov2, 1992 & 0.92 & 4.68 & 16.0 & 64.4 & 37.9 & 38.7 & 6970 & 12100 & 1390 & 4030 \\
\hline EPA & Oct12, 1993 & 0.80 & 0.77 & 5.85 & 30.3 & 14.9 & 21.2 & 374 & 5020 & 836 & 40700 \\
\hline NBP & May10, 1989 & 1.94 & 26.6 & 220 & 344 & 153 & 353 & 3500 & 60100 & 2630 & 590000 \\
\hline NBC & May29, 1990 & 1.41 & & & 144 & 61.3 & 63.9 & & 7870 & 1400 & 223000 \\
\hline NBC & Jun29, 1990 & 0.21 & & & 0.77 & 0.97 & 4.82 & & 167 & 25.5 & 612 \\
\hline NBC & Jul12, 1990 & 1.56 & & & 36 & 12.2 & 18.2 & & 4400 & 912 & 22300 \\
\hline & & & & & & & & & & & \\
\hline
\end{tabular}

BWW 13

\begin{tabular}{|l|l|c|c|c|c|c|c|c|c|c|c|}
\hline Project & Date & Rainfall & Cd & Cr & Cu & Ni & Pb & NH4 & NO3 & PO4 & TSS \\
\hline & & Inch & Lbs & Lbs & Lbs & Lbs & Lbs & Lbs & Lbs & Lbs & Lbs \\
\hline & & & & & & & & & & & \\
\hline EPA & Sep22, 1992 & 0.55 & 1.12 & 0.73 & 2.70 & 2.08 & 2.28 & 92 & 845 & 72 & 2550 \\
\hline EPA & Nov2,1992 & 0.92 & 2.24 & 18.9 & 44.9 & 9.77 & 33.6 & 6200 & 8150 & 673 & 15000 \\
\hline EPA & Oct12,1993 & 0.8 & 1.36 & 11.5 & 33.2 & 22.8 & 21.1 & 338 & 4780 & 767 & 26900 \\
\hline NBP & May10,1989 & 1.94 & 30.5 & 155 & 350 & 204 & 148 & 40600 & 46400 & 3600 & 207000 \\
\hline
\end{tabular}


Table 10.4 Wet Weather Predictive Equations for BWW21 (Load vs Rainfall)

\begin{tabular}{|c|c|c|c|c|}
\hline Constituents & $n$ & $\mathrm{a}$ & $\mathrm{b}$ & $\mathrm{R}^{\wedge} 2$ \\
\hline $\mathrm{Cd}$ & 4 & 2.93 & 3.55 & 0.92 \\
\hline $\mathrm{Cr}$ & 4 & 16.3 & 4.06 & 0.99 \\
\hline & & & & \\
\hline $\mathrm{Cu}$ & 7 & 42.1 & 2.53 & 0.90 \\
\hline $\mathrm{Ni}$ & 7 & 21.1 & 2.02 & 0.80 \\
\hline $\mathrm{Pb}$ & 7 & 35.3 & 1.52 & 0.67 \\
\hline $\mathrm{NH4}$ & 4 & 1680 & 1.55 & 0.34 \\
\hline & & & & \\
\hline $\mathrm{NO3}$ & 7 & 5700 & 2.25 & 0.82 \\
\hline & & & & \\
\hline $\mathrm{PO} 4$ & 7 & 769 & 1.97 & 0.90 \\
\hline & & & & \\
\hline $\mathrm{TSS}$ & 7 & 38100 & 2.87 & 0.81 \\
\hline & & & & \\
\hline
\end{tabular}

Constituent (lbs) $=a^{*}[\text { rainfall(inch) }]^{\wedge} b$ $\mathrm{n}=$ number of observation, $\mathbf{R}^{\wedge} \mathbf{2}=$ Coefficient of Determination

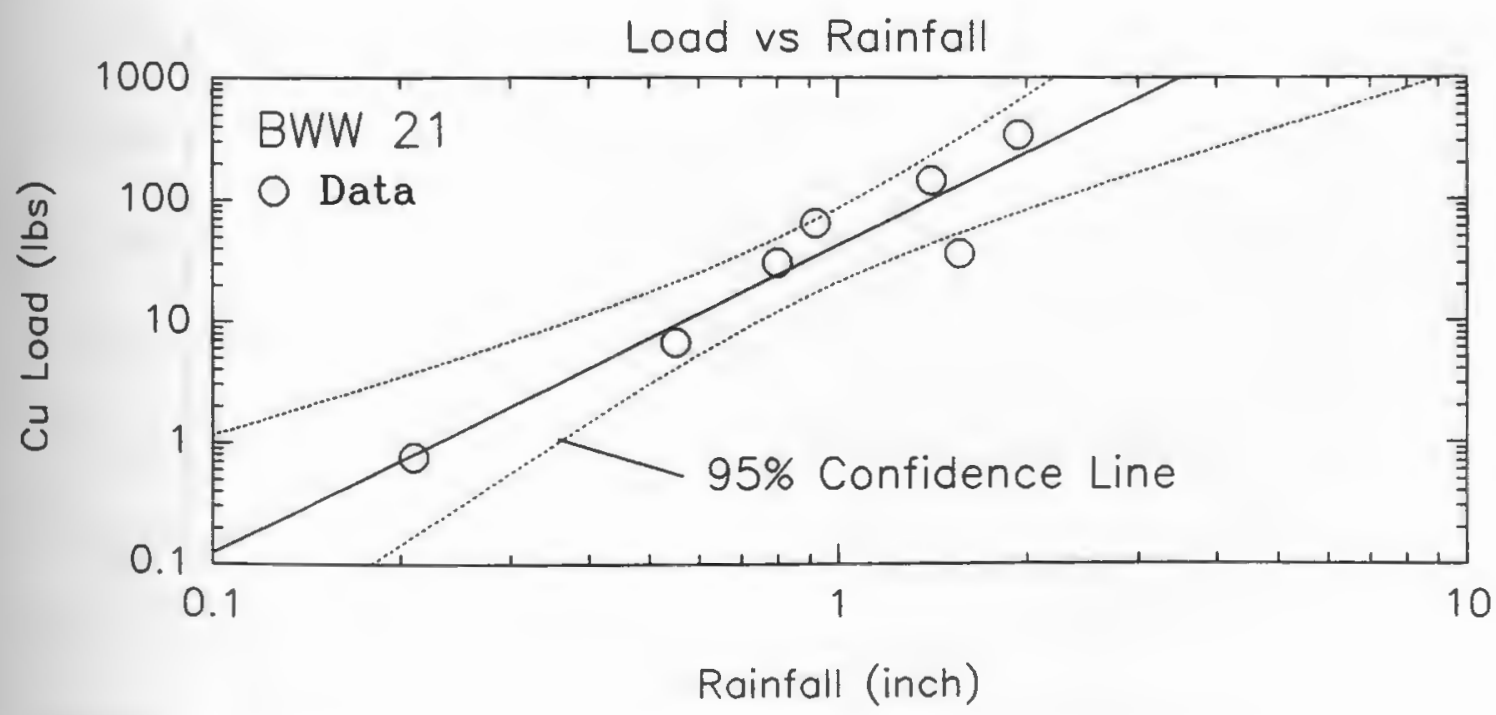

Figure 10.4 Example Plot of Model Regression for Load vs Rainfall for Cu at End of River (BWW21) 
Table 10.5 Wet Weather Predictive Equations for BWW13 (Load vs Rainfall)

\begin{tabular}{|c|c|r|r|r|}
\hline Constituents & $\mathrm{n}$ & $\mathrm{a}$ & \multicolumn{1}{c|}{$\mathrm{b}$} & \multicolumn{1}{c|}{$\mathrm{R}^{\wedge} 2$} \\
\hline $\mathrm{Cd}$ & 4 & 3.78 & 2.79 & 0.93 \\
\hline $\mathrm{Cr}$ & 4 & 15.9 & 4.00 & 0.92 \\
\hline $\mathrm{Cu}$ & 4 & 43.0 & 3.63 & 0.93 \\
\hline & & & & \\
\hline $\mathrm{Ni}$ & 4 & 21.6 & 3.45 & 0.91 \\
\hline & & & & \\
\hline $\mathrm{Pb}$ & 4 & 26.7 & 3.10 & 0.90 \\
\hline & & & & \\
\hline $\mathrm{NH} 4$ & 4 & 1120 & 2.90 & 0.58 \\
\hline & & & & \\
\hline $\mathrm{NO} 3$ & 4 & 7520 & 3.06 & 0.96 \\
\hline & & & & \\
\hline $\mathrm{PO} 4$ & 4 & 718 & 2.85 & 0.88 \\
\hline & & & & \\
\hline TSS & 4 & 26200 & 3.29 & 0.92 \\
\hline & & & & \\
\hline
\end{tabular}

Constituent (lbs) $=\mathrm{a} *$ [rainfall(inch) $]^{\wedge} \mathrm{b}$ $n=$ number of observation, $R^{\wedge} 2=$ Coefficient of Determination

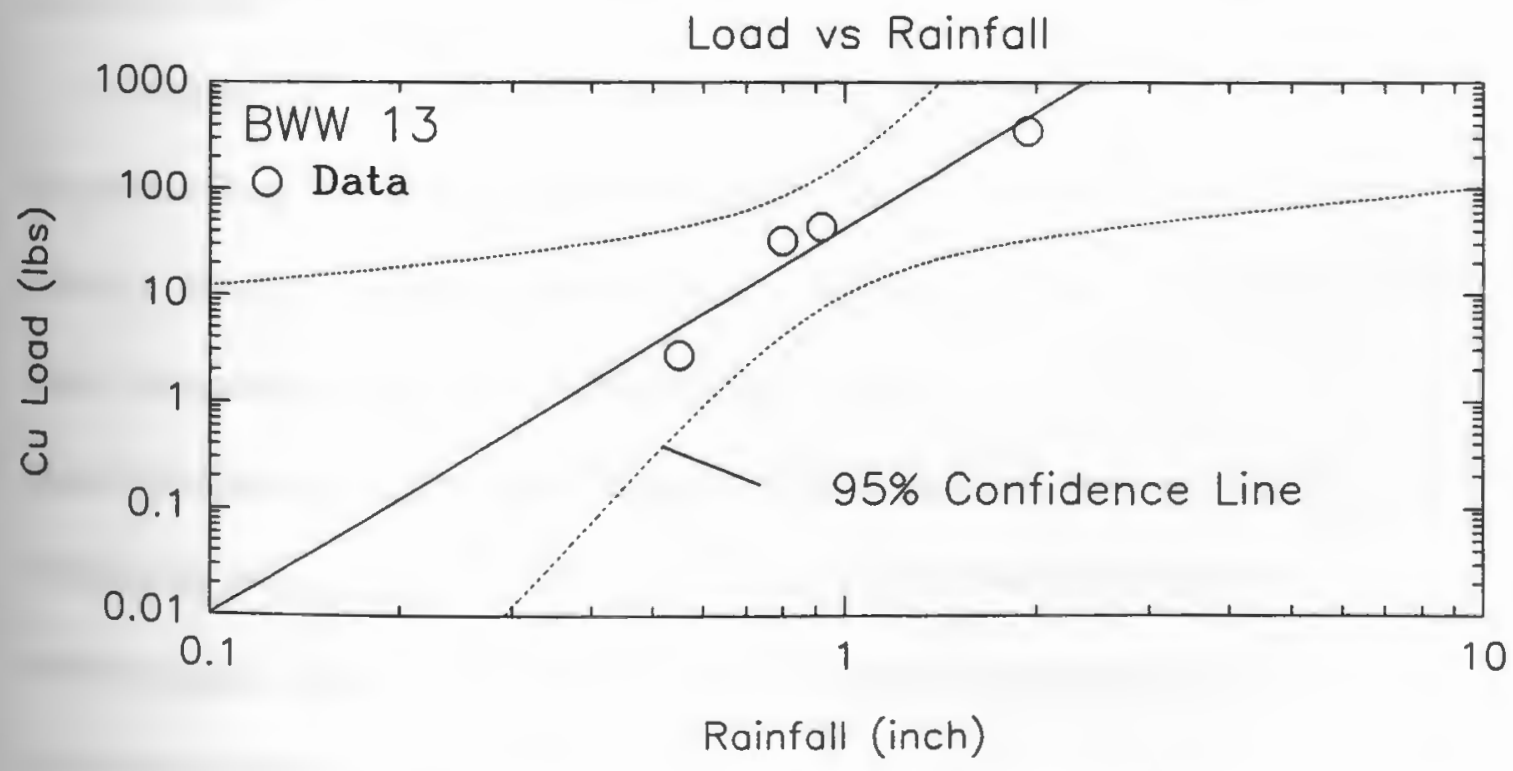

Figure 10.5 Example Plot of Model Regression for Load vs Rainfall for Cu at State Line (BWW13) 
Flows at BWW21 and BWW13 were calculated using flow relationship developed in section 10.1. Spreadsheets were prepared to separate the base flow for each station for the whole year. For this purpose, monthly hydrographs were drawn for each year per station. These hydrographs were compared with the equivalent daily rainfall data to determine the influence of wet weather. During a storm period, the baseflow was separated using the equation:

$$
\mathrm{N}=1.0 \mathrm{~A}^{0.10}
$$

Where $\mathrm{N}=$ number of days from the peakflow

and $\quad \mathrm{A}=$ cumulative drainage area, sq. mile

The equivalent rainfall was calculated by using Thesian Method (Chapter 4) for each day of the rainfall event for the entire watershed of the Blackstone River.

The equations developed in section 10.1 were applied to the base flow for each day of the year to calculate the dry load for that day. The sum of the loadings gave the annual dry load.

Rainfall data for all the NWS stations (Table 4.2) for the entire basin of the Blackstone River were available (Climatological Data of New England 1991-1992, NOAA). Most of the rainfall data available were daily, so daily equivalent rainfall was used. The calculated equivalent rainfall for the Blackstone River watershed was used along with the equations developed in section 10.2 to come up with the estimate of wet loadings for the event for that day. This was repeated for each day of the year which had rainfall records. All calculated wet loads for the year were summed to obtain wet load contributions for the year. 
Total loadings for a particular year were determined by adding wet loads with dry loads for that year as calculated above. Table 10.6 represents the summary of the annual loadings for 1991-92.

\subsection{Load at State Line and End of River}

Annual wet weather loads as a $\%$ of the total load at the state line (BWW13) were: $\mathrm{Pb}-22 \%-28 \%, \mathrm{Cu}-16 \%-24 \%, \mathrm{Ni}-23 \%-32 \%, \mathrm{Cd}-18 \%-22 \%, \mathrm{Cr}-31 \%-44 \%, \mathrm{NO}_{3}-$ $38 \%-46 \%, \mathrm{PO}_{4}-21 \%-26 \%$, and $\mathrm{NH}_{4}-30 \%-37 \%$. Wet weather related loadings as a $\%$ of total load discharged to Narragansett Bay (BWW21) were: $\mathrm{Pb}-18 \%-19 \%, \mathrm{Cu}-9 \%$ $11 \%, \mathrm{Ni}-13 \%-15 \%, \mathrm{Cd}-17 \%-25 \%, \mathrm{Cr}-30 \%-44 \%, \mathrm{NO}_{3}-21 \%-25 \%, \mathrm{PO}_{4}-14 \%-16 \%$, and $\mathrm{NH}_{4}-17 \%-18 \%$.

Percent wet load at BWW13 was higher than that at BWW21 for all constituents. $\mathrm{Cr}$ had highest \% wet load followed by $\mathrm{NO}_{3}$ and $\mathrm{Ni}$ at $\mathrm{BWW} 13$ for 1991 , but $\mathrm{NO}_{3}$ was followed by $\mathrm{Cr}$ and $\mathrm{NH}_{4}$ for 1992 . $\mathrm{Cr}$ had highest \% wet load followed by $\mathrm{Cd}$ and $\mathrm{NO}_{3}$ at BWW21 for 1991, but $\mathrm{Cr}$ was followed by $\mathrm{NO}_{3}$ and $\mathrm{Cd}$ for 1992.

The determination of annual loadings is important. Estimation of the annual loadings at BWW13 gave us an idea of how much pollutants were delivered to Rhode Island border line by the Massachusetts portion of the Blackstone River. The estimated loadings at BWW21 provided us with the information of pollutants delivered to Narragansett Bay by the Blackstone River. The division of the annual loadings into dry and wet loadings provided the contribution by base loadings and the wet weather loadings. Percent wet load delivered by Blackstone River to the Narragansett Bay was less than 
Table 10.6 Annual Mass Loading Forecast Summary for Blackstone River at State Line (BWW13) and End of River (BWW21)

\begin{tabular}{|c|c|c|c|c|c|c|}
\hline Constituent & Year & Equivalent & \multicolumn{2}{|c|}{ BWW13 } & \multicolumn{2}{c|}{ BWW21 } \\
\hline & & Yearly & Dry & Wet & Dry & Wet \\
\hline & & Rainfall & Load & Load & Load & Load \\
\hline & & (in) & $(\%)$ & $(\%)$ & $(\%)$ & $(\%)$ \\
\hline & & & & & & \\
\hline $\mathrm{Cd}$ & 1991 & 49.2 & 78.1 & 21.9 & 74.7 & 25.3 \\
\hline $\mathrm{Cr}$ & 1991 & 49.2 & 55.8 & 44.2 & 55.9 & 44.1 \\
\hline $\mathrm{Cu}$ & 1991 & 49.2 & 76.4 & 23.6 & 89.3 & 10.7 \\
\hline $\mathrm{Ni}$ & 1991 & 49.2 & 68.1 & 31.9 & 84.9 & 15.1 \\
\hline $\mathrm{Pb}$ & 1991 & 49.2 & 72.0 & 28.0 & 81.5 & 18.5 \\
\hline $\mathrm{NH} 4$ & 1991 & 49.2 & 62.8 & 37.2 & 82.2 & 17.8 \\
\hline $\mathrm{NO3}$ & 1991 & 49.2 & 53.5 & 46.5 & 75.3 & 24.7 \\
\hline $\mathrm{PO} 4$ & 1991 & 49.2 & 74.1 & 25.9 & 84.1 & 15.9 \\
\hline & & & & & & \\
\hline $\mathrm{Cd}$ & 1992 & 47.3 & 82.4 & 17.6 & 82.6 & 17.4 \\
\hline $\mathrm{Cr}$ & 1992 & 47.3 & 69.0 & 31.0 & 69.8 & 30.2 \\
\hline $\mathrm{Cu}$ & 1992 & 47.3 & 83.9 & 16.1 & 91.1 & 8.9 \\
\hline $\mathrm{Ni}$ & 1992 & 47.3 & 76.8 & 23.2 & 86.5 & 13.5 \\
\hline $\mathrm{Pb}$ & 1992 & 47.3 & 77.7 & 22.3 & 81.8 & 18.2 \\
\hline $\mathrm{NH} 4$ & 1992 & 47.3 & 69.6 & 30.4 & 83.0 & 17.0 \\
\hline $\mathrm{NO3}$ & 1992 & 47.3 & 62.2 & 37.8 & 78.8 & 21.2 \\
\hline $\mathrm{PO} 4$ & 1992 & 47.3 & 79.5 & 20.5 & 85.9 & 14.1 \\
\hline & & & & & & \\
\hline
\end{tabular}


$50 \%$ for all constituents but wet load is significant if we compare the number of the days of the year that wet weather events occur to the number of days in a year. 


\section{CHAPTER 11}

11.0 Summary of Wet Weather Interpretation - Conclusions and Recommendations Wet weather water quality of the Blackstone River was analyzed. The two flow charts presented in Figures 5.1 and 5.2 describe the procedure at a glance. Three wet weather events were successfully captured for wet weather program: Storm 1 (September 22-24, 1992), Storm 2 (November 2-5, 1992) and storm 3 (October 12-14, 1993). Grab samples were collected at specific time intervals throughout the Blackstone River watershed. In Chapter 5, the concentrations and EMC's (event mean concentration) for different constituents were determined. Chapter 6 deals with violations and toxicity. Two types of violations were compared for fecal coliform violations in the Blackstone River: Violations A (log mean $>200 \mathrm{md} / 100 \mathrm{ml})$ and Violations B (10\% of samples exceeding $400 \mathrm{md} / 100 \mathrm{ml}$ ). Acute and chronic criteria were compared with the concentrations measured for trace metals to come up with the violations. These criteria are used to protect the public health and the environment.

Chapter 7 uses the concentration data from Chapter 5 and flow data from Chapter 4 to calculate the mass loadings. A comparison of wet and total loadings were shown and tributary wet load rankings were provided. Net gains and losses per reach was calculated and major point sources and non point sources were compared.

System ranking and hot spot identification is provided in Chapter 8 using the information from earlier chapters. A procedure is developed in Chapter 9 to separate runoff and resuspension. This procedure is demonstrated for the reach between BWW07 
(Rice City Pond). This reach appears to be a major source of resuspension. An estimate of annual loadings at the MA/RI state line and end of river is provided in Chapter 10. Information developed in earlier chapters leads to the estimation of the annual loads carried by the Blackstone River to Narragansett Bay. For calculation purposes the annual loads were divided into two parts: contribution by dry weather and contribution by wet weather. Total loadings for a particular year were determined by adding wet loads with dry loads for that year.

\subsection{Research Questions}

Can wet weather impact the water quality of the Blackstone River?

Absolutely yes. The analysis of the concentration data collected prior to the storm, during the storm and several hours after the storm supports this. In Chapter 5 it was found that, for UBWPAD there was no violation of maximum ammonia discharge during dry weather conditions but violations did occur in two out of three storms during wet weather (Storm 1 and Storm 3). In Figure 6.1 during peak flow between time 0 and 6 hours, fecal coliforms get by the UBWPAD without instream disinfection. This is probably due to the higher flows at the WWTF and the lower chlorine residual concentrations. Significantly more stations had FC violations under wet weather than dry weather which is clear from Table 6.1.

Wet weather cause acute criteria violations. Figure 6.2 illustrates just such a violation. During the height of the storm, instream hardness drops resulting in lower acute criteria concentrations. The more stringent criteria typically coincided with maximum 
instream concentrations. The result is the possibility of short term violations. The cause of higher metal concentration may be resuspension of the bottom sediments due to high flow and velocity, runoff, or poor performance of treatment facilities, subjected to increased flow during the storm. Acute and chronic criteria violations are summarized in Table 6.2. From the above discussion it is clear that wet weather can impact the water quality of the Blackstone River.

What are the major wet weather pollutant sources and/or areas in the Blackstone River watershed?

Pollutants associated with wet weather may come from either new sources (runoff induced) or old sources (river sediments). It is important to note that the former may be easier to control and regulate than the later. The water quality data coupled with stream flows allow for the calculation of mass loading curves. Each mass loading curve was integrated to obtain the total load (e.g. lbs) for each station for each storm. The total mass was divided by the time of the event to obtain the total loading for that constituent (e.g. lbs/day) for each station. Baseline loading rates (dry load in lbs/day) were estimated for each pollutograph from the initial (pre storm) sample and the final (post storm) samples. These rates were multiplied by the time of the event to obtain the total dry load for that station (lbs). The wet load (lbs) per station per constituent was determined by subtracting the dry load from the total. The data indicate clearly that with only minor exceptions more wet load entered the River during these periods than dry load.

Based on the loading estimates an estimate of pollutant gain or loss by reach was 
made. Net pollutant changes in a reach help to identify locations of major pollutant sources. The results of this evaluation also provides insight into the relative importance of each reach through a system ranking. A system ranking was made using the net gains for each reach and loads from the point sources, headwaters and tributaries. The ranking for each storm was calculated for both wet and total loads. The percent loadings by each reach section, headwater and point sources were averaged to get the summary \% loadings contribution and ranking was done again to come up with the summary rankings for all three storms. The ranking, without point sources for the wet load, were also calculated for each storm. The summary of rankings for wet load is provided in Table 8.1, total load in Table 8.2, and that of rankings without point sources in Table 8.3. These tables lists the major wet weather pollutant sources and/or areas in the Blackstone River watershed. A comparison of wet and dry weather sources for different constituents is provided in Table 8.4.

How to forecast the anmual wet weather loading rates to the Blackstone River?

The information collected during wet weather sampling program provided insights into the behavior of the sources during varying storm conditions. A relation ship was developed between rainfall and wet loadings using the data collected during the three storms (1992-93, EPA) and previous wet weather data available for the state line (BWW13) and end of river (BWW21) (Table 10.3). Regression plots were done for trace metals, nutrients and TSS. Summary tables for the regressions for BWW21 and BWW13 are presented in Tables 10.4 and 10.5, and example plots for copper are shown in Figures 
10.4 and 10.5 for each station, respectively.

These equations were used to estimate the annual wet loading rates for the Blackstone River. The data available had a rainfall range from 0.21 " to $1.94 "$. The model equations are therefore most appropriately applied to storms within that range. If the rainfall is greater than 2 ", the equations will over predict the wet loadings. So, to apply the model beyond 2.0", further observations for rainfall in excess of 2.0 inches is needed to extend the predictive equations.

How the dry and wet weather programs are linked together?

The dry weather data was sufficient to permit the calibration and verification of a model to describe trace metal transport as well as a model for dissolved oxygen (Wright et al., 1996). The dry weather models were used to estimate baseline mass loadings under steady state flow. The relationships developed in Table 10.1 were used to estimate the annual dry weather contributions at MA/RI state line (BWW13) and end of the river (BWW21). These dry weather loadings can be compared with the annual wet weather loadings. In the long run this is exactly what is needed to allow decisions into pollutant control. Addition of dry and wet loads will give the total annual load for a particular year.

\subsection{Conclusions}

The following conclusions were drawn from the results of this study:

\section{Nitrification}

UBWPAD's ability to provide nitrification is inhibited under high storm flows. The 
facility discharges significant levels of ammonia under these conditions.

- In reaches experiencing nitrification under dry weather steady-state condition, nitrification may be inhibited due to high storm flows.

- In reaches not experiencing nitrification under dry weather condition, nitrification may occur due to transient storm related ammonia loads which occur in upstream reaches.

\section{Concentration}

- Under high storm flows, high ammonia concentrations occurs in the reaches around Rice City Pond.

- UBWPAD had no violation of maximum ammonia concentrations discharge of 2.5 $\mathrm{mg} / \mathrm{l}$ under dry weather surveys, but under wet weather conditions violation of ammonia concentrations did occur in two out of three storms.

- WOON has no permitted discharge requirement for ammonia.

- Phosphorous concentrations are dominated by the two point sources UBWPAD and WOON.

- There is no permit requirement for either UBWPAD or WOON for phosphorous.

- The two treatment facilities are major contributors of metals to the Blackstone River. For the UBWPAD several metals were influenced by the higher storm flows through the facility. A comparison of average concentrations between dry and wet weather conditions lead to the following observations: chromium concentrations doubled under storm flows; cadmium and lead concentrations 
decreases under storm flows and copper and nickel did not change significantly.

- A comparison of maximum wet weather and dry weather concentrations lead to the following observations: for chromium wet weather was significantly higher; for cadmium dry weather was significantly higher and for lead, copper and nickel the ranges were not dissimilar.

- Since Woonsocket WWTF is located downstream of the river, so the flow in the river is much higher compared to the flow discharged by Woonsocket facility and the dilution is much higher also. As a result the high concentration discharged by Woonsocket get diluted and has less effect than UBWPAD on the river water quality.

- Headwaters have high concentration of $\mathrm{Pb}$.

Event Mean Concentration (EMC) and Event Mean Mass (EMM)

- The EMC and EMM profiles reflect the operation of UBWPAD with respect to nitrification. It was established earlier that nitrification was being provided at the facility during storm 1 and 3 . The instream data supports this with high nitrate EMC and EMM below UBWPAD and comparatively low ammonia levels. The reverse is true for Storm 2 when nitrification was not being provided at the facility.

- The increase in ammonia EMC and EMM between BWW17 and BWW18 are due to the Woonsocket WWTF discharge.

- For phosphorous the headwater concentrations are generally very low. There are major increases in the EMCs and EMMs between BWW01 and BWW02 and 
between BWW17 and BWW18 reflecting the two major treatment facilities.

- There is an interesting pattern for TSS profiles between BWW01 and BWW02 which again supports the operation of nitrification in the UBWPAD. With nitrification indicating a much higher retention time within the facility solids removal is often better. During Storm 1 and 3 where nitrification was occurring the TSS EMC profiles actually show a decline between BWW01 and BWW02. Storm 2 provides a different result reflecting the higher solids load from the UBWPAD when nitrification was not occurring. In that TSS EMC's were the highest for Storm 2 just below the UBWPAD discharge.

- The sharp decreases in the instream FC and EC EMCs and EMMs below the UBWPAD (between BWW01 and BWW02) for Storms 1 and 3 are most likely due to residual chlorine in the facilities effluent. This was not the case in Storm 2, where higher stream flows resulted in lower residuals. In fact, FC and EC concentrations increases to their highest levels in the reaches immediately below UBWPAD. The impact could be felt as far as BWW08.

- Similar increases of FC and EC are evident in the Woonsocket area including the WWTF and just below it.

- EMCs and EMMs for BOD had a similar trend for all three storms. Generally it increases after UBWPAD discharge and decreases to the mouth of the river. BOD does not appear strongly influenced by the storm related sources and therefore appears governed by point sources.

- Compared to the other metals, lead's $(\mathrm{Pb})$ major source appears to be in the 
headwaters (above BWW00). In fact, the headwater EMCs and EMMs are typically the highest along the entire river. The most probable cause would be urban runoff from Worcester.

- A consistent increase of lead does appear between BWW07 and BWW08 in Rice City Pond and is probably due to sediment resuspension.

- The other 5 metals ( $\mathrm{Cd}, \mathrm{Cr}, \mathrm{Cu}, \mathrm{Ni}$ and $\mathrm{Zn}$ ) have similar EMC and EMM profiles in that there appears to be two distinct peaks. The first occurs in the reaches below UBWPAD and is associated with the wastewater facilities discharge and possibly òther non point sources of metals, such as Patriots Metals. A secondary peak consistently occurs around BWW08, again the probable cause is sediment resuspension within Rice City Pond.

\section{Acute/Chronic Violation}

- High flows moving through Rice City Pond cause violations in the reaches at and below the dam due to resuspension.

- $\mathrm{Cu}$ is continually violated both with respect to chronic and acute criteria in both dry and wet weather starting at station BWW02.

- $\mathrm{Pb}$ chronic violations are continuous violation with respect to both dry and wet weather.

- Cd violations are more limited but also begins in and around BWW02.

- $\mathrm{Ni}$ and $\mathrm{Cr}$ has no acute and chronic violations under dry and wet weather.

- More stations had violations under wet weather than dry weather 
- More violations occurs if the storm event is bigger.

FC Violation

- The high loading at headwaters seems to be the main cause of problem of fecal coliform under both dry and wet weather. Loading may come from nonpoint source triggered by the wet weather. Further study of the collection system of Worcester is recommended.

- Residual chlorine from UBWPAD seems to perform poorly at peak flows under wet weàther

\section{Mass Loading}

- Most of the constituents have more than $50 \%$ wet loadings except for $\mathrm{Ni}$ and $\mathrm{NO}_{3}$.

- The trend of high wet load as the storm intensity increases is true for almost all the constituents except $\mathrm{NH}_{4}$.

- Headwaters has high $\%$ wet loads for most of the constituents and the \%wet load decreases as we move towards the mouth of the river.

- Blackstone River is the highest contributor of pollutants to the Narragansett Bay.

\section{Point and Non-Point Sources}

- $\mathrm{NH}_{4}$ and $\mathrm{PO}_{4}$ are dominated by point sources.

- $\quad \mathrm{Cd}, \mathrm{Cr}, \mathrm{Cu}, \mathrm{Pb}, \mathrm{Ni}, \mathrm{Zn}, \mathrm{TSS}, \mathrm{FC}, \mathrm{NO}_{3}$, and $\mathrm{BOD}$ are dominated by non-point sources. 


\section{System Rankings}

- Major source of $\mathrm{Pb}$ in both wet and dry weather appears to reside in the headwater.

- First five rankings represents $70 \%-90 \%$ of the total loadings for both wet and dry weather except for dry TSS (51\%), and wet $\mathrm{NO}_{3}(53 \%)$.

- UBWPAD is the major source of $\mathrm{Cu}$ ( $35 \%$ for dry, $18 \%$ for wet), $\mathrm{Ni}$ ( $47 \%$ for dry, $33 \%$ for wet), and Cd (37\% for dry, $15 \%$ for wet) for both dry and wet weather.

- Headwater is the major source of $\mathrm{Pb}$ for wet weather.

- WOON appears 3 times within first five rankings for 5 trace metals for dry weather but does not appear within first five rankings during wet weather.

- Head water is a major source of metals for wet weather but not for dry weather.

- Resuspension in Rice City Pond is a major source of metals for both wet and dry weather.

- TSS is mostly non-point source governed loadings.

- UBWPAD, and WOON are major sources of nutrients and WOON is responsible for $68 \%$ loads for $\mathrm{NH}_{4}$ under dry weather.

\section{Resuspension}

- Resuspension is an important phenomena in Rice City Pond.

- $\mathrm{Cu}, \mathrm{Ni}$, and TSS have more than $50 \%$ resuspension in Rice City Pond during wet weather events.

- $\mathrm{Cr}$, and $\mathrm{Pb}$ have less than $50 \%$ resuspension in Rice City Pond during wet weather 
events.

Annual Loading Rate

- $\quad$ Log-log relationship represents the data better for both rainfall vs loadings for wet load and flow vs concentration for dry load.

- To apply the model beyond rainfall of $2.0^{\prime \prime}$, further observation data points for rainfall and loads needs to be added to the database and again predictive equations can be developed.

- When oùr model and Nixon's regression model were compared against 6-data points, our model was found to forecast better for trace metals.

- Post audit of the model tells that model is forecasting well for nutrients.

- Percent wet load at BWW13 is higher than that at BWW21.

- Percent wet load delivered by Blackstone River to the Narragensett Bay is less than $50 \%$ for all constituents.

- Wet load is significant if we compare the number of the days of the year that wet weather events occur to the number of days in a year.

\subsection{Recommendation}

- complete a study of the headwaters (above BWW00) in detail under wet weather conditions, specially for $\mathrm{Pb}, \mathrm{FC}, \mathrm{EC}$ and solids.

- complete a study to determine the sources in Worcester's stormwater collection system for $\mathrm{Pb}, \mathrm{FC}, \mathrm{EC}$ and solids under wet weather conditions. 
The reach between BWW02 and BWW04 should be studied in detail.

Contribution of the local metal processing operations, located in this reach, need further study to determine their role in the problem. UBWPAD effluent violates the discharge permit for ammonia during wet weather events. Nitrification and disinfection is not efficient during the height of the storm (peak volume passing through the facility). Further study to determine operational change at the UBWPAD during the wet weather events is needed.

- Similar studies, as done on Rice City Pond (Wright et. al. 1996) should be done on other impoundments.

- Wetlands may be created along the river to store the flood water and reduce the velocity of flow which might solve the problem of resuspension.

- Some of the tributaries may be further studied for wet weather events.

- UBWPAD effluents may be discharged further downstream where dilution is greater. 


\section{REFERENCES}

Aber, J. D., K. J. Nadelhoffer, P. Steudler, and J. M. Melillo (1989). Nitrogen Saturation in Northern Forest Ecosystems. BioScience 39: 378-386.

Alley, K. D. (1994). Ganga and Gandagi: Interpretations of Pollution and Waste in Benaras. Ethnology. Spring 1994 v33 n2 p127(19).

Anderson, L., and L. Rydberg (1988). Trends in Nutrient and Oxygen Conditions Within the Kattegat: Effects on Local Nutrient Supply. Estuarine Coastal Shelf Sci. 26: 559-579.

Arnolds, J. G., J. R. Williams and D. R. Maidment (1995). Contimuous-Time Water and Sediment-Routing Model for Large Basins. Journal of Hydraulic Engineering. February 1995 v121 n2 p171(13).

Becker, Hank (1994). Streambed Erosion: Measuring Sediment's Ebb and Flow. Agricultural Research. July 1994 v42 n7 p10(2).

Borman, F. H. and G. E. Likens (1979). Pattern and Process in a Forested Ecosystem. Springer-Verlag, New York.

Blackstone River Restoration Study. (1994). US Army Corps of Engineers. Waltham, MA.

Blackstone River Valley National Heritage Corridor (BRVNHC). (1989). The Blackstone River Valley Cultural Heritage and Land Management Plant, revised in April 1993.

Blackstone River National Heritage Corridor Commission, Uxbridge, MA.

Bou-Sabb, J. F. (1993). Runoff as a Resource. Civil Engineering. October 1993 v63 n10 p70(2).

Brown, T., W. Burd, J. Lewis, and G. Chang (1994). Methods and Procedures in Stormwater Data Collection. Stormwater NPDES Related Monitoring Needs.

Proceedings of the Engineering Foundation Conference Held in Colorado, August 7-12, 1994. Edited by H. C. Torno, Published by ASCE, 1994. p194-206.

Browner, Carol M. (1994). The Administration's Proposal. EPA Journal. Summer 1994 $20 \mathrm{n} 1-2 \mathrm{p} 6(1)$.

Brush, S. W., M. E. Jennings, P. J. Young and H. C. McWreath (1994). NPDES Monitoring -Dallas - Fort Worth, Texas Area. Stormwater NPDES Related Monitoring Needs. Proceedings of the Engineering Foundation Conference Held in Colorado, August 
7-12, 1994. Edited by H. C. Torno, Published by ASCE, 1994. p115-143.

Cao, Zhixian, L. Wei, and J. Xie (1995). Sediment-Laden flow in Open Channels from Iwo-Phase Flow Viewpoint. Journal of Hydraulic Engineering. October 1995 v121 n10 p725(11).

Carreli, F. et al. (1995). Blackstone River Qual2E Post Audit Report, Unpublished data, Department of Civil and Environmental Engineering, University of Rhode Island, Kingston, RI.

Cave, K. A. and L. A. Roesner (1994). Overview of Stormwater Monitoring needs. Stormwater NPDES Related Monitoring Needs. Proceedings of the Engineering Foundation Conference Held in Colorado, August 7-12, 1994. Edited by H. C. Torno, Published by ASCE, 1994. p28-38.

Cheela S. (1994). Sediment transport in shallow river systems. A thesis presented to the University of Rhode Island, Kingston, RI, in partial fulfilment of the requirements for the degree of Master of Science.

Climatological Data of New England, National Oceanic and Atmospheric Administration (NOAA) 1991-1993.

Coburn J. (1994). Cleaning up Urban Stormwater: the Storm Drain Stenciling Approach (or Getting to the Nonpoint Source). Joumal of Soil and Water Conservation. July-August $1994 \mathrm{v} 49 \mathrm{n} 4 \mathrm{p} 312(4)$.

Comis, Don (1992). Rain, Runoff, and Underground Water. Agricultural Research. February 1992 v40 n2 p16(2).

Comis, Don (1995). AGNPS Tracks Pollutants to Their Source. Agricultural Research. February 1995 v43 n2 p22(1).

Cook, M. B., K. J. Weiss, and W. F. Swietlik (1994). Trends in NPDES Monitoring for Storm water. Stormwater NPDES Related Monitoring Needs. Proceedings of the Engineering Foundation Conference Held in Colorado, August 7-12, 1994. Edited by H.

C. Torno, Published by ASCE, 1994. p1-10.

Cooke, T., D. Drury, R. Katznelson, C. Lee, P. Mangarella, and K. Whitman (1994). Storm Water NPDES Monitoring in Santa Clara Valley. Stormwater NPDES Related Monitoring Needs. Proceedings of the Engineering Foundation Conference Held in Colorado, August 7-12, 1994. Edited by H. C. Torno, Published by ASCE, 1994. p144171. 
Costin, A. B. (1980). Runoff and Soil Nutrient Losses from an Unimproved Pasture at Ginninderra, South Tablelands, New South Wales. Australian Journal of Agricultural Research. 31: 533-546.

Doering, P. H., C. A. Oviatt, and M. E. Q. Pilson (1989). Monitoring of the Providence and Seekonk Rivers for trace metals and associated parameters. Narragansett Bay Project, NBP-89-16.

Donigian, A.S., and N.H. Crawford (1975). Nonpoint Pollution from the Land Surface. U.S. EPA, Washington, D.C. EPA 600/3-76/083.

EPA, 1971. Storm Water Management Model, SWMM. U.S. EPA, Washington, D.C. EPA no. 11 024D0C07/71 to 11 024D0C10/71.

EPA, 1986. Quality Criteria for Water. Office of Water Regulations and Standards. EPA 440/5-86/001.

EPA, 1987. The Enhanced Stream Water Quality Model OUAL2E. Environmental Research Laboratory, U. S. Environmental Protection Agency, Athens, GA 30613. EPA600/3-87/007/May 1987.

Evans, R. O., J. O. Parsons, K. Stone and W. B. Wells (1992). Watertable Management on a Watershed Scale. Journal of Soil and Water Conservation. January-February 1992 v47 nl p58(7).

Fransz, H. G. And J. H. G. Verhagen (1985). Modelling Research on the Production Cycle of Phytoplankton in the Southern Bight of the North Sea in Relation to Riverborne Nutrient Loads. Netherlands Journal of Sea Research. 19: 241-250.

Frasier, G. W., R. H. Hart, and G. E. Schuman (1995). Rainfall Simulation to Evaluate Infiltration/Runoff Characteristics of a Shortgrass Prairie. Journal of Soil and Water Conservation. September-October 1995, 50(5) 460-463.

French R. H. (1995). Estimating the Depth and Length of Sediment Deposition at Slope Transition on Alluvial Fans During Flood Events. Journal of Soil and Water Conservation. September-October 1995, v50 n5 p521-522.

Garbrecht, J., R. Kuhnle, and C. Alonso 1995. A Sediment Transport Capacity Formulation for Application to Large Channel Networks. Journal of Soil and Water Conservation. September-October 1995, v50 n5 p527-529.

Gillis, A. Maria (1990). Wetlands and water quality. BioScience. November 1990 v40 n10 p717(1). 
Gomez, Bill (1991). Bedload Transport. Earth- Science Reviews. August 1991 v31 n2 p89(44).

Graffin, K. (1990). Watershed Rehabilitation at Redwood National Park. Whole Earth Review, Spring 1990 n66 p49(3).

Haster, T. W. and W. P. James (1994). Predicting Sediment Yield in Storm-Water Runoff from Urban Areas. Journal of Water Resources Planning and Management. SeptemberOctober 1994 v120 n5 p630(21).

Hofmann, L, and R. E. Ries (1991). Relationship of Soil and Plant Characteristics to Erosion and Runoff on Pasture and Range. 46(2): 143-147.

Isensee, A. R. and Sadeghi, A. M. (1993). Impact of Tillage Practice on Runoff and Pesticide Transport. Journal of Soil and Water Conservation. November December 1993 v48 n6 p523(4).

Kibby, H. V. (1978). Effects of wetlands on Water Quality . Proceedings of the Symposium on Strategies for Protection and Management of Floodplain Wetlands and Other Riparian Ecosystems. GTR-WO-12, U. S. Department of Agricultural Forest Service, Washington, D. C. 410 pages.

Kipp, K. V., R. R. Zingarelli, and the staff of the Narragansett Bay Project (1992). Blackstone River "Briefing Paper" and Proceedings from Narragansett Bay Project Management Committee. Current Report the Narragensett Bay Project, RI. NBP-92-88.

Lancelot, C., G. et al. (1987). Phaeocystis blooms and Nutrient Enrichment in the Continental Zones of the North Sea. Ambio 16: 38-46.

Lang, R. D. (1979). The Effect of Ground Cover on Surface Runoff from Experimental. Plots. Journal of Soil Conservation, N.S.W. 35:108-114.

Latimer, J. S. (1989). A Review of the Major Research Done in Rhode Island on polychlorinated biphenyls in Water, Atmosphere, Sediment, and Biota. NBP-89-20.

Massachusetts Department of Environment Protection (MADEP), 1990. Commonwealth of Massachusetts Summary of Water Quality 1990. 1990 305(b) Report to Congress.

McCarthy, B.J. (1986). Fate and transport of heavy metals in the Pawtuxet River. Thesis presented to the University of Rhode Island, Kingston, RI, in partial fulfilment of the requirements for the degree of Master of Science.

McCuen, R. H. (1989). Hydrologic Analysis and Design. Prentice Hall, Inc., Englewood 
Cliffs, New Jersey.

McGinn, J. M. (1981). A Sediment Control Plan for the Blackstone River. Massachusetts Department of Environmental Quality Engineering (DEQE), Office of Planning and Program Management, Boston, MA. Pub. \#14946-244-25-7-30-CR.

Mertes, Leal A. K. (1994). Rates of Flood-Plain Sedimentation on the Central Amazon River. Geology. February 1994 v22 n2 p171(4).

Metcalf and Eddy, Inc. (1991). Assessment of Toxics Pollution in Narragansett Bay. Draft Report to Narragensett Bay Project. Providence, RI.

Pilson, M. E. Q., and C. D. Hunt, (1989). Water Quality Survey of Narragensett Bay. A summary of results from the SINBADD cruises 1985-1985. Narragansett Bay Project, RI. NBP-89-22.

Miller, S.K. (1991). When Pollution Runs Wild. National Wildlife. December-January 1991 v30 n1 p26(3).

Milliman, J. D., and R. Meade (1983). Worldwide Delivery of River Sediment to the Ocean. Journal Geology. 91: 1-21.

Mitchell, John G. (1996). Widespread as Rain and Deadly as Poison: Our Polluted Runoff. National Geographic. February 1996 v189 n2 p106(20).

Nixon, S. W. (1991). Recent Metal Inputs to Narragansett Bay, Current Report, The Narragansett Bay Project, NBP-91-66.

Novoty, V., M. Chin, and H.V. Tran (1979). LANDRUN- An Overland Flow Mathematical Model: Users Manual, Calibration and Use. International Joint Commission, Windsor, Ontario.

Novoty, V. and G. Chesters (1981). Handbook of Nonpoint Pollution Sources and Management. Van Nostrand Reinhold Company, New York, 1981.

Owens, L. B., W.M. Edwards, and R. W. Van Keuren (1996). Sediment Losses from a Pastured Watershed Before and After Stream Fencing. Journal of Soil and Water Conservation, January-February 1996, 51(1) 90-94.

Quinn, J. G., 1989. A Review of the Major Research Studies on Petroleum Hydrocarbons and Polycyclic Aromatic Hydrocarbons in Narragansett Bay. Narragansett Bay Project, RI. NBP-89-19. 
Quinn, J. G., J. S. Latimer, J. T. Ellis, L. A. LeBlanc, and J. Zheng (1988). Analyses of Archived Water Samples for Organic Pollutants. Narragansett Bay Project, RI. NBP-8804.

Raes, E. (1989). Pawtoxic Report. Unpublished data. Department of Civil and Environment Engineering, University of Rhode Island, Kingston, RI.

Reinelt, L.E., R. R. Horner, and B. W. Mar (1988). Nonpoint Source Pollution Monitoring Program Design. Journal of Water Resources Planning and Management. May 1988 v114 No. 3 p335-352.

Renner, R. (1996). Industry Opposition Stops Release of EPA Sediment Contamination Point Source Report. Environmental Science and Technology. February 1996 v30 n2 p69A(2).

Report to Congress: Nonpoint Source Pollution in the U.S. (1984). Operations Water Planning Division. U.S. Environmental Protection Agency, Washington, D.C.

The Rhode Island Committee For The Humanities. (1977). The Blackstone River/Canal Final Report, University of Rhode Island, CPAD Urban Field Center, Providence, RI.

Rhode Island Department of Environmental Management (RIDEM) (1990). The State of the State's Waters - Rhode Island. A report to Congress . P.L. 92-500, 305b.

Rosenberg, R. (1985). Eutrophication- the Future Marine Coastal Nuisance. Marine Pollutant Bulletin 16: 227-231.

Rosenberg, R. and L.O. Loo (1988). Marine Eutrophication Induced Oxygen Deficiency: Effect on Soft Bottom Fauna, Western Sweden. Ophelia 29: 213-225.

Roy Chaudhury, R. (1991). Post Audit of a Water Quality Model and Estimation of Point and Nonpoint Source Loadings in a Watershed. A Thesis Submitted in Partial Fulfillment of the Requirements for the Degree of Master of Science in Civil Engineering, University of Rhode Island, Kingston, RI.

Roy Chaudhury et. al. (1993). Isolation of Wet Weather Inputs into a River. Proceedings of the Runoff Quantity and Quality Modeling Conference, ASCE, Reno, Nevada.

Save The Bay (1990). Bring Back the Blackstone. Save The Bay, Providence, RI.

Science News (1994). Water Toxicity: What EPA Doesn't Know. Science News. April 16 1994 v145 n16 p255(1). 
Schlosser, I. J. And J. R. Karr. (1981). Water Quality in Agricultural watersheds: Impact of Riparian Vegetation During Base Flow. Water Resources Bulletin. 17: 233-240.

Skoch II, E. A. (1993). Regulation of Storm Water Discharges Under the Clean Water Act. Environmental Law. July 199323 n3 p1087-1105.

Soileau, J. M., J. T. Touchton and K. H. Yoo. (1994). Sediment, Nitrogen, and Phosphorous Runoff With Conventional-and Conservation-Tillage Cotton in a Small Watershed. Journal of Soil and Water Conservation. January- February 1994 v49 n1 p82(8).

Southgate, D. and R. Macke (1989). The downstream denefits of soil conservation in Third World Hydroelectic Watersheds. Land Economics. February 1989 v65 nl p38(11).

Srivasta R. And D. N. Contractor (1992). Bed-Load and Suspended-Load Transport of nomuniform sediments. Journal of Hydraulic Engineering. June 1992 v118 n6 p948(3).

Thomman V.R., and Mueller, J.A. (1987). Principles of surface water quality modeling and control. Harper \& Row Publishers, New York.

Tsirkunov, V. V., A. M. Nikanorov, M. M. Laznik and Z. Dongwei (1992). Analysis of Long-Term and seasonal River Water Quality Changes in Lavatia. Water Resources. Volume 26, No. 9 pp1203-1216, 1992.

Taylor, R. A. (1987). Clean Water: adding the Balance Sheet. U. S. News and World Report. February 16, 1987 v102 p22(2).

Thomas, P. M. and S. I. McClelland (1994). NPDES Monitoring - Atlanta, Georgia Region. Stormwater NPDES Related Monitoring Needs. Proceedings of the Engineering Foundation Conference Held in Colorado, August 7-12, 1994. Edited by H. C. Torno, Published by ASCE, 1994. p95-114.

Turner, R. E. And N. N. Rabalais (1991). Changes in Mississippi River Water Quality This Century. BioScience. March 1991 v41 n3 p140(8).

Tucker, S., D. Harrison, and S. Gilson (1995). Stormwater Regulation: Time for Reform. ENR. April 24, 1995 v234 n16 pE42(3).

Uiban Storm Water Runoff. The Hydrologic Engineering Center, U.S. Army Corps of Engineers, Davis, California, 1975.

U. S. Department of Commerce (1985). Pollution Abatement and Control Expenditures, 1980-83. Survey of Current Business. March 1985 v66 p18(5). 
U. S. Environmental Protection Agency (USEPA) (1983). Site Specific Water Quality Assessment: Blackstone River, Massachusetts. Environmental Monitoring Systems Laboratory, Las Vegas, Nevada. EPA 600/X-83-028.

Viessman, W., Lewis, G. L. and Knapp, J. W. (1990). Introduction to Hydrology. Harper \& Row, Publishers, Inc ., New York, N.Y.

Wanielista, Martin P. (1990). Hydrology and Water Quantity Control. John Wiley \& Sons, Inc., New York, N.Y.

Warwick, J. J. and J. D. Edgmon (1988). Wet Weather Water Quality Modeling. Journal of Water Resources Planning and Management. Volume 114, No. 3, May 1988.

White, F. C., J. R. Hairston, W. N. Musser, H. F. Perkins, and J. F. Reed (1981). Relationship Between Increased Crop Acreage and Nonpoint-Source Pollution: A Georgia Case Study. Journal Soil Water Conservation. 36: 172-177.

Wischmeir, W. H. And D. D. Smith,(1978). Predicting Rainfall Losses - A Guide to Conservation Planting, United States Department of Agriculture, Agriculture Handbook No. 537.

Wright, R. M. And B. J. McCarthy (1985). Chemical Monitoring and Computer Modelling of Pollutants in the Pawtixet River, Rhode Island, Vol.II, Computer Modelling of Toxic Pollutants in the Pawtoxet River. RI Department of Environmental Management, Providence, RI.

Wright, R. M. (1988). Development of a One Dimensional Water Quality Model for the Blackstone Rjver. Narragansett Bay Project, NBP-88-10.

Wright, R. M., I. Runge, Y. S. Lee and R. Roy Chaudhury. (1990). Blackstone River 1990. Narragansett Bay Project, NBP-92-85.

Wright et. al. (1991). Problem Assessment and Source Identification and Ranking of Wet Weather Discharges Entering the Providence and Seekonk Rivers, Prepared for the Narragansett Bay Project, Providence, RI and U.S. Environmental Protection Agency, Boston, MA

Wright, R. M., I. Runge, R. Roy Chaudhury, and D. W. Urish (1992). System Wide Modeling for the Providence Area Combined Sewer System, Final Report by Department of Civil and Environmental Engineering University of Rhode Island, Submitted to the Narragansett Bay Commission, Providence, RI. 
Wright, R. M., R. Roy Chaudhury, and S. Makam (1994). Blackstone River Wet Weather Initiative. Stormwater NPDES Related Monitoring Needs. Proceedings of the Engineering Foundation Conference Held in Colorado, August 7-12, 1994. Edited by $\mathrm{H}$. C. Torno, Published by ASCE, 1994. p207-228.

Wulff, F. and L. Rahm. (1988). Long-Term, Seasonal and Spatial Variations of Nitrogen, Phosphorous and Silicate in the Baltic: an Overview. Marine Environmental Research 26: 19-37.

Ziegler, C. Kirk and B. Nisbet (1994). Fine-Grained Sediment Transport in Pawtuxet River, Rhode Island. Journal of Hydraulic Engineering. May 1994 v120 n5 p561(16).

Zobisch, M. A. (1993). Erosion Susceptibility and Soil Loss on Grazing Lands in Semiarid and Subhumid Loactions of Eastern Kenya. Journal of Soil and Water Conservation 48(5):445-448. 


$$
\text { APPENDIX - A }
$$

Contains the following tables:

Table A.1 Water Quality Data for Storm $1 \ldots \ldots \ldots \ldots \ldots \ldots \ldots \ldots \ldots$

Table A.2 Water Quality Data for Storm $2 \ldots \ldots \ldots \ldots \ldots \ldots \ldots \ldots$

Table A.3 Water Quality Data for Storm $3 \ldots \ldots \ldots \ldots \ldots \ldots \ldots \ldots \ldots$ 
Table A.1 Water Quality Data for Storm 1

\begin{tabular}{|c|c|c|c|c|c|c|c|c|c|c|c|c|c|c|}
\hline Station & Run & Date & Time & $\begin{array}{l}\text { Frow } \\
\text { che }\end{array}$ & $\begin{array}{l}\text { Temp } \\
\operatorname{deg} C\end{array}$ & PH & $\begin{array}{l}\text { Cond } \\
\text { umhoevem }\end{array}$ & mon & $\begin{array}{l}B O D \\
\mathrm{mg} /\end{array}$ & $\begin{array}{l}\text { TSS } \\
\mathrm{mgh}\end{array}$ & $\begin{array}{l}\text { VSs } \\
\text { mgh }\end{array}$ & $\stackrel{\mathrm{Cl}}{\mathrm{mgh}}$ & $\begin{array}{c}\text { Ca } \\
\text { mgl }\end{array}$ & $\mathrm{mg}_{\mathrm{g}}$ \\
\hline Exwoo & $\mathbf{P}$ & $9 / 2292$ & 1142 & 15.3 & 18.5 & 6.84 & 255 & 8.4 & 3.8 & 2.4 & 1.6 & 59.6 & 22.1 & 3.36 \\
\hline EMWoo & o & $9 / 22 / 92$ & $\begin{array}{l}2348 \\
0250\end{array}$ & 38.3 & 20 & 6.76 & 182 & 8.3 & 2.85 & 1.3 & 0.7 & 65.5 & 20.9 & 3.52 \\
\hline EMNoo & 3 & $9 / 23 / 92$ & 0250 & 172 & 20 & 6.12 & 132 & 6.4 & 6.6 & 3.4 & 1.8 & 45.5 & 12.1 & 2.31 \\
\hline EXMoo & 6 & $9 / 23 / 92$ & 0540 & 59.5 & 18.8 & 6.6 & 101 & 7.9 & 4.8 & 15.4 & 6.4 & 27.5 & $\theta$ & 1.67 \\
\hline Emmoo & 9 & $9 / 23 / 92$ & 0816 & 53.7 & 18.2 & 6.17 & 97 & 8.4 & 3.95 & 11 & 4 & 30.1 & 9.5 & 1.75 \\
\hline BWMoo & 12 & $9 / 23 / 92$ & 1115 & 43.1 & 18.3 & 6.24 & 124 & 9.1 & 1.8 & 7.4 & 3 & 35.1 & 12.8 & 2.29 \\
\hline onmoo & 16 & $9 / 23 / 92$ & 1536 & 33.8 & 19.2 & 6.47 & 184 & 8.8 & 0.5 & 6.8 & 2.8 & 44.3 & 16.2 & 2.9 \\
\hline BWMoo & 24 & 9/23/92 & 2310 & 21.8 & 16.5 & NA & 183 & 8.85 & 1.6 & 5.6 & 1.6 & 54.2 & 19.6 & 3.28 \\
\hline EMMnco & 32 & $8 / 24 / 92$ & 0722 & 15.3 & 15 & 6.52 & 181 & 7.3 & 0.6 & 8 & 26 & 49.1 & 19.7 & 3.43 \\
\hline ExMoo & 40 & $9 / 24 / 92$ & 1516 & 21.2 & 16 & 6.68 & 168 & 7.3 & 1.3 & 3.2 & 2.6 & 58.7 & 19.5 & 3.23 \\
\hline EMMo1 & $\mathbf{P}$ & 8/22092 & 1200 & 16.5 & 18.8 & 6.68 & 280 & 8.4 & 6.35 & 26 & 22 & 208 & 28.7 & 3.87 \\
\hline EMNo1 & 0 & $9 / 23192$ & 0006 & 41.2 & 19.8 & 6.36 & 240 & 7.6 & 10.3 & 3.4 & 2.4 & 188 & 23.5 & 3.97 \\
\hline BMMO1 & 3 & $9 / 23 / 92$ & 0305 & 185 & 19.1 & 6.58 & 176 & 6.3 & 7.85 & 26.4 & 8.8 & 72.4 & 18.2 & 3.6 \\
\hline BMMO1 & 6 & $8 / 23 / 92$ & 00545 & 64 & 18.5 & 6.65 & 186 & 7.5 & 4.06 & 11.4 & 5.2 & 57.3 & 18.1 & 3.44 \\
\hline BNMO1 & 9 & $9 / 23 / 92$ & 0830 & 57.8 & 18.2 & 6 & 169 & 7.8 & 3.36 & 6 & 3.4 & 55.9 & 16 & 2.87 \\
\hline вмио1 & 12 & 8/23r92 & 1130 & 46.4 & 18.5 & 6.18 & 270 & 8.8 & 2.8 & 5.2 & 28 & 94.8 & 17.3 & 3.66 \\
\hline EMMO1 & 16 & $9 / 23 / 92$ & 1645 & 36.3 & 18.9 & 6.43 & 218 & 8.2 & 255 & 4 & 2.4 & 65.5 & 18.7 & 3.48 \\
\hline BMMO1 & 24 & $9 / 23 / 92$ & 2331 & 23.5 & 16.4 & NA & 238 & 8.15 & 1.6 & 2.8 & 0.6 & 70.2 & 22.6 & 3.87 \\
\hline Exиo1 & 32 & 8/24/92 & 0733 & 16.5 & 14.8 & 6.58 & 242 & 7.2 & 1 & 3.8 & 1.8 & 74.1 & 23.8 & 3.89 \\
\hline EMMO1 & 40 & $9 / 24 / 92$ & 1531 & 23.5 & 16 & 6.86 & 328 & 7.2 & 245 & 22 & 2.2 & 82.1 & 25 & 4.01 \\
\hline BMMo2 & $\mathbf{P}$ & $\$ / 2092$ & 1216 & 73.3 & 20.8 & 6.45 & 40 & 7.7 & 8.7 & 8 & 4.5 & 131 & 25 & 3.66 \\
\hline EWMor & 0 & $9 / 23 \times 92$ & 0025 & 107 & 20.4 & 6.48 & 333 & 7.3 & 7.95 & 4.2 & 3 & 136 & 28.2 & 3.47 \\
\hline EMUñ2 & 3 & $9 / 23 / 92$ & 0330 & 288 & 20.5 & 0.18 & 240 & 6.8 & 8.3 & 7.8 & 5.6 & 87.4 & 23.6 & 3.56 \\
\hline BwWor & 6 & $9 / 23 / 92$ & 0615 & 156 & 19.5 & 6.54 & 271 & 7.1 & 7.1 & 14.2 & 5.6 & 95.4 & 21 & 3.52 \\
\hline Bw402 & 9 & $9723 / 92$ & 0848 & 142 & 19.8 & 6.28 & 258 & 7.5 & 6.3 & 7.2 & 4.4 & $\pi$ & 18.6 & 3.14 \\
\hline EMWO2 & 12 & 9/23/92 & 1150 & 118 & 20 & 8.11 & 230 & 8.3 & 2.4 & 5.4 & 3.8 & 67.3 & 17.2 & 2.85 \\
\hline BuM02 & 16 & $9 / 23 / 92$ & & 88.8 & 20 & 6.16 & 251 & 7.8 & 2.7 & 5.8 & 3.4 & 75.7 & 17.4 & 2.82 \\
\hline EMM02 & 24 & $9 / 23 / 92$ & 2346 & 49.6 & 17.6 & $\mathbf{N A}$ & 300 & 7.45 & 5.8 & 4.8 & 3.4 & 80.4 & 20.1 & 2.99 \\
\hline BWW02 & 32 & $9 / 24 / 92$ & 0755 & 49.6 & 16.5 & 6.27 & 318 & 8 & 1.16 & 5.3 & 3.8 & 77.8 & 21.9 & 3.47 \\
\hline BWWO2 & 40 & $9 / 24 / 92$ & 01545 & 80.7 & 18.2 & 6.45 & 332 & 8 & 245 & 5.8 & 4.2 & 93.6 & 23.8 & 3.38 \\
\hline BMWo4 & $\mathbf{P}$ & 920292 & 1238 & 79 & 20 & 6.84 & 455 & 8.65 & 8.3 & 5 & 4.2 & 106 & 23.7 & 3.69 \\
\hline EMMO4 & 0 & $9 / 23 / 92$ & 0059 & 93 & 20.7 & 6.7 & 313 & 8.15 & 1.75 & 33.8 & 11.6 & 110 & 23.3 & 3.37 \\
\hline EMmod & 3 & $9 / 23192$ & 0400 & 182 & 20 & 6.7 & 310 & 8.6 & 8.55 & 35.8 & 15.2 & 104 & 18.5 & 3.07 \\
\hline BwWo4 & 6 & $9 / 23 / 92$ & 0655 & 245 & 19.2 & 6.66 & 277 & 8.3 & 7.65 & 23.6 & 8.8 & 76.8 & 19.9 & 3.05 \\
\hline Bwnos & 9 & 9/23/92 & 0915 & 163 & 18.4 & 6.95 & 255 & 9 & 6.2 & 10.2 & 5 & 81.6 & 19.3 & 3.02 \\
\hline Exйo4 & 12 & $9 / 23 / 92$ & 1215 & 144 & 20 & 6.52 & 270 & 9.2 & 1.05 & 7.6 & 4.8 & 79.3 & 19.9 & 3.2 \\
\hline вимо & 18 & $9 / 2392$ & 1630 & 116 & 20.8 & 6.49 & 252 & 8.6 & 3.45 & 3.8 & 1.8 & 74.6 & 19.9 & 3.1 \\
\hline Exй & 24 & 8/2492 & 0008 & 80 & 17 & NA & 253 & 9.05 & 3.35 & 2.4 & 1.6 & 73.2 & 98 & 2.85 \\
\hline BWMos & 32 & 82492 & 0820 & 53 & 15.2 & 6.61 & 300 & 8.8 & 3.55 & 1.6 & 0.8 & 80.8 & 19 & 295 \\
\hline BMMO4 & 40 & $9 / 2492$ & 1605 & 66 & 17.2 & 6.72 & 316 & 8.7 & 215 & 28 & 28 & 68.8 & 22.2 & 3.22 \\
\hline BxMOS & $\mathbf{P}$ & $8 / 20 / 92$ & 1312 & 4.5 & 20.7 & 7.3 & 215 & 10.2 & $M$ & 1.5 & 1.5 & 70.6 & 19.3 & 3.37 \\
\hline BMmos & 0 & $8 / 23 / 92$ & 0147 & 3.8 & 19.8 & 6.61 & 182 & 7.15 & NA & 1.7 & 1.3 & 74.4 & 18.7 & 3.22 \\
\hline Bwnos & 3 & 9/23/92 & 0440 & 6.2 & 19.2 & 6.41 & 192 & 7 & $M$ & 1.4 & 1 & 75 & 18.0 & 3.33 \\
\hline Bunos & 6 & 8/23/92 & ores & 6.2 & 18.5 & 6.52 & 199 & 7.2 & MA & 1.4 & 1.2 & 60.9 & 19 & 3.42 \\
\hline Bunos & $\theta$ & $8 / 23992$ & 0045 & 7.8 & 18.8 & 6.48 & 199 & 9.2 & NA & 0.8 & 0.6 & 70.2 & 18 & 3.43 \\
\hline BMmos & 12 & $9 / 23 / 92$ & 1245 & 9.3 & 10 & 6.4 & 202 & 8.6 & NA & 1.6 & 1 & 67.4 & 19.2 & 3.41 \\
\hline BWMOS & 16 & $9 / 2392$ & 1645 & 9.3 & 19.3 & 6.27 & 198 & 8.6 & NA & 1.4 & 1 & 63.3 & 18.9 & 3.44 \\
\hline Bumos & 24 & 9/24/92 & 0038 & 6.7 & 17.6 & MA & 216 & 8 & MA & 0.5 & 0.5 & 66 & 18.8 & 3.37 \\
\hline Bwnos & 32 & 9/24/92 & 0855 & 5.6 & 18 & 8.31 & 2009 & 8.5 & MA & 25 & 2.5 & 63.4 & 19.3 & 3.41 \\
\hline Exwos & 40 & $9 / 2492$ & 1639 & E.1 & 17.5 & 6.86 & 201 & 8.9 & MA & 2 & 2 & 70.6 & 19 & 3.44 \\
\hline BMmos & $\mathbf{P}$ & $9 / 20192$ & 01257 & 70.7 & 18.8 & 6.68 & 380 & 8.3 & 4.85 & 3.8 & 1.8 & 89.2 & 22 & 3.22 \\
\hline Bunns & 0 & 9/23/92 & 0119 & 67.4 & 20.5 & 6.68 & 303 & 7.8 & 8.4 & 7.5 & 5.3 & 105 & 21 & 3 \\
\hline BMNo6 & 3 & $8 / 23192$ & 0440 & 110.8 & 20.5 & 6.60 & 304 & 7.7 & 6.05 & 11.4 & 6.8 & 78.8 & 21.5 & 3.07 \\
\hline BMNDB & 6 & $8 / 23 / 92$ & 0715 & 110.8 & 10.2 & 6.49 & 313 & 7.6 & 20 & 9.8 & 3.8 & 75.8 & 21.3 & 3.01 \\
\hline EMMos & 9 & $9 / 23192$ & 0935 & 141.3 & 19.2 & 6.31 & 318 & 8.5 & 6.3 & 9.4 & 3.8 & 95.8 & 20.8 & 2.83 \\
\hline EmMos & 12 & $9 / 23 / 92$ & 1230 & 168.7 & 20 & 6.34 & 289 & 8.4 & 4.2 & 8.4 & 3.6 & 83.4 & 18.9 & 2.89 \\
\hline Bumos & 16 & $823 / 92$ & 1700 & 168.7 & 20.1 & 6.54 & 262 & 8.7 & 3.85 & 7 & 2 & 73.4 & 19.7 & 2.76 \\
\hline Bumpes & 24 & $9 / 23 / 92$ & 0020 & 120.2 & 17.6 & MA & 270 & 8.5 & 3.25 & 28 & 1.6 & 72 & 18.5 & 2.7 \\
\hline Bumos & 32 & $9 / 2492$ & 0835 & 100 & 15.7 & 6.54 & 260 & 8.7 & 235 & 7 & 3.5 & 76.3 & 18.3 & 2.68 \\
\hline Exм0s & 40 & $9 / 2492$ & 1625 & 90 & 16.5 & 8.81 & 268 & 8.5 & 3.65 & 5.2 & 2.8 & 79.5 & 18.8 & 2.58 \\
\hline EMMN7 & $\mathbf{P}$ & 212201 & 1500 & 107 & 20.5 & 6.65 & 350 & 8.6 & 3.05 & 1.8 & 1.4 & 88.4 & 21.4 & 3.06 \\
\hline BMNo7 & 0 & $9 / 22 / 92$ & 0130 & $\$ 5$ & 21 & 6.7 & 332 & 9.2 & 3.2 & 6.2 & 28 & 83.1 & 21.3 & 3.09 \\
\hline BMwo7 & 3 & $9 \sqrt{23192}$ & 0415 & 99 & 20.8 & 8.68 & 345 & 9.1 & 3.46 & 6.2 & 28 & 85.1 & 20.9 & 3.07 \\
\hline Bนทับ7 & 6 & 9/23/92 & 0715 & 101 & 19.5 & 6.47 & 338 & 8.35 & 23 & 8.8 & 2.6 & 74.8 & 20.8 & 3.22 \\
\hline EMMo7 & 9 & e/23/92 & 1040 & 103 & 10.2 & 6.55 & 3200 & 7.6 & 2.2 & 8.6 & 3.4 & 82.2 & 21.3 & 3.13 \\
\hline EMMOr & 12 & $8 / 23192$ & 1405 & 104 & 19.8 & 6.49 & 335 & 9.2 & 275 & 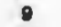 & 4.8 & 80 & 21.6 & 3.1 \\
\hline EMMO7 & 16 & $9 / 23 / 92$ & 1640 & 111 & 20 & 6.25 & 360 & 9.85 & 1.5 & 3.2 & 1.8 & 86.8 & 21.3 & 3 \\
\hline Buพvo7 & 24 & $9 \sqrt{23192}$ & $\cos 5$ & 123 & 18.5 & $\mathrm{MA}$ & 330 & 9.4 & 21 & 124 & 4.8 & 89.8 & 20.1 & 3.09 \\
\hline Buwo7 & 32 & $9 / 24 / 92$ & 0850 & 120 & 18.5 & 8.41 & 290 & 8.1 & 22 & 11 & 2.4 & 78.9 & 20.2 & 3.05 \\
\hline EMMo7 & 40 & $9 / 2 / 92$ & 1736 & 123 & 17.3 & 7.06 & 292 & 8.4 & 236 & 4 & 2.4 & 71.4 & 19.3 & 28 \\
\hline EwMos & $\mathbf{P}$ & $9 / 22 / 92$ & 1440 & 109 & 21 & 6.74 & 338 & 8.8 & 2.98 & 6.2 & 2.6 & 90.3 & 19.6 & 3 \\
\hline BWMOS & 0 & $9 / 22 / 92$ & 0110 & 124 & 20.5 & 6.45 & 322 & 7.7 & 3.65 & 11.8 & 3.8 & 67.2 & 49.5 & 3.02 \\
\hline BWMos & 3 & $9 / 23 / 92$ & 0350 & 129 & 20 & 6.79 & 315 & 7.1 & 5.2 & 18.2 & 6 & 83.2 & 18.8 & 2.95 \\
\hline B'Мм08 & 6 & $9 / 23 / 92$ & 0700 & 115 & 19.5 & 6.62 & 310 & 7.55 & 3.55 & 17.2 & 4.4 & 728 & 17.5 & 2.7 \\
\hline Bwwos & 9 & 923192 & 1005 & 111 & 18 & 6.35 & 320 & 7.65 & 1.85 & 11 & 3.6 & 80.1 & 20.3 & 3.16 \\
\hline BMМ०s & 12 & & & & & 6.45 & 330 & 9.25 & 245 & 4.8 & 1.4 & 81 & 19.8 & 3.13 \\
\hline
\end{tabular}


Table A.1 Water Quality Data for Storm 1 (Continued)

\begin{tabular}{|c|c|c|c|c|c|c|c|c|c|c|c|c|c|c|}
\hline Stution & Run & Oate & Time & Flow & $\begin{array}{l}\text { Temp } \\
\operatorname{deg} C\end{array}$ & pH & $\begin{array}{l}\text { Cond } \\
\text { umhow/em }\end{array}$ & $\begin{array}{c}\text { DO } \\
\mathrm{mgh}\end{array}$ & $\begin{array}{l}\text { BOD } \\
m g h\end{array}$ & $\begin{array}{l}\text { Tss } \\
\text { mal }\end{array}$ & $\begin{array}{l}\text { VSs } \\
\text { mgl }\end{array}$ & $\begin{array}{c}\mathrm{cl} \\
\mathrm{mgh}\end{array}$ & cal & $\mathrm{mg}$ \\
\hline 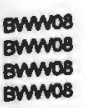 & $\begin{array}{l}16 \\
24 \\
32 \\
40\end{array}$ & $\begin{array}{l}9 / 23 / 92 \\
9 / 23 / 92 \\
9 / 24 / 92 \\
9 / 24 / 92\end{array}$ & $\begin{array}{l}1620 \\
0040 \\
0825 \\
1725\end{array}$ & $\begin{array}{l}125 \\
130 \\
138 \\
136\end{array}$ & $\begin{array}{c}20 \\
17.5 \\
16 \\
17\end{array}$ & $\begin{array}{l}6.41 \\
\mathrm{NA} \\
6.41 \\
7.08\end{array}$ & $\begin{array}{l}312 \\
325 \\
290 \\
315\end{array}$ & $\begin{array}{c}8.3 \\
8.3 \\
8.45 \\
7.8\end{array}$ & $\begin{array}{l}2.1 \\
2.2 \\
2.1 \\
2.4\end{array}$ & $\begin{array}{c}3.4 \\
12.6 \\
10 \\
2.6\end{array}$ & $\begin{array}{l}1.9 \\
4.6 \\
2.4 \\
2.1\end{array}$ & $\begin{array}{l}77.2 \\
80.4 \\
85.8 \\
82.8\end{array}$ & $\begin{array}{l}20.6 \\
20.2 \\
19.1 \\
19.3\end{array}$ & $\begin{array}{l}2.99 \\
3.05 \\
2.96 \\
2.83\end{array}$ \\
\hline 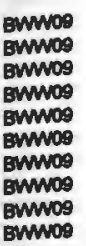 & $\begin{array}{l}P \\
0 \\
3 \\
6 \\
9 \\
12 \\
16 \\
24 \\
32 \\
40\end{array}$ & $\begin{array}{l}9 / 22 / 92 \\
9 / 22 / 92 \\
9 / 23 / 92 \\
9 / 23 / 92 \\
9 / 23 / 92 \\
9 / 23 / 92 \\
9 / 23 / 92 \\
9 / 23 / 92 \\
9 / 24 / 92 \\
9 / 24 / 92\end{array}$ & $\begin{array}{l}1415 \\
0050 \\
0330 \\
0630 \\
1025 \\
1330 \\
1600 \\
0022 \\
0815 \\
1655\end{array}$ & $\begin{array}{l}11.5 \\
12.0 \\
14.2 \\
14.8 \\
13.8 \\
12.5 \\
12.0 \\
11.6 \\
11.0 \\
9.29\end{array}$ & $\begin{array}{c}21 \\
22 \\
21.2 \\
19.8 \\
19.5 \\
20 \\
20.5 \\
18 \\
16 \\
17\end{array}$ & $\begin{array}{l}6.31 \\
5.24 \\
6.7 \\
6.49 \\
6.73 \\
6.24 \\
6.18 \\
\mathrm{MA} \\
6.22 \\
6.9\end{array}$ & $\begin{array}{l}108 \\
105 \\
110 \\
105 \\
85 \\
95 \\
100 \\
95 \\
90 \\
82\end{array}$ & $\begin{array}{c}10.4 \\
8.4 \\
9.6 \\
8.5 \\
8.5 \\
10.3 \\
10.5 \\
10.5 \\
10.2 \\
7.2\end{array}$ & $\begin{array}{c}1.85 \\
1.4 \\
1 \\
\text { ND } \\
\text { ND } \\
1.4 \\
\text { ND } \\
\text { ND } \\
\text { ND } \\
\text { ND }\end{array}$ & $\begin{array}{c}1.8 \\
2 \\
0.8 \\
N D \\
2 \\
2 \\
1 \\
1.4 \\
4.2 \\
2\end{array}$ & $\begin{array}{c}1.4 \\
2 \\
0.8 \\
\text { ND } \\
1 \\
2 \\
1.2 \\
0.6 \\
2.2 \\
1\end{array}$ & $\begin{array}{c}42.4 \\
42 \\
29 \\
24.4 \\
25.5 \\
26.3 \\
21.2 \\
27.2 \\
25.7 \\
27.2\end{array}$ & $\begin{array}{l}6.7 \\
6.5 \\
6.8 \\
6.7 \\
6.8 \\
6.5 \\
6.4 \\
6.6 \\
6.8 \\
6.4\end{array}$ & \begin{tabular}{l|l|l}
1.7 \\
1.68 \\
1.76 \\
1.78 \\
1.75 \\
1.65 \\
1.67 \\
1.71 \\
1.78 \\
1.65
\end{tabular} \\
\hline $\begin{array}{l}\text { BWW10 } \\
\text { BWW10 } \\
\text { BWW10 } \\
\text { BWW10 } \\
\text { BWW10 } \\
\text { BWW10 } \\
\text { BWW10 } \\
\text { BWW10 } \\
\text { BWW10 } \\
\text { BWW10 }\end{array}$ & $\begin{array}{l}P \\
0 \\
3 \\
6 \\
8 \\
12 \\
16 \\
24 \\
32 \\
40\end{array}$ & $\begin{array}{l}9 / 22 / 92 \\
9 / 22 / 92 \\
9 / 23 / 92 \\
9 / 23 / 92 \\
9 / 23 / 92 \\
9 / 23 / 92 \\
9 / 23 / 92 \\
9 / 23 / 92 \\
9 / 24 / 92 \\
9 / 24 / 92\end{array}$ & $\begin{array}{l}1430 \\
0100 \\
0340 \\
0645 \\
1010 \\
1330 \\
1560 \\
0030 \\
0825 \\
1705\end{array}$ & $\begin{array}{l}7.64 \\
7.04 \\
0.42 \\
0.07 \\
9.07 \\
9.24 \\
9.24 \\
9.24 \\
8.74 \\
8.00\end{array}$ & $\begin{array}{c}19.5 \\
20 \\
19 \\
18 \\
17.5 \\
18 \\
18 \\
16 \\
14.8 \\
16.1\end{array}$ & $\begin{array}{l}6.28 \\
6.19 \\
6.83 \\
6.05 \\
6.69 \\
6.17 \\
6.01 \\
M 1 \\
6.22 \\
6.9\end{array}$ & $\begin{array}{l}170 \\
170 \\
160 \\
150 \\
140 \\
160 \\
150 \\
155 \\
150 \\
145\end{array}$ & $\begin{array}{l}9.8 \\
8.85 \\
8.85 \\
8.85 \\
8.8 \\
9.5 \\
10 \\
9.3 \\
9.4 \\
7\end{array}$ & $\begin{array}{l}\text { MA } \\
\text { MA } \\
M A \\
M A \\
N A \\
M A \\
N A \\
M A \\
M A \\
M A\end{array}$ & $\begin{array}{l}2.3 \\
4 \\
2.8 \\
0.8 \\
N D \\
3.8 \\
1.2 \\
9.2 \\
3.2 \\
1.5\end{array}$ & $\begin{array}{l}1.9 \\
3.5 \\
1.8 \\
0.8 \\
\text { ND } \\
2.2 \\
\text { ND } \\
2.8 \\
1 \\
1.5\end{array}$ & $\begin{array}{c}62.4 \\
47 \\
65.5 \\
47 \\
47 \\
51.6 \\
45.6 \\
51.7 \\
47.9 \\
58\end{array}$ & $\begin{array}{c}8.2 \\
7.9 \\
7.9 \\
8 \\
7.6 \\
7.9 \\
7.7 \\
8.3 \\
8.2 \\
8.2\end{array}$ & $\begin{array}{l}1.96 \\
1.93 \\
1.85 \\
1.92 \\
1.82 \\
1.93 \\
1.86 \\
2.06 \\
1.96 \\
1.85\end{array}$ \\
\hline $\begin{array}{l}\text { BYW11 } \\
\text { BWW11 } \\
\text { BWW11 } \\
\text { BWW11 } \\
\text { BWW11 } \\
\text { BWW11 } \\
\text { BWW11 } \\
\text { BWW11 } \\
\text { BWW11 } \\
\text { BWW11 }\end{array}$ & $\begin{array}{c}P \\
0 \\
3 \\
6 \\
9 \\
12 \\
16 \\
24 \\
32 \\
40\end{array}$ & $\begin{array}{l}\text { g/20/92 } \\
9 / 20 / 92 \\
9 / 23 / 92 \\
9 / 23 / 92 \\
9 / 23 / 92 \\
8 / 23 / 92 \\
9 / 23 / 92 \\
9 / 23 / 92 \\
9 / 24 / 92 \\
9 / 24 / 92\end{array}$ & $\begin{array}{l}1400 \\
0040 \\
0315 \\
0315 \\
0950 \\
1310 \\
1540 \\
0010 \\
0805 \\
1645\end{array}$ & $\begin{array}{l}133 \\
142 \\
173 \\
160 \\
156 \\
162 \\
156 \\
148 \\
168 \\
177\end{array}$ & $\begin{array}{c}20.2 \\
21 \\
20.5 \\
20 \\
18.2 \\
20 \\
20 \\
18 \\
18 \\
17\end{array}$ & $\begin{array}{l}6.56 \\
6.61 \\
6.57 \\
6.58 \\
6.44 \\
6.52 \\
6.24 \\
M 4 \\
6.31 \\
6.77\end{array}$ & $\begin{array}{l}285 \\
252 \\
265 \\
265 \\
245 \\
260 \\
255 \\
255 \\
260 \\
288\end{array}$ & $\begin{array}{c}10.4 \\
8.65 \\
8.6 \\
8.45 \\
8.7 \\
8.7 \\
8.7 \\
9.06 \\
9.2 \\
6.6\end{array}$ & $\begin{array}{l}6.1 \\
2.25 \\
2.16 \\
1.85 \\
1.05 \\
2.45 \\
1.8 \\
1.6 \\
1.7 \\
1.85\end{array}$ & \begin{tabular}{|c|}
2.8 \\
6 \\
7.6 \\
11.2 \\
4.2 \\
6.4 \\
3.6 \\
4.4 \\
4.2 \\
3.8
\end{tabular} & $\begin{array}{c}1.8 \\
2.2 \\
2.8 \\
3.6 \\
2.4 \\
3.6 \\
2 \\
4 \\
1 \\
2.4\end{array}$ & $\begin{array}{c}87.7 \\
64 \\
71.9 \\
59.1 \\
66.3 \\
65.6 \\
63.6 \\
68 \\
69.3 \\
62.1\end{array}$ & \begin{tabular}{|c|}
17.4 \\
16 \\
16 \\
16.7 \\
15.7 \\
16.3 \\
16.5 \\
16.3 \\
16.3 \\
16.8 \\
17.1 \\
17.6
\end{tabular} & $\begin{array}{l}2.79 \\
261 \\
268 \\
26 \\
257 \\
26 \\
276 \\
278 \\
282 \\
285\end{array}$ \\
\hline $\begin{array}{l}\text { BWW13 } \\
\text { BWW13 } \\
\text { BWW13 } \\
\text { BWW13 } \\
\text { BWW13 } \\
\text { BWW13 } \\
\text { BWW13 } \\
\text { BWW13 } \\
\text { BWW13 } \\
\text { BWW13 }\end{array}$ & $\begin{array}{c}P \\
0 \\
3 \\
6 \\
9 \\
12 \\
16 \\
24 \\
32 \\
40\end{array}$ & $\begin{array}{l}9 / 22 / 92 \\
8 / 20 / 92 \\
9 / 23 / 92 \\
9 / 23 / 92 \\
9 / 23 / 92 \\
9 / 23 / 92 \\
9 / 23 / 92 \\
9 / 23 / 92 \\
9 / 24 / 92 \\
9 / 24 / 92\end{array}$ & $\begin{array}{l}1340 \\
0015 \\
0300 \\
0550 \\
0930 \\
1250 \\
1520 \\
2358 \\
0850 \\
1625\end{array}$ & $\begin{array}{l}169 \\
188 \\
232 \\
214 \\
205 \\
209 \\
200 \\
192 \\
210 \\
216\end{array}$ & $\begin{array}{c}20.5 \\
20.5 \\
20 \\
10.5 \\
18.6 \\
19.2 \\
20.2 \\
16 \\
18.5 \\
18\end{array}$ & $\begin{array}{l}6.77 \\
6.56 \\
6.81 \\
6.47 \\
6.32 \\
6.4 \\
6.31 \\
N 4 \\
6.2 \\
6.74\end{array}$ & $\begin{array}{l}260 \\
230 \\
255 \\
245 \\
220 \\
215 \\
235 \\
220 \\
190 \\
258\end{array}$ & $\begin{array}{c}11 \\
10 \\
9.85 \\
10.2 \\
10.2 \\
10.6 \\
10.6 \\
10.1 \\
10.6 \\
8.6\end{array}$ & $\begin{array}{c}5.3 \\
1.75 \\
1.8 \\
1.3 \\
1.25 \\
1.8 \\
1.3 \\
1.15 \\
1.25 \\
1.25\end{array}$ & $\begin{array}{l}2.6 \\
3.2 \\
4.4 \\
2.8 \\
2.6 \\
5.2 \\
3.4 \\
4.2 \\
4 \\
4\end{array}$ & $\begin{array}{c}2.8 \\
1.2 \\
2.2 \\
1 \\
1.6 \\
1.4 \\
3.2 \\
2.6 \\
1.6 \\
3\end{array}$ & $\begin{array}{c}72 \\
62.9 \\
68.1 \\
56.7 \\
59 \\
60.4 \\
55.2 \\
56.6 \\
50.6 \\
68\end{array}$ & \begin{tabular}{|l|l|}
15.2 & \\
13.6 & 14.3 \\
13.6 & \\
14.2 & \\
13.4 \\
13.6 \\
13.2 \\
12.6 \\
15.8
\end{tabular} & $\begin{array}{l}2.53 \\
2.26 \\
2.42 \\
2.43 \\
2.42 \\
2.46 \\
2.42 \\
2.38 \\
2.24 \\
2.62\end{array}$ \\
\hline $\begin{array}{l}\text { BWW14 } \\
\text { BWW14 } \\
\text { BWW14 } \\
\text { BWW14 } \\
\text { BWW14 } \\
\text { BWW14 } \\
\text { BWW14 } \\
\text { BWW14 } \\
\text { BWW14 } \\
\text { BWW14 }\end{array}$ & $\begin{array}{l}P \\
0 \\
3 \\
6 \\
9 \\
12 \\
16 \\
24 \\
32 \\
40\end{array}$ & $\begin{array}{l}9 / 22 / 92 \\
9 / 22 / 92 \\
9 / 23 / 92 \\
9 / 23 / 92 \\
9 / 23 / 92 \\
9 / 23 / 92 \\
9 / 23 / 92 \\
9 / 23 / 92 \\
9 / 24 / 92 \\
9 / 24 / 92\end{array}$ & $\begin{array}{l}1530 \\
0150 \\
0440 \\
0750 \\
1100 \\
1430 \\
1650 \\
0120 \\
0910 \\
1755\end{array}$ & $\begin{array}{c}32.8 \\
42 \\
54.7 \\
50.1 \\
46.1 \\
42.8 \\
41.5 \\
40.6 \\
39.8 \\
36.4\end{array}$ & $\begin{array}{c}21.6 \\
21 \\
20.5 \\
19.5 \\
19.5 \\
19.8 \\
20.5 \\
18 \\
18.5 \\
17.2\end{array}$ & \begin{tabular}{|l|}
6.59 \\
6.4 \\
6.66 \\
8.65 \\
6.64 \\
6.13 \\
6.2 \\
.4 \\
6.16 \\
6.32
\end{tabular} & $\begin{array}{l}102 \\
100 \\
85 \\
90 \\
85 \\
85 \\
85 \\
80 \\
82 \\
84\end{array}$ & $\begin{array}{c}10 \\
8.85 \\
9.55 \\
9.7 \\
10.1 \\
10.4 \\
10.6 \\
9.8 \\
10.3 \\
6.2\end{array}$ & $\begin{array}{l}\text { ND } \\
1.75 \\
1.55 \\
\text { ND } \\
\text { ND } \\
\text { ND } \\
1.05 \\
\text { ND } \\
\text { ND } \\
\text { ND }\end{array}$ & $\begin{array}{c}\text { ND } \\
6 \\
2.8 \\
1.6 \\
1 \\
2.2 \\
1 \\
24 \\
4.4 \\
1\end{array}$ & $\begin{array}{c}\text { ND } \\
3.5 \\
1.4 \\
1 \\
\text { ND } \\
1.2 \\
1 \\
0.6 \\
1.6 \\
1\end{array}$ & \begin{tabular}{c|}
29.6 \\
27.8 \\
22.5 \\
22 \\
23.9 \\
21.1 \\
18.4 \\
21.3 \\
20.1 \\
23.5
\end{tabular} & $\begin{array}{l}4.4 \\
4 \\
4.2 \\
4.2 \\
4.2 \\
4.1 \\
4.1 \\
4.1 \\
4.3 \\
4.3\end{array}$ & $\begin{array}{l}1.21 \\
1.09 \\
1.09 \\
1.13 \\
1.12 \\
1.1 \\
1.12 \\
1.14 \\
1.15 \\
1.17\end{array}$ \\
\hline $\begin{array}{l}\text { BWW15 } \\
\text { BWW15 } \\
\text { BWW15 } \\
\text { BWW15 } \\
\text { BWW15 } \\
\text { BWW15 } \\
\text { BWW15 } \\
\text { BWW15 } \\
\text { BWW15 } \\
\text { BWW15 }\end{array}$ & $\begin{array}{c}P \\
0 \\
3 \\
6 \\
9 \\
12 \\
16 \\
24 \\
32 \\
40\end{array}$ & $\begin{array}{l}9 / 20192 \\
9 / 22 / 92 \\
9 / 23 / 92 \\
9 / 23 / 92 \\
9 / 23 / 92 \\
9 / 23 / 92 \\
9 / 23 / 92 \\
9 / 23 / 92 \\
9 / 24 / 92 \\
9 / 24 / 92\end{array}$ & & $\begin{array}{l}6.30 \\
5.80 \\
12.4 \\
12.4 \\
12.4 \\
10.2 \\
8.72 \\
16.7 \\
16.7 \\
15.0\end{array}$ & $\begin{array}{c}22 \\
21 \\
20 \\
21 \\
19 \\
20.5 \\
19.5 \\
17.9 \\
15.8 \\
10\end{array}$ & \begin{tabular}{|l|l|}
6.81 \\
6.51 \\
6.68 \\
6.14 \\
6.56 \\
6.18 \\
6.7 \\
14 \\
6.76 \\
6.98
\end{tabular} & $\begin{array}{l}165 \\
160 \\
150 \\
150 \\
150 \\
162 \\
150 \\
150 \\
145 \\
135\end{array}$ & $\begin{array}{l}8.4 \\
7.9 \\
8.6 \\
8.7 \\
8.8 \\
8.4 \\
8.3 \\
7.9 \\
7.4 \\
9.35\end{array}$ & $\begin{array}{l}M A \\
M A \\
M A \\
M A \\
M A \\
M A \\
M A \\
M A\end{array}$ & $\begin{array}{c}2 \\
2.6 \\
4.2 \\
2.2 \\
2.8 \\
4 \\
5.4 \\
N 4 \\
3.5 \\
4.6\end{array}$ & $\begin{array}{c}2.4 \\
2 \\
2.6 \\
1.4 \\
2.2 \\
1.6 \\
4 \\
N \\
3.5 \\
3.8\end{array}$ & $\begin{array}{l}44.6 \\
33.7 \\
39.4 \\
33.5 \\
34.5 \\
32.4 \\
30.4 \\
39.1 \\
32.9 \\
36.9\end{array}$ & $\begin{array}{l}7.7 \\
7.5 \\
7.2 \\
7.2 \\
7.2 \\
7.4 \\
7.4 \\
7.5 \\
7.4 \\
7.4 \\
7.2 \\
\end{array}$ & $\begin{array}{l}2.18 \\
2.02 \\
1.82 \\
1.85 \\
1.86 \\
1.86 \\
1.91 \\
1.88 \\
1.9 \\
1.86\end{array}$ \\
\hline $\begin{array}{l}\text { BWW16 } \\
\text { BWW16 } \\
\text { BWW16 } \\
\text { BWW16 } \\
\text { BWW16 } \\
\text { BWW16 } \\
\text { BWW16 } \\
\text { BWW16 } \\
\text { BWW16 } \\
\text { BWW18 }\end{array}$ & $\begin{array}{c}P \\
0 \\
3 \\
6 \\
9 \\
12 \\
16 \\
24 \\
32 \\
40\end{array}$ & $\begin{array}{l}9 / 22 / 92 \\
9 / 20192 \\
9 / 23 / 92 \\
9 / 23 / 92 \\
9 / 23 / 92 \\
9 / 23 / 92 \\
9 / 23 / 92 \\
9 / 23192 \\
8 / 2492 \\
9 / 2492\end{array}$ & $\begin{array}{l}1400 \\
0000 \\
0245 \\
0625 \\
1020 \\
1400 \\
1830 \\
2350 \\
0800 \\
1410\end{array}$ & $\begin{array}{l}2.37 \\
3.61 \\
13.2 \\
11.0 \\
7.23 \\
10.5 \\
6.25 \\
4.00 \\
4.00 \\
4.00\end{array}$ & $\begin{array}{c}20 \\
20 \\
20 \\
18 \\
18 \\
18 \\
18.5 \\
16 \\
13.4 \\
16.2\end{array}$ & $\begin{array}{l}6.24 \\
6.31 \\
6.47 \\
6.1 \\
6.09 \\
6.04 \\
6.44 \\
N 4 \\
6.11 \\
6.77\end{array}$ & $\begin{array}{l}180 \\
180 \\
100 \\
155 \\
132 \\
140 \\
120 \\
125 \\
138 \\
138\end{array}$ & $\begin{array}{c}6.4 \\
6.4 \\
7.2 \\
7.3 \\
7.6 \\
7.9 \\
6 \\
5.2 \\
6 \\
8.35\end{array}$ & $\begin{array}{c}3.3 \\
3.35 \\
3.65 \\
0.5 \\
1.15 \\
1.08 \\
1.56 \\
1.45 \\
1 \\
2\end{array}$ & $\begin{array}{c}15 \\
16.2 \\
17 \\
2.8 \\
4 \\
3.6 \\
6 \\
6.8 \\
5.8 \\
1.8\end{array}$ & $\begin{array}{c}4 \\
5.8 \\
6.2 \\
1.6 \\
2 \\
2.2 \\
3.5 \\
2.6 \\
3.2 \\
1.6\end{array}$ & $\begin{array}{l}45.2 \\
37 \\
22.6 \\
29.7 \\
30.7 \\
24.2 \\
20.2 \\
29.2 \\
31.1 \\
39.8\end{array}$ & $\begin{array}{c}10.4 \\
10.3 \\
4.8 \\
9 \\
6.5 \\
7.6 \\
6.6 \\
7.5 \\
8.8 \\
9.6\end{array}$ & $\begin{array}{l}2.38 \\
2.33 \\
1.84 \\
1.88 \\
1.8 \\
1.74 \\
1.47 \\
1.72 \\
1.86 \\
2.11\end{array}$ \\
\hline BWW17 & $\boldsymbol{P}$ & 2/22/02 & 1345 & 162 & 23 & 6.98 & 280 & 9.6 & 1 & 1.4 & 0.6 & 99.2 & 15.4 & 3.25 \\
\hline
\end{tabular}


Table A.1 Water Quality Data for Storm 1 (Continued)

\begin{tabular}{|c|c|c|c|c|c|c|c|c|c|c|c|c|c|c|}
\hline statien & Run & Dato & Trme & Flow & $\operatorname{Temp}$ & pH & $\begin{array}{l}\text { Cond } \\
\text { umhoesem }\end{array}$ & $\begin{array}{c}\infty \\
m g /\end{array}$ & $\begin{array}{l}\text { BOD } \\
\text { mol }\end{array}$ & $\begin{array}{l}\text { TSS } \\
\mathrm{mgh}\end{array}$ & $\begin{array}{l}\text { vss } \\
\text { mar }\end{array}$ & $\begin{array}{c}c l \\
m g h\end{array}$ & $\mathrm{ca}$ & $\underset{m g}{M g}$ \\
\hline BWW17 & 0 & $9 / 22 / 92$ & 2340 & 163 & 22 & 6.7 & 280 & 8.5 & 1.55 & 3.8 & 1.6 & 67.9 & 14.9 & 2.94 \\
\hline ENW17 & 3 & $9 / 23 / 92$ & 0240 & 292 & $x$ & 6.68 & 220 & 9.6 & 3.08 & 9.8 & 4 & 54.2 & 12 & 2.44 \\
\hline BWW17 & 6 & $9 / 23 / 92$ & 0530 & 250 & 19.5 & 6.67 & 215 & 10.05 & 285 & 6.4 & 2.8 & 48.5 & 12 & 2.46 \\
\hline BWN17 & 9 & $9 / 23 / 92$ & 0930 & 205 & 19 & 6.22 & 235 & 8.4 & 0.5 & 3 & 2 & 55.5 & 13.5 & 2.64 \\
\hline EWW17 & 12 & $9 / 23 / 92$ & 1330 & 214 & 19.5 & 6.86 & 246 & 10.4 & 1 & 4.6 & 1.8 & 56 & 13.3 & 2.64 \\
\hline BWW17 & 16 & $9 / 23 / 92$ & & 215 & 19 & 6.7 & 232 & 8.3 & 1.1 & 6 & 24 & 47.2 & 12.4 & 2.5 \\
\hline EWM17 & 24 & $9 / 23 / 92$ & 2345 & 209 & 17.5 & NA & 218 & 10.6 & 9.4 & 7.8 & 5 & 62.3 & 13.9 & 2.72 \\
\hline BWW17 & 32 & $9 / 24 / 92$ & 1000 & 209 & 16 & 6.72 & 210 & 8.5 & 1.8 & 4.6 & 2.2 & 58.3 & 13.6 & 2.63 \\
\hline BWW17 & 40 & $9 / 2492$ & 1605 & 289 & 18 & 6.88 & 211 & 9,2 & 1.5 & 1.4 & 0.8 & 58.4 & 13 & 2.48 \\
\hline EWW18 & $\mathbf{P}$ & $9 / 22 / 92$ & 1450 & 181 & 22 & 6.54 & 380 & 6.9 & 1.6 & 4.2 & 3 & 103 & 16.4 & 2.73 \\
\hline EWW18 & 0 & $9 \sqrt[2092]{ }$ & 0035 & 205 & 21 & 6.47 & 300 & 6.5 & 3.25 & 1.2 & 1 & 80.8 & 15.8 & 2.76 \\
\hline BWW18 & 3 & $9 / 23 / 92$ & 0325 & 250 & 21 & 6.47 & 345 & 7.3 & 1.7 & 4.8 & 2.6 & 86.4 & 15.4 & 276 \\
\hline BพM18 & 6 & $9 / 23192$ & 0700 & 210 & 20 & 6.76 & 300 & 7.3 & 1.7 & 4 & 1.8 & 82.8 & 15.7 & 2.77 \\
\hline EWW18 & 9 & $9 / 23 / 92$ & 1055 & 228 & 20 & 6.29 & 390 & 7.6 & 1.25 & 10.5 & 7 & 91.2 & 15 & 2.64 \\
\hline BWW1B & 12 & $9 / 23 / 92$ & 1442 & 226 & 20.5 & 6.31 & 383 & 7.7 & 1.35 & 6 & 3.6 & 91.5 & 15.8 & 2.7 \\
\hline EXW18 & 16 & $9 / 23 / 92$ & 1910 & 186 & 19.5 & 6.46 & 281 & 6.3 & 1.9 & 3.6 & 2 & 70.4 & 13.1 & 2.48 \\
\hline ВWW18 & 24 & $9 / 23 / 92$ & 0025 & 228 & 18.5 & $\mathrm{NA}$ & 292 & 6 & 1.7 & 5.2 & 3.6 & 72 & 12.3 & 236 \\
\hline BWW18 & 32 & $9 / 24 / 92$ & 0820 & 226 & 17.8 & 6.59 & 260 & 7.85 & 1.8 & 4.8 & 2.8 & 78.6 & 13.3 & 2.41 \\
\hline BWW18 & 40 & $9 / 2492$ & 1646 & 315 & 18.2 & 6.72 & 255 & 7.1 & 1.36 & 2.8 & 2 & 82.5 & 14.3 & 2.51 \\
\hline BMW20 & $\mathbf{P}$ & $9 / 2092$ & 1520 & 210 & 22 & 6.59 & 325 & 8.1 & 1.16 & 1.3 & 0.7 & 101 & 16.1 & 2.78 \\
\hline BWWZO & 0 & $9 / 22192$ & 0100 & 226 & 21 & 6.38 & 355 & 6.7 & 2 & 1.6 & 0.8 & 92.8 & 18.1 & 2.78 \\
\hline BMN20 & 3 & $9 / 23 / 92$ & 0345 & 253 & 21 & 6.52 & 335 & 6.1 & 1.45 & 1.2 & 1.2 & 79.4 & 15.8 & 2.75 \\
\hline BMWEO & 6 & $9 / 2392$ & 0720 & 241 & 19 & 6.49 & 315 & 6.7 & 1.85 & 2.8 & 1.2 & 68.8 & 15.7 & 2.71 \\
\hline BMW20 & 9 & $9 / 23 / 92$ & 1120 & 259 & 19 & 6.17 & 315 & 8.7 & 1.45 & 2 & 1.8 & 77.9 & 15.8 & 2.62 \\
\hline BWMzO & 12 & $2 / 23 / 92$ & 1515 & 265 & 20.5 & 6.38 & 345 & 8.8 & 1.65 & 4.8 & 3.6 & 82.4 & 16.2 & 2.67 \\
\hline BMWZO & 16 & $9 / 23 / 92$ & & 215 & 19 & 6.52 & 351 & 7.5 & 1.6 & 2 & 1.6 & 78.4 & 15.8 & 269 \\
\hline BWwro & 24 & $9 / 23 / 92$ & 0045 & 247 & 18 & NA & 391 & 5.85 & 1.7 & 3.6 & 2.6 & 88.7 & 15.5 & 268 \\
\hline BWW20 & 32 & $9 / 24 / 92$ & 0845 & 271 & 16.8 & 6.58 & 290 & 6.8 & 1.6 & 4.6 & 26 & 83 & 15.6 & 268 \\
\hline BMW & 40 & $9 / 24 / 92$ & 1710 & 200 & 18.5 & 6.74 & 317 & 8.36 & 2.2 & 2.8 & 2 & 96 & 15.6 & 2.52 \\
\hline EMM21 & $\mathbf{P}$ & $9 / 22 / 92$ & 1540 & 239 & 23 & 6.63 & 320 & 0.1 & 0.5 & 5 & 4.5 & 76 & 15.6 & 264 \\
\hline EWW21 & 0 & $9 / 2012$ & 0125 & 250 & 22 & 6.70 & 310 & 8.8 & 1.8 & 1.3 & 0.7 & 68.6 & 15.8 & $2 \pi$ \\
\hline BWW21 & 3 & $9 / 23192$ & 0420 & 253 & 21 & 6.81 & 320 & 8.1 & 205 & 2.8 & 1.4 & 73.2 & 16.2 & 287 \\
\hline EMre1 & 6 & $9 / 23192$ & 0745 & 241 & 10 & 6.52 & 280 & 9.1 & 1.6 & 4 & 2 & 70.6 & 15.3 & 2.66 \\
\hline BWW21 & 8 & $9 / 23 / 92$ & 1158 & 259 & 20 & 6.25 & 310 & 9.6 & 0.5 & 26 & 1.4 & 71.4 & 15.2 & 268 \\
\hline BWW21 & 12 & $9 / 23192$ & 1545 & 265 & 21 & 6.22 & 323 & 9.8 & 1.06 & 2.6 & 2 & 76.4 & 15.4 & 2.59 \\
\hline EWW21 & 18 & $9 \sqrt{23 / 92}$ & 2005 & 215 & 10 & 6.72 & 313 & 8.9 & 1.65 & 2.6 & 1.6 & 73.9 & 15.4 & 27 \\
\hline BuW21 & 24 & $9 / 23 / 92$ & 0145 & 247 & 18.7 & $\mathrm{MA}$ & 318 & 8.05 & 1.45 & 3 & 1.8 & 77 & 15.8 & 269 \\
\hline ENW21 & 32 & $9 / 24 / 92$ & 0000 & 271 & 16.8 & 6.60 & 200 & 8.9 & 1.36 & 1.8 & 1.2 & 86.1 & 16.3 & 272 \\
\hline BWW21 & 40 & $9 / 24 / 92$ & 1730 & 253 & 17.8 & 6.77 & 300 & 9 & 1.4 & 2 & 1.4 & 69.5 & 16.1 & 285 \\
\hline BWw23 & $\mathbf{P}$ & $9 / 2292$ & 1119 & & NA & 6.24 & 480 & NA & 6.5 & 6.2 & 6.2 & 118 & 19.5 & 2.57 \\
\hline EMMEs & 0 & $9 / 22192$ & 2337 & & NA & 6.23 & 371 & NA & 12 & NA & MA & 108 & 18 & 2.42 \\
\hline EWW23 & 3 & $9 / 23 / 92$ & 0200 & & 22.5 & 6.14 & 388 & 6.4 & 13.4 & 9.8 & 9.4 & 100 & 19.9 & 2.5 \\
\hline BWM23 & 6 & $9 / 23 / 92$ & 0515 & & 21 & 6.41 & 358 & 6.9 & 4.9 & 8.2 & 6.6 & 81.3 & 19.6 & 245 \\
\hline BWWV23 & 9 & $9 / 2392$ & 0802 & & NA & 5.94 & 322 & MA & 4.75 & 6.4 & 3.6 & 80.7 & 16.2 & 2.24 \\
\hline BWW23 & 12 & $9 \longdiv { 2 3 9 9 2 }$ & 1100 & & NA & 5.97 & 267 & NA & 4.6 & 6.8 & 5.6 & 67.5 & 15.8 & 1.99 \\
\hline BWW23 & 18 & $9 / 23 / 92$ & 1509 & & 21 & 5.83 & 312 & 7.8 & 4.7 & 6.6 & 5 & 76.4 & 15.8 & 2.02 \\
\hline BWW23 & 24 & $923 / 92$ & 2304 & & NA & NA & 368 & NA & 5.85 & 6.8 & 5.8 & 88.3 & 15.7 & 2.15 \\
\hline BWW23 & 32 & $9 \sqrt{2492}$ & 0703 & & 20 & 6.14 & 402 & NA & 24 & 4.8 & 3.2 & 94 & 18.7 & 2.37 \\
\hline BWWrs & 40 & $9 / 2492$ & 1454 & & MA & 6.14 & 435 & MA & 2.6 & 8.8 & 7.4 & 100 & 22.5 & 2.64 \\
\hline EMW24 & $\mathbf{P}$ & $8 / 22192$ & 1445 & & NA & 6.91 & 782 & NA & 9.75 & 6.8 & 6.2 & 520 & 8.4 & 1.5 \\
\hline BWW24 & 0 & $9 / 2292$ & 0100 & & $\mathrm{Nu}$ & 6.7 & 820 & NA & 14 & 66 & 52 & 526 & 7.7 & 1.1 \\
\hline BWM24 & 3 & $9 / 23 / 92$ & & & NA & 6.63 & 765 & NA & 12.5 & 24.6 & 18.2 & 483 & 8.6 & 1.3 \\
\hline Bunz24 & 6 & $9 / 23 / 92$ & & & NA & 6.52 & 77 & $\mathrm{Na}$ & 5.0 & 17.2 & 12 & 498 & 8.5 & 1.4 \\
\hline BWM24 & 9 & $8 / 23192$ & & & M & 6.72 & 798 & $M$ & 3.7 & 8 & 6.5 & 500 & 8.1 & 1.42 \\
\hline BWW24 & 12 & $9 / 23 / 92$ & & & NA & 6.93 & 825 & MA & 8.1 & 30.5 & 23 & 518 & 11.6 & 1.58 \\
\hline BWW24 & 16 & $9 / 23192$ & 1430 & & NA & 6.88 & 752 & MA & 4.85 & 17 & 14 & 504 & 16.2 & 1.6 \\
\hline BWM24 & 24 & $9 / 23192$ & 0145 & & NA & $\mathrm{MA}$ & 722 & $\mathrm{MA}$ & 3.8 & 30.5 & 23 & 509 & 16.8 & 1.57 \\
\hline BWw24 & 32 & g/24ag2 & 0845 & & $\mathrm{MA}$ & 6.61 & 748 & NA & 3.85 & 42.5 & 31 & 500 & 16.3 & 1.65 \\
\hline BWW24 & 40 & $9 / 24 / 92$ & 1815 & & NA & 6.73 & 812 & MA & 4.76 & 3.4 & 26 & 492 & 23.7 & 1.70 \\
\hline BMMEs & $\mathbf{P}$ & $9 / 22 / 92$ & 1600 & & 24 & 6.56 & 100 & 3.5 & 8.75 & 18.7 & 12.7 & 156.2 & 14.7 & 1.99 \\
\hline BMmes & 0 & $9 / 22 / 92$ & 0140 & & 23 & 6.65 & 510 & 3.2 & 15.3 & 21.3 & 20.7 & 171 & 18.3 & 2.27 \\
\hline BWW25 & 3 & 823392 & & & 23 & 6.39 & 500 & 2.2 & 10.9 & 47.5 & 15.4 & 119 & 16.1 & 2.07 \\
\hline BMM25 & 6 & $8 / 23 / 92$ & 0815 & & 23 & 6.45 & 495 & 23 & 8.6 & 17.4 & 16.8 & 85.8 & 12 & 1.62 \\
\hline BNM25 & 9 & $9 / 23192$ & 1210 & & 22 & 6.4 & 380 & 2.8 & 6.25 & 15.8 & 13.8 & 65 & 9.2 & 1.26 \\
\hline BMmas & 12 & $9 / 23192$ & 1615 & & 21 & 6.31 & 368 & 2.3 & 6.35 & 24.4 & 16.9 & 60.1 & 10.1 & 1.3 \\
\hline Bumas & 16 & 97392 & 2230 & & 19.8 & 8.51 & 420 & 3.1 & 7.8 & 7.4 & 6.2 & 71.2 & 11.5 & 1.46 \\
\hline Bunzs & 24 & $9 / 23192$ & 0120 & & 20.8 & MA & 481 & 1.81 & 4.7 & 17.5 & 15 & 85.1 & 11 & 1.4 \\
\hline EMmes & 32 & 9/2492 & 0930 & & 20.4 & 6.5 & 450 & 2.3 & 3.85 & 17.8 & 15.6 & 91.3 & 11 & 1.52 \\
\hline Bum2s & 40 & $9 / 2492$ & 1747 & & 21 & 6.47 & 380 & 2 & 4.15 & 18.4 & 17.1 & 103 & 15.8 & 1.86 \\
\hline EMW25 & 3 & $8 / 23 / 92$ & 0440 & & 21 & 6.08 & 125 & 7.1 & 39.4 & 75 & 57 & 26.7 & 9 & 0.2 \\
\hline
\end{tabular}

ND = Not Delected

NS= No Sample

NME Not Measured

$M=$ Not Analyzed 
Table A.1 Water Quality Data for Storm 1 (Continued)

\begin{tabular}{|c|c|c|c|c|c|c|c|c|c|c|c|c|c|}
\hline Stutton & Run & $\begin{array}{c}\text { Na } \\
\text { mgl }\end{array}$ & $\log _{\ln }$ & $\begin{array}{l}\text { NH3 } \\
\text { mgl }\end{array}$ & $\begin{array}{l}\mathrm{NO3} \\
\mathrm{mgl}\end{array}$ & $\begin{array}{l}\text { POA } \\
\text { mgl }\end{array}$ & $\begin{array}{l}\text { Cd } \\
\text { ugh }\end{array}$ & $\underset{\text { ugl }}{\text { Cr }}$ & $\begin{array}{c}\mathrm{Cu} \\
\operatorname{ug} \Omega\end{array}$ & $\begin{array}{c}\text { Ni } \\
\text { ugl }\end{array}$ & $\begin{array}{l}\mathrm{Pb} \\
\operatorname{ugg} /\end{array}$ & $\begin{array}{c}\text { F.C. } \\
\text { md/100mL }\end{array}$ & $\begin{array}{c}\text { E.C. } \\
\text { mar100m }\end{array}$ \\
\hline sunnoo & $P$ & 28 & 12 & 0.05 & 0.38 & 0.03 & 0.21 & 1.3 & 6 & 1.6 & 6.5 & 13000 & 410 \\
\hline Bимоo & 0 & 25 & 15 & 0.08 & 0.28 & 0.03 & 0.24 & 1.3 & 4.8 & 1.6 & 7.3 & 3500 & 420 \\
\hline BMMOO & 3 & 19 & so & 0.22 & 0.41 & 0.02 & 0.81 & 4.2 & 7.4 & 3.6 & 32.6 & 3000 & 500 \\
\hline Bwnoo & 6 & 13 & 34 & 0.31 & 0.38 & 0.02 & 1.12 & 22 & 6.4 & 7 & 22 & 18000 & 12000 \\
\hline exmoo & 9 & 13 & 45 & 0.05 & 0.29 & 0.03 & 0.82 & 1.7 & 11.3 & 2.5 & 17.3 & 12000 & 6800 \\
\hline BWWoo & 12 & 17 & 18 & 0.06 & 0.18 & 0.02 & 0.17 & 1.4 & 5.4 & 2 & 10.4 & 4300 & 1700 \\
\hline EWMNo & 16 & 22 & 16 & 0.11 & 0.15 & 0.03 & 0.15 & 9.1 & 4.7 & 1.5 & 8.9 & 2800 & 190 \\
\hline BWWoO & 24 & 26 & 15 & 0.12 & 0.16 & 0.01 & 0.5 & 1.5 & 1.3 & 1.0 & 6.7 & 2500 & 370 \\
\hline Eพm)o & 32 & 26 & 16 & 0.05 & 0.16 & 0.01 & 0.18 & 1 & 3.6 & 1.1 & 6.9 & 1600 & 130 \\
\hline Bunco & 40 & 26 & 10 & 0.35 & 0.16 & 0.03 & 0.08 & 0.6 & 2.4 & 0.8 & 3.9 & 760 & 76 \\
\hline EMmor & $P$ & 35 & 42 & 0.11 & 0.50 & 0.02 & 0.3 & 22 & 7.1 & 8.6 & 3.3 & 8300 & 150 \\
\hline BMMO1 & 0 & 34 & 43 & 0.42 & 0.61 & 0.08 & 0.43 & 4.8 & 1.3 & 3.5 & 11.8 & 11000 & 6800 \\
\hline EMNo1 & 3 & 34 & 50 & 0.2 & 0.36 & 0.01 & 0.5 & 5 & 14.8 & 4.3 & 21.6 & 17000 & 5600 \\
\hline EMMO1 & 6 & 29 & 38 & 0.24 & 0.48 & 0.02 & 0.27 & 24 & 10.4 & 3 & 11.1 & 13000 & 5700 \\
\hline Exno1 & 9 & 28 & 40 & 0.2 & 0.45 & 0.02 & 0.23 & 2.7 & 8.1 & 3.2 & 14 & 9700 & 2900 \\
\hline EMMos & 12 & 51 & 54 & 0.27 & 0.53 & 0.02 & 0.31 & 5.4 & 8.4 & 4.6 & 13.9 & 6700 & 1700 \\
\hline BMWo1 & 16 & 35 & 50 & 0.09 & 0.43 & 0.02 & 0.22 & 3.8 & 6.2 & 2.7 & 7.1 & 5300 & 470 \\
\hline EMmo1 & 24 & 35 & 40 & 0.04 & 0.40 & 0.01 & 0.16 & 3.5 & 4.7 & 3.6 & 3.8 & 6600 & 370 \\
\hline BMNo1 & 32 & 37 & 24 & 0.08 & 0.35 & 0.01 & 0.17 & 3.4 & 2.8 & 2.8 & 3 & 880 & 270 \\
\hline BMmo1 & 40 & 41 & 27 & 0.45 & 0.39 & 0.01 & 0.19 & 3.6 & 3.4 & 2.9 & 6.4 & 1600 & 160 \\
\hline BWnor & $P$ & 59 & 46 & 1.82 & 1.54 & 1.13 & 1.8 & 7.3 & 41.8 & 25.4 & 3.4 & 18 & 1 \\
\hline BพW102 & 0 & 61 & 55 & 295 & 1.47 & 1.13 & 2.2 & 15.7 & 42.7 & 29.8 & 5.5 & 3 & 0.5 \\
\hline Bumo2 & 3 & 53 & 108 & 227 & 0.68 & 0.59 & 1.00 & 18.7 & 3.3 & 4.6 & 31.8 & 1400 & 0.5 \\
\hline BWuO2 & 6 & 44 & 58 & 1.73 & 0.78 & 0.74 & 0.14 & 8.3 & 1.8 & 2.7 & 13.4 & 4 & 0.5 \\
\hline EMMO2 & $9^{3}$ & 42 & 45 & 1.2 & 1.24 & 0.82 & 0.08 & 8.5 & 2.2 & 2.7 & 11 & 17 & 0.5 \\
\hline EMMoz & 12 & 37 & 41 & 0.52 & 0.97 & 0.74 & 1.14 & 5.9 & 11 & 10.6 & 4.5 & 7 & 0.5 \\
\hline Bพ1)02 & 16 & 40 & 51 & 0.56 & 1.21 & 0.22 & 0.13 & 5.1 & 11.7 & 2.8 & 5.3 & 28 & 0.5 \\
\hline BWMo2 & 24 & 52 & 57 & 0.8 & 1.30 & 0.80 & 0.15 & 124 & 2.8 & 3.4 & 8.6 & 28 & 0.5 \\
\hline EMMO2 & 32 & 53 & 40 & 0.005 & 0.97 & 0.27 & 1.01 & 6.2 & 24.2 & 19.3 & 26 & 4 & 1 \\
\hline Bพหาo2 & 40 & 57 & 59 & 1.22 & 1.34 & 0.27 & 1.52 & 5.7 & 41.7 & 25 & 3.8 & 5 & 0.5 \\
\hline BMMO4 & $\mathbf{P}$ & 62 & 41 & 0.81 & 1.75 & 1.11 & 1.09 & 8.2 & 43.6 & 23.8 & 3 & 810 & 4 \\
\hline 8xmo4 & 0 & 56 & 46 & 0.97 & 1.62 & 9.11 & 1.28 & 5.6 & 44.5 & 21.4 & 7.3 & 360 & 69 \\
\hline BMMO4 & 3 & 56 & 86 & 1.16 & 1.80 & 1.15 & 2.8 & 17 & 69.1 & 32.2 & 18.2 & 1600 & 120 \\
\hline Bxnol & 6 & 45 & 70 & 1.66 & 2.63 & 0.76 & 1.23 & 11.3 & 38.6 & 22 & 11.8 & 1400 & 190 \\
\hline BWMO4 & 9 & 43 & 58 & 1.61 & 1.87 & 0.58 & 1.15 & 8.1 & 30 & 17.8 & 14.2 & 580 & 130 \\
\hline Burnos & 12 & 44 & 44 & 1.43 & 1.87 & 0.67 & 0.02 & 5.8 & 27.5 & 17.5 & 8.4 & 150 & 23 \\
\hline BMMO4 & 16 & 44 & 32 & 0.2 & 2.23 & 0.78 & 0.79 & 5.1 & $\mathbf{2 7 . 4}$ & 17.7 & 5.6 & 230 & 21 \\
\hline BWMOA & 24 & 38 & 40 & 0.005 & 2.86 & 0.67 & 0.69 & 4.8 & 24.7 & 16.2 & 7.7 & 220 & 60 \\
\hline BMNO4 & 32 & 49 & 44 & 0.1 & 3.40 & 0.76 & 0.8 & 8.8 & 28.3 & 18.9 & 3.4 & 200 & 12 \\
\hline Bumo4 & 40 & 51 & 34 & 0.005 & 1.70 & 0.38 & 0.68 & 5.2 & 24.4 & 18 & 2.8 & 160 & 23 \\
\hline EMmos & $\mathbf{P}$ & 32 & ND & $\mathbf{M}$ & 0.22 & 0.02 & NO & 03 & 1.1 & 1.5 & ND & $M$ & $\mathbf{M A}$ \\
\hline Bumos & 0 & 30 & 14 & $\mathbf{N A}$ & 0.25 & ND & 0.17 & ND & 3.2 & 0.9 & 30.8 & $\mathbf{M A}$ & MA \\
\hline EMMOS & 3 & 32 & ND & MA & 0.12 & ND & NO & ND & 3.1 & 1.2 & 27 & 580 & 550 \\
\hline BWWos & 6 & 30 & ND & $\mathbf{N A}$ & 0.18 & ND & ND & ND & 22 & 0.9 & 1.2 & $\mathbf{M A}$ & $M$ \\
\hline EMmos & 9 & 31 & ND & $\mathbf{M}$ & 0.13 & 0.02 & NO & ND & 1.3 & 1 & 2 & MA & $\mathrm{MA}$ \\
\hline ExMnos & 12 & 32 & ND & $\mathbf{N A}$ & 0.18 & ND & ND & 1.3 & 1 & 1.3 & 1 & $\mathbf{M A}$ & $\mathbf{M}$ \\
\hline EMmos & 16 & 31 & ND & $M$ & 0.17 & ND & ND & 0.9 & 1.5 & 0.8 & ND & MA & $\mathbf{M A}$ \\
\hline Exunos & 24 & 31 & ND & $\mathbf{M}$ & 0.11 & ND & 0.33 & 1 & 1 & 0.8 & 1.6 & $\mathbf{M}$ & $\mathbf{M}$ \\
\hline Bumos & 32 & 32 & ND & $\mathbf{M A}$ & 0.13 & ND & ND & 1 & 1 & 0.6 & 1.2 & $\mathbf{M A}$ & $\mathbf{M A}$ \\
\hline Ewmos & 40 & 30 & ND & $\mathbf{M}$ & $\mathrm{M}$ & $\begin{array}{l}\mathrm{ND} \\
\mathbf{N}\end{array}$ & ND & 1.1 & 0.8 & 0.8 & 1.1 & $\mathrm{NM}$ & NA \\
\hline Exmos & $P$ & 46 & 32 & 0.38 & 3.36 & $0 . \pi$ & 0.86 & 4.9 & 30.2 & 17.5 & 7.5 & 60 & 10 \\
\hline Bwwos & 0 & 63 & 47 & 0.37 & 3.40 & 0.80 & 1.28 & 8.2 & 43.9 & 20.7 & 33.5 & 330 & 170 \\
\hline BMNos & 3 & 51 & 32 & 0.44 & 3.34 & 0.94 & 0.91 & 7.1 & 41.2 & 20.1 & 9.3 & 980 & 530 \\
\hline BMNos & 6 & 52 & 40 & 0.5 & 3.58 & 0.80 & 1.06 & 7.6 & 38.1 & 20.1 & 8.6 & 560 & 430 \\
\hline Exบ口os & 9 & 52 & 81 & 0.83 & 3.75 & 0.84 & 1.21 & 10 & 40.2 & 22.1 & 10 & 990 & 230 \\
\hline BWMos & 12 & 48 & 39 & 1.01 & 3.64 & 0.88 & 1.22 & 9.2 & 30.4 & 18.5 & 8.0 & 1400 & 110 \\
\hline Bumos & 16 & 42 & 35 & 0.46 & 3.34 & 0.59 & 0.88 & 6.2 & 25.2 & 16.2 & 7.5 & 460 & 99 \\
\hline EMMOS & 24 & 41 & 42 & 0.005 & 3.05 & 0.64 & 0.82 & 5.5 & 26 & 16 & 9.1 & 310 & 61 \\
\hline EWMO6 & 32 & 39 & 30 & 0.22 & 2.81 & 0.55 & 0.02 & 4.8 & 23 & 14.4 & 6.5 & 35 & 46 \\
\hline Emmos & 40 & 4 & 35 & 0.26 & 1.84 & 0.50 & 0.75 & 6.2 & 24.1 & 15.4 & 6.8 & 120 & 16 \\
\hline BMmo7 & $P$ & 45 & 26 & 0.51 & 2.29 & 0.04 & 0.72 & 23 & 23.1 & 15.6 & 5.9 & 230 & 6 \\
\hline Bพm:07 & 0 & 4 & 23 & 1.08 & 3.05 & 0.68 & 0.75 & 26 & 23.2 & 15 & 6.6 & 280 & 29 \\
\hline EMMO7 & 3 & 45 & 31 & 1.35 & 2.71 & 0.62 & 0.85 & 4 & 23.6 & 15.8 & 8.3 & 220 & 1700 \\
\hline BMMOT & 6 & 47 & 34 & 1.13 & 2.88 & 0.04 & 0.73 & 3.5 & 21 & 14.7 & 7.8 & 5300 & 50 \\
\hline BMMO7 & 9 & 50 & 31 & 1.21 & 3.96 & 0.68 & 0.88 & 5.7 & 26 & 18.7 & 8.9 & 370 & 67 \\
\hline Bxmo7 & 12 & 47 & 28 & 1.70 & 3.93 & 0.65 & 0.7 & 5.4 & 23.9 & 18.8 & 8 & 330 & 34 \\
\hline Bพmo7 & 16 & 49 & 29 & 0.46 & 3.32 & 0.72 & 0.77 & 5.1 & 25 & 17 & 6.1 & 300 & 15 \\
\hline BMWo7 & 24 & 48 & 35 & 0.28 & 3.16 & 0.65 & 0.93 & 7.7 & 28.3 & 16.8 & 11.4 & 380 & 13 \\
\hline Bumo7 & 32 & 48 & 32 & 0.58 & 2.69 & 0.68 & 0.99 & 8.2 & 28.6 & 17.1 & 11 & 590 & 56 \\
\hline BMพno7 & 40 & 43 & 32 & 0.08 & 2.22 & 0.81 & 0.8 & 5.4 & 22.9 & 15.9 & 7.1 & 160 & 6 \\
\hline BWMos & $\mathbf{P}$ & 42 & 33 & 0.46 & 262 & 0.65 & 0.83 & 6.7 & 20.9 & 15.3 & 9 & 110 & 6 \\
\hline BMmos & 0 & 44 & 42 & 1.52 & 2.08 & 0.48 & 1.41 & 11.8 & 29.4 & 16.3 & 16.1 & 240 & 29 \\
\hline EMmos & 3 & 44 & 46 & 1.8 & 232 & 0.67 & 1.23 & 8.9 & 32.1 & 16.8 & 14.8 & 230 & 100 \\
\hline Bunos & 6 & 43 & 64 & 1.64 & 2.42 & 0.67 & 2.18 & 16.1 & 45.8 & 19.3 & 23.7 & 230 & 130 \\
\hline Bunos & 8 & 46 & 46 & 1.27 & 2.62 & 0.65 & 0.99 & 7.1 & 27.5 & 15.8 & 12.2 & 60 & 26 \\
\hline Bwnos & 12 & 4 & 36 & & & 0.62 & 0.85 & 4.8 & 226 & 14.8 & 11.8 & 300 & 19 \\
\hline
\end{tabular}


Table A.1 Water Quality Data for Storm 1 (Continued)

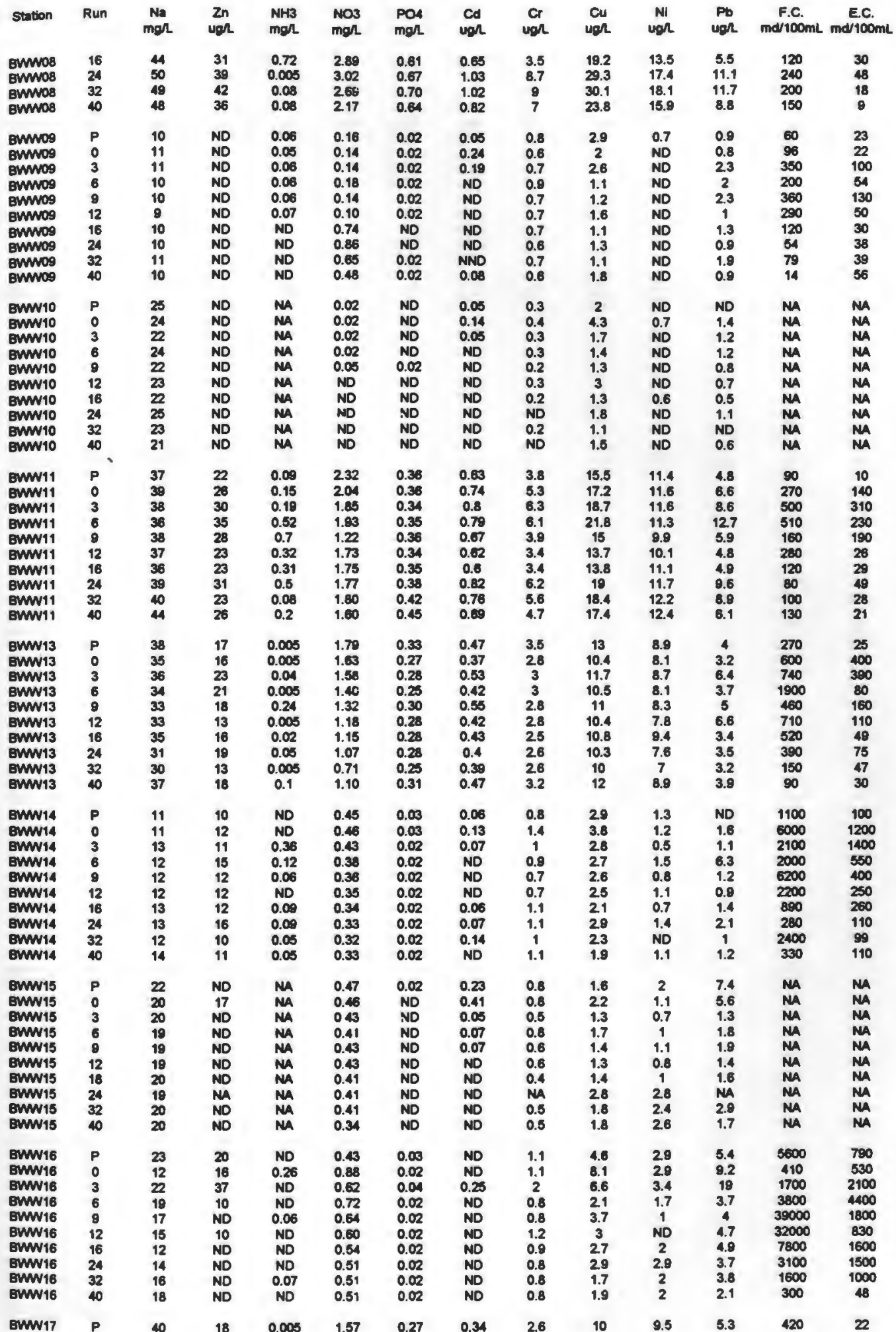


Table A.1 Water Quality Data for Storm 1 (Continued)

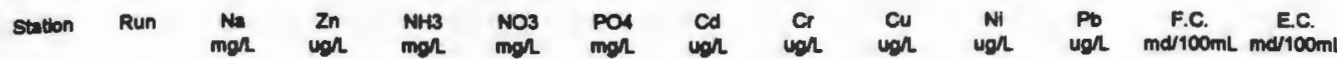

\begin{tabular}{|c|c|c|c|c|c|c|c|c|c|c|c|c|c|}
\hline BW 17 & 0 & 36 & 18 & 0.005 & 1.54 & 0.30 & 0.35 & 2.9 & 10.4 & 9.4 & 5.6 & 510 & 230 \\
\hline BพW17 & 3 & 28 & 32 & 0.005 & 1.39 & 0.28 & 0.61 & 4.1 & 12.6 & 8.9 & 10.2 & 8600 & 2800 \\
\hline BWWI7 & 6 & 29 & 39 & 0.006 & 1.36 & 0.24 & 0.49 & 3.7 & 11.8 & 8.5 & 8.4 & 1700 & 400 \\
\hline BuW17 & 9 & 31 & 16 & 0.08 & 1.36 & 0.23 & 0.39 & 2.8 & $\theta$ & 6.8 & 5.3 & 810 & 400 \\
\hline EWW17 & 12 & 30 & 17 & 0.05 & 1.18 & 0.22 & 0.26 & 2.3 & 8.5 & 7,1 & 4 & 660 & 96 \\
\hline BWW17 & 16 & 28 & 19 & 0.005 & 1.18 & 0.21 & 0.31 & 2.3 & 7.8 & 5.7 & 5.2 & 620 & 70 \\
\hline BWW17 & 24 & 31 & 25 & 0.005 & 1.44 & 0.21 & 0.44 & 3.4 & 11.8 & 8.3 & 6.4 & 410 & 92 \\
\hline BWW17 & 32 & 31 & 18 & 0.12 & 1.44 & 0.22 & 0.38 & 2.5 & 9.5 & 6.6 & 4.3 & 5400 & 52 \\
\hline BMพ17 & 40 & 29 & 18 & 0.09 & 1.34 & 0.28 & 0.38 & 27 & 10.8 & 6.1 & 6.4 & 720 & 32 \\
\hline BNW18 & $P$ & 60 & 33 & 4.2 & 1.38 & 0.48 & 0.47 & 2 & 12.5 & 7 & 4.2 & 120 & 12 \\
\hline BWW18 & 0 & 51 & 34 & 1.6 & 1.41 & 0.36 & 0.64 & 2.7 & 11.3 & 7.1 & 4.7 & 120 & 8 \\
\hline BWW18 & 3 & 51 & 30 & 2.4 & 1.36 & 0.36 & 0.5 & 2 & 10.1 & 6.1 & 2.9 & 59 & 18 \\
\hline BWW18 & 6 & 53 & 32 & 3.2 & 1.36 & 0.41 & 0.4 & 2.2 & 12.3 & 7.3 & 4.4 & 140 & 54 \\
\hline BWW18 & 9 & 55 & 39 & 2.12 & 1.41 & 0.55 & 0.45 & 24 & 15.3 & 7 & 4.9 & 310 & 47 \\
\hline BWW18 & 12 & 55 & 33 & 1.88 & 1.46 & 0.56 & 0.4 & 1.9 & 12.0 & 6.2 & 3.6 & 420 & 80 \\
\hline BWW18 & 16 & 42 & 35 & 3.5 & 1.25 & 0.38 & 0.38 & 2.2 & 12.3 & 4 & 6 & 1700 & 190 \\
\hline BWN18 & 24 & 37 & 40 & 1.76 & 1.20 & 0.36 & 0.39 & 1.9 & 11.1 & 5.4 & 5.3 & 1300 & 110 \\
\hline BWW18 & 32 & 47 & 40 & 1.97 & 1.20 & 0.36 & 0.39 & 2.5 & 11 & 5.2 & 9.6 & 14 & 3 \\
\hline BNW18 & 40 & 43 & 34 & 2.13 & 1.31 & 0.30 & 0.35 & 1.9 & 10 & 4 & 3.4 & 58 & 4 \\
\hline BWWZO & P & 45 & 20 & 0.32 & 1.80 & 0.21 & 0.32 & 1.2 & 9.4 & 4.2 & 3.4 & 61 & 8 \\
\hline BYM20 & 0 & 47 & 20 & 0.54 & 1.90 & 0.19 & 0.28 & 1.2 & 8.5 & 3.5 & 4 & 48 & 24 \\
\hline BWW20 & 3 & 47 & 38 & 0.42 & 1.88 & 0.21 & 0.35 & 1.4 & 9.4 & 4 & 5.7 & 230 & 120 \\
\hline BWWZO & 6 & 48 & 23 & 0.58 & 1.83 & 0.26 & 0.29 & 1.4 & 10.3 & 4.6 & 3.2 & 270 & 160 \\
\hline BWWZO & 9 & 46 & 25 & 0.72 & 1.86 & 0.21 & 0.3 & 1.3 & 10 & 5.7 & 3.3 & 180 & 11 \\
\hline BWW20 & 12 & 51 & 26 & 0.92 & 1.85 & 0.26 & 0.3 & 1.3 & 10.3 & 5.2 & 4.3 & 87 & 12 \\
\hline BWW20 & 16 & 54 & 23 & 0.41 & 2.08 & 0.32 & 0.43 & 2.1 & 11.6 & 6.4 & 2.8 & 86 & 28 \\
\hline BWW20 & 24 & 52 & 27 & 0.62 & 2.10 & 0.28 & 0.36 & 2.3 & 11.7 & 4.8 & 3.7 & $\pi$ & 13 \\
\hline BWW20 & 32 & 51 & 27 & 0.21 & 2.36 & 0.28 & 0.38 & 2.3 & 11.4 & 5.3 & 5.1 & 72 & 15 \\
\hline BWW20 & 40 & 54 & 22 & 0.74 & 2.10 & 0.38 & 0.33 & 2.3 & 11.6 & 6.1 & 2.8 & 51 & 10 \\
\hline BMW21 & $\mathbf{P}$ & 44 & 19 & 0.42 & 1.60 & 0.21 & 0.3 & 1.7 & 8.8 & 3.8 & 3.1 & 270 & 7 \\
\hline Bun21 & 0 & 43 & 22 & 0.41 & 1.57 & 0.17 & 1.23 & 2 & 9.1 & 3.8 & 3 & 180 & 110 \\
\hline BMW21 & 3 & 43 & 25 & 0.54 & 149 & 2.12 & 0.37 & 23 & 9.8 & 4.5 & 20.2 & 11000 & 1100 \\
\hline BuW21 & 6 & 40 & 42 & 0.5 & 1.42 & 0.10 & 0.28 & 2.2 & 10.6 & 5 & 16.8 & 8000 & 1800 \\
\hline Bพพ21 & 8 & 45 & 24 & 0.58 & 1.68 & 0.13 & 0.2 & 1.8 & 8.8 & 3.6 & 4.3 & 400 & 56 \\
\hline BMW21 & 12 & 45 & 21 & 0.36 & 1.78 & 0.16 & 0.21 & 1.7 & 8.2 & 4.2 & 3.9 & 580 & 36 \\
\hline BMW21 & 16 & 41 & 25 & 0.22 & 1.88 & 0.18 & 0.27 & 1.8 & 8.6 & 5.2 & 3.1 & 600 & 44 \\
\hline BWW21 & 24 & 44 & 24 & 0.11 & 1.47 & 0.18 & 0.26 & 21 & 10.5 & 5.5 & 3.8 & 1700 & 38 \\
\hline EWM21 & 32 & 40 & 25 & 0.08 & 2.28 & 0.23 & 0.35 & 22 & 11.1 & 5.7 & 4.4 & 210 & 22 \\
\hline 8พnบ21 & 40 & 49 & 25 & 0.43 & 2.13 & 0.28 & 0.39 & 2.6 & 16.6 & 4.8 & 3 & 80 & 23 \\
\hline
\end{tabular}

\begin{tabular}{|c|c|c|c|c|c|c|c|c|c|c|c|c|c|}
\hline BWW23 & $P$ & 68 & 47 & 1.34 & 4.75 & 1.97 & 2.22 & 9 & 68.2 & 46.4 & 3.8 & 120 & $<1.00$ \\
\hline BWW23 & 0 & 68 & $\infty$ & 4.32 & 5.00 & 2.04 & 2.49 & 9.7 & 71.9 & 46.1 & 4.3 & 7 & $<1,00$ \\
\hline Bun:3 & 3 & 68 & 60 & 3.46 & 4.53 & 2.00 & 2.41 & 20.9 & 74.1 & 46.7 & 3.3 & 2000 & 36 \\
\hline BWW23 & 6 & 50 & 54 & 4.12 & 2.87 & 1.97 & 2.25 & 12.3 & 60.1 & 40.2 & 24 & 56 & $<1.00$ \\
\hline BWW23 & 8 & 53 & 67 & 1.8 & 3.43 & 1.54 & 2.07 & 10.7 & 56.8 & 33.8 & 5.7 & 110 & $<1.00$ \\
\hline BWW 23 & 12 & 46 & 50 & 1.5 & 3.37 & 1,40 & 1.46 & 8.6 & 47.9 & 30 & 2.3 & 14 & 1 \\
\hline BWW 23 & 16 & 43 & 50 & 2.1 & 4.28 & 1.40 & 1.64 & 8.4 & 47.5 & 27.7 & 2.3 & 97 & $<1, \infty 0$ \\
\hline BWu23 & 24 & 65 & 56 & 1.14 & 5.64 & 1.54 & 1.93 & 21.8 & 58.6 & 34.6 & 2.7 & 210 & 1 \\
\hline Bun 23 & 32 & 75 & 61 & 0.46 & 4.42 & 0.68 & 211 & 10.6 & 48.9 & 38.9 & 2 & 36 & $<1.00$ \\
\hline BXY 23 & 40 & 69 & 66 & 1.86 & 4.18 & 0.54 & 2.37 & 7.4 & 55.7 & 39.4 & 24 & 43 & $<1.00$ \\
\hline BuY24 & $P$ & 343 & 90 & 34.3 & 0.64 & 4.21 & 1.68 & 4.8 & 33.2 & 5.2 & 8.4 & 5 & 1.00 \\
\hline Bun24 & 0 & 336 & 148 & 23.7 & 1.01 & 5.97 & 280 & 7.4 & 68.9 & 6.4 & 21.6 & $<1.00$ & $<1.00$ \\
\hline Bun24 & 3 & 320 & 145 & 30 & 0.43 & 4.30 & 2.91 & 7.4 & 71.2 & 6.3 & 21.3 & $<1.00$ & $<1,00$ \\
\hline BWW24 & 6 & 321 & 75 & 25.3 & 0.10 & 5.69 & 1.04 & 4.8 & 23.5 & 5.1 & 6.7 & $<1.00$ & $<1.00$ \\
\hline BWW24 & $\theta$ & 318 & 69 & 20.3 & 0.32 & 5.27 & 1.16 & 3.0 & 22.2 & 4.8 & 5.8 & $<1.00$ & $<1.00$ \\
\hline BWW24 & 12 & 325 & 7 & 23 & 0.63 & 281 & 1.87 & 5.8 & 27.4 & 4.9 & 6.8 & $<1.00$ & $<1.00$ \\
\hline BWW124 & 16 & 330 & 81 & 31 & 0.36 & 246 & 1.68 & 5.2 & 23.6 & 2.7 & 5.3 & 14000 & 120 \\
\hline BWW124 & 24 & 322 & 89 & 16.3 & 0.45 & 2.45 & 1.68 & 6.4 & 324 & 4 & 9 & 2 & $<1.00$ \\
\hline BWU24 & 32 & 318 & 92 & 17.7 & 0.88 & 2.28 & 2.41 & 6.5 & 49.7 & 3.4 & 12.3 & $<1.00$ & $<1.00$ \\
\hline BWW24 & 40 & 330 & 89 & 21.3 & 0.42 & 3.51 & 2.37 & 8 & 48.9 & 4 & 11.2 & $<1.00$ & $<1.00$ \\
\hline BWY25 & $P$ & 108 & 82 & 2 & 2.40 & 6.25 & 0.17 & 5 & 16.7 & 97.2 & 8.2 & 47 & $<1.00$ \\
\hline Eun/25 & 0 & 111 & 130 & 3.2 & 1.33 & 5.40 & 0.46 & 6.3 & 26.5 & 128.8 & 9.7 & 210 & 8 \\
\hline Bum25 & 3 & 103 & 85 & 8.2 & 0.16 & 5.64 & 0.14 & 4.5 & 18.8 & 118.8 & 6.1 & 800 & 21 \\
\hline BWw25 & 6 & 79 & 70 & 6 & 0.04 & 5.03 & 0.17 & 4.3 & 19.2 & 85.6 & 7.4 & 5 & $<1.00$ \\
\hline Eunzs & 9 & 62 & 58 & 7.2 & 0.03 & 4.27 & 0.14 & 3.4 & 17.4 & 78.3 & 6.7 & 80 & $<1.00$ \\
\hline BYunzs & 12 & 57 & 68 & 1.8 & 1.4 & 3.67 & 0.19 & 4.6 & 18 & 69 & 10.6 & 76 & 4 \\
\hline Bumas & 16 & 70 & 75 & 1.2 & 3.44 & 3.51 & 0.13 & 5.4 & 20.2 & 74.6 & 9.7 & 39 & $<1.00$ \\
\hline exunzs & 24 & 86 & 76 & 1.8 & 1.08 & 3.97 & 0.23 & 5.3 & 22.5 & 89.4 & 7.3 & 180 & 1 \\
\hline Bunzs & 32 & 86 & 78 & 0.4 & 236 & 3.51 & 0.13 & 5.1 & 18.9 & 86.1 & 7 & 350 & 4 \\
\hline Bun?25 & 40 & 96 & 74 & 3.6 & 0.86 & 3.67 & 0.24 & 3.8 & 16 & 73.4 & 5.4 & $<1.00$ & $<1.00$ \\
\hline BMW26 & 3 & 18 & 62 & 8.9 & 0.20 & 1.38 & 1.83 & 48 & 112 & 118 & 36 & 790000 & 100000 \\
\hline
\end{tabular}

ND $=$ Not Dotected

NS= No Samplo

NM= Not Measured

NA = Not Analyzed 
Table A.2 Water Quality Data for Storm 2

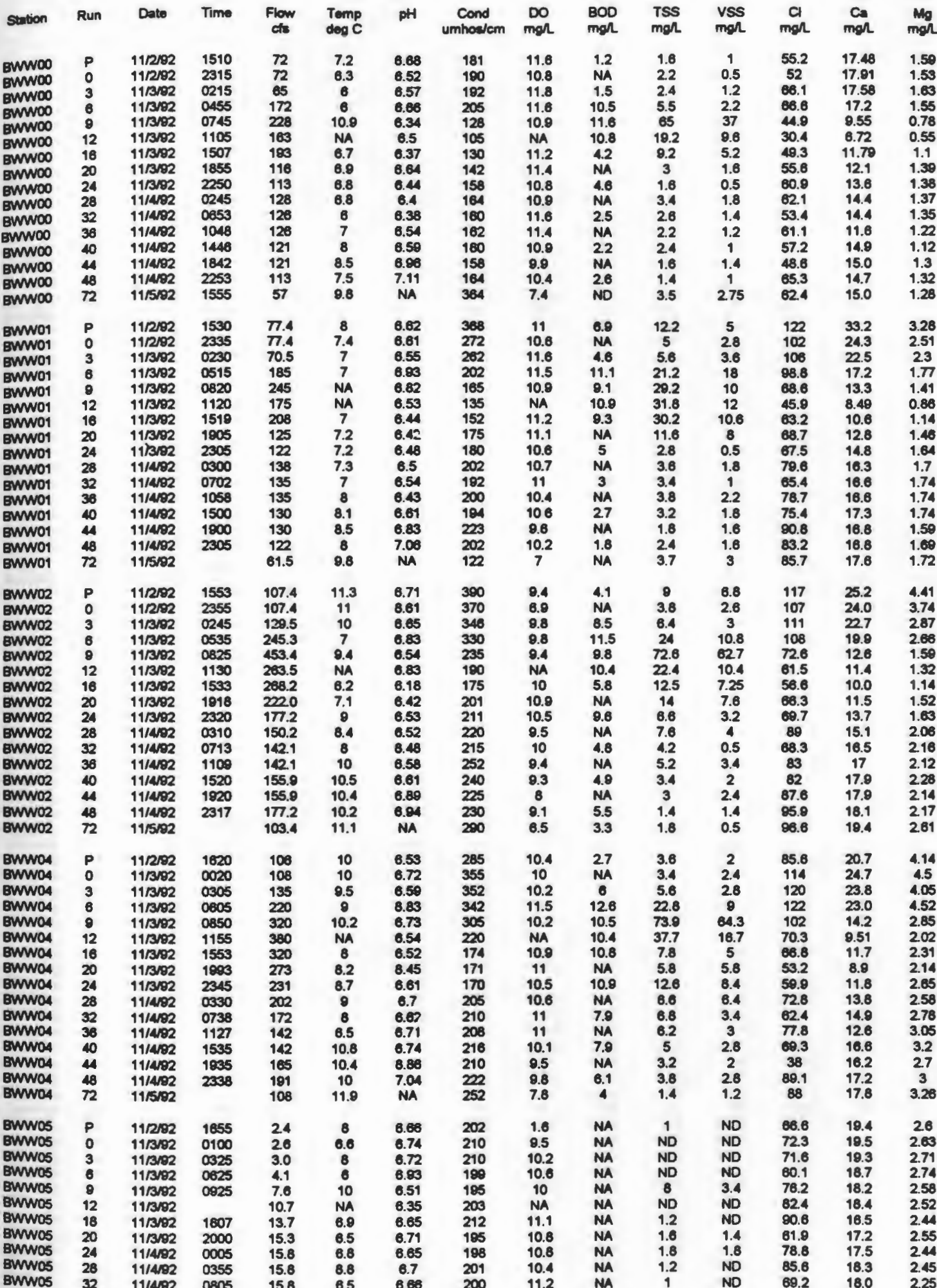


Table A.2 Water Quality Data for Storm 2 (Continued)

\begin{tabular}{|c|c|c|c|c|c|c|c|c|c|c|c|c|c|c|}
\hline sution & Run & Date & Time & $\begin{array}{l}\text { Flow } \\
\text { of }\end{array}$ & $\begin{array}{l}\text { Temp } \\
\operatorname{deg} C\end{array}$ & pH & $\begin{array}{l}\text { Cond } \\
\text { umhos/em }\end{array}$ & $\underset{m g l}{D}$ & $\begin{array}{l}B O D \\
m g h\end{array}$ & $\begin{array}{l}\text { TSS } \\
\text { mgl }\end{array}$ & $\begin{array}{l}\text { VSS } \\
\text { mod }\end{array}$ & $\begin{array}{c}\mathrm{Cl} \\
\mathrm{mgh}\end{array}$ & $\mathrm{C}_{\mathrm{m}}$ & $\underset{m g h}{M g}$ \\
\hline $\begin{array}{l}\text { BwMos } \\
\text { EMwos } \\
\text { BMmos } \\
\text { BwMos } \\
\text { BMmos }\end{array}$ & $\begin{array}{l}36 \\
40 \\
44 \\
48 \\
72\end{array}$ & $\begin{array}{l}11 / 4 / 92 \\
11 / 4 / 92 \\
11 / 492 \\
11 / 4 / 92 \\
11 / 5 \sqrt{ } 92\end{array}$ & $\begin{array}{l}1154 \\
1610 \\
2010 \\
2353\end{array}$ & $\begin{array}{l}15.3 \\
15.3 \\
14.8 \\
14.8 \\
15.8\end{array}$ & $\begin{array}{c}7 \\
8 \\
8 \\
7.5 \\
9\end{array}$ & $\begin{array}{l}8.53 \\
6.83 \\
6.94 \\
7.00 \\
\text { NA }\end{array}$ & $\begin{array}{l}188 \\
202 \\
208 \\
196 \\
182\end{array}$ & $\begin{array}{c}10 \\
10.8 \\
9.6 \\
10.2 \\
7.2\end{array}$ & $\begin{array}{l}\text { NA } \\
\text { NA } \\
\text { NA } \\
\text { NA } \\
\text { NA }\end{array}$ & $\begin{array}{c}\text { ND } \\
1.4 \\
\text { ND } \\
\text { ND } \\
1\end{array}$ & $\begin{array}{c}\text { ND } \\
1 \\
\text { ND } \\
\text { ND } \\
\text { ND }\end{array}$ & $\begin{array}{l}82.6 \\
82.3 \\
85.5 \\
86.4 \\
81.6\end{array}$ & \begin{tabular}{l|l|}
17.8 & \\
18.6 \\
16.6 \\
18.4 \\
18.6
\end{tabular} & $\begin{array}{l}2.3 \\
2.5 \\
2.48 \\
2.57 \\
2.42\end{array}$ \\
\hline $\begin{array}{l}\text { BWW08 } \\
\text { BWW08 } \\
\text { BWW08 } \\
\text { BWW08 } \\
\text { BWW08 } \\
\text { BWW08 } \\
\text { BWW08 } \\
\text { BWW08 } \\
\text { BWW08 } \\
\text { BWW08 } \\
\text { BWW08 } \\
\text { BWW08 } \\
\text { BWW08 } \\
\text { BWW08 } \\
\text { BWW08 } \\
\text { BWW08 }\end{array}$ & $\begin{array}{c}P \\
0 \\
3 \\
6 \\
9 \\
12 \\
18 \\
20 \\
24 \\
26 \\
32 \\
36 \\
40 \\
44 \\
48 \\
72\end{array}$ & $\begin{array}{l}11 / 2 / 92 \\
11 / 2 / 92 \\
11 / 3 / 92 \\
11 / 3 / 92 \\
11 / 3 / 92 \\
11 / 3 / 92 \\
11 / 3 / 92 \\
11 / 3 / 92 \\
11 / 4 / 92 \\
11 / 4 / 92 \\
11 / 4 / 92 \\
11 / 4 / 92 \\
11 / 492 \\
11 / 4992 \\
11 / 4 / 92 \\
11 / 5 / 92\end{array}$ & $\begin{array}{l}1637 \\
0040 \\
0345 \\
0640 \\
0010 \\
1220 \\
1617 \\
1946 \\
0020 \\
0340 \\
0757 \\
1142 \\
1600 \\
1955 \\
0005\end{array}$ & $\begin{array}{l}111 \\
153 \\
175 \\
104 \\
240 \\
286 \\
334 \\
286 \\
245 \\
217 \\
179 \\
141 \\
141 \\
179 \\
245 \\
126\end{array}$ & $\begin{array}{c}8.8 \\
9 \\
9.5 \\
9 \\
10 \\
N A \\
8.7 \\
8.2 \\
8 \\
8.5 \\
8 \\
8.5 \\
8.3 \\
8.9 \\
8.8 \\
10.6\end{array}$ & $\begin{array}{l}6.59 \\
6.68 \\
6.5 \\
6.68 \\
6.81 \\
6.68 \\
6.62 \\
6.74 \\
6.7 \\
6.74 \\
8.48 \\
6.46 \\
6.8 \\
6.61 \\
7.04 \\
N A\end{array}$ & $\begin{array}{l}202 \\
355 \\
200 \\
326 \\
310 \\
205 \\
220 \\
185 \\
178 \\
190 \\
200 \\
108 \\
203 \\
210 \\
225 \\
230\end{array}$ & $\begin{array}{c}10.3 \\
9.8 \\
10.4 \\
11.5 \\
10 \\
N A \\
10.5 \\
11 \\
10.4 \\
10.4 \\
10.8 \\
10.6 \\
10.2 \\
9.5 \\
9.2 \\
7\end{array}$ & $\begin{array}{c}2.3 \\
\text { NA } \\
5.1 \\
12.2 \\
5.3 \\
10.6 \\
8 \\
N A \\
N A \\
N A \\
8.7 \\
N A \\
7.4 \\
N A \\
6.9 \\
4.2\end{array}$ & $\begin{array}{c}3.2 \\
3.8 \\
5.2 \\
6.2 \\
1.6 \\
51.3 \\
20.8 \\
5.6 \\
2 \\
11.4 \\
6.6 \\
8.4 \\
6.4 \\
6 \\
2.8 \\
1.4\end{array}$ & $\begin{array}{c}2.4 \\
0.5 \\
2.8 \\
3.6 \\
1.2 \\
18 \\
18.4 \\
4.2 \\
0.5 \\
5.2 \\
3.4 \\
3.4 \\
3 \\
2.2 \\
1.6 \\
0.5\end{array}$ & $\begin{array}{l}81.8 \\
81.3 \\
91.3 \\
119 \\
112 \\
95.9 \\
81.4 \\
63.5 \\
45 \\
65.6 \\
59.5 \\
72.5 \\
73.2 \\
81.4 \\
86.8 \\
84.7\end{array}$ & $\begin{array}{l}20.0 \\
20.2 \\
20.6 \\
22.8 \\
21.3 \\
15.1 \\
14.6 \\
11.7 \\
11.1 \\
12.0 \\
13.7 \\
14.2 \\
15.5 \\
16.3 \\
16.9 \\
18.5\end{array}$ & $\begin{array}{c}1.85 \\
2 \\
1.88 \\
1.03 \\
1.9 \\
1.6 \\
1.4 \\
1.27 \\
1.4 \\
1.53 \\
1.4 \\
1.63 \\
1.5 \\
2.03 \\
1.63 \\
1.68\end{array}$ \\
\hline $\begin{array}{l}\text { BWW07 } \\
\text { BWW07 } \\
\text { BWW07 } \\
\text { BWW07 } \\
\text { BWW07 } \\
\text { BWW07 } \\
\text { BWW07 } \\
\text { BWW07 } \\
\text { EWW07 } \\
\text { EWW07 } \\
\text { BWW07 } \\
\text { BWW07 } \\
\text { BWW07 } \\
\text { BWW07 } \\
\text { BWW07 } \\
\text { BWW07 }\end{array}$ & $\begin{array}{c}P \\
0 \\
3 \\
8 \\
9 \\
12 \\
16 \\
20 \\
24 \\
28 \\
32 \\
36 \\
40 \\
44 \\
46 \\
72\end{array}$ & $\begin{array}{l}11 / 02 / 92 \\
11 / 03 / 92 \\
11 / 03 / 92 \\
11 / 03 / 92 \\
11 / 03 / 92 \\
11 / 03 / 92 \\
11 / 03 / 92 \\
11 / 03 / 92 \\
11 / 03 / 92 \\
11 / 04 / 92 \\
11 / 0492 \\
11 / 0492 \\
11 / 0492 \\
11 / 0492 \\
11 / 0492 \\
11 / 05 / 92\end{array}$ & $\begin{array}{l}1730 \\
0005 \\
0305 \\
0600 \\
0930 \\
1255 \\
1030 \\
1050 \\
2345 \\
0400 \\
0755 \\
1120 \\
1430 \\
1055 \\
2315 \\
1645\end{array}$ & $\begin{array}{l}100 \\
100 \\
120 \\
149 \\
225 \\
302 \\
367 \\
339 \\
200 \\
235 \\
221 \\
215 \\
205 \\
200 \\
206 \\
183\end{array}$ & $\begin{array}{c}7.4 \\
7.5 \\
6 \\
8 \\
8.2 \\
8.5 \\
9.8 \\
10 \\
8.8 \\
9.2 \\
9.5 \\
10 \\
10.8 \\
9.9 \\
10.3 \\
11.2\end{array}$ & $\begin{array}{l}6.75 \\
6.8 \\
6.68 \\
8.57 \\
6.61 \\
6.57 \\
6.48 \\
6.35 \\
8.67 \\
6.57 \\
6.7 \\
6.54 \\
6.65 \\
6.72 \\
6.72 \\
\text { NA }\end{array}$ & $\begin{array}{l}255 \\
250 \\
245 \\
248 \\
232 \\
238 \\
302 \\
283 \\
230 \\
190 \\
180 \\
175 \\
180 \\
183 \\
205 \\
235\end{array}$ & $\begin{array}{c}8.5 \\
12.2 \\
8.3 \\
9.2 \\
11.4 \\
9.1 \\
8.9 \\
9.6 \\
8.6 \\
8.4 \\
8.8 \\
9.6 \\
6.5 \\
N 4 \\
9.8 \\
7.75\end{array}$ & $\begin{array}{c}2.7 \\
N A \\
4.4 \\
3 \\
2.5 \\
2.8 \\
6.6 \\
N A \\
7.9 \\
N A \\
6.8 \\
N A \\
7.8 \\
N A \\
5.9 \\
3.8\end{array}$ & $\begin{array}{c}3.4 \\
2.8 \\
4 \\
4.8 \\
3 \\
5.4 \\
9 \\
3.8 \\
3.4 \\
9.8 \\
11 \\
7.4 \\
4.2 \\
11.4 \\
4 \\
5.66\end{array}$ & $\begin{array}{c}2.4 \\
2 \\
1.6 \\
2.6 \\
2.2 \\
2.4 \\
3.4 \\
2.8 \\
0.5 \\
6.4 \\
5.7 \\
3.2 \\
2.8 \\
6 \\
2 \\
3\end{array}$ & $\begin{array}{l}83.3 \\
96.6 \\
88.1 \\
68.2 \\
92.2 \\
92.3 \\
95.5 \\
93.9 \\
67.6 \\
74.8 \\
58.3 \\
62.4 \\
62 \\
46.1 \\
74.1 \\
78.4\end{array}$ & $\begin{array}{l}19.8 \\
19.5 \\
19.2 \\
19.1 \\
18.9 \\
19.0 \\
21.1 \\
19.4 \\
14.9 \\
14.3 \\
13.0 \\
12.8 \\
12.8 \\
14.0 \\
14.0 \\
15.8\end{array}$ & $\begin{array}{l}1.38 \\
1.41 \\
1.47 \\
1.38 \\
1.43 \\
1.4 \\
1.81 \\
1.07 \\
1.22 \\
1.18 \\
1.15 \\
1.1 \\
1.11 \\
1.16 \\
1.15 \\
1.34\end{array}$ \\
\hline $\begin{array}{l}\text { EWW08 } \\
\text { EWW08 } \\
\text { BWW08 } \\
\text { BWW08 } \\
\text { BWW08 } \\
\text { EWW08 } \\
\text { EWW08 } \\
\text { BWW08 } \\
\text { BWW08 } \\
\text { BWW08 } \\
\text { BWW08 } \\
\text { BWW08 } \\
\text { BWW08 } \\
\text { BWW08 } \\
\text { BWW08 } \\
\text { BWW08 }\end{array}$ & $\begin{array}{c}P \\
0 \\
3 \\
8 \\
9 \\
12 \\
16 \\
20 \\
24 \\
28 \\
32 \\
36 \\
40 \\
44 \\
48 \\
72\end{array}$ & $\begin{array}{l}11 / 02 / 92 \\
11 / 02 / 92 \\
11 / 03 / 92 \\
11 / 03 / 92 \\
11 / 03 / 92 \\
11 / 03 / 92 \\
11 / 03 / 92 \\
11 / 03 / 92 \\
11 / 03 / 92 \\
11 / 0492 \\
11 / 0492 \\
11 / 04 / 92 \\
11 / 04 / 92 \\
11 / 04 / 92 \\
11 / 04 / 92 \\
11 / 05 / 92\end{array}$ & $\begin{array}{l}1705 \\
2315 \\
0245 \\
0545 \\
0915 \\
1225 \\
1600 \\
1935 \\
2330 \\
0350 \\
0745 \\
1110 \\
1420 \\
1945 \\
2305 \\
1625\end{array}$ & $\begin{array}{l}208 \\
160 \\
105 \\
139 \\
171 \\
211 \\
269 \\
303 \\
438 \\
288 \\
282 \\
288 \\
283 \\
287 \\
269 \\
279\end{array}$ & $\begin{array}{c}7 \\
7.2 \\
7.2 \\
7.5 \\
8 \\
8.2 \\
8.9 \\
9.4 \\
9.5 \\
9.5 \\
9 \\
10 \\
10.5 \\
9.7 \\
9.2 \\
11\end{array}$ & $\begin{array}{l}6.41 \\
6.53 \\
6.55 \\
6.48 \\
8.05 \\
6.84 \\
6.35 \\
6.48 \\
6.86 \\
8.65 \\
6.60 \\
6.51 \\
6.65 \\
6.61 \\
6.63 \\
N 4\end{array}$ & $\begin{array}{l}255 \\
245 \\
238 \\
220 \\
230 \\
232 \\
268 \\
292 \\
290 \\
232 \\
202 \\
190 \\
135 \\
180 \\
196 \\
226\end{array}$ & $\begin{array}{c}6.3 \\
10 \\
7.8 \\
7.7 \\
12 \\
10.1 \\
9 \\
9.4 \\
9.6 \\
8.75 \\
8.7 \\
8.6 \\
7.7 \\
6.7 \\
8.3 \\
7.75\end{array}$ & $\begin{array}{l}1.3 \\
N A \\
2.6 \\
3.4 \\
2.5 \\
3.4 \\
6.5 \\
N A \\
2.4 \\
N A \\
8.8 \\
N A \\
6.2 \\
N A \\
8.3 \\
3.5\end{array}$ & $\begin{array}{c}3.4 \\
7.5 \\
1.2 \\
7.8 \\
6 \\
7.8 \\
19.8 \\
1.8 \\
2.2 \\
22.2 \\
12.4 \\
10.6 \\
8.6 \\
11.6 \\
4.2 \\
11.68\end{array}$ & $\begin{array}{c}1.6 \\
2.5 \\
0.5 \\
3.8 \\
2.4 \\
3 \\
8.2 \\
1.4 \\
0.5 \\
7.4 \\
5.2 \\
3.8 \\
4.33 \\
3.8 \\
2 \\
9.7\end{array}$ & $\begin{array}{c}84.6 \\
92.6 \\
88 \\
97.4 \\
96.6 \\
94.8 \\
83 \\
94.7 \\
97.3 \\
88.6 \\
86.1 \\
67.8 \\
64.6 \\
56.9 \\
77.2 \\
80.5\end{array}$ & \begin{tabular}{|l|l|}
19.5 & \\
19.3 & 18.8 \\
18.8 \\
18.4 \\
18.3 \\
17.8 \\
16.3 \\
19.3 \\
18.4 \\
16.1 \\
14.7 \\
13.6 \\
13.3 \\
12.6 \\
13.4 \\
16.4
\end{tabular} & $\begin{array}{l}2.23 \\
2.22 \\
2.13 \\
2.14 \\
2.08 \\
2.1 \\
1.99 \\
2.18 \\
2.09 \\
1.9 \\
1.68 \\
1.54 \\
1.55 \\
1.49 \\
1.62 \\
1.93\end{array}$ \\
\hline $\begin{array}{l}\text { BWW0s } \\
\text { BWW09 } \\
\text { BWW09 } \\
\text { BWW09 } \\
\text { EWW09 } \\
\text { BWW09 } \\
\text { BWW09 } \\
\text { BWW09 } \\
\text { BWW09 } \\
\text { BWW09 } \\
\text { BWW09 } \\
\text { BWW09 } \\
\text { BWW09 } \\
\text { BWW09 } \\
\text { BWW09 } \\
\text { BWW09 }\end{array}$ & $\begin{array}{c}P \\
0 \\
3 \\
8 \\
9 \\
12 \\
16 \\
20 \\
24 \\
28 \\
32 \\
38 \\
40 \\
44 \\
48 \\
72\end{array}$ & $\begin{array}{l}11 / 02 / 92 \\
11 / 02 / 92 \\
11 / 03 / 92 \\
11 / 03 / 92 \\
11 / 03 / 92 \\
11 / 03 / 92 \\
11 / 03 / 92 \\
11 / 03 / 92 \\
11 / 03 / 92 \\
11 / 04 / 92 \\
11 / 04 / 92 \\
11 / 04 / 92 \\
11 / 0492 \\
11 / 04 / 92 \\
11 / 04 / 92 \\
11 / 05 / 92\end{array}$ & $\begin{array}{l}1640 \\
2315 \\
0230 \\
0505 \\
0845 \\
1205 \\
1530 \\
1900 \\
2300 \\
0325 \\
0715 \\
1040 \\
1405 \\
1917 \\
2250 \\
1600\end{array}$ & $\begin{array}{c}33.6 \\
33.6 \\
33.8 \\
44.4 \\
60.8 \\
78.7 \\
86.1 \\
104 \\
96.5 \\
104 \\
104 \\
104 \\
104 \\
100 \\
92 . \\
73.8\end{array}$ & $\begin{array}{c}7 \\
8.5 \\
7.2 \\
7.5 \\
6 \\
8.2 \\
8.3 \\
8.2 \\
8.5 \\
9 \\
9 \\
9 \\
10.5 \\
8.7 \\
9.1 \\
9.4\end{array}$ & $\begin{array}{l}8.48 \\
6.69 \\
6.7 \\
6.65 \\
6.54 \\
8.50 \\
6.45 \\
8.54 \\
6.74 \\
8.61 \\
6.75 \\
6.62 \\
6.61 \\
6.33 \\
6.7 \\
N A\end{array}$ & $\begin{array}{l}72 \\
65 \\
65 \\
70 \\
60 \\
65 \\
71 \\
70 \\
70 \\
62 \\
62 \\
60 \\
80 \\
60 \\
73 \\
68\end{array}$ & $\begin{array}{c}9.4 \\
10.2 \\
8.7 \\
10.9 \\
11.2 \\
10.5 \\
10.2 \\
9.8 \\
10.4 \\
8 \\
10.1 \\
9.8 \\
8.7 \\
9.3 \\
9 \\
6.35\end{array}$ & $\begin{array}{c}\text { ND } \\
\text { NA } \\
1 \\
1.9 \\
\text { ND } \\
2.7 \\
3.8 \\
\text { NA } \\
2 \\
N A \\
1.5 \\
N A \\
\text { ND } \\
\text { NA } \\
\text { ND } \\
\text { ND }\end{array}$ & $\begin{array}{c}\text { ND } \\
\text { ND } \\
2.4 \\
2.6 \\
2 \\
2.2 \\
1.4 \\
2.8 \\
1 \\
2.8 \\
1.7 \\
1.8 \\
1.6 \\
1.2 \\
\text { ND } \\
\text { ND }\end{array}$ & $\begin{array}{c}\text { ND } \\
\text { ND } \\
\text { ND } \\
1.2 \\
1.4 \\
1.4 \\
1 \\
2.6 \\
\text { ND } \\
1.8 \\
1.3 \\
\text { ND } \\
1.2 \\
1 \\
\text { ND } \\
\text { ND }\end{array}$ & $\begin{array}{c}55.2 \\
26 \\
21.4 \\
30.2 \\
28 \\
27 \\
28.7 \\
28.5 \\
22.8 \\
28.3 \\
22.3 \\
24.1 \\
23.7 \\
23 \\
22.7 \\
20.2\end{array}$ & $\begin{array}{c}7.34 \\
6.29 \\
8.17 \\
6.2 \\
5.82 \\
5.71 \\
5.48 \\
5.1 \\
4.2 \\
4.4 \\
4.65 \\
4.2 \\
4.5 \\
4.39 \\
4.08 \\
4.05\end{array}$ & $\begin{array}{l}0.86 \\
0.77 \\
0.73 \\
0.74 \\
0.7 \\
0.7 \\
0.64 \\
0.63 \\
0.63 \\
0.58 \\
0.58 \\
0.51 \\
0.52 \\
0.51 \\
0.53 \\
0.48\end{array}$ \\
\hline $\begin{array}{l}\text { EWW10 } \\
\text { BWW10 } \\
\text { EWW10 } \\
\text { EWW10 }\end{array}$ & $\begin{array}{l}P \\
0 \\
3 \\
6\end{array}$ & $\begin{array}{l}11,0292 \\
11,02192 \\
11,03192 \\
11,03192\end{array}$ & $\begin{array}{l}1655 \\
2325 \\
0235 \\
0515\end{array}$ & $\begin{array}{l}12.8 \\
13.0 \\
13.2 \\
14.4\end{array}$ & $\begin{array}{l}8.8 \\
6.5 \\
7 \\
6.8\end{array}$ & $\begin{array}{l}6.55 \\
6.37 \\
6.74 \\
6.81\end{array}$ & $\begin{array}{l}127 \\
115 \\
112 \\
118\end{array}$ & $\begin{array}{c}9.1 \\
12.2 \\
8.3 \\
9.1\end{array}$ & $\begin{array}{l}\text { NA } \\
\text { NA } \\
\text { NA } \\
\text { NA }\end{array}$ & $\begin{array}{l}\text { ND } \\
\text { ND } \\
1.6 \\
\text { ND }\end{array}$ & $\begin{array}{l}\text { ND } \\
\text { ND } \\
1.8 \\
\text { ND }\end{array}$ & $\begin{array}{l}93.8 \\
60.5 \\
59.8 \\
70.4\end{array}$ & $\begin{array}{l}6.25 \\
7.38 \\
7.41 \\
7.34\end{array}$ & $\begin{array}{l}1.03 \\
1.21 \\
1.21 \\
1.10\end{array}$ \\
\hline
\end{tabular}


Table A.2 Water Quality Data for Storm 2 (Continued)

\begin{tabular}{|c|c|c|c|c|c|c|c|c|c|c|c|c|c|c|}
\hline Stution & Run & Date & Time & $\begin{array}{c}\text { Flow } \\
\text { cts }\end{array}$ & $\begin{array}{l}\text { Temp } \\
\operatorname{deg} C\end{array}$ & pH & $\begin{array}{l}\text { Cond } \\
\text { umhow/cm }\end{array}$ & $\begin{array}{c}\text { DO } \\
\mathrm{mol}\end{array}$ & $\begin{array}{l}\text { BOD } \\
\text { mol }\end{array}$ & $\begin{array}{l}\text { TSS } \\
\text { mghl }\end{array}$ & $\begin{array}{l}\text { VSS } \\
\text { mgh }\end{array}$ & $\begin{array}{c}\mathrm{Cl} \\
\mathrm{mgl}\end{array}$ & $\underset{m a d}{c a}$ & $\mathrm{Mg}_{\mathrm{mg}}$ \\
\hline BWW10 & $\theta$ & $11 / 03 / 92$ & 0800 & 17.0 & 7 & 6.73 & 110 & 8.8 & NA & 1.6 & ND & 64.5 & 7.1 & 1.12 \\
\hline BWW10 & 12 & $11 / 03 / 92$ & 1215 & 19.4 & 7.8 & 6.74 & 110 & 10.6 & NA & 1.2 & ND & 58.8 & 0.55 & 1.1 \\
\hline BMW10 & 16 & $11 / 03 / 92$ & 1545 & 21.0 & 7.8 & 6.76 & 120 & 11.2 & NA & ND & ND & 67.4 & 8.64 & 1.08 \\
\hline BWW1O & 20 & 11 ros:2 & 1815 & 20.0 & 7.5 & 6.50 & 130 & 9.6 & NA & 3 & 1.8 & 59.8 & 6.7 & 1.11 \\
\hline BWW10 & 24 & $11 / 03 / 92$ & 2315 & 20.8 & 7.5 & 6.74 & 130 & 9.8 & NA & ND & ND & 59.4 & 5.9 & 1.09 \\
\hline BWN10 & 28 & $11 / 04 / 82$ & 0330 & 220 & 8.2 & 8.65 & 115 & 8.8 & NA & 1.2 & 1 & 67.8 & 6.3 & 1.12 \\
\hline BMW10 & 32 & $11 / 0492$ & 0730 & 227 & 9 & 6.73 & 122 & 8.1 & NA & ND & ND & 57.2 & 8.63 & 1.1 \\
\hline BMW1O & 38 & $11 / 04 / 92$ & 1055 & 23.4 & 9 & 6.64 & 125 & 6.1 & NA & 1.2 & ND & 61.7 & MA & 1.04 \\
\hline BWN10 & 40 & $11 / 04 / 82$ & 1410 & 25.2 & 9.8 & 6.7 & 125 & 8.3 & NA & ND & ND & 62.3 & 6.4 & 1.09 \\
\hline BWW10 & 44 & $11 / 04 / 92$ & 1927 & 26.8 & 6.1 & 8.59 & 127 & 9.1 & NA & 1.8 & 1.2 & 62.7 & 8.56 & 1.08 \\
\hline BWW10 & 48 & $11 / 04 / 92$ & 2255 & 27.2 & 6.3 & 8.72 & 133 & 8.4 & NA & ND & ND & 65.1 & 8.07 & 1.03 \\
\hline BWW10 & 72 & $11 / 05 / 92$ & 1610 & 28.8 & 9.7 & NA & 138 & 8.3 & NA & 2.67 & 2.3 & 57.1 & 6.33 & 1.04 \\
\hline BMW11 & $\mathbf{P}$ & $11 / 02 / 92$ & 1630 & 252 & 6.8 & 8.39 & 101 & 8.0 & 2.3 & 4.2 & 2.6 & 84.3 & 14.5 & 2.07 \\
\hline BWW11 & 0 & 11/02/92 & 2305 & 207 & 7 & 6.57 & 168 & 12.2 & NA & 4.2 & 2.8 & 42.3 & 14.0 & 2 \\
\hline BWW11 & 3 & $11 / 03 / 92$ & 0210 & 152 & 7.5 & 8.61 & 160 & 7.8 & 1.7 & 2,4 & 1.8 & 55.8 & 13.0 & 1.84 \\
\hline BWW11 & 6 & $11 / 03 / 92$ & 0450 & 188 & 7.5 & 8.50 & 152 & 10.8 & 23 & 3.5 & 2.5 & 71.4 & 12.9 & 1.01 \\
\hline BWW11 & 9 & $11 / 03 / 92$ & 0830 & 250 & 8 & 8.69 & 152 & 7.6 & 27 & 3.8 & 3 & 84.2 & 12.6 & 1.84 \\
\hline BWW11 & 12 & $11 / 03 / 92$ & 1155 & 307 & 6.2 & 8.82 & 155 & 13.6 & 3.5 & 8.6 & 2.6 & 68.6 & 12.4 & 1.64 \\
\hline BWW11 & 18 & $11 / 03 / 92$ & 1520 & 378 & 6.8 & 6.65 & 182 & 9.7 & 8.3 & 16 & 6.3 & 62 & 11.4 & 1.73 \\
\hline BWW11 & 20 & $11 / 03 / 92$ & 1845 & 517 & 0.1 & 6.58 & 185 & 8 & NA & 23 & 6 & 69.2 & 12.1 & 1.72 \\
\hline BWW11 & 24 & $11 / 03 / 92$ & 2240 & 553 & 8.2 & 8.68 & 210 & 9 & 8 & 39 & 11.5 & 63.9 & 10.3 & 1.47 \\
\hline BWW11 & 28 & $11 / 0492$ & 0315 & 412 & 9 & 6.57 & 205 & 9.1 & NA & 14 & 9 & 81.7 & 13.8 & 1.78 \\
\hline BWW11 & 32 & $11 / 04 / 92$ & 0710 & 409 & 9.5 & 8.62 & 185 & 8.3 & 6.2 & 1.4 & 0.5 & 64.7 & 12.9 & 1.83 \\
\hline BWW11 & 36 & $11 / 04 / 92$ & 1035 & 413 & 9.8 & 6.58 & 185 & 10.2 & NA & 6.2 & 3 & 61.3 & 11.1 & 1.87 \\
\hline BWW11 & 40 & $11 / 04 / 92$ & 1400 & 412 & 10.5 & 6.61 & 158 & 8.2 & 5 & 8.4 & 28 & 59.1 & 10.8 & 1.54 \\
\hline BWW11 & 44 & $11 / 04 / 92$ & 1905 & 414 & 0.1 & 8.72 & 140 & 8.4 & NA & 6 & 3.8 & 55.8 & 0.4 & 1.33 \\
\hline BMW11 & 48 & $11 / 04 / 92$ & 2240 & 389 & 8.3 & 8.68 & 147 & 8.7 & 4 & 1.2 & 0.5 & 54.3 & 9.2 & 1.48 \\
\hline BWM11 & 72 & $11 / 05 / 92$ & 1540 & 382 & 10.2 & NA & 155 & 6.25 & NA & 28 & 1.6 & 46.2 & 10.4 & 1.55 \\
\hline EWW13 & $\mathbf{P}$ & $11 / 02 / 92$ & 1610 & 321 & 6.5 & 6.89 & 140 & 9.9 & ND & 3.4 & 2 & 53.1 & 10.9 & 1.52 \\
\hline EWN13 & 0 & $11 / 0292$ & 2240 & 274 & 6.8 & 6.75 & 138 & 11.8 & NA & 24 & 1.4 & 57.3 & 11.2 & 1.56 \\
\hline EWN13 & 3 & $11 / 03 / 92$ & 0150 & 222 & 7 & 8.63 & 140 & 8 & 1.1 & 24 & 2 & 55.1 & 11.2 & 1.57 \\
\hline EMN13 & 8 & $11 / 03 / 92$ & 0430 & 273 & 7.5 & 6.59 & 135 & 9.7 & 2.1 & 4.7 & 2.7 & 59.8 & 10.9 & 1.5 \\
\hline EMW13 & 0 & $11 / 03 / 92$ & 0800 & 353 & 7.5 & 6.62 & 125 & 8.6 & 1.4 & 2.8 & 1.8 & 55.1 & 8.88 & 1.48 \\
\hline EMN13 & 12 & $11 / 03 / 92$ & 1135 & 408 & 6.2 & 8.58 & 120 & 10.6 & 2.0 & 2.2 & 1 & 53.3 & 0.45 & 1.35 \\
\hline BWW13 & 18 & $11 / 03 / 92$ & 1500 & 483 & 8 & 6.67 & 140 & 10.7 & 3.5 & 2.8 & 1.6 & 61.5 & 10.4 & 1.51 \\
\hline EWN13 & 20 & $11 / 03 / 92$ & 1830 & 635 & 8.7 & 6.72 & 100 & 9 & NA & 4 & 3.2 & 56.2 & 11.1 & 1.51 \\
\hline EWW13 & 24 & $11 / 03192$ & 2220 & 676 & 6 & 6.76 & 150 & 7.8 & 2.5 & 1.6 & 0.5 & 55.8 & 7.3 & 1.47 \\
\hline EMW13 & 28 & $11 / 0492$ & 0300 & 542 & $\theta$ & 6.50 & 145 & 8.15 & NA & 8 & 2.8 & 57.7 & 9.2 & 1.43 \\
\hline EWW13 & 32 & $11 / 0492$ & Daso & 540 & 9.5 & 8.78 & 155 & 0.4 & 3.3 & 1.6 & 0.5 & 54 & 10.3 & 1.44 \\
\hline BWW13 & 36 & $11 / 04 / 22$ & 1015 & 545 & 9.6 & 6.69 & 162 & 9.8 & NA & 7 & 2.8 & 58.2 & 8.3 & 1.42 \\
\hline EWW13 & 40 & $11 / 0492$ & 1340 & 545 & 10.5 & 6.63 & 185 & 8.8 & 20 & 5.8 & 2.4 & 63.7 & 11.3 & 1.5 \\
\hline EMW13 & 44 & $11 / 04 / 92$ & 1850 & 547 & 0.2 & 6.72 & 151 & 10.6 & NA & 6.8 & 3.5 & 62.0 & 10.6 & 1.52 \\
\hline Bum13 & 48 & $11 / 04 / 22$ & 2230 & 520 & 10 & 6.76 & 145 & 8.3 & 3 & 2 & 1.8 & 60.3 & 9.28 & 1.15 \\
\hline BWW13 & 72 & $11 / 05 / 2$ & 1525 & 497 & 10 & NA & 133 & 8.1 & 21 & 3.7 & 3 & 43.2 & 7.8 & 1.21 \\
\hline EMW14 & $\mathbf{P}$ & $11 / 0292$ & 1800 & 67.6 & 7.2 & 8.68 & 61 & 8.6 & ND & 1.4 & ND & 20.4 & 4.35 & 0.49 \\
\hline EMW14 & 0 & $11 / 03 / 92$ & 0000 & 66.2 & 8 & 8.64 & 60 & 12.8 & NA & ND & ND & 24.7 & 4.13 & $0.4 \theta$ \\
\hline EWW14 & 3 & $11 / 03 / 92$ & 0330 & 68.4 & 7.5 & 6.76 & $\infty$ & 8.8 & 1.4 & 1.6 & 1.4 & 22.2 & 4.12 & $0.4 \theta$ \\
\hline EWM14 & 6 & $11 / 03 / 92$ & 0030 & 74.2 & 8 & 8.8 & 60 & 7.0 & 21 & 2.8 & 1 & 28.4 & 4.07 & 0.45 \\
\hline BWW14 & 9 & $11 / 03 \% 22$ & 1000 & 101 & 8.2 & 6.73 & $\infty$ & 10.6 & 1.4 & 24 & 1.6 & 26.9 & 4.07 & 0.47 \\
\hline BWW14 & 12 & $11 / 03 / 92$ & 1325 & 89.4 & 8.5 & 8.72 & 60 & 9.8 & 1.6 & 1.6 & 1 & 26.8 & 3.95 & 0.46 \\
\hline EWW14 & 18 & $11 / 03 / 92$ & 1700 & 105 & 0 & 6.64 & 60 & 11.3 & 3 & 2.67 & NA & 27.9 & 4.02 & 0.47 \\
\hline EMW14 & 20 & $11 / 0002$ & 2020 & 116 & 0.3 & 6.74 & 70 & 10.4 & NA & 28 & 2.2 & 24.8 & 3.7 & 0.44 \\
\hline EMW14 & 24 & $11 / 04 / 92$ & 0015 & 121 & 0.1 & 6.52 & 68 & 0.4 & 2 & ND & ND & 23.1 & 3.2 & 0.46 \\
\hline BWW14 & 28 & $11 / 0402$ & 0430 & 127 & 0 & 6.74 & 62 & 10 & NA & 1.6 & 1.2 & 27.1 & 3.4 & 0.46 \\
\hline BWW14 & 32 & $11 / 10492$ & 0830 & 129 & 8 & 6.74 & 65 & 9.7 & 1.5 & 4.67 & 4 & 23.7 & 3.69 & 0.45 \\
\hline EWN14 & 38 & $11 / 04 / 2$ & 1145 & 129 & 0.5 & 6.63 & 85 & 9.5 & NA & 1.8 & 1.4 & 25.4 & 3.2 & 0.44 \\
\hline EWW14 & 40 & $11 / 04 / 92$ & 1505 & 130 & 10.5 & 6.81 & 70 & 8.2 & 1.0 & 1.2 & 1 & 27 & 3.6 & 0.43 \\
\hline EWW14 & 44 & $11 / 04 / 82$ & 2030 & 130 & 10.8 & 6.44 & 71 & NA & NA & 1.2 & 1 & 26.2 & 3.62 & 0.43 \\
\hline EMW14 & 48 & $11 / 04 / 82$ & 2340 & 128 & 0.5 & 6.67 & 85 & 8.7 & ND & 1 & ND & 27.2 & 3.65 & 0.43 \\
\hline BWM14 & 72 & $11 / 05 / 22$ & 1730 & 113 & 10 & $\mathrm{NA}$ & 82 & $\ddot{\theta}$ & ND & 1.6 & 1.8 & 24.5 & 3.69 & 0.43 \\
\hline BWM15 & $\mathbf{P}$ & $11 / 02 / 92$ & 1600 & 9.8 & 6.5 & 6.26 & 125 & 5.8 & NA & 2.2 & ND & 47 & 8.53 & 1.07 \\
\hline BWW15 & 0 & $11 / 02 / 92$ & 2205 & 9.4 & 5 & 6.62 & 127 & 8.5 & NA & 3 & 1.6 & 54.1 & 8.03 & 1.04 \\
\hline BWW15 & 3 & $11 / 03 / 92$ & 0145 & 9.8 & 7 & 6.72 & 122 & 7 & NA & 24 & NA & 44.3 & 8.54 & 1.08 \\
\hline BWW15 & $\boldsymbol{6}$ & $11 / 03 / 92$ & 0.435 & 11.5 & 6.7 & 8.55 & 121 & 7.2 & NA & ND & ND & 48.6 & 8.37 & 1.07 \\
\hline BWW15 & 9 & $11 / 03 / 92$ & 0800 & 19.7 & 9 & 8.71 & 120 & 7.3 & NA & 4 & 3 & 51.3 & 8.2 & 1.06 \\
\hline BWW15 & 12 & $11 / 03 / 82$ & 1135 & 21.6 & 8.5 & 6.65 & 128 & 7.2 & NA & 3.6 & 1.6 & 53.9 & 8.15 & 1.07 \\
\hline BWW15 & 16 & $11 / 03 / 92$ & 1500 & 20.1 & 10 & 6.7 & 130 & 6.9 & NA & 5.4 & 26 & 58.7 & 8.09 & 1 \\
\hline BWW15 & 20 & $11 / 03 / 92$ & 1855 & 18.1 & 11.2 & 6.65 & 122 & 6 & NA & 4.4 & 3 & 52.4 & 8.1 & 1.08 \\
\hline BWW15 & 24 & $11 / 03 / 92$ & 2210 & 18.0 & 11.1 & 8.44 & 125 & 6.7 & NA & 2.4 & 1.6 & 50.7 & 7.1 & 1.01 \\
\hline BWW15 & 28 & $11 / 04 / 2$ & 0250 & 21.8 & 7.5 & 8.65 & 120 & 7.8 & NA & 4 & 1.8 & 55.9 & 7.6 & 1.03 \\
\hline BWW15 & 32 & $11 / 04 / 82$ & 0840 & 24.0 & 9 & 6.52 & 121 & 8.65 & NA & 3.4 & 1.6 & 48.9 & 8.15 & 0.09 \\
\hline BWW15 & 36 & $11 / 04 / 92$ & 1016 & 24.0 & 0.5 & 8.53 & 120 & 7.7 & NA & 26 & 1.2 & 52.4 & 7.6 & 1.09 \\
\hline BWW15 & 40 & $11 / 0492$ & 1445 & 23.2 & 10.5 & 8.50 & 128 & 7.1 & NA & 2.4 & 1.4 & 56.2 & 7.8 & 1.08 \\
\hline BWW15 & 4 & $11 / 04 / 22$ & 1845 & 30.7 & 10.8 & 8.65 & 132 & 8.6 & NA & 2.8 & 1.2 & 54.7 & 8.18 & 1.07 \\
\hline
\end{tabular}


Table A.2 Water Quality Data for Storm 2 (Continued)

\begin{tabular}{|c|c|c|c|c|c|c|c|c|c|c|c|c|c|c|}
\hline Station & Run & Date & Time & $\begin{array}{l}\text { Flow } \\
\text { cts }\end{array}$ & $\begin{array}{l}\text { Temp } \\
\operatorname{deg} C\end{array}$ & pH & $\begin{array}{l}\text { Cond } \\
\text { umhoesem }\end{array}$ & $\begin{array}{c}\text { DO } \\
\text { mgn }\end{array}$ & $\begin{array}{l}B O D \\
m a n\end{array}$ & $\begin{array}{l}\text { TSS } \\
\text { mgh }\end{array}$ & $\begin{array}{l}\text { vss } \\
\text { mgr }\end{array}$ & $\begin{array}{c}\mathrm{Cl} \\
\mathrm{mgh}\end{array}$ & $\underset{m g h}{C a}$ & $\begin{array}{l}\text { Mg } \\
\text { mgr }\end{array}$ \\
\hline $\begin{array}{l}\text { BWN15 } \\
\text { BWN15 }\end{array}$ & $\frac{48}{72}$ & $\begin{array}{l}11 / 0492 \\
11 / 05 \times 22\end{array}$ & $\begin{array}{l}2215 \\
1450\end{array}$ & $\begin{array}{l}20.8 \\
18.0\end{array}$ & $\begin{array}{l}11 \\
9.5\end{array}$ & $\begin{array}{l}6.65 \\
N A\end{array}$ & $\begin{array}{l}127 \\
148\end{array}$ & $\begin{array}{l}8.6 \\
8.7\end{array}$ & $\begin{array}{l}\text { NA } \\
\text { NA }\end{array}$ & $\begin{array}{c}2.8 \\
2\end{array}$ & $\begin{array}{l}1.4 \\
1.4\end{array}$ & $\begin{array}{c}60 \\
52.9\end{array}$ & $\begin{array}{l}8.13 \\
8.22\end{array}$ & $\begin{array}{l}1.09 \\
1.11\end{array}$ \\
\hline $\begin{array}{l}\text { BWW16 } \\
\text { BWW18 } \\
\text { BWW18 } \\
\text { BWW18 } \\
\text { BWW16 } \\
\text { BWW16 } \\
\text { BWW18 } \\
\text { BWW16 } \\
\text { BWW16 } \\
\text { BWW16 } \\
\text { BWW16 } \\
\text { BWW18 } \\
\text { BWW16 } \\
\text { BWW18 } \\
\text { BWW16 } \\
\text { BWW16 }\end{array}$ & $\begin{array}{c}P \\
0 \\
3 \\
6 \\
9 \\
12 \\
16 \\
20 \\
24 \\
28 \\
32 \\
36 \\
40 \\
44 \\
48 \\
72\end{array}$ & $\begin{array}{l}11 / 02 / 92 \\
11 / 02 / 92 \\
11 / 03 / 92 \\
11 / 03 / 92 \\
11 / 03 / 92 \\
11 / 03 / 92 \\
11 / 03 / 92 \\
11 / 03 / 92 \\
11 / 03 / 92 \\
11 / 04 / 92 \\
11 / 04 / 92 \\
11 / 04 / 92 \\
11 / 04 / 92 \\
11 / 0492 \\
11 / 0492 \\
11 / 05 / 92\end{array}$ & $\begin{array}{l}1540 \\
2235 \\
0130 \\
0420 \\
0740 \\
1120 \\
1445 \\
1840 \\
2200 \\
0240 \\
0630 \\
1010 \\
1430 \\
1830 \\
2200 \\
1425\end{array}$ & $\begin{array}{c}8.2 \\
5.9 \\
5.6 \\
8.3 \\
20.9 \\
27.5 \\
27.5 \\
19.8 \\
21.3 \\
17.8 \\
17.8 \\
18.4 \\
18.4 \\
13.7 \\
11.5 \\
10.8 \\
\end{array}$ & $\begin{array}{c}6.5 \\
6.3 \\
6 \\
5.9 \\
6 \\
7 \\
6 \\
11 \\
11.3 \\
8 \\
7.8 \\
8.2 \\
10 \\
9.2 \\
10 \\
8.6\end{array}$ & $\begin{array}{l}6.34 \\
6.84 \\
6.74 \\
6.52 \\
6.81 \\
6.65 \\
6.74 \\
6.68 \\
6.44 \\
6.65 \\
6.42 \\
6.59 \\
6.55 \\
6.88 \\
6.53 \\
\text { NA }\end{array}$ & $\begin{array}{c}135 \\
115 \\
112 \\
110 \\
60 \\
118 \\
102 \\
81 \\
100 \\
80 \\
88 \\
108 \\
112 \\
120 \\
115 \\
\text { NA }\end{array}$ & $\begin{array}{c}6.25 \\
6.8 \\
6.8 \\
6.5 \\
7.25 \\
6.1 \\
6.2 \\
6.5 \\
6.8 \\
7.4 \\
8.1 \\
7.6 \\
6.2 \\
6.7 \\
7 \\
7\end{array}$ & $\begin{array}{c}3.1 \\
\text { NA } \\
3.3 \\
4.8 \\
6 \\
3.7 \\
7.6 \\
\text { NA } \\
6 \\
\text { NA } \\
3 \\
\text { NA } \\
3.1 \\
\text { NA } \\
2.4 \\
2.3\end{array}$ & $\begin{array}{c}2 \\
90.4 \\
2 \\
45.2 \\
\mathrm{ND} \\
3 \\
3.6 \\
6.8 \\
1.4 \\
2.5 \\
2 \\
2.4 \\
2 \\
7.2 \\
\mathrm{ND} \\
22\end{array}$ & $\begin{array}{c}1.6 \\
31.2 \\
1 \\
15.6 \\
\text { ND } \\
2 \\
3 \\
4.8 \\
\text { ND } \\
1.7 \\
1.5 \\
2 \\
1.4 \\
4.8 \\
\text { ND } \\
1.6\end{array}$ & $\begin{array}{l}38.8 \\
44.8 \\
42.2 \\
45.6 \\
28.8 \\
43.1 \\
38.3 \\
32.5 \\
33.8 \\
38.5 \\
33.7 \\
37.1 \\
40.4 \\
32.7 \\
43.2 \\
38.4\end{array}$ & $\begin{array}{c}10.25 \\
9.52 \\
9.81 \\
9.88 \\
7.03 \\
9.2 \\
7.78 \\
7.3 \\
7.1 \\
8.1 \\
8.83 \\
8.3 \\
8.5 \\
8.5 \\
7.72 \\
8\end{array}$ & $\begin{array}{l}1.21 \\
1.05 \\
1.2 \\
1.14 \\
0.7 \\
1.08 \\
0.81 \\
0.86 \\
0.88 \\
1.01 \\
1.05 \\
1.1 \\
1.02 \\
1.03 \\
0.85 \\
0.88\end{array}$ \\
\hline $\begin{array}{l}\text { BWW17 } \\
\text { BWW17 } \\
\text { BWW17 } \\
\text { BWW17 } \\
\text { BWW17 } \\
\text { BWW17 } \\
\text { BWW17 } \\
\text { BWW17 } \\
\text { BWW17 } \\
\text { BWW17 } \\
\text { BWW17 } \\
\text { BWW17 } \\
\text { BWW17 } \\
\text { BWW17 } \\
\text { BWW17 } \\
\text { BWW17 }\end{array}$ & $\begin{array}{c}P \\
0 \\
3 \\
6 \\
8 \\
12 \\
18 \\
20 \\
24 \\
28 \\
32 \\
36 \\
40 \\
44 \\
48 \\
72\end{array}$ & $\begin{array}{l}11 / 02 / 92 \\
11 / 02 / 92 \\
11 / 03 / 92 \\
11 / 03 / 92 \\
11 / 03 / 92 \\
11 / 13 / 92 \\
11 / 03 / 92 \\
11 / 03 / 92 \\
11 / 03 / 92 \\
11 / 04 / 92 \\
11 / 04 / 92 \\
11 / 04 / 92 \\
11 / 04 / 92 \\
11 / 04 / 92 \\
11 / 04 / 92 \\
11 / 05 / 92\end{array}$ & $\begin{array}{l}1545 \\
2230 \\
0135 \\
0415 \\
0730 \\
1105 \\
1440 \\
1810 \\
2200 \\
0245 \\
0625 \\
1000 \\
1320 \\
1835 \\
2215 \\
1500\end{array}$ & $\begin{array}{l}259 \\
286 \\
282 \\
286 \\
310 \\
328 \\
365 \\
445 \\
529 \\
675 \\
693 \\
683 \\
640 \\
660 \\
606 \\
569\end{array}$ & $\begin{array}{c}7.3 \\
\text { NA } \\
7.2 \\
7.5 \\
8 \\
8.2 \\
8.2 \\
8.3 \\
8 \\
9 \\
9 \\
9.5 \\
10.2 \\
10 \\
10.2 \\
10\end{array}$ & $\begin{array}{l}6.25 \\
6.6 \\
6.7 \\
6.63 \\
6.65 \\
6.65 \\
6.68 \\
6.49 \\
6.63 \\
6.68 \\
6.8 \\
6.61 \\
6.7 \\
6.91 \\
6.7 \\
\text { NA }\end{array}$ & $\begin{array}{l}184 \\
140 \\
140 \\
135 \\
125 \\
135 \\
150 \\
152 \\
145 \\
150 \\
145 \\
150 \\
160 \\
175 \\
175 \\
150\end{array}$ & $\begin{array}{c}11.4 \\
12 \\
11.4 \\
11.6 \\
8.8 \\
10.5 \\
10.8 \\
10.8 \\
10 \\
8.75 \\
8.3 \\
9.7 \\
8.2 \\
10.4 \\
9.2 \\
8\end{array}$ & $\begin{array}{l}\text { ND } \\
\text { NA } \\
1.7 \\
2.5 \\
3.2 \\
2.3 \\
4 \\
N A \\
2.5 \\
N A \\
2.2 \\
N A \\
2.5 \\
N A \\
N A \\
1.8\end{array}$ & $\begin{array}{c}2 \\
1.6 \\
1.4 \\
3.8 \\
3.6 \\
2 \\
2.8 \\
1.6 \\
5.3 \\
8.75 \\
4.2 \\
5 \\
4.4 \\
4.8 \\
1.4 \\
8.7\end{array}$ & $\begin{array}{c}1.4 \\
1.2 \\
1.2 \\
2.2 \\
1.8 \\
1.2 \\
1.4 \\
0.5 \\
2.2 \\
4 \\
1.5 \\
2 \\
2 \\
2.2 \\
0.5 \\
1.33\end{array}$ & $\begin{array}{l}50.2 \\
54.1 \\
58.9 \\
63.8 \\
56.3 \\
59.7 \\
65.5 \\
54.9 \\
50.1 \\
63.6 \\
52.3 \\
57.3 \\
63.4 \\
67.1 \\
74.4 \\
48.9\end{array}$ & $\begin{array}{c}12.0 \\
11.5 \\
11.1 \\
11.2 \\
10.3 \\
11.0 \\
11.0 \\
10.7 \\
8.8 \\
10.6 \\
10.5 \\
10.0 \\
11.0 \\
11.8 \\
11.7 \\
6.85\end{array}$ & $\begin{array}{l}2.13 \\
2.12 \\
1.98 \\
1.99 \\
1.82 \\
1.9 \\
1.89 \\
1.91 \\
1.8 \\
1.83 \\
1.77 \\
1.64 \\
1.75 \\
1.94 \\
1.9 \\
1.47\end{array}$ \\
\hline $\begin{array}{l}\text { BW118 } \\
\text { EWW18 } \\
\text { BWW18 } \\
\text { BWW18 } \\
\text { BWW18 } \\
\text { EWW18 } \\
\text { BWW18 } \\
\text { BWW18 } \\
\text { BWW18 } \\
\text { BWW18 } \\
\text { BWW18 } \\
\text { BWW18 } \\
\text { BWW18 } \\
\text { BWW18 } \\
\text { BWW18 } \\
\text { BWW18 }\end{array}$ & $\begin{array}{c}P \\
0 \\
3 \\
8 \\
9 \\
12 \\
18 \\
20 \\
24 \\
28 \\
32 \\
36 \\
40 \\
44 \\
48 \\
72\end{array}$ & $\begin{array}{l}11 / 02 / 92 \\
11 / 02 / 92 \\
11 / 0392 \\
11 / 03 / 92 \\
11 / 03 / 92 \\
11 / 03 / 92 \\
11 / 03 / 92 \\
11 / 03192 \\
11 / 03 / 92 \\
11 / 04 / 92 \\
11 / 04 / 92 \\
11 / 0492 \\
11 / 0492 \\
11 / 0492 \\
11 / 04992 \\
11 / 05192\end{array}$ & $\begin{array}{l}1630 \\
2315 \\
0205 \\
0500 \\
0830 \\
1200 \\
1510 \\
1915 \\
22000 \\
0305 \\
0655 \\
1050 \\
1500 \\
1900 \\
2230 \\
1500\end{array}$ & $\begin{array}{l}285 \\
272 \\
205 \\
272 \\
451 \\
305 \\
500 \\
451 \\
528 \\
597 \\
787 \\
712 \\
712 \\
730 \\
628 \\
588\end{array}$ & $\begin{array}{c}6 \\
8.5 \\
8.5 \\
6.2 \\
8.2 \\
8.5 \\
8.7 \\
8 \\
8 \\
8 \\
8 \\
8.5 \\
8.8 \\
10.2 \\
9.7 \\
10\end{array}$ & $\begin{array}{l}6.05 \\
6.69 \\
6.76 \\
6.53 \\
6.45 \\
6.72 \\
6.50 \\
6.61 \\
8.37 \\
6.57 \\
8.5 \\
6.48 \\
6.63 \\
6.91 \\
6.78 \\
\mathrm{NA}\end{array}$ & $\begin{array}{l}170 \\
171 \\
190 \\
178 \\
180 \\
175 \\
172 \\
170 \\
181 \\
163 \\
152 \\
160 \\
162 \\
104 \\
191 \\
200\end{array}$ & $\begin{array}{l}8.1 \\
7.2 \\
6.8 \\
7.4 \\
6.45 \\
6.6 \\
6.7 \\
9.7 \\
6.1 \\
7.55 \\
8.25 \\
7.2 \\
8.4 \\
8.4 \\
8.6 \\
8.2\end{array}$ & $\begin{array}{l}21 \\
N A \\
2.2 \\
3.2 \\
3.3 \\
2.8 \\
4.1 \\
N A \\
5.3 \\
N A \\
3 \\
N A \\
3.1 \\
N A \\
3.5 \\
2.9\end{array}$ & $\begin{array}{c}3 \\
1.8 \\
3.8 \\
3.2 \\
2.2 \\
1.8 \\
3 \\
5.8 \\
8.8 \\
10.6 \\
3.4 \\
8 \\
7.4 \\
11.8 \\
22.5 \\
1.6\end{array}$ & $\begin{array}{c}2.6 \\
1.4 \\
2.2 \\
2.2 \\
1.8 \\
1 \\
1 \\
3.4 \\
4.8 \\
6.6 \\
1 \\
2.8 \\
3.6 \\
6 \\
15.5 \\
0.5\end{array}$ & $\begin{array}{c}56.8 \\
57 \\
71.8 \\
77.2 \\
71.8 \\
73.5 \\
75.2 \\
67.1 \\
69.1 \\
71.4 \\
56.6 \\
62.2 \\
68.5 \\
39.5 \\
80 \\
62.4\end{array}$ & $\begin{array}{c}12.4 \\
12.2 \\
12.4 \\
12.3 \\
11.6 \\
11.3 \\
11.4 \\
10.8 \\
9.7 \\
10 \\
10.2 \\
10.4 \\
10.4 \\
10.6 \\
11.3 \\
9.46\end{array}$ & \begin{tabular}{r|}
1.5 \\
1.57 \\
1.97 \\
1.5 \\
1.6 \\
1.69 \\
1.69 \\
1.70 \\
1.64 \\
1.71 \\
1.64 \\
2.1 \\
1.61 \\
1.7 \\
1.50 \\
1.6
\end{tabular} \\
\hline $\begin{array}{l}\text { BWW20 } \\
\text { BWW20 } \\
\text { BWW20 } \\
\text { BWW20 } \\
\text { BWW20 } \\
\text { BWW20 } \\
\text { BWW20 } \\
\text { BWW20 } \\
\text { BWW20 } \\
\text { BWW20 } \\
\text { BWW20 } \\
\text { BWW20 } \\
\text { BWW20 } \\
\text { BWW20 } \\
\text { BWW20 } \\
\text { BWW20 }\end{array}$ & $\begin{array}{l}P \\
0 \\
3 \\
6 \\
9 \\
12 \\
16 \\
20 \\
24 \\
28 \\
32 \\
38 \\
40 \\
44 \\
48 \\
72\end{array}$ & $\begin{array}{c}11 / 02 / 92 \\
11 / 02 / 92 \\
11 / 03 / 92 \\
11 / 03 / 92 \\
11 / 03 / 92 \\
11 / 03 / 92 \\
11 / 03 / 92 \\
11 / 03 / 92 \\
\text { NS } \\
11 / 0492 \\
11 / 0492 \\
11 / 04 / 92 \\
11 / 04 / 92 \\
11 / 04 / 92 \\
11 / 04 / 92 \\
11 / 05 / 92\end{array}$ & $\begin{array}{l}1655 \\
2335 \\
0230 \\
0530 \\
0300 \\
1230 \\
1530 \\
1840 \\
\text { NS } \\
0330 \\
0710 \\
1055 \\
1510 \\
1925 \\
2300 \\
1755\end{array}$ & $\begin{array}{l}328 \\
302 \\
294 \\
302 \\
500 \\
430 \\
554 \\
500 \\
584 \\
683 \\
852 \\
700 \\
700 \\
810 \\
607 \\
630\end{array}$ & $\begin{array}{c}8.5 \\
6 \\
8 \\
6 \\
8.7 \\
9 \\
9 \\
8.8 \\
N S \\
8.1 \\
8.2 \\
9 \\
10.5 \\
9.1 \\
9.8 \\
10.5\end{array}$ & $\begin{array}{l}6.34 \\
6.58 \\
6.7 \\
6.61 \\
6.58 \\
6.34 \\
6.48 \\
6.48 \\
\mathrm{NS} \\
6.63 \\
6.48 \\
6.64 \\
6.57 \\
6.94 \\
6.81 \\
\mathrm{NA}\end{array}$ & $\begin{array}{l}185 \\
180 \\
180 \\
173 \\
187 \\
178 \\
178 \\
180 \\
N S \\
172 \\
170 \\
180 \\
162 \\
180 \\
170 \\
210\end{array}$ & $\begin{array}{c}8.5 \\
7.2 \\
6.65 \\
7.7 \\
6.8 \\
6.8 \\
6.9 \\
7.3 \\
\text { NS } \\
7.8 \\
7.6 \\
7 \\
6.6 \\
7.4 \\
7.8 \\
8\end{array}$ & $\begin{array}{c}1.8 \\
N A \\
2.5 \\
3 \\
24 \\
3.7 \\
4.7 \\
N A \\
N S \\
N A \\
5 \\
N A \\
4.6 \\
N A \\
3 \\
41\end{array}$ & $\begin{array}{c}2.8 \\
24 \\
2 \\
4.2 \\
4 \\
4.67 \\
2.6 \\
4.2 \\
6.9 \\
8.8 \\
12.8 \\
13.8 \\
8.6 \\
8.2 \\
3.8 \\
7\end{array}$ & $\begin{array}{c}2 \\
1.6 \\
1.4 \\
2.2 \\
2.2 \\
3.3 \\
2.8 \\
2.4 \\
3.4 \\
4.4 \\
7.6 \\
8.6 \\
4.6 \\
4.2 \\
2.2 \\
8\end{array}$ & $\begin{array}{c}61.5 \\
80 \\
75.8 \\
61 \\
73.5 \\
70.5 \\
73.5 \\
69.5 \\
72 \\
74.8 \\
62 \\
69.1 \\
70.8 \\
69 \\
74.1 \\
71.5\end{array}$ & $\begin{array}{l}12.9 \\
12.7 \\
13.1 \\
13.0 \\
12.5 \\
13.0 \\
12.3 \\
12.5 \\
11.5 \\
10.5 \\
10.3 \\
10.1 \\
10.3 \\
10.4 \\
10.7 \\
11.9\end{array}$ & $\begin{array}{r}1.4 \\
1.35 \\
1.41 \\
1.38 \\
1.49 \\
1.68 \\
1.48 \\
1.48 \\
1.31 \\
1.35 \\
1.38 \\
1.33 \\
1.24 \\
1.37 \\
1.27 \\
1.34\end{array}$ \\
\hline $\begin{array}{l}\text { BWW21 } \\
\text { BWW21 } \\
\text { BWW21 } \\
\text { EWW21 } \\
\text { BWW21 } \\
\text { BWW21 } \\
\text { BWW21 }\end{array}$ & $\begin{array}{c}P \\
0 \\
3 \\
8 \\
9 \\
12 \\
16\end{array}$ & $\begin{array}{l}11 / 02 / 92 \\
11 / 02 / 92 \\
11 / 03 / 92 \\
11 / 03 / 92 \\
11 / 03 / 92 \\
11 / 03 / 92 \\
11 / 03 / 92\end{array}$ & $\begin{array}{l}1715 \\
2355 \\
0245 \\
0545 \\
0925 \\
1250 \\
1545\end{array}$ & $\begin{array}{l}204 \\
311 \\
302 \\
208 \\
410 \\
458 \\
458\end{array}$ & $\begin{array}{c}8 \\
6 \\
8.3 \\
8 \\
8.5 \\
9.2 \\
9\end{array}$ & $\begin{array}{l}6.3 \\
8.62 \\
8.68 \\
8.57 \\
8.75 \\
8.61 \\
6.58\end{array}$ & $\begin{array}{l}175 \\
192 \\
191 \\
171 \\
172 \\
185 \\
190\end{array}$ & $\begin{array}{c}8.8 \\
7.6 \\
7.3 \\
8 \\
7.15 \\
7.2 \\
7.3\end{array}$ & $\begin{array}{l}\text { ND } \\
\text { NA } \\
1.6 \\
2.7 \\
3.3 \\
2.4 \\
4.3\end{array}$ & $\begin{array}{c}1.4 \\
2.4 \\
3 \\
3.8 \\
5.3 \\
3.4 \\
2\end{array}$ & $\begin{array}{c}1 \\
2 \\
2.2 \\
2.2 \\
4.3 \\
1.2 \\
1.2\end{array}$ & $\begin{array}{l}67.7 \\
63.6 \\
79.3 \\
80.1 \\
69.9 \\
74.7 \\
68.4\end{array}$ & $\begin{array}{l}12.7 \\
13.1 \\
12.9 \\
13.0 \\
12.5 \\
12.7 \\
12.9\end{array}$ & \begin{tabular}{|c|}
1.82 \\
2.1 \\
1.85 \\
1.8 \\
1.92 \\
1.86 \\
2.09
\end{tabular} \\
\hline
\end{tabular}


Table A.2 Water Quality Data for Storm 2 (Continued)

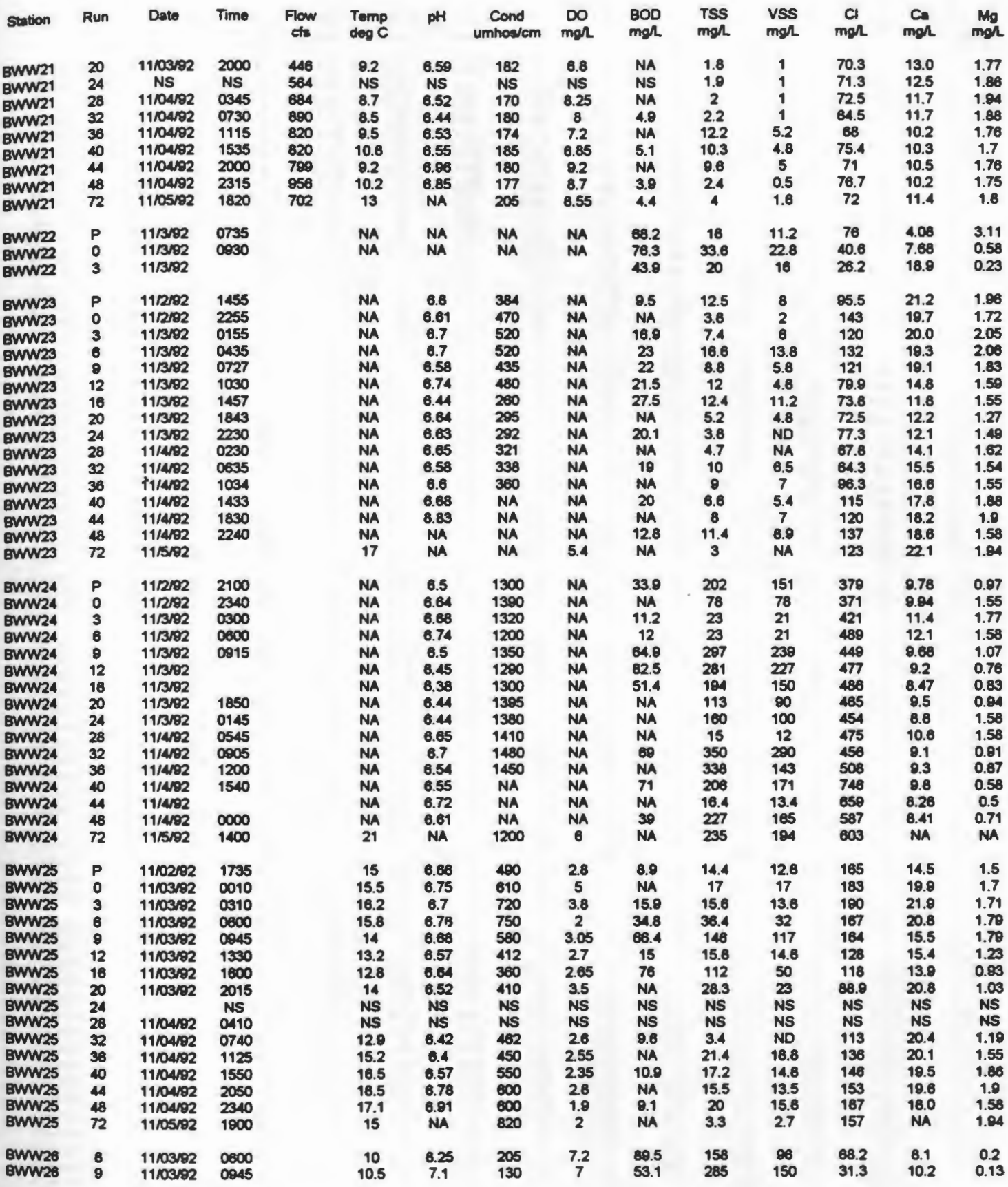

NO = Not Detected

NS= No Sample

NM= Not Measured

MA $=$ Not Analyzed 
Table A.2 Water Quality Data for Storm 2 (Continued)

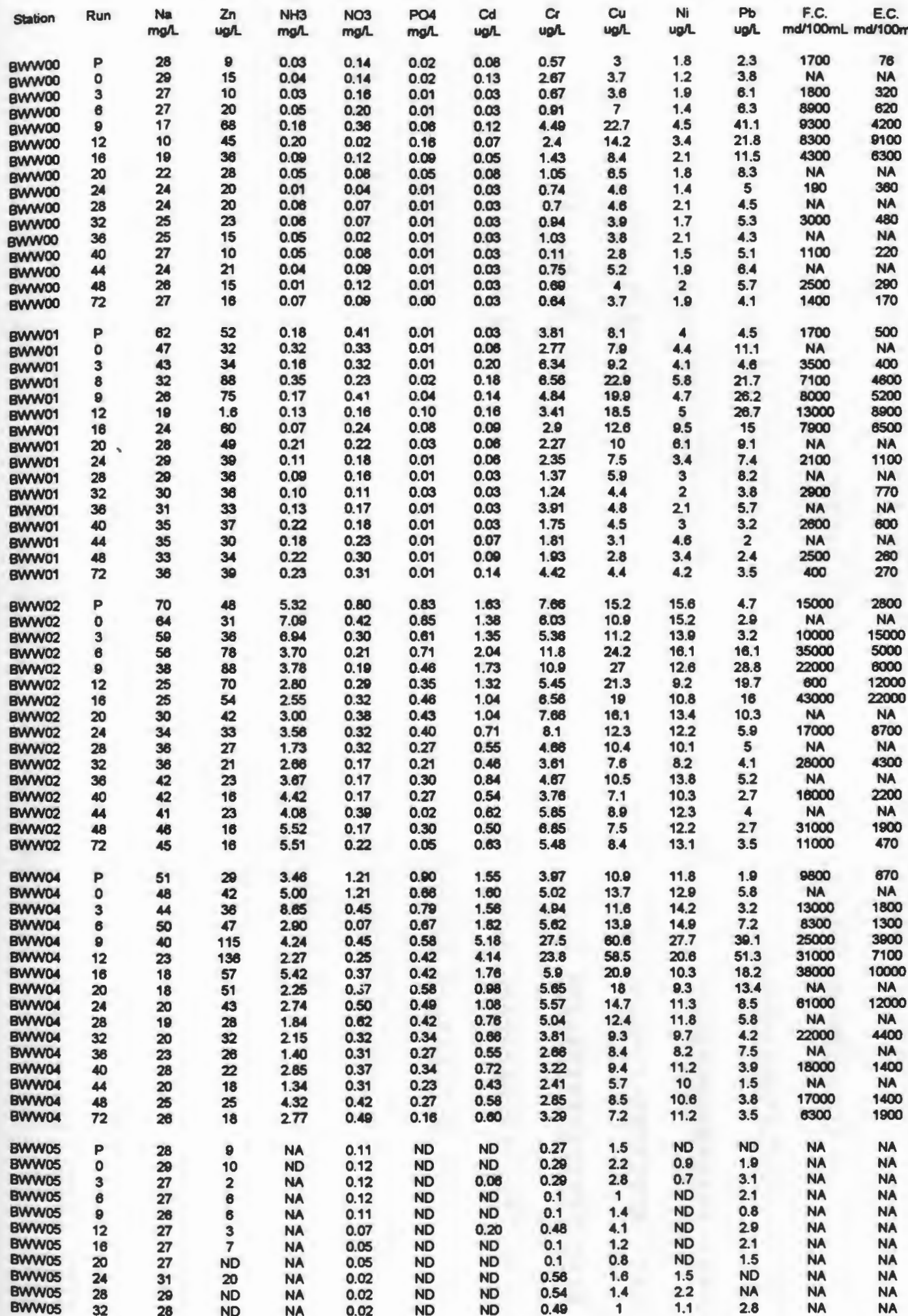


Table A.2 Water Quality Data for Storm 2 (Continued)

\begin{tabular}{|c|c|c|c|c|c|c|c|c|c|c|c|c|c|}
\hline Sration & Run & $\mathrm{Na}$ & $\begin{array}{l}Z_{n} \\
\text { uad }\end{array}$ & $\begin{array}{l}\text { NH3 } \\
\text { mal }\end{array}$ & $\begin{array}{l}\text { NOS } \\
\text { mal }\end{array}$ & $\begin{array}{l}\text { POA } \\
\text { mal }\end{array}$ & $\begin{array}{c}\text { Cd } \\
\text { uor }\end{array}$ & $\begin{array}{c}C r \\
\log L\end{array}$ & $\cos$ & $\begin{array}{c}\mathrm{Ni} \\
\operatorname{ug} / \mathrm{L}\end{array}$ & $\begin{array}{l}\mathrm{Pb} \\
\cos \Omega\end{array}$ & $\begin{array}{l}\text { F.C. } \\
\text { morooml }\end{array}$ & $\begin{array}{l}\text { EC. } \\
\text { droom }\end{array}$ \\
\hline Bunos & 36 & 25 & 4 & NA & 0.02 & ND & ND & 0.39 & 1.4 & 0.7 & 4.7 & NA & NA \\
\hline Bwwos & 40 & 30 & 6 & NA & ND & ND & ND & 0.42 & 2 & 0.6 & 2.9 & NA & NA \\
\hline BMNOS & 44 & 27 & ND & NA & 0.02 & ND & ND & 0.84 & 1.8 & 3 & 7 & NA & NA \\
\hline Buwos & 48 & 28 & 3 & NA & 0.02 & ND & ND & 0.55 & 1 & 21 & 0.9 & NA & NA \\
\hline Emwos & 72 & 30 & ND & NA & & ND & ND & 0.5 & 1 & 1.2 & 1 & NA & NA \\
\hline BWWOS & $\mathbf{P}$ & 40 & 27 & 4.25 & 1.75 & 0.71 & 1.40 & 246 & 13 & 12.3 & 2.8 & 1700 & 220 \\
\hline EMNOS & 0 & 42 & 43 & 4.7 & 1.88 & 0.77 & 1.57 & 3.27 & 14.5 & 11.4 & 5.5 & NA & NA \\
\hline BWWOs & 3 & 40 & 32 & 4.83 & 1.04 & 0.68 & 1.47 & 20 & 14.5 & 12 & 5.5 & 3700 & 290 \\
\hline BMWos & 6 & 50 & 43 & 3.02 & 1.54 & 0.55 & 1.38 & 3.39 & 13.1 & 10.4 & 10.6 & 5100 & 100 \\
\hline EWWOS & 9 & 47 & 33 & 3.89 & 1.22 & 0.61 & 1.40 & 4.25 & 120 & 11.3 & 5.4 & 8500 & 2500 \\
\hline EYWDOS & 12 & 41 & 102 & 0.17 & 0.29 & 0.48 & 3.64 & 20 & 50.8 & 19.7 & 37.7 & 38000 & 2400 \\
\hline BWNOS & 18 & 30 & 54 & 3.79 & 0.35 & 0.40 & 1.85 & 7.49 & 20.7 & 11.8 & 19.2 & 26000 & 7100 \\
\hline BWWOS & 20 & 21 & 48 & 2.80 & 0.75 & 0.40 & 1.38 & 4.29 & 18 & 8.2 & 14.8 & NA & NA \\
\hline BwWos & 24 & 19 & 42 & 201 & 0.58 & 0.38 & 1.12 & 4.3 & 15.6 & 8.6 & 18.2 & 24000 & 11000 \\
\hline BWWos & 28 & 22 & 39 & 1.71 & 0.40 & 0.33 & 1.05 & 5.11 & 13.6 & 8.2 & 15.1 & NA & NA \\
\hline BWW08 & 32 & 25 & 36 & 3.00 & 0.55 & 0.30 & 0.86 & $4 . \pi$ & 12.8 & 9 & 8.2 & 36000 & 6200 \\
\hline EMNOS & 38 & 28 & 38 & 1.83 & 0.44 & 0.30 & 0.81 & 4.02 & 11.2 & 8.4 & 19.4 & NA & NA \\
\hline BWWOS & 40 & 28 & 34 & 2.03 & 0.52 & 0.21 & 0.70 & 3.12 & 10.3 & 7.8 & 7.4 & 11000 & 810 \\
\hline BMWOS & 44 & 28 & 27 & 2.80 & 0.58 & 0.24 & 0.69 & 3.34 & 0.7 & 8.8 & 6.8 & NA & NA \\
\hline BWWOS & 48 & 31 & 28 & 252 & 0.41 & 0.24 & 0.71 & 3.23 & 10.5 & 8.2 & 6.1 & 8400 & 1000 \\
\hline BWWOS & 72 & 30 & 22 & 1.40 & 0.52 & 0.18 & 0.60 & 3.57 & 8.9 & 7 & 6.2 & 1400 & 300 \\
\hline BWMO7 & $\mathbf{p}$ & 46 & 38 & 257 & 1.72 & 0.60 & 1.48 & 3.80 & 13.2 & 13.5 & 3.5 & 1200 & 78 \\
\hline BMพ07 & 0 & 45 & 39 & 3.51 & 1.68 & 0.68 & 1.31 & 3.92 & 13.3 & 12.8 & 3.8 & NA & NA \\
\hline BWw07 & 3 & 41 & 45 & 2.92 & 1.72 & 0.69 & 1.41 & 3.80 & 13.3 & 13.2 & 4.7 & 2100 & 40 \\
\hline BWw07 & 6 & 37 & 37 & 267 & 1.77 & 0.66 & 1.31 & 3.52 & 127 & 12.6 & 5.2 & 2200 & 130 \\
\hline BWW07 & 9 & 43 & 31 & 2.65 & 1.43 & 0.68 & 1.31 & 3.48 & 13.3 & 12 & 4.8 & 3800 & 870 \\
\hline BWw07 & 12 & 38 & 33 & 4.40 & 1.57 & 0.62 & 1.31 & 3.64 & 14.2 & 12.8 & $\mathbf{5}$ & 1200 & 280 \\
\hline BMWO7 & 18 & 49 & 43 & 3.10 & 1.10 & 0.52 & 1.42 & 4.80 & 15.8 & 10.2 & 6.5 & 5000 & 500 \\
\hline Bพm07 & 20 & 45 & 24 & 3.73 & 0.63 & 0.39 & 0.49 & 1.23 & 15.4 & 6.2 & 8.75 & NA & NA \\
\hline EWW07 & 24 & 37 & 42 & 4.56 & 0.63 & 0.32 & 1.38 & 5.13 & 16.5 & 7.8 & 11.6 & 20000 & 2000 \\
\hline EMMO7 & 28 & 33 & 47 & 1.55 & 0.84 & 0.20 & 1.28 & 4.35 & 16 & 8.6 & 10.2 & NA & NA \\
\hline Bพw07 & 32 & 30 & 40 & 260 & 0.68 & 0.20 & 1.18 & 4.1 & 14.7 & 8.2 & 9.3 & 17000 & 2600 \\
\hline EMNo7 & 36 & 28 & 48 & 2.28 & 0.83 & 0.25 & 1.72 & 4.35 & 15 & 9.9 & 8.8 & NA & NA \\
\hline EMW07 & 40 & 27 & 50 & 1.64 & 0.54 & 0.32 & 0.88 & 4.41 & 12 & 8.5 & 7.4 & 11000 & 6400 \\
\hline BWw07 & 44 & 29 & 45 & 1.26 & 0.54 & 0.32 & 1.00 & 4.04 & 13.3 & 8.8 & 7.2 & NA & NA \\
\hline EพMW07 & 48 & 30 & 54 & 1.25 & 0.54 & 0.25 & 1.11 & 3.20 & 9.3 & 8.5 & 6.3 & 16000 & 2400 \\
\hline BWW07 & 72 & 33 & 53 & 1.16 & 0.54 & 0.25 & 1.10 & 4.19 & 12.8 & 8.9 & 8 & 4900 & 410 \\
\hline BWWos & $\mathbf{P}$ & 50 & 38 & 1.65 & 200 & 0.63 & 1.55 & 4.83 & 14 & 14.3 & 4.1 & 1400 & 91 \\
\hline BWW08 & 0 & 47 & 47 & 247 & 1.05 & 0.58 & 1.56 & 4.88 & 14.9 & 13.8 & 5 & NA & NA \\
\hline BMW08 & 3 & 46 & 48 & 212 & 200 & 0.55 & 1.03 & 4.89 & 14.7 & 14 & 5.4 & 910 & 70 \\
\hline BWYOS & 6 & 47 & 47 & 217 & 1.63 & 0.61 & 1.61 & 4.74 & 14.9 & 13.5 & 5.9 & 760 & 40 \\
\hline BWW08 & 9 & 45 & 41 & 2.14 & 1.60 & 0.05 & 1.49 & 4.20 & 15.3 & 13.1 & 8.9 & 3000 & 55 \\
\hline BWW08 & 12 & 45 & 49 & 282 & 1.60 & 0.61 & 1.65 & 5.08 & 16.8 & 127 & 7.3 & 5000 & 220 \\
\hline BWW0S & 16 & 43 & 61 & 3.48 & 1.57 & 0.81 & 238 & 13.6 & 33 & 14.8 & 18.5 & 1800 & 300 \\
\hline Bww0s & 20 & 48 & 50 & 3.31 & 1.49 & 0.58 & 213 & 11.4 & 25.8 & 13.4 & 15.9 & NA & NA \\
\hline BWw08 & 24 & 48 & 45 & 295 & 0.88 & 0.43 & 200 & 9.44 & 22 & 129 & 127 & 3200 & 780 \\
\hline Bwwos & 28 & 41 & 46 & 1.97 & 0.60 & 0.36 & 1.83 & 7.44 & 20.8 & 12.3 & 13.6 & NA & NA \\
\hline EWwos & 32 & 33 & 42 & 2.83 & 0.60 & 0.34 & 1.68 & 6.65 & 19.8 & 10.4 & 13.1 & 19000 & 3800 \\
\hline BWW08 & 36 & 30 & 39 & 2.00 & 0.58 & 0.34 & 1.35 & 4.15 & 15.5 & 9.4 & 9.4 & NA & NA \\
\hline Bumos & 40 & 28 & so & 2.55 & 0.57 & 0.35 & 215 & 4.91 & 17.1 & $\theta$ & 123 & 10000 & 2300 \\
\hline BWwos & 44 & 28 & 45 & 211 & 0.52 & n.s5 & 1.41 & 6.44 & 16.7 & 9.8 & 14 & NA & MA \\
\hline BWwos & 48 & 30 & 36 & 220 & 0.52 & 0.30 & 1.57 & 263 & 122 & 10.1 & 17.4 & 15000 & 3300 \\
\hline EMWos & 72 & 34 & 28 & 1.05 & 0.52 & 0.30 & 0.81 & 3.52 & 10.1 & 8.6 & 5.8 & 4700 & 580 \\
\hline BMmos & $\mathbf{P}$ & 5 & 3 & 0.01 & 0.12 & ND & ND & 0.42 & 23 & ND & ND & 3 & 3 \\
\hline BWWOS & 0 & 5 & 7 & ND & 0.13 & 0.01 & ND & 0.78 & 0.7 & ND & 0.0 & NA & NA \\
\hline BMWOS & 3 & 4 & 12 & ND & 0.17 & 0.01 & ND & 0.63 & 1.4 & ND & 0.7 & 70 & 30 \\
\hline BWwos & 8 & 4 & 9 & ND & 0.15 & 0.00 & ND & 0.8 & 0.8 & ND & 1 & 60 & 11 \\
\hline BWW09 & 9 & 5 & 15 & ND & 0.16 & 0.01 & ND & 0.83 & 1 & ND & 21 & 200 & 88 \\
\hline EMWOS & 12 & 5 & 11 & 0.05 & 0.15 & 0.01 & ND & 0.97 & 1.1 & ND & 24 & 350 & 130 \\
\hline EWWOS & 16 & ND & 16 & ND & 0.14 & 0.01 & ND & 0.03 & 1.4 & ND & 1.2 & 170 & 250 \\
\hline BWWOS & 20 & 4 & 12 & ND & 0.12 & 0.00 & ND & 1.00 & 1 & ND & 0.8 & NA & NA \\
\hline BWWos & 24 & 2 & 14 & ND & 0.00 & 0.00 & ND & 0.85 & 1.2 & ND & 1.6 & 200 & 200 \\
\hline BWWOS & 28 & 3 & 17 & 0.05 & 0.11 & 0.00 & ND & 0.83 & 1.2 & ND & 1.1 & NA & NA \\
\hline BWMos & 32 & 2 & 15 & ND & 0.11 & 0.00 & ND & 0.92 & 1.2 & ND & 8.9 & 130 & 180 \\
\hline BWwos & 38 & ND & 8 & 0.08 & 0.04 & 0.00 & ND & 0.6 & 1.1 & ND & 3.9 & NA & NA \\
\hline BMNOS & 40 & ND & 14 & NO & 0.00 & 0.00 & ND & 0.51 & 1.3 & ND & 1.2 & 80 & 83 \\
\hline BWWOS & 44 & ND & 13 & 0.02 & 0.07 & 0.00 & ND & 0.49 & 1.5 & ND & 1.4 & NA & NA \\
\hline BWwos & 48 & ND & 16 & ND & 0.38 & $0 . \infty 0$ & 0.05 & 0.28 & 1.3 & ND & 0.8 & 140 & 83 \\
\hline BWw09 & 72 & ND & 12 & 0.01 & NA & NA & 0.00 & 0.24 & 0.9 & ND & 1.3 & 190 & 81 \\
\hline BMW10 & $\mathbf{P}$ & 10 & 4 & NA & 0.10 & 0.01 & 0.05 & 0.45 & 1 & ND & 0.8 & NA & NA \\
\hline BWW10 & 0 & 20 & 6 & 0.10 & 0.00 & ND & ND & ND & 1,1 & ND & 0.5 & NA & NA \\
\hline BWW10 & 3 & 28 & 7 & NA & 0.02 & 0.01 & $\mathbf{N D}$ & ND & 0.8 & ND & 1 & NA & NA \\
\hline BWW10 & 8 & 25 & 8 & NA & 0.22 & ND & ND & ND & 1.4 & ND & 1.7 & NA & NA \\
\hline
\end{tabular}


Table A.2 Water Quality Data for Storm 2 (Continued)

\begin{tabular}{|c|c|c|c|c|c|c|c|c|c|c|c|c|c|}
\hline Stution & Run & $\mathrm{ma}$ & $\operatorname{Zn}_{\operatorname{lon}}$ & $\begin{array}{l}\mathrm{NH3} \\
\mathrm{mol}\end{array}$ & $\begin{array}{l}\text { NOS } \\
\text { mgll }\end{array}$ & $\begin{array}{l}P O 4 \\
m g h\end{array}$ & $\underset{u g h}{C d}$ & $\underset{\mathrm{ug} h}{\mathrm{Cr}}$ & $\begin{array}{c}\mathrm{Cu} \\
\mathrm{ugh}\end{array}$ & $\begin{array}{c}\mathrm{Ni} \\
\text { ugh }\end{array}$ & $\underset{u g h}{P b}$ & $\begin{array}{l}\text { F.C. } \\
\text { md } / 100 \mathrm{~mL}\end{array}$ & $\begin{array}{c}\text { E.C. } \\
\mathrm{nd} / 100 \mathrm{~m}\end{array}$ \\
\hline BWW10 & 9 & 25 & 9 & NA & 0.39 & ND & ND & ND & 1 & ND & 1.5 & NA & MA \\
\hline BWW10 & 12 & 24 & 12 & NA & 0.02 & ND & ND & ND & 1 & ND & 1 & NA & NA \\
\hline BWW10 & 16 & 25 & 8 & NA & 0.02 & ND & ND & ND & 0.9 & ND & 0.7 & NA & NA \\
\hline BWW10 & 20 & 24 & 7 & NA & 0.02 & ND & ND & ND & 0.9 & ND & 1 & NA & MA \\
\hline BWW10 & 24 & 25 & 10 & NA & 0.00 & ND & NO & No & 1.7 & ND & 1 & NA & NA \\
\hline BWW10 & 28 & 25 & 7 & NA & 0.03 & ND & ND & ND & 0.9 & ND & 2.1 & NA & NA \\
\hline BWW10 & 32 & 24 & 8 & NA & 0.02 & NO & 0.07 & ND & 1 & NO & 0.9 & NA & NA \\
\hline BWW10 & 36 & 24 & 5 & NA & 0.01 & ND & ND & ND & 0.6 & ND & 0.4 & NA & NA \\
\hline BWW10 & 40 & 24 & 7 & NA & 0.04 & ND & ND & 0.49 & 1.5 & NO & 0.8 & NA & NA \\
\hline BWW10 & 44 & 24 & 4 & NA & 0.03 & NO & ND & 0.41 & 1.1 & ND & 0.6 & NA & NA \\
\hline BWW10 & 48 & 22 & 9 & NA & 0.08 & 0.04 & 0.19 & 0.8 & 1.0 & ND & 0.9 & NA & NA \\
\hline BWW10 & 72 & 23 & 5 & NA & NA & NA & 0.10 & 0.42 & 1.4 & ND & 0.8 & NA & NA \\
\hline BWW11 & $\mathbf{P}$ & 37 & 28 & 0.61 & 2.08 & 0.31 & 0.73 & 3.73 & 125 & 7.4 & 3.5 & 120 & 5 \\
\hline BWW11 & 0 & 34 & 28 & 0.73 & 2.08 & 0.30 & 0.68 & 3.08 & 10.6 & 7 & 2.6 & NA & NA \\
\hline BWW11 & 3 & 33 & 27 & 0.63 & 2.05 & 0.25 & 0.57 & 268 & 9 & 5.7 & 2.1 & 250 & 30 \\
\hline BWY11 & 6 & 31 & 25 & 0.68 & 1.10 & 0.26 & 0.58 & 2.72 & 8.4 & 6.3 & 24 & 260 & 40 \\
\hline BWW11 & 9 & 30 & 24 & 0.68 & 2.22 & 0.25 & 0.04 & 2.0 & 10.2 & 6.4 & 3.6 & 310 & 80 \\
\hline BMW11 & 12 & 30 & 40 & 0.82 & 0.85 & 0.28 & 0.80 & 4.67 & 13.8 & 8.5 & 5.7 & 370 & 300 \\
\hline BWW11 & 16 & 30 & 47 & 1.15 & 1.03 & 0.30 & 1.30 & 8.58 & 22 & 8.1 & 10.9 & 680 & 160 \\
\hline BWW11 & 20 & 32 & 55 & 0.88 & 1.05 & 0.34 & 1.58 & 11.1 & $\overline{224}$ & 9.5 & 14.3 & NA & NA \\
\hline BWW11 & 24 & 34 & 71 & 1.41 & 1.40 & 0.39 & 2.38 & 18.3 & 41.3 & 125 & 28.5 & 1300 & 180 \\
\hline BWW11 & 28 & 38 & 43 & 1.15 & 1.13 & 0.30 & 222 & 8.31 & 19.6 & 9.2 & 12.2 & NA & NA \\
\hline BWW11 & 32 & 33 & 36 & 1.04 & 0.80 & 0.25 & 1.98 & 6.02 & 15.4 & 7.7 & 9.4 & 5100 & 730 \\
\hline BWW11 & 36 & 30 & 38 & 2.10 & 0.70 & 0.23 & 1.21 & 5.14 & 14.3 & 6.4 & 8.8 & NA & NA \\
\hline BWW11 & 40 & 26 & 31 & 1.60 & 0.70 & 0.23 & 1.08 & 4.25 & 13.4 & 7.2 & 8.4 & 0200 & 890 \\
\hline BWW11 & 4 & 22 & 42 & 1.07 & 0.67 & 0.21 & 0.58 & 6.74 & 16.1 & 6.5 & 11.6 & NA & NA \\
\hline BWW11 & 48 & 20 & 42 & 1.10 & 1.67 & 0.19 & 0.64 & 1.89 & 7.5 & 5.3 & 7.8 & 8800 & 460 \\
\hline BWW11 & 72 & 23 & 33 & 0.72 & 1.07 & 0.18 & 0.63 & 3.49 & 9.8 & 5.6 & 10.3 & 4700 & 410 \\
\hline BWW13 & $\mathbf{p}$ & 27 & 15 & 0.12 & 1.28 & 0.18 & 0.43 & 2.21 & 7.8 & 5.5 & 27 & 79 & 23 \\
\hline BWW13 & 0 & 28 & 22 & 0.22 & 0.62 & 0.17 & 0.52 & 2.18 & 8.5 & 5.4 & 3.1 & NA & NA \\
\hline EWW13 & 3 & 28 & 26 & 0.17 & 0.62 & 0.18 & 0.49 & 25 & 8.2 & 5.3 & 5.6 & 100 & 40 \\
\hline BWW13 & 6 & 20 & 20 & 0.20 & 0.81 & 0.17 & 0.39 & 211 & 6.7 & 5.1 & 24 & 50 & 5 \\
\hline BWW13 & $\theta$ & 25 & 17 & 0.13 & 0.56 & 0.18 & 0.44 & 2.14 & 6.5 & 4.8 & 3.3 & 140 & 63 \\
\hline BWW13 & 12 & 22 & 20 & 0.30 & 0.47 & 0.14 & 0.48 & 200 & 6.3 & 4 & 3.0 & 240 & 88 \\
\hline BWW13 & 16 & 20 & 17 & 0.49 & 0.85 & 0.17 & 0.44 & 2.58 & 7.8 & 4.8 & 3.8 & 110 & 88 \\
\hline BWW13 & 20 & 27 & 19 & 0.36 & 1.46 & 0.18 & 0.46 & 3.75 & 8.6 & 5.6 & 3.9 & NA & NA \\
\hline BWW13 & 24 & 28 & 21 & 0.48 & 0.65 & 0.18 & 0.42 & 3.48 & 8.3 & 4.7 & 4 & 230 & 72 \\
\hline BWM/3 & 28 & 26 & 24 & 0.47 & 1.43 & 0.18 & 0.56 & 4.05 & 11.9 & 5.5 & 7.5 & NA & NA \\
\hline EWW13 & 32 & 28 & 28 & 1.37 & 5.07 & 0.25 & 0.55 & 4.65 & 11.7 & 5.4 & 7 & 800 & 220 \\
\hline EWN13 & 36 & 28 & 21 & 1.18 & 1.41 & 0.25 & 0.70 & 5.23 & 13.3 & 5.9 & 14.4 & NA & NA \\
\hline BWW13 & 40 & 28 & 20 & 1.87 & 2.68 & 0.24 & 0.59 & 3.77 & 10 & 4.7 & 6.3 & 1500 & 170 \\
\hline BWW13 & 44 & 27 & 18 & 1.68 & 1.38 & 0.20 & 0.56 & 4.9 & 12.4 & 5.6 & 7.7 & NA & NA \\
\hline BWW13 & 48 & 23 & 25 & 1.53 & 1.20 & 0.14 & 0.49 & 1.57 & 6.5 & 3.5 & 8.2 & 1900 & 330 \\
\hline EWW13 & 72 & 18 & 27 & 0.56 & 1.20 & 0.14 & 0.52 & 5.08 & 12.1 & 4.1 & 10.2 & 2100 & 2100 \\
\hline BWW14 & $\mathbf{P}$ & 3 & 7 & 0.08 & 0.37 & ND & ND & 0.04 & 2.2 & NO & 1.3 & 320 & 120 \\
\hline BWW14 & 0 & 3 & 10 & 0.08 & 0.38 & NO & ND & 0.33 & 1.6 & ND & 1 & NA & NA \\
\hline BWW14 & 3 & 3 & 10 & 0.08 & 0.37 & ND & ND & 0.54 & 1.7 & NO & 1.4 & 400 & 70 \\
\hline BWMIA & 6 & 3 & 8 & 0.11 & 0.42 & NO & 0.08 & 1.65 & 2.3 & NO & 7.8 & 380 & 110 \\
\hline EWW14 & 9 & 2 & 9 & 0.07 & 0.31 & ND & 0.05 & 0.62 & 1.0 & ND & 1.8 & 440 & 140 \\
\hline EWW14 & 12 & 3 & 11 & 0.14 & 0.42 & ND & 0.08 & 0.47 & 1.9 & ND & 1.5 & 210 & 100 \\
\hline BWW14 & 16 & 4 & 2 & 0.10 & 0.33 & ND & NO & 0.21 & 1.7 & ND & 0.9 & 130 & 87 \\
\hline BWN14 & 20 & 4 & 4 & 0.00 & 0.32 & ND & ND & $\mathbf{N A}$ & 1.7 & 0.6 & 1.2 & NA & NA \\
\hline BWN14 & 24 & 3 & 5 & 0.08 & 0.33 & ND & ND & 0.45 & 1.5 & 0.6 & 1.2 & 80 & 53 \\
\hline EWW14 & 28 & 3 & 4 & 0.17 & 0.28 & ND & ND & 0.23 & 1.8 & No & 1.2 & NA & NA \\
\hline BWM14 & 32 & 3 & ND & 0.03 & 0.38 & ND & ND & 0.38 & 1.9 & 1 & 2.2 & 170 & 2600 \\
\hline EMN14 & 38 & 3 & ND & 0.17 & 0.32 & ND & 0.05 & 0.73 & 1.8 & ND & 2 & NA & NA \\
\hline BWW14 & 40 & 2 & NO & 0.03 & 0.31 & ND & 0.05 & 0.47 & 21 & 0.7 & 1.5 & 170 & 160 \\
\hline BWM14 & 44 & 4 & 5 & 0.13 & 0.33 & ND & ND & 0.45 & 1.5 & NO & 1.2 & NA & NA \\
\hline BWW14 & 48 & 3 & 6 & 0.05 & 0.32 & ND & ND & 0.31 & 1.6 & 1 & 0.6 & 60 & 40 \\
\hline BWW14 & 72 & 9 & 5 & 0.15 & MA & NA & 0.08 & 0.27 & 23 & 1.1 & 1.7 & 380 & 850 \\
\hline BWW15 & $\mathbf{P}$ & 21 & 10 & 0.31 & 0.55 & ND & ND & 0.6 & 1.7 & 0.5 & 1 & NA & NA \\
\hline BMM15 & 0 & 20 & 9 & 0.33 & 0.55 & 4.00 & 0.07 & 0.1 & 5.6 & 0.9 & 3.1 & NA & NA \\
\hline BMW15 & 3 & 20 & 14 & 0.35 & 0.54 & NO & NO & 0.7 & 1.1 & 1 & 1.8 & NA & NA \\
\hline BMN15 & 6 & 21 & 5 & 0.32 & 0.54 & ND & ND & 0.51 & 1 & ND & 1.2 & NA & NA \\
\hline EMN15 & 0 & 10 & 0 & .0 .45 & NA & 0.00 & 0.00 & 0.46 & 1.5 & ND & 3.3 & NA & NA \\
\hline BMN15 & 12 & 19 & 10 & 0.36 & 0.67 & 0.02 & NO & 0.24 & 1.1 & 0.8 & 6.1 & NA & NA \\
\hline BMW15 & 16 & 20 & 11 & 0.38 & 0.46 & 0.08 & 0.05 & 0.38 & 1.2 & 0.7 & 2.8 & NA & NA \\
\hline BWW15 & 20 & 21 & 4 & 0.38 & 0.43 & 0.01 & 0.05 & 0.35 & 1.2 & 0.6 & 3.4 & NA & NA \\
\hline BWw15 & 24 & 20 & 6 & 0.26 & 0.43 & 0.00 & NO & 0.21 & 1.4 & 1 & 2 & NA & NA \\
\hline EMN15 & 28 & 20 & 7 & 0.37 & 0.47 & ND & ND & 0.28 & 1.5 & 0.7 & 1.4 & MA & NA \\
\hline EWW15 & 32 & 21 & 5 & 0.39 & 0.48 & ND & ND & 0.54 & 1.2 & 0.7 & 1.4 & NA & NA \\
\hline EMW15 & 36 & 20 & 8 & 0.38 & 0.49 & 0.01 & ND & 0.29 & 1.1 & 0.8 & 1.1 & NA & NA \\
\hline EWW15 & 40 & 17 & 4 & 0.34 & 0.49 & 0.01 & ND & ND & 0.8 & 1.2 & 0.9 & NA & NA \\
\hline BWW15 & 44 & 18 & 4 & 0.35 & 0.49 & 0.01 & ND & ND & 1.2 & ND & 1.4 & NA & NA \\
\hline
\end{tabular}


Table A.2 Water Quality Data for Storm 2 (Continued)

\begin{tabular}{|c|c|c|c|c|c|c|c|c|c|c|c|c|c|}
\hline Sution & Run & $\mathrm{mal}$ & $\underset{\text { ugd }}{Z n}$ & $\begin{array}{l}\mathrm{NH3} \\
\mathrm{mgl}\end{array}$ & $\begin{array}{l}\text { NO3 } \\
\text { mol }\end{array}$ & $\begin{array}{l}\text { PO4 } \\
\text { mgl }\end{array}$ & $\begin{array}{l}\text { Cd } \\
\text { ugh }\end{array}$ & $\begin{array}{c}\text { Cr } \\
\text { uol }\end{array}$ & $\underset{\text { ugl }}{C u}$ & $\underset{\operatorname{ug}}{\mathrm{Ni}}$ & $\begin{array}{l}\mathrm{Pb} \\
\text { ugl }\end{array}$ & $\begin{array}{c}\text { F.C. } \\
\mathrm{md} / 100 \mathrm{~mL}\end{array}$ & $\begin{array}{l}\text { E.C. } \\
\mathrm{md} / 100 \mathrm{~mL}\end{array}$ \\
\hline BWW15 & 48 & 20 & 5 & 0.33 & 0.48 & ND & 0.14 & ND & 4.5 & 1.5 & 1.5 & NA & NA \\
\hline BWW15 & 72 & 18 & 4 & 0.26 & NA & NA & 0.25 & ND & 1.7 & ND & 1 & NA & NA \\
\hline BWW16 & $\mathbf{P}$ & 19 & 16 & 0.28 & 0.75 & 0.03 & 0.39 & ND & 3.0 & 0.8 & 1.0 & 46000 & 3000 \\
\hline BWW16 & 0 & 18 & 24 & 0.54 & 0.75 & 0.07 & 0.15 & ND & 3.5 & 0.6 & 8.6 & NA & NA \\
\hline BWW16 & 3 & 18 & 25 & 0.17 & 0.81 & 0.00 & 0.14 & ND & 24 & ND & 4.3 & 59000 & 6700 \\
\hline BWW16 & 6 & 18 & 23 & 0.19 & 0.82 & 0.04 & 0.17 & ND & 3.1 & ND & 5.8 & 45000 & 1700 \\
\hline BWW16 & 9 & 12 & 67 & 0.18 & 0.54 & 0.00 & 0.37 & ND & 7.3 & 1.6 & 5.35 & 62000 & 12000 \\
\hline BWW16 & 12 & 16 & 15 & 0.10 & 0.75 & 0.04 & 0.10 & ND & 2 & 0.8 & 2.0 & 44000 & 3800 \\
\hline BWW16 & 16 & 14 & 24 & 0.01 & 0.63 & 0.04 & 0.11 & ND & 5.7 & 0.8 & 8.7 & 79000 & 4800 \\
\hline BWW16 & 20 & 13 & 21 & 0.14 & 0.48 & 0.01 & 0.07 & 4.93 & 3.8 & 9 & 3.8 & NA & NA \\
\hline BWW16 & 24 & 12 & 18 & ND & 0.52 & 0.01 & 0.12 & ND & 3.7 & 0.5 & 8.3 & 42000 & 2800 \\
\hline BWW16 & 28 & 13 & 8 & 0.13 & 0.45 & 0.01 & 0.10 & ND & 3.1 & 0.5 & 6 & NA & NA \\
\hline BWW16 & 32 & 12 & 4 & ND & 0.42 & 0.01 & ND & ND & 1.6 & ND & 4.1 & 28000 & 1500 \\
\hline BWW16 & 36 & 15 & 8 & 0.51 & 0.40 & 0.03 & 0.07 & ND & 1.6 & 1 & 1.5 & NA & NA \\
\hline BWW16 & 40 & 14 & 5 & 0.05 & 0.47 & 0.01 & ND & ND & 1.8 & 0.0 & 23 & 28000 & 1600 \\
\hline BWW16 & 44 & 15 & 3 & 0.21 & 0.45 & 0.01 & 0.07 & 0.14 & 1.7 & 1.1 & 26 & NA & NA \\
\hline BWW16 & 48 & 14 & 82 & 0.03 & 0.74 & 0.01 & 0.24 & 1.07 & 2.1 & NO & 20 & 14000 & 2200 \\
\hline BWW16 & 72 & 15 & 5 & 0.34 & 0.74 & 0.01 & ND & 0.40 & 1.7 & ND & 1.8 & 28000 & 3400 \\
\hline BWW17 & $\mathbf{P}$ & 28 & 17 & 0.12 & 213 & 0.10 & 0.52 & 205 & 8 & 4.9 & 24 & 110 & 43 \\
\hline BWW17 & 0 & 27 & 33 & 0.10 & 1.58 & 0.18 & 0.41 & 1.81 & 8.9 & 4.7 & 27 & NA & NA \\
\hline BWW17 & 3 & 26 & 27 & 0.10 & 1.44 & 0.16 & 0.35 & 1.92 & 6.8 & 4.7 & 26 & 120 & 40 \\
\hline BWW17 & 6 & 28 & 18 & 0.08 & 1.51 & 0.18 & 0.41 & 212 & 6.7 & 4.7 & 3.5 & 840 & 310 \\
\hline BWW17 & 9 & 124 & 27 & 0.01 & 1.37 & 0.16 & 0.34 & 23 & 0.2 & 4 & 5.1 & 1200 & 1100 \\
\hline BWW17 & 12 & 28 & 24 & 0.11 & 1.41 & 0.17 & 0.34 & 1.07 & 7 & 4.7 & 5.3 & 990 & 300 \\
\hline BWW17 & 16 & 28 & 18 & 0.18 & 1.44 & 0.18 & 0.38 & 1.99 & 7.6 & 5 & 3.4 & 200 & 780 \\
\hline BWW17 & 20 & 25 & 13 & 0.17 & 1.31 & 0.16 & 0.38 & 2.09 & 7.4 & 5.9 & 3.3 & NA & NA \\
\hline BWW17 & 24 & 24 & 12 & 0.21 & 1.17 & 0.16 & 0.30 & 1.75 & 7 & 4.2 & 124 & 750 & 170 \\
\hline BWW17 & 28 & 27 & 12 & 0.48 & 1.88 & 0.19 & 0.51 & 252 & 9.9 & 6 & 3.4 & NA & NA \\
\hline BWW17 & 32 & 28 & 10 & 0.37 & 1.27 & 0.16 & 0.52 & 2.87 & 8.2 & 5.4 & 5.8 & 340 & 160 \\
\hline BWW17 & 36 & 27 & 15 & 0.88 & 1.31 & 0.10 & 0.84 & 3.24 & 0.4 & 5.6 & 6.1 & NA & NA \\
\hline BWW17 & 40 & 27 & 24 & 0.18 & 1.51 & 0.24 & 0.88 & 3.31 & 10.5 & 6.3 & 5.7 & 870 & 330 \\
\hline EWW17 & 44 & 28 & 19 & 1.20 & 1.34 & 0.25 & 0.70 & 3.09 & 10.8 & 6.6 & 5.5 & NA & NA \\
\hline BWW17 & 48 & 28 & 17 & 0.05 & 2.60 & 0.21 & 0.54 & 1.66 & 6.8 & 5.7 & 1.5 & 1200 & 350 \\
\hline 8WW17 & 72 & 20 & 27 & 0.74 & 260 & 0.21 & 1.04 & 3.07 & 0.5 & 5 & 9.3 & 2000 & 820 \\
\hline BWW18 & $\mathbf{P}$ & 32 & 20 & 0.80 & 274 & 0.16 & 0.42 & 1.68 & 8.5 & 5 & 2.6 & 120 & 12 \\
\hline BWW18 & 0 & 33 & 33 & 0.42 & 1.72 & 0.30 & 0.38 & 1.40 & 7.4 & 4.3 & 25 & NA & NA \\
\hline BWW18 & 3 & 34 & 22 & 1.87 & 1.62 & 0.31 & 0.39 & 1.6 & 6.9 & 5.1 & 3 & 630 & 46 \\
\hline BWW18 & 6 & 35 & 20 & 1.38 & 1.72 & 0.31 & 0.41 & 1.94 & 0.2 & 4.6 & 4.1 & 890 & $\pi$ \\
\hline BWW18 & $\theta$ & 35 & 38 & 0.88 & 1.55 & 0.36 & 0.71 & 272 & 10.2 & 4.6 & 8.3 & 930 & 130 \\
\hline EWW18 & 12 & 32 & 29 & 1.08 & 1.51 & 0.31 & 0.41 & 1.71 & 6.5 & 4.3 & 3 & 280 & 24 \\
\hline BWW18 & 16 & 32 & 17 & 1.52 & 1.48 & 0.28 & 0.37 & 1.53 & 8.6 & 4 & 2.7 & 310 & 80 \\
\hline EWW18 & 20 & 34 & 20 & 1.62 & 1.23 & 0.28 & 0.37 & 1.84 & 9 & 4.4 & 3.0 & NA & NA \\
\hline BWW18 & 24 & 35 & 22 & 1.19 & 1.35 & 0.31 & 0.50 & 2.28 & 10.6 & 4.1 & 6 & 1300 & $\mathbf{5 7 0}$ \\
\hline EWW18 & 28 & 32 & 20 & 0.75 & 1.51 & 0.28 & 0.57 & 1.92 & 12 & 4.0 & 4.3 & NA & NA \\
\hline BWW18 & 32 & 29 & 21 & 1.24 & 1.40 & 0.25 & 0.51 & 3.36 & 10 & 4.5 & 5.07 & 1000 & 56 \\
\hline BWW18 & 36 & 29 & 17 & 0.62 & 1.31 & 0.23 & 0.52 & 2.67 & 9 & 5.2 & 4.5 & NA & NA \\
\hline BWW18 & 40 & 30 & 18 & 1.30 & 1.12 & 0.25 & 0.50 & 3.04 & 11.3 & 4.9 & 4.7 & 560 & 130 \\
\hline BWW18 & 44 & 33 & 23 & 0.74 & 1.15 & 0.31 & 0.84 & 3 & 11.6 & 5.6 & 4.8 & NA & NA \\
\hline BWW18 & 48 & 31 & 10 & 1.52 & 1.47 & 0.33 & 0.40 & 1.31 & 7.7 & 5.3 & 1.3 & 890 & 170 \\
\hline BWW18 & 72 & 28 & 18 & 2.08 & 1.47 & 0.33 & 0.62 & 2.53 & 11.1 & 3.8 & 5.2 & 2100 & 630 \\
\hline BWW20 & $\mathbf{P}$ & 32 & 17 & 0.54 & 1.80 & 0.23 & 0.35 & 1.36 & 6.8 & 3.7 & 22 & 140 & 3 \\
\hline BWW20 & 0 & 33 & 32 & 0.56 & 1.71 & 0.19 & 0.35 & 1.39 & 7.1 & 4.3 & 2.7 & NA & NA \\
\hline BWW:20 & 3 & 33 & 15 & 0.70 & 1.40 & 0.20 & 0.35 & 1.42 & 7.2 & 3.0 & 27 & 290 & 11 \\
\hline BWw20 & 6 & 34 & 20 & 0.78 & 1.40 & 0.23 & 0.23 & 0.93 & 6.9 & 4.7 & 3.3 & 120 & $\theta$ \\
\hline BWw20 & $\theta$ & 32 & 23 & 0.47 & 1.40 & 0.23 & 0.28 & 0.88 & 6.7 & 5.6 & 2.7 & 300 & 45 \\
\hline BWw20 & 12 & 30 & 28 & 0.72 & 1.7 & 0.23 & 0.43 & 1.28 & 7.5 & 4.2 & 4.2 & 120 & 73 \\
\hline BWWro & 18 & 30 & 23 & 0.80 & 1.77 & 0.22 & 0.44 & 1.07 & 9.8 & 7.7 & 3.6 & $\infty$ & 34 \\
\hline BWw20 & 20 & 31 & 13 & 1.15 & 1.70 & 0.27 & 0.41 & 1.05 & 8.9 & 4.8 & 28 & NA & NA \\
\hline BWMro & 24 & 31 & 21 & 0.80 & 1.00 & 0.20 & 0.47 & 1.68 & 6.3 & 5.0 & 4.4 & NS & NS \\
\hline BWWro & 28 & 31 & 29 & 0.32 & 1.50 & 0.32 & 0.55 & 237 & 9.7 & 7 & 6 & NA & NA \\
\hline Bพר20 & 32 & 32 & 26 & 1.10 & 1.40 & 0.28 & 0.64 & 3.12 & 11.4 & 6.1 & 7.0 & 590 & 290 \\
\hline BWWZO & 38 & 31 & 32 & 0.69 & 0.82 & 0.25 & 0.71 & 2.6 & 10.2 & 7 & 6.2 & NA & NA \\
\hline BWW 20 & 40 & 30 & 24 & 0.58 & 1.38 & 0.20 & 0.40 & 242 & 11.4 & 6.8 & 5.7 & 760 & 120 \\
\hline BWW20 & 44 & 28 & 28 & 0.88 & 1.38 & 0.27 & 0.52 & 1.82 & 8.9 & 6 & 5.4 & NA & NA \\
\hline BWW20 & 48 & 28 & 28 & 0.93 & 1.39 & 0.23 & 0.37 & 0.85 & 5.6 & 6.1 & 1.8 & 150 & 3 \\
\hline BW & 72 & 31 & 26 & 1.48 & 1.33 & 0.23 & 0.62 & 247 & 8.9 & 7.0 & 5.4 & 840 & 86 \\
\hline BWW21 & $\mathbf{P}$ & 29 & 19 & 0.73 & 1.91 & 0.32 & 0.31 & 0.72 & 5.1 & 3.2 & 3.7 & 86 & 17 \\
\hline BYnV21 & 0 & 28 & 38 & 0.33 & 1.82 & 0.25 & 0.39 & 0.64 & 5.9 & 4.5 & 6 & NA & NA \\
\hline BWW21 & 3 & 29 & 18 & 1.07 & 1.52 & 0.22 & 0.30 & 0.75 & 5 & 4.8 & 9 & 200 & 20 \\
\hline BWW21 & 6 & 30 & 18 & 0.89 & 1.61 & 0.22 & 0.28 & 0.42 & 5.7 & 6 & 10.1 & 60 & 40 \\
\hline BWM21 & 9 & 28 & 26 & 0.58 & 1.58 & 0.20 & 0.40 & 228 & 8.2 & 5.4 & 2.7 & 15000 & 4300 \\
\hline BWW21 & 12 & 28 & 25 & 0.94 & 1.78 & 0.18 & 0.20 & 1.60 & 7.4 & 4.6 & 3.8 & 5100 & 540 \\
\hline BWW21 & 16 & 28 & 10 & 0.84 & 1.63 & 0.20 & 0.35 & 1.08 & 7.6 & 5 & 2.9 & 1700 & 550 \\
\hline
\end{tabular}


Table A.2 Water Quality Data for Storm 2 (Continued)

\begin{tabular}{|c|c|c|c|c|c|c|c|c|c|c|c|c|c|}
\hline Station & Run & $\begin{array}{c}\mathrm{Na} \\
\mathrm{mgh}\end{array}$ & $\begin{array}{l}\mathrm{Zn} \\
\mathrm{ugh}\end{array}$ & $\begin{array}{l}\text { NH3 } \\
\text { mgh }\end{array}$ & $\begin{array}{l}\text { NO3 } \\
\text { mgh }\end{array}$ & $\begin{array}{l}\mathrm{POA} \\
\mathrm{mgh}\end{array}$ & $\begin{array}{c}\text { Co } \\
\text { ugh }\end{array}$ & $\begin{array}{c}c r \\
\log l\end{array}$ & $\begin{array}{l}\text { Cu } \\
\text { uor }\end{array}$ & $\underset{\operatorname{Ni}}{\mathrm{Ni}}$ & $\begin{array}{l}\text { Pb } \\
\text { ugh }\end{array}$ & $\begin{array}{c}\text { F.C. } \\
\text { marooml. }\end{array}$ & $\begin{array}{c}E . C . \\
\mathrm{md} / 100 \mathrm{~mL}\end{array}$ \\
\hline BWW21 & 20 & 27 & 20 & 1.18 & 1.83 & 0.17 & 0.44 & 0.82 & 6.7 & 4.5 & 3 & NA & NA \\
\hline BWW21 & 24 & 27 & 20 & 0.85 & 1.77 & 0.17 & 0.44 & 0.78 & 6.7 & 5 & 4 & NS & NS \\
\hline BWW21 & 28 & 26 & 21 & 0.50 & 1.73 & 0.17 & 0.43 & 0.74 & 6.7 & 5.5 & 4.8 & NA & NA \\
\hline BWW21 & 32 & 27 & 27 & 0.89 & 1.88 & 0.28 & 0.63 & 1.67 & 8 & 4.2 & 5 & 340 & 88 \\
\hline BWW21 & 38 & 27 & 23 & 0.62 & 1.45 & 0.25 & 0.65 & 2.62 & 9.5 & 5.3 & 7.3 & NA & NA \\
\hline BWW21 & 40 & 27 & 34 & 0.62 & 1.58 & 0.25 & 0.72 & 2.82 & 10.9 & 5.8 & 10.9 & 800 & 140 \\
\hline BWW21 & 44 & 27 & 35 & 0.76 & 1.62 & 0.24 & 0.63 & 2.25 & 10.7 & 4.3 & 7.2 & NA & NA \\
\hline BWW21 & 48 & 27 & 30 & 0.67 & 1.75 & 0.25 & 0.88 & 2.11 & 8.8 & 5.6 & 5.9 & 630 & 73 \\
\hline BWW21 & 72 & 26 & 31 & 1.33 & 1.75 & 0.25 & 0.73 & 1.92 & 0.2 & 5 & 6.8 & 880 & 410 \\
\hline EWW22 & $\boldsymbol{P}$ & 20 & 82 & 3.20 & 1.58 & 0.00 & 0.40 & 4.2 & 15 & 8.8 & 20 & 400000 & 24000 \\
\hline EWW22 & 0 & 16 & 103 & 1.28 & 1.43 & $n .23$ & 0.25 & 4.8 & 13 & 6 & 35 & 190000 & 84000 \\
\hline EWW22 & 3 & 12 & 88 & 0.35 & 1.24 & 0.31 & 0.20 & 3.8 & $\boldsymbol{2}$ & 4.3 & 22 & & \\
\hline BWN23 & $P$ & 59 & 24 & 13.1 & 1.70 & 1.15 & 2.88 & 244 & 17.9 & 17.8 & 1.6 & 28000 & 4900 \\
\hline BWw23 & 0 & 74 & 30 & 17.7 & 0.68 & 1.53 & 2.68 & 8.6 & 15.4 & 26.3 & 1.9 & NA & NA \\
\hline EWW23 & 3 & 75 & 40 & 20.6 & 0.34 & 1.30 & 2.82 & 7.67 & 15.5 & 30.1 & 1.9 & 12000 & 8500 \\
\hline BWW23 & 6 & 74 & 39 & 12.7 & 0.18 & 1.45 & 2.75 & 5.03 & 15.5 & 27.7 & 4.3 & 120000 & 13000 \\
\hline BWW23 & 9 & 63 & 35 & 7.38 & 0.63 & 1.45 & 2.38 & 4.2 & 13 & 22 & 2.4 & 100000 & 11000 \\
\hline BWW23 & 12 & 38 & 20 & 12.6 & 0.38 & 1.30 & 1.77 & 3.42 & 14.9 & 17.1 & 3.1 & 120000 & 16000 \\
\hline BWW23 & 18 & 32 & 35 & 12.7 & 0.43 & 1.45 & 1.63 & 11.3 & 19.1 & 15.5 & 4.7 & 120000 & 13000 \\
\hline EWW23 & 20 & 30 & 40 & 120 & 0.18 & 1.61 & 1.63 & 13.8 & 20.5 & 21.8 & 4.3 & NA & NA \\
\hline EMN23 & 24 & 42 & 36 & 12.5 & 0.08 & 1.45 & 1.49 & 128 & 21.7 & 23 & 2.7 & 39000 & 13000 \\
\hline BWW23 & 28 & NS & 38 & 12.8 & 0.05 & 1.45 & 1.56 & 10.9 & 22 & 25.9 & 3.2 & NA & NA \\
\hline EWW23 & 32 & V 48 & 33 & 12.5 & 0.03 & 1.22 & 1.59 & 10.1 & 18.2 & 28.8 & 3.6 & 100000 & 14000 \\
\hline EWW23 & 36 & 48 & 38 & 8.1 & 0.05 & 0.84 & 2.02 & 8.43 & 16.7 & 28.9 & 4.5 & NA & NA \\
\hline BWW23 & 40 & 54 & 30 & 127 & 0.08 & 0.89 & 2.45 & 124 & 15.6 & 23 & 4.1 & 90000 & 12000 \\
\hline EWW23 & 44 & 55 & 32 & 13.3 & 0.01 & 1.22 & 2.52 & 13.9 & 17.9 & 28 & 1.8 & NA & NA \\
\hline EWW23 & 48 & 62 & 28 & 17.6 & 0.01 & 1.30 & 2.35 & 20.2 & 18.3 & 31.7 & 2.5 & 110000 & 16000 \\
\hline BWW23 & 72 & 62 & 27 & 12.5 & 0.61 & 0.24 & 266 & 31.5 & 14 & 45.5 & 3.2 & 21000 & 5600 \\
\hline EMW24 & $\mathbf{P}$ & 230 & 232 & 29.0 & 0.21 & 4.70 & 0.80 & 2.55 & 40.8 & 4.4 & 19.1 & 70 & 10 \\
\hline BWW24 & 0 & 228 & 121 & 223 & 0.03 & 4.18 & 0.48 & 1.49 & 24.8 & 3.6 & 8.5 & NA & NA \\
\hline BWW24 & 3 & 223 & 63 & 32.7 & 0.05 & 3.58 & 0.25 & 1.5 & 7.4 & 4.8 & 3.2 & $<1.0 E+\infty 0$ & $<1.0 E+\infty$ \\
\hline BWW24 & 8 & 238 & 55 & 18.4 & 0.04 & 2.81 & 0.23 & 6.74 & 8.5 & 3.2 & 3.3 & 2 & 1 \\
\hline BWW24 & 9 & 240 & 275 & 19.2 & 0.08 & 3.13 & 1.50 & 3.87 & 48.3 & 5 & 18.5 & 48000 & 3000 \\
\hline BWW24 & 12 & 242 & 311 & 20.5 & 0.84 & 3.43 & 1.30 & 3.68 & 55.7 & 5.4 & 17.4 & 69000 & 14000 \\
\hline EWM24 & 18 & 282 & 248 & 24.0 & 0.07 & 4.18 & 1.14 & 3.03 & 53 & 4.4 & 14.5 & 3 & 70 \\
\hline EWW24 & 20 & 255 & 236 & 25.2 & 0.04 & 4.77 & 0.70 & 2.91 & 41.8 & 4.1 & 15 & NA & NA \\
\hline BWW24 & 24 & 254 & 47 & 33.6 & 0.03 & 4.77 & 0.16 & 0.62 & 7.3 & 3.6 & 2.8 & 810 & 3 \\
\hline BWW24 & 28 & 267 & 45 & 28.0 & 0.03 & 3.43 & 0.11 & 0.33 & 4.6 & 4.1 & 2.5 & NA & NA \\
\hline BWW24 & 32 & 287 & 367 & 24.8 & 0.31 & 3.21 & 0.63 & 2.69 & 61.8 & 5.6 & 22.7 & 70000 & 15000 \\
\hline BWW24 & 38 & 280 & 328 & 28.9 & 0.21 & 4.85 & 1.30 & 5.3 & 53.7 & 4.4 & 21 & NA & NA \\
\hline BWW24 & 40 & 298 & 255 & 26.7 & 0.02 & 7.16 & 1.01 & 5.11 & 43 & 4.2 & 17.8 & 230 & 13 \\
\hline BWW24 & 44 & 297 & 180 & 25.8 & 0.01 & 6.19 & 0.60 & 3.88 & 26.5 & 5 & 11.4 & NA & NA \\
\hline EWM24 & 48 & 289 & 100 & 28.4 & 0.01 & 5.88 & 0.65 & 3.87 & 28.1 & 4.8 & 10.5 & 1 & 1 \\
\hline EMW24 & 72 & NA & NA & 20.8 & NA & NA & NA & NA & NA & NA & NA & 10 & 15 \\
\hline Bumes & $\mathbf{P}$ & 82 & 63 & 14.1 & 3.60 & .76 & 0.25 & 4.88 & 20.5 & 111 & 10.6 & 110 & $<1.0 E+\infty 0$ \\
\hline EMN2s & 0 & 108 & 72 & 17.9 & 1.38 & 4.76 & 0.30 & 4.02 & 21.7 & 112 & 11.3 & NA & NA \\
\hline Bunzes & 3 & 111 & is & 25.0 & 1.30 & 4.76 & 0.34 & 4.01 & 25.8 & 108 & 7.8 & 200 & $<1.0 E+\infty 0$ \\
\hline BMW2S & 8 & 122 & 104 & 15.6 & 1.40 & 5.23 & 0.42 & 6.78 & 34.6 & 101 & 7.4 & 1800 & 48 \\
\hline BMW2S & 9 & 98 & 200 & 10.3 & 1.20 & 4.56 & 0.43 & 17.3 & 87.2 & 86.5 & 24.8 & 3000 & 210 \\
\hline BMW2S & 12 & 75 & 50 & 8.8 & 1.48 & 3.10 & 0.21 & 4.24 & 16.0 & 55.2 & 5 & 140 & 3 \\
\hline BMW25 & 18 & 60 & 180 & 9.9 & 1.88 & 2.03 & 0.34 & 17.1 & 88.8 & 72.8 & 24 & 1400 & 110 \\
\hline BW125 & 20 & 60 & 107 & 18.6 & 1.48 & 2.43 & 0.32 & 6.16 & 24.2 & 53.7 & 9.1 & NA & NA \\
\hline BMW25 & 24 & NS & NS & NS & NS & NS & NS & NS & NS & NS & NS & NS & NS \\
\hline BWW25 & 28 & NS & NS & NS & NS & NS & NS & NS & NS & NS & NS & NS & NS \\
\hline BWW25 & 32 & 81 & 86 & 10.3 & 0.28 & 3.10 & 0.20 & 40.12 & 30.5 & 53.5 & 7.7 & 11 & 25 \\
\hline BMW25 & 38 & 83 & $\infty$ & 0.5 & 0.22 & 238 & 0.20 & 6 & 35.2 & 73.4 & 7.7 & NA & NA \\
\hline EMW2s & 40 & 68 & 82 & 10.3 & 0.32 & 3.10 & 0.20 & 5.44 & 37 & 73.6 & 12.0 & 320 & $\theta$ \\
\hline Eurv25 & 44 & 88 & 107 & 15.6 & NA & 3.63 & 0.23 & 4.15 & 32.3 & 65.9 & 4.3 & NA & NA \\
\hline EMW 25 & 48 & 95 & 372 & 16.7 & NA & 4.16 & 0.22 & 11.77 & 53.4 & 35 & 72.3 & 240 & 2 \\
\hline BWW25 & 72 & NA & NA & 18.3 & NA & NA & NA & NA & NA & NA & NA & 1600 & 14 \\
\hline $\begin{array}{l}\text { BWW26 } \\
\text { BWW28 }\end{array}$ & 6 & NA & 474 & 3.70 & 0.40 & 1.00 & $\begin{array}{l}1.20 \\
0.98\end{array}$ & $\begin{array}{c}6.1 \\
5.86\end{array}$ & $\begin{array}{l}54.2 \\
54.8\end{array}$ & $\begin{array}{l}120 \\
112\end{array}$ & $\begin{array}{l}40.2 \\
39.8\end{array}$ & $\begin{array}{c}1500000 \\
210000\end{array}$ & $\begin{array}{c}200000 \\
1200\end{array}$ \\
\hline
\end{tabular}

ND = Not Detected

NS= No Sumple

NM= Not Measured

NA = Not Analyzed 
Table A.3 Water Quality Data for Storm 3

\begin{tabular}{|c|c|c|c|c|c|c|c|c|c|c|c|c|c|c|}
\hline Station & Run & Date & Time & $\begin{array}{c}\text { Flow } \\
\text { cte }\end{array}$ & $\begin{array}{l}\text { Temp } \\
\operatorname{deg} C\end{array}$ & PH & $\begin{array}{l}\text { Cond } \\
\text { umhos/em }\end{array}$ & $\begin{array}{c}\text { DO } \\
\text { mgh }\end{array}$ & $\begin{array}{l}\text { BOD } \\
m g h\end{array}$ & $\begin{array}{l}\text { TSS } \\
\text { mgl }\end{array}$ & $\begin{array}{l}\text { vss } \\
\text { mgl }\end{array}$ & $\begin{array}{c}\mathrm{Cl} \\
\mathrm{mgl}\end{array}$ & $\begin{array}{c}\mathrm{c} \\
\mathrm{mgh}\end{array}$ & $\begin{array}{l}\mathrm{Mg} \\
\mathrm{mg} / \mathrm{L}\end{array}$ \\
\hline EWWOO & $\mathbf{P}$ & $10 / 12 / 93$ & 0730 & 38.3 & 8.5 & 6.69 & 178 & 8 & 4.6 & 2.6 & 0.5 & 54.7 & 18 & 3.47 \\
\hline EWWOO & 0 & $10 / 2 / 23$ & 1230 & 38.3 & 9.5 & 6.82 & 160 & 10.4 & 2.3 & 1.2 & 1 & 61.8 & 16 & 2.88 \\
\hline BWWOO & 9 & $10 / 12 / 23$ & 2025 & 530 & 9 & 6.28 & 22 & 10.6 & 12.3 & 73 & 21.6 & 16.9 & 6 & 1.08 \\
\hline BWWOO & 12 & $1013 \times 3$ & 0030 & 407 & 10.4 & 6.26 & 71 & 10.4 & 4 & 24.2 & 8.6 & 14.6 & 8 & 1.53 \\
\hline EMNOO & 16 & $10113 / 93$ & 0420 & 140 & 0 & 6.53 & 147 & 11 & 1.35 & 12 & 3.8 & 38.5 & 11 & 2.26 \\
\hline EWWOO & 20 & $10 / 13 / 23$ & 0840 & 128 & 7 & 6.63 & 160 & 10 & 2.1 & 4 & 2 & 50.5 & 11 & 2.61 \\
\hline EWNOO & 24 & $10 / 13 / 33$ & 1219 & 122 & $\theta$ & 6.70 & 180 & 11.2 & 2.1 & 1.8 & 1 & 88.1 & 13.1 & 2.33 \\
\hline BWNOO & 28 & $10 / 13 / 93$ & 1628 & 109 & 9.5 & 6.88 & 190 & 11.3 & 4.6 & 4.8 & 2.2 & 53.2 & 13 & 2.78 \\
\hline BWWOO & 32 & $10 / 13 / 93$ & 2018 & 48.4 & 10 & 6.81 & 130 & 11.8 & 1.3 & 3.4 & 1.8 & 54.3 & 13 & 2.50 \\
\hline BWWOO & 38 & $10 / 14 / 93$ & 0035 & 100 & 9 & 6.71 & 135 & 10.2 & 3.3 & 2 & 1 & 54.1 & 13 & 2.62 \\
\hline ENWOO & 44 & $10 / 14 / 93$ & 0830 & 76 & 8 & 6.75 & 140 & 11.2 & 1.0 & 1.8 & 1.6 & 55.2 & 13 & 3 \\
\hline BWNoO & 52 & $10 / 1493$ & 1800 & 78 & 9.2 & 6.83 & NA & 10.9 & 1.6 & 2.2 & 1.6 & 48.1 & 13 & 3.15 \\
\hline EMrwo1 & $\mathbf{P}$ & $10 / 1283$ & 0740 & 41.2 & 10 & 6.67 & 258 & $\theta$ & 5.2 & 0.8 & 0.5 & 81.6 & 23 & 4.42 \\
\hline EMWo1 & 0 & 1011293 & 1240 & 41.2 & 9.8 & 6.73 & 230 & 10 & 3.1 & 0.5 & 0.5 & 89.9 & 21 & 3.75 \\
\hline EWW01 & $\theta$ & $10 / 1283$ & 2050 & 570 & 9 & 6.46 & 110 & 10.6 & 13.7 & 53.4 & 15.8 & 28.8 & 8 & 1.68 \\
\hline BWW01 & 12 & $10 / 13 / 23$ & 0040 & 438 & 11 & 6.34 & 92 & 11 & 4.15 & 43.4 & 10 & 21.8 & 10 & 2.2 \\
\hline EMWN1 & 16 & $10 / 13 / 83$ & 0430 & 150 & $\theta$ & 6.53 & 142 & 11 & 2 & 14.4 & 4.4 & 38.7 & 12 & 4.2 \\
\hline EMrwo1 & 20 & $10 / 13 / 33$ & 0854 & 138 & 7.2 & 6.84 & 162 & 11 & 2.3 & 5.4 & 2.6 & 55 & 11 & 2.75 \\
\hline EWMO1 & 24 & $10 / 13 \times 3$ & 1229 & 131 & 0 & 8.88 & 182 & 11 & 4.8 & 13 & 5.4 & 54.5 & 14 & 2.55 \\
\hline SWWor & 28 & $10 / 13 / 83$ & 1634 & 117 & 10 & 6.92 & 209 & 10.8 & 5.2 & 3.6 & 4.4 & 57.8 & 14 & 2.81 \\
\hline BWWO1 & 32 & $10 / 13 / 93$ & 2026 & 52 & 10 & 6.73 & 155 & 11.4 & 2.2 & 2.2 & 1.4 & 68.4 & 14 & 2.72 \\
\hline ENW01 & 38 & $10 / 14 / 23$ & 0045 & 108 & 9 & 6.53 & 150 & $\theta$ & 24 & 3 & 1.4 & 63 & 14 & 2.04 \\
\hline BWWO1 & 4 & $10 / 14 / 23$ & 0840 & 81.7 & 7 & 5.96 & 180 & 10.8 & 1.85 & 4.8 & 2.4 & 65.8 & 14 & 3.38 \\
\hline EWMO1 & 52 & $10 / 14 / 23$ & 1618 & 81.7 & 8.5 & 6.72 & 186 & 10.4 & NA & 1.8 & 1.8 & 63.4 & 14 & 3.50 \\
\hline Bunvo2 & $\mathbf{P}$ & $10 / 1293$ & 0750 & 60.4 & 13 & 6.38 & 322 & 7.0 & 6.8 & 0.4 & 1,8 & 88.8 & 20 & 4.28 \\
\hline BWwor & 0 & $10 / 12 / 23$ & 1255 & 73.3 & 13.8 & 6.49 & 285 & 8.6 & 4.8 & 1.2 & 0.5 & 103 & 16 & 3.46 \\
\hline EWWO2 & $\boldsymbol{\theta}$ & $10 / 12 / 23$ & 2120 & 828 & 10.5 & 6.47 & 155 & 10.1 & 13.5 & 39 & 12.6 & 59.9 & 10 & 2.59 \\
\hline EMWO2 & 12 & $10 / 13 / 93$ & 0050 & 637 & 125 & 6.34 & 120 & 12.5 & 5 & 37.4 & 12.6 & 37.6 & 0 & 2.32 \\
\hline BWWO2 & 16 & $10 / 13 / 23$ & 0445 & 165 & 10 & 6.42 & 178 & 10.5 & 2.8 & 17 & 6.4 & 45.1 & $\theta$ & 2.28 \\
\hline EMwor & 20 & $10 / 13 / 93$ & 0005 & 153 & 9.8 & 6.2 & 182 & 10 & 4.5 & 7.2 & 3.6 & 524 & 9 & 2 \\
\hline EMWO2 & 24 & $10 / 13 / 23$ & 1245 & 148 & 11 & 6.45 & 172 & 9.4 & 3.8 & 3.6 & 2.8 & 58.1 & 11 & 1.67 \\
\hline BMWO2 & 28 & $10 / 13 / 93$ & 1644 & 130 & 11.5 & 6.71 & 235 & 10.1 & 6.8 & 13.8 & 11.4 & 60.9 & 13 & 2.81 \\
\hline EMW02 & 32 & $10 / 13 / 93$ & 2040 & 130 & 12 & 6.49 & 168 & 9.8 & 4.1 & 2.2 & 0.5 & 70.9 & 12 & 2.04 \\
\hline BWW02 & 36 & 1014493 & 0055 & 107 & 11 & 6.34 & 200 & 0 & 4.2 & 2.8 & 1.6 & 72.6 & 12 & 2.21 \\
\hline EMMor & 44 & 1014 19s & 0852 & 103 & 10.5 & 6.71 & 205 & 9.6 & 1.3 & 2.4 & 2.6 & 7.2 & 11 & 2.59 \\
\hline BWW02 & 52 & $10 / 14 / 23$ & 1628 & 105 & 13 & 6.55 & 250 & 9.1 & 1.3 & 1.4 & 1.4 & 76.8 & 13 & 3.74 \\
\hline BMWO4 & $\mathbf{p}$ & $10 / 12 / 23$ & 0810 & 100 & 11 & 6.65 & 249 & 0.2 & 7 & 3 & 1.4 & 80.6 & 16 & 3.18 \\
\hline EMmod & 0 & $1012 / 23$ & 1315 & 109 & 11.2 & 6.68 & 240 & 10.5 & 3.1 & 0.5 & 0.5 & 89.2 & 15 & 3.1 \\
\hline EWMO4 & 9 & $10 / 12 / 23$ & 2155 & 746 & 11.1 & 6.51 & 240 & 10.5 & 13.5 & 129 & 38.2 & 63.4 & 3 & ND \\
\hline EMWO4 & 12 & $10 / 13 / 23$ & 0120 & 541 & 12.5 & 6.53 & 155 & 12.5 & 5 & 74 & 23.4 & 52.1 & 5 & 2.04 \\
\hline BWWOA & 16 & $10 / 13 / 93$ & 0505 & 378 & 10 & 6.63 & 170 & 11.5 & 28 & 28.6 & 28 & 46.8 & 8 & 2.11 \\
\hline BWWO4 & 20 & $10 / 1399$ & 0921 & 246 & 8.5 & 6.57 & 160 & 11.2 & 4.5 & 8.2 & 3.4 & 50.1 & 7 & 1.75 \\
\hline BWWO4 & 24 & $10 / 13 / 93$ & 1300 & 271 & 10 & 6.67 & 180 & 10.8 & 3.8 & 4.4 & 3.0 & 53.2 & 11 & 2.03 \\
\hline BMWO4 & 28 & $10 / 13 / 93$ & 1700 & 277 & 12 & 6.0 & 212 & 10.9 & 6.8 & 6.2 & 24 & 58.5 & 12 & 2.8 \\
\hline BWwO4 & 32 & $10 / 13 / 93$ & 2100 & 230 & 10 & 6.75 & 160 & 10.9 & 4.1 & 6 & 2.6 & 60.0 & 12 & 25 \\
\hline BWWO4 & 36 & $10 / 14 / 23$ & 0105 & 215 & 10 & 6.63 & 210 & 9.4 & 4.2 & 4.2 & 1.4 & 64.0 & 11 & 2.62 \\
\hline BWWO4 & 44 & $1014 / 23$ & 0008 & 173 & 0 & 7 & 165 & 10.6 & 1.3 & 2.6 & 2.2 & 71.2 & 12 & 3.08 \\
\hline BwWo4 & 52 & $10 / 4 / 93$ & 1845 & 187 & 11.8 & 6.82 & 220 & 10.2 & NS & 2 & 2 & 73.8 & 13 & 3 \\
\hline BWWos & $P$ & $10 / 12 / 93$ & 0835 & 8.3 & 10 & NA & 200 & 8.2 & NA & ND & ND & 57.5 & 18 & 4.02 \\
\hline BWWOS & 0 & $10 / 1213$ & 1348 & 8.6 & 10.5 & 6.73 & 218 & 0.85 & NA & 0.8 & ND & 78.6 & 17 & 3.0 \\
\hline Bumos & 8 & $10 / 2123$ & 1235 & 20.2 & 10.1 & 6.50 & 225 & 10.4 & NA & 0.6 & ND & 70.1 & 12 & 2.87 \\
\hline BWWos & 12 & $10 / 13 / 23$ & 0200 & 20.8 & 12.5 & 6.67 & 232 & 125 & NA & 1.4 & 1.2 & 73.3 & 13 & 3.1 \\
\hline BWWos & 16 & $1013 / 93$ & 0540 & 25.8 & 10 & 6.50 & 230 & 10 & NA & 24 & 1.4 & 78.1 & 14 & 3.89 \\
\hline EWWos & 20 & $10 / 13 / 03$ & 0052 & 26.9 & 8.2 & 6.60 & 188 & 10.1 & NA & ND & ND & 74.2 & 12 & 3.49 \\
\hline BWwos & 24 & $10 / 1303$ & 1325 & 29.9 & 10 & 6.71 & 181 & 10.4 & NA & 1.2 & ND & 73.2 & 14 & 3.29 \\
\hline EMwos & 28 & $1013 \times 3$ & 1723 & 28.8 & 11 & 675 & 248 & 10.5 & NA & 4 & 1.4 & 75.6 & 12 & 270 \\
\hline Bwwos & 32 & 1013103 & 2128 & 26.5 & 10 & 6.77 & 192 & 10.8 & NA & 2.2 & ND & 76.8 & 14 & 3.3 \\
\hline BWwos & 36 & $10 / 14 / 23$ & 0145 & 24.7 & $\theta$ & 6.67 & 203 & 10 & NA & ND & ND & 75.3 & 14 & 3.33 \\
\hline EWWOS & 44 & $10 / 4 / 93$ & 0020 & 22.7 & 9 & 6.42 & 205 & 10 & NA & 2.4 & 2 & 78.8 & 11 & 2.91 \\
\hline BWwOS & 52 & $10 / 14 / 93$ & 1713 & 21.0 & 10.2 & 8.65 & 190 & 10.2 & NA & ND & ND & 83.6 & 12 & 3.13 \\
\hline Bunvos & $\mathbf{P}$ & $10 / 12193$ & 0825 & 97.0 & 10.8 & 6.71 & 240 & 8.2 & 5.2 & 0.8 & 0.5 & 70.8 & 16 & 3.56 \\
\hline Bwwos & 0 & $10 / 2 / 93$ & 1332 & 97.0 & 10.3 & 8.65 & 200 & 10.4 & 3 & 2 & 1 & 88.7 & 14 & 3.35 \\
\hline Burvos & 9 & $10 / 1293$ & 1215 & 220 & 10.8 & 6.75 & 209 & 0.1 & 3.6 & 7.4 & $i$ & 73.5 & 11 & 2.74 \\
\hline BWWOS & 12 & $10 / 3 / 23$ & 0140 & 456 & 14 & 6.60 & 271 & 14 & 4.6 & 98.2 & 28.8 & 75.2 & $\theta$ & 2.5 \\
\hline EWWOS & 16 & $10 / 13 / 93$ & 0525 & 456 & 10 & 6.57 & 200 & 11.5 & 4 & 29.4 & 11.2 & 52.8 & 7 & 2.47 \\
\hline BWWOS & 20 & $10 / 13 \mathrm{ys}$ & - & 216 & 7 & 6.65 & 155 & 10.3 & 6.7 & 15.2 & 5.8 & 53.0 & 8 & 2.37 \\
\hline BWWos & 24 & $10 / 13 / 03$ & 1313 & 244 & 10 & 8.63 & 183 & 10.8 & 5.3 & 6.4 & 4.2 & 51.0 & 11 & 2.21 \\
\hline BWWos & 28 & $10113 / 93$ & 1712 & 220 & 11.5 & 6.81 & 200 & 10.8 & 5.2 & 12.4 & 8.4 & 53.8 & 10 & 2.63 \\
\hline BWWOS & 32 & $10 / 13 / 93$ & 2113 & 220 & 10 & 6.70 & 150 & 10.8 & 3.3 & 12.2 & 10.2 & 58.2 & 12 & 2.62 \\
\hline BWWOS & 38 & $10 / 14 / 23$ & 0130 & 260 & $\theta$ & 6.75 & 180 & 0.4 & 3.8 & 5.8 & 3.2 & 60.3 & 13 & 3.00 \\
\hline BWwos & 44 & $10 / 14 / 93$ & 0932 & 224 & 0 & 6.68 & 201 & 9.8 & 1.15 & 5.4 & 3.4 & 70.3 & 12 & 3.52 \\
\hline BWWos & 52 & $10 / 14 / 23$ & 1701 & 110 & 10.4 & 6.65 & 210 & 10.8 & NS & 2.6 & 26 & 73.6 & 12 & 2.83 \\
\hline BWWO7 & $\mathbf{P}$ & $10 / 12 / 93$ & 1015 & 144 & 10 & 6.79 & 300 & 8.8 & 6.5 & 4.8 & 1.2 & 75.2 & 15 & 3.49 \\
\hline
\end{tabular}


Table A.3 Water Quality Data for Storm 3 (Continued)

\begin{tabular}{|c|c|c|c|c|c|c|c|c|c|c|c|c|c|c|}
\hline Sution & Run & Date & Time & Flow & $\begin{array}{l}\text { Temp } \\
\operatorname{deg} C\end{array}$ & pH & $\begin{array}{l}\text { Cond } \\
\text { umbos/cm }\end{array}$ & $\underset{m g h}{D O}$ & $\begin{array}{l}B O D \\
m g h\end{array}$ & $\begin{array}{l}\text { TSS } \\
\text { mgl. }\end{array}$ & $\begin{array}{l}\text { vss } \\
\text { mgl }\end{array}$ & $\underset{m g h}{c l}$ & $\mathrm{Ca}$ & $\mathrm{Mg}$ \\
\hline Bumo7 & 0 & $10 / 12 / 83$ & 1440 & 144 & 10 & 6.71 & 300 & 8.8 & 2.1 & 8.8 & 4.2 & 87.1 & 14 & 3.27 \\
\hline EWW07 & 9 & $10 / 1203$ & 2325 & 201 & 10 & 6.77 & 280 & 9.5 & 2.2 & 8.2 & 6 & 76.5 & 11 & 2.81 \\
\hline EWWO7 & 12 & $10113 \times 3$ & 0315 & 421 & 10.5 & 6.69 & 275 & 8.8 & 2.85 & 6.6 & 4 & 83.2 & 12 & 3.37 \\
\hline BMW07 & 16 & $10 / 13 / 23$ & 0845 & 570 & 0.5 & 6.72 & 270 & 10.6 & 4.3 & 18.6 & 5.8 & 75.2 & 11 & 3.35 \\
\hline BWW07 & 20 & $10 / 13 / 93$ & 1250 & 300 & 11 & 6.79 & 180 & 9.6 & 7.4 & 14.8 & 19.2 & 58.5 & $\theta$ & 2.47 \\
\hline EWwo7 & 24 & $10 / 13193$ & 1600 & 278 & 10 & 6.68 & 21 & 14.4 & 6.3 & 11 & 5.4 & 57.8 & 11 & 2.37 \\
\hline swMo7 & 28 & $10 / 13 / 93$ & 1815 & 287 & 10 & 6.65 & 230 & 12.3 & 6.5 & 8.4 & 3 & 56.0 & 12 & 2.51 \\
\hline EWW07 & 32 & $10 / 3 \% 93$ & 2230 & 205 & 10 & 6.63 & 142 & 124 & 4.2 & 11 & 4.8 & 56.8 & 11 & 2.39 \\
\hline BWWO7 & 36 & $10 / 1483$ & 0245 & 249 & $\theta$ & 8.61 & 170 & 13 & 2.8 & 8 & 3.6 & 55.8 & 10 & 2.46 \\
\hline EพM07 & 44 & 101493 & 1300 & 238 & 10.5 & 6.71 & 208 & 10 & 1.05 & 4.2 & 2.8 & 63.8 & 12 & 3.3 \\
\hline EwWo7 & 52 & $10 / 14 / 23$ & 1805 & 144 & 11 & 6.72 & 220 & 10.8 & NA & 8.4 & 3.6 & 71.8 & 12 & 3.3 \\
\hline EพMN07 & 72 & $10 / 15 / 93$ & 1135 & 144 & 11 & NA & 240 & 10 & NA & 7.2 & 3.8 & 75.7 & 12 & 3 \\
\hline BMNOS & $\mathbf{P}$ & $10 / 12 / 23$ & 0955 & 152 & 10 & 6.68 & 300 & $\theta$ & 4.1 & 8.2 & 2.2 & 76.5 & 16 & 3.51 \\
\hline EWWOS & 0 & $10 / 12 / 93$ & 1425 & 229 & 10 & 6.89 & 300 & 9.2 & 2.6 & 7.8 & 3.8 & 87.4 & 14 & 3.39 \\
\hline EWWOS & 9 & $10 / 12 / 93$ & 2315 & 127 & 10 & 6.65 & 262 & 8.4 & 2.1 & 9.8 & 3 & 74.4 & 11 & 28 \\
\hline BWMos & 12 & $10 / 13 / 93$ & 0255 & 184 & 10.5 & 8.69 & 260 & 0.4 & 2.3 & 8.6 & 4.4 & 77.7 & 13 & 3.24 \\
\hline BWWOS & 16 & $10 / 1393$ & 0030 & 384 & 10 & 6.71 & 275 & 10 & 2.8 & 62.0 & 12.8 & 81.1 & 8 & 2.52 \\
\hline EWWOS & 20 & $10 / 13 / 93$ & 1210 & 414 & 11 & 6.74 & 210 & 9.6 & 6.7 & 25.6 & 8 & 65.4 & 9 & 2.60 \\
\hline EMWOS & 24 & $10 / 13 \times 3$ & 1545 & 352 & 10 & 6.59 & 240 & 124 & 7.2 & 14.2 & 2.4 & 60.7 & 11 & 2.42 \\
\hline BMYNOB & 28 & $10 / 13 / 93$ & 1810 & 332 & 10 & 6.63 & 220 & 11.8 & 4.1 & 13.6 & 8.4 & 59.2 & 12 & 2.73 \\
\hline EWMos & 32 & $10 / 13 / 23$ & 2215 & 284 & 10 & 6.59 & 152 & 13 & 4.5 & 122 & 3.6 & 60.2 & 8 & 2.50 \\
\hline EMWOS & 36 & $10 / 14 / 93$ & 0220 & 301 & 8.5 & 6.67 & 180 & 12.4 & 4.3 & 9.6 & 4.2 & 57.7 & 10 & 2.37 \\
\hline EMNOS & 44 & $10 / 4 / 93$ & 1250 & 283 & 10 & 6.92 & 190 & 11.1 & 1.1 & 8 & 3 & 60.8 & 11 & 3.08 \\
\hline BMmos & 52 & 10114183 & 1755 & 283 & 10 & 6.83 & 205 & 10.6 & MA & 8.2 & 3.2 & 68.7 & 10 & 3.18 \\
\hline Bumos & 72 & $1 d / 15 / 93$ & 1120 & 266 & 10.5 & NA & 230 & 10.2 & NA & 5.6 & 3 & 72.1 & 12 & 2.88 \\
\hline Eurwos & $\mathbf{P}$ & $10 / 12 / 83$ & 0945 & 16.6 & 10 & 7 & 150 & 8.8 & 1.7 & 1.6 & ND & 19.3 & 7 & 2.31 \\
\hline BWWos & 0 & $10 / 12 / 93$ & 1400 & 23.1 & 10 & 6.83 & 120 & 9.4 & 1.2 & 2.2 & 0.6 & 23.3 & 6 & 2.28 \\
\hline BWWOA & $\theta$ & $10 / 12123$ & 2250 & 38.8 & 10 & 6.4 & $\infty 0$ & 0.4 & ND & 2 & ND & 20.1 & 7 & 1.88 \\
\hline BWWOS & 12 & $10 / 13 / 93$ & 0225 & 41.2 & 10 & 6.82 & $\infty$ & 10.4 & 1.6 & 3 & 1.2 & 17.3 & 5 & 2.2 \\
\hline BWWOS & 16 & $10 / 13 / 23$ & 0605 & 37.1 & 10 & 6.0 & 100 & 10 & 1.25 & 3 & 2 & 10.3 & 6 & 2.41 \\
\hline BWWos & 20 & $10 / 13 / 83$ & 1140 & 17.8 & 10 & 6.88 & 75 & 0.8 & 1.7 & 1.6 & 1.2 & 21 & 6 & 2.03 \\
\hline BMWos & 24 & 101353 & 1530 & 29.5 & 10 & 6.64 & 111 & 14 & 1.1 & 4 & 7 & 22.2 & 8 & 1.85 \\
\hline BMWOS & 28 & $1013 / 23$ & 1745 & 29.5 & 10 & 6.16 & 105 & 122 & 1.7 & 3 & 3 & 22.5 & 7 & 2.08 \\
\hline BWMOS & 32 & $10 / 13 / 23$ & 2200 & 25.8 & 10.5 & 0.55 & 162 & 13.2 & 1 & 11.2 & 10.2 & 21.5 & 6 & 1.80 \\
\hline BWWOS & 36 & $10 / 1493$ & 0200 & 25.8 & 8 & 6.71 & 80 & 13.2 & 1.8 & 1.2 & ND & 21.2 & 6 & 2 \\
\hline BWWOS & 4 & 1011403 & 1200 & 27.3 & 11 & 6.81 & 215 & 11 & ND & 1.4 & 1.4 & 23.5 & 5 & 2.42 \\
\hline BWwos & 52 & $10 / 14103$ & 1735 & 25.1 & 10 & 6.75 & 80 & 10.8 & NA & 1 & 1 & 24.7 & 5 & 2.36 \\
\hline BWWOS & 72 & $10 / 15 / 23$ & 1105 & 28.6 & 10.5 & NA & 85 & 10.3 & NA & 3.8 & 1.2 & 22.7 & 5 & 2.14 \\
\hline BWW10 & $\mathbf{P}$ & $10 / 12 / 23$ & 0245 & 0.1 & 8.5 & 6.57 & 250 & 8.2 & $\mathbf{N A}$ & 1 & ND & 62.0 & 10 & 277 \\
\hline BWW10 & 0 & $10 / 12 \times 3$ & 1405 & 0.2 & 8 & 6.43 & 200 & 8.3 & NA & 1 & ND & 69.3 & 10 & 2.83 \\
\hline BWW10 & $e$ & $10 / 12 / 23$ & 2300 & 11.9 & 10 & 6.00 & 180 & 8.2 & NA & 5.2 & 2 & 59.5 & $\theta$ & 2.35 \\
\hline BWW10 & 12 & $1013 \times 3$ & 0235 & 12.8 & 10 & 6.32 & 200 & 8.8 & NA & 28 & 2.6 & 61 & 8 & 2.52 \\
\hline BWW10 & 16 & $10 / 13 / 23$ & 0010 & 12.6 & 9.5 & 6.4 & 185 & 9 & NA & 4 & 1.6 & 59.8 & 10 & 274 \\
\hline BWW10 & 20 & $10 / 13 / 23$ & 1150 & 12.1 & 10 & 6.45 & 170 & 8.8 & NA & 1.2 & ND & 64.3 & 8 & 234 \\
\hline BWW10 & 24 & $10 / 13 / 23$ & 1540 & 12.6 & 10 & 6.59 & 212 & 11.3 & NA & 24 & 12 & 63.1 & 10 & 2.10 \\
\hline BWW10 & 28 & $10 / 13 / 23$ & 1745 & 11.7 & 10 & 6.03 & 200 & 11 & NA & 1.6 & 1.6 & 64.2 & 8 & 2.43 \\
\hline BWW10 & 32 & $10 / 13 \times 3$ & 2000 & 11.7 & 9 & 6.32 & 105 & 13 & NA & 2.6 & 2.4 & 64.8 & $\theta$ & 2.44 \\
\hline BWW10 & 36 & $10 / 14 / 23$ & 0200 & 12.1 & 8 & 6.12 & 175 & 11.8 & NA & 1.8 & 1 & 61.5 & 6 & 2.32 \\
\hline EWW10 & 44 & $10 / 14 \times 3$ & 1230 & 12.3 & 0 & 6.67 & 165 & 9.6 & NA & 2.8 & 2.2 & 65.6 & 9 & 20 \\
\hline BWW10 & 52 & $10 / 14 / 23$ & 1735 & 13.0 & 10 & 6.45 & 175 & 10 & NA & 1 & ND & 70.9 & 7 & 2.71 \\
\hline BWW10 & 72 & $10 / 15 / 93$ & 1105 & 13.0 & 10.5 & NA & 185 & 10.8 & NA & 0.6 & ND & 62.7 & 7 & 2.4 \\
\hline EWW11 & $\mathbf{P}$ & $10 / 12 / 93$ & 0010 & 202 & 10 & 6.65 & 350 & 6.5 & 5.2 & 5.8 & 2 & 73.7 & 15 & 2.65 \\
\hline BWW11 & 0 & $10 / 12 / 93$ & 1330 & 149 & 10 & 6.82 & 300 & 0.1 & 21 & 2.8 & 1.8 & 80.3 & 14 & 3.37 \\
\hline BMW11 & 9 & $10 / 12 / 93$ & 2230 & 372 & 10 & 6.61 & 255 & 8 & 1.35 & 6 & 3.2 & 70.3 & 10 & 2.8 \\
\hline EMW11 & 12 & $10 / 13 / 93$ & 0215 & 143 & 10 & 6.59 & 240 & 10.8 & 23 & 5.2 & 28 & 60 & 12 & 3.04 \\
\hline EWW11 & 16 & $10 / 13 / 93$ & 0550 & 188 & 10 & 6.60 & 240 & 0.4 & 1.5 & 8.4 & 3.8 & 73.3 & 13 & 3.4 \\
\hline EWW11 & 20 & $1013 \mathrm{ks}$ & 1115 & 341 & 10 & 6.59 & 250 & 8.8 & 3.2 & 424 & 10.8 & 78.9 & 10 & 3.03 \\
\hline BWW11 & 24 & $10 / 13 / 23$ & 1510 & 404 & 10.5 & 6.61 & 285 & 11.7 & 3.2 & 35.4 & 25.8 & 70.1 & 13 & 276 \\
\hline BWW11 & 28 & $10 / 13 / 23$ & 1725 & 460 & 10 & 6.63 & 252 & 13.5 & 5.2 & 6 & 6 & 65.5 & 11 & 2.83 \\
\hline BWW11 & 32 & $10 / 1323$ & 2135 & 346 & 10 & 6.65 & 180 & 124 & 4.5 & 14.2 & 5.2 & 65.3 & 11 & 2.6 \\
\hline EWW11 & 38 & $10 / 14 / 23$ & 0145 & 288 & $\theta$ & 6.65 & 200 & 11.8 & 4.5 & 12.8 & 4.6 & 60.8 & 11 & 2.57 \\
\hline EWW11 & 4 & $10 / 1493$ & 1215 & 287 & 10 & 6.71 & 185 & 10.1 & 4 & 10 & 3.8 & 58.4 & 10 & 3 \\
\hline BWW11 & 52 & $10 / 1493$ & 1720 & 235 & 10.5 & 6.6 & 180 & 10.3 & NA & 5.2 & 2.8 & 65 & 10 & 2.85 \\
\hline BWW11 & 72 & $10 / 15 / 93$ & 1100 & 228 & 10.5 & NA & 200 & 10 & NA & 2.2 & 1.2 & 65.3 & $\theta$ & 2.84 \\
\hline BWN13 & $\mathbf{P}$ & $10 / 2 / 83$ & & 228 & 8.8 & & 250 & 10.5 & 24 & 4.8 & 1.6 & 68.6 & 15 & 3.46 \\
\hline EWW13 & 0 & $10 / 12 / 93$ & 1305 & 177 & 10.5 & 6.88 & 300 & 0.6 & 21 & 24 & 1.6 & 76.7 & 13 & 3.61 \\
\hline EMW13 & $\theta$ & $10 / 12 / 93$ & 2205 & 423 & 10 & 6.60 & 220 & 0.4 & 1.15 & 3.6 & 3.2 & 63.9 & $\theta$ & 228 \\
\hline EMW13 & 12 & $10 / 13 \times 3$ & 0148 & 186 & 11 & 3.69 & 240 & 10.2 & 265 & 3.6 & 3 & 69.3 & 11 & 3.07 \\
\hline EWW13 & 16 & $10 / 13 / 23$ & 0530 & 223 & 10 & 6.71 & 250 & 10.2 & 1.8 & 5.2 & 2.6 & 72 & 12 & 3.38 \\
\hline Buw13 & 20 & $10 / 13 / 23$ & 1057 & 378 & 10 & 6.60 & 205 & 10.2 & 1.5 & 4.4 & 2 & 67.3 & 10 & 278 \\
\hline EMN13 & 24 & $10 / 13 / 03$ & 1455 & 580 & 10 & 8.04 & 270 & 12.0 & 1.6 & 4.4 & 3.2 & 68.5 & 13 & 2.84 \\
\hline BMW13 & 28 & $10 / 13 / 93$ & 1710 & 530 & 10 & 6.77 & 250 & 124 & 2.4 & 3.8 & 3.8 & 64.7 & 12 & 3.01 \\
\hline EWW13 & 32 & $10 / 13 \% 3$ & 2120 & 405 & 10 & 6.69 & 170 & 13.5 & 2 & 13.4 & 8.6 & 68.3 & 11 & 2.64 \\
\hline
\end{tabular}


Table A.3 Water Quality Data for Storm 3 (Continued)

\begin{tabular}{|c|c|c|c|c|c|c|c|c|c|c|c|c|c|c|}
\hline Sution & Run & Date & Time & $\begin{array}{l}\text { Flow } \\
\text { cts }\end{array}$ & $\begin{array}{l}\text { Temp } \\
\operatorname{deg} C\end{array}$ & pH & $\begin{array}{l}\text { Cond } \\
\text { umhostem }\end{array}$ & $\underset{m g l}{D O}$ & $\begin{array}{l}\text { BOD } \\
\text { mar. }\end{array}$ & $\begin{array}{l}\text { TSS } \\
\text { mol }\end{array}$ & $\begin{array}{l}\text { VSS } \\
\text { man. }\end{array}$ & $\underset{m a r}{c}$ & Ca & Mg \\
\hline $\begin{array}{l}\text { BWW13 } \\
\text { BWW13 } \\
\text { BWW13 } \\
\text { BWW13 }\end{array}$ & $\begin{array}{l}36 \\
44 \\
52 \\
72\end{array}$ & $\begin{array}{l}10 / 14 / 23 \\
10 / 14 / 93 \\
10 / 14 / 83 \\
10 / 15 / 93\end{array}$ & $\begin{array}{l}0135 \\
1200 \\
1710 \\
1045\end{array}$ & $\begin{array}{l}379 \\
320 \\
299 \\
259\end{array}$ & $\begin{array}{c}9 \\
10 \\
10 \\
10.5\end{array}$ & $\begin{array}{c}6.60 \\
6.8 \\
6.85 \\
\text { NA }\end{array}$ & $\begin{array}{l}220 \\
215 \\
180 \\
175\end{array}$ & $\begin{array}{l}12.8 \\
11.6 \\
10.5 \\
10.7\end{array}$ & $\begin{array}{l}2.1 \\
3.3 \\
\text { NA } \\
\text { NA }\end{array}$ & $\begin{array}{l}4.4 \\
12 \\
8.2 \\
3.4\end{array}$ & $\begin{array}{l}2.6 \\
6.2 \\
4.2 \\
3\end{array}$ & $\begin{array}{c}68.6 \\
65.4 \\
68.3 \\
55\end{array}$ & $\begin{array}{c}11 \\
12 \\
10 \\
8\end{array}$ & $\begin{array}{l}2.82 \\
3.2 \\
2.0 \\
2.42\end{array}$ \\
\hline $\begin{array}{l}\text { BWW14 } \\
\text { BWW14 } \\
\text { BWW14 } \\
\text { BWW14 } \\
\text { BWW14 } \\
\text { BWW14 } \\
\text { BWW14 } \\
\text { BWW14 } \\
\text { BWW14 } \\
\text { BWW14 } \\
\text { BWW14 } \\
\text { BWW14 }\end{array}$ & $\begin{array}{c}P \\
0 \\
0 \\
12 \\
18 \\
20 \\
24 \\
28 \\
32 \\
38 \\
4 \\
52\end{array}$ & $\begin{array}{l}10 / 1293 \\
10 / 1293 \\
10 / 1293 \\
10 / 13 / 93 \\
10 / 13 / 93 \\
10 / 13 / 93 \\
10 / 13 / 93 \\
10 / 13 / 93 \\
10 / 13 / 93 \\
10 / 14 / 93 \\
10 / 14 / 93 \\
10 / 1493\end{array}$ & $\begin{array}{c}1035 \\
1520 \\
2350 \\
0345 \\
0705 \\
- \\
1815 \\
1830 \\
2245 \\
0300 \\
1320 \\
1820\end{array}$ & $\begin{array}{l}40.6 \\
43.2 \\
62.1 \\
58.2 \\
54.4 \\
48.4 \\
45 \\
44.5 \\
45 \\
45 \\
45 \\
4.5\end{array}$ & $\begin{array}{c}11.5 \\
11.5 \\
10 \\
12 \\
11.5 \\
12 \\
10 \\
10 \\
11 \\
10 \\
12 \\
12\end{array}$ & \begin{tabular}{|c|}
6.8 \\
6.47 \\
6.4 \\
6.87 \\
6.72 \\
6.7 \\
6.61 \\
6.82 \\
6.67 \\
6.71 \\
6.92 \\
6.85
\end{tabular} & $\begin{array}{c}150 \\
150 \\
100 \\
110 \\
105 \\
90 \\
111 \\
115 \\
165 \\
85 \\
82 \\
340\end{array}$ & \begin{tabular}{|c|}
9.1 \\
9.4 \\
8.4 \\
8.8 \\
10.5 \\
9.75 \\
12.4 \\
12.8 \\
13.4 \\
12.6 \\
10.5 \\
10.3
\end{tabular} & $\begin{array}{c}2.2 \\
1.7 \\
1.3 \\
2 \\
1.2 \\
1.2 \\
1.2 \\
2.2 \\
1.5 \\
1.3 \\
\text { ND } \\
\text { NA }\end{array}$ & $\begin{array}{c}2.8 \\
1 \\
2.8 \\
2.8 \\
5.8 \\
2 \\
2 \\
20.2 \\
2 \\
1 \\
44 \\
1.8\end{array}$ & $\begin{array}{c}1 \\
\text { ND } \\
1.6 \\
2.4 \\
4.6 \\
1 \\
1.8 \\
13.6 \\
1.2 \\
1 \\
1.6 \\
1.4\end{array}$ & $\begin{array}{c}23.5 \\
28.3 \\
25 \\
27.1 \\
22 \\
24.7 \\
25 \\
25.8 \\
24.7 \\
25.8 \\
26.3 \\
27.8\end{array}$ & $\begin{array}{l}5 \\
4 \\
6 \\
5 \\
5 \\
6 \\
6 \\
5 \\
4 \\
4 \\
6 \\
4\end{array}$ & $\begin{array}{l}1.67 \\
1.68 \\
1.41 \\
1.69 \\
1.63 \\
1.44 \\
1.34 \\
1.49 \\
1.46 \\
1.46 \\
1.76 \\
1.81\end{array}$ \\
\hline $\begin{array}{l}\text { BWW15 } \\
\text { BWW15 } \\
\text { BWW15 } \\
\text { BWW15 } \\
\text { BWW15 } \\
\text { BWW15 } \\
\text { BWW15 } \\
\text { BWW15 } \\
\text { BWW15 } \\
\text { BWW15 } \\
\text { BWW15 } \\
\text { BWW15 } \\
\text { BWW15 }\end{array}$ & $\begin{array}{l}P \\
0 \\
0 \\
12 \\
16 \\
20 \\
24 \\
28 \\
32 \\
36 \\
44 \\
52 \\
72\end{array}$ & $\begin{array}{l}10 / 12 / 93 \\
10 / 12 / 93 \\
1012 / 93 \\
10 / 13 / 93 \\
10 / 13 / 93 \\
10 / 13 / 93 \\
10113 / 93 \\
10 / 13 / 93 \\
10 / 13 / 93 \\
10 / 1493 \\
10 / 1493 \\
10 / 1493 \\
10 / 15 / 93\end{array}$ & $\begin{array}{l}0840 \\
1315 \\
2145 \\
0130 \\
0515 \\
1105 \\
1410 \\
1905 \\
2210 \\
0220 \\
1105 \\
1705 \\
1030\end{array}$ & & $\begin{array}{c}9.75 \\
11.5 \\
11 \\
11 \\
10 \\
11 \\
13.5 \\
10.8 \\
8.9 \\
8.5 \\
9.9 \\
12 \\
11\end{array}$ & $\begin{array}{c}5.8 \\
5.91 \\
6.2 \\
6.03 \\
6.1 \\
5.9 \\
8.25 \\
6.28 \\
6.08 \\
6.22 \\
5.38 \\
5.8 \\
N A\end{array}$ & $\begin{array}{l}138 \\
138 \\
125 \\
131 \\
135 \\
180 \\
138 \\
148 \\
135 \\
130 \\
130 \\
150 \\
160\end{array}$ & $\begin{array}{c}5.3 \\
8.3 \\
7.8 \\
7.4 \\
4.7 \\
8.4 \\
7.8 \\
8.1 \\
7 \\
5.2 \\
6 \\
6 \\
4.7\end{array}$ & $\begin{array}{l}\text { NA } \\
\text { NA } \\
\text { NA } \\
\text { NA } \\
\text { NA } \\
\text { NA } \\
\text { NA } \\
\text { NA } \\
\text { NA } \\
\text { NA } \\
\text { NA } \\
\text { NA }\end{array}$ & $\begin{array}{c}8 \\
4.2 \\
43.2 \\
3.8 \\
6.4 \\
10.4 \\
7.4 \\
6.2 \\
28 \\
2.2 \\
0.2 \\
7.4 \\
6.6\end{array}$ & $\begin{array}{c}3.2 \\
2.4 \\
15.8 \\
3 \\
2 \\
2.8 \\
4.8 \\
4 \\
28.4 \\
1.8 \\
3 \\
3.4 \\
3.4\end{array}$ & $\begin{array}{l}32.2 \\
39.8 \\
30.4 \\
29.8 \\
31.1 \\
32.2 \\
33.8 \\
34.9 \\
34.5 \\
33 \\
36.2 \\
38.8 \\
36\end{array}$ & $\begin{array}{c}13 \\
10 \\
8 \\
9 \\
7 \\
8 \\
8 \\
9 \\
9 \\
8 \\
7 \\
7 \\
8\end{array}$ & $\begin{array}{l}2.74 \\
2.75 \\
2.1 \\
2.52 \\
2.44 \\
2.24 \\
2.05 \\
2.30 \\
2.46 \\
2.37 \\
2.6 \\
2.59 \\
2.47\end{array}$ \\
\hline $\begin{array}{l}\text { BWW16 } \\
\text { BWW16 } \\
\text { BWW18 } \\
\text { BWW16 } \\
\text { BWW16 } \\
\text { BWW18 } \\
\text { BWW18 } \\
\text { BWW18 } \\
\text { BWW18 } \\
\text { BWW18 } \\
\text { BWW18 } \\
\text { BWW18 } \\
\text { BWW16 }\end{array}$ & $\begin{array}{l}P \\
0 \\
0 \\
12 \\
16 \\
20 \\
24 \\
28 \\
32 \\
38 \\
44 \\
52 \\
72\end{array}$ & $\begin{array}{l}10 / 12 / 93 \\
10 / 12 / 93 \\
10 / 12 / 93 \\
10 / 13 / 93 \\
10 / 13 / 93 \\
10 / 13 / 93 \\
10 / 13 / 93 \\
10 / 13 / 93 \\
10 / 13 / 93 \\
10 / 14 / 93 \\
10 / 1493 \\
10 / 14 / 93 \\
10 / 15 / 93\end{array}$ & $\begin{array}{l}0855 \\
1305 \\
2125 \\
0120 \\
0520 \\
1045 \\
1425 \\
1655 \\
2105 \\
0115 \\
1140 \\
1635 \\
1000\end{array}$ & $\begin{array}{l}1.6 \\
1.5 \\
6.5 \\
4.4 \\
3.6 \\
3.6 \\
3.6 \\
3.2 \\
3.1 \\
3.2 \\
3.1 \\
5.1 \\
8.5\end{array}$ & $\begin{array}{c}8.8 \\
9.3 \\
10 \\
9.5 \\
8 \\
9 \\
10.4 \\
9.5 \\
8.5 \\
7.3 \\
6.2 \\
10 \\
11\end{array}$ & $\begin{array}{l}6.1 \\
6.12 \\
8.3 \\
8.34 \\
6.12 \\
6.16 \\
6.2 \\
6.34 \\
8.36 \\
8.44 \\
6.46 \\
8.38 \\
\text { NA }\end{array}$ & $\begin{array}{l}152 \\
155 \\
100 \\
130 \\
142 \\
190 \\
135 \\
120 \\
105 \\
115 \\
120 \\
360 \\
155\end{array}$ & $\begin{array}{c}6.3 \\
7.1 \\
8.4 \\
6.8 \\
7 \\
6.1 \\
7.45 \\
7.3 \\
8.4 \\
7.75 \\
8.8 \\
7.6 \\
8.5\end{array}$ & $\begin{array}{c}6.8 \\
3.5 \\
6.35 \\
4 \\
4 \\
4.4 \\
5.0 \\
6.8 \\
6.1 \\
5.7 \\
4.45 \\
\text { NA } \\
\text { NA }\end{array}$ & $\begin{array}{c}3.4 \\
3 \\
4 \\
3.4 \\
16.8 \\
9 \\
3.2 \\
53.4 \\
56 \\
13 \\
2 \\
3.6 \\
2.4\end{array}$ & $\begin{array}{c}1.8 \\
1.8 \\
18 \\
2.6 \\
6.2 \\
6.6 \\
2.6 \\
18.2 \\
54.8 \\
7.6 \\
1.6 \\
2 \\
2.2\end{array}$ & $\begin{array}{c}39.8 \\
45.2 \\
34.4 \\
33.9 \\
37 \\
39.7 \\
33.3 \\
31.7 \\
29.4 \\
25.8 \\
32.3 \\
36.8 \\
42.6\end{array}$ & $\begin{array}{c}10 \\
11 \\
8 \\
8 \\
11 \\
8 \\
9 \\
8 \\
8 \\
7 \\
8 \\
10 \\
7\end{array}$ & $\begin{array}{l}3.24 \\
3.28 \\
2.5 \\
2.75 \\
3.35 \\
2.73 \\
2.34 \\
2.42 \\
2.27 \\
2.41 \\
3.05 \\
3.4 \\
2.68\end{array}$ \\
\hline $\begin{array}{l}\text { BWW17 } \\
\text { BWW17 } \\
\text { BWW17 } \\
\text { BWW17 } \\
\text { BWW17 } \\
\text { BWW17 } \\
\text { BWW17 } \\
\text { BWW17 } \\
\text { BWW17 } \\
\text { BWW17 } \\
\text { BWW17 } \\
\text { BWW17 } \\
\text { BWW17 }\end{array}$ & $\begin{array}{l}P \\
0 \\
9 \\
12 \\
18 \\
20 \\
24 \\
28 \\
32 \\
36 \\
44 \\
52 \\
72\end{array}$ & $\begin{array}{l}10 / 12 / 93 \\
10 / 12 / 93 \\
10 / 12 / 93 \\
10 / 13 / 93 \\
10 / 13 / 93 \\
10 / 13 / 93 \\
10 / 13 / 93 \\
10 / 13 / 93 \\
10 / 13 / 93 \\
1011493 \\
1011493 \\
10 / 1493 \\
10 / 15 / 93\end{array}$ & $\begin{array}{l}0840 \\
1300 \\
2130 \\
0120 \\
0520 \\
1045 \\
1425 \\
1655 \\
2105 \\
0115 \\
1140 \\
1635 \\
1000\end{array}$ & $\begin{array}{l}165 \\
172 \\
204 \\
248 \\
207 \\
223 \\
420 \\
707 \\
551 \\
418 \\
416 \\
408 \\
280\end{array}$ & $\begin{array}{c}11 \\
11.5 \\
10 \\
11 \\
10 \\
11 \\
10 \\
10 \\
10 \\
9 \\
10 \\
10 \\
10.5\end{array}$ & $\begin{array}{l}6.86 \\
8.81 \\
6.87 \\
6.75 \\
6.77 \\
6.73 \\
6.75 \\
6.75 \\
8.69 \\
8.69 \\
6.81 \\
6.81 \\
\text { NA }\end{array}$ & $\begin{array}{l}300 \\
300 \\
180 \\
250 \\
245 \\
220 \\
263 \\
250 \\
172 \\
225 \\
210 \\
230 \\
220\end{array}$ & \begin{tabular}{|c|}
10.8 \\
9.8 \\
9.2 \\
10.4 \\
10 \\
11.2 \\
13.4 \\
13 \\
13.2 \\
13.6 \\
10.6 \\
11.8 \\
10.8
\end{tabular} & $\begin{array}{c}2.3 \\
2.7 \\
2.2 \\
2.4 \\
1.8 \\
2.9 \\
1.8 \\
2.3 \\
2 \\
2.2 \\
1.4 \\
N A \\
N A\end{array}$ & $\begin{array}{c}4.2 \\
1.8 \\
30.8 \\
3.6 \\
11.6 \\
6.2 \\
5.4 \\
5.8 \\
11.2 \\
10.2 \\
4.0 \\
5.8 \\
5.6\end{array}$ & $\begin{array}{l}2.4 \\
1 \\
4 \\
2.8 \\
2.4 \\
2.6 \\
4.2 \\
8.4 \\
4.4 \\
3.6 \\
4.4 \\
1.4 \\
1.3\end{array}$ & $\begin{array}{c}63.9 \\
75.6 \\
47 \\
69.6 \\
73 \\
73.3 \\
65.2 \\
67.6 \\
70.9 \\
68.4 \\
68.8 \\
78.4 \\
60.9\end{array}$ & $\begin{array}{c}13 \\
13 \\
9 \\
13 \\
13 \\
10 \\
11 \\
12 \\
12 \\
11 \\
11 \\
9 \\
10\end{array}$ & $\begin{array}{l}3.28 \\
3.23 \\
2.13 \\
3.17 \\
3.7 \\
2.85 \\
27 \\
3.1 \\
2.68 \\
2.78 \\
3.3 \\
3.32 \\
2.52\end{array}$ \\
\hline $\begin{array}{l}\text { BWW18 } \\
\text { BWW18 } \\
\text { BWW18 } \\
\text { BWW18 } \\
\text { BWW18 } \\
\text { EWW18 } \\
\text { BWW18 } \\
\text { BWW18 } \\
\text { BWW18 } \\
\text { BWW18 } \\
\text { EWW18 } \\
\text { BWW18 }\end{array}$ & $\begin{array}{c}P \\
0 \\
9 \\
12 \\
16 \\
20 \\
24 \\
28 \\
32 \\
36 \\
44 \\
52\end{array}$ & $\begin{array}{l}10 / 12 / 93 \\
10 / 12 / 93 \\
10 / 12 / 93 \\
10 / 13 / 93 \\
10 / 13 / 93 \\
10 / 13 / 93 \\
10 / 13 / 93 \\
10 / 13 / 93 \\
10 / 13 / 93 \\
10 / 14 / 93 \\
10 / 14 / 93 \\
10 / 14 / 93\end{array}$ & $\begin{array}{l}0915 \\
1410 \\
2215 \\
0140 \\
0530 \\
1120 \\
1505 \\
1035 \\
2305 \\
0240 \\
0830 \\
1845\end{array}$ & $\begin{array}{l}240 \\
280 \\
218 \\
280 \\
238 \\
302 \\
403 \\
682 \\
420 \\
420 \\
338 \\
395\end{array}$ & $\begin{array}{c}13 \\
13 \\
12 \\
12 \\
11.6 \\
12.7 \\
12.5 \\
11.5 \\
10.5 \\
10.5 \\
0.3 \\
11\end{array}$ & $\begin{array}{l}6.57 \\
6.5 \\
6.53 \\
6.71 \\
6.55 \\
6.57 \\
6.5 \\
6.70 \\
6.67 \\
6.77 \\
6.84 \\
6.82\end{array}$ & $\begin{array}{l}270 \\
282 \\
222 \\
285 \\
255 \\
291 \\
245 \\
225 \\
285 \\
240 \\
240 \\
340\end{array}$ & $\begin{array}{c}9.1 \\
10.3 \\
9.7 \\
9 \\
9.5 \\
10 \\
9.4 \\
10 \\
11.2 \\
10.3 \\
9.8 \\
10.2\end{array}$ & $\begin{array}{l}2.3 \\
1.9 \\
0.5 \\
2.25 \\
1.25 \\
1.9 \\
3.5 \\
2.3 \\
2.3 \\
1.8 \\
0.5 \\
\text { NA }\end{array}$ & \begin{tabular}{|c|}
4.8 \\
4 \\
3.6 \\
11.6 \\
6.2 \\
5.4 \\
5.6 \\
11.2 \\
10.2 \\
4.8 \\
5.6 \\
5.6
\end{tabular} & $\begin{array}{l}2.8 \\
1.6 \\
1.4 \\
3.4 \\
2.6 \\
3.2 \\
3.6 \\
7.4 \\
6.6 \\
3.2 \\
3.2 \\
2.8\end{array}$ & $\begin{array}{l}74 \\
70.3 \\
68.5 \\
74.5 \\
76.8 \\
80.9 \\
70.4 \\
78.4 \\
81.8 \\
73.5 \\
75.9 \\
87.3\end{array}$ & $\begin{array}{c}13 \\
12 \\
9 \\
11 \\
12 \\
10 \\
10 \\
12 \\
11 \\
11 \\
11 \\
11\end{array}$ & \begin{tabular}{l|}
3.16 \\
3.22 \\
2.68 \\
3.2 \\
3.41 \\
2.69 \\
2.58 \\
3.03 \\
2.68 \\
2.72 \\
3.08 \\
3.22 \\
\end{tabular} \\
\hline $\begin{array}{l}\text { BWW20 } \\
\text { BWW20 } \\
\text { BWW20 } \\
\text { BWW20 } \\
\text { BWW20 }\end{array}$ & $\begin{array}{c}P \\
0 \\
9 \\
12 \\
16\end{array}$ & $\begin{array}{l}10 / 1293 \\
10 / 12 / 93 \\
10 / 12 / 83 \\
10 / 13 \% 3 \\
10 / 1393\end{array}$ & $\begin{array}{l}0040 \\
1435 \\
2245 \\
0205 \\
0555\end{array}$ & $\begin{array}{l}255 \\
300 \\
231 \\
300 \\
250\end{array}$ & $\begin{array}{r}12 \\
13 \\
12 \\
123 \\
11.8\end{array}$ & $\begin{array}{l}6.61 \\
6.69 \\
6.69 \\
6.69 \\
6.68\end{array}$ & $\begin{array}{l}272 \\
252 \\
265 \\
250 \\
250\end{array}$ & $\begin{array}{c}0.2 \\
11.1 \\
10.9 \\
9.4 \\
9.45\end{array}$ & $\begin{array}{c}3.1 \\
1.4 \\
0.5 \\
1.95 \\
0.5\end{array}$ & $\begin{array}{c}3.8 \\
2 \\
11.8 \\
5 \\
5.8\end{array}$ & $\begin{array}{c}1.8 \\
1 \\
4 \\
2.8 \\
24\end{array}$ & $\begin{array}{c}79.3 \\
87.1 \\
72.1 \\
72 \\
71.7\end{array}$ & $\begin{array}{c}13 \\
12 \\
8 \\
11 \\
12\end{array}$ & $\begin{array}{l}3.12 \\
3.22 \\
2.51 \\
3.02 \\
3.49\end{array}$ \\
\hline
\end{tabular}


Table A.3 Water Quality Data for Storm 3 (Continued)

\begin{tabular}{|c|c|c|c|c|c|c|c|c|c|c|c|c|c|c|}
\hline Station & Run & Date & Time & $\begin{array}{c}\text { Flow } \\
\text { ef }\end{array}$ & $\begin{array}{l}\text { Temp } \\
\operatorname{deg} C\end{array}$ & PH & $\begin{array}{l}\text { Cond } \\
\text { umhoes/em }\end{array}$ & $\begin{array}{c}\text { DO } \\
\text { mol }\end{array}$ & $\begin{array}{l}B O D \\
m g l\end{array}$ & $\begin{array}{l}\text { TSS } \\
\text { mgl }\end{array}$ & $\begin{array}{l}\text { VSS } \\
\mathrm{mgl}\end{array}$ & $\begin{array}{c}\mathrm{Cl} \\
\mathrm{mgl}\end{array}$ & $\mathrm{mgl}$ & $\begin{array}{l}\text { Mg } \\
\mathbf{m g l}\end{array}$ \\
\hline BWW20 & 20 & $10 / 13 / 93$ & 1145 & 323 & 12.6 & 6.71 & 280 & 13.2 & 2 & 9 & 2.8 & 73.9 & 10 & 2.60 \\
\hline BWWZO & 24 & $10 / 13 / 93$ & 1610 & 437 & 12.6 & 6.60 & 240 & 10.7 & 1.6 & 6 & 4.2 & 70.3 & 10 & 2.68 \\
\hline BWWZO & 28 & $10 / 13 / 23$ & 2005 & 746 & 11 & 6.69 & 235 & 6.2 & 3.1 & 26.4 & 6.4 & 66.6 & 12 & 3.12 \\
\hline BWW20 & 32 & $10 / 13 / 93$ & 2335 & 404 & 11 & 6.69 & 205 & 12 & 21 & 12 & 4.4 & 77.8 & 11 & 3.04 \\
\hline BWW20 & 36 & $10 / 14 / 93$ & 0310 & 455 & 11.3 & 6.67 & 255 & 10.5 & 1.9 & 8 & 3.6 & 76.3 & 11 & 2.83 \\
\hline BWW20 & 44 & $10 / 1493$ & 0915 & 383 & 10 & 6.74 & 225 & 10.3 & 1.4 & 9.4 & 4.4 & 78.9 & 11 & 3.49 \\
\hline BWW20 & 52 & $10 / 1493$ & 1900 & 427 & 11.5 & 6.68 & 260 & 10.6 & NA & 6.8 & 1.4 & 85.2 & 11 & 3.24 \\
\hline BWW21 & $\mathbf{P}$ & $10 / 12 / 93$ & 1000 & 254 & 12.8 & 6.53 & 260 & 9.7 & 2.3 & 5 & 2 & 74.6 & 12 & 3.02 \\
\hline BWW21 & 0 & $10 / 12 / 23$ & 1500 & 284 & 13 & 6.78 & 295 & 11.1 & 2 & 3 & 1.8 & 89.6 & 11 & 3.2 \\
\hline BWW21 & 9 & $10 / 12 / 93$ & 2315 & 385 & 128 & 6.67 & 200 & 11.8 & 1 & 8 & 3.4 & 75.3 & $\theta$ & 252 \\
\hline BWW21 & 12 & $10 / 13 / 93$ & 0230 & 314 & 12 & 6.92 & 243 & 9.6 & 2.25 & 31.4 & 21.8 & 78.7 & 10 & 3.01 \\
\hline BWW21 & 18 & $10 / 13 / 23$ & 0615 & 290 & 12 & 6.81 & 255 & 10 & 1 & 1.8 & 1 & 73 & 12 & 3.3 \\
\hline BMW21 & 20 & $10 / 13 / 23$ & 1205 & 314 & 12.8 & 6.69 & 260 & 13.6 & 1.6 & 6.2 & 2.2 & 74.6 & 9 & 2.66 \\
\hline BWW21 & 24 & $10 / 13 / 23$ & 1645 & 302 & 12.8 & 6.85 & 235 & 10.2 & 1.6 & 3.2 & 2.8 & 68.2 & 10 & 2.67 \\
\hline BWW21 & 26 & $10 / 13 / 93$ & 2045 & 485 & 11.8 & 6.82 & 220 & 10.2 & 2.3 & 9.8 & 5.6 & 61.8 & 13 & 2.81 \\
\hline BWW21 & 32 & $10 / 13 / 03$ & 0010 & 688 & 11.0 & 6.81 & 250 & 12.1 & 2.1 & 6.2 & 1.4 & 79.3 & 112 & 2.85 \\
\hline BWW21 & 36 & $10 / 14 / 23$ & 0315 & 558 & 11.3 & 6.77 & 231 & 11.1 & 1.8 & 11 & 7.2 & 68.6 & 11 & 2.89 \\
\hline BWW21 & 4 & $10 / 14 / 23$ & 0935 & 429 & 10.5 & 6.88 & 248 & 10.4 & 1.45 & 9 & 4.8 & 73.2 & 11 & 3.56 \\
\hline BWW21 & 52 & $10 / 14 / 23$ & 1920 & 402 & 12 & 6.82 & 285 & 10.6 & MA & 7.4 & 3.2 & 88.4 & 10 & 3.5 \\
\hline BWw22 & 0 & 10/12/93 & 2111 & & 11 & 6.1 & 120 & NA & 51.7 & 67.3 & 24 & 30.5 & 4 & \\
\hline BWM22 & 3 & $10 / 12 / 23$ & 2132 & & 10 & 6.26 & 80 & NA & 41.7 & 96 & 38.3 & 44.4 & ND & 0.25 \\
\hline EWW22 & 8 & $10 / 12 / 23$ & 2152 & & 8.5 & 6.18 & 60 & NA & 24.7 & 83.2 & 33.6 & 11.3 & 1 & 0.39 \\
\hline BWW22 & 9 & $10 / 12 / 93$ & 2212 & & 8 & 6.22 & 50 & NA & 7.75 & 73.4 & 22.4 & 17.3 & 1 & 0.37 \\
\hline BWW22 & 12 & $10 / 12 / 23$ & 2312 & & 8.5 & 6.3 & 60 & MA & 16.7 & 47.4 & 13.8 & NA & 2 & 0.41 \\
\hline BWW22 & 18 & $10 / 12 / 83$ & 0012 & & 8 & 6.14 & 85 & NA & 6.6 & 52 & 26.2 & NA & 2 & 0.38 \\
\hline BWWZ3 & $P$ & $10 / 42 / 23$ & 0715 & & NA & 6.18 & 290 & NA & 10.3 & 2.6 & ND & 93.3 & 14 & 3.33 \\
\hline BWW 23 & 0 & $10 / 12 / 23$ & 1210 & & 19 & 6.14 & 300 & NA & 7.2 & 1.6 & 1.4 & 105 & 13 & 3.35 \\
\hline BWW23 & 9 & $10 / 12 / 23$ & 2130 & 33 & 14 & 8.14 & 335 & NA & 13 & 8.2 & 8.8 & 101 & 10 & 3.02 \\
\hline BWW23 & 12 & $10 / 3 / 23$ & 0000 & 69 & NA & 6.32 & 385 & NA & 29.5 & 6.4 & 5.4 & 109 & 10 & 2.85 \\
\hline BWWZ3 & 16 & $10 / 13 / 93$ & ouns & 75 & NA & 6.12 & 312 & NA & 17 & 3.8 & 3 & 78.1 & 8 & 2.52 \\
\hline BWW23 & 20 & $10 / 13 / 23$ & 0815 & 30 & 16 & 6.1 & 310 & NA & 6.8 & 5.6 & 3.8 & 63.5 & 8 & 1.85 \\
\hline BWW23 & 24 & $10 / 13 / 23$ & 1200 & 42 & 15 & 6.01 & 255 & NA & 7.9 & 1.4 & ND & 63.9 & 10 & 2.24 \\
\hline BWW23 & 28 & $10 / 13 / 23$ & 1613 & 38 & 16.5 & 6.2 & 302 & NA & 10.3 & 5.2 & 4.8 & 68.7 & 10 & 2.51 \\
\hline BWW23 & 32 & $10 / 13 / 23$ & 2005 & 31 & MA & 6.18 & 200 & NA & 8 & 1.8 & ND & 80.5 & 6 & 2.18 \\
\hline BWW23 & 38 & $10 / 14 / 83$ & 0020 & 33 & 17.5 & 6.2 & 280 & NA & 6.6 & 7.8 & 6.8 & 84.4 & 10 & 2.8 \\
\hline BWW23 & 44 & $10 / 1493$ & 0800 & & 17 & 6.30 & 300 & NA & 4.5 & 3.6 & 3.4 & 01.1 & 11 & 3.25 \\
\hline BWW 23 & 52 & $10 / 14 / 23$ & 1557 & & 16 & 6.14 & 315 & NA & NA & 26 & 2 & 112 & 11 & 3.27 \\
\hline 8mw24 & $P$ & $10 / 12 / 23$ & & & NA & 3.45 & 690 & NA & 29 & 29.2 & 22 & 224 & 7 & 3.65 \\
\hline BWW24 & 0 & $10 / 12 / 23$ & & & NA & 4.2 & 720 & NA & 21.7 & 34.4 & 23.2 & 308 & 5 & 2.84 \\
\hline BWW24 & 9 & $10 / 1203$ & & & NA & 5.09 & 720 & NA & 11.5 & 30.6 & 11.4 & 281 & 5 & 2.85 \\
\hline BWW24 & 12 & $10 / 3 / 23$ & & & NA & 5.23 & 800 & NA & 13 & 25.2 & 23.8 & 314 & 4 & 2.51 \\
\hline 8W124 & 16 & $10 / 13 / 93$ & & & NA & 5.05 & 1100 & NA & 9 & 26.4 & 18.8 & 399 & 4 & 255 \\
\hline BMW24 & 20 & $10 / 13 / 23$ & & & NA & 5.58 & 1080 & NA & 15.4 & 41.3 & 27.3 & 388 & 4 & 1.93 \\
\hline BWW24 & 24 & $10 / 13 / 183$ & & & NA & 5.68 & 1150 & NA & 20.8 & 30.8 & 27.6 & 350 & 5 & 1.85 \\
\hline BWW24 & 28 & $10 / 13 / 25$ & & & NA & 5.68 & 1400 & NA & 20 & 33.7 & 22.5 & 394 & 3 & 2.00 \\
\hline BWW24 & 32 & $10 / 13 / 3$ & & & NA & 5.60 & 1200 & NA & 13.2 & 25.6 & 20.6 & 373 & 2 & 2 \\
\hline EMW24 & 38 & $10 / 4 \sqrt{23}$ & & & NA & 5.69 & 880 & NA & 12.1 & 30.4 & 23.2 & 374 & 2 & 1.97 \\
\hline BWW24 & 44 & $10 / 14 / 83$ & & & NA & 5.6 & 800 & NA & 8 & 13.3 & 2.4 & 383 & 2 & 2.5 \\
\hline BWW25 & $P$ & $10 / 1293$ & 1020 & 23 & 18 & 8.55 & 550 & 5.2 & 15 & 10 & 6 & 87.1 & 21 & 2.99 \\
\hline BWW2S & 0 & $10 / 12 / 23$ & 1515 & 23.6 & 17 & 6.61 & 520 & 5 & 26.2 & 9 & 3.6 & 95 & 17 & 3.01 \\
\hline BWW25 & 9 & $10 / 12 / 23$ & 2323 & & 18 & 6.04 & 600 & 24 & 8 & 35.6 & 33.2 & 116 & 7 & 2.49 \\
\hline BWW25 & 12 & 10/1323 & 0240 & 18 & 18 & 6.81 & 505 & 4.55 & 14.5 & 20.4 & 18.8 & 112 & 5 & 2.49 \\
\hline BWW25 & 16 & $10 / 13 \times 3$ & 0020 & 12.3 & 17.6 & 6.44 & 500 & 4.5 & $\theta$ & 10 & 7.2 & 108 & 12 & 3.04 \\
\hline BWw25 & 20 & $10 / 13 \times 3$ & 1220 & 23.6 & 17.3 & 8.62 & 550 & 3.55 & 7.8 & 8.4 & 6.2 & 85.8 & 10 & 1.0 \\
\hline BWW25 & 24 & $10 / 13 \times 3$ & 1700 & 20.5 & 18.5 & 6.73 & 435 & 3.1 & 10.6 & 43.2 & 19.2 & 80.8 & $\cdot 12$ & 1.67 \\
\hline BWW25 & 26 & $10 / 13 / 23$ & 2115 & 22.2 & 17.5 & 6.79 & 420 & 3 & 15 & 120 & 10.7 & 93.4 & 16 & 2.22 \\
\hline BWM25 & 32 & $10 / 1393$ & 0035 & 18.2 & 18.5 & 6.70 & 500 & 3.6 & 6.7 & 31.2 & 28 & 110 & 15 & 2.2 \\
\hline BWW25 & 36 & $10 / 14 / 23$ & 0335 & 13.8 & 17.3 & 6.9 & 658 & 20 & 8.0 & 6.8 & 4.2 & 110 & 18 & 2.24 \\
\hline BWW2S & 44 & $10 / 14 / 83$ & 0950 & 23.3 & 15.5 & 6.76 & 500 & 27 & 6 & 120 & 12.4 & 122 & 17 & 2.8 \\
\hline BWW25 & 52 & $10 / 14 / 83$ & 1930 & 227 & 18 & 6.8 & 720 & 2.25 & NA & 11 & 10 & 149 & 15 & 2.68 \\
\hline
\end{tabular}

ND = Not Detected

NS= No Sample

NM= Not Measured

NA = Not Analyzed 
Table A.3 Water Quality Data for Storm 3 (Continued)

\begin{tabular}{|c|c|c|c|c|c|c|c|c|c|c|c|c|c|}
\hline Station & Run & $\mathrm{Na}$ & $\begin{array}{l}\mathrm{Zn} \\
\mathrm{ugh}\end{array}$ & $\begin{array}{l}\text { NH3 } \\
\text { mgh }\end{array}$ & $\begin{array}{l}\text { NO3 } \\
m g h\end{array}$ & $\begin{array}{l}\text { POA } \\
\text { mgll }\end{array}$ & cod & $\begin{array}{c}c r \\
u g h\end{array}$ & $\begin{array}{c}\text { Cu } \\
\text { ual }\end{array}$ & $\underset{\operatorname{cog} /}{\mathrm{Ni}}$ & $\begin{array}{c}\mathrm{Pb} \\
\mathrm{ual}\end{array}$ & $\begin{array}{l}\text { F.C. } \\
\text { mdr100mL }\end{array}$ & $\begin{array}{c}\text { EC. } \\
\mathrm{md} / 100 \mathrm{~mL}\end{array}$ \\
\hline Eumwoo & $\mathbf{P}$ & 33 & 5 & 0.04 & 0.25 & 0.01 & 0.38 & 0.35 & 0.9 & 1.4 & 7.7 & 1100 & 290 \\
\hline BWWDO & 0 & 33 & 11 & 0.08 & 0.25 & 0.01 & 0.35 & 0.5 & 3.7 & 1.5 & 3 & 930 & 520 \\
\hline BWWOO & 9 & 9 & 90 & 0.07 & 0.3 & 0.01 & 0.56 & 14.4 & 44 & 7.3 & 89.2 & 52000 & 13000 \\
\hline BWWOO & 12 & 12 & 10 & 0.07 & 0.21 & 0.01 & 0.6 & 12 & 21 & 5 & 56.2 & 14000 & 16000 \\
\hline BWWoo & 16 & 22 & 25 & 0.07 & 0.16 & 0.01 & 0.12 & 1.08 & 4.9 & 29 & 8.1 & 4700 & 4800 \\
\hline EMWOO & 20 & 28 & 15 & 0.01 & 0.16 & 0.01 & 0.08 & 0.78 & 3.2 & 1.5 & 5.8 & 2300 & 1800 \\
\hline BMWOO & 24 & 28 & 19 & 0.02 & 0.21 & 0.01 & 0.33 & 1.08 & 3.4 & 1.8 & 4.8 & 8200 & 1800 \\
\hline BMWNoO & 28 & 27 & 16 & 0.01 & 0.18 & 0.01 & 0.07 & 0.91 & 28 & 1.1 & 3.9 & 2700 & 750 \\
\hline BWWOo & 32 & 28 & 5 & 0.02 & 0.18 & 0.01 & 0.02 & 0.4 & 5.2 & 0.3 & 3.7 & NS & NS \\
\hline BWWOD & 36 & 28 & 15 & 0.01 & 0.18 & 0.01 & 0.02 & 0.84 & 28 & 1.8 & 5.3 & 2100 & 590 \\
\hline BWWoo & 44 & 27 & 5 & 0.02 & 0.18 & 0.01 & 0.09 & 0.78 & 27 & ND & 2.6 & NS & NS \\
\hline BWwoo & 52 & 28 & 12 & 0.01 & 0.18 & 0.01 & 0.07 & 0.51 & 2.9 & 0.3 & 25 & NS & NS \\
\hline EMmo1 & $\mathbf{P}$ & 48 & 29 & 0.30 & 0.5 & 0.01 & 0.27 & 0.7 & 3.5 & 2.7 & 26 & 1500 & 390 \\
\hline BMWO1 & 0 & 51 & 23 & 0.20 & 0.5 & 0.01 & 0.37 & 0.7 & 1.2 & 2.3 & 3.2 & 2100 & 600 \\
\hline BWWot & 9 & 20 & 71 & 0.05 & 0.37 & 0.01 & 0.43 & 8.8 & 30.4 & 6.4 & 53.4 & 16000 & 7100 \\
\hline BWMO1 & 12 & 22 & 123 & 0.05 & 0.29 & 0.01 & 0.62 & 14 & 28 & 7.5 & 48 & 12000 & 8000 \\
\hline BWWo1 & 16 & 30 & 42 & 0.04 & 0.33 & 0.01 & 0.03 & 3.00 & 14.1 & 7.7 & 18 & 5300 & 5800 \\
\hline BWW01 & 20 & 28 & 37 & 0.08 & 0.33 & 0.01 & 0.17 & 1.3 & 5.8 & 2.6 & 9.7 & 2800 & 2500 \\
\hline BWWO1 & 24 & 29 & 413 & 0.05 & 0.37 & 0.01 & 0.73 & 3.89 & 21.4 & 5.6 & 67.2 & 6700 & 2500 \\
\hline BWWo1 & 28 & 31 & 111 & 0.09 & 0.41 & 0.01 & 0.07 & 1.44 & 3.1 & 1.7 & 1.8 & 3100 & 580 \\
\hline BMW01 & 32 & 34 & 5 & 0.05 & 0.25 & 0.01 & 0.02 & 1.00 & 28 & 0.3 & 3.8 & NS & NS \\
\hline BMWot & 36 & 31 & 12 & 0.05 & 0.37 & 0.01 & 0.02 & 1.64 & 3.3 & 26 & 5.6 & 1600 & 560 \\
\hline BWW01 & 4 & 35 & 20 & 0.05 & 0.29 & 0.01 & 0.02 & 1.32 & 17.9 & 4.5 & 2.8 & NS & NS \\
\hline BWwo1 & 52 & 36 & 5 & 0.15 & 0.09 & 0.01 & 0.24 & 1.8 & 3.1 & 2.3 & 3 & NS & NS \\
\hline BWW02 & $\mathbf{P}$ & 63 & 17 & 0.40 & 3.56 & 0.74 & 0.37 & 1.47 & 11.8 & 11.5 & 3 & 1200 & 130 \\
\hline BWW02 & 0 & 67 & 20 & 0.17 & 3.89 & 0.92 & 0.5 & 1.25 & 13.3 & 13.4 & 1.2 & 400 & 240 \\
\hline EMWO2 & 9 & 38 & 88 & 0.35 & 0.89 & 0.2 & 1.18 & 12.8 & 40.8 & 12.3 & 68 & 13000 & 130 \\
\hline BWW02 & 12 & 28 & 43 & 0.71 & 0.89 & 0.28 & 1.05 & 10 & 42 & 13 & 24.7 & 350 & 170 \\
\hline BWW02 & 16 & 29 & 43 & 0.24 & 1.28 & 0.28 & 0.87 & 3.71 & 15.7 & 11.5 & 15 & 8000 & 8200 \\
\hline BWW02 & 20 & 34 & 37 & 0.11 & 1.45 & 0.28 & 0.33 & 238 & 13.9 & 8.7 & 6.4 & 2100 & 1600 \\
\hline BMNO2 & 24 & 35 & 21 & 0.14 & 1.63 & 0.23 & 0.52 & 23 & 13.2 & 9.5 & 6.7 & 2800 & 1300 \\
\hline BYYW02 & 28 & 35 & 15 & 0.00 & 1.75 & 0.23 & 0.33 & 3.13 & 14.1 & 8.8 & 21.1 & 2800 & 340 \\
\hline BWWo2 & 32 & 48 & 28 & 0.00 & 2.14 & 0.33 & 0.3 & 271 & 13.4 & 9.6 & 3.3 & NS & NS \\
\hline EMWO2 & 36 & 47 & 26 & 011 & 201 & 0.33 & 0.17 & 3.32 & 13.4 & 11.4 & 2.7 & 900 & 510 \\
\hline BWw02 & 44 & 48 & 12 & 0.08 & 1.73 & 0.33 & 0.21 & 228 & 122 & 10.6 & 2.7 & NS & NS \\
\hline BWWO2 & 52 & 45 & 25 & 0.35 & 1.44 & 0.26 & 0.4 & 232 & 13.9 & 11.3 & 1.0 & NS & NS \\
\hline BWwo4 & $\mathbf{P}$ & 50 & 17 & 0.16 & 26 & 0.48 & 0.41 & 1.82 & 11.6 & 8.1 & 3 & 210 & 160 \\
\hline BWWO4 & 0 & 52 & 20 & 0.13 & 2.07 & 0.41 & 0.45 & 0.85 & 6.5 & 7.8 & 1.3 & 1000 & 110 \\
\hline BWMO4 & 9 & ND & 5 & 0.24 & 1.75 & 0.22 & 0.45 & 0.85 & 6.5 & 8 & 1.3 & 16000 & 5000 \\
\hline BWWO4 & 12 & 28 & 12 & 0.65 & 0.77 & 0.19 & 1.1 & 18 & 38 & 8.5 & 24 & 20 & 30 \\
\hline BWWo4 & 16 & 30 & 58 & 0.48 & 0.86 & 0.28 & 0.50 & 4.16 & 22 & 9.5 & 20.0 & 3200 & 1700 \\
\hline BMWO4 & 20 & 30 & 48 & 0.24 & 0.94 & 0.25 & 0.51 & 3.24 & 13.8 & 9.7 & 126 & 4100 & 1600 \\
\hline BWWO4 & 24 & 33 & 5 & 0.00 & 1.22 & 0.22 & 0.18 & 0.47 & 5.8 & 5.0 & 0.3 & 2000 & 830 \\
\hline BWWO4 & 28 & 35 & 5 & 0.12 & 1.18 & 0.25 & 0.27 & 1.71 & 11.5 & 7.7 & 4.0 & 700 & 310 \\
\hline BWWOA & 32 & 36 & o1 & 0.21 & 1.3 & 0.25 & 0.38 & 1.70 & 125 & 6.2 & 9.3 & NS & NS \\
\hline BWWo4 & 36 & 39 & 36 & 0.14 & 1.50 & 0.20 & 0.17 & 26 & 11.3 & 8.5 & 4.6 & 1100 & 420 \\
\hline BWMO4 & 44 & 43 & 19 & 0.16 & 1.34 & 0.25 & 0.31 & 1.02 & 9.8 & 7.8 & 3 & NS & NS \\
\hline Burvou & 52 & 37 & 17 & 0.14 & 1.71 & 0.39 & 0.34 & 2.32 & 11.8 & 127 & 31.2 & NS & NS \\
\hline BWwos & $\mathbf{P}$ & 40 & ND & 0.05 & 0.04 & ND & 0.22 & 0.25 & ND & 0.8 & 1.6 & NS & NS \\
\hline BWWos & 0 & 40 & ND & 0.01 & 0.04 & ND & 0.16 & ND & ND & 1.6 & ND & NS & NS \\
\hline Bmwos & $\theta$ & 30 & ND & 0.01 & 0.03 & ND & 0.23 & ND & 1.4 & 1.5 & 1.6 & NS & NS \\
\hline Bunvos & 12 & 38 & ND & 0.01 & 0.03 & ND & 0.1 & 0.32 & 1 & 1.2 & 2 & NS & NS \\
\hline BWWos & 16 & 40 & ND & 0.02 & 0.03 & ND & ND & 0.29 & 0.7 & 0.8 & 1.1 & NS & NS \\
\hline BWMOS & 20 & 38 & ND & 0.01 & 0.03 & ND & ND & 0.45 & ND & 1.1 & 3 & NS & NS \\
\hline BWWOS & 24 & 38 & ND & 0.04 & 0.03 & ND & ND & 0.37 & 0.5 & 1 & 0.7 & NS & NS \\
\hline BWwas & 28 & 41 & ND & ND & 0.00 & ND & ND & 0.21 & ND & ND & ND & NS & NS \\
\hline swwos & 32 & 40 & ND & 0.08 & 0.03 & ND & ND & 0.33 & ND & ND & 1.4 & NS & NS \\
\hline BWwos & 36 & 37 & ND & 0.05 & 0.00 & ND & ND & 0.62 & 0.6 & 0.8 & 21 & NS & NS \\
\hline BMmos & 44 & 43 & ND & 0.00 & 0.00 & ND & 0.08 & 0.22 & 0.7 & ND & 1.5 & NS & NS \\
\hline Bunvos & 52 & 42 & NS & 0.08 & 0.03 & ND & ND & 0.51 & 0.8 & 0.7 & 0.6 & NS & NS \\
\hline BMWOS & $\mathbf{P}$ & 48 & 12 & 0.18 & 23 & 0.54 & 0.38 & 0.36 & 7.2 & 7.7 & 5 & 420 & 56 \\
\hline BWWOS & 0 & 51 & 18 & 0.10 & 254 & 0.54 & 0.38 & 0.45 & 6 & 7.6 & 25 & 140 & 90 \\
\hline BWW0s & 9 & 50 & 15 & 0.00 & 2.02 & 0.5 & 0.48 & 3 & 17 & 9.5 & 11.7 & 710 & 3500 \\
\hline BWWOS & 12 & 38 & 22 & 0.16 & 250 & 0.54 & 0.84 & 6.25 & 28 & 10 & 23 & 4100 & 2900 \\
\hline EWMOS & 16 & 33 & 79 & 0.32 & 1.08 & 0.29 & 0.75 & 8.14 & 35.8 & 12.2 & 37.9 & 6100 & 1600 \\
\hline BWwos & 20 & 32 & 53 & 0.35 & 1.08 & 0.32 & 0.52 & 3.77 & 19 & 9.5 & 14.6 & 3300 & 830 \\
\hline BWwos & 24 & 32 & 32 & 0.35 & 1.67 & 0.32 & 0.85 & 288 & 15.7 & 9.9 & 11.7 & 2800 & 1000 \\
\hline BWWOs & 28 & 31 & 26 & 0.08 & 1.12 & 0.25 & 0.41 & 1.74 & 12.3 & 6.3 & 6.3 & 2100 & 370 \\
\hline BWWOS & 32 & 34 & 22 & 0.09 & 1.23 & 0.24 & 0.38 & 1.76 & 11.8 & 6.4 & 1.5 & NS & NS \\
\hline BWWos & 36 & 39 & 57 & 0.08 & 1.34 & 0.24 & 0.32 & 2.85 & 15.2 & 7.8 & 24.9 & 1900 & 290 \\
\hline BWWOB & 44 & 43 & 23 & 0.10 & 1.4 & 0.24 & 0.39 & 213 & 10.8 & 7.5 & 4.5 & NS & NS \\
\hline Bunos & 52 & 62 & 5 & 0.07 & 1.45 & 0.24 & 0.28 & 203 & 8.7 & 7.7 & 3.6 & NS & NS \\
\hline BWW07 & $\mathbf{P}$ & 50 & 22 & 0.05 & 2.28 & 0.30 & 0.43 & 2.41 & 14.2 & 9.5 & 4.9 & 280 & 75 \\
\hline
\end{tabular}


Table A.3 Water Quality Data for Storm 3 (Continued)

\begin{tabular}{|c|c|c|c|c|c|c|c|c|c|c|c|c|c|}
\hline Station & Run & $\mathrm{Na}$ & $\begin{array}{l}\mathrm{Zn} \\
\log L\end{array}$ & $\begin{array}{l}\text { NHB } \\
\text { mgll }\end{array}$ & $\begin{array}{l}\text { NOS } \\
\text { mol }\end{array}$ & $\begin{array}{l}\text { PO4 } \\
\text { mgl }\end{array}$ & $\begin{array}{l}\text { Cd } \\
\text { ugr }\end{array}$ & $\begin{array}{c}\mathrm{Cr} \\
\text { ugh }\end{array}$ & $\begin{array}{l}\mathrm{Cu} \\
\text { ugl }\end{array}$ & $\underset{\text { wgh }}{\mathrm{Ni}}$ & $\begin{array}{l}P b \\
u g h\end{array}$ & $\begin{array}{l}\text { F.C. } \\
\text { mo/100mL }\end{array}$ & $\begin{array}{c}\text { EC. } \\
\text { marooml }\end{array}$ \\
\hline Buพv7 & 0 & 50 & 24 & 0.05 & 2.28 & 0.43 & 0.47 & 0.64 & 10.5 & 8.5 & 4.7 & 290 & 70 \\
\hline EWW07 & $\theta$ & 50 & 14 & 0.11 & 2.32 & 0.43 & 0.38 & 2.2 & 17.2 & 8.5 & 5.4 & 1100 & 86 \\
\hline EWW07 & 12 & 48 & 10 & 0.12 & 2.44 & 0.43 & 0.35 & 3.64 & 24 & 10.5 & 7.1 & 510 & 310 \\
\hline BWW07 & 18 & 45 & 49 & 0.17 & 2.6 & 0.39 & 0.67 & 8.11 & 30.2 & 120 & 10.2 & 5200 & 420 \\
\hline BWWo7 & 20 & 33 & 57 & 0.28 & 1.18 & 0.25 & 0.44 & 4 & 10 & 9.2 & 23.1 & 3400 & 480 \\
\hline BWWO7 & 24 & 35 & 45 & 0.40 & 1.28 & 0.25 & 0.40 & 3.77 & 18.1 & 0 & 12.1 & 2000 & 200 \\
\hline BWWO7 & 28 & 34 & 37 & 0.30 & 1.22 & 0.29 & 0.42 & 3.72 & 17.8 & $\theta$ & 12 & 1600 & 380 \\
\hline BWWO7 & 32 & 34 & 27 & 0.28 & 1.18 & 0.20 & 0.33 & 3.78 & 18.8 & 10.2 & 11.5 & NS & NS \\
\hline BWW07 & 38 & 31 & 30 & 0.11 & 1.14 &. .25 & 0.45 & 3.58 & 17.0 & 8 & 0.2 & 2300 & 400 \\
\hline BWW07 & 44 & 37 & 23 & 0.07 & 1.3 & 0.22 & 0.4 & 1.02 & 10.2 & 8.4 & 7.4 & NS & NS \\
\hline BWW07 & 52 & 39 & 24 & 0.08 & 0.41 & 0.11 & 0.5 & 3.15 & 12.1 & 8.7 & 8.8 & NS & NS \\
\hline Buพ07 & 72 & 38 & 34 & NA & 1.26 & 0.11 & 0.38 & 3.45 & 14.7 & 20.1 & 7.8 & NS & NS \\
\hline EMWos & $P$ & 51 & 21 & 0.11 & 2.45 & 0.36 & 0.45 & 0.37 & 7 & 7.7 & 5.1 & 130 & 37 \\
\hline BWWos & 0 & 50 & 34 & 0.05 & 2.54 & 0.30 & 0.87 & 3.73 & 17.8 & 10.2 & 8.1 & 100 & 140 \\
\hline BMWos & 0 & 49 & 30 & 0.18 & 235 & 0.38 & 0.47 & 24 & 6.4 & 8.7 & 7.5 & 270 & 87 \\
\hline EMNOS & 12 & 45 & 24 & 0.10 & 2.45 & 0.30 & 0.43 & 8.83 & 7.4 & 8.5 & 10.1 & 310 & 170 \\
\hline BWW0S & 16 & 45 & 148 & 0.10 & 254 & 0.43 & 0.65 & 47.6 & 97 & 22.5 & 68 & 1900 & 250 \\
\hline BWWos & 20 & 41 & 71 & 0.29 & 1.87 & 0.36 & 0.68 & 7.82 & 31 & 11.5 & 22 & 4600 & 730 \\
\hline BWWos & 24 & 38 & 52 & 0.31 & 1.68 & 0.34 & 0.6 & 5.78 & 22.7 & 10.8 & 17.1 & 3400 & 380 \\
\hline BWWos & 28 & 38 & 45 & 0.31 & 1.40 & 0.32 & 0.48 & 4.75 & 20.4 & 10.2 & 14.1 & 2900 & 1200 \\
\hline BWwos & 32 & 35 & 40 & 0.16 & 1.4 & 0.32 & 0.48 & 4.78 & 19.7 & 10.1 & 14.8 & NS & NS \\
\hline Bunos & 38 & 33 & 47 & 0.19 & 1.25 & 0.20 & 0.52 & 4.58 & 17.8 & 0.9 & 12.8 & 2000 & 620 \\
\hline BWW08 & 44 & 34 & 26 & 0.11 & 1.05 & 0.2 & 0.49 & 1.88 & 11.3 & 6.8 & 6.8 & NS & NS \\
\hline BWWos & & 39 & 20 & 0.02 & 0.83 & 0.11 & 0.49 & 3.15 & 12.2 & $\theta$ & 220 & NS & NS \\
\hline BWW08 & 72 & 38 & 26 & NA & 0.25 & 0.11 & 0.26 & 2.84 & 14.2 & 15.1 & 8.9 & NS & NS \\
\hline Bunos & $P$ & 13 & ND & ND & 0.13 & 0.28 & 0.21 & 0.18 & ND & 0.7 & 0.8 & 34 & 53 \\
\hline BuWos & 0 & 14 & ND & 0.03 & 0.13 & 0.23 & 0.05 & 0.37 & ND & ND & 1.1 & 41 & 58 \\
\hline Bunos & 8 & 13 & ND & ND & 0.13 & 0.33 & 0.05 & ND & ND & 0.8 & 2.1 & 82 & 54 \\
\hline BWWOS & 12 & 12 & ND & ND & 0.13 & 0.28 & ND & 0.28 & ND & ND & 1.3 & 200 & 160 \\
\hline BWWos & 16 & 13 & ND & ND & 0.13 & 0.28 & 0.2 & 215 & 0.5 & 0.7 & 1.4 & 430 & 120 \\
\hline BWWos & 20 & 12 & ND & ND & 0.13 & 0.26 & ND & 0.53 & ND & 0.8 & 0.7 & 200 & 170 \\
\hline BWMos & 24 & 13 & ND & ND & 0.08 & 0.24 & ND & 0.46 & 1.6 & ND & 1.6 & 270 & 60 \\
\hline BWWOS & 28 & 12 & ND & ND & 0.08 & 0.24 & 0.08 & 0.78 & 1 & 0.6 & 1.6 & 140 & 49 \\
\hline BWYOS & 32 & 13 & ND & ND & 0.08 & 0.24 & 0.05 & 0.83 & ND & 1.3 & 0.8 & NS & NS \\
\hline EWWos & 36 & 12 & ND & ND & 0.08 & 0.24 & ND & 0.65 & 1.7 & ND & 1.9 & 82 & 61 \\
\hline BWwos & 44 & 14 & ND & ND & 0.08 & 0.24 & 0.08 & 0.49 & 1.7 & ND & 2.2 & NS & NS \\
\hline BWWOS & 52 & 13 & ND & ND & 0.08 & 0.24 & 0.05 & 0.05 & 1.2 & ND & 0.0 & NS & NS \\
\hline BWW09 & 72 & 12 & ND & ND & NA & NA & ND & 0.62 & 1.0 & 27 & 1.4 & NS & NS \\
\hline BWW10 & $\mathbf{P}$ & 38 & ND & 0.01 & ND & ND & 0.19 & ND & 0.7 & 1.4 & 2.6 & NS & NS \\
\hline BWW10 & 0 & 30 & ND & 0.02 & ND & ND & 0.08 & ND & ND & 1.2 & 0.9 & NS & NS \\
\hline BWW10 & 8 & 38 & ND & 0.05 & ND & ND & 0.06 & ND & ND & ND & 2.8 & NS & NS \\
\hline BWW10 & 12 & 35 & ND & 0.04 & ND & ND & ND & 0.26 & 1.4 & ND & 2.2 & NS & NS \\
\hline BWW10 & 16 & 38 & ND & 0.02 & NE & : 10 & 0.1 & 1.1 & 1.5 & ND & 2.8 & NS & NS \\
\hline BWW10 & 20 & 34 & 12 & 0.02 & ND & ND & ND & 0.2 & 0.8 & ND & 0.5 & NS & NS \\
\hline BWW10 & 24 & 35 & ND & 0.04 & ND & ND & 0.06 & ND & 1 & ND & 28 & NS & NS \\
\hline BWW10 & 28 & 35 & ND & 0.00 & ND & ND & ND & ND & ND & ND & 0.7 & NS & NS \\
\hline BWW10 & 32 & 36 & ND & 0.02 & ND & ND & ND & 0.32 & ND & 0.8 & 1.2 & NS & NS \\
\hline BWW10 & 36 & 34 & ND & 0.08 & ND & ND & ND & 0.64 & ND & ND & 3 & NS & NS \\
\hline BWW10 & 44 & 30 & ND & 0.02 & ND & ND & ND & ND & 0.5 & ND & 0.9 & NS & NS \\
\hline BWW10 & 52 & 35 & ND & 0.01 & ND & ND & ND & 0.34 & 0.9 & 0.8 & 2.3 & NS & NS \\
\hline BWW10 & 72 & 38 & ND & NA & ND & ND & ND & 0.34 & 1.7 & 1.7 & 3.2 & NS & NS \\
\hline BWw11 & $\mathbf{P}$ & 50 & 15 & 0.01 & 2.11 & 0.33 & 0.51 & 0.44 & 6.8 & 8.5 & 5.8 & 110 & 38 \\
\hline BWW11 & 0 & 51 & 20 & 0.01 & 240 & 0.3 & 0.51 & 1.47 & 6.4 & 8.0 & 4.2 & 99 & 47 \\
\hline BMW11 & 9 & 13 & 25 & 0.04 & 2.24 & 0.3 & 0.41 & 3.6 & 14 & 10 & 10.9 & 230 & 75 \\
\hline BWW11 & 12 & 41 & 27 & 0.01 & 0.34 & 0.3 & 0.37 & 3.44 & 9.6 & 6.3 & 25.2 & 330 & 300 \\
\hline BWW11 & 16 & 43 & 24 & 0.03 & 0.34 & 0.23 & 0.39 & 4.04 & 13.5 & 7.3 & 6.8 & 200 & 170 \\
\hline BWW11 & 20 & 46 & 74 & 0.08 & 0.34 & 0.23 & 1.04 & 18.43 & 41.2 & 13.1 & 25.8 & 400 & 310 \\
\hline BWW11 & 24 & 43 & 45 & 0.10 & 0.34 & 0.23 & 0.74 & 8.64 & 29.2 & 11.7 & 15.2 & 1200 & 340 \\
\hline BWW11 & 28 & 30 & 42 & 0.18 & 0.34 & 0.23 & 0.53 & 6.65 & 21.8 & 10.6 & 12.7 & 1900 & 270 \\
\hline BWW11 & 32 & 36 & 4 & 0.23 & 0.34 & 0.28 & 0.43 & 5.9 & 25.1 & 8.7 & 15.2 & NS & NS \\
\hline BWW11 & 36 & 35 & 57 & 0.12 & 0.34 & 0.28 & 0.23 & 5.45 & 21.6 & 9.8 & 57.4 & 1100 & 350 \\
\hline BWW11 & 44 & 34 & 37 & 0.21 & 0.43 & 0.28 & 0.56 & 2.75 & 12.2 & 7.4 & 8.8 & NS & NS \\
\hline BWW11 & 52 & 35 & 27 & 0.11 & 0.08 & 0.20 & 1.00 & 3.56 & 12.1 & 8 & 15.8 & NS & NS \\
\hline BWW11 & 72 & 36 & 72 & NA & 0.08 & 0.22 & 0.4 & 4.42 & 13.7 & 8.5 & 7.0 & NS & NS \\
\hline BWw13 & $\mathbf{P}$ & 46 & 12 & 0.08 & 2.25 & 0.36 & 0.32 & 0.3 & 6.1 & 7.4 & 5.1 & 67 & 41 \\
\hline BWW13 & 0 & 49 & 14 & 0.05 & 2.20 & 0.36 & 0.82 & 1.17 & 9.5 & 9.8 & 1.3 & 130 & 32 \\
\hline BWW13 & 0 & 43 & 5 & 0.04 & 1.85 & 0.3 & 0.4 & 1.4 & 3.3 & 7.1 & 4 & 360 & 300 \\
\hline BWW13 & 12 & 42 & 11 & 0.07 & 1.85 & 0.3 & 0.28 & 1.82 & 7.4 & 7.2 & 4 & 380 & 120 \\
\hline BWW13 & 16 & 42 & 18 & 0.04 & 1.77 & 0.24 & 0.3 & 263 & 0.2 & 8.3 & 4.8 & 90 & 75 \\
\hline BWN13 & 20 & 40 & 15 & 0.01 & 1.81 & 0.27 & 0.21 & 2.4 & 9.5 & 7.7 & 4 & 290 & 83 \\
\hline BMW13 & 24 & 43 & 20 & 0.05 & 1.85 & 0.3 & 0.55 & 3.76 & 13.4 & 6.9 & 11.8 & 130 & 71 \\
\hline BMN13 & 28 & 40 & 23 & 0.04 & 1.77 & 0.3 & 0.27 & 3.90 & 14.7 & 8.8 & 6.2 & 130 & 80 \\
\hline BMN13 & 32 & 40 & 5 & 0.03 & 1.77 & 0.3 & 0.14 & 3.5 & 13 & 8.7 & 0.3 & NS & NS \\
\hline
\end{tabular}


Table A.3 Water Quality Data for Storm 3 (Continued)

\begin{tabular}{|c|c|c|c|c|c|c|c|c|c|c|c|c|c|}
\hline Station & Run & $\begin{array}{c}\mathrm{Na} \\
\mathrm{mal}\end{array}$ & $\begin{array}{l}2 n \\
u g l\end{array}$ & $\begin{array}{l}\text { NH3 } \\
\text { mon }\end{array}$ & $\begin{array}{l}\mathrm{NO3} \\
\mathrm{moh}\end{array}$ & $\begin{array}{l}\mathrm{POA} \\
\mathrm{mgh}\end{array}$ & $\begin{array}{l}\text { Cd } \\
\text { ugl }\end{array}$ & $\begin{array}{c}\mathrm{Cr} \\
\mathrm{ugl}\end{array}$ & $\begin{array}{l}\mathrm{Cu} \\
\mathrm{ugl}\end{array}$ & $\begin{array}{c}\mathrm{Ni} \\
\mathrm{ugl}\end{array}$ & $\begin{array}{l}\mathrm{Pb} \\
\mathrm{ugl}\end{array}$ & $\begin{array}{c}\text { F.C. } \\
\mathrm{md} / 100 \mathrm{~mL}\end{array}$ & $\begin{array}{c}\text { EC. } \\
\text { mdr100mL }\end{array}$ \\
\hline BMW13 & 36 & 39 & 26 & 0.08 & 1.85 & 0.3 & 0.13 & 2.87 & 12.2 & 7.8 & 6.6 & 230 & 190 \\
\hline EWW13 & 44 & 38 & 37 & 0.18 & 1.05 & 0.3 & 0.58 & 3.85 & 14.1 & 7.8 & 10.7 & NS & NS \\
\hline BWW13 & 52 & 35 & 18 & 0.10 & 1.85 & 0.3 & 0.86 & 3.73 & 126 & 7.6 & 13.3 & NS & NS \\
\hline EWW13 & 72 & 37 & 5 & NA & 1.13 & 0.3 & 0.02 & 0.74 & 4.1 & 9.1 & 4 & NS & NS \\
\hline EMN14 & $\mathbf{P}$ & 17 & ND & 0.01 & 0.08 & ND & 0.21 & ND & ND & 0.8 & 1.1 & 1800 & 210 \\
\hline EMN14 & 0 & 16 & ND & 0.05 & 0.08 & ND & 0.06 & ND & ND & 0.8 & 0.9 & 1300 & 1000 \\
\hline EMN14 & 9 & 14 & ND & 0.08 & 0.08 & ND & 0.10 & 0.6 & ND & 0.6 & 2.6 & 1100 & 740 \\
\hline BMW14 & 12 & 17 & ND & 0.07 & 0.08 & ND & ND & 0.3 & 1 & 0.9 & 0.2 & 460 & 280 \\
\hline BWW14 & 16 & 16 & ND & 0.05 & 0.35 & ND & 0.00 & 1.20 & 1.3 & 0.1 & 28 & 5800 & 1300 \\
\hline BWM14 & 20 & 14 & ND & 0.07 & 0.35 & ND & ND & 0.71 & 1 & ND & 2.3 & 1200 & 240 \\
\hline BWW14 & 24 & 14 & ND & 0.02 & 0.35 & ND & ND & 0.65 & 1 & ND & 1.2 & 460 & 79 \\
\hline BWW14 & 26 & 13 & ND & 0.03 & 0.35 & ND & ND & 0.85 & 1.3 & 0.8 & 1.1 & 370 & 100 \\
\hline BWW14 & 32 & 14 & ND & 0.07 & 0.35 & ND & ND & 0.91 & 0.7 & 1 & 1.7 & NS & NS \\
\hline BWW14 & 38 & 16 & ND & 0.10 & 0.35 & ND & ND & 0.68 & 1.1 & ND & 1.4 & 230 & 120 \\
\hline EMW14 & 4 & 16 & ND & 0.08 & 0.35 & ND & ND & 0.58 & 1.4 & ND & 1.1 & NS & NS \\
\hline BWW14 & $\mathbf{5 2}$ & 16 & ND & 0.08 & 0.48 & ND & ND & 0.87 & 1.5 & ND & 1.1 & NS & NS \\
\hline BWW15 & $P$ & 20 & ND & 0.67 & 1.3 & ND & 0.18 & ND & 1.8 & 0.5 & 0.8 & NS & NS \\
\hline BWW15 & 0 & 22 & 16 & 0.85 & 1.32 & ND & ND & ND & ND & 1.2 & 1 & NS & NS \\
\hline BWW15 & 9 & 18 & ND & 1.09 & 1.14 & ND & 0.05 & ND & ND & 0.5 & 27 & NS & NS \\
\hline BWW15 & 12 & 18 & ND & 0.63 & 1.32 & ND & 0.05 & 0.37 & 1.5 & 0.6 & 2 & NS & NS \\
\hline EWW15 & 16 & 19 & ND & 0.88 & 1.3 & ND & 0.05 & 1.64 & 0.5 & 0.5 & 4.1 & NS & NS \\
\hline BWW15 & 20 & 18 & ND & 1.12 & 1.35 & ND & 0.05 & 0.37 & 26 & ND & 5.1 & NS & NS \\
\hline BWW15 & 24 & - 20 & ND & NA & 1.38 & ND & 0.07 & ND & 0.7 & ND & 1.3 & NS & NS \\
\hline BWW15 & 28 & 18 & ND & 1.03 & 1.65 & ND & ND & 0.68 & ND & 0.6 & 0.8 & NS & NS \\
\hline BWW15 & 32 & 19 & ND & 0.82 & 1.89 & ND & ND & 0.3 & 0.5 & 1.5 & 22 & NS & NS \\
\hline BWW15 & 36 & 20 & ND & 0.98 & 1.52 & ND & ND & 0.27 & ND & ND & 1.4 & NS & NS \\
\hline BWW15 & 44 & 20 & ND & 0.98 & 1.38 & ND & ND & 0.35 & 1 & 1.2 & 0.8 & NS & NS \\
\hline BWW15 & 52 & 19 & ND & 0.97 & 1.56 & ND & ND & 0.33 & 0.9 & ND & 3.8 & NS & NS \\
\hline BWW15 & 72 & 19 & ND & NA & 1.81 & ND & ND & 0.47 & 1.3 & 3.5 & 1.6 & NS & NS \\
\hline BWW16 & $\mathbf{P}$ & 24 & ND & 0.03 & 0.59 & ND & 0.23 & ND & 22 & 0.5 & 1.3 & 63 & 800 \\
\hline BWW16 & 0 & 26 & ND & 0.02 & 0.59 & ND & ND & ND & 0.5 & 1.4 & 3.8 & 84 & 570 \\
\hline BWW16 & $\theta$ & 22 & 15 & ND & 0.51 & ND & 0.11 & ND & 3.2 & 1.5 & 7.5 & 1000 & 3800 \\
\hline BWW16 & 12 & 22 & 18 & 0.03 & 0.51 & ND & 0.08 & 0.32 & 2.4 & 1.7 & 3.3 & 1200 & 7300 \\
\hline BWW16 & 16 & 24 & ND & 0.01 & 0.51 & ND & 0.26 & 0.65 & 1.5 & 0.1 & 7.3 & 460 & 1000 \\
\hline BWW16 & 20 & 21 & 13 & 0.05 & 0.59 & ND & 0.12 & 0.33 & 1.8 & 0.8 & 4.4 & 94000 & 600 \\
\hline BWW16 & 24 & 22 & ND & 0.04 & 0.48 & ND & 0.08 & 0.2 & 2.6 & 1 & 4.6 & 71000 & 1000 \\
\hline BWW16 & 28 & 20 & 18 & 0.05 & 0.50 & ND & 0.08 & 0.24 & 3.8 & 1.4 & 5.8 & 80000 & 1100 \\
\hline BWW16 & 32 & 17 & ND & 0.01 & 0.51 & ND & 0.05 & 0.51 & 2 & 2.2 & 27 & NS & NS \\
\hline BWW16 & 36 & 17 & 21 & 0.08 & 0.42 & ND & ND & 1.17 & 3 & 1.1 & 6.6 & 13000 & 3800 \\
\hline BWW18 & 44 & 20 & ND & 0.05 & 0.42 & ND & ND & 0.47 & 1.7 & 1.1 & 2 & NS & NS \\
\hline BWW16 & 52 & 21 & ND & 0.05 & 0.42 & ND & ND & 0.81 & 1.9 & 0.9 & 4.8 & NS & NS \\
\hline BWW16 & 72 & 18 & ND & NA & 0.36 & ND & ND & ND & 1.3 & 3.1 & 2.6 & NS & NS \\
\hline BWW17 & P & 44 & 14 & 0.02 & 2.00 & 0.08 & 0.38 & 2 & 9.9 & 6.9 & 3.7 & 1800 & 84 \\
\hline EMW17 & 0 & 43 & 11 & 0.03 & 2.09 & 0.08 & 0.22 & 0.1 & 4.7 & 7.4 & 4.4 & 550 & 48 \\
\hline BWW17 & 9 & 27 & 57 & 0.03 & 1.41 & 0.04 & 0.20 & 3.3 & 14 & 5.6 & 4.8 & 12000 & 8100 \\
\hline BWW17 & 12 & 43 & 22 & 0.03 & 217 & 0.08 & 0.26 & 2.69 & 10.5 & 8 & 17.5 & 1600 & 840 \\
\hline BWN17 & 16 & 45 & 10 & 0.03 & 225 & 0.08 & 0.3 & 2.88 & 10.1 & 6.4 & 5.2 & 880 & 540 \\
\hline BWW17 & 20 & 42 & 18 & 0.08 & 2.13 & 0.08 & 0.32 & 1.85 & 9.2 & 7 & 4.5 & 760 & 380 \\
\hline BWW17 & 24 & 43 & 10 & 0.08 & 1.83 & 0.08 & 0.24 & 1.72 & 9.6 & 8 & 4.3 & 430 & 150 \\
\hline EWW17 & 28 & 43 & 21 & 0.01 & 1.85 & 0.08 & 0.22 & 241 & 10.6 & 6.6 & 5.2 & 490 & 220 \\
\hline BWW17 & 32 & 40 & 5 & 0.00 & 1.85 & 0.08 & 0.18 & 2.32 & 9.5 & 8.2 & 5.0 & NS & NS \\
\hline BWW17 & 38 & 40 & 24 & 0.02 & 1.77 & 0.09 & 0.09 & 2.41 & 10.2 & 7.5 & 5.5 & 150 & 374 \\
\hline BWW17 & 44 & 41 & 20 & 0.01 & 1.7 & 0.00 & 0.36 & 2.4 & 10.5 & 7.1 & 5.6 & NS & NS \\
\hline BWW17 & $\mathbf{5 2}$ & 40 & 12 & 0.01 & 1.85 & 0.04 & 0.32 & 3.08 & 13.4 & 8.4 & 9.6 & NS & NS \\
\hline BWW17 & 72 & 38 & 12 & 0.01 & 1.48 & 0.08 & 0.21 & 235 & 11.6 & 8.1 & 7.8 & NS & NS \\
\hline BWW18 & $\mathbf{P}$ & 49 & 14 & 0.01 & 2.58 & 0.46 & 0.5 & 1.4 & 122 & 6.8 & 3.7 & 220 & 28 \\
\hline EWW18 & 0 & 50 & 23 & 0.03 & 2.62 & 0.46 & 0.31 & 1.2 & 6.3 & 5.2 & 4.4 & 380 & 30 \\
\hline BWW18 & 9 & 43 & 15 & 0.02 & 2.46 & 0.38 & 0.20 & 1 & 4.4 & 5.9 & 4.5 & 4800 & 160 \\
\hline BWW18 & 12 & 48 & 20 & 0.04 & 270 & 0.41 & 0.3 & 1.75 & 13.6 & 6.9 & 4.5 & 1600 & 130 \\
\hline BWW18 & 18 & 48 & 28 & 0.02 & 201 & 0.52 & 0.34 & 217 & 11 & 6.7 & 6.8 & 1500 & $\pi$ \\
\hline BWW18 & 20 & 49 & 21 & 0.50 & 2.87 & 0.46 & 0.31 & 2.18 & 11.8 & 6.4 & 6 & 1400 & 250 \\
\hline BWW18 & 24 & 43 & 27 & 0.49 & 250 & 0.41 & 0.3 & 214 & 13.7 & 7.6 & 7.6 & 10000 & 950 \\
\hline BWW18 & 28 & 53 & 22 & 0.18 & 2.58 & 0.46 & 0.23 & 247 & 12.4 & 8.1 & 6.5 & 1400 & 390 \\
\hline BWW18 & 32 & 49 & 5 & 0.17 & 2.25 & 0.35 & 0.24 & 208 & 10.7 & 7.7 & 5.6 & NS & NS \\
\hline BWW18 & 38 & 46 & 22 & 0.24 & 2 & 0.3 & 0.00 & 203 & 10 & 7.7 & 4.9 & 260 & 70 \\
\hline BWW18 & 44 & 49 & 15 & 0.28 & 2 & 0.27 & 0.22 & 0.46 & 8.5 & 7.1 & 5.7 & NS & NS \\
\hline BWW18 & 52 & 49 & 5 & 0.27 & 2 & 0.25 & 0.08 & 2.09 & 11.2 & 7.5 & 6.5 & NS & NS \\
\hline BWW20 & $\mathbf{P}$ & 53 & 5 & 0.17 & 201 & 0.44 & 0.3 & 0.91 & 9.8 & 5.2 & 4.1 & 120 & 52 \\
\hline BWw20 & 0 & $\mathbf{5 2}$ & 10 & 0.19 & 1.80 & 0.4 & 0.2 & 0.1 & 4.5 & 4.8 & 3.3 & 120 & 21 \\
\hline EWW20 & 9 & 48 & 18 & 0.27 & 2.08 & 0.4 & 0.27 & 23 & 10 & 5.8 & 8 & 480 & 340 \\
\hline EWW & 12 & 40 & 11 & 0.31 & 201 & 0.37 & 0.22 & 1.67 & 10.7 & 5.3 & 4 & 770 & 700 \\
\hline EWN20 & 16 & 4 & 16 & 0.27 & 1.98 & 0.33 & 0.2 & 1.38 & 11.7 & 6 & 4.4 & 100 & 120 \\
\hline
\end{tabular}


Table A.3 Water Quality Data for Storm 3 (Continued)

\begin{tabular}{|c|c|c|c|c|c|c|c|c|c|c|c|c|c|}
\hline Station & Run & $\begin{array}{c}\mathrm{Na} \\
\mathrm{mgh}\end{array}$ & $\begin{array}{l}\mathrm{Zn} \\
\mathrm{ug} /\end{array}$ & $\begin{array}{l}\mathrm{NH3} \\
\text { mal }\end{array}$ & $\begin{array}{l}\text { NO3 } \\
\text { mgl }\end{array}$ & $\begin{array}{l}\mathrm{PO4} \\
\mathrm{mgh}\end{array}$ & $\operatorname{cd}_{\log }$ & $\begin{array}{c}\text { cr } \\
\text { ugh }\end{array}$ & $\begin{array}{c}\mathrm{Cu} \\
\text { ugh }\end{array}$ & $\begin{array}{c}\mathrm{Ni} \\
\text { ugh }\end{array}$ & $\begin{array}{c}\mathrm{Pb} \\
\text { ugn }\end{array}$ & $\begin{array}{c}\text { F.C. } \\
\mathrm{md} / 100 \mathrm{~mL}\end{array}$ & $\begin{array}{l}\text { E.C. } \\
\mathrm{md} / 100 \mathrm{~mL}\end{array}$ \\
\hline BWW20 & 20 & 4 & 22 & 0.57 & 2.22 & 0.4 & 0.21 & 1.55 & 10.5 & 5.7 & 5.5 & 440 & 120 \\
\hline BWW20 & 24 & 45 & 5 & 0.21 & 2.33 & 0.44 & 0.2 & 1.41 & 10.6 & 6.3 & 4.1 & 630 & 80 \\
\hline BWW20 & 28 & 44 & 23 & 0.25 & 2.47 & 0.41 & 0.31 & 2.05 & 15.4 & 8 & 9.4 & 800 & 400 \\
\hline BWW20 & 32 & 48 & 16 & 0.08 & 2.85 & 0.78 & 0.25 & 1.8 & 13.1 & 7.6 & 7.5 & NS & NS \\
\hline BWW2O & 38 & 49 & 28 & 0.19 & 2.82 & 0.89 & 0.1 & 2.41 & 13 & 6.7 & 6.7 & 1900 & 540 \\
\hline BWW20 & 44 & 49 & 23 & 0.35 & 2.41 & 0.89 & 0.18 & 1.83 & 10.9 & 6.6 & 6.2 & NS & NS \\
\hline BWW20 & 52 & 49 & 11 & 0.32 & 1.87 & 0.84 & 0.07 & 2.33 & 14.0 & 7.9 & 9.6 & NS & NS \\
\hline BWW21 & $\mathbf{P}$ & 54 & 5 & 0.01 & 1.88 & 0.39 & 0.34 & 0.92 & 8.4 & 5 & 3.6 & 19 & 15 \\
\hline BWW21 & 0 & 52 & 12 & 0.38 & 2.07 & 0.41 & 0.20 & 1.2 & 9 & 4.6 & 5.8 & 13 & 31 \\
\hline BWW21 & 9 & 49 & 20 & 0.20 & 2.03 & 0.41 & 0.23 & 1.40 & 9.4 & 4.1 & 6.6 & 2500 & 6100 \\
\hline BWW21 & 12 & 47 & 24 & 0.05 & 2.07 & 0.37 & 0.21 & 1.54 & 9.6 & 5.5 & 5.4 & 6900 & 1800 \\
\hline BWW21 & 16 & 47 & 16 & 0.10 & 2.17 & 0.42 & 0.18 & 1.38 & 7.3 & 4.5 & 3.8 & 1100 & 390 \\
\hline BWW21 & 20 & 43 & 15 & 0.07 & $2 \approx$ & $: 42$ & 0.19 & 1.55 & 9.6 & 4.3 & 6.9 & 1200 & 200 \\
\hline BWW21 & 24 & 48 & 5 & 0.05 & 2.13 & 0.38 & 0.18 & 1.41 & 7.8 & 5.1 & 4.9 & 650 & 71 \\
\hline BWW21 & 28 & 43 & 5 & 0.05 & 2.25 & 0.38 & 0.17 & 2.05 & 9.9 & 6 & 4.5 & 610 & 80 \\
\hline BWW21 & 32 & 40 & 5 & 0.13 & 2.61 & 0.42 & 0.16 & 1.9 & 10.1 & 5 & 5.6 & NS & NS \\
\hline BWWZ1 & 38 & 42 & 29 & 0.11 & 2.65 & 0.42 & 0.31 & 2.41 & 11.3 & 6.1 & 6.8 & 650 & 380 \\
\hline BWW21 & 44 & 48 & 22 & 0.12 & 2.61 & 0.46 & 0.28 & 1.83 & 9.8 & 6 & 5.8 & NS & NS \\
\hline BWW21 & 52 & 48 & 20 & 0.04 & 1.57 & 0.38 & 0.41 & 2.33 & 12.5 & 8.6 & 6.9 & NS & NS \\
\hline BWW22 & 0 & 16 & 100 & 1.50 & 0.21 & 0.34 & 0.62 & 0.77 & 10.6 & 9.9 & 28 & 13000 & 7800 \\
\hline BWW22 & 3 & 15 & 127 & 0.67 & 0.17 & 0.34 & 0.88 & 7.89 & 67.1 & 11 & 57.6 & 80 & 46 \\
\hline BWW22 & 8 & 12 & $\pi$ & 0.22 & 0.17 & 0.29 & 0.25 & 0.83 & 38.4 & 3.5 & 2 & 40 & 110 \\
\hline BWW22 & 9 & 18 & 60 & 0.36 & 0.17 & 0.23 & 0.2 & 0.35 & 13.8 & 29 & 28 & 52000 & 18000 \\
\hline BWN22 & 12 & 14 & 68 & 0.07 & 0.17 & 0.20 & 0.1 & ND & 9.7 & ND & ND & ND & ND \\
\hline BWW22 & 18 & 12 & 52 & 0.64 & 0.17 & 0.23 & 0.12 & ND & ND & ND & ND & ND & ND \\
\hline BWW23 & $P$ & 65 & 10 & 1.74 & 7.32 & 1.85 & 0.23 & 3.88 & 30 & 24.9 & 0.8 & 30 & 4 \\
\hline BWW23 & 0 & 69 & 18 & 0.07 & 4.16 & 1.6 & 0.18 & 1.3 & 22.4 & 19.5 & 1.5 & 55 & 1 \\
\hline BWW23 & 9 & 23 & 28 & 1.84 & 4.5 & 1.83 & 0.91 & 6.07 & 32.2 & 28.1 & 2.2 & 80 & 33 \\
\hline BWW23 & 12 & 28 & 28 & 0.80 & 4.73 & 1.08 & 1.2 & 4.5 & 28 & 25 & 2 & 35 & 250 \\
\hline BWW23 & 16 & 55 & 35 & 208 & 4.5 & 1.34 & 0.7 & 4.30 & 24.4 & 23.6 & 3.4 & 21 & 16 \\
\hline BWW23 & 20 & 43 & 21 & 0.15 & 6.65 & 0.00 & 0.61 & 3.30 & 24 & 21.8 & 1.1 & 120 & 13 \\
\hline BWw23 & 24 & 42 & 15 & 0.63 & NA & NA & 0.42 & 2.74 & 25.3 & 21 & 1.3 & 37 & ND \\
\hline BWW23 & 28 & 53 & 23 & 0.85 & 9.02 & 0.90 & 0.41 & 3.6 & 20.1 & 20.3 & 1.3 & 28 & 4 \\
\hline BWW23 & 32 & 63 & 15 & 0.17 & 5.07 & 1.1 & 0.4 & 6.17 & 30.4 & 24.8 & 1.05 & NS & NS \\
\hline EWW23 & 38 & 69 & 38 & 0.16 & 4.62 & 1.16 & 0.67 & 6.77 & 33.4 & 31 & 3.4 & 180 & 2 \\
\hline EWW23 & 44 & 70 & 20 & 0.08 & 4.62 & 1.1 & 0.58 & 4.00 & 25.7 & 24.9 & 3 & NS & NS \\
\hline Bunz2s & 52 & 73 & 15 & 0.80 & 4.62 & 1.04 & 0.68 & 4.15 & 71.1 & 26.1 & 1.8 & NS & NS \\
\hline Bun24 & $\mathbf{P}$ & 217 & 324 & NA & 9.27 & 6.88 & 1.84 & 5.28 & 87.1 & 10.6 & 31,4 & ND & 18 \\
\hline BWW24 & 0 & 158 & 191 & 0.50 & 8.88 & 6.14 & 273 & 4.31 & 72.5 & 7.3 & 30 & ND & ND \\
\hline BWW24 & 9 & 236 & 134 & 0.53 & 14.65 & 5.11 & 1.76 & 5.37 & 72.2 & 6.9 & 27 & 4 & 2 \\
\hline BWW24 & 12 & 220 & 108 & 0.53 & 14.65 & 5.11 & 1.64 & 7.2 & 84 & 7.1 & 24.5 & 6 & ND \\
\hline BWW24 & 16 & 282 & 124 & 0.37 & 13.74 & 5.01 & 1.68 & 6.58 & 75.8 & 7.3 & 21.4 & 36 & 52 \\
\hline BWn24 & 20 & 200 & 134 & 0.26 & 13.74 & 5.01 & 1.68 & 7.28 & 84.7 & 5.8 & 28.7 & 30 & 46 \\
\hline BWW24 & 24 & 300 & 112 & 0.43 & 13.52 & 5.22 & 1.42 & 7.49 & 84.3 & 6.7 & 2.8 & 8 & 50 \\
\hline Bun'24 & 28 & 272 & 108 & 0.42 & 13.52 & 4.81 & 1.4 & 7.88 & 82.5 & 8 & 20.6 & 31 & 40 \\
\hline BWW24 & 32 & 300 & $\pi$ & 0.24 & 13.52 & 4.39 & 1.08 & 7.64 & 72.4 & 6.8 & 22.8 & NS & NS \\
\hline BWW24 & 36 & 303 & 105 & 0.38 & 13.52 & 4.81 & 1.62 & 7.60 & 74.3 & 6 & 21.2 & ND & ND \\
\hline BWW24 & 44 & 297 & 100 & 0.20 & 13.5 & 4.81 & 1.78 & 8.38 & 71.1 & 6.4 & 20.5 & NS & NS \\
\hline BWW 25 & $\mathbf{P}$ & $\pi$ & 16 & 23.20 & 0.88 & 1.83 & 0.21 & 1.21 & 9.9 & 27.1 & 27 & 1 & 1 \\
\hline BWW25 & 0 & $\pi$ & 25 & 20.60 & 0.78 & 1.85 & 0.08 & 1.17 & 4.5 & 19.8 & 3.2 & $\infty 0$ & 9 \\
\hline BWw25 & 9 & 88 & 50 & 25.10 & ND & 5.84 & 0.35 & 3.04 & 128 & 31.6 & 9.2 & 900 & 83 \\
\hline BWw25 & 12 & 84 & 21 & 12.50 & ND & 5.64 & 0.08 & 4.38 & 16 & 30 & 4 & 180 & 51 \\
\hline BWW2S & 18 & 65 & 24 & 8.94 & ND & 3.25 & ND & 3.24 & 9.0 & 24.7 & 3.5 & 82 & 3 \\
\hline BMN25 & 20 & 73 & 25 & 10.50 & 0.14 & 1.22 & 0.05 & 261 & 8.2 & 23.5 & 3.4 & 110 & 8 \\
\hline BMW25 & 24 & 75 & 18 & 1220 & 0.14 & 0.67 & 0.08 & 247 & 13.2 & 24.4 & 3.2 & 32 & 1 \\
\hline BWWZs & 28 & 88 & 23 & 1250 & NO & 0.85 & ND & 270 & 15.3 & 24.4 & 27 & 110 & 17 \\
\hline BWW25 & 32 & 99 & 12 & 12.20 & ND & 0.91 & No & 3.16 & 125 & 33.7 & 3.2 & NS & NS \\
\hline BMm2s & 38 & 102 & 37 & 16.80 & ND & 0.97 & 0.08 & 3.68 & 126 & 34.4 & 29 & 40 & 3 \\
\hline BWMZ25 & 44 & 103 & 46 & NA & 0.34 & 0.91 & 0.05 & 3.42 & 124 & 30.5 & 2.5 & NS & NS \\
\hline BMW25 & 52 & 117 & 37 & 18.00 & 0.34 & 0.97 & 0.22 & 8.14 & 14 & 30.9 & 7.3 & NS & NS \\
\hline
\end{tabular}


Contains the following plots:

Figure B.1 Hardness, Chloride and Sodium plots for BWW00, Storm 1 . . . . 242

Figure B.2 Hardness, Chloride and Sodium plots for BWW08, Storm 1 . . . . 243

Figure B.3 Hardness, Chloride and Sodium plots for BWW21, Storm 1 . . . . . 244

Figure B.4 Hardness, Chloride and Sodium plots for BWW00, Storm $2 \ldots \ldots \ldots 245$

Figure B.5 Hardness, Chloride and Sodium plots for BWW08, Storm $2 \ldots \ldots \ldots 246$

Figure B.6 Hardness, Chloride and Sodium plots for BWW21, Storm $2 \ldots \ldots$. . . 247

Figure B.7 Hardness, Chloride and Sodium plots for BWW00, Storm 3 . . . . . 248

Figure B.8 Hardness, Chloride and Sodium plots for BWW08, Storm $3 \ldots \ldots .249$

Figure B.9 Hardness, Chloride and Sodium plots for BWW21, Storm $3 \ldots \ldots 250$

Figure B.10 Dissolved Oxygen, Temperature and pH plots for BWW00, Storm 1 . 251

Figure B.11 Dissolved Oxygen, Temperature and pH plots for BWW08, Storm 1 . 252

Figure B. 12 Dissolved Oxygen, Temperature and pH plots for BWW21, Storm 1 . 253

Figure B.13 Dissolved Oxygen, Temperature and pH plots for BWW00, Storm 2 . 254

Figure B.14 Dissolved Oxygen, Temperature and pH plots for BWW08, Storm 2 . 255

Figure B.15 Dissolved Oxygen, Temperature and pH plots for BWW21, Storm 2 . 256

Figure B.16 Dissolved Oxygen, Temperature and pH plots for BWW00, Storm 3 . . 257

Figure B.17 Dissolved Oxygen, Temperature and pH plots for BWW08, Storm 3 . 258

Figure B.18 Dissolved Oxygen, Temperature and pH plots for BWW21, Storm 3 . 259 

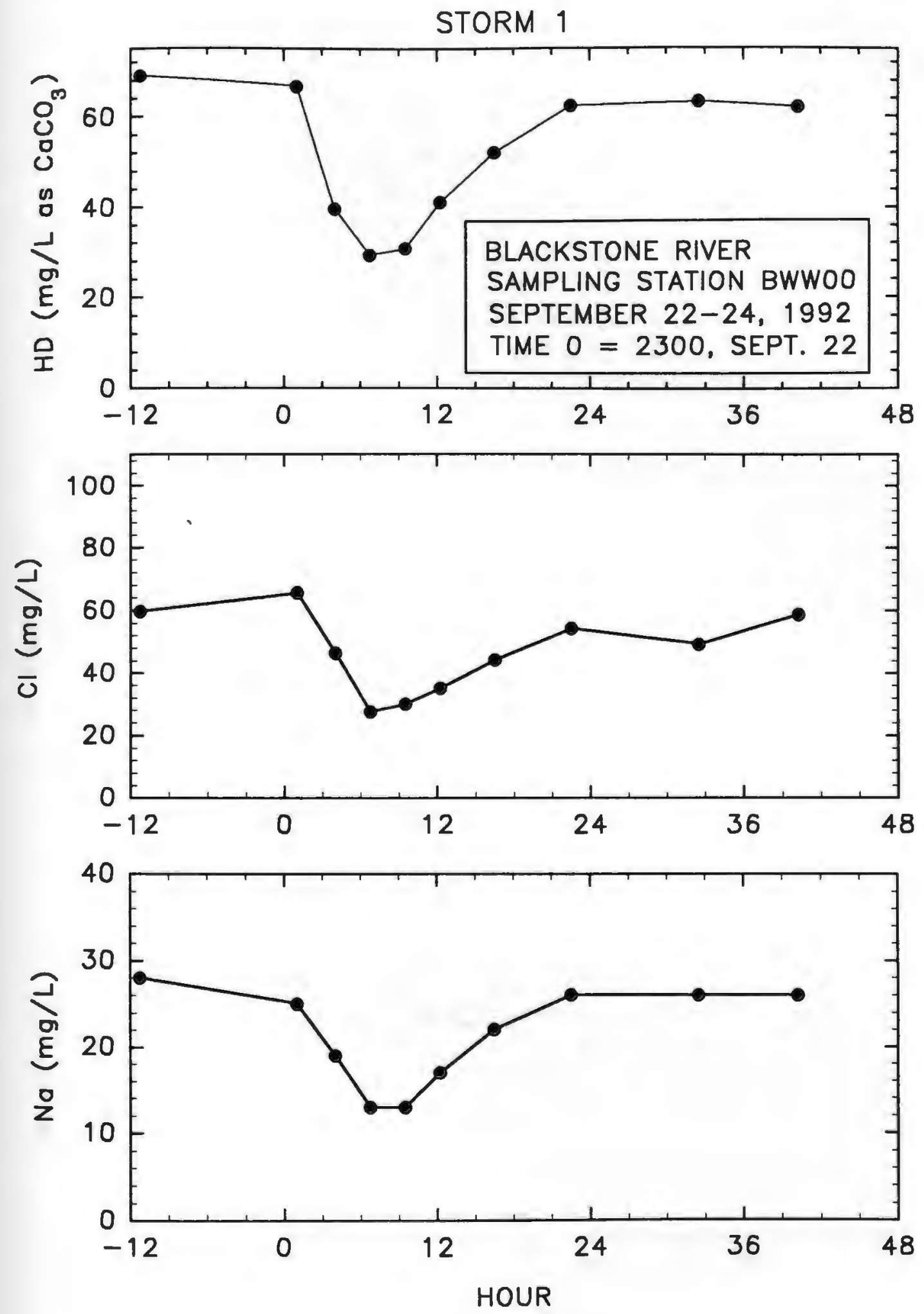

Figure B.1 Hardness, Chloride and Sodium plots for BWW00, Storm 1 

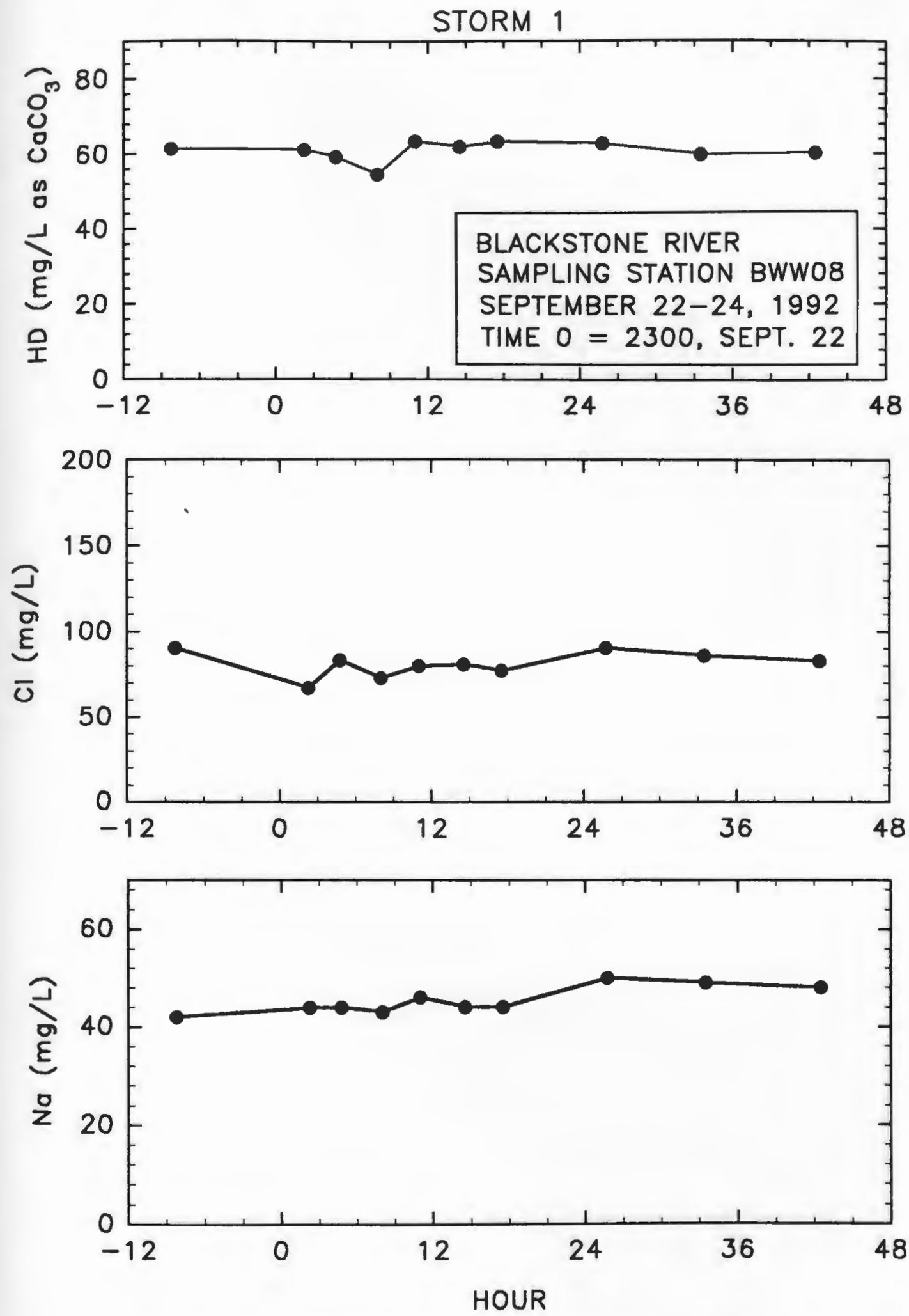

Figure B.2 Hardness, Chloride and Sodium plots for BWW08, Storm 1 

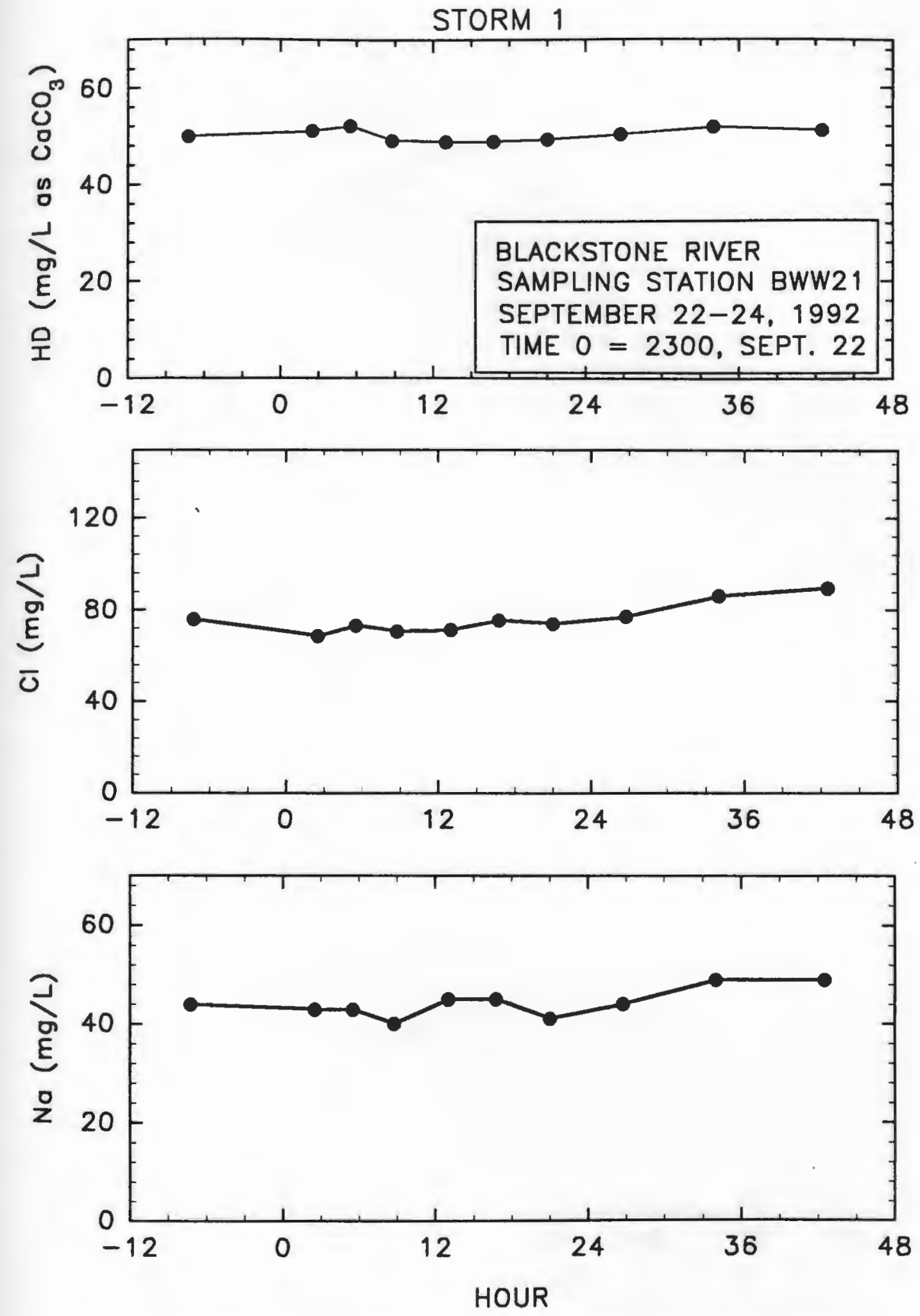

Figure B.3 Hardness, Chloride and Sodium plots for BWW21, Storm 1 

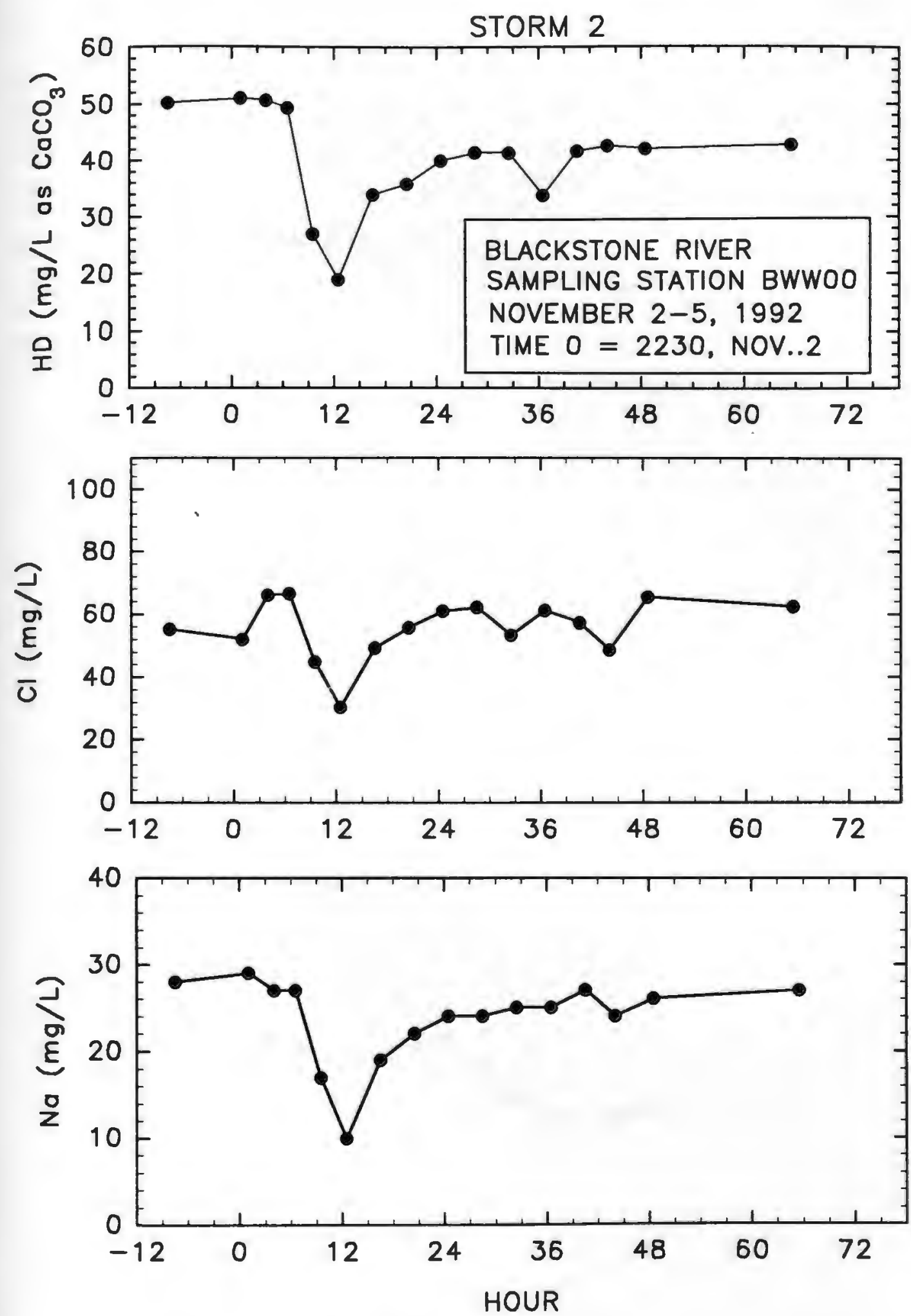

Figure B.4 Hardness, Chloride and Sodium plots for BWW00, Storm 2 

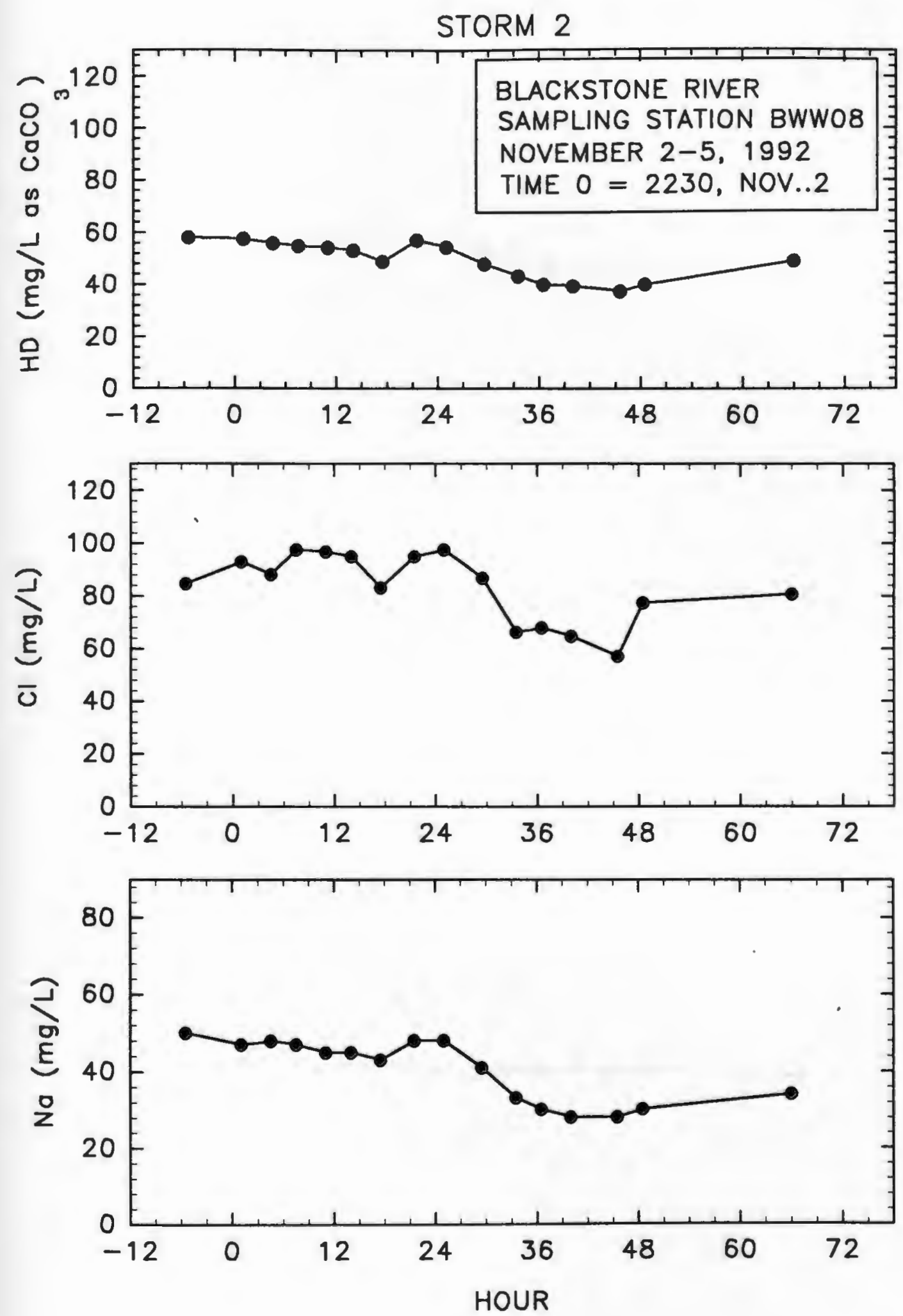

Figure B.5 Hardness, Chloride and Sodium plots for BWW08, Storm 2 
STORM 2
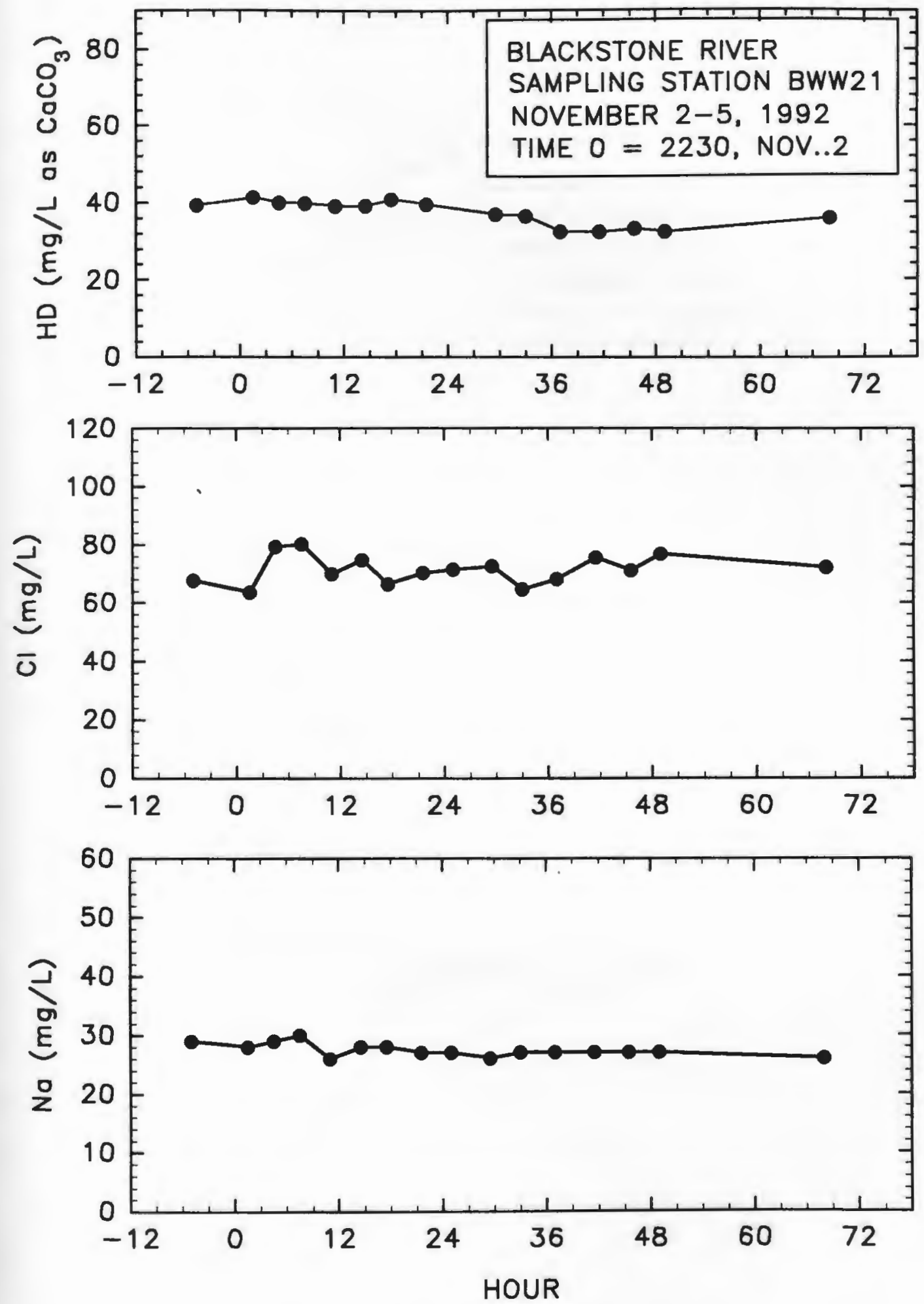

Figure B.6 Hardness, Chloride and Sodium plots for BWW21, Storm 2 

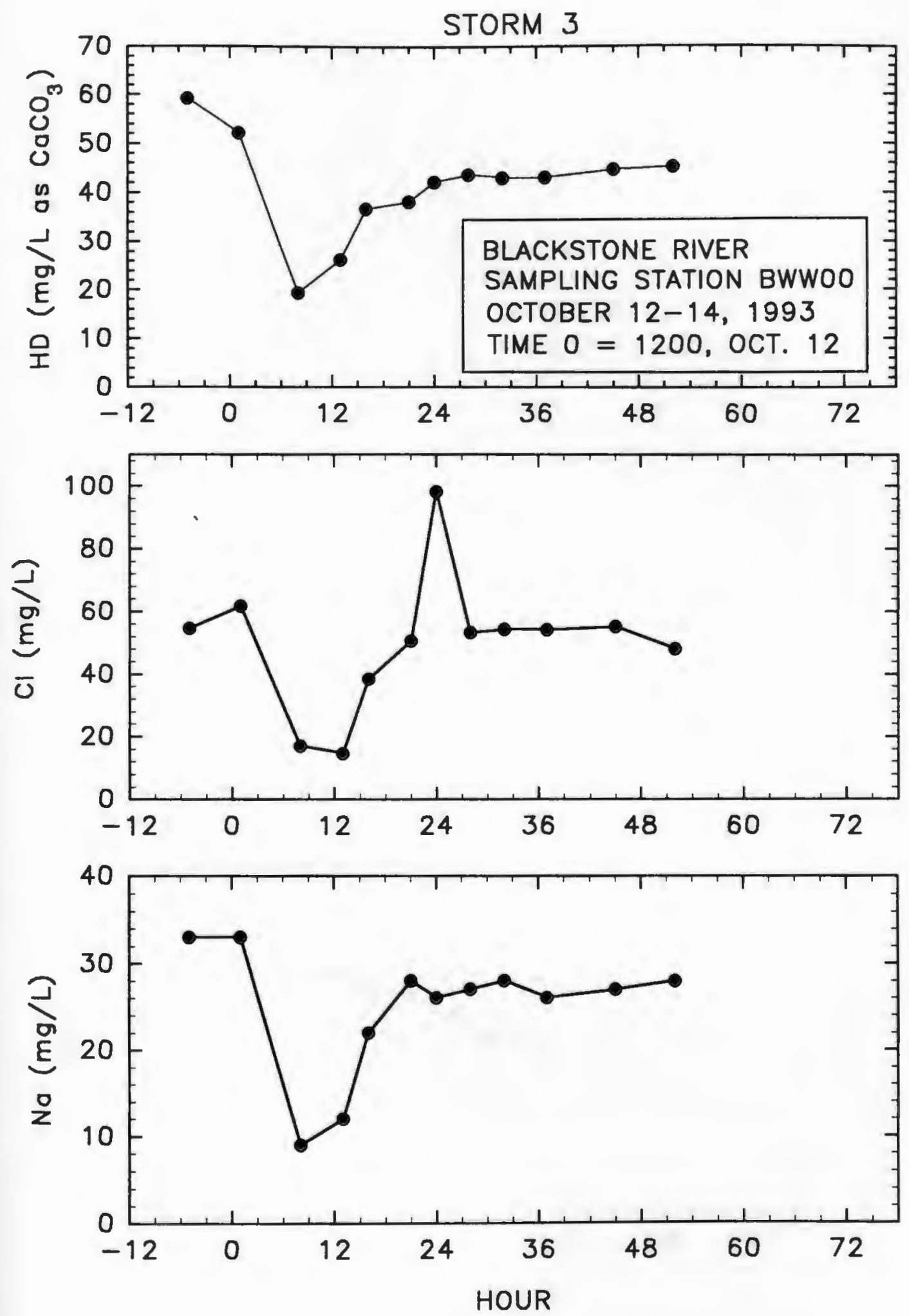

Figure B.7 Hardness, Chloride and Sodium plots for BWW00, Storm 3 

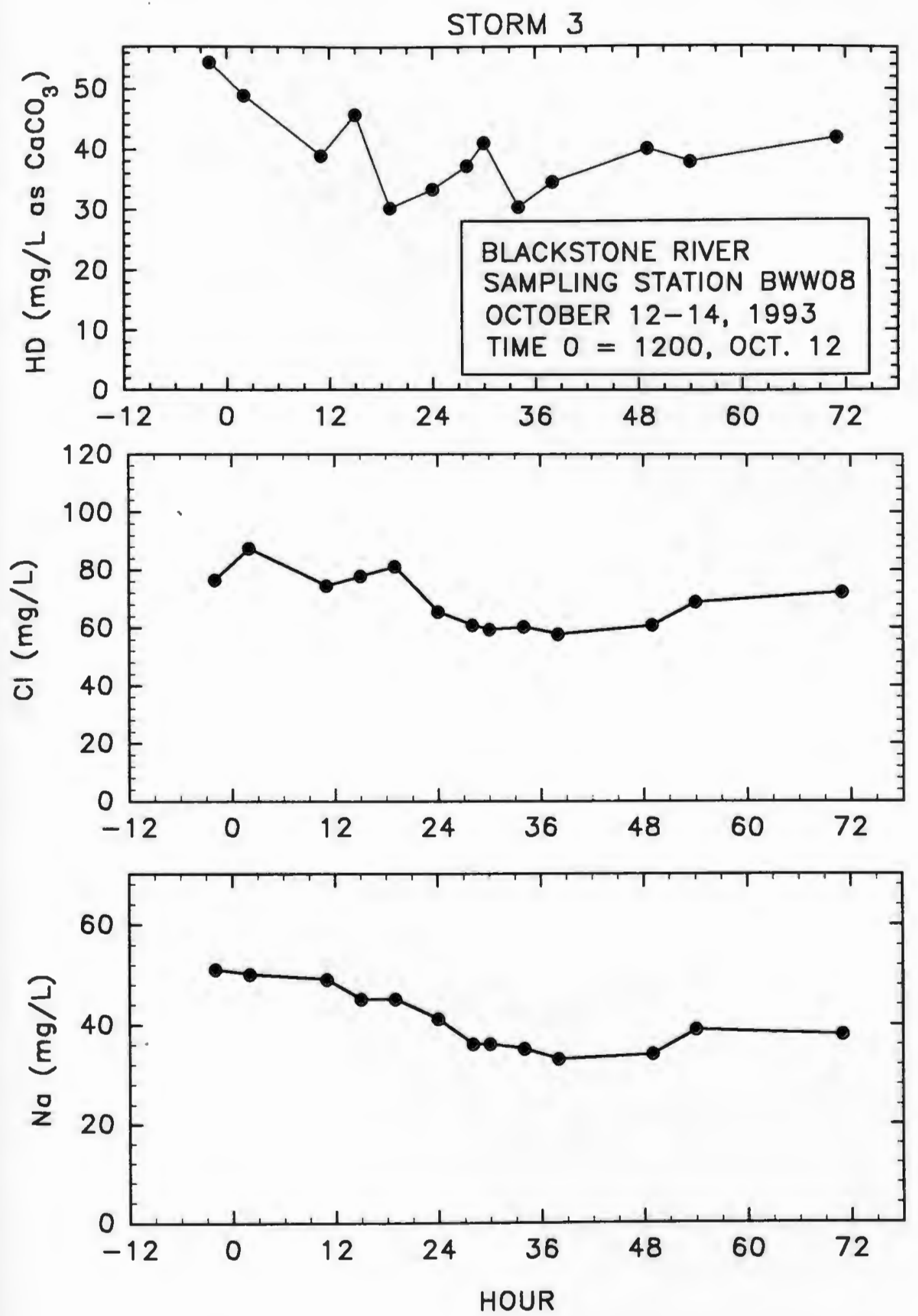

Figure B.8 Hardness, Chloride and Sodium plots for BWW08, Storm 3 
STORM 3
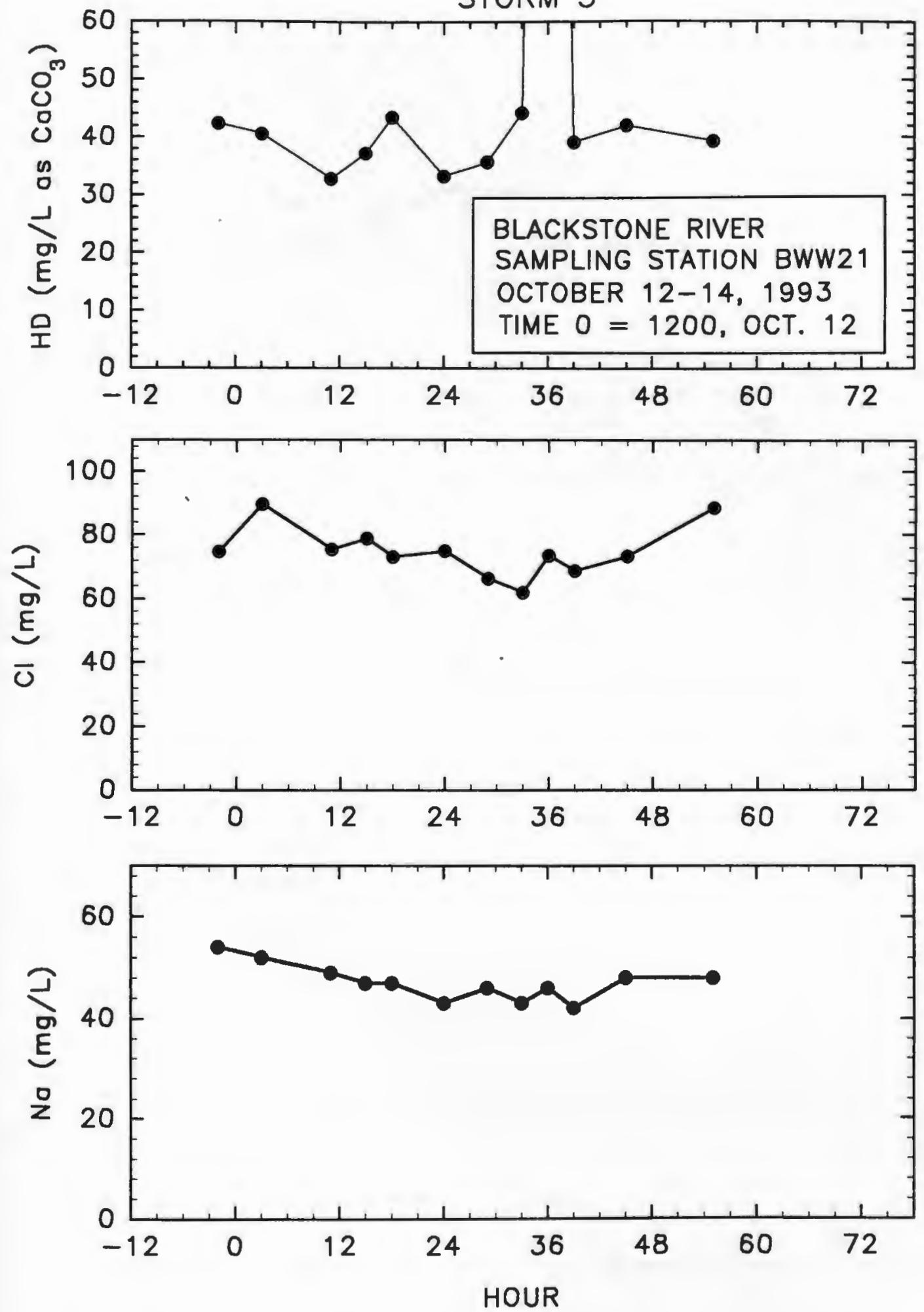

Figure B.9 Hardness, Chloride and Sodium plots for BWW21, Storm 3 

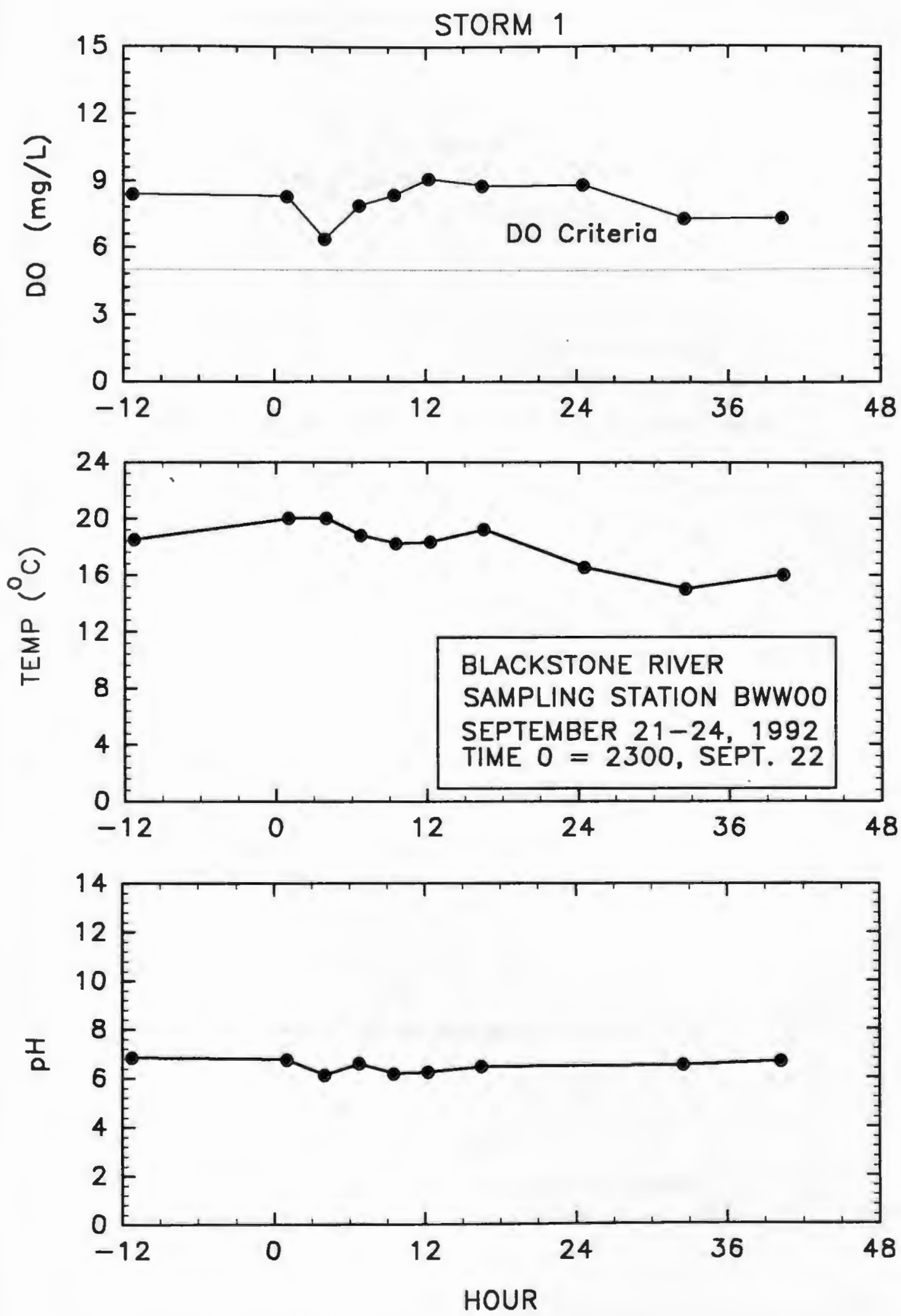

Figure B.10 Dissolved Oxygen, Temperature and pH plots for BWW00, Storm 1 

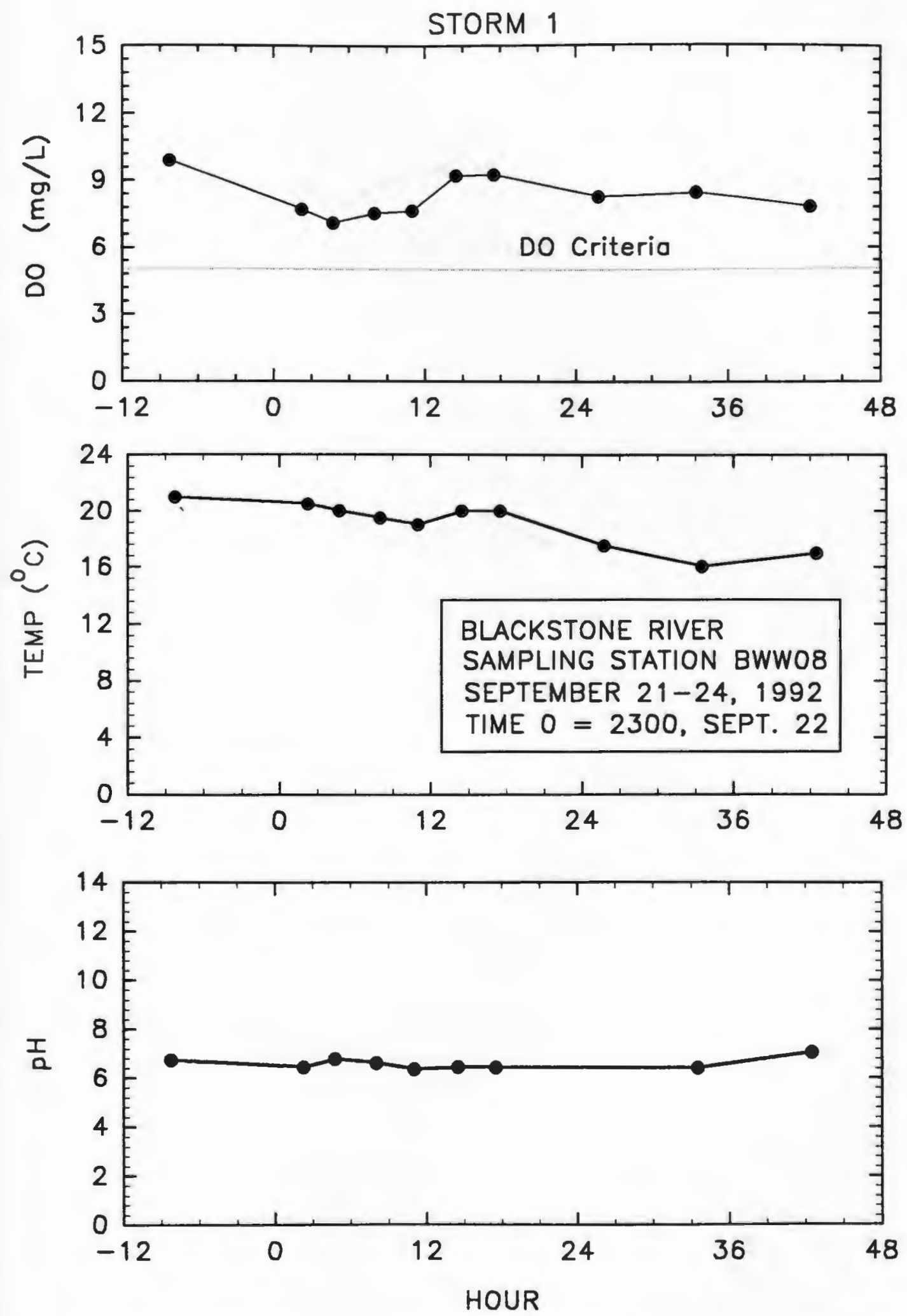

Figure B.11 Dissolved Oxygen, Temperature and pH plots for BWW08, Storm 1 

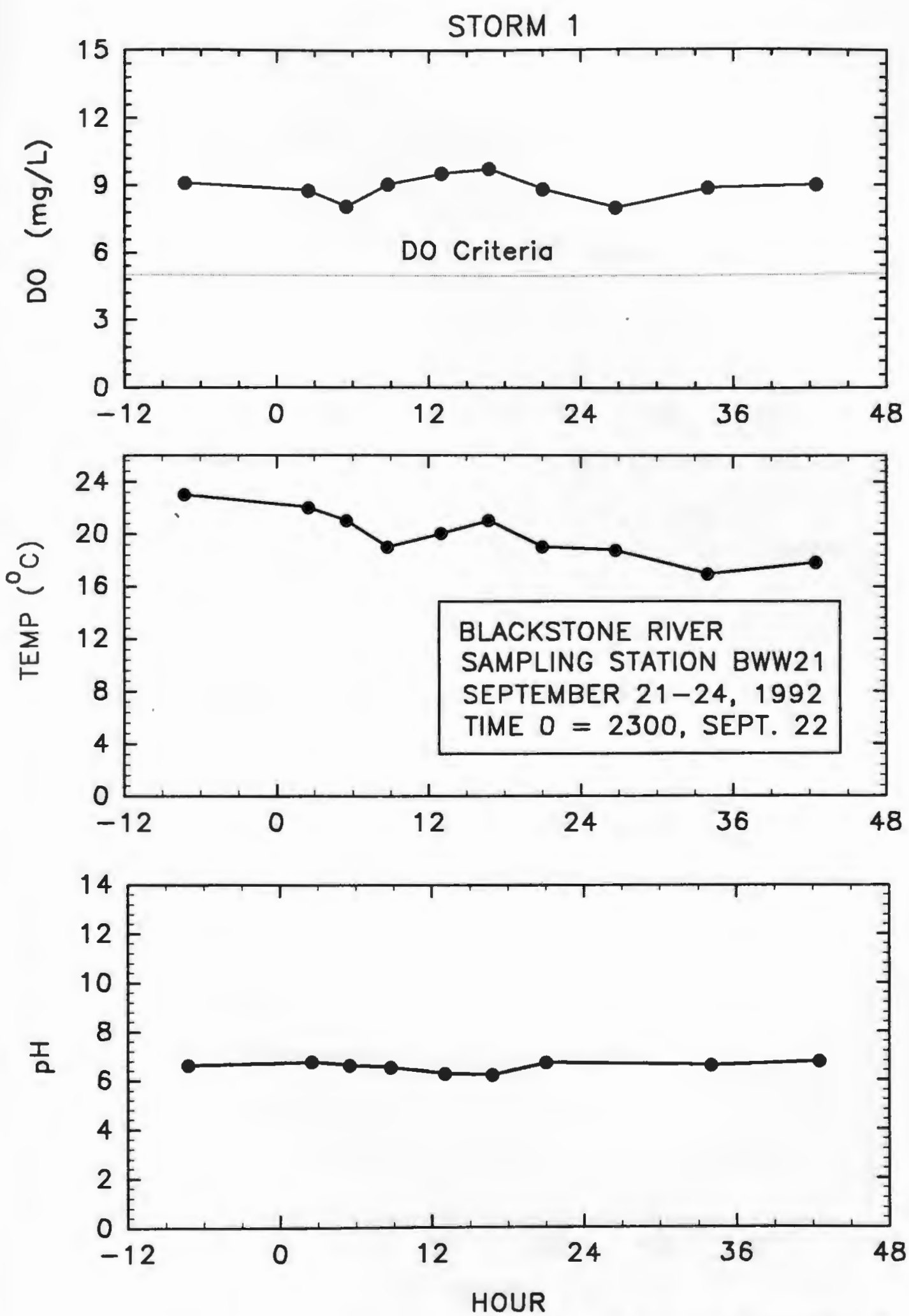

Figure B.12 Dissolved Oxygen, Temperature and pH plots for BWW21, Storm 1 

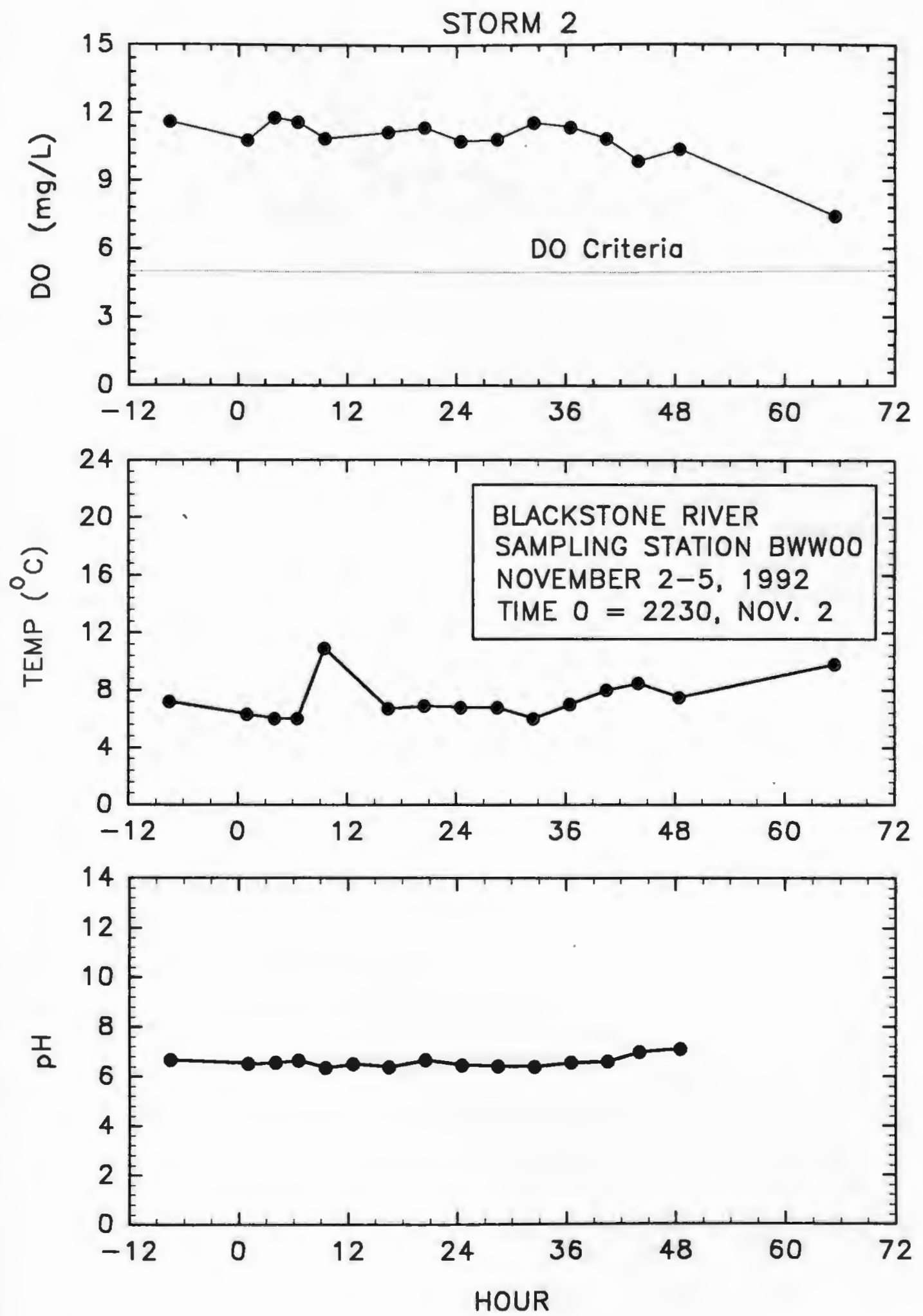

Figure B.13 Dissolved Oxygen, Temperature and pH plots for BWW00, Storm 2 

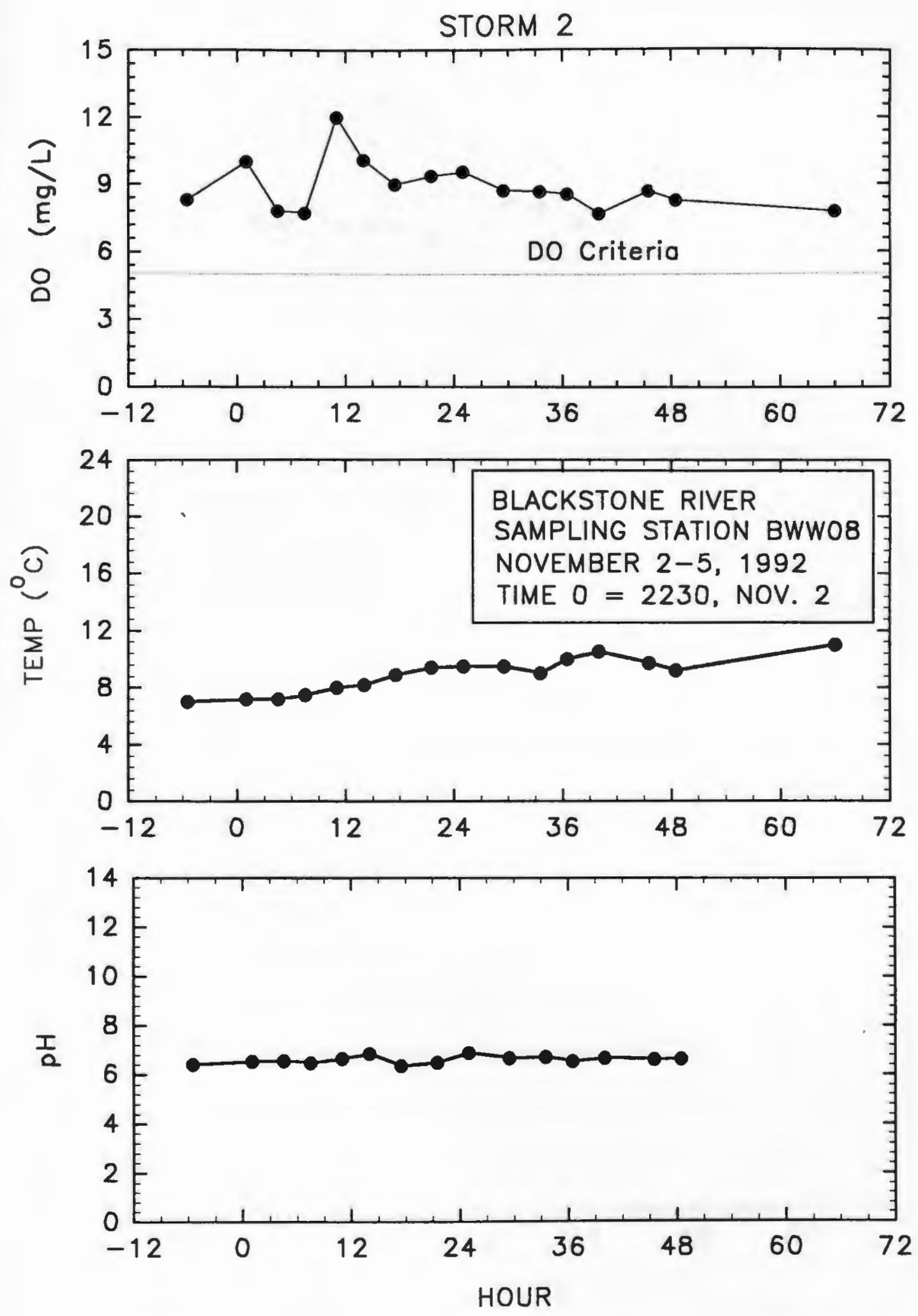

Figure B.14 Dissolved Oxygen, Temperature and pH plots for BWW08, Storm 2 

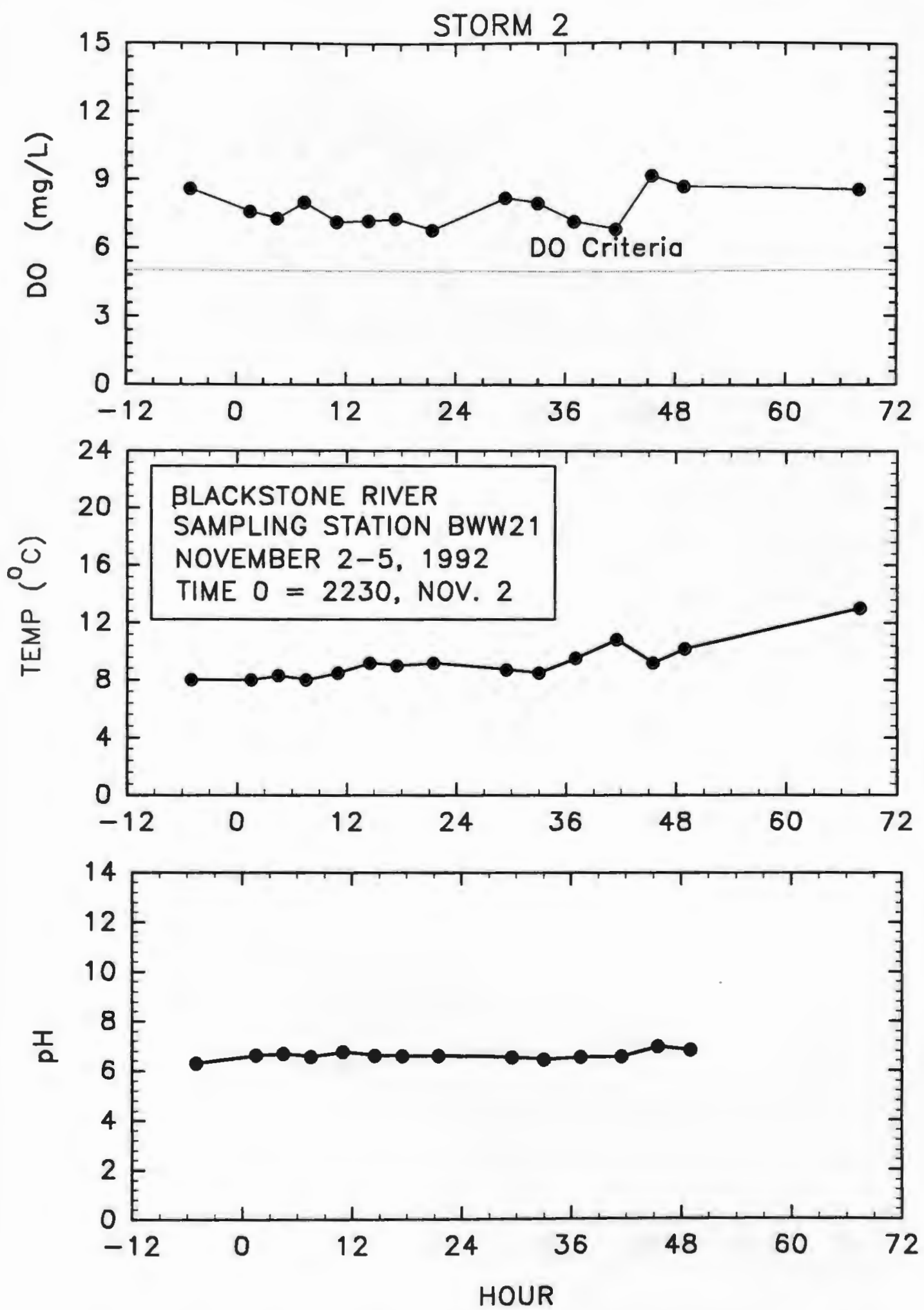

Figure B.15 Dissolved Oxygen, Temperature and pH plots for BWW21, Storm 2 

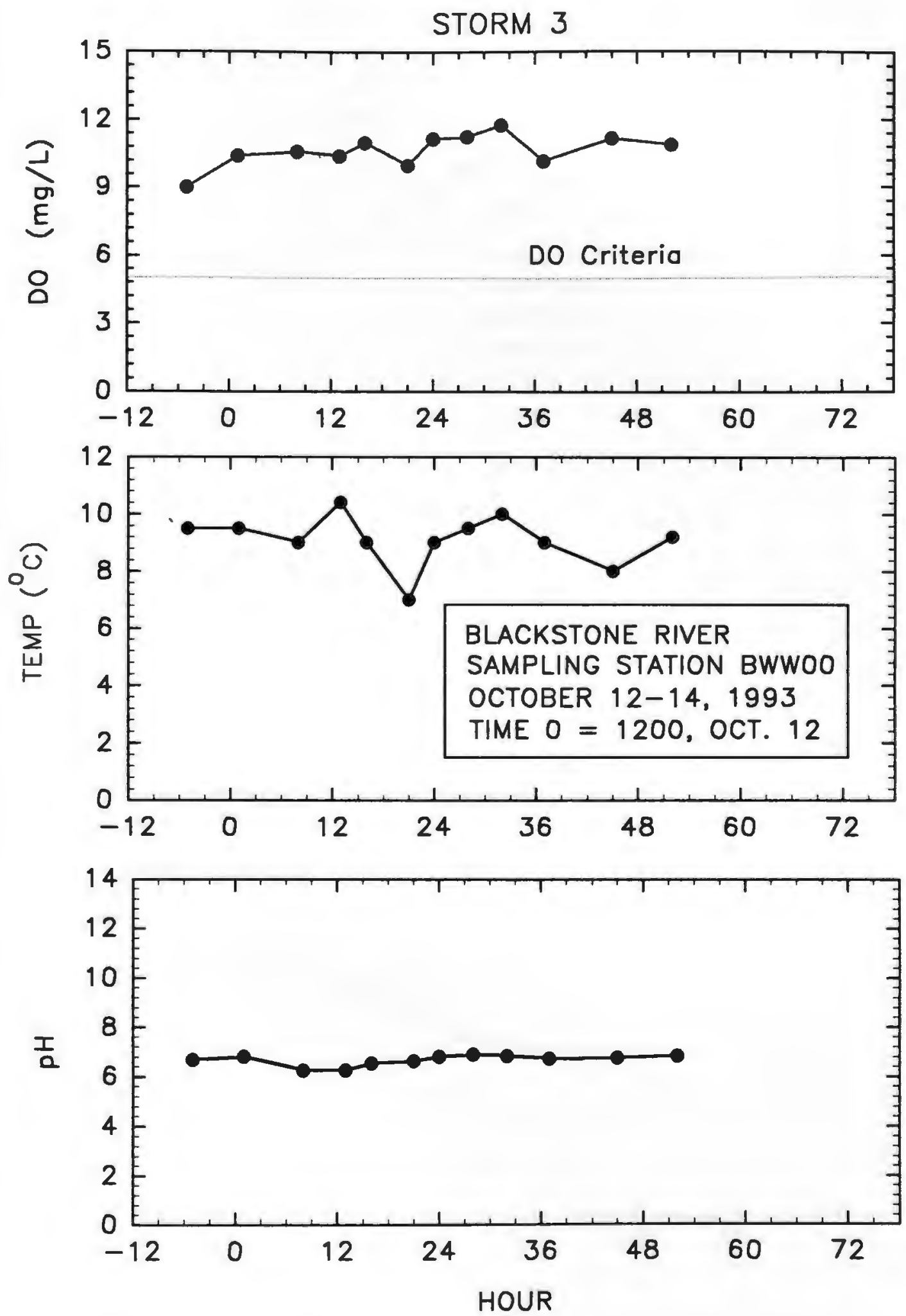

Figure B.16 Dissolved Oxygen, Temperature and $\mathrm{pH}$ plots for BWW00, Storm 3 

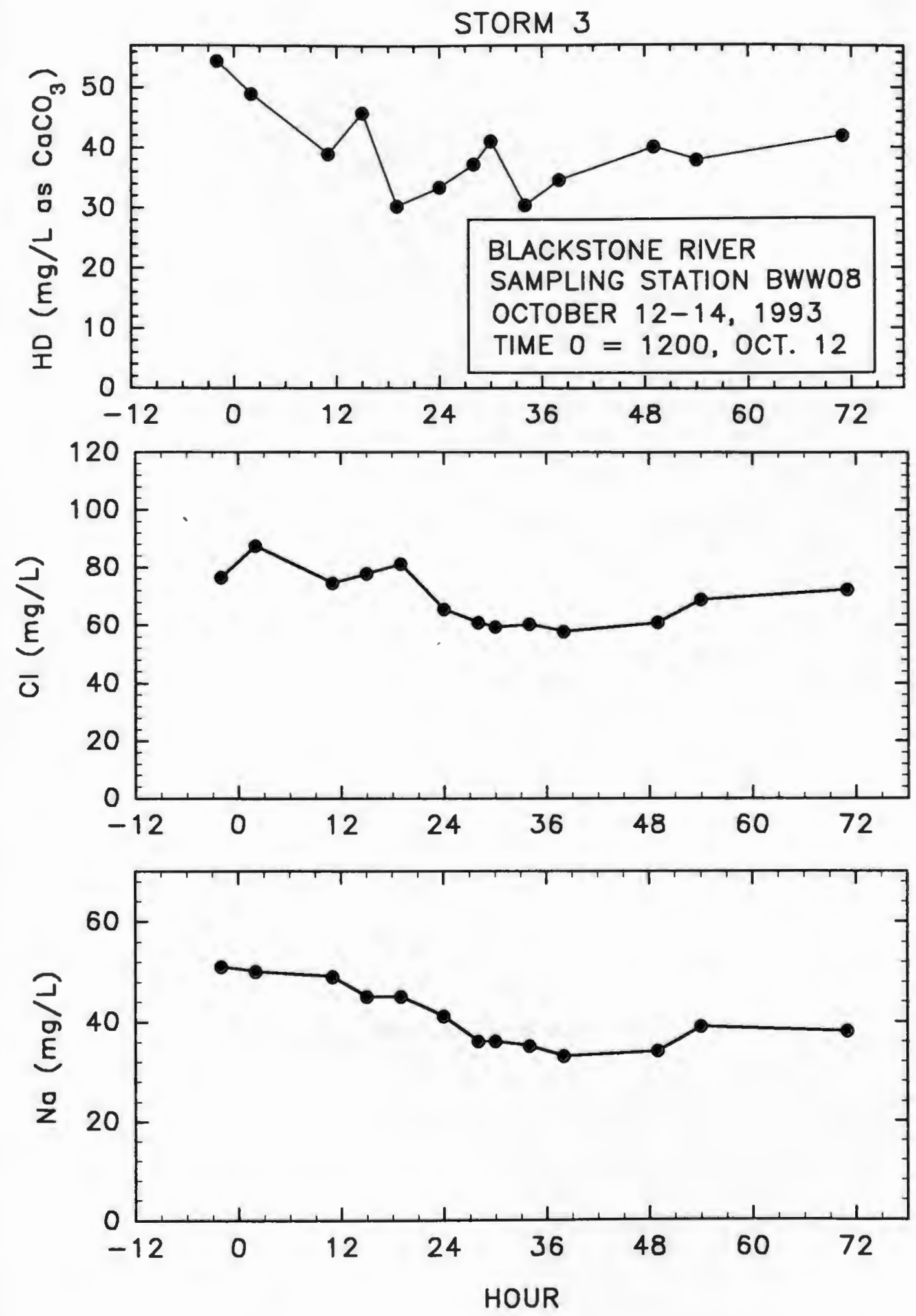

Figure B.17 Dissolved Oxygen, Temperature and pH plots for BWW08, Storm 3 

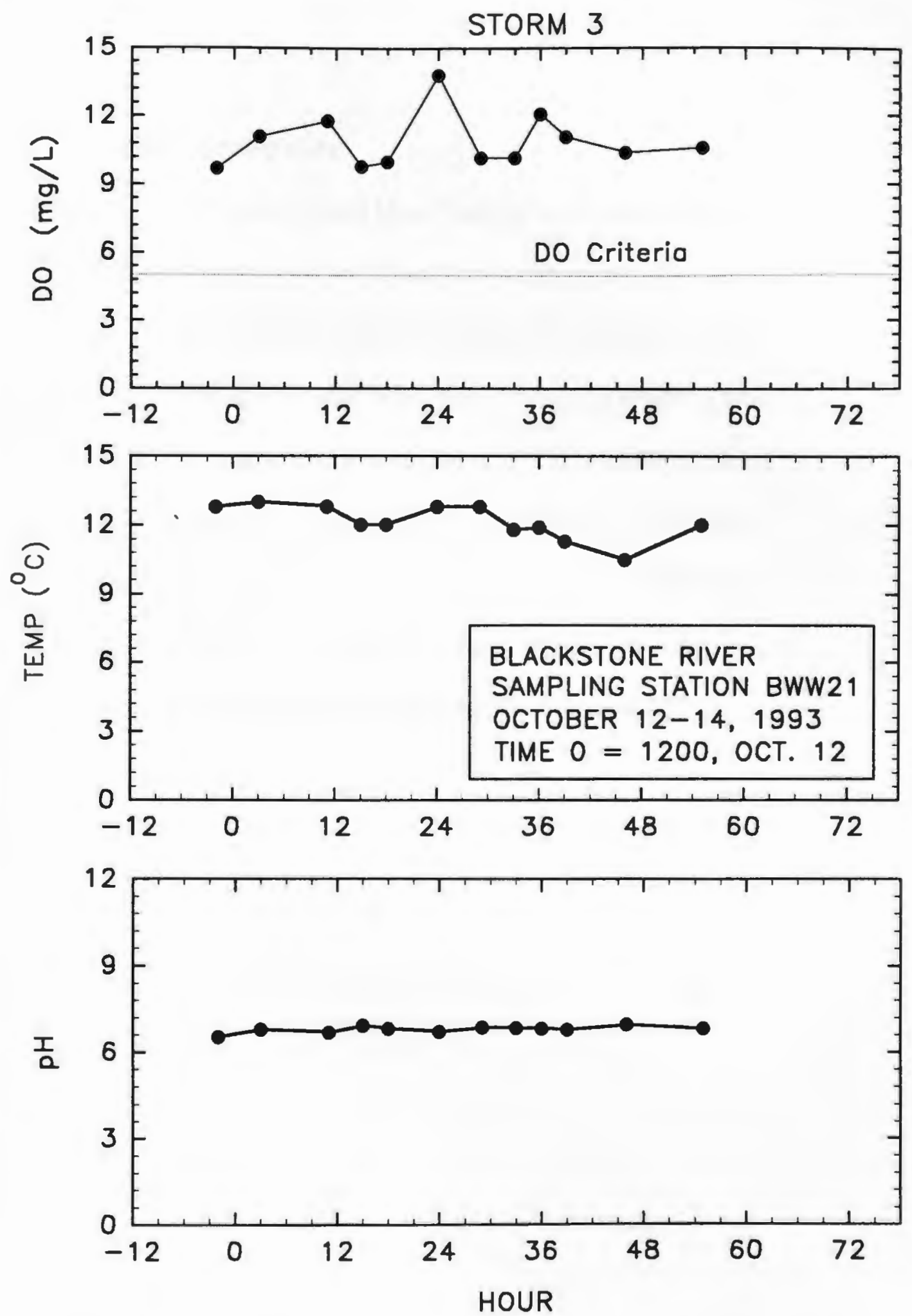

Figure B.18 Dissolved Oxygen, Temperature and pH plots for BWW21, Storm 


\section{APPENDIX - C}

Contains the following plots:

Figure C.1 Concentration and Mass Plots for Pb @ BWW00, Storm 1......... 261

Figure C.2 Concentration and Mass Plots for Pb @ BWW08, Storm 1 ......... 262

Figure C.3 Concentration and Mass Plots for Pb @ BWW21, Storm 1......... 263

Figure C.4 Concentration and Mass Plots for Pb @ BWW00, Storm 2 ......... 264

Figure C.5 Concentration and Mass Plots for Pb @ BWW08, Storm 2 ......... 265

Figure C.6 Concentration and Mass Plots for Pb @ BWW21, Storm 2 ......... 266

Figure C.7 Concentration and Mass Plots for Pb @ BWW00, Storm 3 ......... 267

Figure C.8 Concentration and Mass Plots for Pb @ BWW08, Storm 3 ........ 268

Figure C.9 Concentration and Mass Plots for Pb @ BWW21, Storm 3 ......... 269 

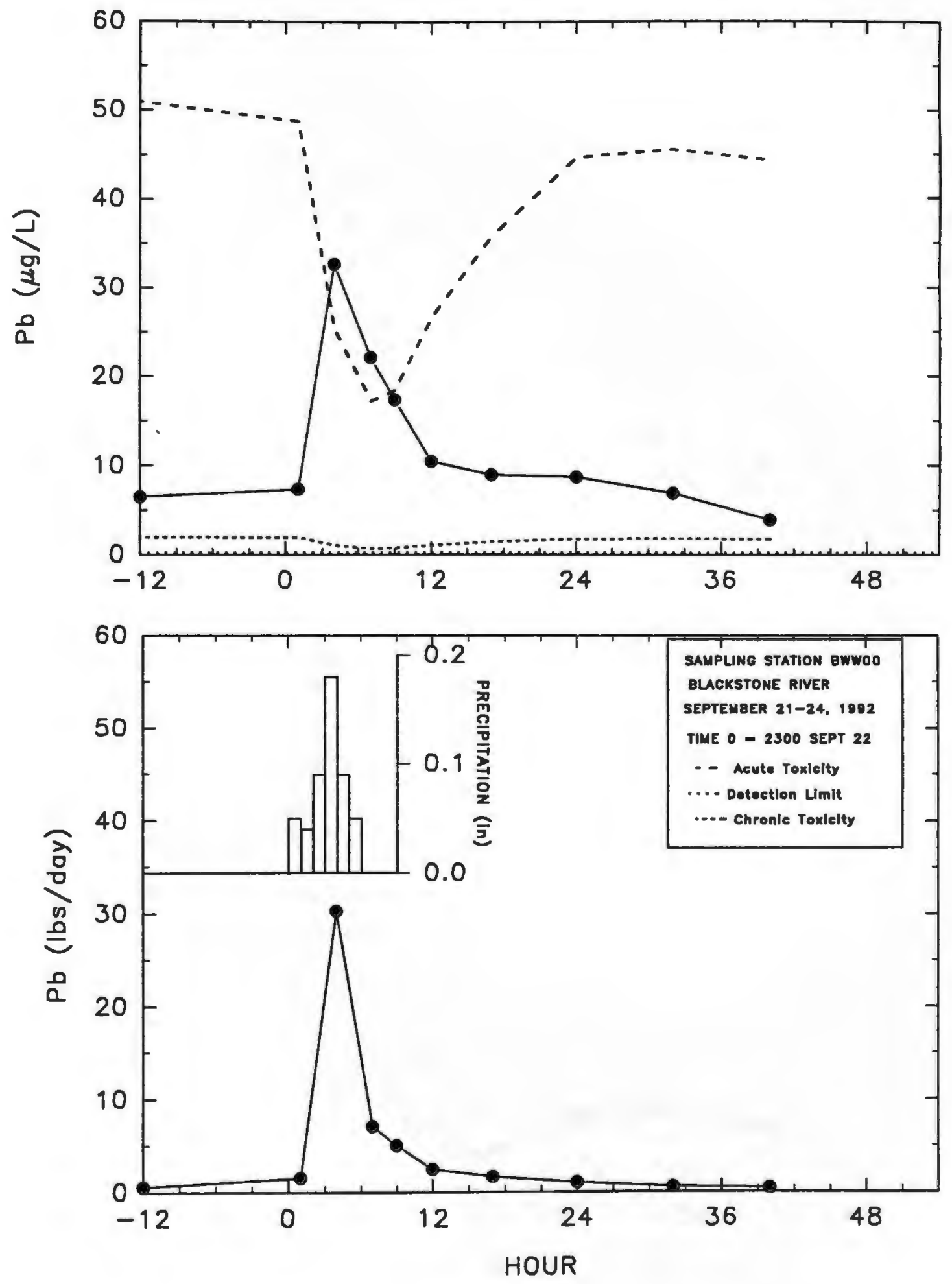

Figure C.1 Concentration and Mass Plots for Pb @ BWW00, Storm 1 

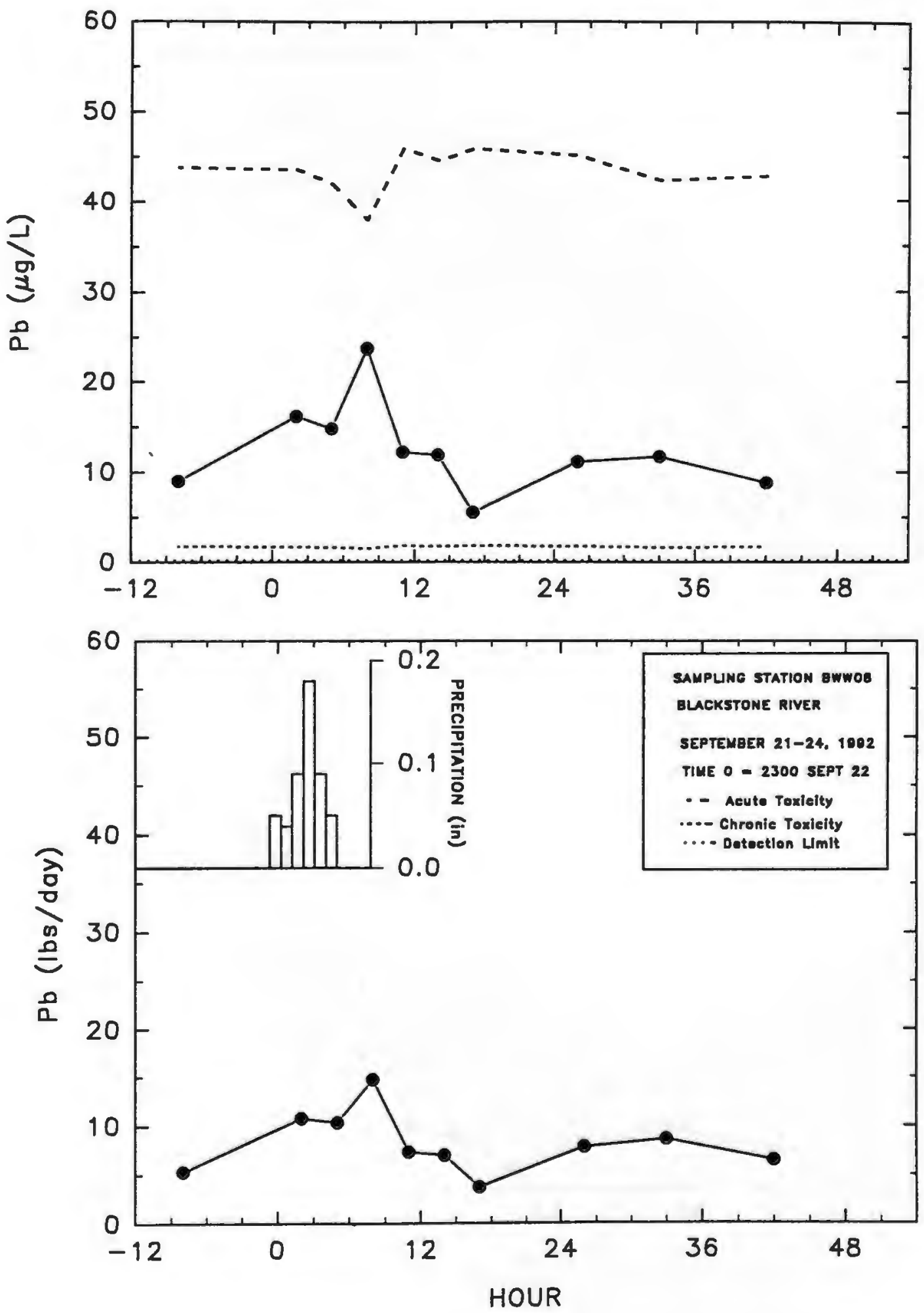

Figure C.2 Concentration and Mass Plots for Pb @ BWW08, Storm 1 

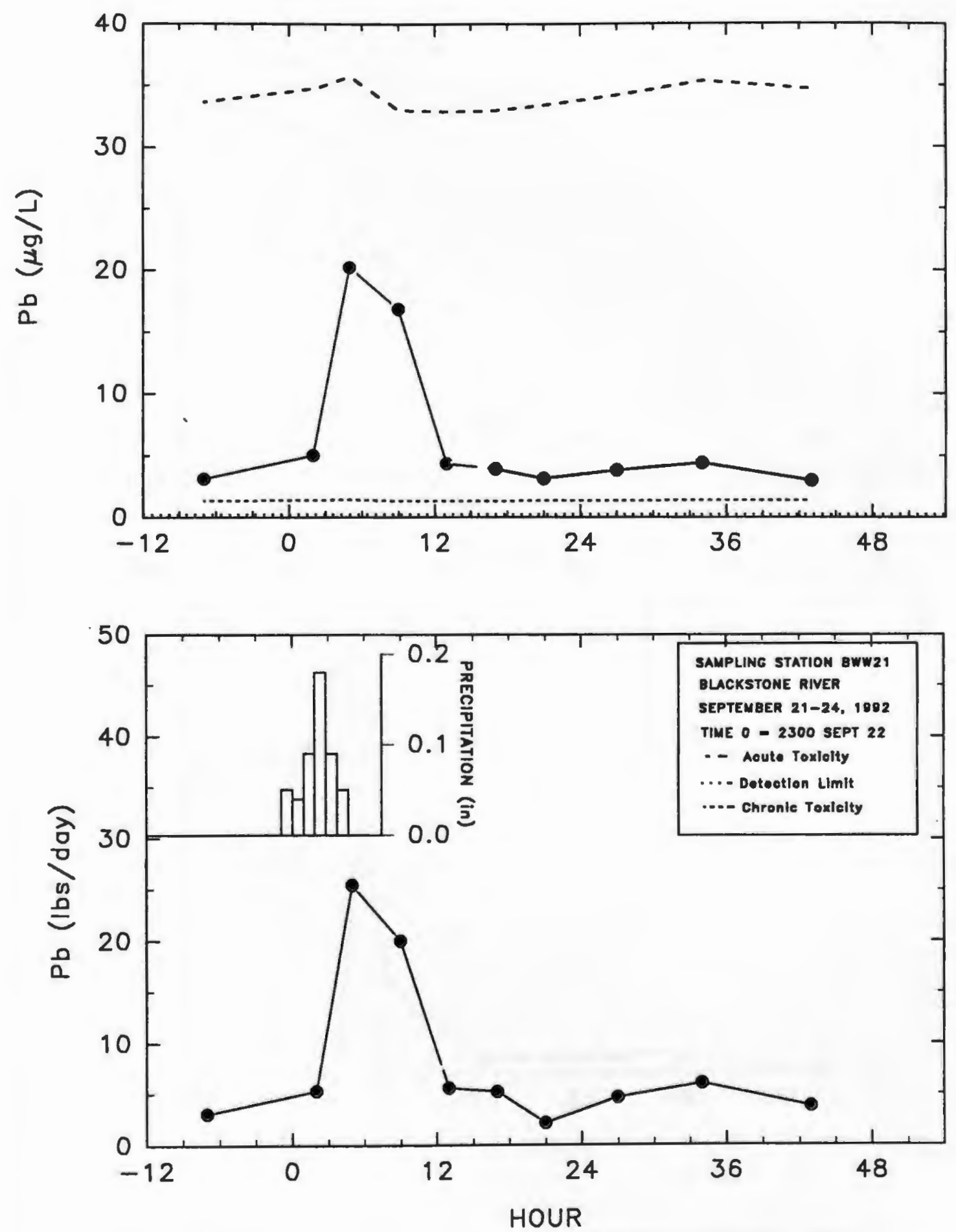

Figure C.3 Concentration and Mass Plots for Pb @ BWW21, Storm 1 

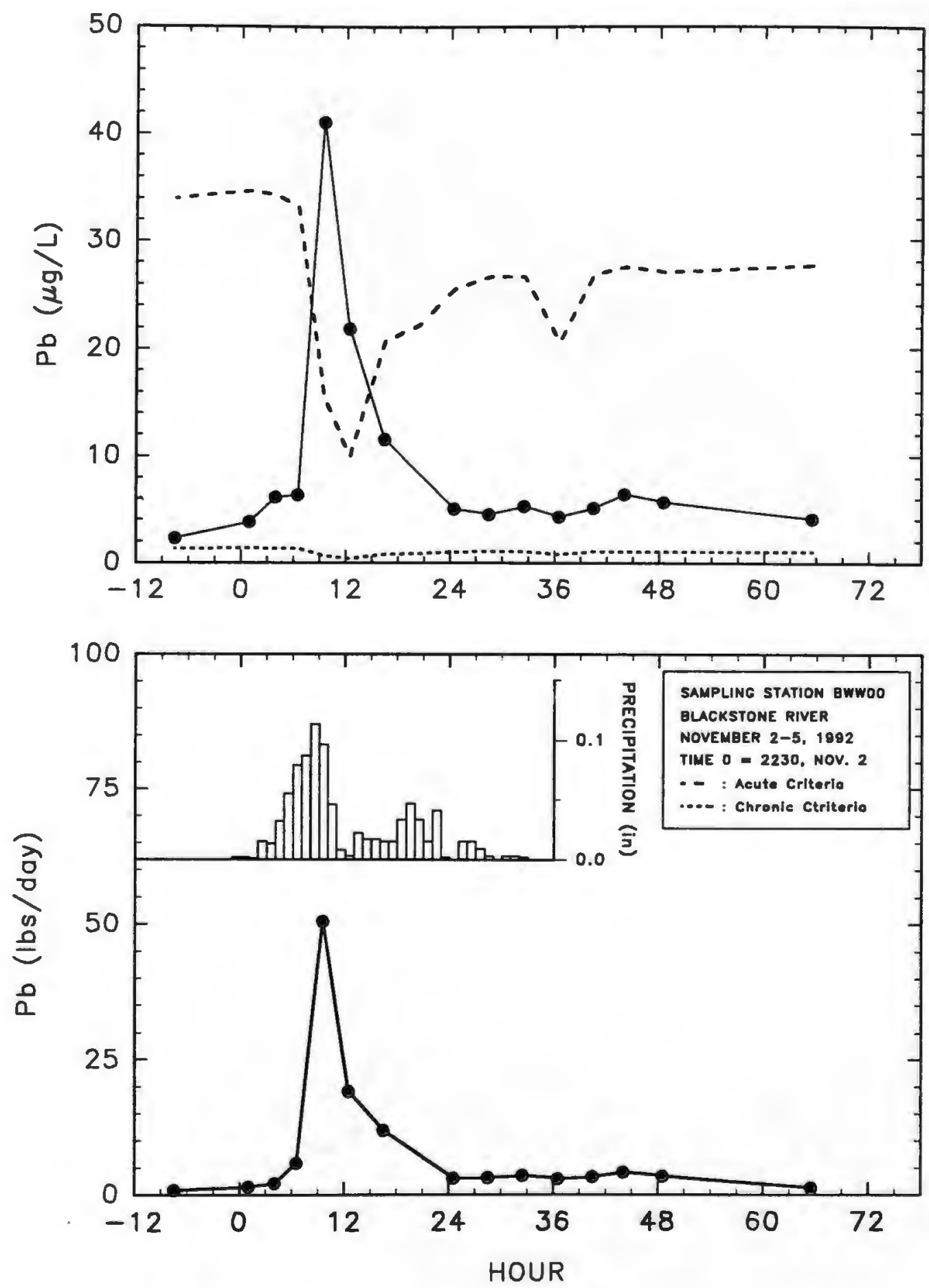

Figure C.4 Concentration and Mass Plots for Pb @ BWW00, Storm 2 

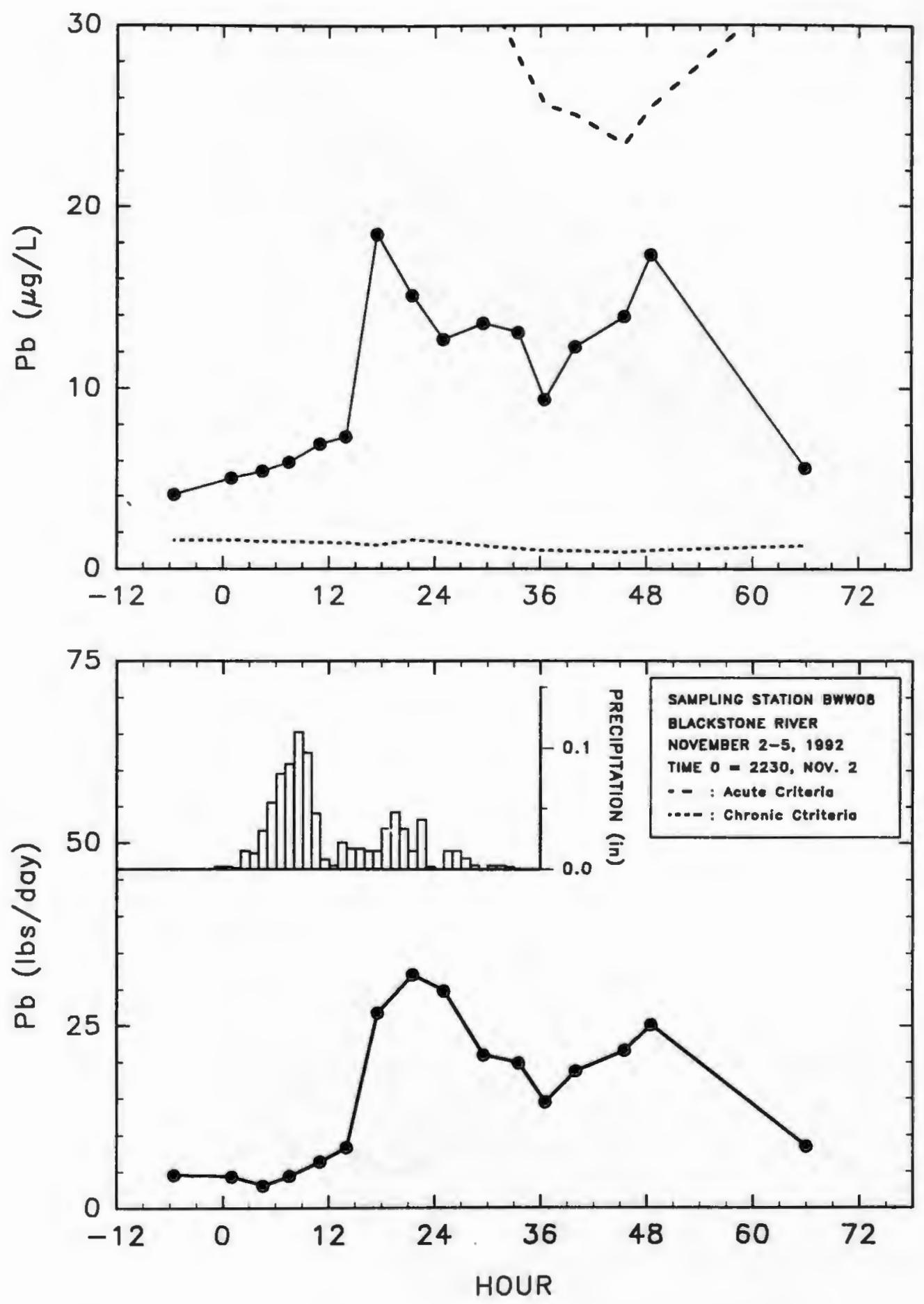

Figure C.5 Concentration and Mass Plots for Pb @ BWW08, Storm 2 

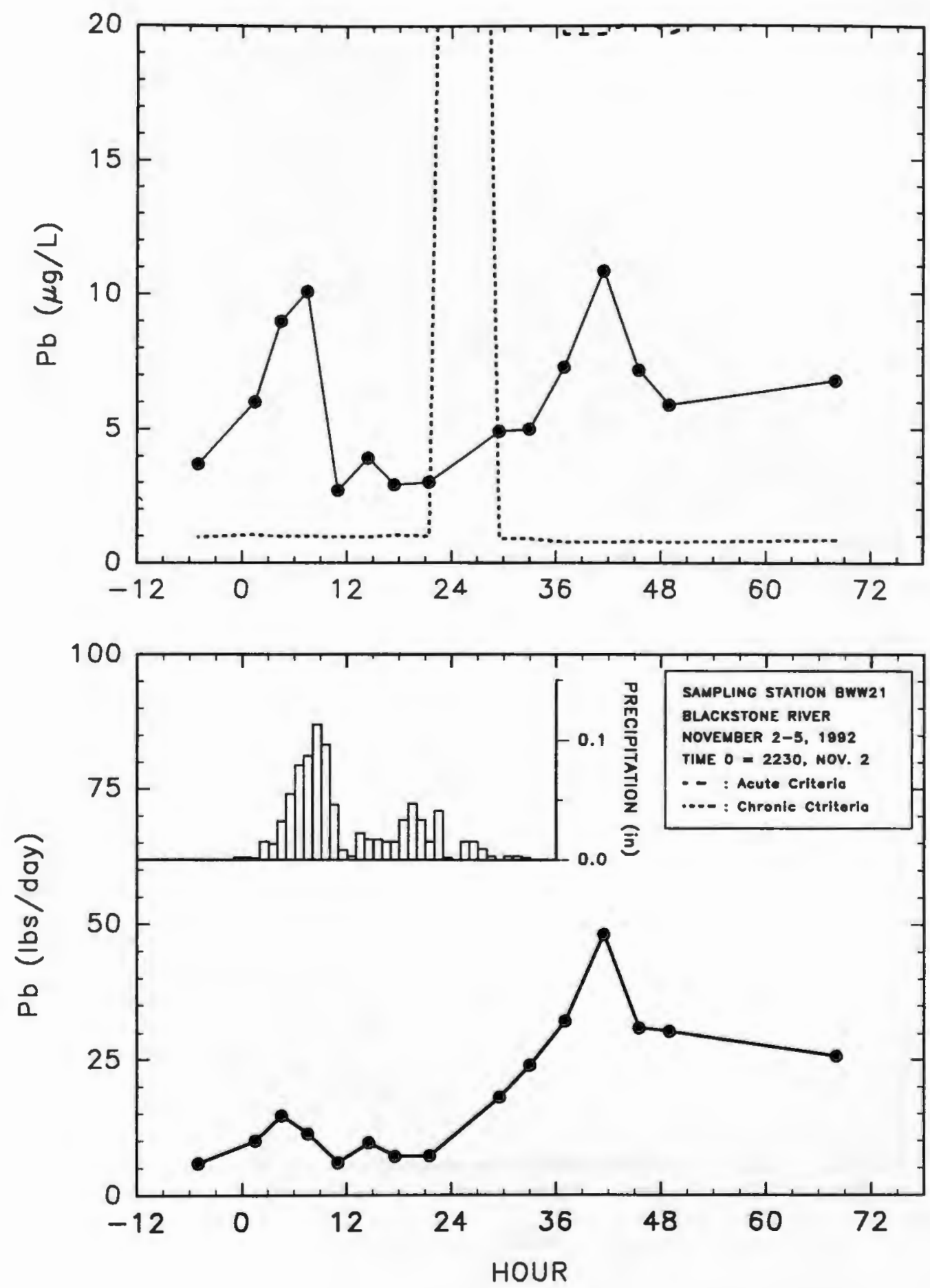

Figure C.6 Concentration and Mass Plots for Pb @ BWW21, Storm 2 

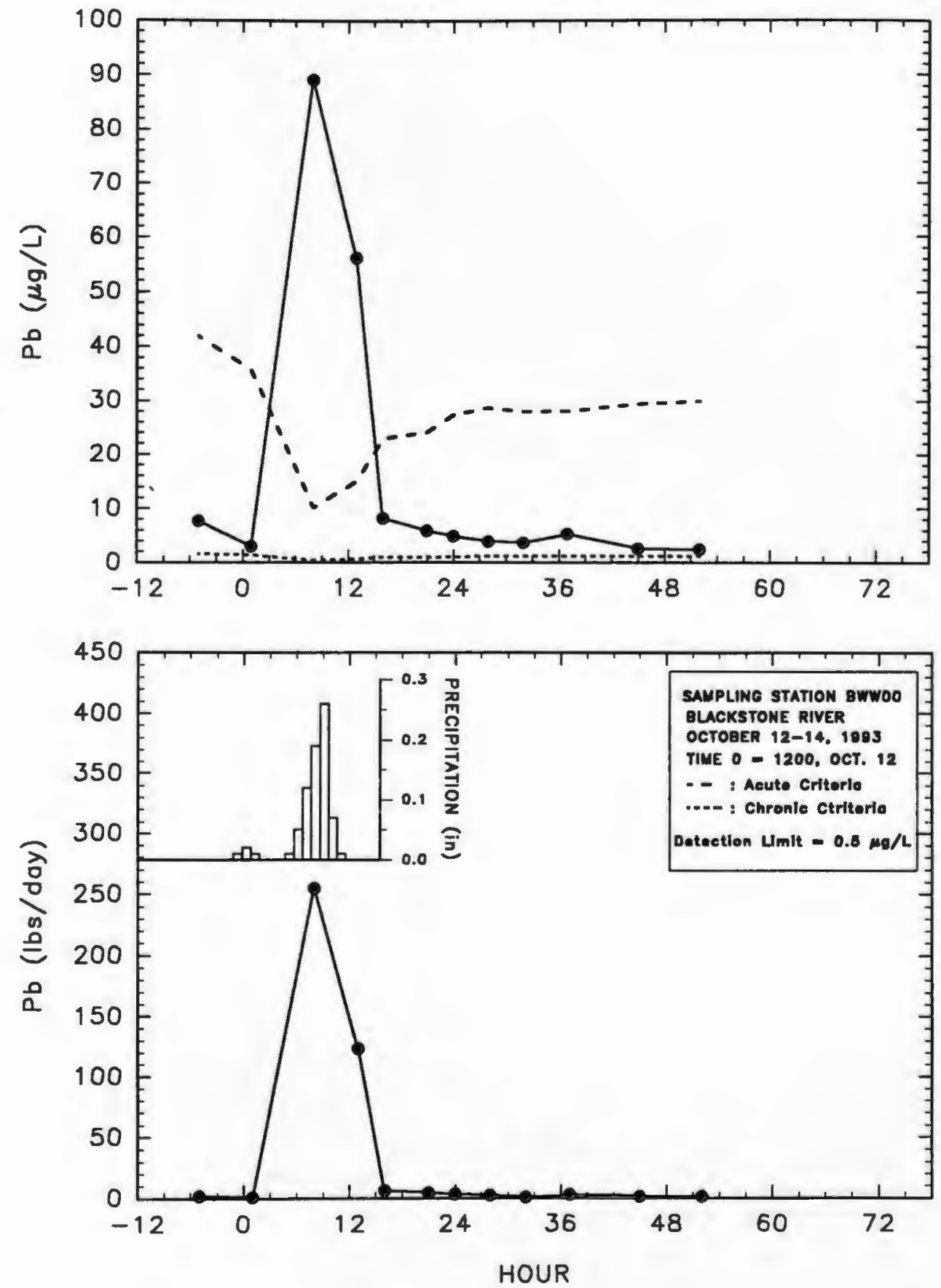

Figure C.7 Concentration and Mass Plots for Pb @ BWW00, Storm 3 

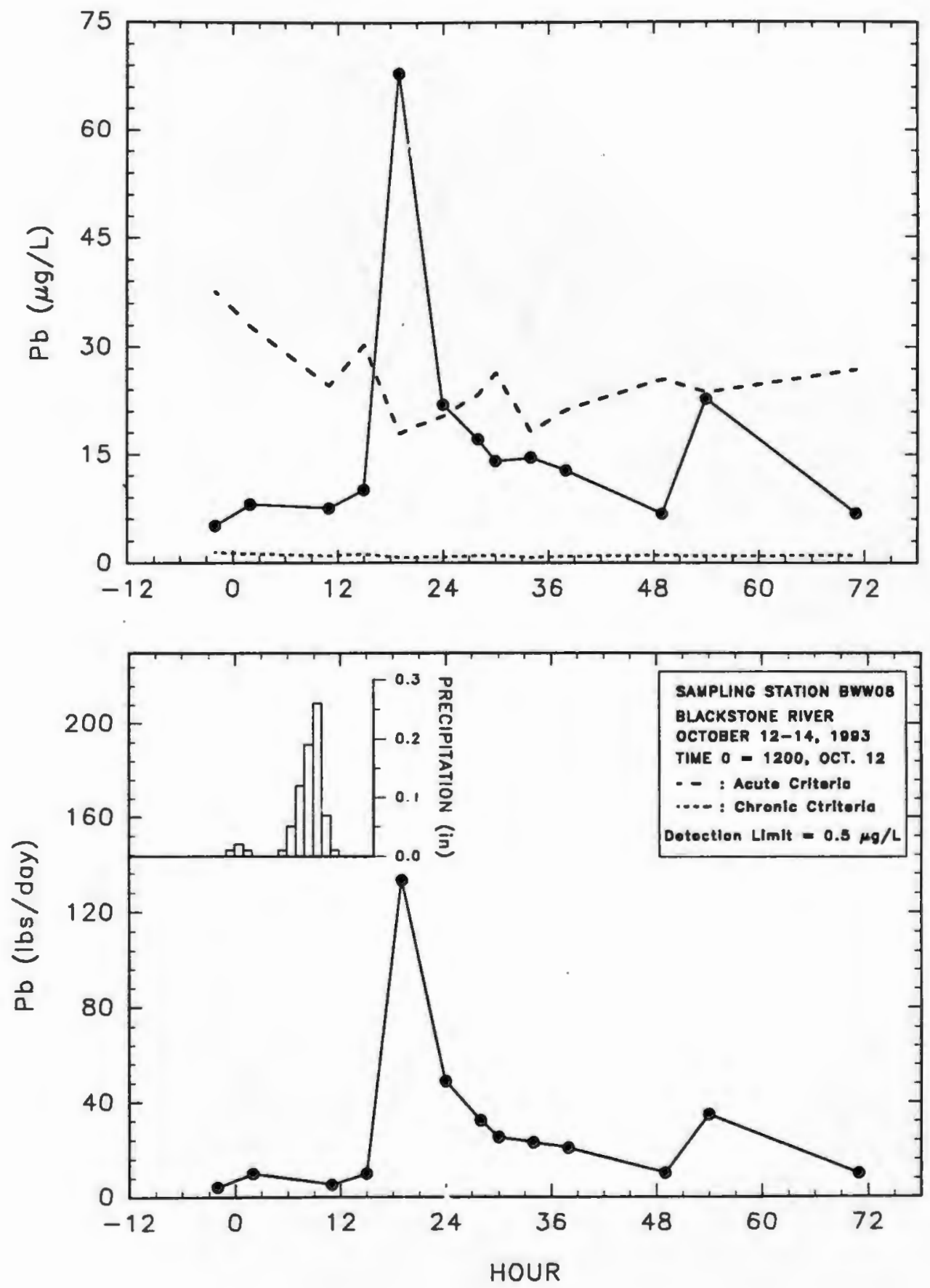

Figure C.8 Concentration and Mass Plots for Pb @ BWW08, Storm 3 

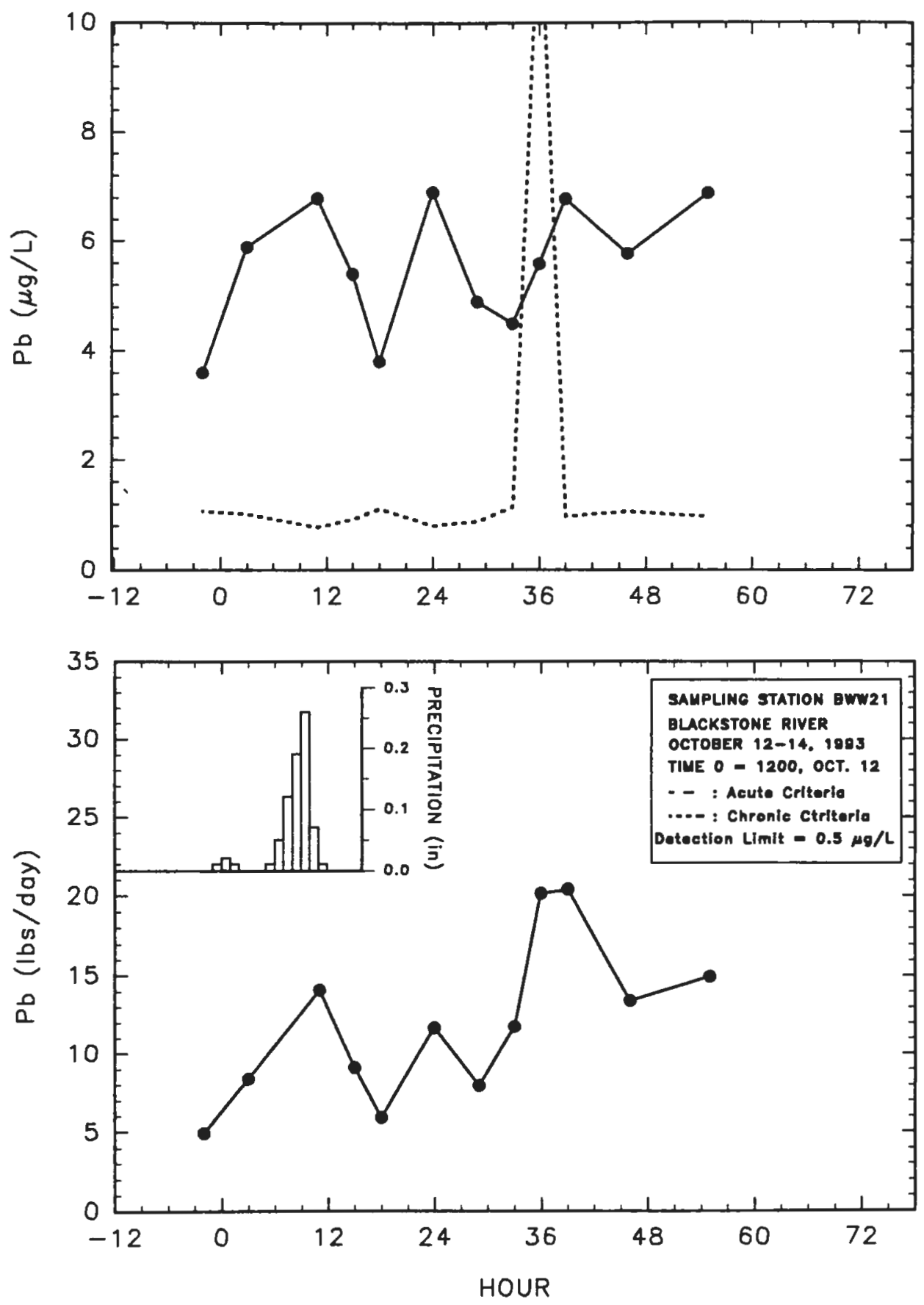

Figure C.9 Concentration and Mass Plots for Pb @ BWW21, Storm 3 


\section{BIBLIOGRAPHY}

Alley, K. D. (1994). Ganga and Gandagi: Interpretations of Pollution and Waste in Benaras. Ethnology. Spring 1994 v33 n2 p127(19).

Anderson, L., and L. Rydberg (1988). Trends in Nutrient and Oxygen Conditions Within the Kattegat: Effects on Local Nutrient Supply. Estuarine Coastal Shelf Sci. 26: 559-579.

Arnolds, J. G., J. R. Williams and D. R. Maidment (1995). Contimuous-Time Water and Sediment-Routing Model for Large Basins. Journal of Hydraulic Engineering. February 1995 v121 n2 p171(13).

Borman, F. H. and G. E. Likens (1979). Pattern and Process in a Forested Ecosystem. Springer-Verlag, New York.

Blackstone River Restoration Study. (1994). US Army Corps of Engineers. Waltham, MA.

Blackstone River Valley National Heritage Corridor (BRVNHC). (1989). The Blackstone River Valley Cultural Heritage and Land Management Plant, revised in April 1993. Blackstone River National Heritage Corridor Commission, Uxbridge, MA.

Bou-Sabb, J. F. (1993). Runoff as a Resource. Civil Engineering. October 1993 v63 n10 p70(2).

Brown, T., W. Burd, J. Lewis, and G. Chang (1994). Methods and Procedures in Stormwater Data Collection. Stormwater NPDES Related Monitoring Needs.

Proceedings of the Engineering Foundation Conference Held in Colorado, August 7-12, 1994. Edited by H. C. Torno, Published by ASCE, 1994. p194-206.

Brush, S. W., M. E. Jennings, P. J. Young and H. C. McWreath (1994). NPDES Monitoring -Dallas - Fort Worth, Texas Area. Stormwater NPDES Related Monitoring Needs. Proceedings of the Engineering Foundation Conference Held in Colorado, August 7-12, 1994. Edited by H. C. Torno, Published by ASCE, 1994. p115-143.

Cao, Zhixian, L. Wei, and J. Xie (1995). Sediment-Laden flow in Open Channels from Two-Phase Flow Viewpoint. Journal of Hydraulic Engineering. October 1995 v121 n10 p725(11).

Carreli, F. et al. (1995). Blackstone River Qual2E Post Audit Report, Unpublished data, Department of Civil and Environmental Engineering, University of Rhode Island, Kingston, RI. 
Cave, K. A. and L. A. Roesner (1994). Overview of Stormwater Monitoring needs. Stormwater NPDES Related Monitoring Needs. Proceedings of the Engineering Foundation Conference Held in Colorado, August 7-12, 1994. Edited by H. C. Torno, Published by ASCE, 1994. p28-38.

Cheela S. (1994). Sediment transport in shallow river systems. A thesis presented to the University of Rhode Island, Kingston, RI, in partial fulfilment of the requirements for the degree of Master of Science.

Climatological Data of New England, National Oceanic and Atmospheric Administration (NOAA) 1991-1993.

Coburn J. (1994). Cleaning up Urban Stormwater: the Storm Drain Stenciling Approach (or Getting to the Nonpoint Source). Journal of Soil and Water Conservation. July-August 1994 v49 n4 p312(4).

Comis, Don (1992). Rain, Runoff, and Underground Water. Agricultural Research. February 1992 v40 n2 p16(2).

Comis, Don (1995). AGNPS Tracks Pollutants to Their Source. Agricultural Research. February 1995 v43 n2 p22(1).

Cook, M. B., K. J. Weiss, and W. F. Swietlik (1994). Trends in NPDES Monitoring for Storm water. Stormwater NPDES Related Monitoring Needs. Proceedings of the Engineering Foundation Conference Held in Colorado, August 7-12, 1994. Edited by $\mathrm{H}$. C. Torno, Published by ASCE, 1994. p1-10.

Cooke, T., D. Drury, R. Katznelson, C. Lee, P. Mangarella, and K. Whitman (1994). Storm Water NPDES Monitoring in Santa Clara Valley. Stormwater NPDES Related Monitoring Needs. Proceedings of the Engineering Foundation Conference Held in Colorado, August 7-12, 1994. Edited by H. C. Torno, Published by ASCE, 1994. p144171.

Costin, A. B. (1980). Runoff and Soil Nutrient Losses from an Unimproved Pasture at Ginninderra, South Tablelands, New South Wales. Australian Journal of Agricultural Research. 31: 533-546.

Doering, P. H., C. A. Oviatt, and M. E. Q. Pilson (1989). Monitoring of the Providence and Seekonk Rivers for trace metals and associated parameters. Narragansett Bay Project, NBP-89-16.

Donigian, A.S., and N.H. Crawford (1975). Nonpoint Pollution from the Land Surface. U.S. EPA, Washington, D.C. EPA 600/3-76/083. 
EPA, 1971. Storm Water Management Model, SWMM. U.S. EPA, Washington, D.C. EPA no. 11 024D0C07/71 to 11 024D0C10/71.

EPA, 1986. Quality Criteria for Water. Office of Water Regulations and Standards. EPA 440/5-86/001.

EPA, 1987. The Enhanced Stream Water Quality Model QUAL2E. Environmental Research Laboratory, U. S. Environmental Protection Agency, Athens, GA 30613. EPA/600/3-87/007/May 1987.

Evans, R. O., J. O. Parsons, K. Stone and W. B. Wells (1992). Watertable Management on a Watershed Scale. Journal of Soil and Water Conservation. January-February 1992 v47 nl p58(7).

Fransz, H. G. And J. H. G. Verhagen (1985). Modelling Research on the Production Cycle of Phytoplankton in the Southern Bight of the North Sea in Relation to Riverborne Nutrient Loads. Netherlands Journal of Sea Research. 19: 241-250.

French R. H. (1995). Estimating the Depth and Length of Sediment Deposition at Slope Transition on Alluvial Fans During Flood Events. Journal of Soil and Water

Conservation. September-October 1995, v50 n5 p521-522.

Garbrecht, J., R. Kuhnle, and C. Alonso 1995. A Sediment Transport Capacity Formulation for Application to Large Channel Networks. Journal of Soil and Water Conservation. September-October 1995, v50 n5 p527-529.

Gillis, A. Maria (1990). Wetlands and water quality. BioScience. November 1990 v40 n10 p717(1).

Graffin, K. (1990). Watershed Rehabilitation at Redwood National Park. Whole Earth Review, Spring 1990 n66 p49(3).

Haster, T. W. and W. P. James (1994). Predicting Sediment Yield in Storm-Water Runoff from Urban Areas. Journal of Water Resources Planning and Management. SeptemberOctober 1994 v120 n5 p630(21).

Hofmann, L, and R. E. Ries (1991). Relationship of Soil and Plant Characteristics to Erosion and Runoff on Pasture and Range. 46(2): 143-147.

Isensee, A. R. and Sadeghi, A. M. (1993). Impact of Tillage Practice on Runoff and Pesticide Transport. Journal of Soil and Water Conservation. November December 1993 v48 n6 p523(4). 
Kibby, H. V. (1978). Effects of wetlands on Water Quality. Proceedings of the Symposium on Strategies for Protection and Management of Floodplain Wetlands and Other Riparian Ecosystems. GTR-WO-12, U. S. Department of Agricultural Forest Service, Washington, D. C. 410 pages.

Kipp, K. V., R. R. Zingarelli, and the staff of the Narragansett Bay Project (1992). Blackstone River "Briefing Paper" and Proceedings from Narragansett Bay Project Management Committee. Current Report the Narragensett Bay Project, RI. NBP-92-88.

Lancelot, C., G. et al. (1987). Phaeocystis blooms and Nutrient Enrichment in the Continental Zones of the North Sea. Ambio 16: 38-46.

Lang, R. D. (1979). The Effect of Ground Cover on Surface Runoff from Experimental Plots. Journal of Soil Conservation, N.S.W. 35:108-114.

Latimer, J. S. (1989). A Review of the Major Research Done in Rhode Island on polychlorinated biphenyls in Water, Atmosphere, Sediment, and Biota. NBP-89-20.

Massachusetts Department of Environment Protection (MADEP), 1990. Commonwealth of Massachusetts Summary of Water Quality 1990. 1990 305(b) Report to Congress.

McCarthy, B.J. (1986). Fate and transport of heavy metals in the Pawtuxet River. Thesis presented to the University of Rhode Island, Kingston, RI, in partial fulfilment of the requirements for the degree of Master of Science.

McCuen, R. H. (1989). Hydrologic Analysis and Design. Prentice Hall, Inc., Englewood Cliffs, New Jersey.

McGinn, J. M. (1981). A Sediment Control Plan for the Blackstone River. Massachusetts Department of Environmental Quality Engineering (DEQE), Office of Planning and Program Management, Boston, MA. Pub. \#14946-244-25-7-30-CR.

Metcalf and Eddy, Inc. (1991). Assessment of Toxics Pollution in Narragansett Bay. Draft Report to Narragensett Bay Project. Providence, RI.

Pilson, M. E. Q., and C. D. Hunt, (1989). Water Quality Survey of Narragensett Bay. A summary of results from the SINBADD cruises 1985-1985. Narragansett Bay Project, RI. NBP-89-22.

Miller, S.K. (1991). When Pollution Runs Wild. National Wildlife. December-January 1991 v30 n1 p26(3).

Milliman, J. D., and R. Meade (1983). Worldwide Delivery of River Sediment to the 
Ocean. Journal Geology. 91: 1-21.

Mitchell, John G. (1996). Widespread as Rain and Deadly as Poison: Our Polluted Runoff. National Geographic. February 1996 v189 n2 p106(20).

Nixon, S. W. (1991). Recent Metal Inputs to Narragansett Bay, Current Report, The Narragansett Bay Project, NBP-91-66.

Novoty, V., M. Chin, and H.V. Tran (1979). LANDRUN- An Overland Flow

Mathematical Model: Users Manual, Calibration and Use. International Joint Commission, Windsor, Ontario.

Novoty, V. and G. Chesters (1981). Handbook of Nonpoint Pollution Sources and Management. Van Nostrand Reinhold Company, New York, 1981.

Owens, L. B., W.M. Edwards, and R. W. Van Keuren (1996). Sediment Losses from a Pastured Watershed Before and After Stream Fencing. Journal of Soil and Water Conservation, January-February 1996, 51(1) 90-94.

Quinn, J. G., 1989. A Review of the Major Research Studies on Petroleum Hydrocarbons and Polycyclic Aromatic Hydrocarbons in Narragansett Bay. Narragansett Bay Project, RI. NBP-89-19.

Quinn, J. G., J. S. Latimer, J. T. Ellis, L. A. LeBlanc, and J. Zheng (1988). Analyses of Archived Water Samples for Organic Pollutants. Narragansett Bay Project, RI. NBP-8804.

Raes, E. (1989). Pawtoxic Report. Unpublished data. Department of Civil and Environment Engineering, University of Rhode Island, Kingston, RI.

Reinelt, L.E., R. R. Horner, and B. W. Mar (1988). Nonpoint Source Pollution Monitoring Program Design. Journal of Water Resources Planning and Management. May 1988 v114 No. 3 p335-352.

Renner, R. (1996). Industry Opposition Stops Release of EPA Sediment Contamination Point Source Report. Environmental Science and Technology. February 1996 v30 n2 p69A(2).

Report to Congress: Nonpoint Source Pollution in the U.S. (1984). Operations Water Planning Division. U.S. Environmental Protection Agency, Washington, D.C.

The Rhode Island Committee For The Humanities. (1977). The Blackstone River/Canal, Final Report, University of Rhode Island, CPAD Urban Field Center, Providence, RI. 
Rhode Island Department of Environmental Management (RIDEM) (1990). The State of the State's Waters - Rhode Island. A report to Congress . P.L. 92-500, 305b.

Rosenberg, R. (1985). Eutrophication- the Future Marine Coastal Nuisance. Marine Pollutant Bulletin 16: 227-231.

Roy Chaudhury, R. (1991). Post Audit of a Water Quality Model and Estimation of Point and Nonpoint Source Loadings in a Watershed. A Thesis Submitted in Partial Fulfillment of the Requirements for the Degree of Master of Science in Civil Engineering, University of Rhode Island, Kingston, RI.

Roy Chaudhury et. al. (1993). Isolation of Wet Weather Inputs into a River. Proceedings of the Runoff Quantity and Quality Modeling Conference, ASCE, Reno, Nevada.

Save The Bay (1990). Bring Back the Blackstone. Save The Bay, Providence, RI.

Science News (1994). Water Toxicity: What EPA Doesn't Know. Science News. April 16 1994 v145 n16 p255(1).

Schlosser, I. J. And J. R. Karr. (1981). Water Quality in Agricultural watersheds: Impact of Riparian Vegetation During Base Flow. Water Resources Bulletin. 17: 233-240.

Skoch II, E. A. (1993). Regulation of Storm Water Discharges Under the Clean Water Act. Environmental Law. July 199323 n3 p1087-1105.

Soileau, J. M., J. T. Touchton and K. H. Yoo. (1994). Sediment, Nitrogen, and Phosphorous Runoff With Conventional-and Conservation-Tillage Cotton in a Small Watershed. Journal of Soil and Water Conservation. January- February 1994 v49 nl p82(8).

Southgate, D. and R. Macke (1989). The downstream denefits of soil conservation in Third World Hydroelectic Watersheds. Land Economics. February 1989 v65 n1 p38(11).

Srivasta R. And D. N. Contractor (1992). Bed-Load and Suspended-Load Transport of nonuniform sediments. Journal of Hydraulic Engineering. June 1992 v1 18 n6 p948(3).

Thomman V.R., and Mueller, J.A. (1987). Principles of surface water quality modeling and control. Harper \& Row Publishers, New York.

Tsirkunov, V. V., A. M. Nikanorov, M. M. Laznik and Z. Dongwei (1992). Analysis of Long-Term and seasonal River Water Quality Changes in Lavatia. Water Resources. Volume 26, No. 9 pp1203-1216, 1992. 
Taylor, R. A. (1987). Clean Water: adding the Balance Sheet. U. S. News and World Report. February 16, 1987 v102 p22(2).

Thomas, P. M. and S. I. McClelland (1994). NPDES Monitoring - Atlanta, Georgia Region. Stormwater NPDES Related Monitoring Needs. Proceedings of the Engineering Foundation Conference Held in Colorado, August 7-12, 1994. Edited by H. C. Torno, Published by ASCE, 1994. p95-114.

Tucker, S., D. Harrison, and S. Gilson (1995). Stormwater Regulation: Time for Reform. ENR. April 24, 1995 v234 n16 pE42(3).

Urban Storm Water Runoff. The Hydrologic Engineering Center, U.S. Army Corps of Engineers, Davis, California, 1975.

U. S. Department of Commerce (1985). Pollution Abatement and Control Expenditures, 1980-83. Survey of Current Business. March 1985 v66 p18(5).

U. S. Environmental Protection Agency (USEPA) (1983). Site Specific Water Quality Assessment: Blackstone River, Massachusetts. Environmental Monitoring Systems Laboratory, Las Vegas, Nevada. EPA 600/X-83-028.

Viessman, W., Lewis, G. L. and Knapp, J. W. (1990). Introduction to Hydrology. Harper \& Row, Publishers, Inc ., New York, N.Y.

Wanielista, Martin P. (1990). Hydrology and Water Quantity Control. John Wiley \& Sons, Inc., New York, N.Y.

Warwick, J. J. and J. D. Edgmon (1988). Wet Weather Water Quality Modeling. Journal of Water Resources Planning and Management. Volume 114, No. 3, May 1988.

White, F. C., J. R. Hairston, W. N. Musser, H. F. Perkins, and J. F. Reed (1981). Relationship Between Increased Crop Acreage and Nonpoint-Source Pollution: A Georgia Case Study. Journal Soil Water Conservation. 36: 172-177.

Wischmeir, W. H. And D. D. Smith,(1978). Predicting Rainfall Losses - A Guide to Conservation Planting. United States Department of Agriculture, Agriculture Handbook No. 537.

Wright, R. M. And B. J. McCarthy (1985). Chemical Monitoring and Computer Modelling of Pollutants in the Pawtixet River. Rhode Island, Vol.II, Computer Modelling of Toxic Pollutants in the Pawtoxet River. RI Department of Environmental Management, Providence, RI. 
Wright, R. M. (1988). Development of a One Dimensional Water Quality Model for the Blackstone River. Narragansett Bay Project, NBP-88-10.

Wright, R. M., I. Runge, Y. S. Lee and R. Roy Chaudhury. (1990). Blackstone River 1990. Narragansett Bay Project, NBP-92-85.

Wright et. al. (1991). Problem Assessment and Source Identification and Ranking of Wet Weather Discharges Entering the Providence and Seekonk Rivers, Prepared for the Narragansett Bay Project, Providence, RI and U.S. Environmental Protection Agency, Boston, MA

Wright, R. M., I. Runge, R. Roy Chaudhury, and D. W. Urish (1992). System Wide Modeling for the Providence Area Combined Sewer System, Final Report by Department of Civil and Environmental Engineering University of Rhode Island, Submitted to the Narragansett Bay Commission, Providence, RI.

Wright, R. M., R. Roy Chaudhury, and S. Makam (1994). Blackstone River Wet Weather Initiative. Stormwater NPDES Related Monitoring Needs. Proceedings of the Engineering Foundation Conference Held in Colorado, August 7-12, 1994. Edited by H. C. Torno, Published by ASCE, 1994. p207-228.

Ziegler, C. Kirk and B. Nisbet (1994). Fine-Grained Sediment Transport in Pawtuxet River, Rhode Island. Journal of Hydraulic Engineering. May 1994 v120 n5 p561(16). 